\title{
Deep Vadose Zone Treatability Test for the Hanford Central Plateau: Soil Desiccation Pilot Test Results
}
MJ Truex
AL Ward
M Oostrom
RE Clayton
CE Strickland
TC Johnson
MJ Lindberg
JE Petersen
VL Freedman
SS Hubbard
CD Johnson
GB Chronister
WJ Greenwood
MW Benecke

May 2012

Pacific Northwest

NATIONAL LABORATORY

Proudly Operated by Battelle Since 1965 


\title{
DISCLAIMER
}

This report was prepared as an account of work sponsored by an agency of the United States Government. Neither the United States Government nor any agency thereof, nor Battelle Memorial Institute, nor any of their employees, makes any warranty, express or implied, or assumes any legal liability or responsibility for the accuracy, completeness, or usefulness of any information, apparatus, product, or process disclosed, or represents that its use would not infringe privately owned rights. Reference herein to any specific commercial product, process, or service by trade name, trademark, manufacturer, or otherwise does not necessarily constitute or imply its endorsement, recommendation, or favoring by the United States Government or any agency thereof, or Battelle Memorial Institute. The views and opinions of authors expressed herein do not necessarily state or reflect those of the United States Government or any agency thereof.

\author{
PACIFIC NORTHWEST NATIONAL LABORATORY \\ operated by \\ BATTELLE \\ for the \\ UNITED STATES DEPARTMENT OF ENERGY \\ under Contract DE-AC05-76RL01830
}

Printed in the United States of America

Available to DOE and DOE contractors from the

Office of Scientific and Technical Information,

P.O. Box 62, Oak Ridge, TN 37831-0062;

ph: (865) 576-8401

fax: $(865) 576-5728$

email: reports@adonis.osti.gov

\author{
Available to the public from the National Technical Information Service \\ 5301 Shawnee Rd., Alexandria, VA 22312 \\ ph: (800) 553-NTIS (6847) \\ email: orders@ntis.gov <http://www.ntis.gov/about/form.aspx> \\ Online ordering: http://www.ntis.gov
}

This document was printed on recycled paper. 


\section{Deep Vadose Zone Treatability Test for the Hanford Central Plateau: Soil Desiccation Pilot Test Results}

\author{
MJ Truex \\ M Oostrom \\ CE Strickland \\ TC Johnson \\ VL Freedman \\ CD Johnson \\ WJ Greenwood
}

\author{
AL Ward \\ RE Clayton \\ MJ Lindberg \\ JE Petersen ${ }^{1}$ \\ SS Hubbard ${ }^{1}$ \\ GB Chronister ${ }^{2}$ \\ MW Benecke ${ }^{2}$
}

May 2012

Prepared for

the U.S. Department of Energy

under Contract DE-AC05-76RL01830

Pacific Northwest National Laboratory

Richland, Washington 99352

\footnotetext{
${ }^{1}$ Lawrence Berkeley National Laboratory, Berkeley, California.

${ }^{2}$ CH2M HILL Plateau Remediation Company, Richland, Washington.
} 


\section{Summary}

Over decades of operation, the U.S. Department of Energy (DOE) and its predecessors have released nearly 2 trillion L ( 450 billion gal) of liquid into the vadose zone at the Hanford Site. Much of this liquid waste discharge into the vadose zone occurred in the Central Plateau, a $200 \mathrm{~km}^{2}\left(75 \mathrm{mi}^{2}\right)$ area that includes approximately 800 waste sites. Some of the inorganic and radionuclide contaminants in the deep vadose zone at the Hanford Site are at depths below the limit of direct exposure pathways, but may need to be remediated to protect groundwater (DOE 2008a; Dresel et al. 2011). The Tri-Party Agencies (DOE, U.S. Environmental Protection Agency, and Washington State Department of Ecology) established Milestone M-015-50, which directed DOE to submit a treatability test plan for remediation of Tc-99 and uranium in the deep vadose zone. These contaminants are mobile in the subsurface environment and have been detected at high concentrations deep in the vadose zone, and at some locations have reached groundwater. Testing technologies for remediating Tc-99 and uranium will also provide information relevant for remediating other contaminants in the vadose zone. The desiccation test described herein was conducted as an element of the test plan published in March 2008 to meet Milestone M-015-50 (DOE 2008a). This field test report was prepared and submitted in response to Milestone M-015-110D, which set a date for desiccation field test activities to be reported to the Tri-Party Agencies.

The desiccation field test was conducted at the Hanford Site 200-BC-1 Operable Unit. This waste site contains 26 cribs and trenches that received about 110 million L (29 million gal) of liquid waste primarily in the mid-1950s. The waste contained about 410 curies of Tc-99 (Corbin et al. 2005). There is no evidence the contamination has reached groundwater, located about $100 \mathrm{~m}(330 \mathrm{ft})$ below ground surface (bgs) in this area. Initial characterization efforts indicated the Tc-99 inventory is located mostly at a depth in the vadose zone of between about 30 and $70 \mathrm{~m}$ (98 and $230 \mathrm{ft}$ ) bgs. However, transport model predictions have indicated the potential for this contamination to adversely impact groundwater in the future (Ward et al. 2004).

The test was conducted in two steps to provide information about desiccation that is intended for use in subsequent feasibility studies for waste sites with inorganic and radionuclide contaminants in the deep vadose zone. The first step was field-scale test site characterization conducted as described in a characterization work plan (DOE 2008b). Results of the characterization effort have been previously reported in DOE (2010a) and Um et al. (2009). A field test plan (DOE 2010b) was prepared and used to guide the desiccation field testing effort. Laboratory and numerical modeling efforts (Truex et al. 2011; Ward et al. 2008; Oostrom et al. 2009, 2011, 2012, In Press) preceded and accompanied the field test and are incorporated herein as their results pertain to assessment of desiccation for future feasibility studies.

Desiccation technology relies on removal of water from a portion of the subsurface such that the resultant low moisture conditions inhibit downward movement of water and dissolved contaminants. Implementation requires establishing sufficiently dry conditions within the targeted zone to inhibit downward water transport effectively. Nominally, the targeted desiccation zone would need to extend laterally across the portion of the vadose zone where contaminants have the potential to move downward at a flux that would cause groundwater contaminant concentrations above the groundwater remediation objective. Overall objectives for the field test were to provide technical data as a design basis for desiccation, demonstrate desiccation at the field scale, and provide scale-up information for use in subsequent feasibility tests. Key performance factors identified for the field test included providing field-scale information to evaluate 1) the distribution of the desiccated zone within the subsurface, 2) the 
desiccation rate, 3) the achievable end-state moisture conditions within the desiccated zone, and 4) the rate and extent of moisture content increase after desiccation is completed.

The objectives outlined in the field test plan (DOE 2010b) were successfully addressed through the field testing and associated laboratory and modeling efforts conducted as part of this treatability test. A design basis to apply desiccation for vadose zone remediation was developed and is available for use in subsequent feasibility and remedial design efforts. Analysis of data and use of numerical simulations indicate that full-scale designs can be made more cost effective than the design of the field test (which was designed to collect specific data, not as a full-scale remediation) through use of ambient air as the injected dry gas and use of an injection-only design (i.e., no extraction well). Using desiccation performance calculations developed from the treatability test information, a nominal Hanford Site design with a 10-year operating period and an injection rate of $100 \mathrm{cfm}$ per meter of well screen leads to an injection well spacing on the order of $25+\mathrm{m}(2-3$ wells per acre).

The field test successfully provided information addressing key performance factors for desiccation. In the relatively short 6-month duration of the field test, a zone of the subsurface about 3-m (10-ft) thick out to a radius of about $3 \mathrm{~m}(10 \mathrm{ft}$ ) was desiccated (dark red zone in lower portion of the injection interval; panel B, Figure S.1), creating conditions that reduce the rate of moisture and contaminant movement toward the groundwater. Moisture content of the subsurface was also reduced to a lesser extent over a larger portion of the test area. The distribution of desiccation was controlled by permeability contrasts that affect the injected gas flow patterns. The lateral and vertical distribution of drying from the injection well was influenced by the subsurface heterogeneity with initial drying in higher permeability zones. Figure S.2 shows details of the vertical moisture-content profile for an example monitoring location within the desiccated zone (Figure S.2). Pre-desiccation moisture content (purple line) varied with depth where wetter zones (generally above $0.08 \mathrm{~m}^{3} / \mathrm{m}^{3}$ moisture content) are associated with finer-grained, lower permeability zones and drier zones are coarser, higher permeability zones. Significant desiccation (reduction of moisture content to below $0.01 \mathrm{~m}^{3} / \mathrm{m}^{3}$ ) occurred primarily in the higher permeability zones with an example shown by bracket A in Figure S.2. With time, small, initially wetter and lower permeability zones of limited thickness such as shown at bracket B (Figure S.2) were desiccated. However, thick zones containing low-permeability porous media and with initially wet conditions desiccate slowly (bracket C, Figure S.2). Desiccation removed over 18,000 kg of water from the test zone within the 151-day active desiccation period and reduced volumetric moisture content in over $1300 \mathrm{~m}^{3}$ of soil with values lower than $0.04 \mathrm{~m}^{3} / \mathrm{m}^{3}$ in $225 \mathrm{~m}^{3}$ of the test site and lower than $0.01 \mathrm{~m}^{3} / \mathrm{m}^{3}$ in $68 \mathrm{~m}^{3}$. When desiccated to these very low moisture contents, water relative permeability in the desiccated zone is significantly decreased, effectively zero when the moisture content is below the residual moisture content for the sediment, and limits the rate of contaminant and water movement.

The rate and extent of desiccation observed in the field test was consistent with laboratory data and associated modeling calculations also conducted as part of the overall treatability test effort. These efforts demonstrated that the desiccation rate is related to the water-holding capacity of the injected gas, which is a function of temperature and is influenced by evaporative cooling processes during desiccation. Thus, the overall desiccation rate and extent are controlled by the water-holding capacity of the injected gas, temperature, and number of pore volumes of dry gas that contact the targeted treatment zone. With sufficient time, moisture content can be reduced to near zero through evaporative processes during desiccation as shown in both laboratory tests and the field test (e.g., Figure S.2, bracket A). In the field test, a range of desiccation responses (e.g., Figures S.1 and S.2) were induced over the finite duration of the test as observed by the range in moisture-content values at the end of desiccation. The distribution of 
desiccation depended on the radial distance from the injection well and the pattern of injected gas flow. While a full-scale remediation using desiccation would be operated long enough to achieve a more uniform low moisture content throughout the targeted treatment zone, the field test was conducted to provide a range of desiccation intensity so that post-desiccation rewetting could be evaluated for different desiccation conditions. Over time, the rate of moisture rewetting of the desiccated zones is a function of the hydraulic gradient, water relative permeability, and porous media unsaturated flow properties.

Rewetting data over the initial 8 months after the end of active desiccation are consistent with expectations based on related laboratory data and numerical simulation analyses where thinner, moderately dried zones have begun to rewet and thicker, very dry zones have remained dry.

These test results provide information to guide design and implementation of desiccation for future applications. However, while laboratory and modeling efforts have shown significant reduction in moisture movement over time following desiccation, field-scale data are needed to verify the longer-term performance in mitigating moisture and contaminant movement toward the groundwater. Continued monitoring of moisture conditions at the test site is needed to quantify the rate of rewetting for the desiccated zone. Long-term monitoring of the desiccation site is underway and is planned to continue for at least 5 years per the field test plan (DOE 2010b).

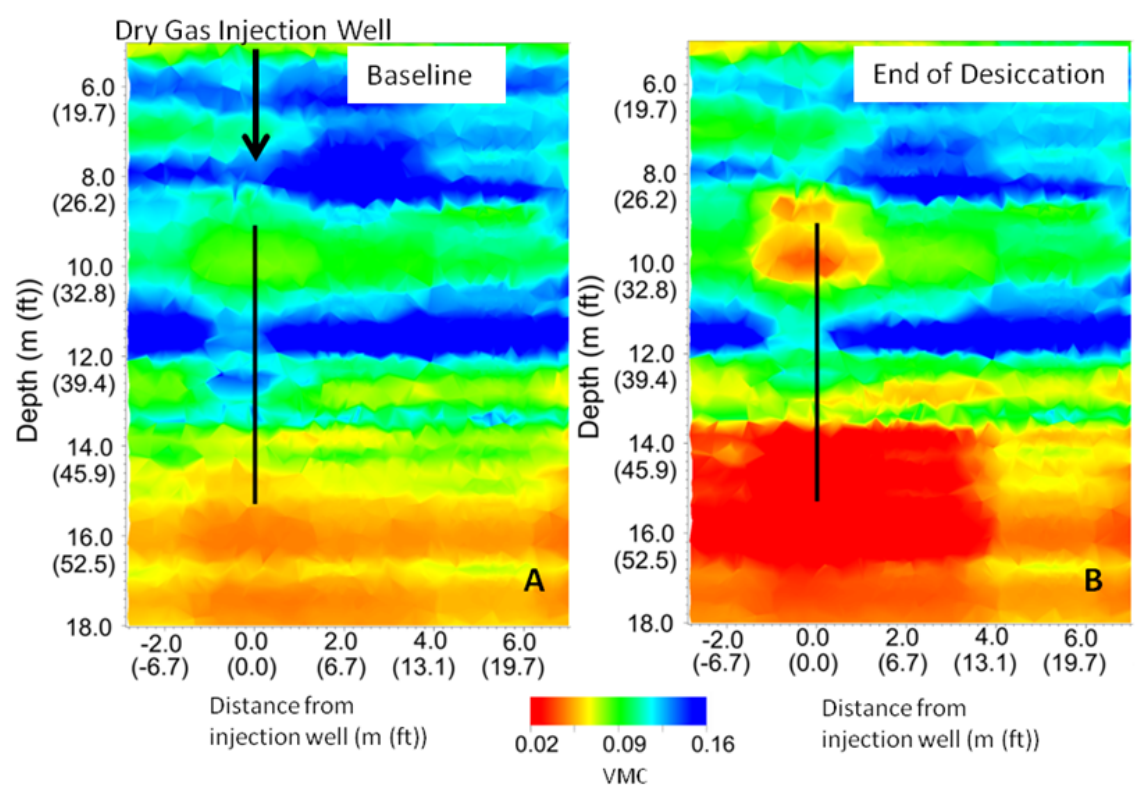

Figure S.1. Interpolation of Volumetric Moisture Content (VMC) from Neutron Moisture Logging Data Along the Axis Between the Injection and Extraction Wells, Prior to (A) and at the End of Active Desiccation (B). In panel B, desiccation is indicated by shift toward red colors with the dark red zone in the lower portion of the injection interval indicating the zone of most significant desiccation. 


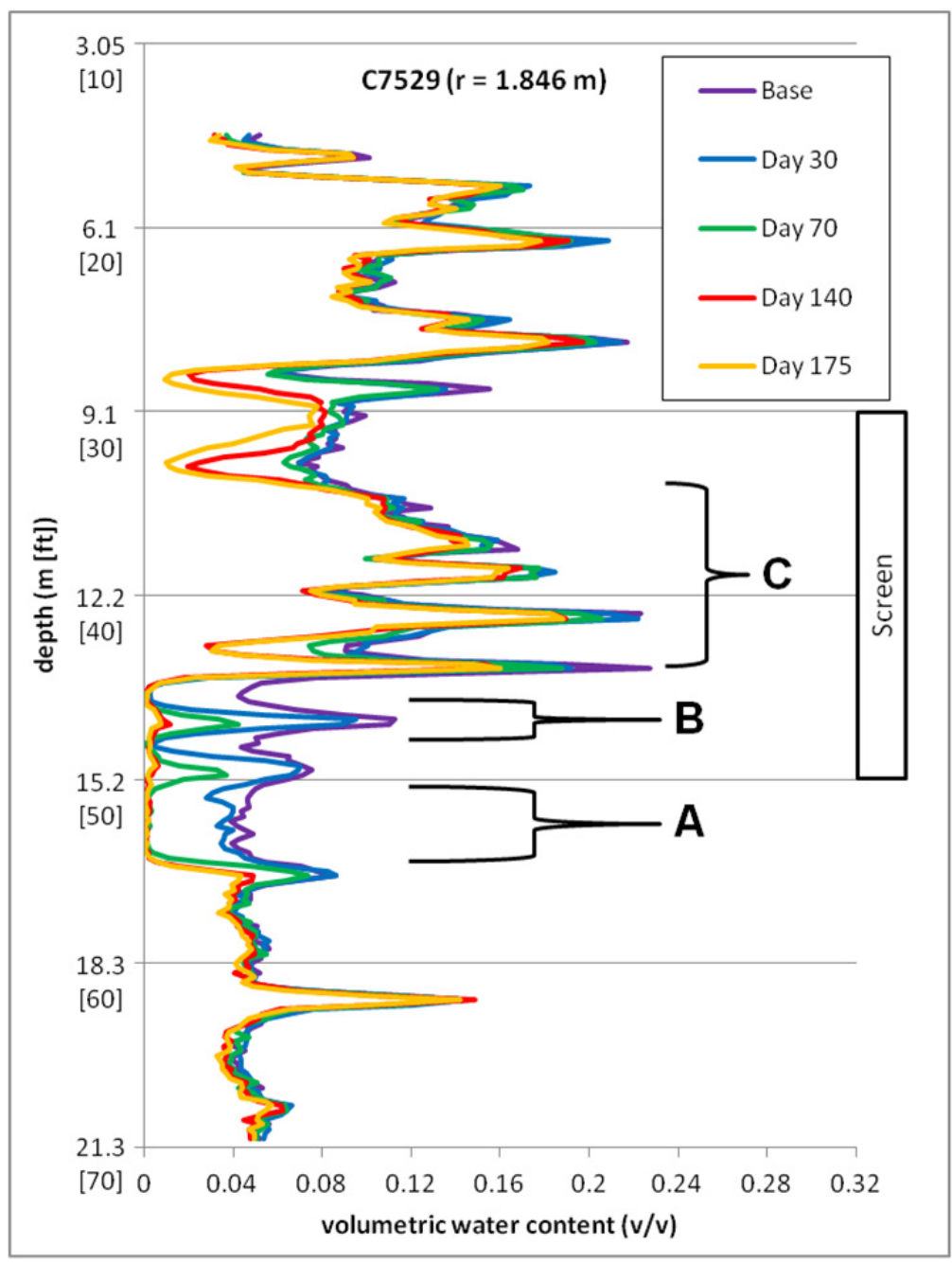

Figure S.2. Example Neutron Moisture Probe Response Over Time for Location C7529 (1.846 m from injection well). The base time is a logging event in December 2010, prior to the continuous active desiccation period. Other data are for logging events in nominal days from the start of active desiccation with day 175 representing the end of active desiccation. 


\section{Acronyms and Abbreviations}

$\begin{array}{ll}\text { ARAR } & \text { applicable or relevant and appropriate requirement } \\ \text { bgs } & \text { below ground surface } \\ \text { CERCLA } & \text { Comprehensive Environmental Response, Compensation, and Liability Act of } \\ & 1980 \\ \text { cfm } & \text { cubic feet per minute } \\ C_{R} & \text { count ratio } \\ \text { DOE } & \text { U.S. Department of Energy } \\ \text { DPHP } & \text { Dual-Probe Heat Pulse } \\ \text { DQO } & \text { data quality objective } \\ \text { Ecology } & \text { Washington State Department of Ecology } \\ \text { EPA } & \text { U.S. Environmental Protection Agency } \\ \text { ERT } & \text { electrical resistivity tomography } \\ \text { GPR } & \text { ground penetrating radar } \\ \text { HDU } & \text { Heat Dissipation Unit } \\ K_{\text {sat }} & \text { saturated hydraulic conductivity } \\ \text { PNNL } & \text { Pacific Northwest National Laboratory } \\ \text { PSQ } & \text { principle study question } \\ \text { PVC } & \text { polyvinyl chloride } \\ \text { TCP } & \text { Thermocouple Psychrometer } \\ \text { VMC } & \text { volumetric moisture content } \\ \text { VMC } & \text { ratio of volumetric moisture content } \\ \text { WAE } & \text { water-air-energy } \\ \end{array}$




\section{Contents}

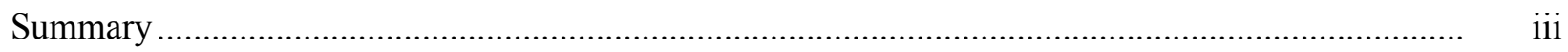

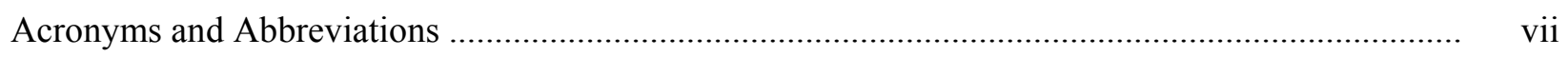

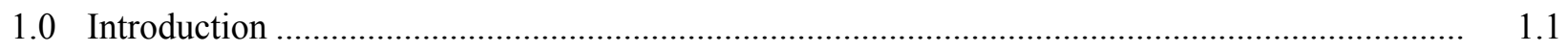

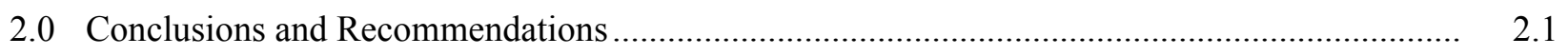

2.1 Overall Conclusions ............................................................................................. 2.1

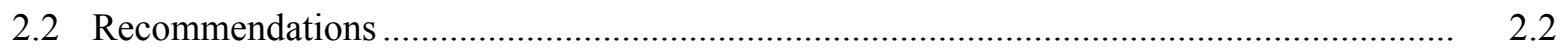

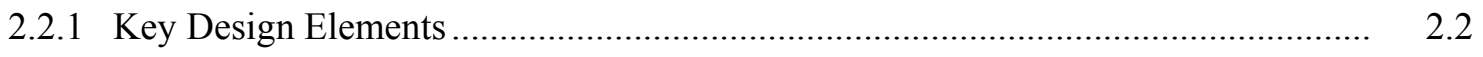

2.2.2 Example Conceptual Design .................................................................... 2.3

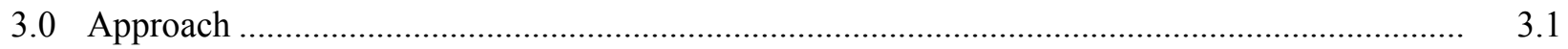

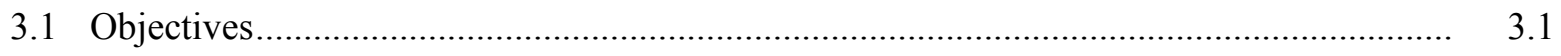

3.2 Experimental Design and Procedures.................................................................... 3.1

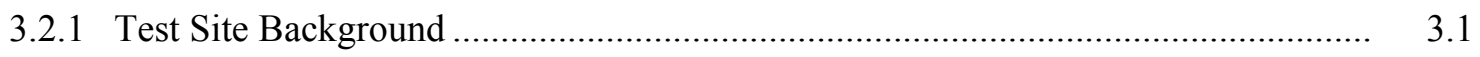

3.2.2 Test Layout and Operations ….................................................................... 3.3

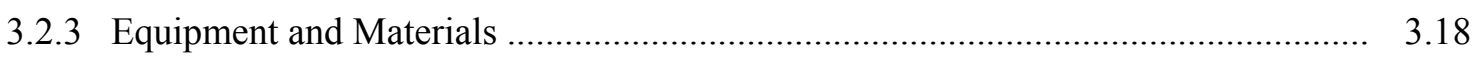

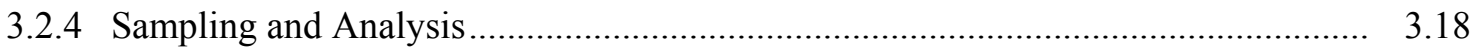

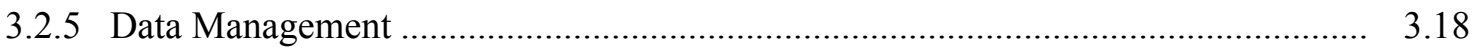

3.2.6 Deviations from Work Plan....................................................................... 3.19

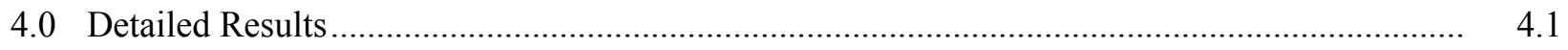

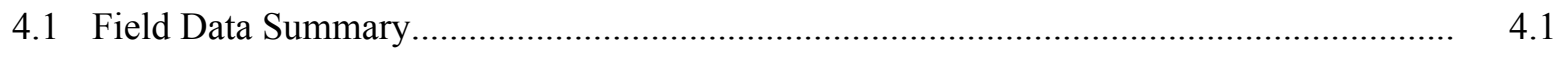

4.1.1 Desiccation Implementation ................................................................... 4.1

4.1.2 Desiccation Performance.............................................................................. 4.8

4.2 Data Assessment with Respect to Field Test Objectives................................................ 4.50

4.2.1 Design Parameters ..................................................................................... 4.50

4.2.2 Desiccation Field Test Performance................................................................. 4.71

4.2.3 Instrumentation and Monitoring Assessment..................................................... 4.94

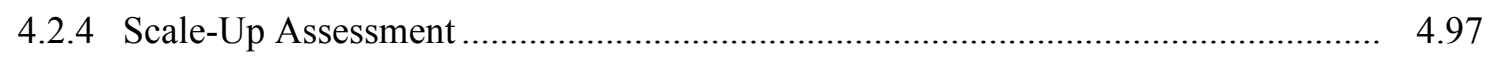

5.0 Quality Assurance Results ........................................................................................... 5.1

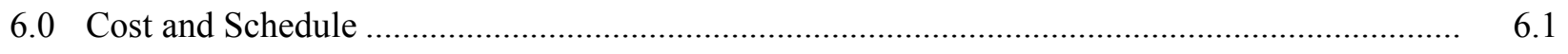

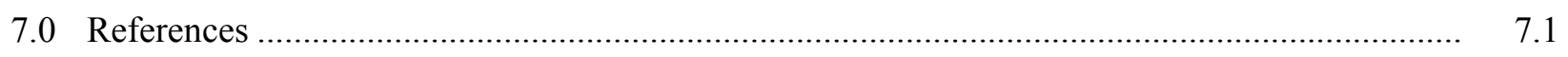

Appendix A - Analytical Data Report for Sediment Samples Collected from Post-Desiccation Boreholes C8387 and C8388 ........................................................................... A.1

Appendix B - Supplemental Temperature, Neutron Moisture Log, Electrical Resistivity Tomography, and Ground Penetrating Radar Data Plots ......................................... B. B 


\section{Figures}

S.1 Interpolation of Volumetric Moisture Content from Neutron Moisture Logging Data Along the Axis Between the Injection and Extraction Wells, Prior to and at the End of Active Desiccation

S.2 Example Neutron Moisture Probe Response Over Time for Location C7529 ...................... vi

2.1 Example Well Layout Concept for Cribs Portion of BC Cribs and Trenches ....................... 2.3

3.1 Test Site Location in the BC Cribs and Trenches Area of the Hanford Site.......................... 3.2

3.2 Injection Well Borehole Data and Screened Interval........................................................ 3.3

3.3 Basic Components of the Desiccation Field Test System.................................................... 3.4

3.4 Location of Test Site Logging Wells, Sensor Boreholes, and Post-Desiccation Boreholes for Collection of Sediment Samples ................................................................ 3.5

3.5 Calibration Relation for Neutron Moisture Probe Count Ratio Data and Corresponding Laboratory-Measured Volumetric Moisture Content.......................................................... 3.10

3.6 Test Site Injection and Extraction Equipment .................................................................. 3.15

3.7 Stilling Well Design for Desiccation Field Test ........................................................ 3.17

4.1 Injection and Extraction Well Borehole Initial Laboratory Moisture Content, Extracted Pore Water Electrical Conductivity, and Well Screened Interval.

$4.2 \quad 3-D$ Interpolation of Initial Volumetric Moisture Content from Neutron Moisture Logging Data Prior to Desiccation.

4.3 2-D Interpretation of Initial Volumetric Moisture Content from Cross-Hole Ground Penetrating Radar Data Prior to Desiccation

4.4 Three-Dimensional Pre-Desiccation Bulk Conductivity at Desiccation Treatability Test Site as Determined via ERT

4.5 Oxygen Response at the C7534 and C7536 Locations Along the Axis Between the Injection and Extraction Wells.

4.6 Equilibration Response for Heat Dissipation Units ......................................................... 4.5

4.7 Equilibration Response for Dual-Probe Heat-Pulse Sensors .............................................. 4.6

4.8 Equilibration Response for Humidity Probes .................................................................. 4.6

4.9 Flow Conditions and Cumulative Volumes for Field Test Operations ................................. 4.7

4.10 Comparison of Baseline and Day 107 Tracer Responses at the $47 \mathrm{ft}$ bgs Depth Interval for Monitoring Locations C7534 and C7536.....

4.11 Temperature Response Over Time for the Sensors at a Depth of $32.5 \mathrm{ft}$ Below Ground Surface

4.12 Temperature Response Over Time for the Sensors at a Depth of $36.5 \mathrm{ft}$ Below Ground Surface

4.13. Temperature Response Over Time for the Sensors at a Depth of $42.5 \mathrm{ft}$ Below Ground Surface

4.14 Temperature Response Over Time for the Sensors at a Depth of $46.5 \mathrm{ft}$ Below Ground Surface

4.15. Heat Dissipation Unit Response Over Time for the Sensors at a Depth of $32.5 \mathrm{ft}$ Below Ground Surface. 
4.16 Heat Dissipation Unit Response Over Time for the Sensors at a Depth of $37.5 \mathrm{ft}$ Below Ground Surface

4.17 Heat Dissipation Unit Response Over Time for the Sensors at a Depth of $42.5 \mathrm{ft}$ Below Ground Surface

4.18 Heat Dissipation Unit Response Over Time for the Sensors at a Depth of $47.5 \mathrm{ft}$ Below Ground Surface.

4.19 Dual-Probe Heat-Pulse Sensor Response Over Time for the Sensors at a Depth of $32.5 \mathrm{ft}$ Below Ground Surface

4.20 Dual-Probe Heat-Pulse Sensor Response Over Time for the Sensors at a Depth of $37.5 \mathrm{ft}$ Below Ground Surface

4.21 Dual-Probe Heat-Pulse Sensor Response Over Time for the Sensors at a Depth of $42.5 \mathrm{ft}$ Below Ground Surface

4.22 Dual-Probe Heat-Pulse Sensor Response Over time for the Sensors at a Depth of $47.5 \mathrm{ft}$ Below Ground Surface

4.23 Relative Humidity Probe Response Over Time for the Sensors at a Depth of $32.5 \mathrm{ft}$ Below Ground Surface.

4.24 Relative Humidity Probe Response Over Time for the Sensors at a Depth of $37.5 \mathrm{ft}$ Below Ground Surface....

4.25 Relative Humidity Probe Response Over Time for the Sensors at a Depth of $42.5 \mathrm{ft}$ Below Ground Surface.

4.26 Relative Humidity Probe Response Over Time for the Sensors at a Depth of $47.5 \mathrm{ft}$ Below Ground Surface.

4.27 Neutron Moisture Probe Response Over Time for Location C7523.

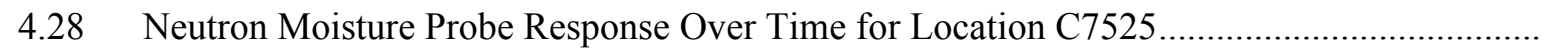

4.29 Neutron Moisture Probe Response Over Time for Location C7527......

4.30 Neutron Moisture Probe Response Over Time for Location C7529

4.31 Neutron Moisture Probe Response Over Time for Location C7531 ...................................... 4.22

4.32 Neutron Moisture Probe Response Over Time for Location C7533 ..................................... 4.23

4.33 Neutron Moisture Probe Response Over Time for Location C7537..

4.34 Change in Water Content at the End of Active Desiccation Compared to PreDesiccation Baseline Based on Neutron Moisture Probe Data for Locations C7523, C7525, C7527, C7529, C7531, and C7533.

4.35 Change in Water Content at the End of Active Desiccation Compared to PreDesiccation Baseline Based on Neutron Moisture Probe Data for Location C7541, Near the Extraction Well on the Side Opposite from the Injection Well.....

4.36 Change in Water Content at the End of Active Desiccation Compared to PreDesiccation Baseline Based on Neutron Moisture Probe Data for Locations C7531, C7537, and C7539, Along the Axis Between the Injection and Extraction Wells at Distances of $2.62 \mathrm{~m}, 5.343 \mathrm{~m}$, and $8.64 \mathrm{~m}$ from the Injection Well, Respectively.

4.37 Neutron Moisture Log Response in the Injection Well Comparing Pre-Injection and After $13,000 \mathrm{~m}^{3}$ of Dry Nitrogen were Injected

4.38 Interpolated Temperature Response Along the Axis Between the Injection and Extraction Wells, Indirectly Showing Desiccation Through the Evaporative Cooling Effect. 
4.39 Interpolation of Volumetric Moisture Content from Neutron Moisture Logging Data Along the Axis Between the Injection and Extraction Wells, Prior to and at the End of Active Desiccation.

4.40 Ratio of Volumetric Moisture Content to Pre-desiccation Volumetric Moisture Content Over Time Along the Axis Between the Injection and Extraction Wells from CrossHole Electrical Resistivity Tomography.

4.41 Volumetric Moisture Content Data Estimated for Location C7531 Using Neutron Moisture Logging and GPR

4.42 Injection and Extraction Well Borehole Data and Well Screened Interval.....

4.43 2-D Interpretation of Volumetric Moisture Content from Cross-Hole Ground Penetrating Radar Data Prior to Desiccation and at Day 137 After the Start of Active Desiccation....

4.44 Post-Desiccation Temperature Response Over Time for the Sensors at a Depth of $32.5 \mathrm{ft}$ Below Ground Surface

4.45 Post-Desiccation Temperature Response Over Time for the Sensors at a Depth of $36.5 \mathrm{ft}$ Below Ground Surface

4.46 Post-Desiccation Temperature Response Over Time for the Sensors at a Depth of $42.5 \mathrm{ft}$ Below Ground Surface

4.47 Post-Desiccation Temperature Response Over Time for the Sensors at a Depth of $46.5 \mathrm{ft}$ Below Ground Surface

4.48 Post-Desiccation Heat Dissipation Unit Response Over Time for the Sensors at a Depth of $42.5 \mathrm{ft}$ Below Ground Surface

4.49 Post-Desiccation Heat Dissipation Unit Response Over Time for the Sensors at a Depth of $47.5 \mathrm{ft}$ Below Ground Surface

4.50 Post-Desiccation Dual-Probe Heat-Pulse Sensor Response Over Time for the Sensors at a Depth of $42.5 \mathrm{ft}$ Below Ground Surface.

4.51 Post-Desiccation Dual-Probe Heat-Pulse Sensor Response Over Time for the Sensors at a Depth of $47.5 \mathrm{ft}$ Below Ground Surface

4.52 Post-Desiccation Relative Humidity Probe Response Over Time for the Sensors at a Depth of $42.5 \mathrm{ft}$ Below Ground Surface

4.53 Post-Desiccation Relative Humidity Probe Response Over Time for the Sensors at a Depth of $47.5 \mathrm{ft}$ Below Ground Surface

4.54 Neutron Moisture Probe Response Over Time for Location C7523.......

4.55 Neutron Moisture Probe Response Over Time for Location C7525.

4.56 Neutron Moisture Probe response Over Time for Location C7527.

4.57 Neutron Moisture Probe Response Over Time for Location C7529......

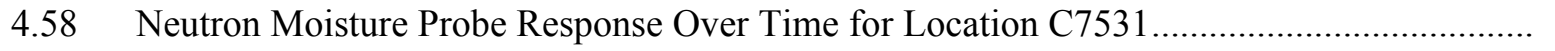

4.59 Neutron Moisture Probe Response Over Time for Location C7533

4.60 Neutron Moisture Probe Response Over Time for Location C7537

4.61 2-D Interpretation of Volumetric Moisture Content from Cross-Hole Ground Penetrating Radar Data During Desiccation at Day 137 and After the End of Active Desiccation at Days 193 and 265. 
4.62 Ratio of Volumetric Moisture Content to the Volumetric Moisture Content at the End of Active Desiccation Over Time Along the Axis Between the Injection and Extraction Wells from Cross-Hole Electrical Resistivity Tomography.....

4.63 Conceptual Model of Well Configuration Used to Simulate Airflow Between Two Wells

4.64 Simulated Desiccation Along the Centerline from the Injection to the Extraction Wells for 300/100 cfm Injection/Extraction Flow Rates

4.65 Simulated Desiccation Along the Centerline from the Injection to the Extraction Wells for 100/100 cfm Injection/Extraction Flow Rates.

4.66 Simulated Desiccation Along the Centerline from the Injection to the Extraction Wells for 300/300 cfm Injection/Extraction Flow Rates.

4.67 Depiction of Gas Flow Rate in a Y-Z Plane Located Between the Injection and Extraction Wells at a Distance of $3 \mathrm{~m}$ from the Injection Well.

4.68 Depiction of Gas Flow Rate in a Y-Z Plane Located Between the Injection and Extraction Wells at a Distance of $9 \mathrm{~m}$ from the Injection Well

4.69 Simulated Temperature Profile During Desiccation Along the Centerline from the Injection to the Extraction Wells for 300/100 cfm Injection/Extraction Flow Rates

4.70 Simulated Temperature Profile During Desiccation Along the Centerline from the Injection to the Extraction Wells for 100/100 cfm Injection/Extraction Flow Rates

4.71 Simulated Temperature Profile During Desiccation Along the Centerline from the Injection to the Extraction Wells for 300/300 cfm Injection/Extraction Flow Rates

4.72 Simulated Plan and Cross Sectional Views of the Pressure Gradients for 300/100 cfm Injection/Extraction Flow Rates

4.73 Simulated Plan and Cross Sectional Views of the Pressure Gradients for 100/100 cfm Injection/Extraction Flow Rates

4.74 Simulated Plan and Cross Sectional Views of the Pressure Gradients for 300/300 cfm Injection/Extraction Flow Rates

4.75 Simulated Desiccation Response at Location C7522 for a Layered Model Domain in Terms of Volumetric Moisture Content, Matric Potential, Relative Humidity, and Temperature Changes at the Nominal Mid-Depth of the Sensor Intervals for the Field Test......

4.76 Simulated Desiccation Response at Location C7524 for a Layered Model Domain in Terms of Volumetric Moisture Content, Matric Potential, Relative Humidity, and Temperature Changes at the Nominal Mid-Depth of the Sensor Intervals for the Field Test.

4.77 Simulated Desiccation Response at Location C7526 for a Layered Model Domain in Terms of Volumetric Moisture Content, Matric Potential, Relative Humidity, and Temperature Changes at the Nominal Mid-Depth of the Sensor Intervals for the Field Test. .

4.78 Simulated Desiccation Response at Location C7528 for a Layered Model Domain in Terms of Volumetric Moisture Content, Matric Potential, Relative Humidity, and Temperature Changes at the Nominal Mid-Depth of the Sensor Intervals for the Field Test. 
4.79 Simulated Desiccation Response at Location C7530 for a Layered Model Domain in Terms of Volumetric Moisture Content, Matric Potential, Relative Humidity, and Temperature Changes at the Nominal Mid-Depth of the Sensor Intervals for the Field Test......

4.80 Simulated Desiccation Response at Location C7532 for a Layered Model Domain in Terms of Volumetric Moisture Content, Matric Potential, Relative Humidity, and Temperature Changes at the Nominal Mid-Depth of the Sensor Intervals for the Field Test.

4.81 Simulated Desiccation Response at Location C7534 for a Layered Model Domain in Terms of Volumetric Moisture Content, Matric Potential, Relative Humidity, and Temperature Changes at the Nominal Mid-Depth of the Sensor Intervals for the Field Test.

4.82 Overview of the Three Considered Configurations ....................................................... 4.76

4.83 Moisture Contents at Various Times during Rewetting for Case I-1 ................................. 4.78

4.84 Moisture Contents at Various Times during Rewetting for Case I-2 ................................... 4.79

4.85 Moisture Contents at Various Times during Rewetting for Case I-3 .................................... 4.79

4.86 Moisture Contents at Various Times during Rewetting for Case I-4 ................................. 4.80

4.87 Moisture Contents at Various Times during Rewetting for Case I-5 ................................... 4.81

4.88 Moisture Contents at Various Times during rewetting for Case I-6 ................................... 4.81

4.89 Moisture Contents at Various Times during Rewetting for Case I-7 .................................. 4.82

4.90 Moisture Contents at Various Times during Rewetting for Case I-8 .................................. 4.83

4.91 Moisture Contents at Various Times during Rewetting for Case I-9 ................................ 4.83

4.92 Moisture Contents at Various Times during Rewetting for Case I-10................................ 4.84

4.93 Moisture Contents at Various Times during Rewetting for Case I-11 .................................. 4.84

4.94 Moisture Contents at Various Times during Rewetting for Case I-12 ............................... 4.85

4.95 Moisture Contents at Various Times during Rewetting for Case II-1 ................................. 4.86

4.96 Moisture Contents at Various Times during Rewetting for Case II-2 ............................... 4.87

4.97 Moisture Contents at Various Times during Rewetting for Case II-3 ................................ 4.87

4.98 Moisture Contents at Various Times during Rewetting for Case II-4 ................................ 4.88

4.99 Moisture Contents at Various Times during Rewetting for Case III-1 ................................. 4.89

4.100 Moisture Contents at Various Times during Rewetting for Case III-2 ............................... 4.90

4.101 Moisture Contents at Various Times during Rewetting for Case III-3a .............................. 4.91

4.102 Moisture Contents at Various Times during Rewetting for Case III-3b ............................... 4.91

4.103 Moisture Contents at Various Times during Rewetting for Case II-4 ................................ 4.92

4.104 Schematic of Cylindrical Domain Used to Simulate Injection of Ambient Air.................... 4.97

4.105 Ambient Air Desiccation as a Function of Injected Gas Relative Humidity for an Injected Gas Temperature of $0^{\circ} \mathrm{C}$

4.106 Ambient Air Desiccation as a Function of Injected Gas Relative Humidity for an Injected Gas Temperature of $10^{\circ} \mathrm{C}$

4.107 Ambient Air Desiccation as a Function of Injected Gas Relative Humidity for an Injected Gas Temperature of $20^{\circ} \mathrm{C}$ 
4.108 Ambient Air Desiccation as a Function of Injected Gas Relative Humidity for an Injected Gas Temperature of $30^{\circ} \mathrm{C}$

4.109 Ambient Air Desiccation as a Function of Injected Gas Temperature for an Injected Gas Relative Humidity of $0 \%$

4.110 Ambient Air Desiccation as a Function of Injected Gas Temperature for an Injected Gas Relative Humidity of $20 \%$

4.111 Ambient Air Desiccation as a Function of Injected Gas Temperature for an Injected Gas Relative Humidity of $40 \%$

4.112 Ambient Air Desiccation as a Function of Injected Gas Temperature for an Injected Gas Relative Humidity of $60 \%$

4.113 Ambient Air Desiccation as a Function of Injected Gas Temperature for an Injected Gas Relative Humidity of $80 \%$

4.114 Ambient Air Desiccation as a Function of Injected Gas Relative Humidity for an Injected Gas Temperature of $0^{\circ} \mathrm{C}$, High Initial Saturation Condition.

4.115 Ambient Air Desiccation as a Function of Injected Gas Relative Humidity for an Injected Gas Temperature of $10^{\circ} \mathrm{C}$, High Initial Saturation Condition.

4.116 Ambient Air Desiccation as a Function of Injected Gas Relative Humidity for an Injected Gas Temperature of $20^{\circ} \mathrm{C}$, High Initial Saturation Condition.

4.117 Ambient Air Desiccation as a Function of Injected Gas Relative Humidity for an Injected Gas Temperature of $30^{\circ} \mathrm{C}$, High Initial Saturation Condition

4.118 Ambient Air Desiccation as a Function of Injected Gas Relative Humidity for an Injected Gas Temperature of $0^{\circ} \mathrm{C}$, High Injection Rate Condition

4.119 Ambient Air Desiccation as a Function of Injected Gas Relative Humidity for an Injected Gas Temperature of $10^{\circ} \mathrm{C}$, High Injection Rate Condition

4.120 Ambient Air Desiccation as a Function of Injected Gas Relative Humidity for an Injected Gas Temperature of $20^{\circ} \mathrm{C}$, High Injection Rate Condition

4.121 Ambient Air Desiccation as a Function of Injected Gas Relative Humidity for an Injected Gas Temperature of $30^{\circ} \mathrm{C}$, High Injection Rate Condition

4.122 Model Domain

$4.1233 \%$ Saturation Contour After 1 Year of Desiccation 4.119

4.124 Relative Permeability as a Function of Moisture Content, Using a van Genuchten (1980) $n$ value of 3.64 and Residual Moisture Contents of $0,0.03,0.42$, and 0.06 


\section{Tables}

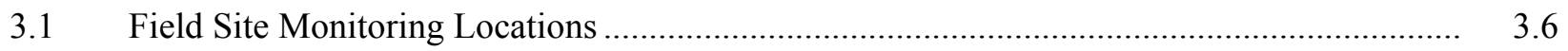

4.1 Summary of Injected Gas Volumes .........................................................................

$4.2 \quad$ Post-Desiccation Sediment Core Analysis Results............................................................ 4.29

$4.3 \quad$ Condensate Sampling Results ..................................................................................... 4.36

4.4 Simulated Gas Flow Rate Through a Y-Z Plane Located Between the Injection and Extraction Wells at a Distance of $3 \mathrm{~m}$ from the Injection Well in a Cross Sectional Area of $57 \mathrm{~m}^{2}$ on the Centerline Between the Injection and Extraction Wells ...................... 4.57

4.5 Neutron Moisture Logging Data Showing the Number of 7.6-cm-thick Intervals at or Below the Specified Threshold Volumetric Moisture Content at the End of Active Desiccation.

4.6 Computed Volume of Soil Desiccated to at or Below the Specified Threshold Volumetric Moisture Content at the End of Active Desiccation Using the Data from Table 4.5, an Assumption of Radial Symmetry, and the Specified Radial Distances to Each Monitoring Location.

4.7 Overview of the Rewetting Simulations .................................................................... 4.77

$4.8 \quad$ Hydraulic Properties of Porous Media .............................................................................. 4.77

$4.9 \quad$ Hydraulic Properties of the Porous Medium...................................................................... 4.98

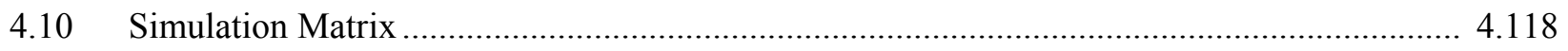

4.11 Gas Flow Rate Out of the Top Domain Surface .................................................................. 4.119

4.12 Information to Support Threshold Criteria .................................................................... 4.123

4.13 Information to Support Long-Term Effectiveness and Permanence Criterion ...................... 4.124

4.14 Information to Support Reduction of Toxicity, Mobility, or Volume Criterion ..................... 4.124

4.15 Information to Support Short-Term Effectiveness Criterion .............................................. 4.125

4.16 Information to Support Implementability Criterion ........................................................ 4.125

4.17 Information Supporting Estimating Cost for Desiccation................................................ 4.126

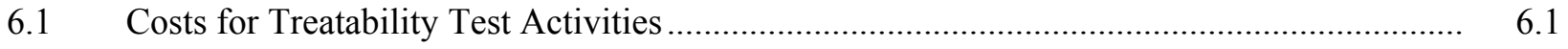




\subsection{Introduction}

Some of the inorganic and radionuclide contaminants in the deep vadose zone at the Hanford Site are at depths below the limit of direct exposure pathways, but may need to be remediated to protect groundwater (DOE 2008a; Dresel et al. 2011). The Hanford Site contains a significant amount of contamination that resides in a 60-to-100-m-thick vadose zone as a result of past discharges associated with plutonium production operations. Much of this contamination is deep in the vadose zone where remediation options are limited by the physical and hydrogeologic properties of the vadose zone. There are several distinct categories of deep vadose zone problems at the Hanford Site. The two principal deep vadose zone contaminants of concern are Tc-99 and uranium (DOE 2008a). Other contaminants - such as iodine-129 and nitrate - are also prevalent in the deep vadose zone and groundwater.

The Hanford Site 200-BC-1 Operable Unit is an example of vadose zone contamination issues. This waste site contains 26 cribs and trenches that received about 110 million liters of liquid waste primarily in the mid-1950s. The waste contained about 410 curies of Tc-99 (Corbin et al. 2005). There is no evidence the contamination has reached groundwater, located about $100 \mathrm{~m}$ below ground surface (bgs) in this area. Initial characterization efforts indicated the Tc-99 inventory is located mostly at a depth in the vadose zone of between about 30 and $70 \mathrm{~m}$ bgs. However, transport model predictions indicated the potential for this contamination to adversely impact groundwater in the future (Ward et al. 2004). The groundwater contaminant concentrations that can result from vadose zone contamination are a function of the rate of contaminant movement through the vadose zone. For remediation, the magnitude of contaminant discharge from the vadose zone to the groundwater must be maintained low enough to achieve groundwater protection goals.

In response to the Tri-Party Agreement Milestone M-015-50, the Deep Vadose Treatability Test Plan for the Hanford Central Plateau was issued in March 2008 (DOE 2008a). This plan is for a treatability test program to evaluate potential deep vadose zone remedies for groundwater protection. The field test of vadose zone desiccation was conducted as part of this effort.

Desiccation of a portion of the vadose zone, in conjunction with a surface infiltration barrier, has the potential of minimizing migration of deep vadose zone contaminants towards the water table (Truex et al. 2011). To apply desiccation, a dry gas (relative humidity less than $100 \%$ at the in situ temperature) is injected into the subsurface. The dry gas evaporates water from the porous medium until the gas reaches $100 \%$ relative humidity after which the gas can no longer evaporate water. Evaporation can remove pore water and may result in very low moisture contents and decreased water relative permeability in the desiccated zone (Ward et al. 2008; Oostrom et al. 2009, 2012, In Press; Truex et al. 2011). Due to these desiccation-induced changes, the future rate of movement of moisture and contaminants through this zone is decreased.

Laboratory and modeling studies have been conducted to study desiccation and provide a technical basis for its use as a potential remedy (Truex et al. 2011; Ward et al. 2008; Oostrom et al. 2009, 2011, 2012, In Press). In these studies, the overall performance of desiccation in limiting water and contaminant flux to the groundwater was shown to be a function of the final moisture content, contaminant concentration, sediment properties, size of the desiccated zone, the hydraulic properties and conditions in surrounding subsurface zones, and the net surface recharge rate. Desiccation was shown to be capable of reducing the moisture content to below the residual moisture content of the porous medium 
(Truex et al. 2011; Ward et al. 2008; Oostrom et al. 2009). Under these conditions, the relative aqueousphase permeability is near zero and subsequent moisture movement is significantly hindered. Truex et al. (2011) demonstrated through numerical modeling that combinations of a surface infiltration barrier and subsurface desiccation enhanced protection of groundwater compared to no-treatment or surface-barrieronly scenarios. The effectiveness of desiccation was related to the thickness and vertical location of the imposed desiccated zone in relation to the location of the elevated moisture and contaminant conditions. While the concentration of solutes increased in the desiccated zone in these simulations, this effect did not lead to a significant high-concentration pulse to the groundwater.

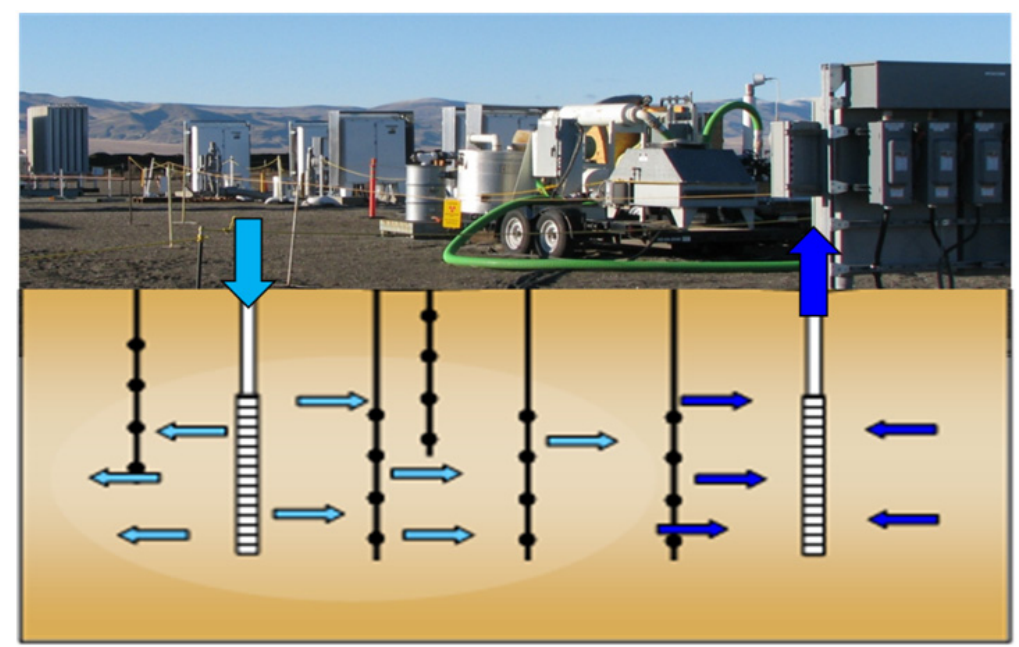

Soil Desiccation Test Site and Depiction of Subsurface Gas Flow
After a targeted portion of the vadose zone is desiccated, rewetting of this zone can occur by vapor- and aqueous-phase moisture transport. The timescale of rewetting is related to the overall performance of desiccation in minimizing contaminant flux to the groundwater. Truex et al. (2011) examined rewetting of desiccated zones in the laboratory and found that vapor-phase rewetting from adjacent humid soil gas, in the absence of advective soil gas movement, occurs slowly by diffusion of water vapor and

increases the moisture content of desiccated porous medium to a limited extent, nominally to near the residual moisture content for the porous medium. The aqueous-phase rewetting rate was found to be a function of the relative aqueous-phase permeability of the porous medium and hydraulic capillary pressure gradients.

Key factors that impact applying desiccation are the initial moisture content, permeability contrasts between adjacent sediment layers, and temperature and relative humidity of the injected gas. Laboratory studies (Truex et al. 2011; Ward et al. 2008; Oostrom et al. 2009, 2012, In Press) and field testing have shown the rate of desiccation is directly related to the water-holding capacity of the injected dry gas, the initial moisture content, and the number of pore volumes of dry gas transported through the porous medium. Because the transport of dry gas is directly related to the permeability of the porous medium, higher permeability zones in soil columns and flow cells packed with heterogeneous media dried more quickly than lower permeability zones (Oostrom et al. 2009, 2012, In Press). Modeling studies (Truex et al. 2011; Ward et al. 2008) demonstrated the desiccation rate is increased with higher temperature and lower relative humidity of the injected dry gas, consistent with laboratory studies where the thermodynamic factors controlling the water-holding capacity of the injected dry gas were correlated with the desiccation rate (Truex et al. 2011; Ward et al. 2008; Oostrom et al. 2009, 2012, In Press). Laboratory studies have also demonstrated the concentration of solutes in the pore water does not significantly affect the desiccation rate for solute concentrations ranging up to $5.8 \mathrm{M}$ of sodium nitrate (Truex et al. 2011).

The field test described herein builds on the above technical basis developed for desiccation and provides information about desiccation that is intended for use in subsequent feasibility studies for waste 
sites with inorganic and radionuclide contaminants in the deep vadose zone. The test was conducted in two steps. The first step was field-scale test site characterization conducted as described in a characterization work plan (DOE 2008b). Results of the characterization effort have been previously reported (DOE 2010a; Um et al. 2009). A field test plan (DOE 2010b) was prepared and used to guide the field testing effort. Laboratory and numerical modeling efforts (Truex et al. 2011; Ward et al. 2008; Oostrom et al. 2009, 2011, 2012, In Press) preceded and accompanied the field test and are incorporated herein as their results pertain to assessment of desiccation for future feasibility studies.

This report is organized following the guidelines for reporting of Comprehensive Environmental Response, Compensation, and Liability Act of 1980 (CERCLA) treatability tests (EPA 1992). Section 2.0 provides the conclusions and recommendations for the study. The test approach is described in Section 3.0, followed by a presentation of the detailed results in Section 4.0. Quality assurance and the cost and schedule for the project are presented in Sections 5.0 and 6.0, respectively. 


\subsection{Conclusions and Recommendations}

\subsection{Overall Conclusions}

The objectives outlined in the field test plan (DOE 2010b) were successfully addressed through the field testing and associated laboratory and modeling efforts conducted as part of this treatability test. In the field test, a portion of the subsurface was desiccated, creating conditions that reduce the rate of moisture and contaminant movement toward the groundwater. A design basis to apply desiccation for vadose zone remediation was developed and is available for use in subsequent feasibility and remedial design efforts. Initial post-desiccation monitoring shows expected rewetting responses with thicker, significantly desiccated zones remaining dry. Overall, the favorable desiccation performance at the 200-BC-1 Operable Unit field test site demonstrates that desiccation is a potential component of the remedy for the vadose zone Tc-99 contamination at this operable unit.

The field test demonstrated that desiccation can be applied at the field scale and reduce subsurface moisture content to levels expected to significantly decrease future water and contaminant movement. The distribution, rate, and extent of desiccation observed in the field were impacted by subsurface heterogeneity; however, over time, the moisture content in initially wetter, lower permeability zones of limited extent was also reduced. Field test results were consistent with expectations based on previous laboratory and modeling efforts that investigated aspects of the desiccation process. Note the field test targeted applying desiccation in a portion of the subsurface with significant contrasts in permeability to enable evaluation of the performance of desiccation across multiple types of subsurface conditions. As discussed in this report, full-scale application of desiccation would seek target depth intervals for dry gas injection that enable creation of thick desiccated zones and avoid zones where injected gas flow would be minimal.

The test results and related laboratory and modeling efforts provide information to guide design and implementation of desiccation. Desiccation observed in the field test was consistent with design calculations and simulations based on the water-holding capacity of the injected gas. Additionally, the distribution of desiccated zones followed expectations with higher permeability zones drying first, but with expansion of desiccation into lower permeability over time. Analysis of data and use of numerical simulations indicate that full-scale designs can be made more cost effective than the design of the field test (which was designed to collect specific data, not as a full-scale remediation) through use of ambient air as the injected dry gas and through use of an injection-only design (i.e., no extraction well).

The overall effectiveness of field-scale desiccation in reducing vertical moisture movement has not yet been fully verified with test monitoring data. Initial monitoring data indicate that redistribution of moisture occurs when active desiccation ceases in thin zones where moisture content reductions were small to moderate and there are adjacent zones that still contain high moisture. Where significant desiccation occurred in thick zones, moisture changes have been negligible during the initial 8 months of the post-desiccation monitoring period. Continued monitoring of moisture conditions at the test site is needed to quantify the rate of rewetting for the desiccated zone as a function of the endstate moisture conditions achieved during testing. This type of additional long-term monitoring is planned as part of the overall treatability test effort and will help in defining appropriate performance targets for desiccation. Assessment of controlling factors for rewetting phenomena show that thicker desiccation zones and lower overall permeability within and surrounding the desiccated zone will result in slower rewetting rates. 


\subsection{Recommendations}

The field test results provide a basis to recommend design features for consideration in future feasibility studies for the vadose zone. A description of key design elements and an example conceptual full-scale desiccation design is presented below to highlight the recommended approach and integrate the primary conclusions from the laboratory, modeling, and field testing efforts conducted as a part of the desiccation treatability test. Rewetting performance monitoring is continuing, so use of the design recommendations in the future should also incorporate any new results from the rewetting aspect of the field test.

\subsubsection{Key Design Elements}

For full-scale desiccation, the following key design elements should be considered and were incorporated into the example design that follows.

- Ambient air can be injected to induce desiccation at the Hanford Site except during ambient conditions when the temperature is above $30^{\circ} \mathrm{C}$ and concurrently, the relative humidity is above $70 \%$ (Section 4.2.4).

- No extraction well is needed as long as the injection well is 1) deep enough that injected air exhaust at the surface is very diffuse; or 2) a gas barrier is used to move injected gas laterally and ensure that injected air exhaust at the surface is very diffuse (movement of air at the surface is only an issue when low temperatures can cause water condensation) (Section 4.2.4).

- Designs can consider heating to $20^{\circ} \mathrm{C}$ to help enhance the desiccation rate and facilitate use of temperature monitoring during desiccation to interpret subsurface gas flow. Potentially, however, systems could operate without heating of air, although some additional operational constraints may be needed.

- While operational time is variable, longer operational time will lead to a larger radius of influence for each injection well. Because the desiccation occurs in both lateral and vertical directions from a well, the design should consider the combination of well screen length, air distribution, well spacing, and operating time to optimize the balance between capital and operational costs. Scoping calculations (Section 4.2.4) and injection simulations (Section 4.2.4) from the treatability test results can be used to help guide these decisions for well spacing. As shown in the example conceptual design, a nominal Hanford Site design with a 10-year operating period leads to a well spacing on the order of $25+\mathrm{m}(2-3$ wells per acre) .

- Temperature changes can be used as a useful indicator of subsurface gas flow and desiccation patterns, with limitations based on the spacing/density of monitoring locations and interpolation uncertainty. Of the other monitoring processes, electrical resistivity tomography (ERT) is likely useful for larger scale applications and can be set to collect data autonomously to provide volumetric images of desiccation progress that would useful in supporting operational decisions (Section 4.2.3).

- Neutron moisture logging provides valuable information about the extent of desiccation at selected locations that can be directly correlated to desiccation performance goals, with limitations based on the spacing/density of monitoring locations. When used jointly with temperature and ERT data, periodic neutron moisture data can guide decisions for when desiccation can be shut down (Section 4.2.3). 
- Post-desiccation monitoring with neutron logging and ERT can be applied to determine the rate of rewetting (moisture re-equilibration within the desiccated zone) and whether additional desiccation cycles are needed (Section 4.2.3).

- Additional desiccation operations can be conducted as needed to continue drying after the first few moisture re-equilibration periods (over a 5- to 10-year period). After the moisture re-equilibration rate slows, rewetting would be mostly driven by surface recharge and would be considered primarily for long-term remedy performance (Section 4.2.2.2).

\subsubsection{Example Conceptual Design}

Using the above design elements, an example conceptual design for full-scale desiccation was developed, nominally covering the areal dimensions $(80$ by $160 \mathrm{~m}$ ) of the cribs portion of the 200-BC-1 Operable Unit. Figure 2.1 shows a conceptual layout of 11 injection wells to cover this area (about 2.5 wells/acre desiccated). Each well uses a 10-m well screen with an injection rate of $1000 \mathrm{cfm}$ (100 cfm per meter of well screen). At this injection rate, the expected injection pressure is less than $20 \mathrm{psi}$ based on the pneumatic properties at the field test site.

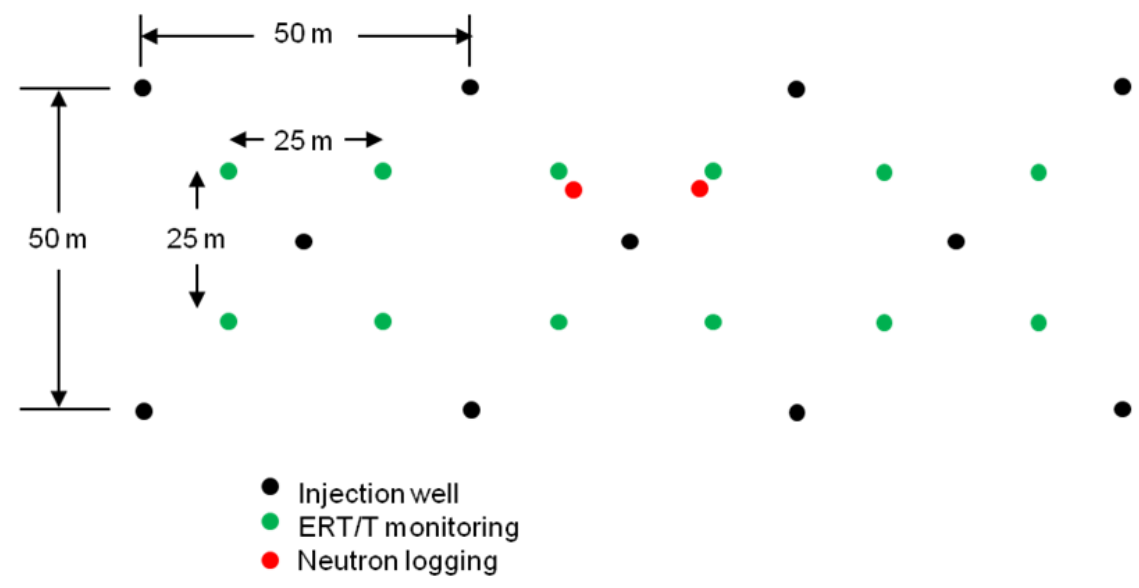

Figure 2.1. Example Well Layout Concept for Cribs Portion of BC Cribs and Trenches

To estimate desiccation volume, it was assumed the volumetric soil moisture content in the desiccated zone needs to be reduced by on average $0.065\left(\mathrm{~m}^{3} / \mathrm{m}^{3}\right)$. Assuming that injection of ambient air is $75 \%$ as efficient as use of anhydrous gas, $0.00017 \mathrm{~m}^{3}$-soil are desiccated for every cubic meter of ambient air injected (see also Section 4.2.4.4). Over a 10-year operating period, the nominal lateral radius of influence from each injection well is about $24 \mathrm{~m}$. For the cribs portion of the 200-BC-1 Operable Unit, it was assumed the desiccation would occur deep enough that a surface gas barrier is not needed during active desiccation (see Section 4.2.4). However, for long-term effectiveness, emplacement of infiltration control at the surface is needed to limit the recharge rate (Truex et al. 2011). For full-scale monitoring, the conceptual design uses two access boreholes installed to conduct neutron moisture logging. Temperature and ERT monitoring are conducted by installing electrodes and thermistors in 12 locations.

A total of 25 boreholes (11 as 4-in. diameter wells screened for injection, 2 as 2 -in. diameter cased wells for neutron probe access, and 12 as boreholes instrumented with thermistors and ERT electrodes) are used in the design. The system would require 11 air blowers capable of $1000 \mathrm{cfm}$ and 20 psi pressure. 
Moderate heating of the injected gas to maintain a minimum of $20^{\circ} \mathrm{C}$ is anticipated to be needed to assist in maintaining desiccation at near $75 \%$ of the rate with anhydrous gas injection. However, a study of average meteorological conditions could be used to refine the design in terms of the need for heating and the portion of the year during which heating would be needed. Thermistor and ERT monitoring could be implemented with data loggers and a data computer for autonomous operation, similar to the system used in the field test. No specific performance modeling or analyses were conducted as part of this example to determine the depth or thickness necessary to meet overall performance requirements for protection of groundwater. Rather, scoping calculations and the key design elements were translated into an example design to address a relevant areal extent for desiccation application and conceptually depict the type of design that future feasibility study evaluations can use based on the information obtained in the treatability test of desiccation.

The base operating period of 10 years was used to obtain desiccation coverage of the targeted area. In future feasibility studies, an assumption of additional desiccation cycles after moisture re-equilibration (estimated as 5 years of no-operation) may be warranted. For these additional cycles, the operating period required would diminish each time because much less moisture would need to be removed. As an estimate, if the first additional cycle needed to remove $25 \%$ of the water removed in the first application, 2.5 years of operation would be required. If the next application needed to remove $50 \%$ of the water removed in the previous application, 1.5 years of operation would be required. The need for these additional desiccation cycles depends on the number and characteristics of low-permeability zones present in the targeted desiccation zone. 


\subsection{Approach}

\subsection{Objectives}

Test objectives were developed and presented in the field test plan (DOE 2010b). These objectives are summarized in the bulleted items below and have the overall goal of providing information about desiccation such that the technology can be effectively evaluated in subsequent feasibility studies for waste sites with inorganic and radionuclide contaminants in the deep vadose zone.

- Design Parameters: Determine the design parameters for applying soil desiccation, including operational parameters such as injected nitrogen flow rate and injected temperature, and identifying soil moisture reduction targets to achieve acceptable reduction of contaminant transport in the vadose zone.

- Desiccation Field Test Performance: Demonstrate field-scale desiccation for targeted areas within the vadose zone.

- Quantify the nitrogen flow, water extraction rate, and other operational parameters to evaluate implementability of the process on a large scale.

- Determine the extent of soil moisture reduction in the targeted treatment zone to evaluate the short-term effectiveness of the process.

- After desiccation is completed, determine the rate of change in soil moisture for the desiccated zone.

- Determine the best types of instrumentation for monitoring key subsurface and operational parameters to provide feedback to operations and evaluate long-term effectiveness.

- Scale-up Assessment: Determine the number of injection and extraction wells, screened intervals, type of equipment and instrumentation, and operational strategy such that costs for full-scale application can be effectively estimated.

\subsection{Experimental Design and Procedures}

The experimental design and procedures are summarized below with subsections on Test Site Background (3.1.1), Test Layout and Operations (3.2.2), Equipment and Materials (3.2.3), Sampling and Analysis (3.2.4), Data Management (3.2.5), and Deviations from the Test Plan (3.2.6).

\subsubsection{Test Site Background}

The field treatability test for desiccation was conducted in the Hanford Site 200-BC-1 Operable Unit, commonly referred to as the BC Cribs and Trenches Area (Figure 3.1). The 6 cribs and 20 trenches at this waste disposal site received about 110 million $\mathrm{L}$ of aqueous waste containing high nitrate and radionuclide concentrations, primarily from Hanford Site operations in the mid-1950s. The site was selected for the field test because relatively high concentrations of mobile Tc-99 contamination and high moisture contents are present at relatively shallow depths, facilitating test operations, yet representing conditions found deeper in the vadose zone where desiccation could be considered as part of a remedy. The test area is located between adjacent waste disposal cribs where the subsurface was impacted by 
lateral movement of crib discharges in the subsurface but drilling and other test operations could take place outside the hazardous footprint of the former disposal cribs. Figure 3.2 shows the vertical stratigraphy, technetium, and moisture distribution at the injection well location in relation to the well screen interval. Porous media grain-size variations in the test interval generally range from sands to loamy sands with some zones of silty sand and silt, similar to the porous media observed throughout the full depth interval.

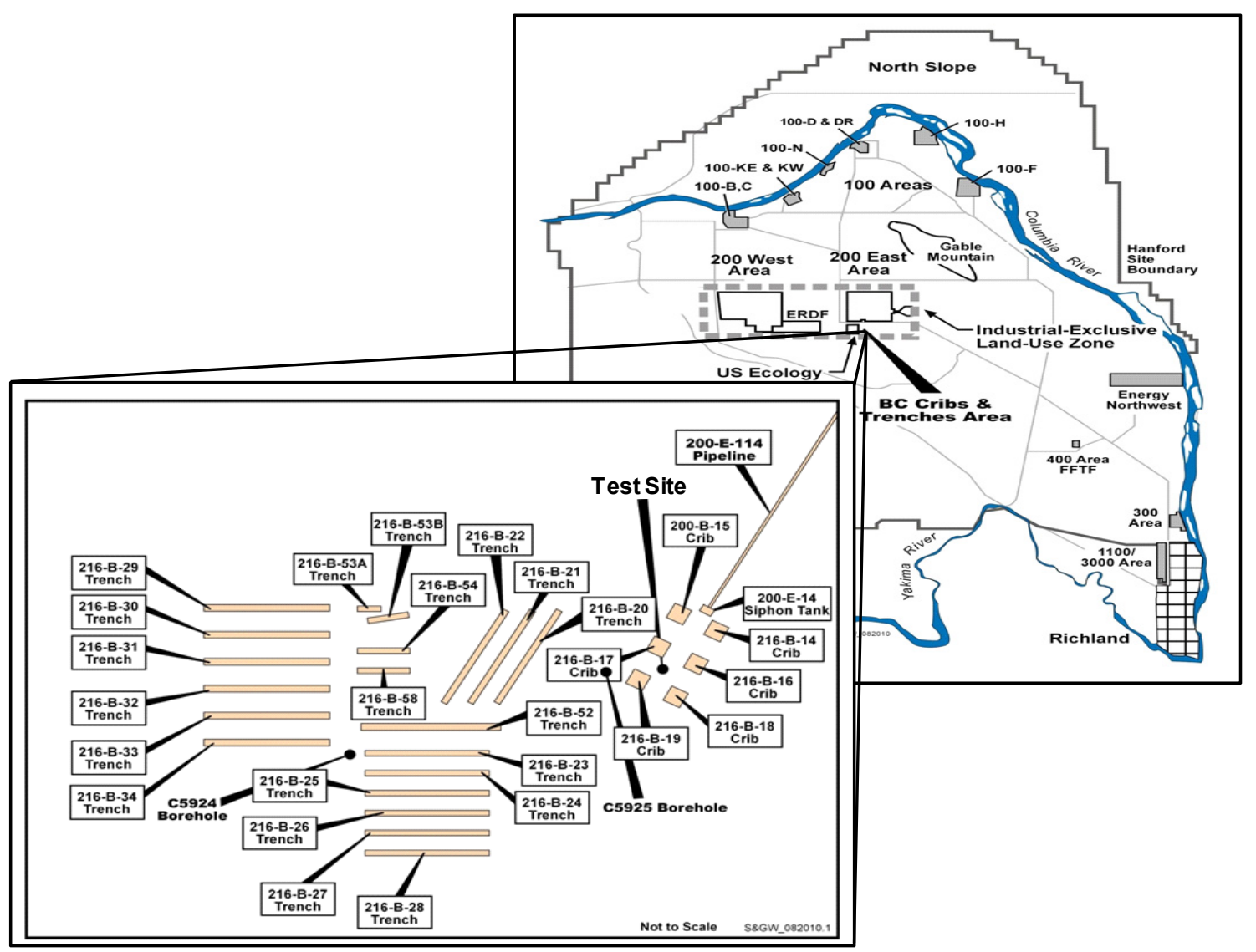

Figure 3.1. Test Site Location in the BC Cribs and Trenches Area (inset, 200-BC-1 Operable Unit) of the Hanford Site (map) (after DOE 2010b). Note the test site is centered around borehole C7523, one of three characterization boreholes (C7523, C7524, C7525) from site investigation activities associated with electrical resistivity studies at the site (Serne et al. 2009).

Previous characterization of the cribs region indicated a plume of mobile contamination beneath the cribs (Serne et al. 2009). Nature and extent of the plume is defined by waste stream composition, the quantity of waste discharged, and the heterogeneity of the vadose zone sediments. At the test site, centered around the 299-E13-62 borehole and located between the 216-B-17 and 216-B-19 Cribs, significant concentrations of Tc-99 and nitrate contamination were observed from approximately $12.2 \mathrm{~m}$ (40 ft) bgs to approximately $76.2 \mathrm{~m}(250 \mathrm{ft})$ bgs. Local contaminant maxima were observed at $15.2 \mathrm{~m}$ $(50 \mathrm{ft}), 27.4-29.0 \mathrm{~m}(90-95 \mathrm{ft}), 38.1-39.6 \mathrm{~m}(125-130 \mathrm{ft})$, and 67.1-70.1 m (220-230 ft) bgs.

Near-surface contamination within the footprint of the 216-B-14 Crib has been characterized by geophysical logging of shallow boreholes (DOE 2009). High concentrations of Cs-137 were observed, 
with peak concentrations located near the bottom of the as-built crib excavation and extending several feet deeper. Sr-90 is expected to coexist with the Cs-137, based on characterization of the 216-B-26 Trench that included sampling for that radionuclide (Ward et al. 2004). Note that in contrast to the excavation-based treatability test (DOE 2009), the desiccation field treatability test avoided highactivity contamination associated with the footprint of the cribs, and instead focused on mobile contamination that has migrated laterally and vertically from the cribs.

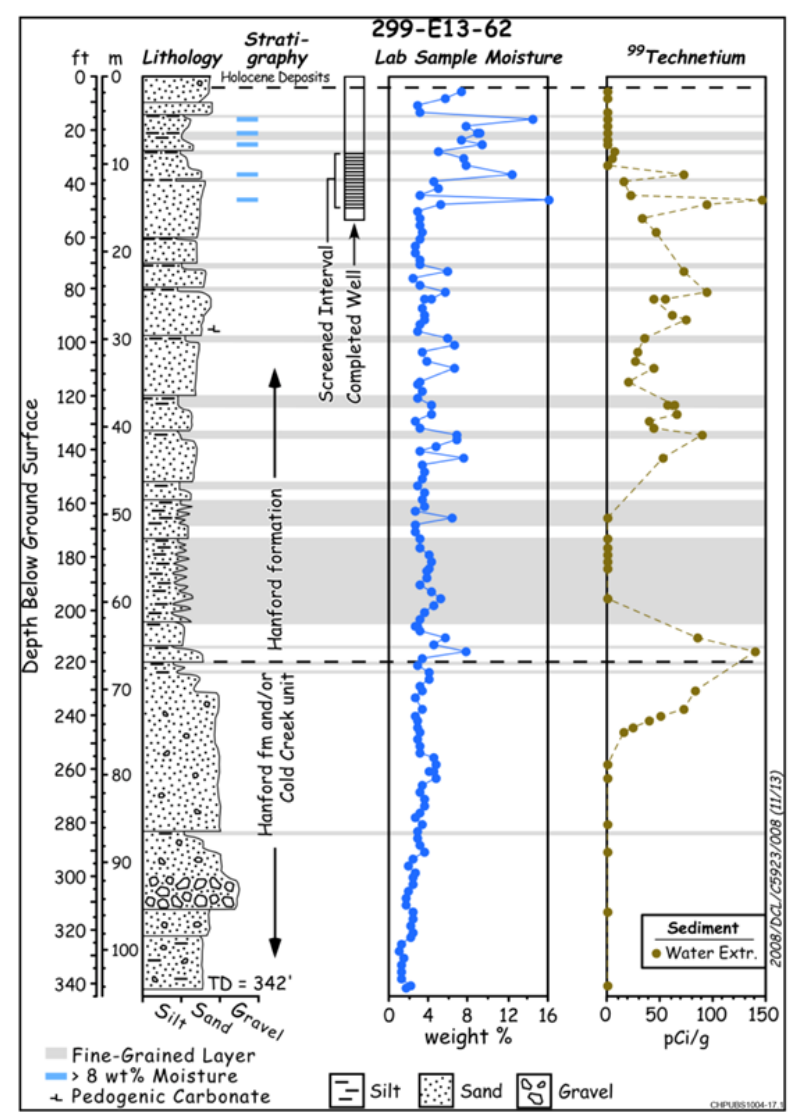

Figure 3.2. Injection Well Borehole Data and Screened Interval (after DOE 2010b)

Although the overall objective of the Deep Vadose Zone Treatability Test Plan is to address groundwater threat from mobile contaminants deep in the vadose zone, the desiccation field test focused on the shallowest component of significant Tc-99 and nitrate contamination centered near 13.7-15.2 $\mathrm{m}$ (45-50 ft) bgs. Installation of injection/extraction wells and monitoring instrumentation was less costly at this depth while allowing critical elements of soil desiccation to be evaluated. The deep vadose zone was mimicked by covering the ground surface with an impermeable barrier to limit surface interaction with the test injection and extraction operations.

\subsubsection{Test Layout and Operations}

The desiccation technology relies on removal of water from a portion of the subsurface such that the resultant low moisture conditions inhibit downward movement of water and dissolved contaminants. Implementation requires establishing sufficiently dry conditions within the targeted zone to effectively 
inhibit downward water transport. Nominally, the targeted zone would need to extend laterally across the portion of the vadose zone where contaminants have the potential to move downward at a flux that will impact groundwater above the remediation objective groundwater concentration. Thus, the experimental design was developed to evaluate the process of establishing a desiccated zone that extends laterally away from a dry gas injection well within a specific depth interval of the vadose zone. To obtain this type of desiccation zone, the field test design used a dipole configuration with injection of nitrogen and extraction of soil gas through wells screened in a target depth interval to favor soil gas flow within this interval and within a defined monitoring zone (Figure 3.3).

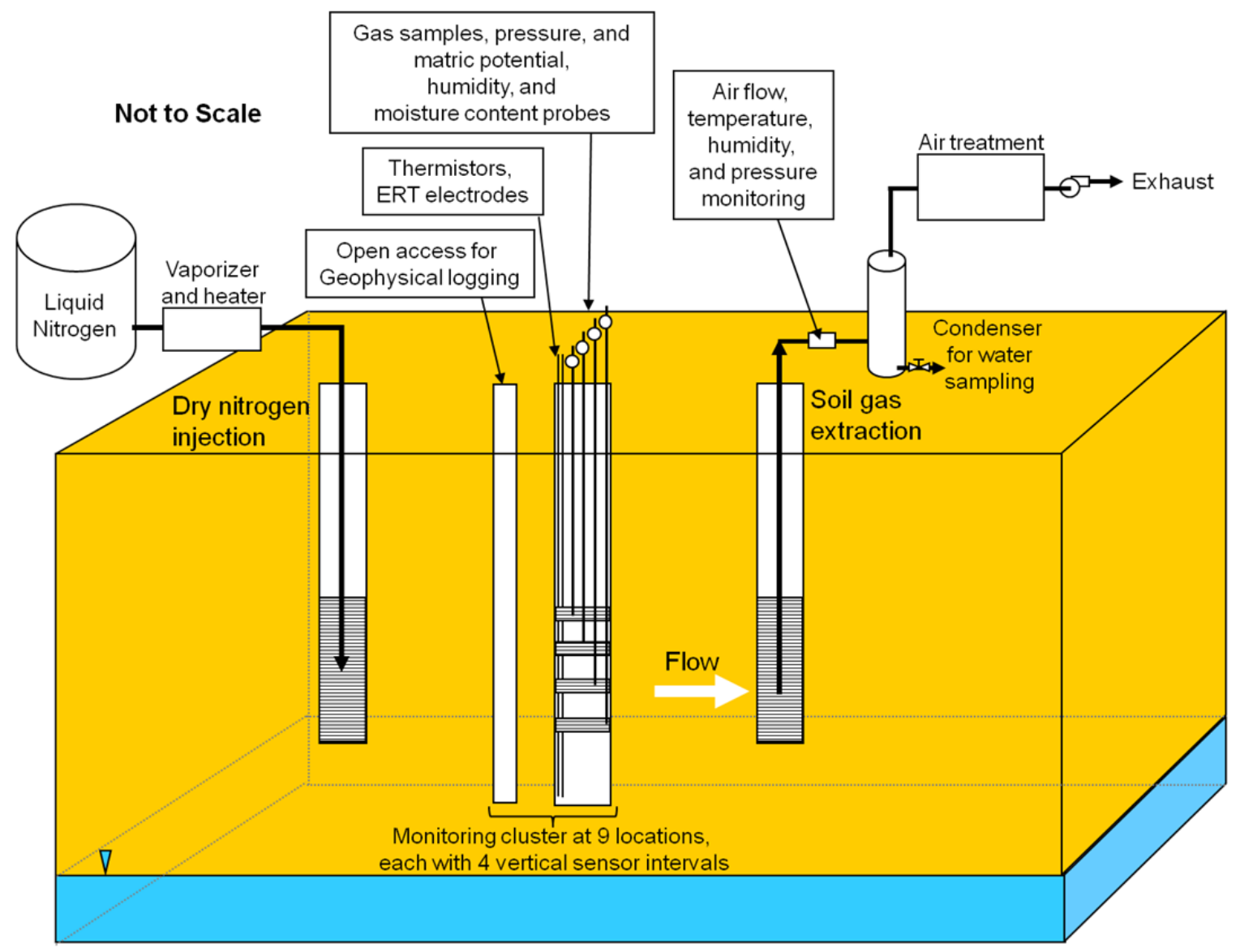

Figure 3.3. Basic Components of the Desiccation Field Test System

The general operational and in situ monitoring strategy is depicted in Figure 3.3. Dry nitrogen gas produced from liquid nitrogen tankers was injected at a controlled temperature of $20^{\circ} \mathrm{C}$ into a screened interval from 9.1 to $15.2 \mathrm{~m} \mathrm{(30} \mathrm{to} 50 \mathrm{ft}$ ) bgs. Equipment testing, including trial nitrogen gas injections and the initial tracer test, occurred between November 22 and December 6, 2010. The active desiccation portion of the field test occurred with nitrogen injection at a stable flow rate of $510 \mathrm{~m}^{3} / \mathrm{h}(300$ cubic feet per minute [cfm]) from January 17, 2011, through June 30, 2011, (164 days) except during a 13-day interval from April 21 through May 4, 2011, when there was no injection. Extraction of soil gas from a well screened from 9.1 to $15.2 \mathrm{~m}$ ( 30 to $50 \mathrm{ft}$ ) bgs was maintained for the full test duration at a stable flow rate of $170 \mathrm{~m}^{3} / \mathrm{h}(100 \mathrm{cfm})$. Extracted soil gas was routed through a heat exchanger to condense water that was collected and periodically sampled. The injection and extraction wells were 12-m apart. 
Figure 3.4 depicts the lateral layout of injection and extraction wells and the monitoring locations. Distances from the injection well to the monitoring locations are listed in Table 3.1. A 30-m by 45-m gas-impermeable membrane barrier was installed at the surface centered over the well network.

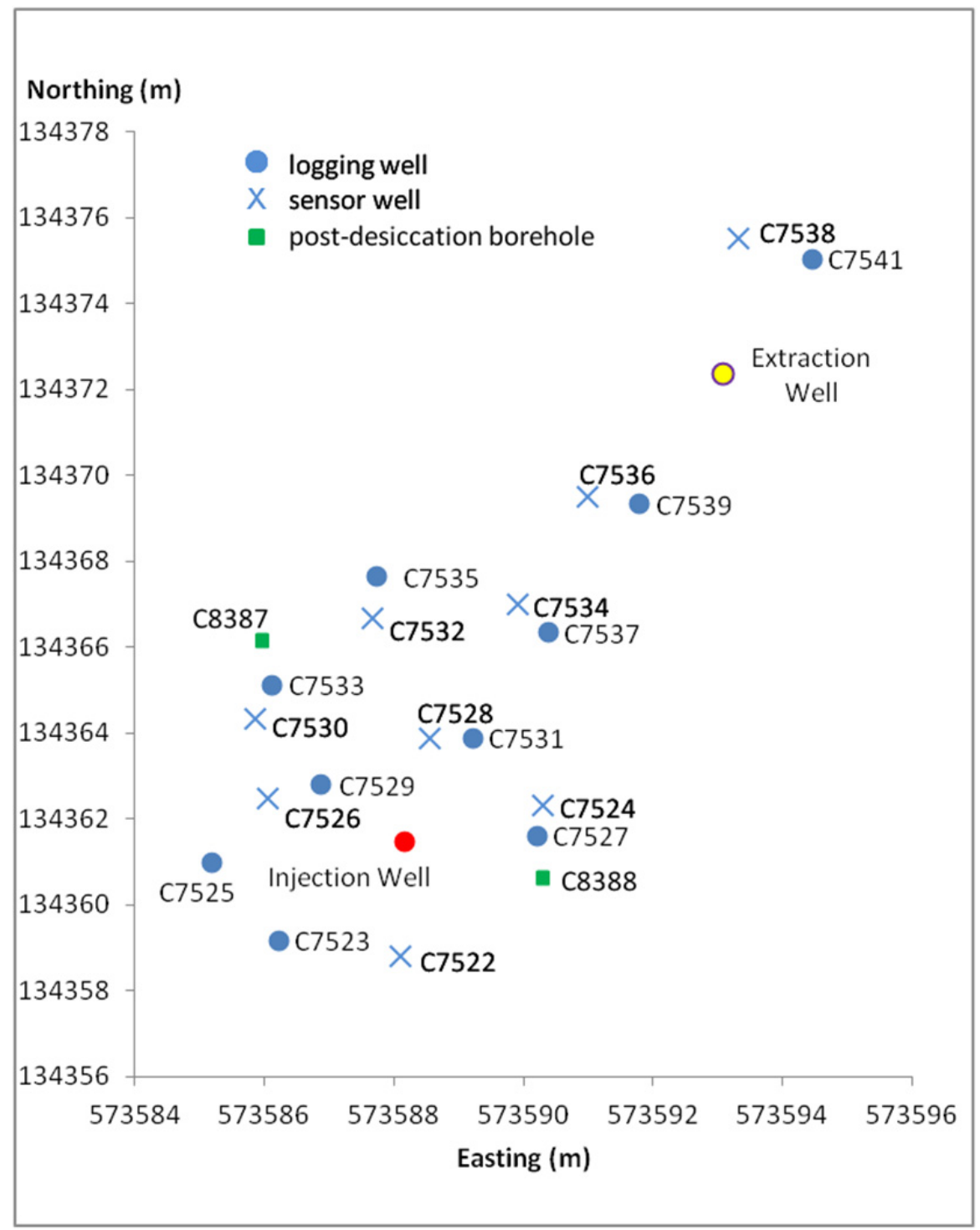

Figure 3.4. Location of Test Site Logging Wells, Sensor Boreholes, and Post-Desiccation Boreholes for Collection of Sediment Samples. A background sensor borehole (C7540, not shown) was $15 \mathrm{~m}$ southeast from the injection well. 
Table 3.1. Field Site Monitoring Locations

\begin{tabular}{cc}
\hline $\begin{array}{c}\text { Monitoring } \\
\text { Location }\end{array}$ & $\begin{array}{c}\text { Distance from } \\
\text { Injection Well }(\mathrm{m})\end{array}$ \\
\hline C7526-S & 2.33 \\
C7529-L & 1.85 \\
C7524-S & 2.28 \\
C7527-L & 2.04 \\
C7528-S & 2.43 \\
C7531-L & 2.62 \\
C7522-S & 2.68 \\
C7523-L & 3.02 \\
C7525-L & 3.02 \\
C7530-S & 3.67 \\
C7533-L & 4.18 \\
C7534-S & 5.79 \\
C7537-L & 5.34 \\
C7532-S & 5.22 \\
C7535-L & 6.18 \\
C7536-S & 8.49 \\
C7539-L & 8.64 \\
C7538-S & 14.96 \\
C7541-L & 14.94 \\
\hline An "S" designation is a borehole that contained in situ \\
sensors. An "L" designation is for cased wells that \\
were used for logging access. \\
\hline
\end{tabular}

A clustered monitoring approach was used in the test whereby a borehole (sensor borehole) containing sensors, gas-sampling ports, and electrical resistance tomography electrodes was placed nominally adjacent to a cased, unscreened well (logging well) that was used to conduct neutron moisture logging and for application of cross-hole ground penetrating radar (GPR). Sensor boreholes contained four intervals of 100 -mesh $(>0.125$ and $<0.149 \mathrm{~mm}$ ) Colorado sand (Colorado Silica, Colorado Springs, Colorado) containing matric potential sensors, moisture content sensors, humidity sensors (sensors described in Section 3.2.2.1), and porous polyethylene gas sampling ports (model X-6081, Porex Technologies Corporation) separated by granular bentonite. The sand intervals were placed nominally at 9.5-10.1, 11-11.6, 12.5-13.1, and 14-14.6 $\mathrm{m}(31-33,36-38,41-43$, and 46-48 ft) bgs to provide vertically discrete monitoring across the injection/extraction well screen interval. The boreholes

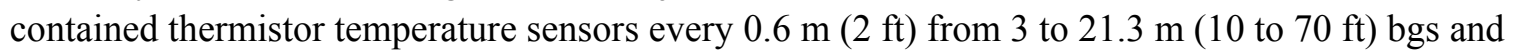

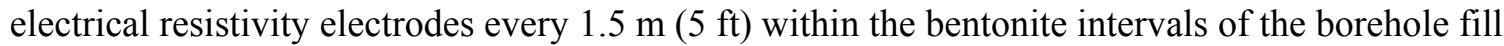
material from 3 to $21.3 \mathrm{~m}$ (10 to $70 \mathrm{ft}$ ) bgs. ERT electrodes were placed within the bentonite zones with tubing installed to enable addition of water around each electrode to locally hydrate the bentonite and maintain effective coupling between the electrode and the subsurface. Electrical connectivity was checked periodically during the test and water added when necessary to maintain adequate coupling. Logging wells to provide access for neutron moisture logging and cross-hole GPR extended to $21.3 \mathrm{~m}$ (70 ft) bgs with a 2-in. polyvinyl chloride (PVC) casing (plugged at the bottom) in a 4-in. diameter borehole and 100-mesh Colorado sand in the annular space. 


\subsubsection{Borehole Sensor Descriptions}

Thermistors (USP8242 encapsulated negative temperature coefficient thermistors, U.S. Sensor, Orange, California) were used to monitor temperature. To achieve accurate temperature measurements over the range of interest, a fifth-order polynomial was used to relate resistance to temperature for each of the thermistors used in the field test. The manufacturer's calibration relationship was verified for a subset of the thermistors in a precision water bath spanning the $0^{\circ} \mathrm{C}-40^{\circ} \mathrm{C}$ temperature range with measured accuracies better than $0.07^{\circ} \mathrm{C}$.

Temperatures were logged continuously (10-minute intervals) at each thermistor. The three-dimensional temperature field was estimated at selected times using the same interpolation technique that was used for the neutron moisture data. In addition to providing important information concerning desiccation progress, the temperature field data are also used to correct the ERT-derived electrical conductivity to a standard temperature prior to using the ERT data for estimating volumetric water content.

Matric potential data were collected using Heat Dissipation Unit (HDU) sensors (229-L HDU, Campbell Scientific, Inc., Logan, UT) to indirectly determine the air-water capillary pressure. A 50-mA current excitation module was used to supply current to the HDU sensors. The HDU temperature was measured prior to heating and again at $1 \mathrm{~s}$ and $30 \mathrm{~s}$ after the onset of heating; these values were used to compute the associated matric potential (Oostrom et al. 2012). The measurement range of the units is typically from -0.01 to $-2.5 \mathrm{MPa}(-0.1$ to -25 bar) with an accuracy of $1 \mathrm{kPa}$ (Flint et al. 2002). The procedure described by Bilskie et al. (2007) was used for HDU calibration, which simplifies the extended procedure forwarded by Flint et al. (2002) by only requiring calibration data in the range up to $-70 \mathrm{kPa}$. Once installed, the sand zones containing the HDU sensors were allowed to equilibrate with the conditions in the native formation before the injection operations were initiated.

Thermocouple Psychrometer (TCP) units (PST-55, Wescor Inc., Logan, UT) were also installed to collect matric potential data. A TCP determines the capillary pressure by essentially making very precise measurements of equilibrium vapor pressure (Brown and Bartos 1982). The capillary pressure is computed using Kelvin's law for vapor pressure lowering. The sensor consists of two adjacent thermocouples. The primary thermocouple is surrounded by a porous membrane or stainless-steel screen that allows contact with the sediment sample. The other thermocouple is sealed in the sensor housing preventing any vapor contact. The temperature depression of the wet sensing junction relative to the dry depends upon the relative humidity of the surrounding air. The units were calibrated in solutions of known water potential. The TCP have a capillary pressure range of -0.2 to $-8 \mathrm{MPa}$ ( -2 to -80 bar) with an accuracy of $30 \mathrm{kPa}$. Practical difficulties in applying this sensor are due to the extreme sensitivity to any thermal differences between the sensor and sample, as well as pressure and temperature effects on the measurement. Sensors were calibrated using $\mathrm{NaCl}$ solutions spanning the capillary pressure range from -0.2 to $-8 \mathrm{MPa}$ ( -2 to $-80 \mathrm{bar}$ ) at temperatures of $10^{\circ} \mathrm{C}, 20^{\circ} \mathrm{C}$, and $30^{\circ} \mathrm{C}$. Twenty-milliliter glass vials were each filled with separate $\mathrm{NaCl}$ solutions and an individual TCP was immersed in the salt solution using caps that centered the TCP within each vial. Using this procedure, a linear relationship between the sensor output and the matric potential was obtained for each sensor over the range from $-0.2 \mathrm{MPa}$ to $-5 \mathrm{MPa}$ (-2 to -50 bar). At larger capillary pressures, the functional dependence became nonlinear for all of the TCPs. 
Dual-Probe Heat Pulse (DPHP) sensors (Specific Heat Sensors, East 30 Sensors, Pullman, WA) were used to measure water content. The sensor type (described in detail in Campbell et al. 1991) consists of two parallel hypodermic tubes separated by a fixed distance. A heating element is placed in one tube and a thermistor or thermocouple is located in the other tube. A controlled heat pulse is generated by the heating element and the temperature rise is measured. The maximum temperature rise $T_{m}\left({ }^{\circ} \mathrm{C}\right)$ for each measurement is related to the soil volumetric heat capacity $C\left(\mathrm{~J}^{\circ} \mathrm{C}^{-1} \mathrm{~m}^{-3}\right)$, probe spacing $r(\mathrm{~m})$, and the amount of heat delivered $q\left(\mathrm{~J} \mathrm{~m}^{-1}\right)$ as follows (Basinger et al. 2000).

$$
T_{m}=\frac{q}{e \pi r^{2} C}
$$

The heat capacity is a composite of the effects from both the liquid and solid components and can be described using the relationship:

$$
C=C_{w} \theta+\rho_{b} c_{s}
$$

where $C_{w}$ is the volumetric heat capacity of water, $\rho_{b}$ is the soil bulk density, and $c_{s}$ is the specific heat of the soil component. The soil volumetric water content can then be estimated by combining Equations (3.1) and (3.2), as follows

$$
\theta=\frac{\left(\frac{q}{e \pi r^{2} T_{m}}-\rho_{b} c_{s}\right)}{C_{w}}
$$

A direct calibration relation was obtained for each of the DPHP sensors. Six different mixtures of water and sediment were made for each porous medium and the maximum temperature rise was subsequently measured for each sensor. For the 100-mesh sand and the Hanford Site sediment, the mixtures consisted of $0,15,30,45,60$, and $75 \mathrm{~g}$ water per $1000 \mathrm{~g}$ porous medium. For the 200-mesh sand, the mixtures were $0,30,60,90,120$, and $150 \mathrm{~g}$ water per $1000 \mathrm{~g}$ porous medium. Calibration of this sensor type was highly dependent on tube separation.

Soil gas relative humidity was monitored using a CS215 capacitive relative humidity and temperature sensor (Campbell Scientific, Inc., Logan, UT) with the electronics integral to the unit. The signal excitation and measurement are all completed within the device, followed by a conversion to a digital signal that can be monitored remotely. The sensing element is housed within a sintered high-density polyethylene filter to protect it from impact and environmental conditions. Each humidity probe is factory calibrated and the accuracy of the device is $2 \%$ within the $10 \%$ to $90 \%$ relative humidity range and $4 \%$ from $0 \%$ to $100 \%$ relative humidity. Temperature dependence is better than $2 \%$; from $20^{\circ} \mathrm{C}$ to $60^{\circ} \mathrm{C}$.

\subsubsection{Neutron Moisture Logging Measurements}

Soil moisture content determination using neutron scattering probes has become a standard method over the past several decades (Hignett and Evett 2002). A neutron probe consists of a high energy neutron source, a low energy or thermal neutron detector, and the electronics required for counting and 
storing the measured response. A fast neutron source placed within moist soil develops a dense cloud of thermal neutrons around it and a thermal neutron detector placed near the source samples the density of the generated cloud. The concentration of thermalized neutrons is affected by both soil density and elemental composition. Elements that absorb neutrons are often in low concentration in the soil solid phase and when clay content is also low, the neutron probe response is mainly affected by changes in moisture content (Greacen et al. 1981; Hignett and Evett 2002). For the desiccation field test, neutron probes were deployed periodically in wells at the site to collect neutron moisture logs with data at discrete depth intervals in the subsurface. Neutron probe data were converted to volumetric moisture content using a site-specific relationship that was developed from core measurements of gravimetric moisture content and bulk density.

Neutron moisture logging was conducted using a CPN 503DR Hydroprobe (InstroTek Inc., Raleigh, NC). Neutron probe measurements were acquired at depth increments of approximately $7.5 \mathrm{~cm}$ using a count time of $30 \mathrm{~s}$ and then converted to count ratio $\left(\mathrm{C}_{\mathrm{R}}\right)$ by dividing each measurement by the standard count. Neutron moisture logging was conducted by S.M. Stoller Corporation at the logging well locations and by Pacific Northwest National Laboratory (PNNL) at the injection well.

Neutron probe data were converted to volumetric moisture content using a site specific relationship that was developed from core measurements of gravimetric moisture content and bulk density. Core samples were collected adjacent to logging location C7527 after the active desiccation phase of the test. For this type of neutron probe, and over the normal range of soil moisture content, the calibration relationship between instrument response and volumetric moisture content for a specific soil is approximately linear (Hignett and Evett 2002). However, numerical instrument response simulations have shown a nearly linear relationship between probe counts and volumetric moisture content over the range from 0.05 to $0.3 \mathrm{~m}^{3} / \mathrm{m}^{3}$, and non-linear behavior at very low moisture contents $<0.05 \mathrm{~m}^{3} / \mathrm{m}^{3}$ (Ward and Wittman 2009; Li et al. 2003).

Soil textures were identified from the post-desiccation core samples ( 6 to $18 \mathrm{~m} \mathrm{bgs}$ ) and ranged from medium sand to loamy sand with the exception of one sample of sandy silt. Clay content can also affect moisture content calibration (Greacen et al. 1981); however clay content was low at the desiccation field site, ranging between $2.4 \%$ and $8 \%$. Using the relationship developed by Greacen et al. (1981), the contribution of the clay hydrogen-equivalent water content was small, ranging from $0.018-0.025 \mathrm{~m}^{3} / \mathrm{m}^{3}$ with a maximum difference of $0.007 \mathrm{~m}^{3} / \mathrm{m}^{3}$ between the soils present at the desiccation field site.

For sites with multiple soil layers, separate linear calibrations for individual soil layers may be appropriate (Yao et al. 2004). Samples were grouped into sand and loamy sand texture materials. Neutron moisture probe $C_{R}$ data were plotted with corresponding post-desiccation laboratory-measured volumetric moisture content (computed using measured gravimetric moisture content and bulk density) from samples at the same depth, laterally within $0.9 \mathrm{~m}$ of the neutron logging well (Figure 3.5). With the assumption that soil moisture content values are not substantially different at that lateral distance from the logging well, the laboratory data can be used to establish a calibration for the neutron moisture probe data. While air flow preferentially occurred through sand layers, adjacent loamy sand layers were also seen to desiccate. For desiccation, very dry conditions $\left(<0.01 \mathrm{~m}^{3} / \mathrm{m}^{3}\right)$ not typically used in neutron probe calibrations were measured within some depth intervals in post-desiccation core samples. While the neutron count ratio data and corresponding laboratory measured moisture content for all samples followed 
a relatively linear relationship above approximately $0.05 \mathrm{~m}^{3} / \mathrm{m}^{3}$, the calibration relationship shows nonlinear behavior at lower moisture content values (Figure 3.5).

Prior to desiccation, the range of moisture contents was $0.05-0.35 \mathrm{~m}^{3} / \mathrm{m}^{3}$ as determined from samples collected during installation of the injection well about $2 \mathrm{~m}$ away from the post-desiccation borehole. Using only samples above $0.05 \mathrm{~m}^{3} / \mathrm{m}^{3}$, a linear calibration relationship is observed for both sand and loamy sand. Post-desiccation volumetric moisture contents for some of the very dry core samples within the highly desiccated zones (loamy sand and sand textures) were $0.004+/-0.002 \mathrm{~m}^{3} / \mathrm{m}^{3}$ from laboratory gravimetric analyses, with corresponding count ratios of $0.21+/-0.007$ (Figure 3.5). For the loamy sand, using the linear relationship based on only samples above $0.05 \mathrm{~m}^{3} / \mathrm{m}^{3}$ would predict a count ratio of 0.34 for a moisture content of $0.004 \mathrm{~m}^{3} / \mathrm{m}^{3}$, substantially different from the actual observations. Linear relationships over the full range of data could be applied but provide a poor fit to the data. For this study, a non-linear neutron probe calibration relationship captures the response for both soil types and provides a better fit to the data over the full range (Figure 3.5). Regression of volumetric moisture content $(\theta)$ (see Appendix A) and $C_{R}$ data for all core samples resulted in the relationship $\theta=0.714 C_{R}{ }^{2}-0.1363 C_{R}$, with a root mean square error of 0.015 for $\theta$ and a coefficient of determination of 0.93 .

Volumetric moisture content values from neutron logging events were interpolated to a finely spaced grid encompassing the logging wells using a weighted inverse-distance interpolation scheme. Due to the high vertical resolution of the data along the logging wells, the corresponding low lateral resolution, and the expected high lateral correlation in moisture content, a 5 to 1 horizontal to vertical weighting was selected in the interpolation. This interpolation provides a smoothed three-dimensional estimate of volumetric moisture content distribution. Subtracting the pre-desiccation interpolation from subsequent interpolations provides an estimated change in volumetric moisture content with time.

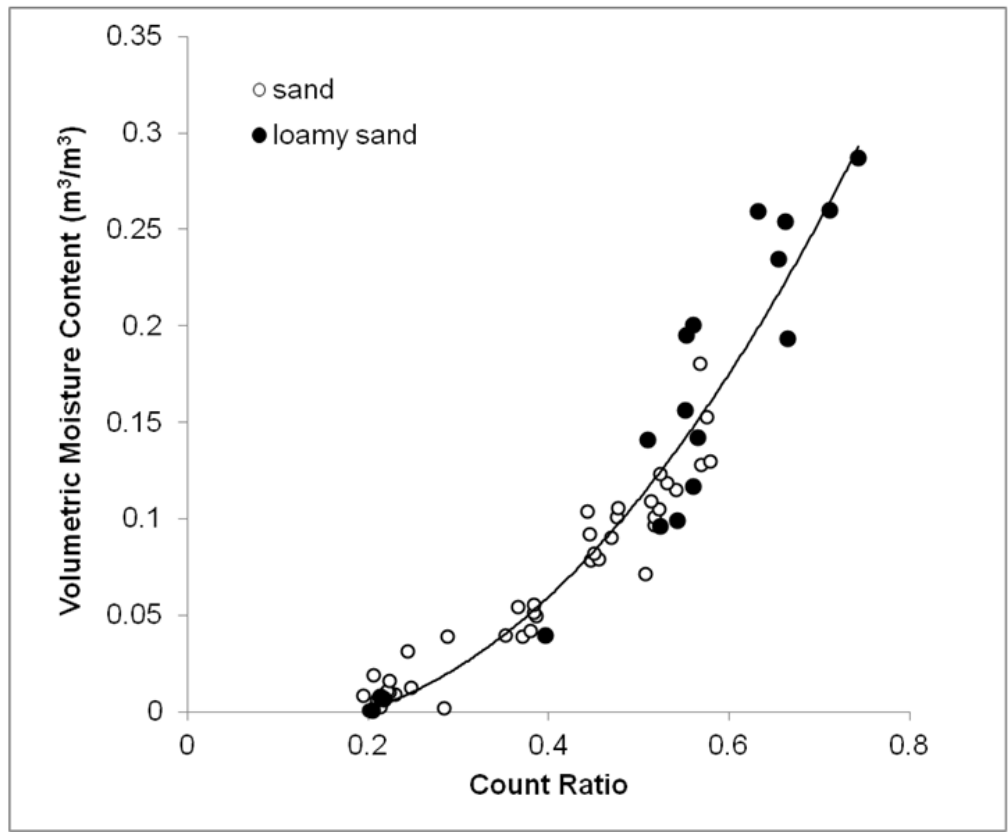

Figure 3.5. Calibration Relation for Neutron Moisture Probe Count Ratio Data and Corresponding Laboratory-Measured Volumetric Moisture Content 


\subsubsection{Cross-Hole Electrical Resistivity Measurements}

ERT is a method of remotely imaging the electrical conductivity (EC) of the subsurface. Electrodes installed along the ground surface and/or within boreholes are used to strategically inject currents and measure the resulting potentials to produce a data set that is used to reconstruct the subsurface EC structure (Daily and Owen 1991; Johnson et al. 2010). With respect to soil desiccation, EC is a useful metric for characterizing the subsurface because it is governed by properties that influence gas flow, including soil texture and moisture content. EC is also a useful metric for monitoring desiccation because it is sensitive to moisture content and temperature (Slater and Lesmes 2002), the two primary properties altered during desiccation.

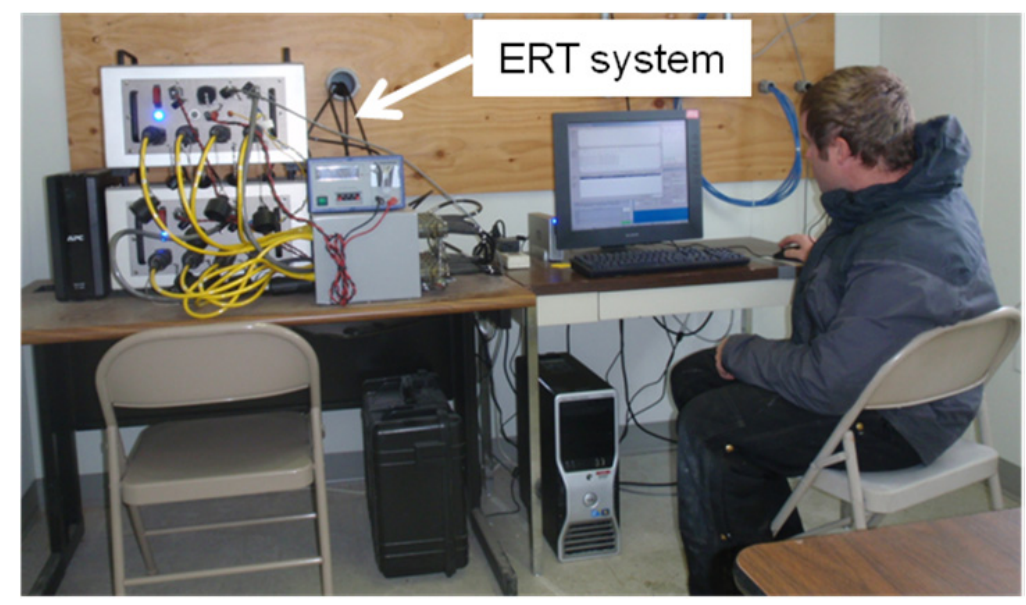

Control System for Electrical Resistivity Tomography
The ERT electrode array deployed in this study was first used to characterize pre-desiccation subsurface structure, providing important three-dimensional information regarding permeability and likely gas flow pathways. During desiccation, the same array was used to image threedimensional changes in EC from background caused primarily by decreasing moisture content but also by evaporative cooling. ERT surveys were collected twice per day, and the resulting changes in EC

were temperature corrected and converted to changes in moisture content using a site-specific laboratory validated relationship (Archie 1942).

ERT data were collected prior to and during desiccation using 99 electrodes - 11 electrodes in each of the 9 sensor wells. Full forward and reciprocal measurements were collected twice per day to estimate data noise and quality, and each data set contained 6114 measurements after filtering. Measurements were collected using an 8-channel MPT DAS-1 impedance tomography system. ${ }^{1}$ These data were inverted with isotropic regularization smoothing constraints on an unstructured tetrahedral mesh with 354,544 elements using the imaging software described by Johnson et al. (2010).

The bulk EC of the subsurface has been widely observed to follow the empirical Archie's Law (Archie 1942) in clean (i.e., clay free), non-conductive sands. Archie's Law is given by Equation (3.4):

$$
E C=\frac{1}{a} \sigma_{f} \emptyset^{m} S_{w}^{n}
$$

where

$$
\begin{aligned}
a & =\text { tortuosity factor } \\
\sigma_{f} & =\text { fluid conductivity } \\
\phi & =\text { porosity }
\end{aligned}
$$

\footnotetext{
${ }^{1} \mathrm{http}: / /$ www.mpt3d.com/.
} 


$$
\begin{aligned}
S_{w} & =\text { water saturation } \\
m & =\text { cementation exponent } \\
n & =\text { saturation exponent. }
\end{aligned}
$$

The relationship between temporal changes in water saturation and the corresponding changes in electrical conductivity that occur during subsurface desiccation are simplified under the following assumptions:

1. Parameters $a, \phi$, and $m$ are constant in time. This assumption is justified if each of these parameters, dependent on the textural properties of the soil, do not change significantly during desiccation.

2. The parameter $\sigma_{f}$ is constant in time. This assumption is not strictly valid because ionic concentrations increase as pore water is evaporated during desiccation. However, $\sigma_{f}$ becomes independent of water content at a critical saturation limit, or the lower saturation limit where mineral precipitation begins. In addition, core-scale testing on site sediments shows the electrical conductivity response to be primarily governed by decreases in saturation as opposed to increases in fluid conductivity during desiccation. Therefore, it was assumed that fluid conductivity did not change during desiccation.

3. The parameter $n$ is independent of saturation. This assumption is generally valid except at low saturation $(<\sim 5 \%)$ where $n$ has been observed to decrease with decreasing saturation (Han et al. 2009; Hamammoto et al. 2010). Laboratory testing on site sediments has shown $n$ to be $\sim 2.0$ within the saturation range indicated by neutron moisture data during the desiccation test.

Because desiccation is a nonisothermal process, the effects of temperature on bulk conductivity must also be considered. The temperature dependence of bulk conductivity in the vadose zone depends on water content, but is always monotonic. A decrease in temperature will cause a corresponding decrease in bulk conductivity and vice versa. Laboratory testing on site sediments showed a temperature dependence of $0.00013 \mathrm{~S} / \mathrm{m} \mathrm{C}^{\circ}$ at $5 \%$ volumetric moisture content and $0.00023 \mathrm{~S} / \mathrm{m} \mathrm{C}^{\circ}$ at $12 \%$ volumetric moisture content, consistent with published values (Friedman 2005; Ruijin et al. 2011). A constant value of $0.00020 \mathrm{~S} / \mathrm{m} \mathrm{C}^{\circ}$ was assumed for the temperature dependence and used to correct all electrical conductivity results to a temperature of $20^{\circ} \mathrm{C}$ based on the interpolated temperature field.

With the assumptions stated in 1-3 above, a desiccation induced change in saturation can be expressed in terms of the corresponding change in bulk conductivity as shown in Equation (3.5):

$$
\frac{S_{t}}{S_{0}}=10^{\frac{1}{n} \log _{10}\left(\frac{E C_{t}}{E C_{0}}\right)}
$$

where $\mathrm{S}_{\mathrm{t}}$ is the saturation at time $t, \mathrm{~S}_{0}$ is the pre-desiccation baseline saturation, and $\mathrm{EC}_{\mathrm{t}}$ and $\mathrm{EC}_{0}$ are the corresponding bulk conductivity at time $t$ and pre-desiccation. Note that the ratios of volumetric moisture content and saturation are equivalent. Thus, the EC data from ERT provide a means to image changes in the volumetric moisture content over time in three dimensions with high temporal resolution due to the ability to autonomously collect ERT data. 


\subsubsection{Cross-Hole Ground Penetrating Radar Measurements}

Ground Penetrating Radar (GPR) methods are also commonly used to characterize or monitor subsurface moisture content. GPR systems consist of an impulse generator which repeatedly sends a particular voltage and frequency source to a transmitting antenna. Cross-hole GPR methods involve lowering a transmitter into a wellbore and measuring the energy with a receiving antenna that is lowered down another wellbore, and moving the transmitting and receiving antennas manually to different positions in the wellbores to facilitate transmission of the energy through a large fraction of the targeted area.

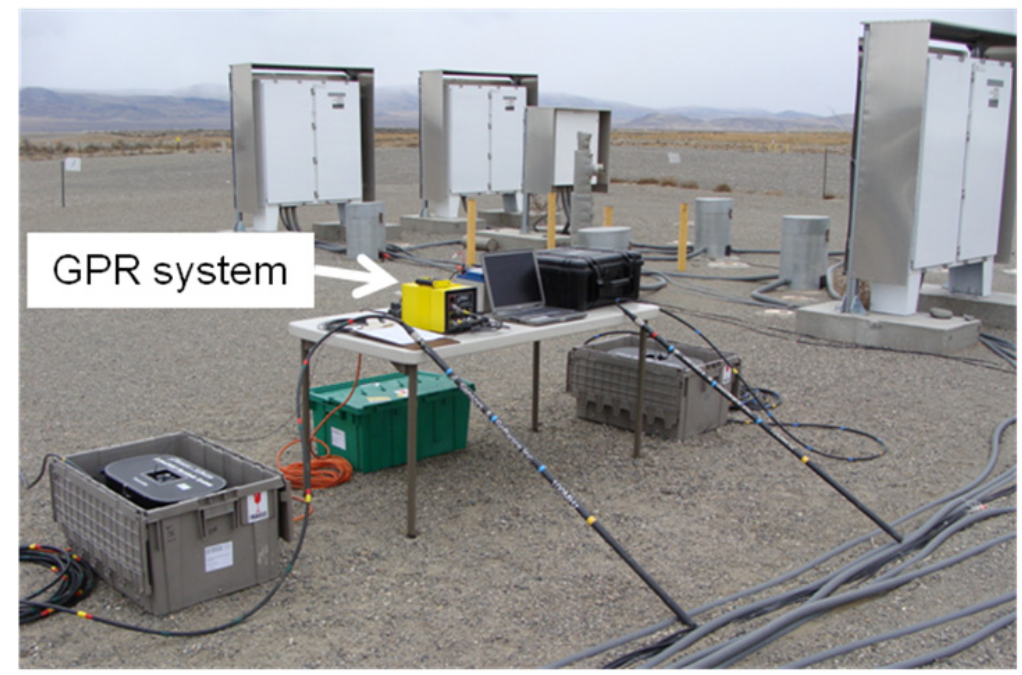

Ground Penetrating Radar Data Collection Equipment
Soil electrical permittivity is strongly dependent on moisture content because of the large difference between water and bulk soil permittivity. The relative permittivity of water is approximately 80 , compared to values between 3 and 7 for typical soil mineral components. The permittivity can be determined from the observed velocity of an electromagnetic pulse propagating through the soil matrix. Studies have demonstrated that GPR methods can effectively estimate subsurface moisture content using measured electromagnetic velocities

(Hubbard et al. 1997; Van Overmeeren et al. 1997; Huisman et al. 2001). At the desiccation site, crossborehole GPR surveys were conducted with the transmitting and receiving antennae for the electromagnetic energy placed in separate boreholes to measure the electromagnetic velocity between boreholes. Using measurements acquired from antennae located at many different vertical positions within each borehole, a two-dimensional image of properties between boreholes can be produced (Jackson and Tweeton 1994). These images can provide information that can be interpreted with respect to the geologic structure and moisture content between boreholes (Binley et. al 2002; Day-Lewis et al. 2002). For the desiccation field test, two-dimensional images of electromagnetic velocity were generated with GPR and converted to volumetric moisture content changes using an established petrophysical relationship assuming low-loss conditions (Topp and Ferré 2002; Evett 2005).

GPR data was collected with a PulseEKKO 100 using $100 \mathrm{MHz}$ borehole antennae (Sensors and Software, Inc. Missasauga, Ontario, Canada). Multiple offset gather surveys were periodically collected in a set of four logging well pairs (using locations C7523, C7531, C7537, C7539, and the injection well). From these data, two-dimensional electromagnetic velocity images were constructed using MIGRATOM, a curved ray inversion software (Jackson and Tweeton 1994).

Electromagnetic velocity is a function of the various electromagnetic properties of the media through which the electromagnetic wave propagates. The material properties are seldom known so to simplify the relationship, assumptions are often adopted. The first assumption is the media does not contain 
significant quantities of ferromagnetic materials such that the magnetic permeability of the media is equal to that of free space. Another assumption is that low-loss conditions are present - that is, the electrical conductivity is much less than the product of the frequency of the electromagnetic wave and the electrical permittivity, and the electromagnetic velocity only depends on the electrical permittivity. When these assumptions are valid, it has been shown that the volumetric moisture content, $\theta$, is a linear function of the square root of the soil apparent electrical permittivity, $\varepsilon_{\mathrm{a}}$ (Ledieu et al. 1986; White and Zegelin 1995; Topp and Ferré 2002):

$$
\theta=A \sqrt{\varepsilon_{a}}+B
$$

The term apparent is used here to mean the permittivity value that is inferred from measurement of the velocity of an electromagnetic wave at a given frequency.

For the desiccation site, a linear regression of GPR-determined electromagnetic velocity values in the vicinity of each logging well and the corresponding neutron moisture data were used to determine the coefficients A and B in Equation (3.6). At the desiccation site, the electrical conductivity varies between $0-0.250 \mathrm{~S} / \mathrm{m}$ and the low-loss assumption is not valid at all locations. Only data from locations with electrical conductivity less than $0.025 \mathrm{~S} / \mathrm{m}$ were used in determining the coefficients A and B and were found to be very close to those obtained from the modified form of Topp's equation (Topp and Ferré 2002). Given the good fit to data from the field site, Topp's equation was used to convert GPR-derived permittivity to volumetric moisture content. Note this approach is a standard method to estimate moisture content from GPR data with the above assumptions. Interpretation of GPR data for conditions with higher electrical conductivity may be impacted by violation of the low-loss assumption.

\subsubsection{Gas-Phase Tracer Test System}

To examine subsurface gas flow patterns of the injected gas, a tracer test was conducted at the beginning of desiccation operations. Because pure nitrogen gas was used as the injected gas and the subsurface soil gas prior to injection contained nominally atmospheric concentrations of oxygen, the breakthrough of injected nitrogen gas was determined by monitoring the displacement of oxygen. Oxygen concentrations were monitored at the gas-sampling ports during initial nitrogen injection operations with an injection flow rate of $510 \mathrm{~m}^{3} / \mathrm{h}$ $(300 \mathrm{cfm})$ and extraction of soil gas at $170 \mathrm{~m}^{3} / \mathrm{h}(100 \mathrm{cfm})$ at the extraction well, the same flow conditions that were used for the full desiccation operational period. Zirconium oxide sensors (model 65 oxygen probe analyzer, Advanced Micro Instruments, Huntington Beach, California) were used to measure oxygen

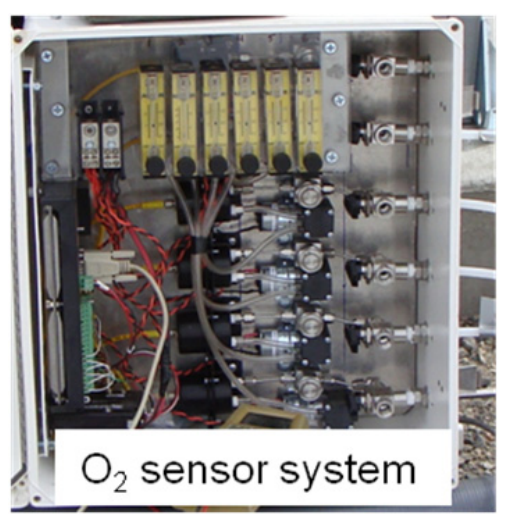

Tracer Test Oxygen Sensor System concentration in extracted soil gas. Soil gas was extracted from sampling ports and routed through the oxygen sensors with a gas pump (model UNMP830 KNDC, KNF Neuberger Inc., Trenton, New Jersey). A gas flow rate of $0.5 \mathrm{~L} / \mathrm{min}$ was metered and measured with an adjustable flow meter (model FMA-4491, Advanced Equipment Inc.) and maintained throughout the duration of the tracer test. An array of six independent oxygen sensor, pump, and flow meter assemblies 
were used to simultaneously measure oxygen levels at different sampling ports. A data acquisition and control system (model CR1000, Campbell Scientific Inc., Logan, UT) was used to record the sensor output.

\subsubsection{Above Ground Equipment and Overall Data Collection System}

Figure 3.6 shows the general test layout including the primary above-ground equipment for gas injection and extraction.

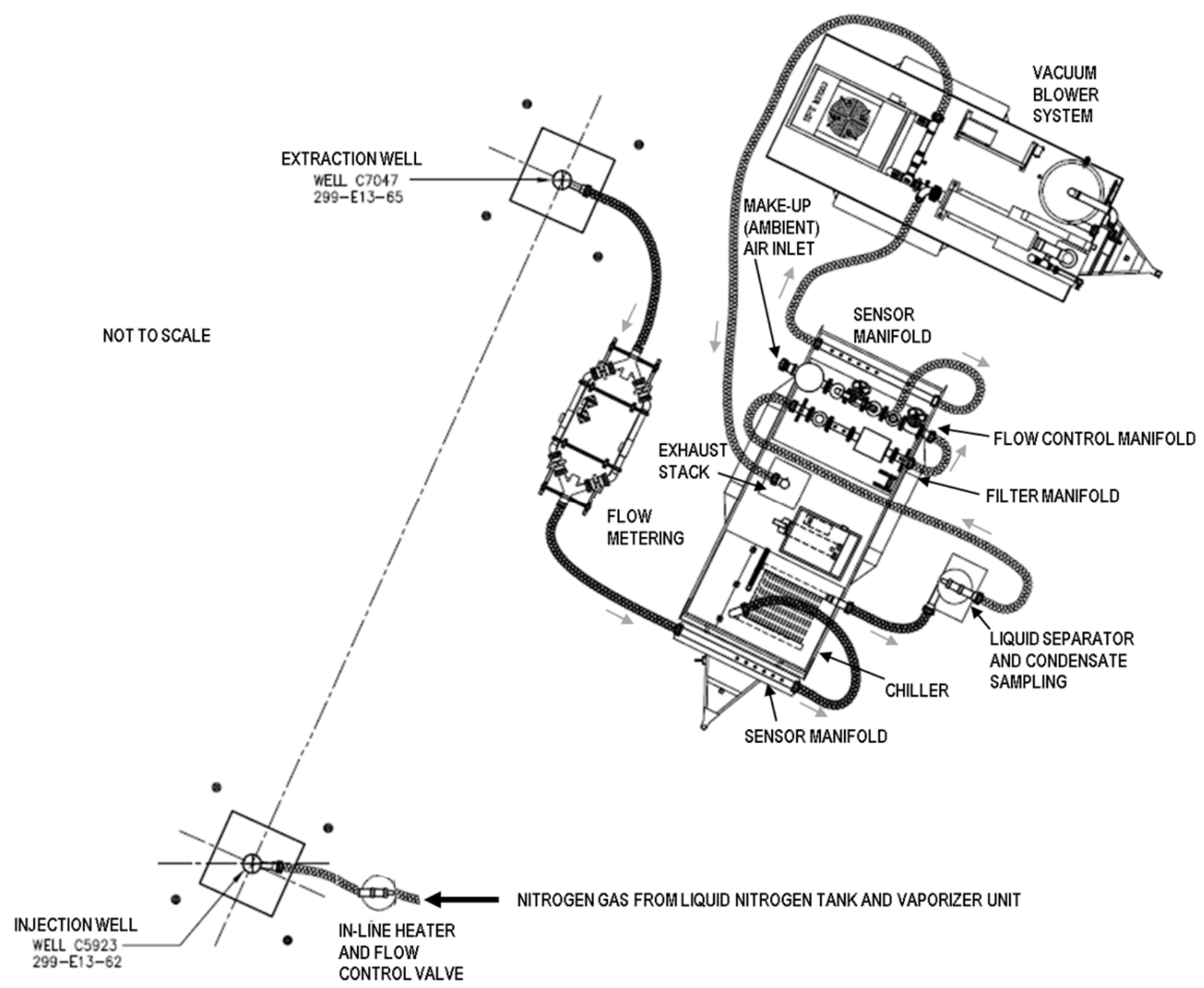

Figure 3.6. Test Site Injection and Extraction Equipment 
Injection System. Liquid nitrogen tankers (two, 5000 gallon) were connected to a vaporizer unit to provide the gaseous nitrogen source for injection. An in-line heater with a temperature controller was used to maintain the injection temperature at $20^{\circ} \mathrm{C}$ (except during portions of June when an ambient temperature of greater than $20^{\circ} \mathrm{C}$ caused the injection gas temperature to be higher than $20^{\circ} \mathrm{C}$ ). Nitrogen gas was plumbed to the injection well which was configured to enable gas injection and provide access for geophysical measurements through a stilling well (Figure 3.7). Data collected for the injection system included a manual log of nitrogen use and electronic sensors and logging for nitrogen gas flow rate and temperature.

\section{$\mathrm{N}_{2}$ vaporizers}

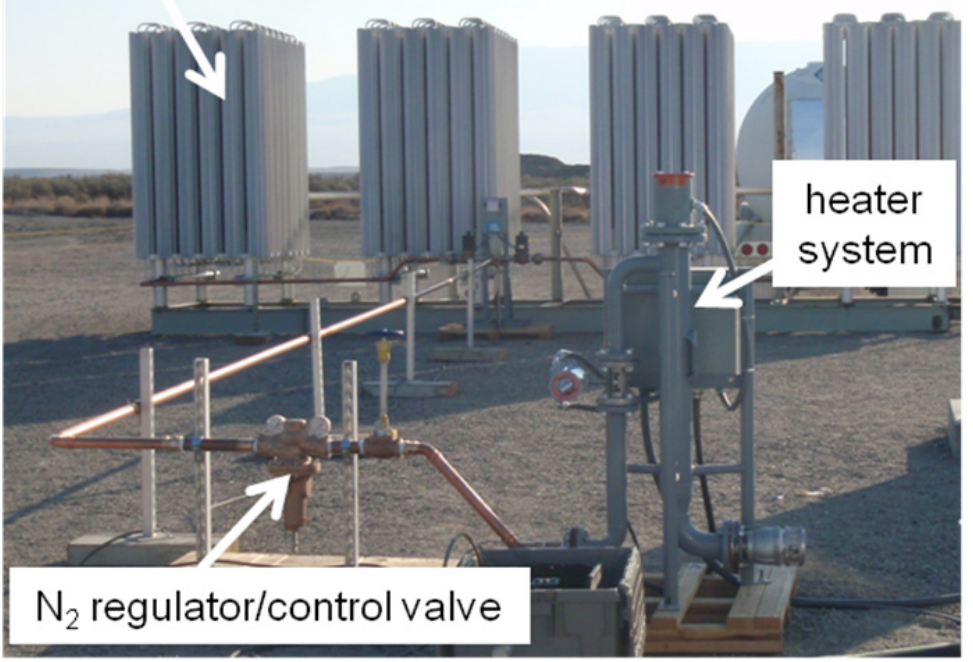

Nitrogen Gas Injection System

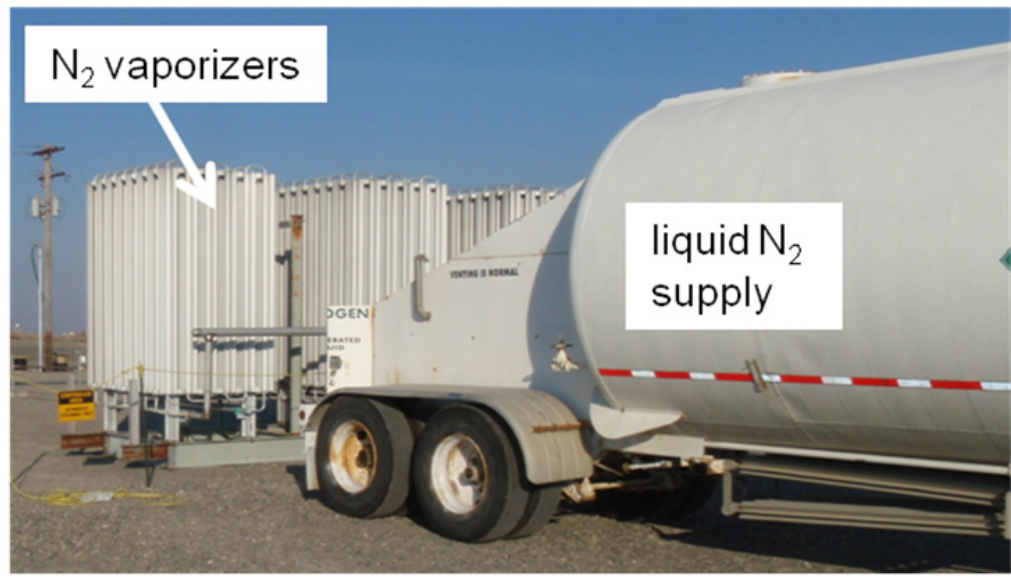

Liquid Nitrogen Supply to Produce Nitrogen Gas for Injection 


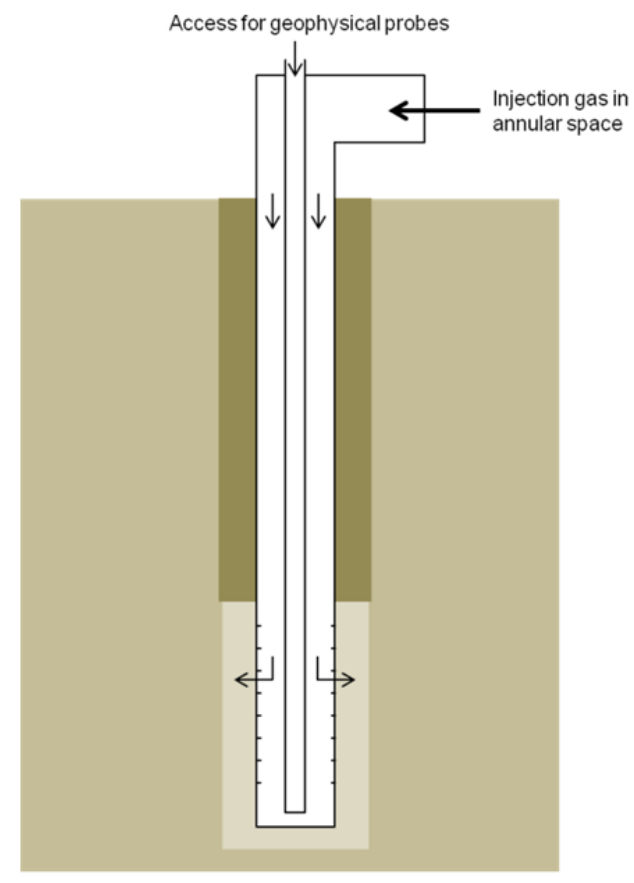

Figure 3.7. Stilling Well Design for Desiccation Field Test

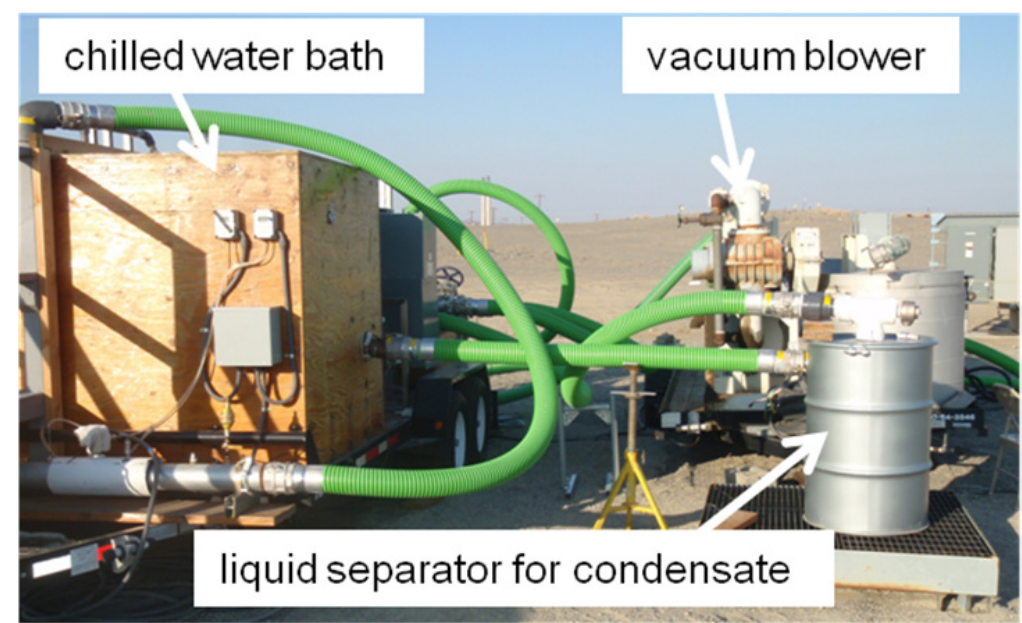

Major Extraction System Components
Extraction System. A vacuum blower system that had been previously used at the 200-PW-1 Operable Unit was used to extract soil gas from the extraction well. The extraction well was plumbed to a manifold with sensors for gas flow rate, temperature, pressure, and relative humidity. The gas was then routed through a custom-built chilled water bath and a commercial liquid separator drum to remove water from the extracted gas. Gas was then routed through a HEPAgrade filter and then to the vacuum blower which exhausted to

atmosphere. Gas flow rate was controlled by a valve that enabled throttling of the extraction well gas flow and a valve that controlled the amount of makeup air added to the system just upstream of the blower. Gas flow rate, temperature, and pressure were monitored using sensors just up and down stream of the blower.

Data Collection System. Sensor data for the field test were collected using CR3000 (Campbell Scientific Inc., Logan, Utah) data loggers (DPHP, HDU, Thermistor, Pressure transducer, and Flow meters) or CR7X data loggers (TCP sensors). The separate data logger was used for the thermocouple psychrometers because these sensors generate extremely low voltage signals and required the use of 
electronics capable of measuring nanovolt level signals. Data were continuously and automatically retrieved from the data loggers and stored on a Dell T3400 computer located at the field site. A Raven X cellular phone modem (Sierra Wireless, Richmond, British Columbia, Canada) was installed which allowed for remote monitoring of the data acquisition system and data transfer.

\subsubsection{Equipment and Materials}

Primary equipment and materials for the test are summarized in Section 3.2.2.

\subsubsection{Sampling and Analysis}

Condensate collected in the liquid separator (Figure 3.6) was periodically drained and transferred to waste storage drums for subsequent waste disposal. During draining operations on December 2, 2010, February 3, 2011, and June 13, 2011, samples were collected and sent to the laboratory for analysis of Tc-99, nitrate, and gross beta concentrations.

\subsubsection{Data Management}

Data from sensors was maintained on both data loggers and an on-site computer and backed up periodically to an office computer. Sensor data were imported to spreadsheets at least twice per month during active desiccation and every 3 months during the rewetting phase. The spreadsheets were used to convert raw sensor data to the required outputs, to plot results, and to serve as an additional data storage file for the plotted data. Manual test logs were maintained to document primary test events and for operations where no electronic sensor was available (e.g., condensate collection). The electronic and manual data are stored as part of CHPRC and PNNL project records and are documented in the following project reports and in this report.

- Truex MJ, M Oostrom, VL Freedman, C Strickland, and AL Ward. 2011. Laboratory and Modeling Evaluations in Support of Field Testing for Desiccation at the Hanford Site. PNNL-20146, Pacific Northwest National Laboratory, Richland, Washington.

- Um W, RJ Serne, MJ Truex, AL Ward, MM Valenta, CF Brown, C Iovin, KN Geiszler, IV Kutnyakov, ET Clayton, H-S Chang, SR Baum, and DM Smith. 2009. Characterization of Sediments from the Soil Desiccation Pilot Test (SDPT) Site in the BC Cribs and Trenches Area. PNNL-18800, Pacific Northwest National Laboratory, Richland, Washington.

- DOE. 2010a. Characterization of the Soil Desiccation Pilot Test Site. DOE/RL-2009-119, Rev. 0, U.S. Department of Energy, Richland Operations Office, Richland, Washington.

- Ward AL, M Oostrom, and DH Bacon. 2008. Experimental and Numerical Investigations of Soil Desiccation for Vadose Zone Remediation: Report for Fiscal Year 2007. PNNL-17274, Pacific Northwest National Laboratory, Richland, Washington.

Additional test data are documented in the following journal articles and conference proceedings.

- Truex MJ, TC Johnson, CE Strickland, JE Peterson, and SS Hubbard. 2012. "Monitoring Vadose Zone Desiccation with Geophysical Methods." Submitted to Vadose Zone Journal. 
- Oostrom M, VL Freedman, TW Wietsma, and MJ Truex. In Press. "Effects of Porous Medium Heterogeneity on Vadose Zone Desiccation: Intermediate-Scale Laboratory Experiments and Simulations." Vadose Zone Journal.

- Truex MJ, M Oostrom, CE Strickland, GB Chronister, MW Benecke, and CD Johnson. In Press. "Field-Scale Assessment of Desiccation Implementation for Deep Vadose Zone Contaminants." Vadose Zone Journal.

- Chronister GB, MJ Truex, and MW Benecke. 2012. "Soil Desiccation Techniques - Strategies for Immobilization of Deep Vadose Contaminants at the Hanford Central Plateau." In Proceedings of Waste Management Symposia 2012.

- Truex MJ, M Oostrom, JE Szecsody, CE Strickland, GB Chronister, and MW Benecke. 2012. "Technical Basis for Gas-Phase Vadose Zone Remediation Technologies at Hanford: A Review." In Proceedings of Waste Management Symposia 2012.

- Oostrom M, TW Wietsma, CE Strickland, VL Freedman, and MJ Truex. 2012. "Instrument Testing during Desiccation and Rewetting at the Intermediate Laboratory Scale. Vadose Zone Journal, doi:10.2136/vzj2011.0089.

- Oostrom M, GD Tartakovsky, TW Wietsma, MJ Truex, and JH Dane. 2011. "Determination of Water Saturation in Relatively Dry and Desiccated Porous Media Using Gas-Phase Partitioning Tracer Tests. Vadose Zone Journal 10:1-8; doi:10.2136/vzj2010.0101.

- Oostrom M, TW Wietsma, JH Dane, MJ Truex, and AL Ward. 2009. "Desiccation of Unsaturated Porous Media: Intermediate-Scale Experiments and Numerical Simulation." Vadose Zone Journal 8:643-650.

\subsubsection{Deviations from Work Plan}

The field test plan was followed for the test with the following exception. While initial results with gas-phase tracers for monitoring desiccation were favorable in artificial porous media, Oostrom et al. (2011) showed that significant sorption of all gas-phase tracers, even those injected as conservative tracers, occurred once sediments were desiccated. Because the injection point for the tracers would have been the injection well where significant desiccation occurs rapidly, gas-phase tracers were not viable for the test. Instead, the oxygen displacement tracer technique described in Section 3.2.2.4 was applied to evaluate soil gas flow patterns. 


\subsection{Detailed Results}

Results of the field test are presented in the next two sections. First, the results from sensors and geophysical monitoring are presented in Section 4.1. The data are then assessed with respect to the field test objectives in Section 4.2.

\subsection{Field Data Summary}

The field test of desiccation was conducted to collect data on technology implementation (Section 4.1.1), to quantify the performance of the desiccation process (Section 4.1.2), to quantify the stability of the desiccated zone (i.e., the rate of rewetting) (Section 4.1.3), and to evaluate field performance of monitoring instruments (Section 4.1.4). The sections below compile the data with respect to each of these basic field test elements.

\subsubsection{Desiccation Implementation}

Implementation of an in situ technology needs to consider the subsurface properties of the target application site. For the field test, these types of data were collected to set a baseline for the desiccation operations (Section 4.1.1.1). Operational data were then collected during the test to describe test conditions (Section 4.1.1.2) as a foundation for interpreting the sensor and geophysical data that are indicators of subsurface desiccation performance (Section 4.1.2).

\subsubsection{Pre-Desiccation Data}

Bulk air permeability. Step and constant rate discharge tests were conducted as described in Characterization of the Soil Desiccation Pilot Test Site (DOE 2010a). These data can be used to evaluate the injection and extraction pressure requirements.

Vertical distribution of permeability. At the injection and extraction well locations, particle size distribution and neutron logging information are available (DOE 2010a; Serne et al. 2009; Um et al. 2009). The vertical distribution of permeability is related to the distribution of injected gas flow. As shown by laboratory and field data, finer, wetter zones will dry more slowly than coarser, dryer zones.

Initial moisture and contaminant distribution. Borehole neutron logs and laboratory analysis of samples were conducted to evaluate the vertical distribution of moisture and contaminant concentrations at the injection and extraction well locations (Figure 4.1) (Serne et al. 2009; Um et al. 2009). In addition, interpolated pre-desiccation neutron logging data (Figure 4.2) and 2-D cross-hole GPR images (Figure 4.3) provide an interpretation of the initial distribution of moisture. The baseline ERT conductivity image (Figure 4.4) can also be interpreted in terms of lithology and contaminant distributions. 


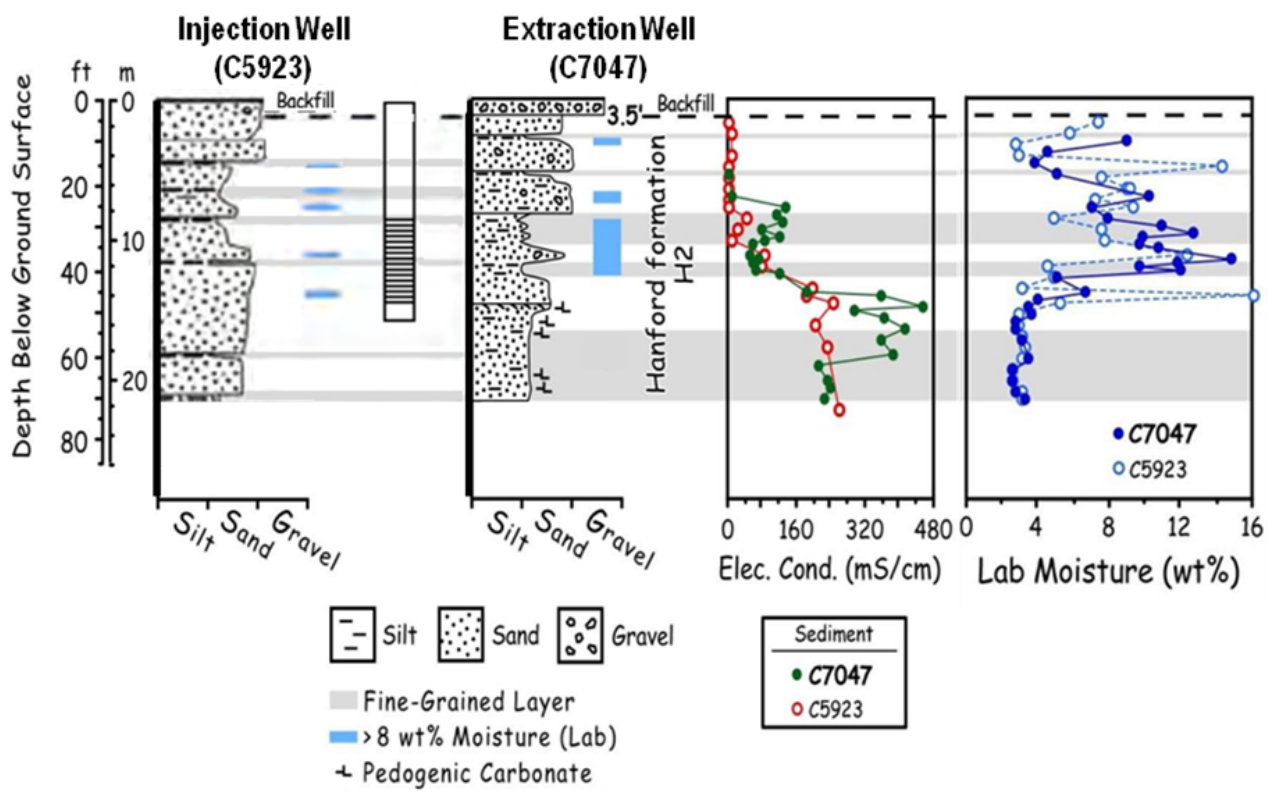

Figure 4.1. Injection and Extraction Well Borehole Initial Laboratory Moisture Content, Extracted Pore Water Electrical Conductivity, and Well Screened Interval (after DOE 2010a; Serne et al. 2008; Um et al. 2009)

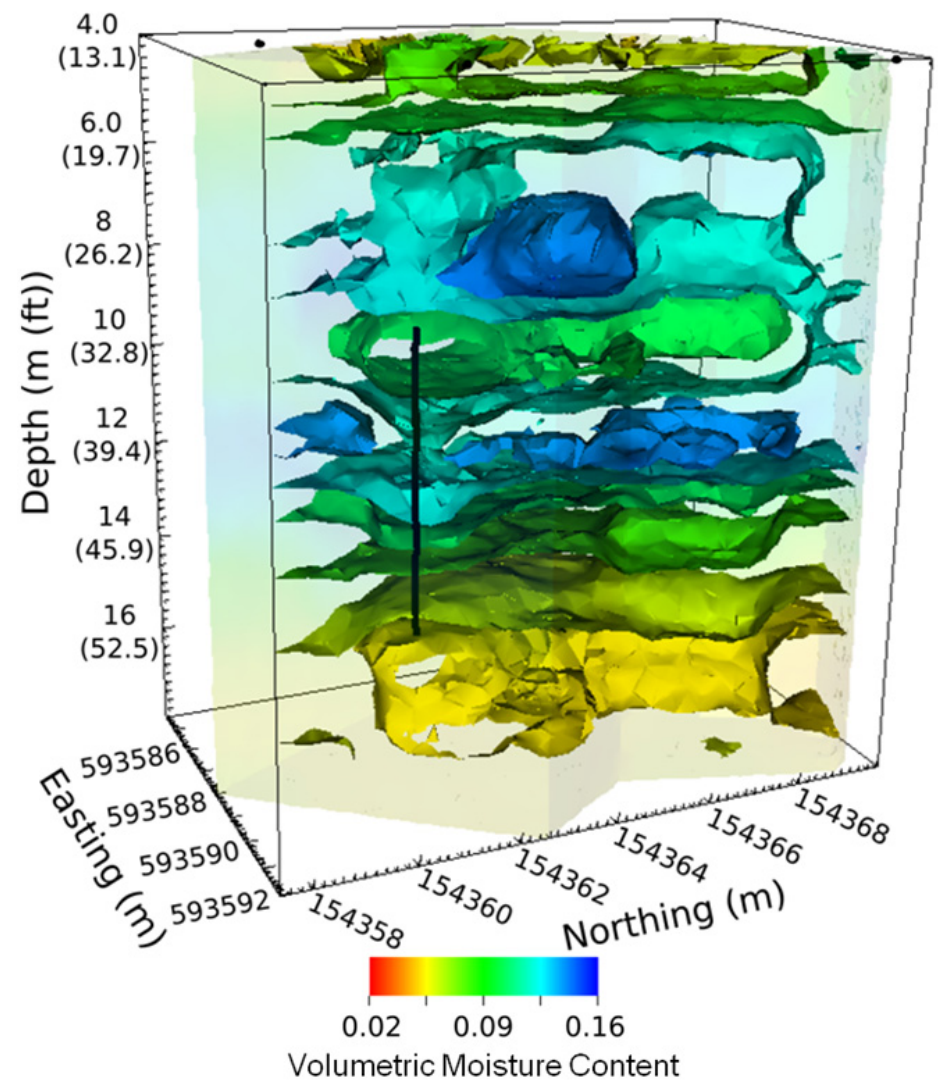

Figure 4.2. 3-D Interpolation of Initial Volumetric Moisture Content from Neutron Moisture Logging Data Prior to Desiccation. Neutron moisture data from are from logging at locations C7523-C7537 (Figure 3.4). 


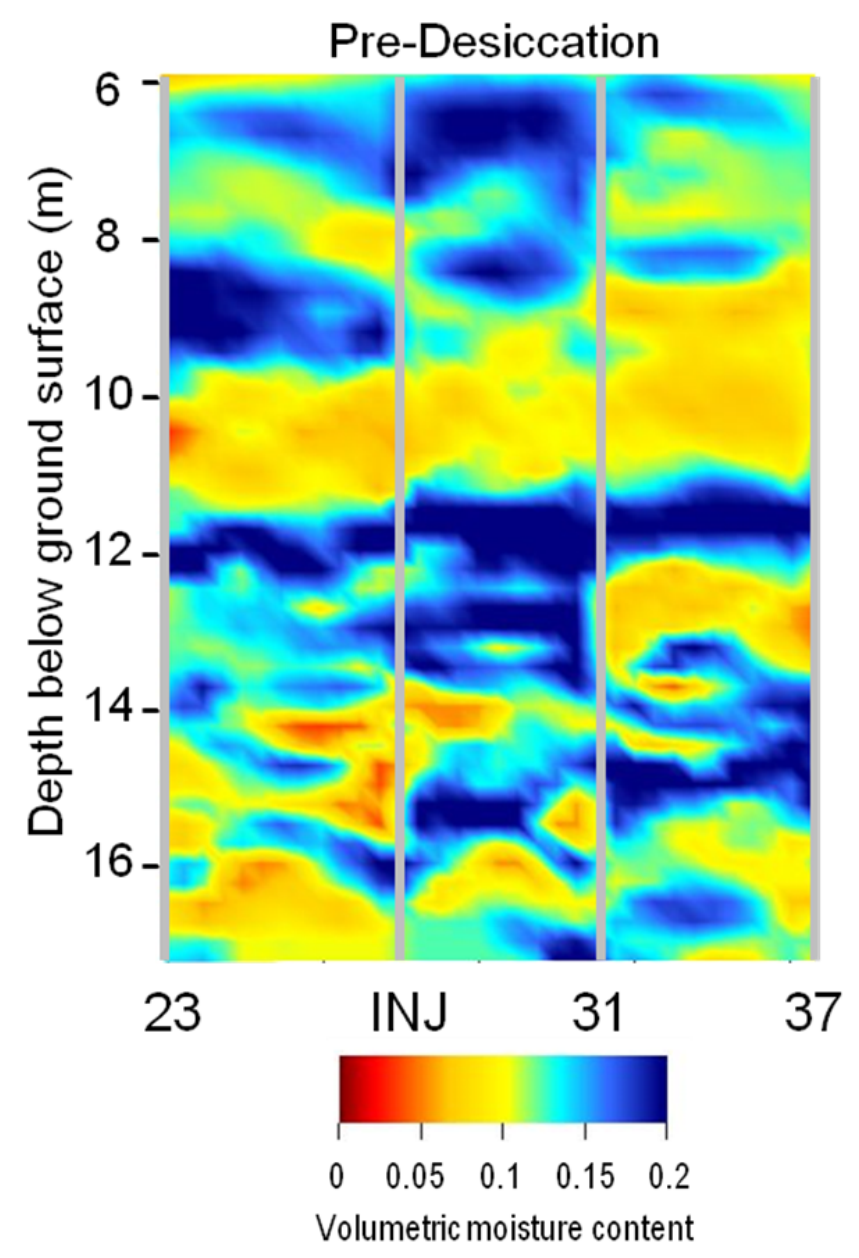

Figure 4.3. 2-D Interpretation of Initial Volumetric Moisture Content from Cross-Hole Ground Penetrating Radar Data Prior to Desiccation. Locations are shown as INJ (injection well) and logging well locations indicated by the last two numbers in the location identifier (e.g., $23=\mathrm{C} 7523$ ). 


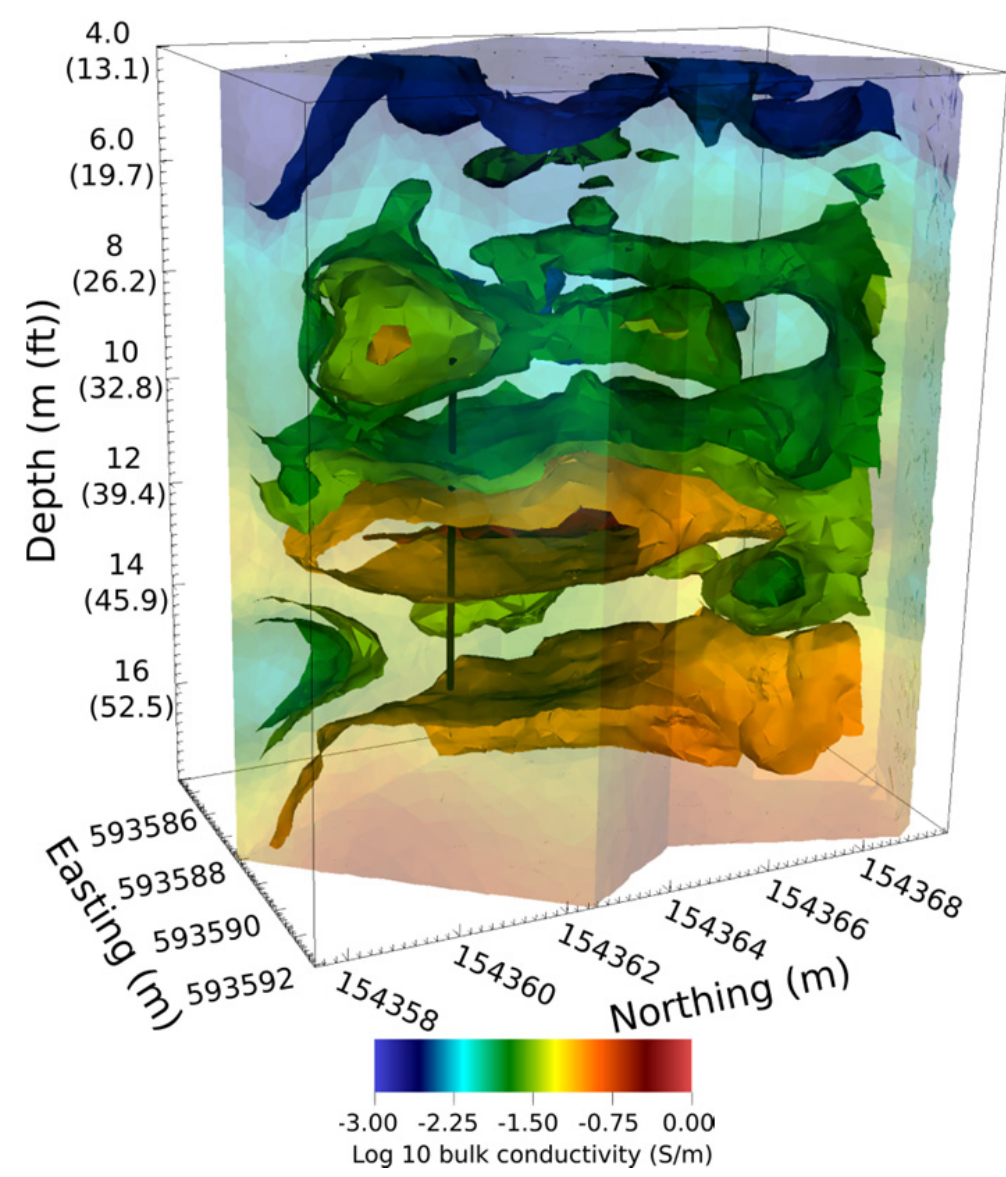

Figure 4.4. Three-Dimensional Pre-Desiccation Bulk Conductivity at Desiccation Treatability Test Site as Determined via ERT. Elevated conductivities (warmer colors) are associated with finer grained material and/or elevated ionic strength (i.e., nitrate). Lower bulk conductivity is associated with coarser grained, less contaminated zones.

Injected gas flow and distribution. The rate of desiccation is proportional to the rate of dry gas flow through the targeted zone. Injected gas flow distribution is impacted by the heterogeneity in air permeability. Based on the pre-test stratigraphic information, it was expected that soil gas flow would not be uniform in the treatment zone. Tracers were used as a means to examine the degree of variability in the soil gas flow distribution. Tracer response was monitored at four vertical points at each monitoring location. Thus, the resolution of the gas flow permeability is limited to the distribution of these monitoring locations. Because pure nitrogen gas was injected, the movement of injected nitrogen could be tracked by measuring the displacement of soil gas oxygen. Figure 4.5 shows that breakthrough of injected nitrogen occurs first in the $47 \mathrm{ft}$ and $42 \mathrm{ft}$ bgs intervals. Injected nitrogen flow is much slower in the upper intervals ( $32 \mathrm{ft}$ and $37 \mathrm{ft}$ bgs). These data suggested that most of the injected dry gas would travel through the lower portion of the test site. 

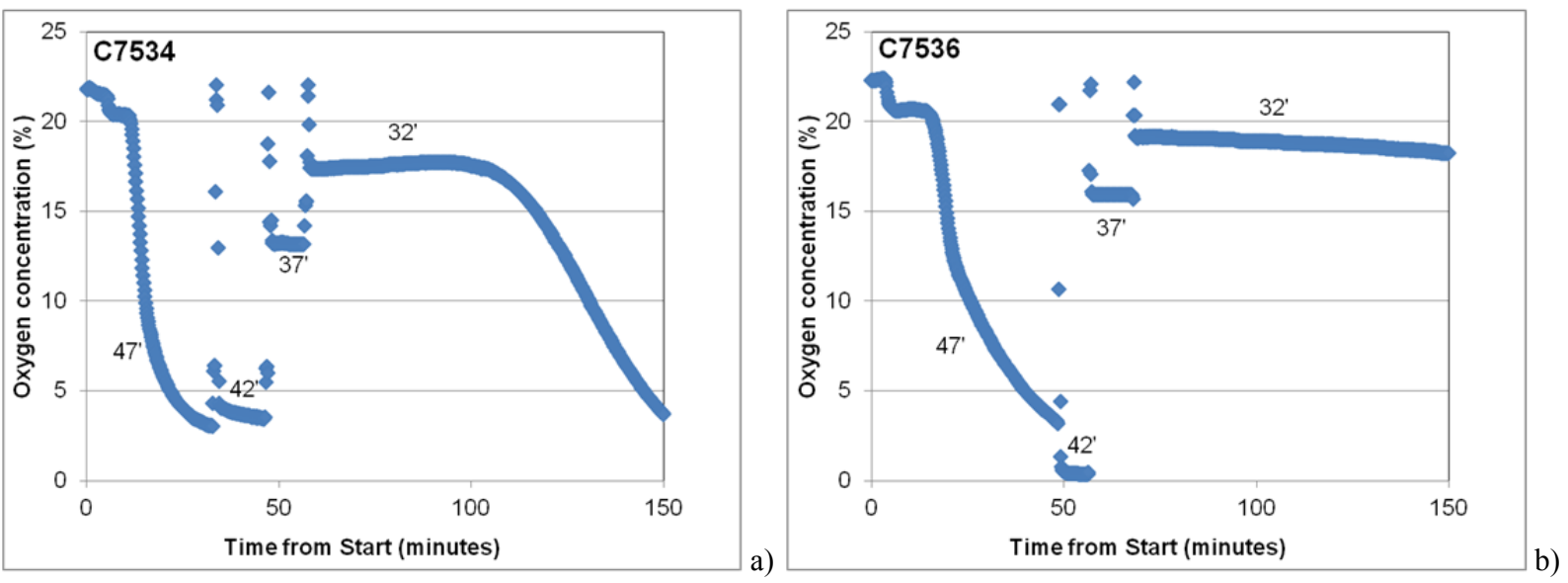

Figure 4.5. Oxygen Response (inverse of injected nitrogen gas tracer breakthrough) at the C7534 and C7536 Locations Along the Axis Between the Injection and Extraction Wells. Data are for a test with an injection rate of $300 \mathrm{cfm}$ and an extraction rate of $100 \mathrm{cfm}$. Separate curves are for readings at the different gas sample port vertical positions as denoted in feet below ground surface (e.g., 47').

Baseline in situ sensor data. Monitoring for desiccation involved monitoring for changes from baseline conditions induced by the desiccation process. One type of monitoring was conducted using in situ sensors for temperature, humidity, moisture content, and matric potential. In situ sensors were emplaced in a borehole configured in four depth interval monitoring zones, nominally at 32.5, 37.5, 42.5, and $47.5 \mathrm{ft}$ bgs. The 100-mesh sand used in each of the sensor intervals was added dry and had to equilibrate to the surrounding native formation moisture conditions as shown in with example sensor responses in Figures 4.6 through 4.8. Specific probes are not identified in these figures; the end of the equilibration represents the starting point for desiccation monitoring which is shown in more detail in Section 4.1.2. These moisture conditions are specific to the emplaced sand properties (the saturationpressure relationship) in equilibrium with the mixture of native material present adjacent to the sand pack.

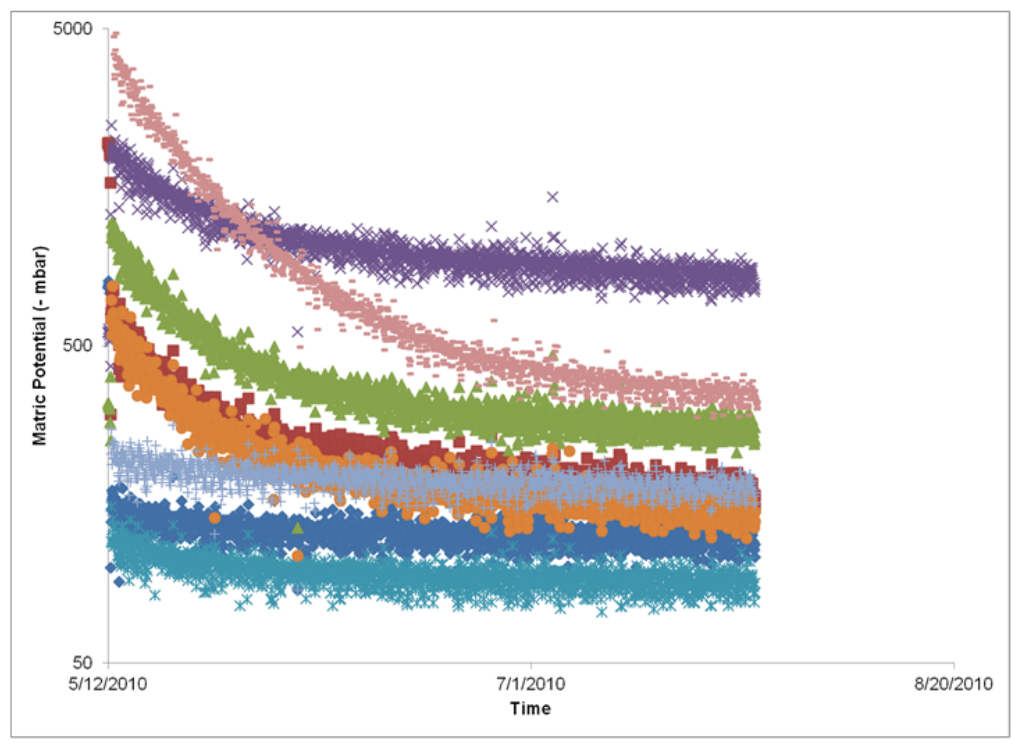

Figure 4.6. Equilibration Response for Heat Dissipation Units 


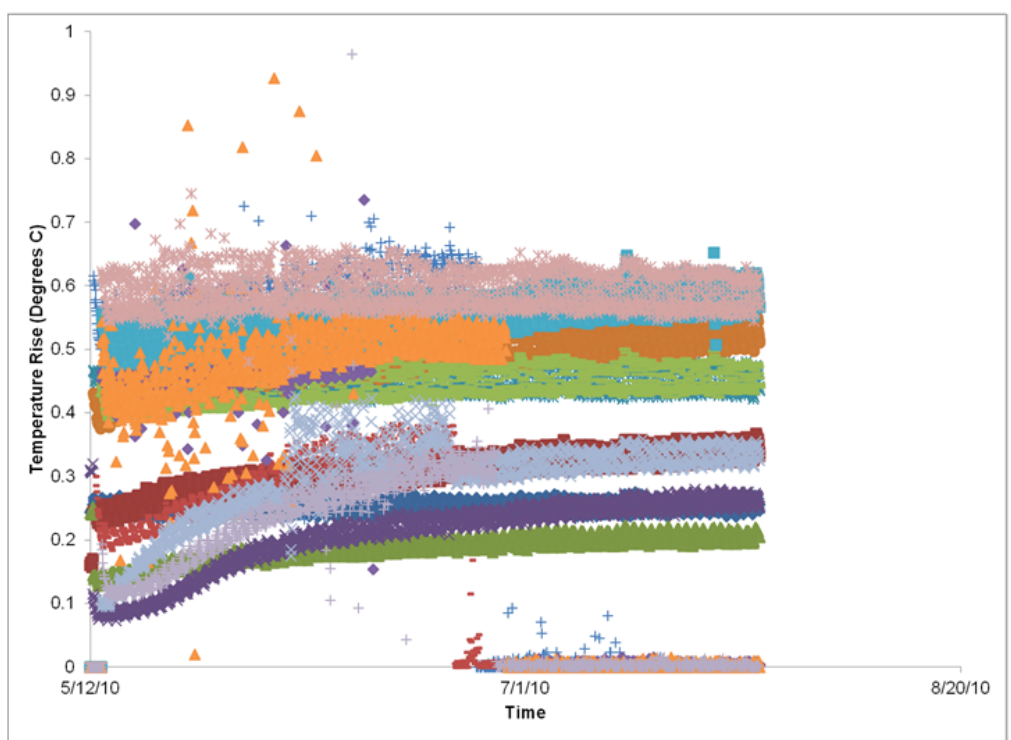

Figure 4.7. Equilibration Response for Dual-Probe Heat-Pulse Sensors. Note that several probes failed at the end of June 2010.

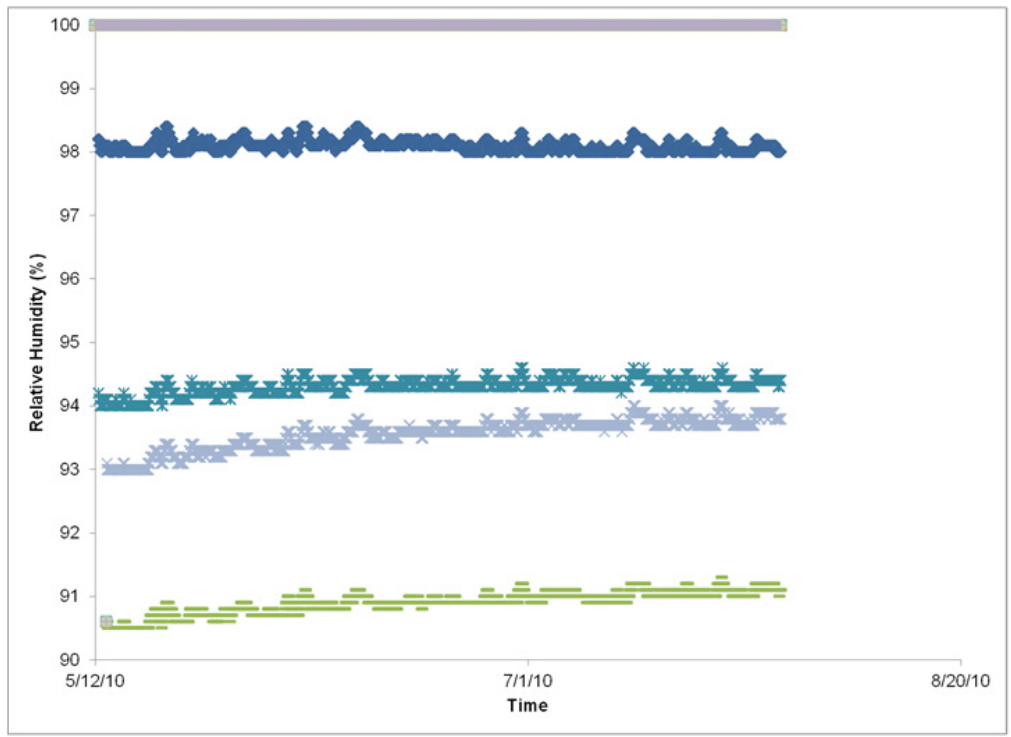

Figure 4.8. Equilibration Response for Humidity Probes

\subsubsection{Desiccation Operational Data}

Operational data were collected during injection and extraction operations at the test site. Of these parameters, the injected gas flow rate and temperature are key drivers for desiccation. Dry nitrogen (relative humidity of zero) was used for the injection gas during the test (Table 4.1). If ambient air were used, then the relative humidity of the injection gas would also be an important parameter as discussed in Section 4.2.4. Extraction parameters were also measured to define test conditions, but are not specifically related to the desiccation rate other than the impact on soil gas flow rates and patterns. Figure 4.9 shows the operational parameter data of injection gas flow and extraction flow rate for the duration of active desiccation. Injection gas temperature was held essentially constant at about $20^{\circ} \mathrm{C}$. The extracted gas 
relative humidity was also measured. However, this parameter is significantly impacted by the temperature at the monitoring location. Because the monitoring location was above ground and not immediately at the extraction well, changes in temperature impacted the measured value. Based on the measured progression of the desiccated zone (other data), there is no expectation that the extracted soil gas would have less than a relative humidity of $100 \%$.

Table 4.1. Summary of Injected Gas Volumes

\begin{tabular}{llllc}
\hline \multicolumn{2}{c}{ Time On } & \multicolumn{2}{c}{ Time Off } & Cumulative Volume Injection $\left(\mathrm{m}^{3}\right)$ \\
\hline $11 / 22 / 2010$ & $09: 00$ & $11 / 23 / 2010$ & $10: 24$ & 12,812 \\
$11 / 29 / 2010$ & $11: 13$ & $11 / 30 / 2010$ & $08: 20$ & 16,354 \\
$12 / 2 / 2010$ & $09: 40$ & $12 / 6 / 2010$ & $11: 40$ & 32,969 \\
$1 / 17 / 2011$ & $15: 35$ & $4 / 21 / 2011$ & $13: 00$ & $1,108,884$ \\
$5 / 2 / 2011$ & $12: 30$ & $5 / 2 / 2011$ & $12: 45$ & $1,109,014$ \\
$5 / 4 / 2011$ & $10: 15$ & $6 / 30 / 2011$ & $13: 55$ & $1,799,790$ \\
\hline
\end{tabular}

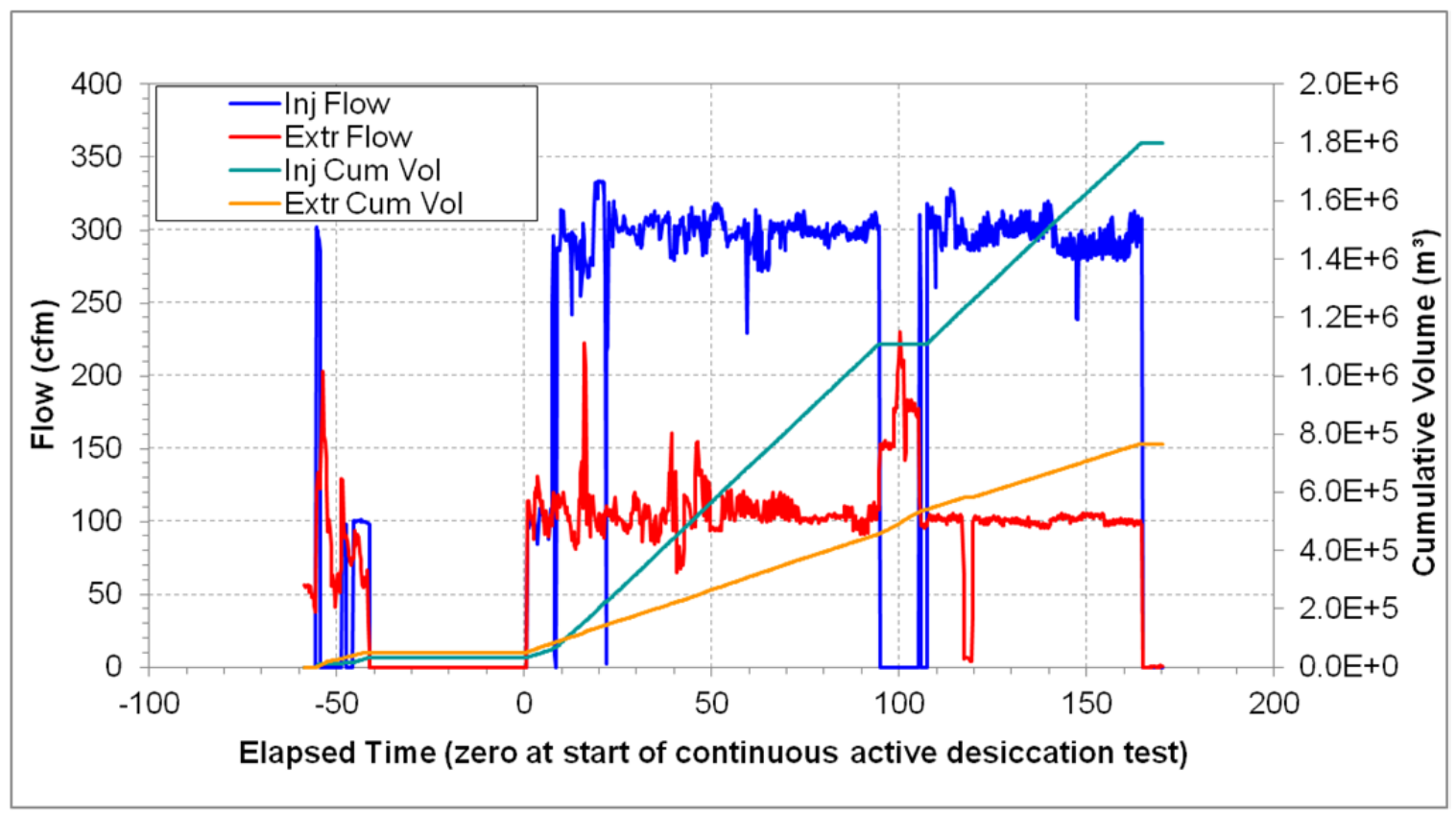

Figure 4.9. Flow Conditions and Cumulative Volumes for Field Test Operations

As desiccation progressed, reduced moisture was expected to increase the air permeability of the subsurface. Tracer data was collected again at day 107 (Figure 4.10) to examine the difference in injected gas flow rate distribution compared to the pre-desiccation tracer test results (Figure 4.5). This assessment along with other data to evaluate the distribution of dry gas from the injection well can be used to assess the uniformity of the desiccation process. Figure 4.10 shows the day 107 tracer data compared to the initial tracer response. Both the initial and day 107 tracer data show a very short term drop in oxygen that is interpreted as a small fast-path for injected gas flow. The fast-path response is accentuated in the day 107 tracer response, as would be expected with desiccation making this path more permeable and 
potentially larger in size. The bulk gas response occurs later in time as the more gradual drop in oxygen concentration for both the day 107 and initial tracer data. The time of this bulk drop is very similar for both day 107 and initial tracer, indicating that the impact of desiccation on the bulk gas flow was small at day 107 . Note that these responses are for wells where only a minor desiccation response was observed; the dominant desiccation response occurred closer to the injection well.

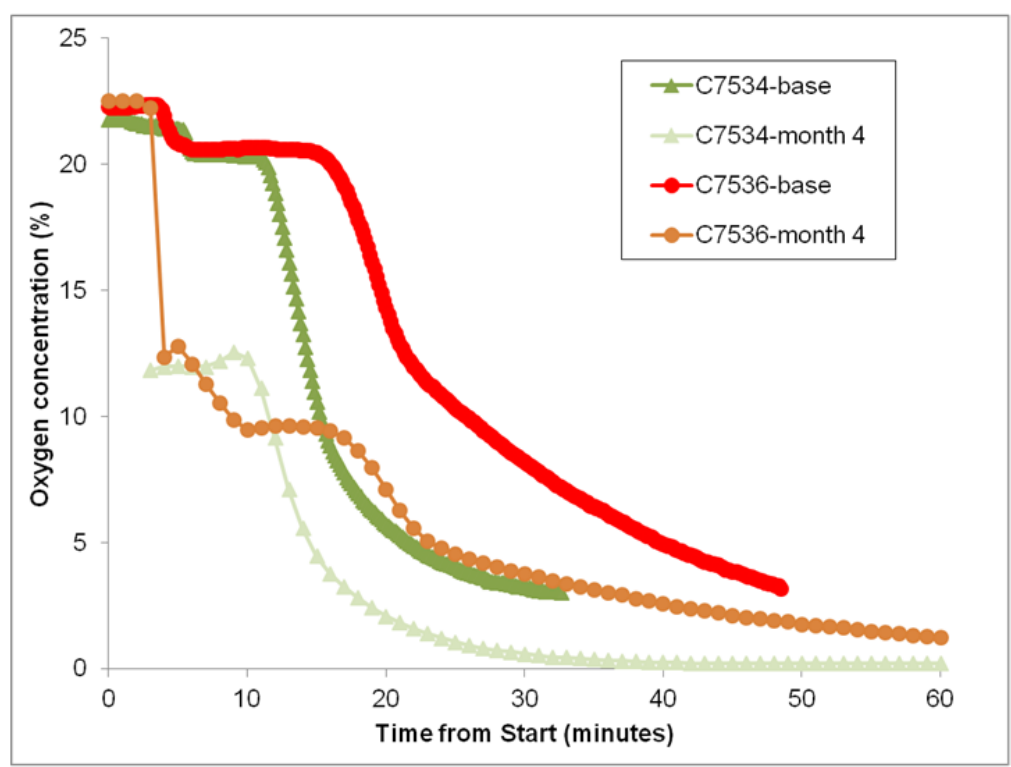

Figure 4.10. Comparison of Baseline and Day 107 (month 4) Tracer Responses at the $47 \mathrm{ft}$ bgs Depth Interval for Monitoring Locations C7534 and C7536

\subsubsection{Desiccation Performance}

This section presents the data collected during active desiccation (Section 4.1.2.1) and post-desiccation (rewetting, Section 4.1.2.2) elements of the test.

\subsubsection{Active Desiccation}

Performance of the desiccation process in terms of reducing the moisture content was quantified using several types of data and analyses. Both discrete and spatial analyses were used in assessing the active desiccation process. Data from individual sensors and single logging locations are presented first, followed by data analyzed to provide spatial information about the desiccation process. The final section presents results of analyses on condensate collected during active desiccation.

\subsubsection{Sensor and Discrete Location Data}

The lateral locations of sensor boreholes containing in situ sensors and Electrical Resistivity Tomography electrodes and the location of wells for neutron moisture logging and GPR access are shown in Figure 3.4 (Section 3.2.2). In situ sensors were emplaced to provide a detailed temporal response to desiccation at the monitoring locations. Temperature data over time at the nominal sensor interval depths are presented in Figures 4.11 through 4.14. Matric potential (heat dissipation units), moisture content (dual-probe heat-pulse sensors), and humidity data are presented at the sensor depth intervals in 
Figures 4.15 through 4.26. None of the thermocouple psychrometers provided meaningful data. Periodically, neutron moisture logging was conducted to examine how the vertical profile of moisture content changed at the monitoring locations (Figures 4.27 through 4.33). A summary of changes in neutron moisture probe during active desiccation are presented in Figures 4.34 through 4.36. Neutron moisture information at the injection well (Figure 4.37) shows locations of dominant injected gas flow at those intervals that start drying first (e.g., flow occurs mainly in the upper and lower portion of the screen).

At the completion of active desiccation, two boreholes were drilled to collect samples for laboratory analysis of moisture content and for Tc-99 and nitrate concentration. Data for the core analyses are contained in Appendix A and summarized on Table 4.2.

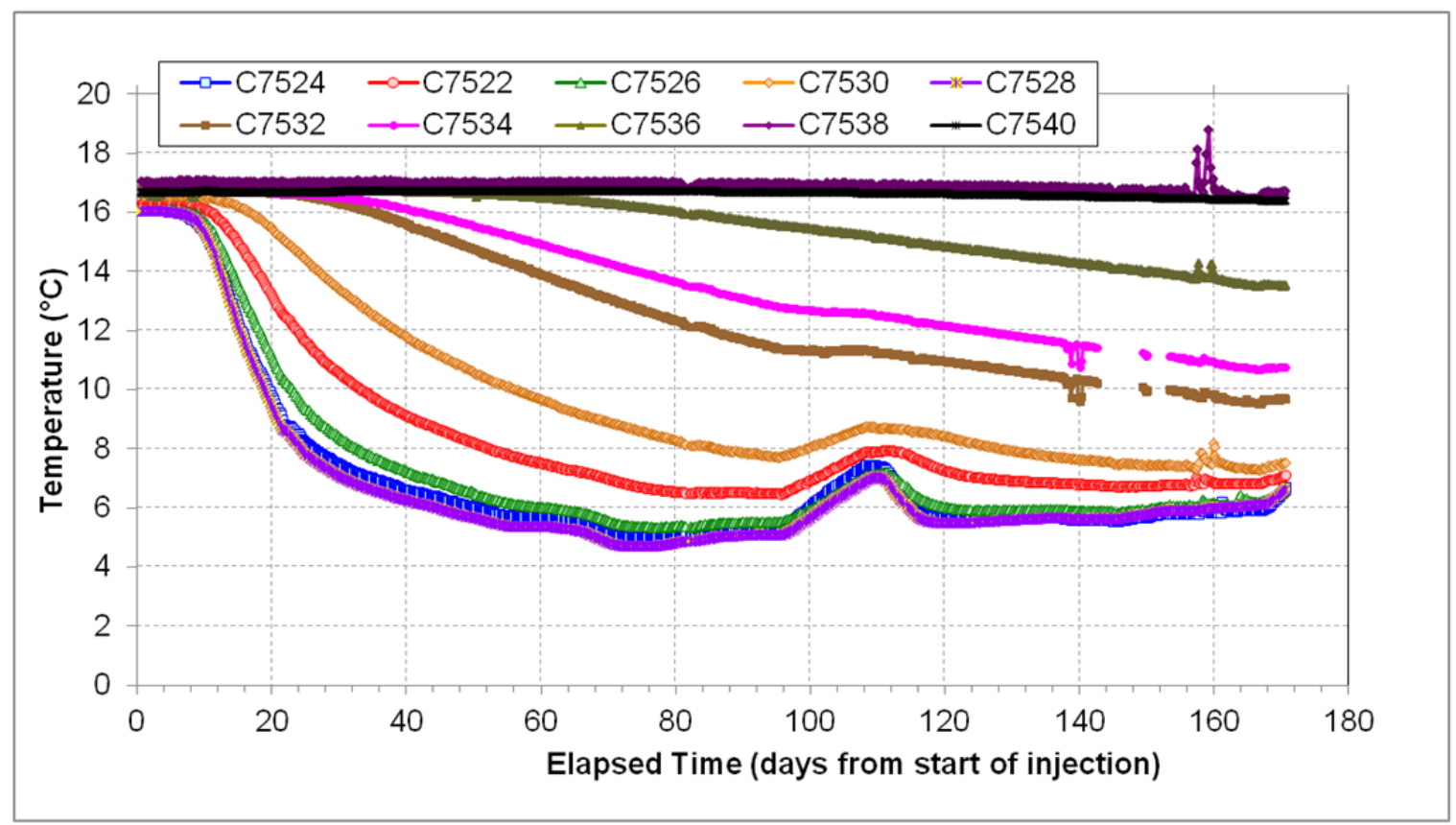

Figure 4.11. Temperature Response Over Time for the Sensors at a Depth of $32.5 \mathrm{ft}$ Below Ground Surface 


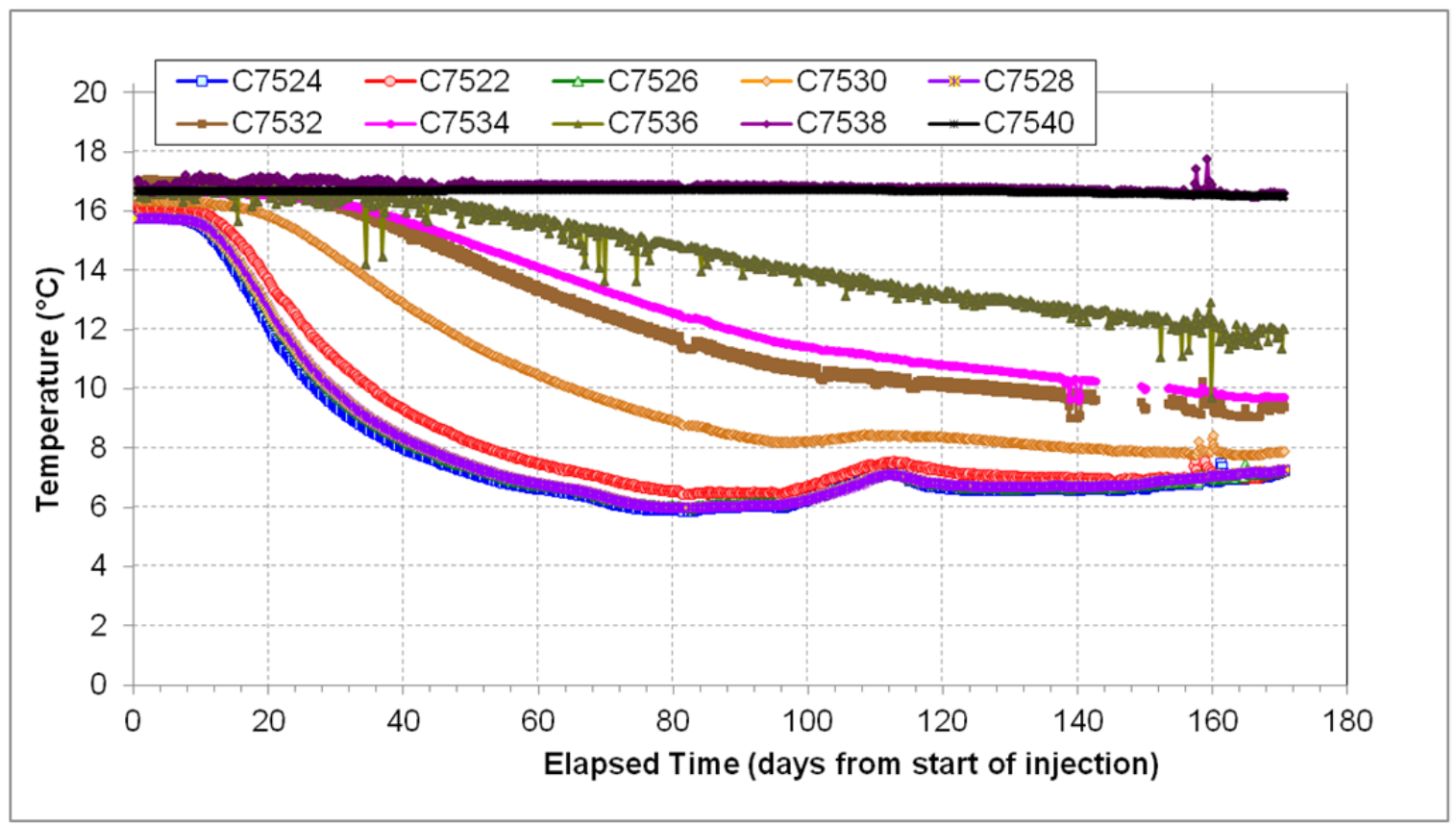

Figure 4.12. Temperature Response Over Time for the Sensors at a Depth of $36.5 \mathrm{ft}$ Below Ground Surface

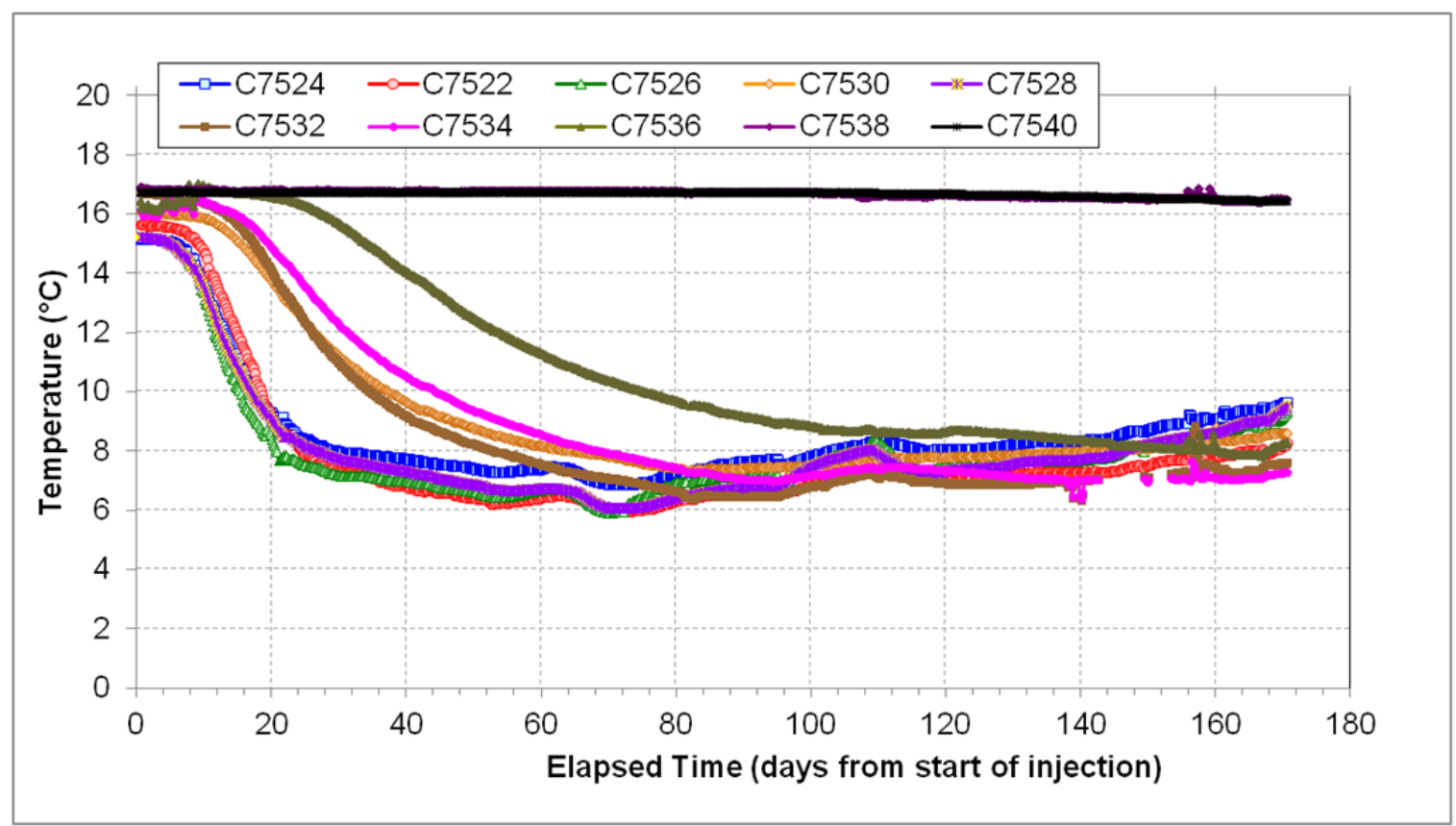

Figure 4.13. Temperature Response Over Time for the Sensors at a Depth of $42.5 \mathrm{ft}$ Below Ground Surface 


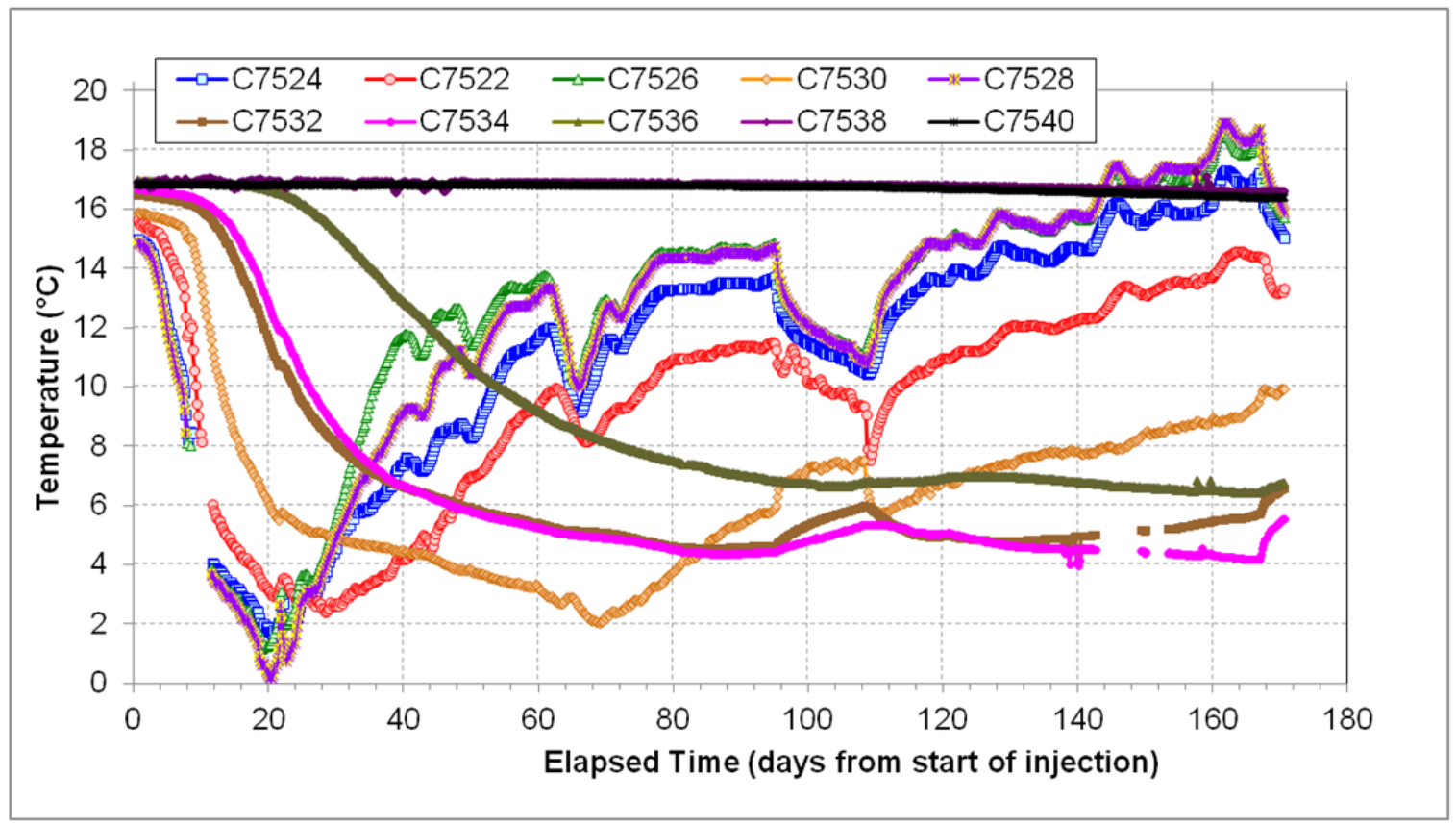

Figure 4.14. Temperature Response Over Time for the Sensors at a Depth of $46.5 \mathrm{ft}$ Below Ground Surface

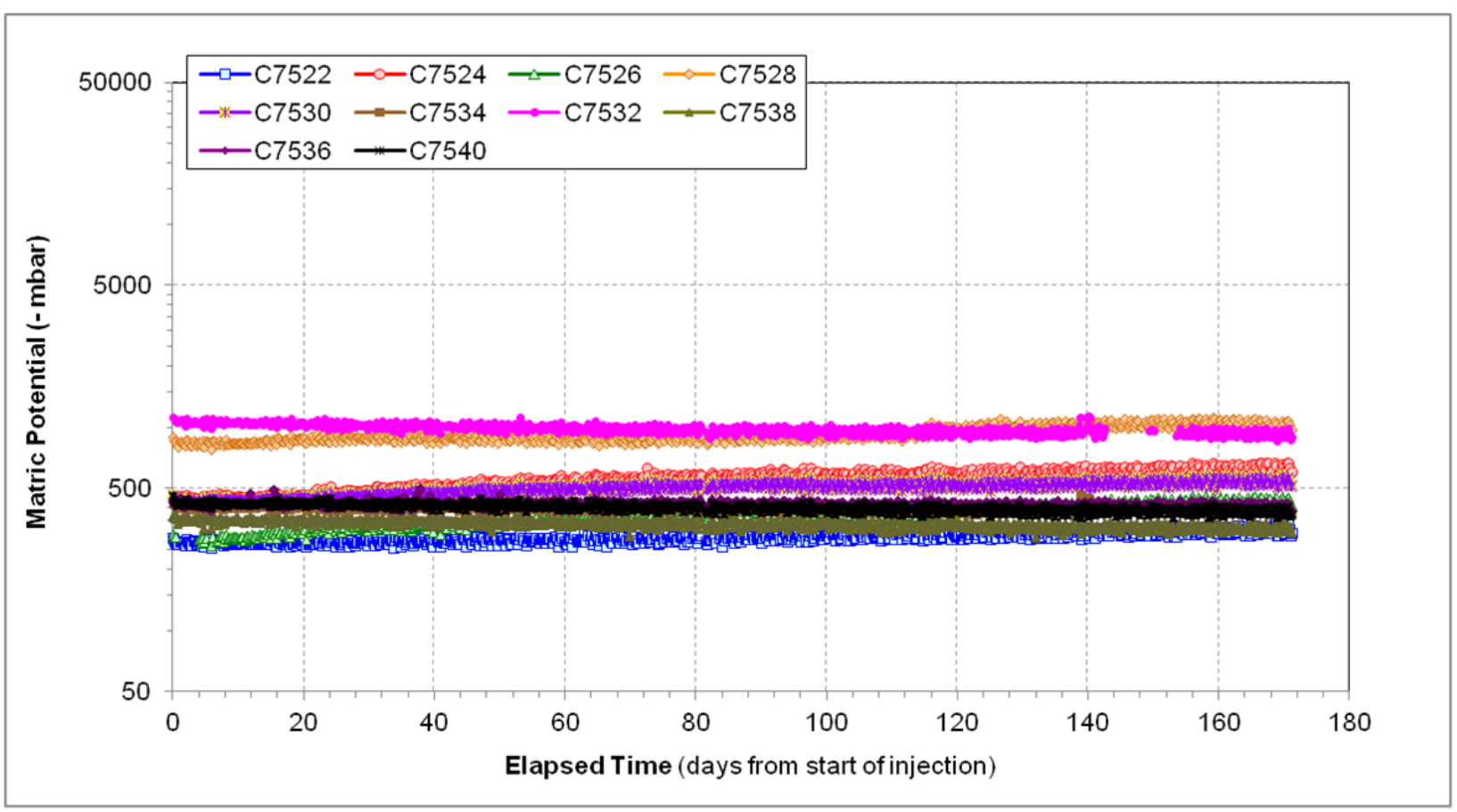

Figure 4.15. Heat Dissipation Unit (matric potential) Response Over Time for the Sensors at a Depth of $32.5 \mathrm{ft}$ Below Ground Surface 


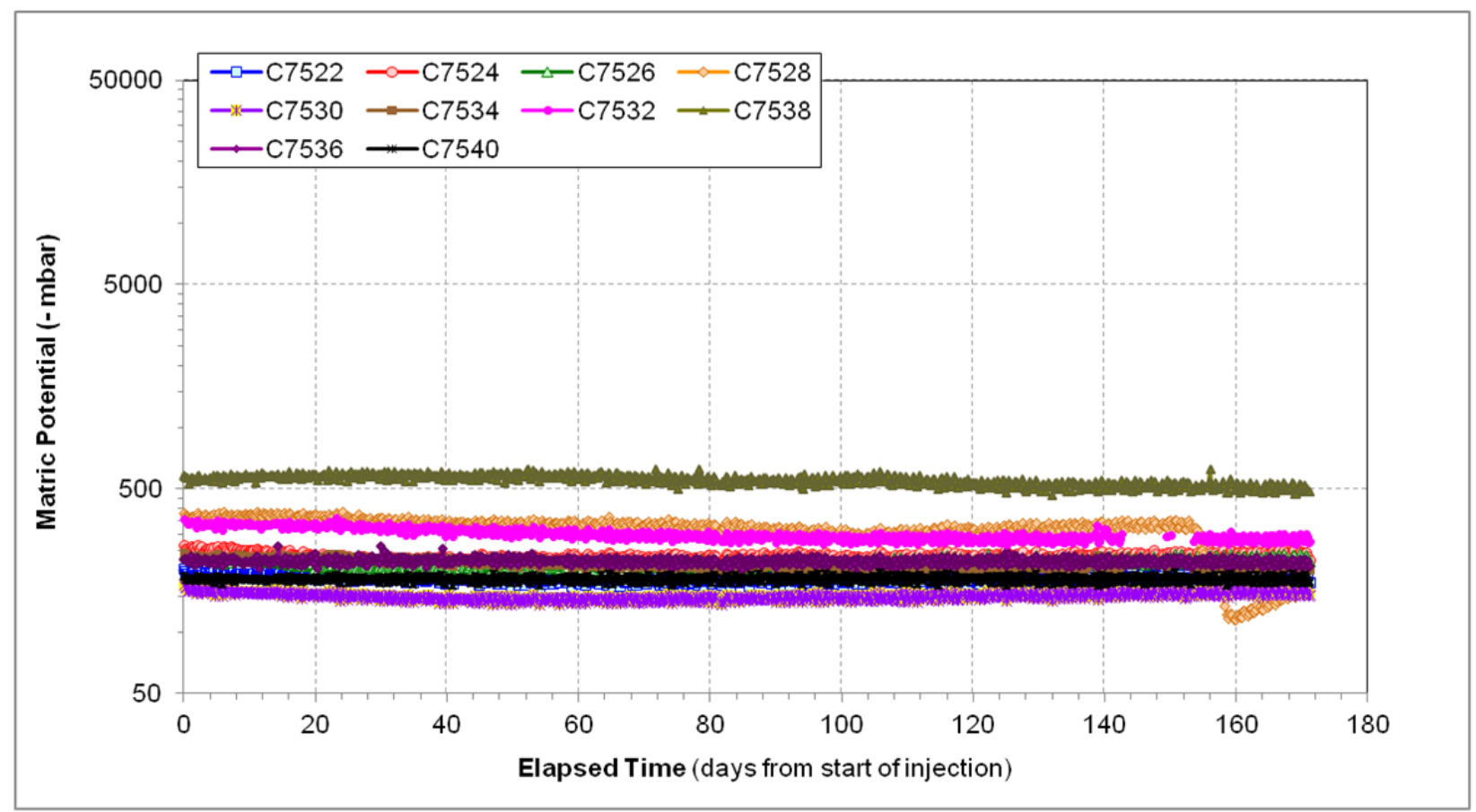

Figure 4.16. Heat Dissipation Unit (matric potential) Response Over Time for the Sensors at a Depth of $37.5 \mathrm{ft}$ Below Ground Surface

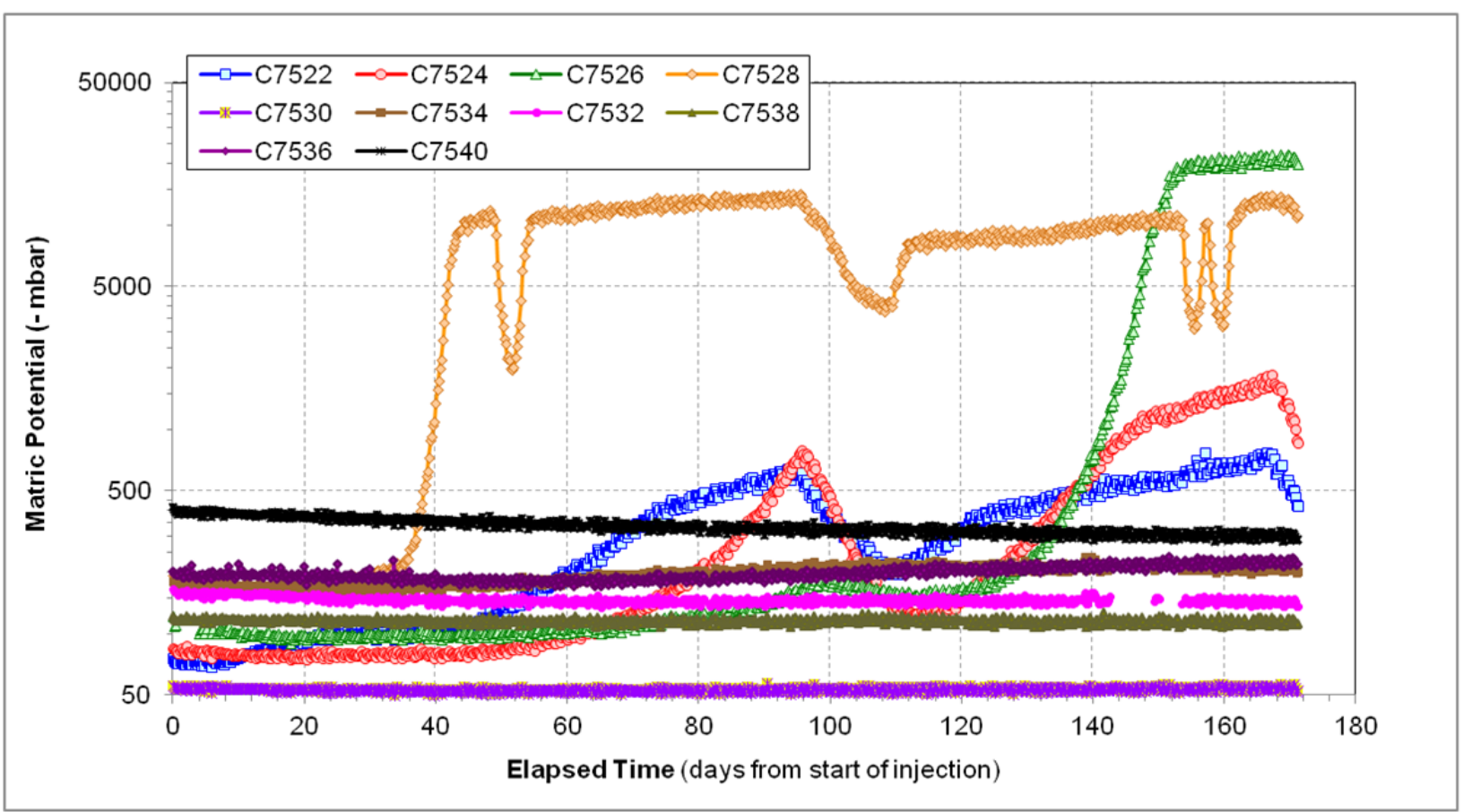

Figure 4.17. Heat Dissipation Unit (matric potential) Response Over Time for the Sensors at a Depth of $42.5 \mathrm{ft}$ Below Ground Surface 


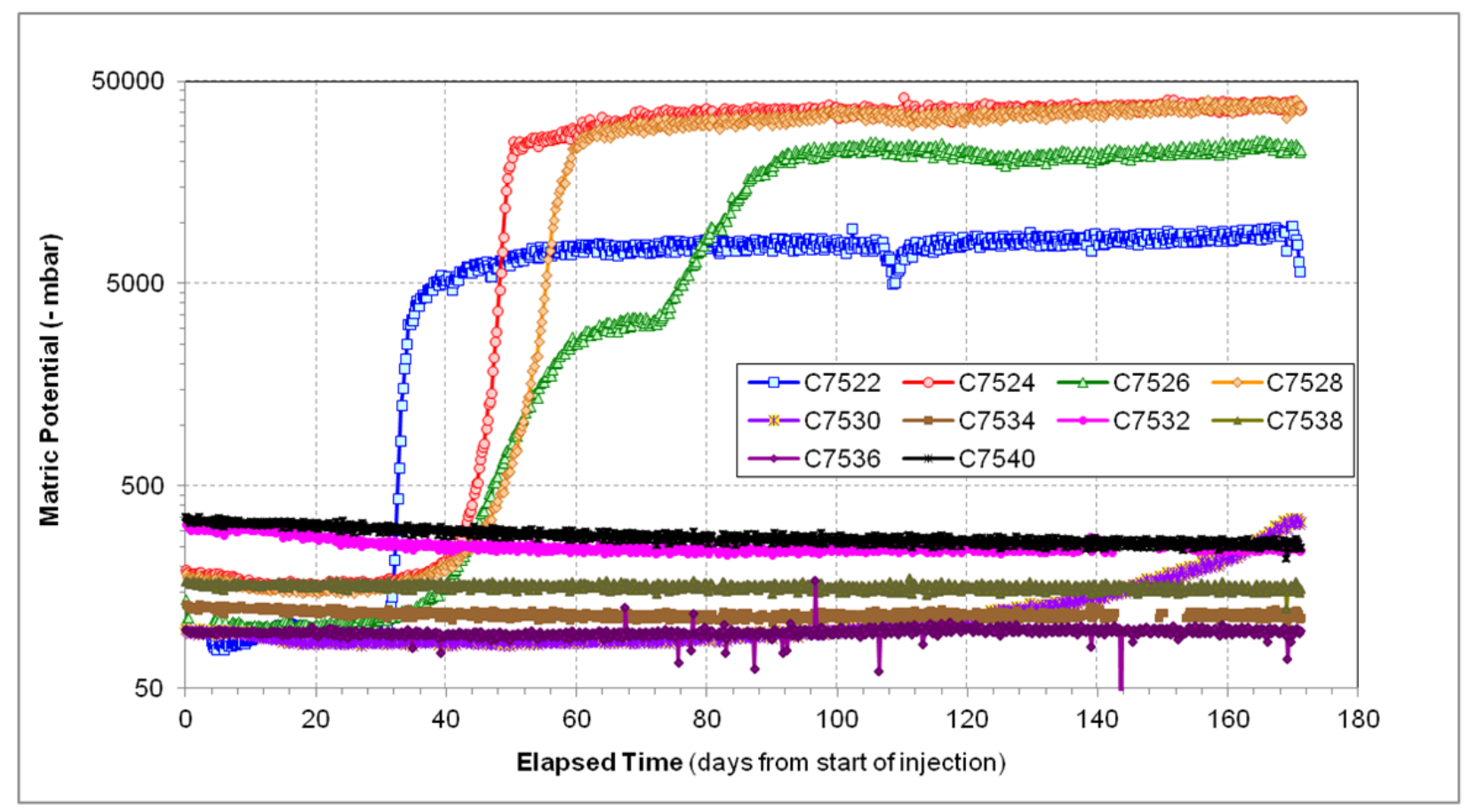

Figure 4.18. Heat Dissipation Unit (matric potential) Response Over Time for the Sensors at a Depth of $47.5 \mathrm{ft}$ Below Ground Surface

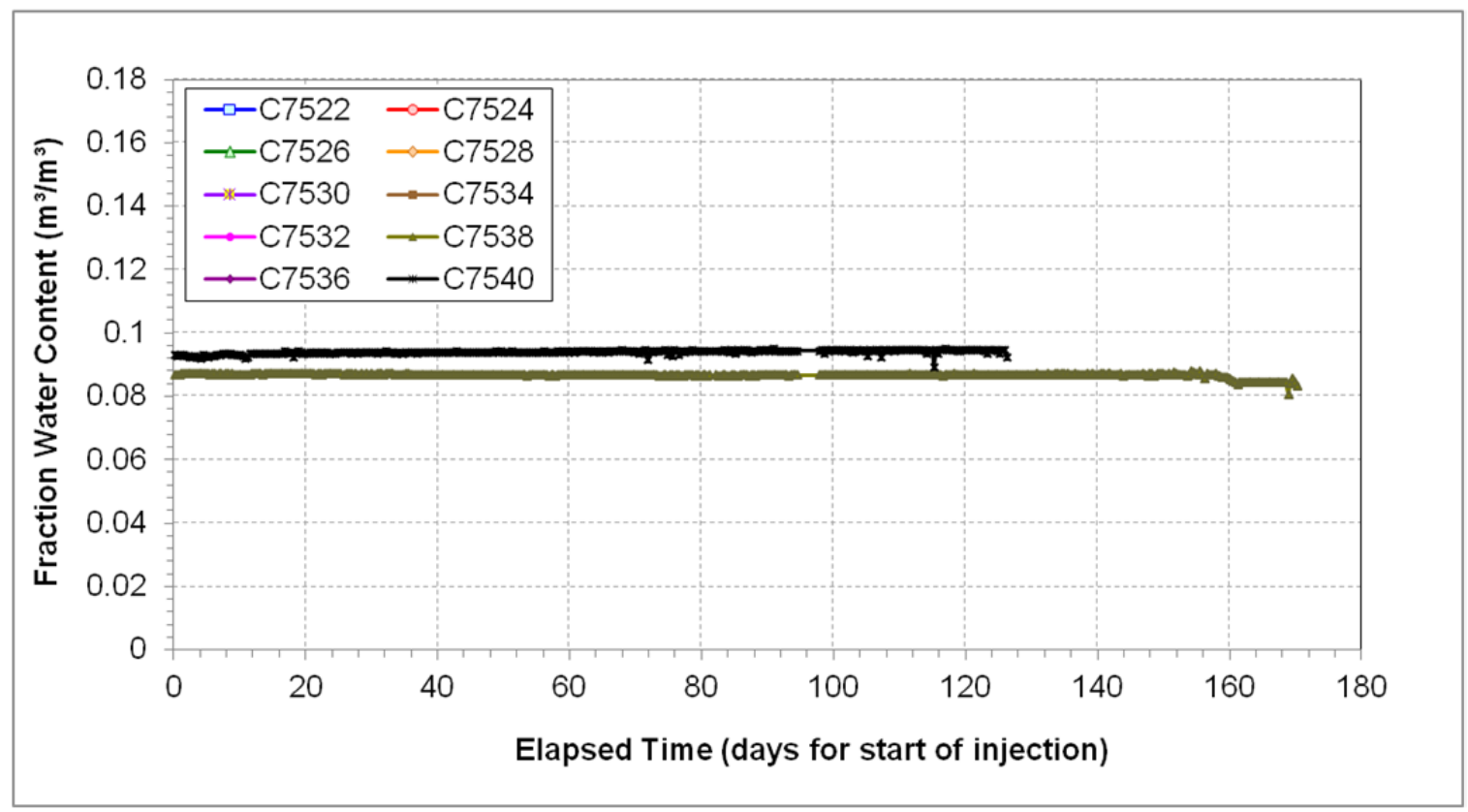

Figure 4.19. Dual-Probe Heat-Pulse Sensor (moisture content) Response Over Time for the Sensors at a Depth of $32.5 \mathrm{ft}$ Below Ground Surface 


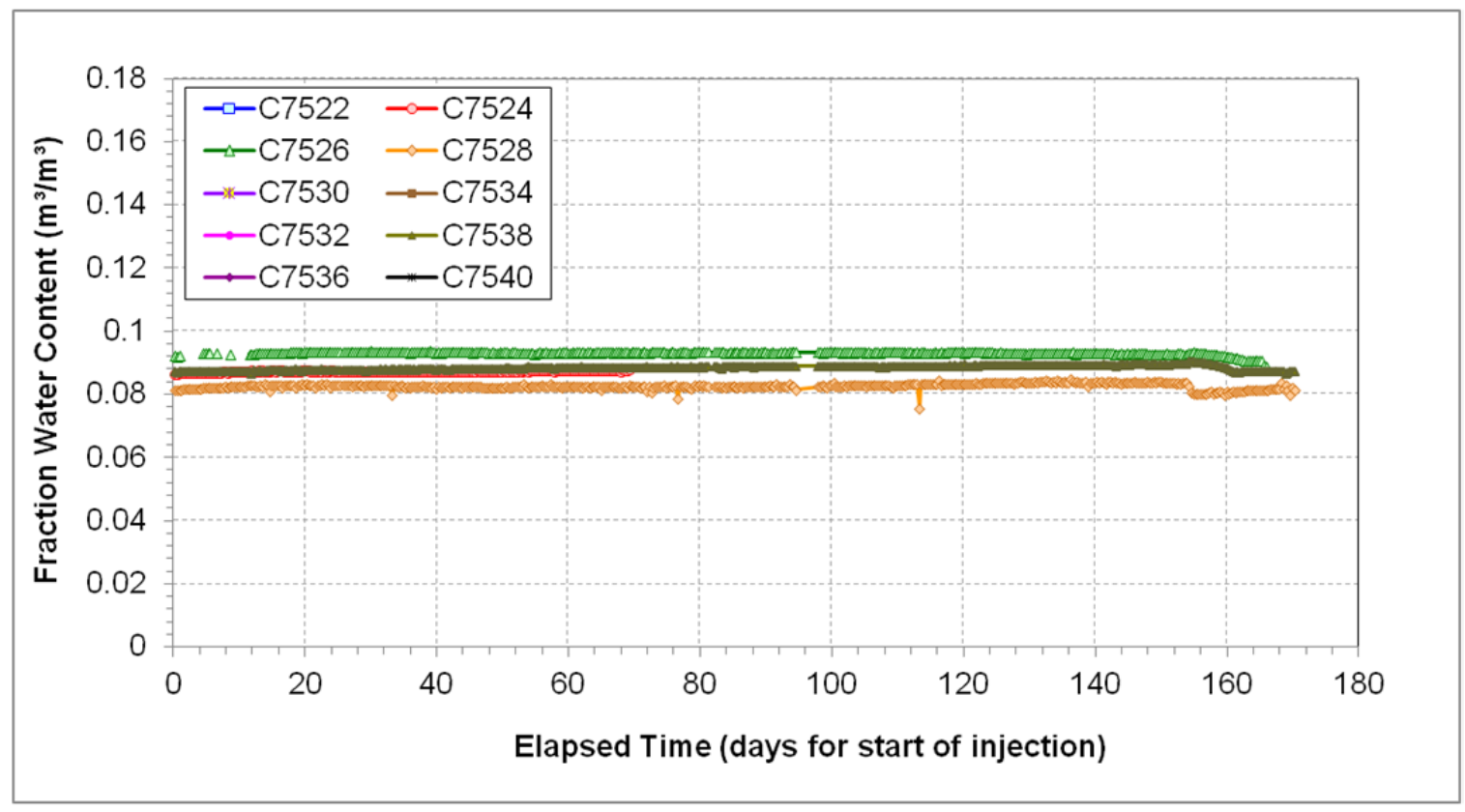

Figure 4.20. Dual-Probe Heat-Pulse Sensor (moisture content) Response Over Time for the Sensors at a Depth of $37.5 \mathrm{ft}$ Below Ground Surface

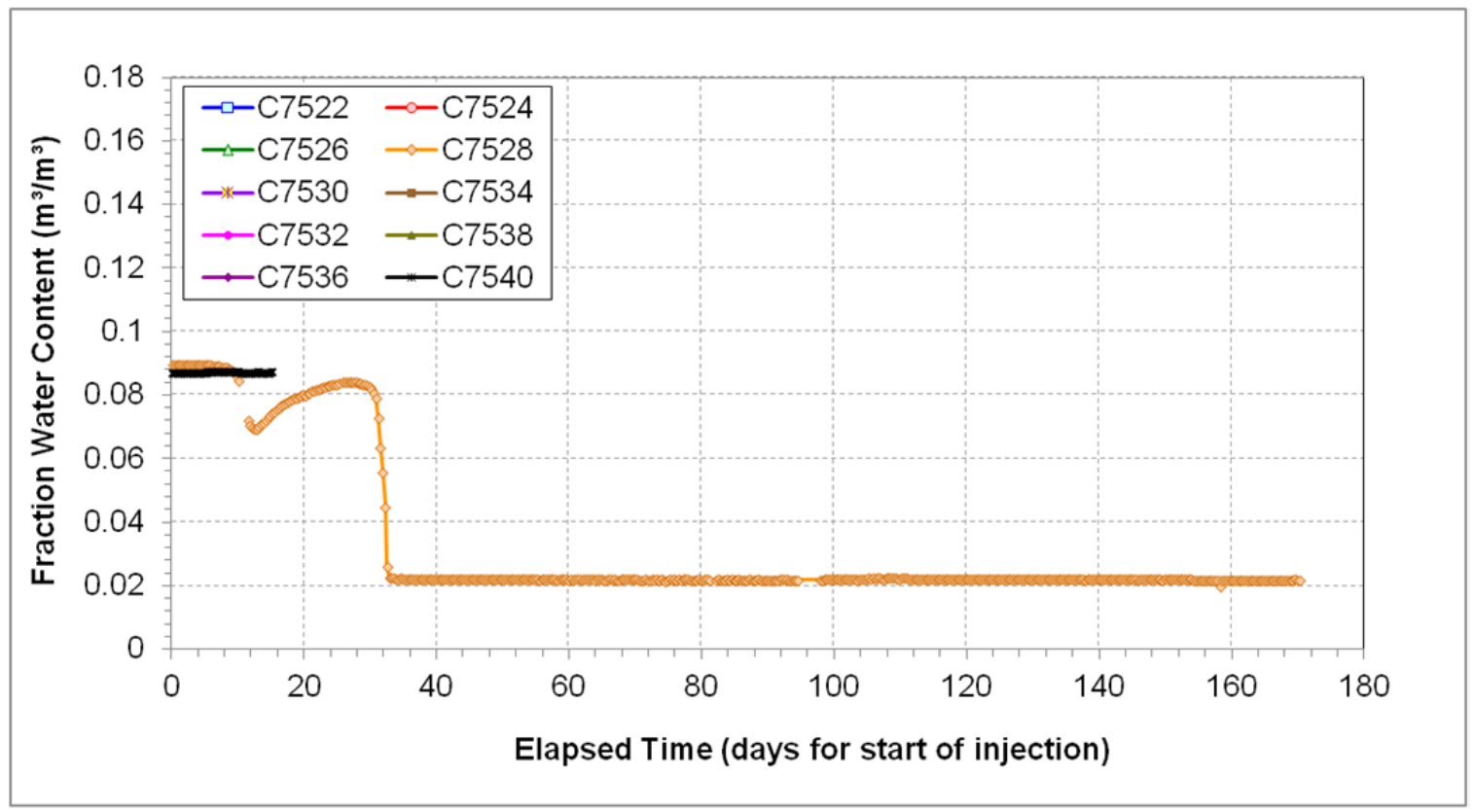

Figure 4.21. Dual-Probe Heat-Pulse Sensor (moisture content) Response Over Time for the Sensors at a Depth of $42.5 \mathrm{ft}$ Below Ground Surface 


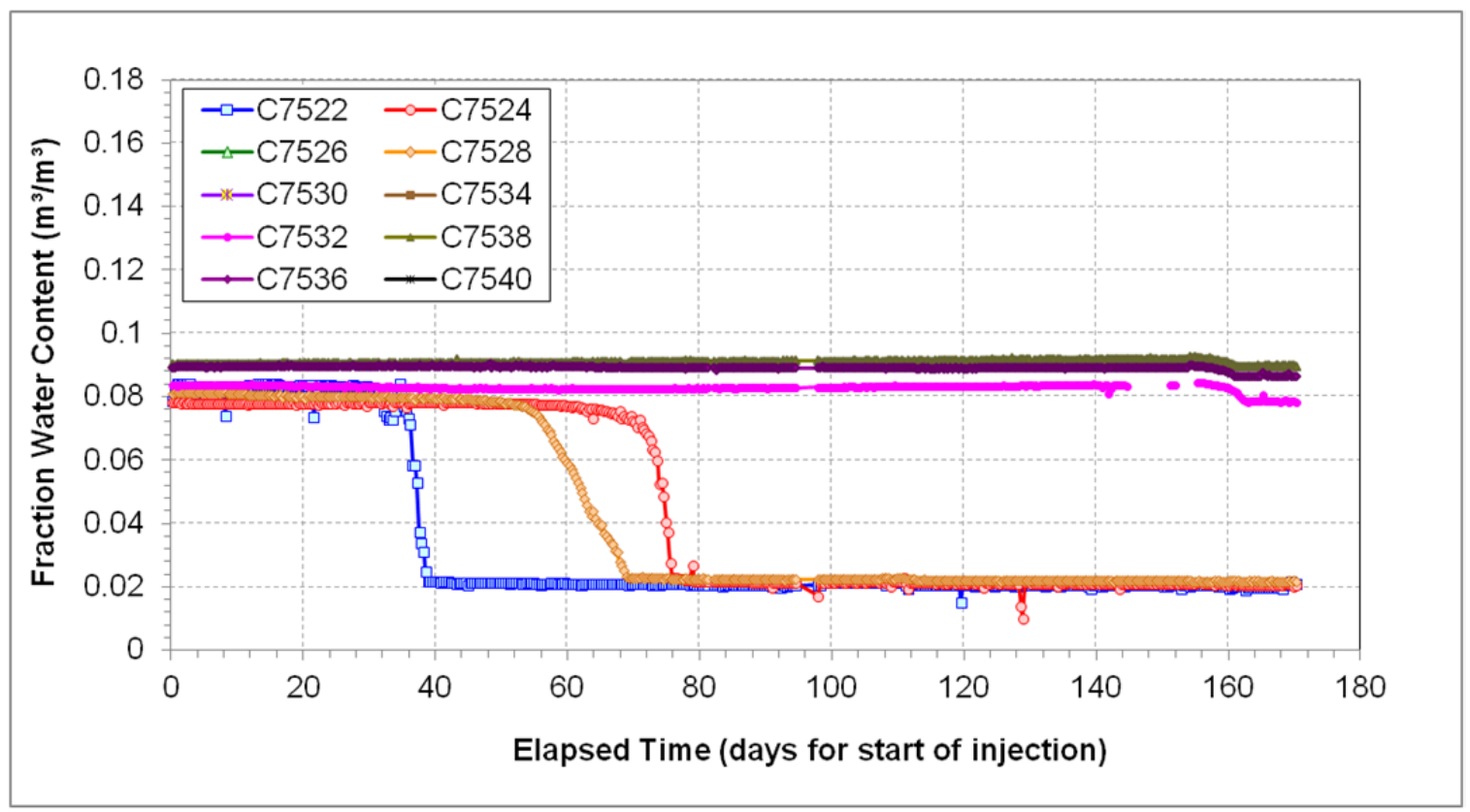

Figure 4.22. Dual-Probe Heat-Pulse Sensor (moisture content) Response Over time for the Sensors at a Depth of $47.5 \mathrm{ft}$ Below Ground Surface

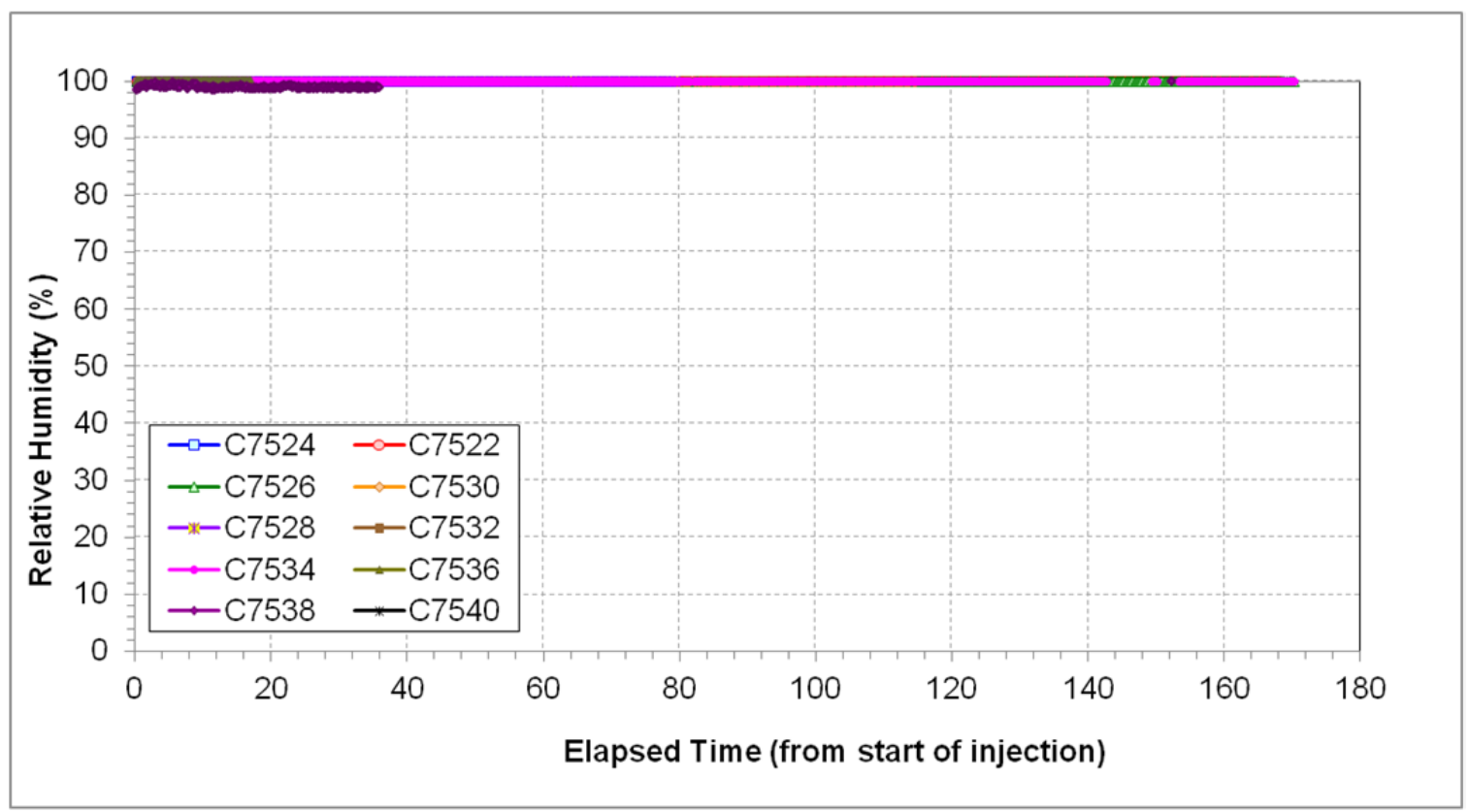

Figure 4.23. Relative Humidity Probe Response Over Time for the Sensors at a Depth of $32.5 \mathrm{ft}$ Below Ground Surface 


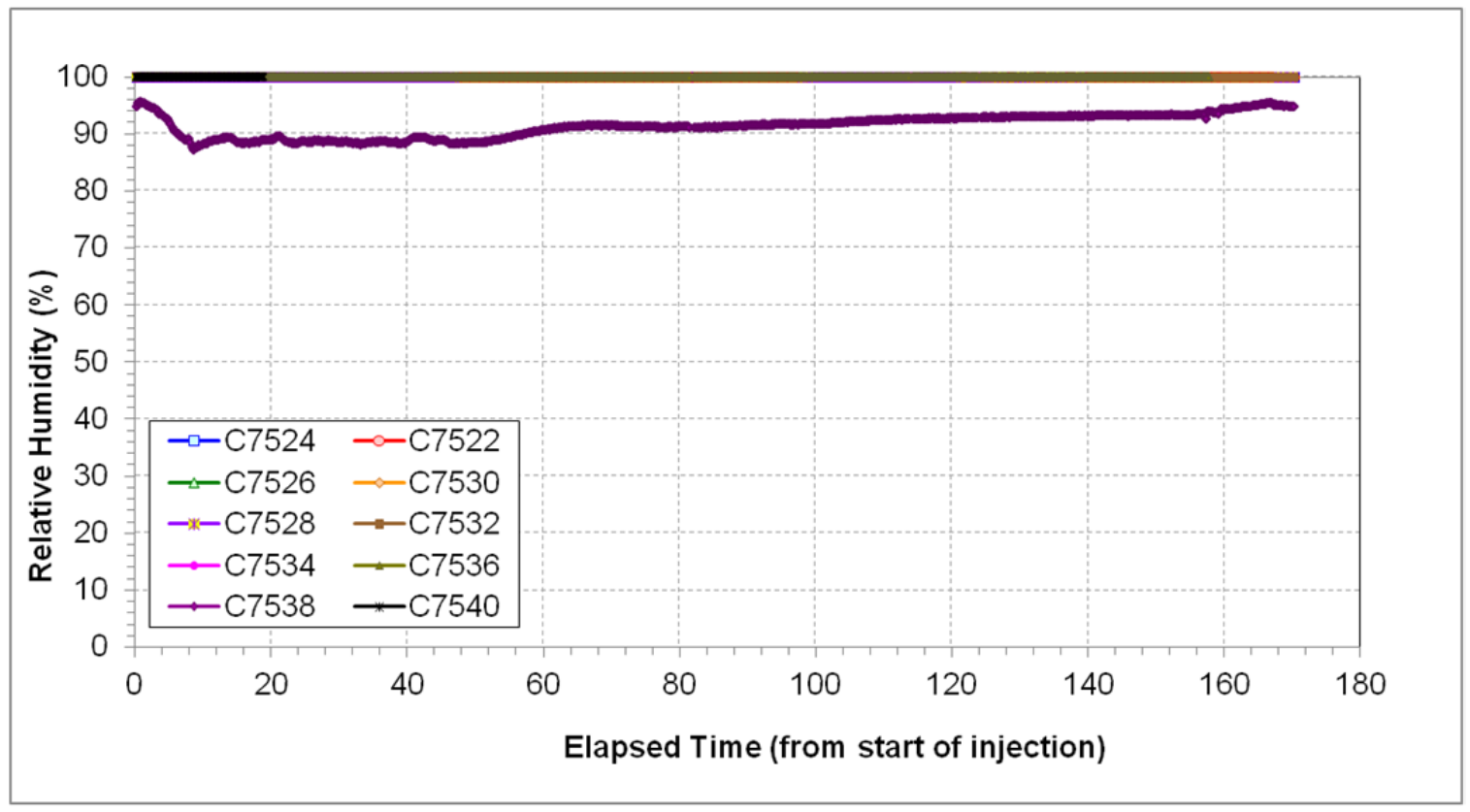

Figure 4.24. Relative Humidity Probe Response Over Time for the Sensors at a Depth of $37.5 \mathrm{ft}$ Below Ground Surface

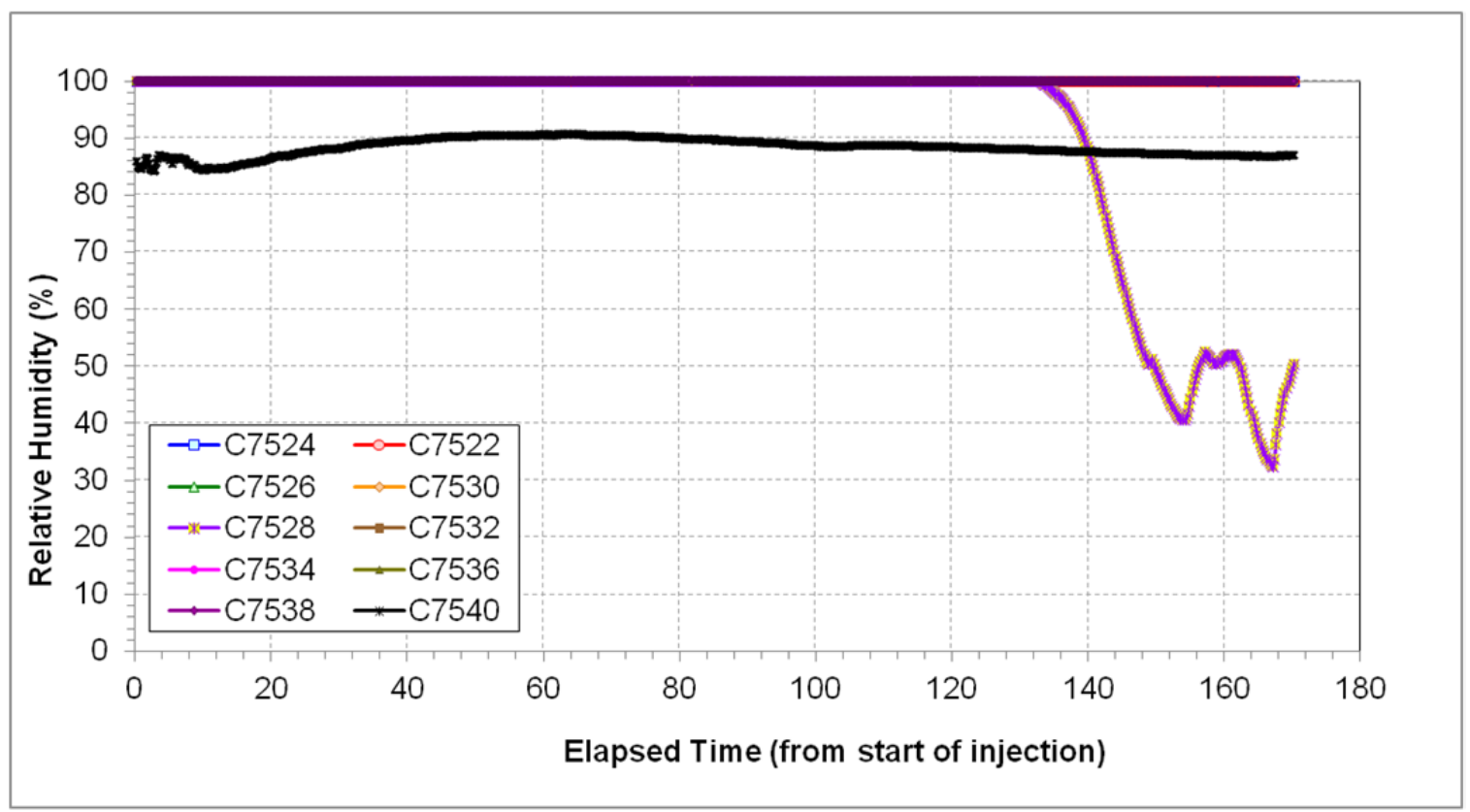

Figure 4.25. Relative Humidity Probe Response Over Time for the Sensors at a Depth of $42.5 \mathrm{ft}$ Below Ground Surface 


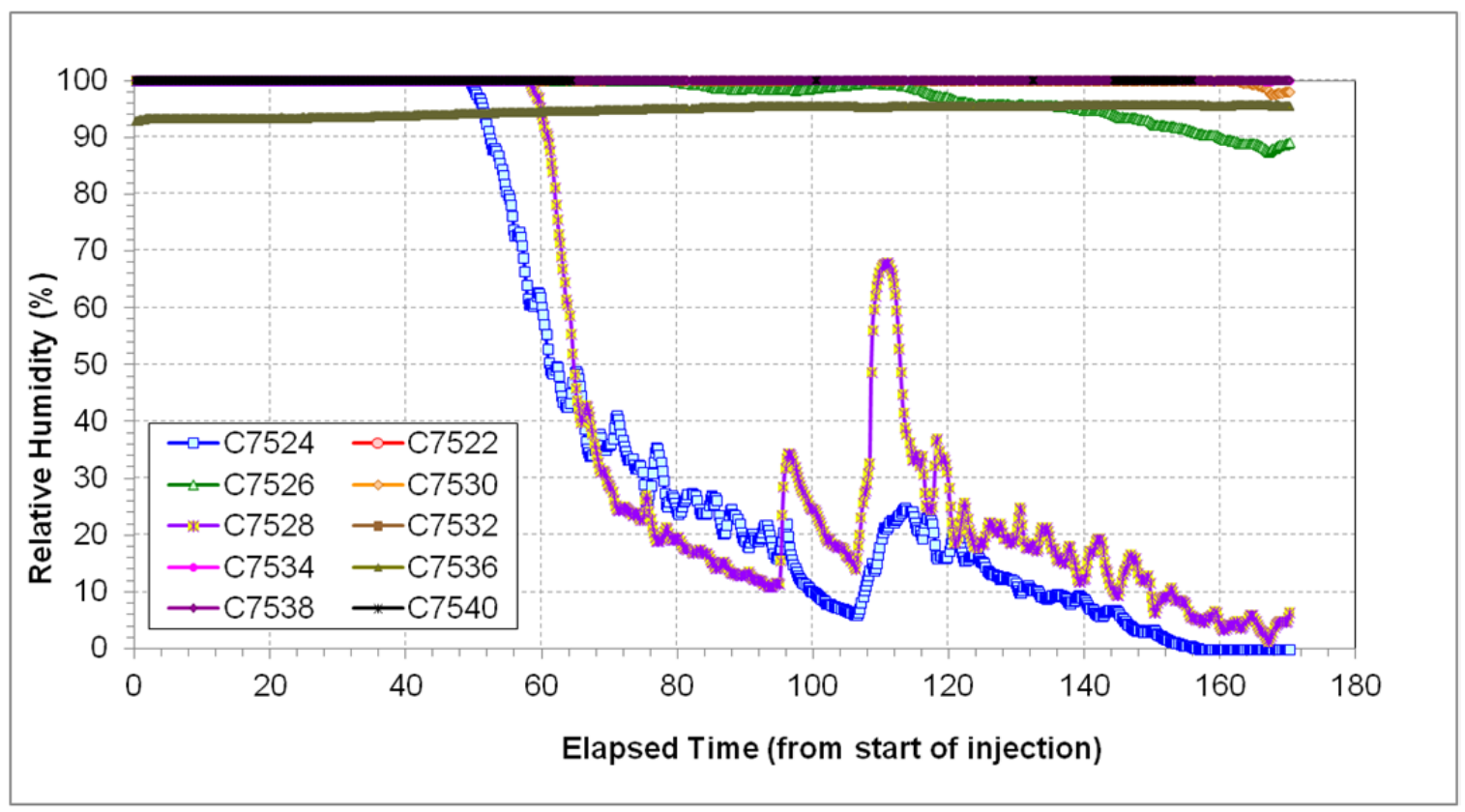

Figure 4.26. Relative Humidity Probe Response Over Time for the Sensors at a Depth of $47.5 \mathrm{ft}$ Below Ground Surface 


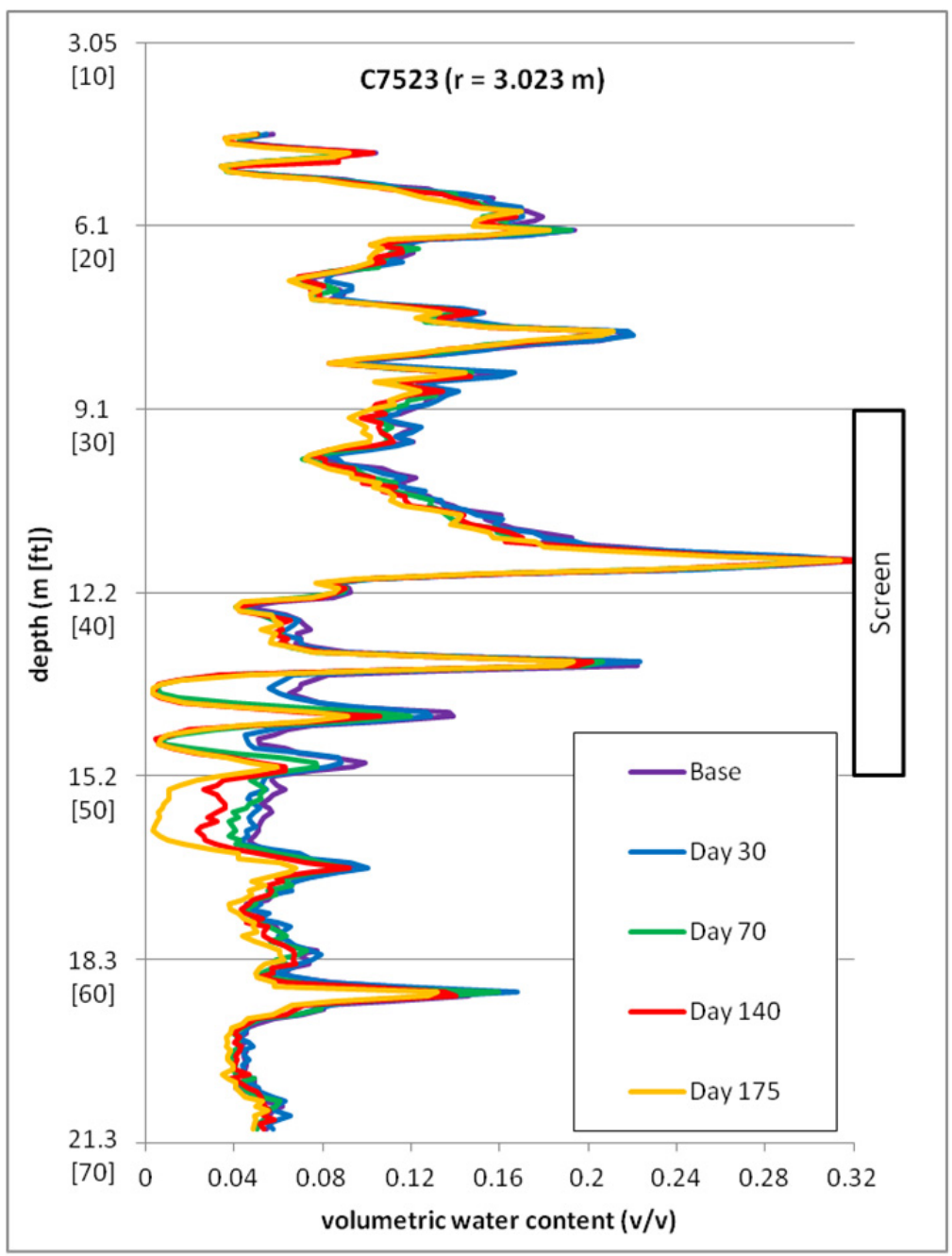

Figure 4.27. Neutron Moisture Probe Response Over Time for Location C7523 (3.023 m from injection well). The base time is a logging event in December 2010, prior to the continuous active desiccation period. Other data are for logging events in nominal days from the start of active desiccation. 


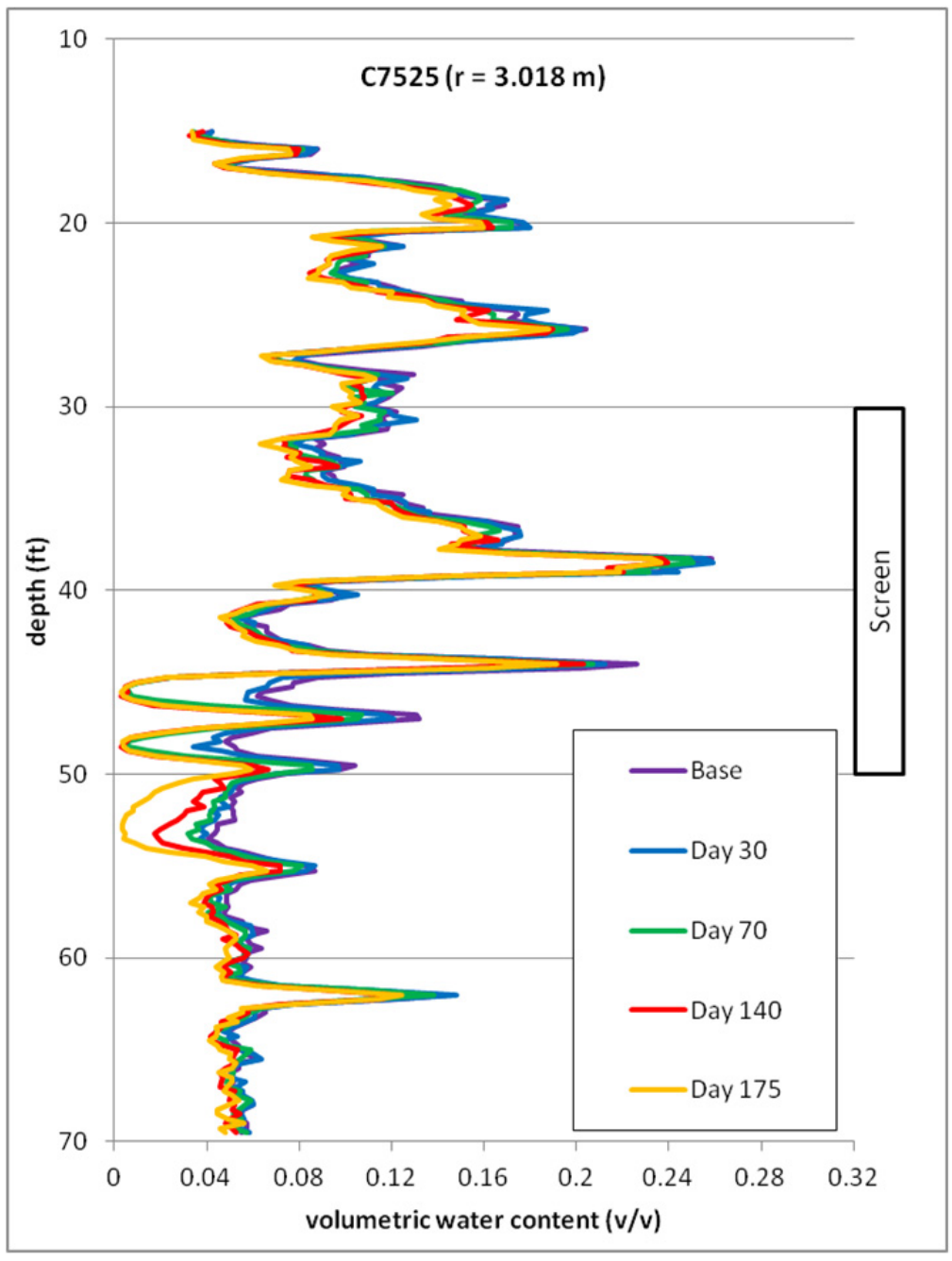

Figure 4.28. Neutron Moisture Probe Response Over Time for Location C7525 (3.018 m from injection well). The base time is a logging event in December 2010, prior to the continuous active desiccation period. Other data are for logging events in nominal days from the start of active desiccation. 


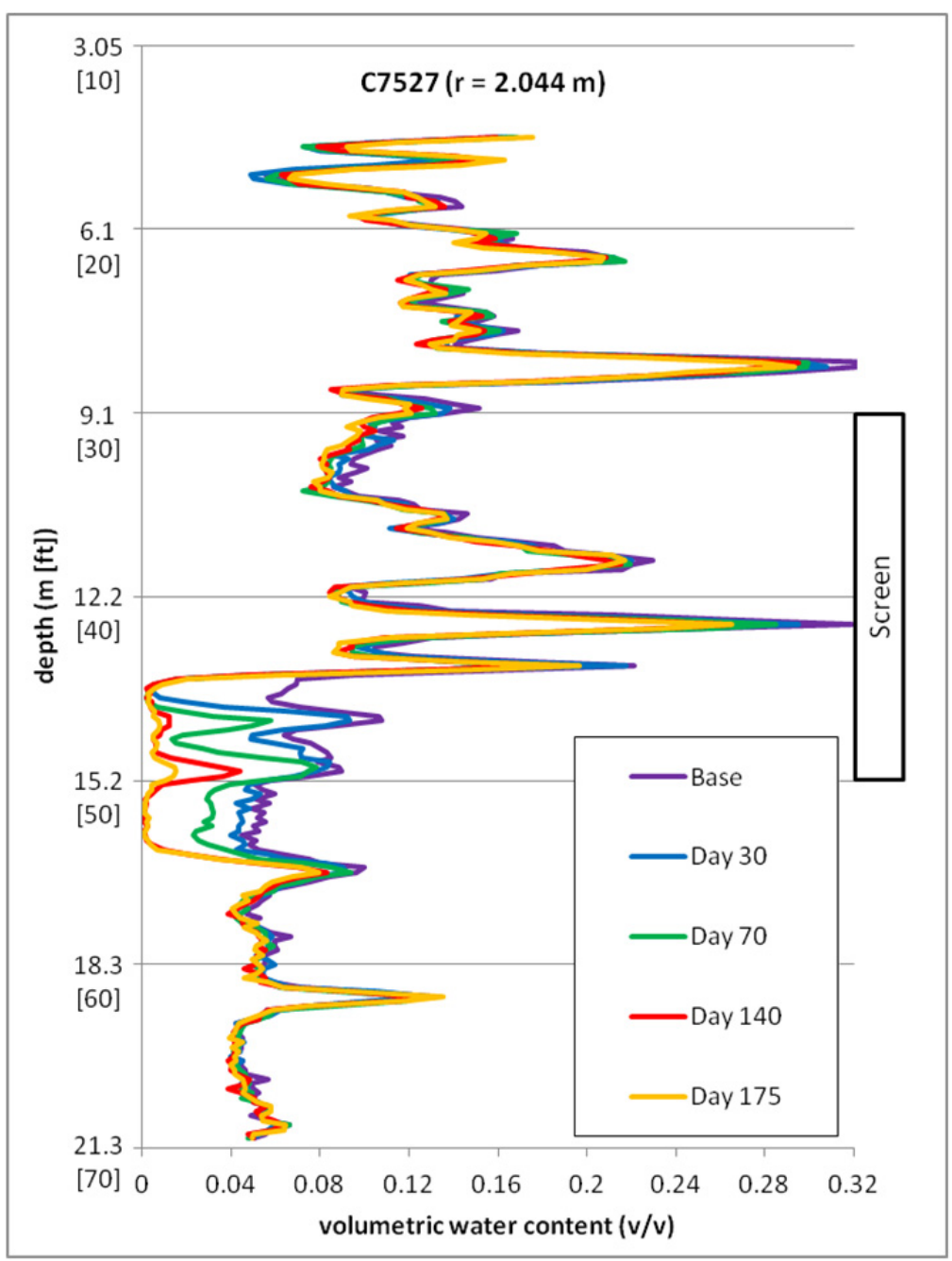

Figure 4.29. Neutron Moisture Probe Response Over Time for Location C7527 (2.044 m from injection well). The base time is a logging event in December 2010, prior to the continuous active desiccation period. Other data are for logging events in nominal days from the start of active desiccation. 


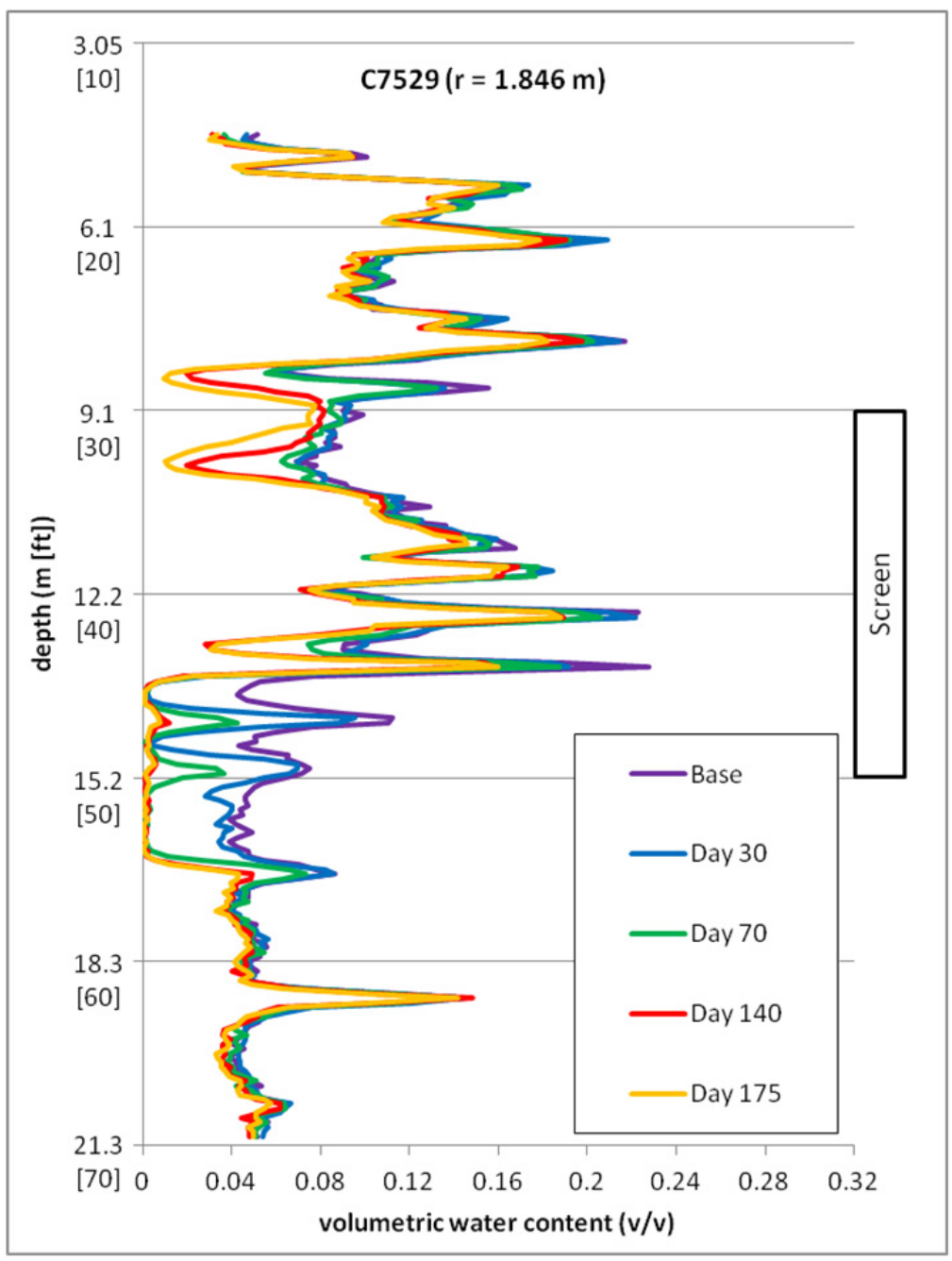

Figure 4.30. Neutron Moisture Probe Response Over Time for Location C7529 (1.846 m from injection well). The base time is a logging event in December 2010, prior to the continuous active desiccation period. Other data are for logging events in nominal days from the start of active desiccation. 


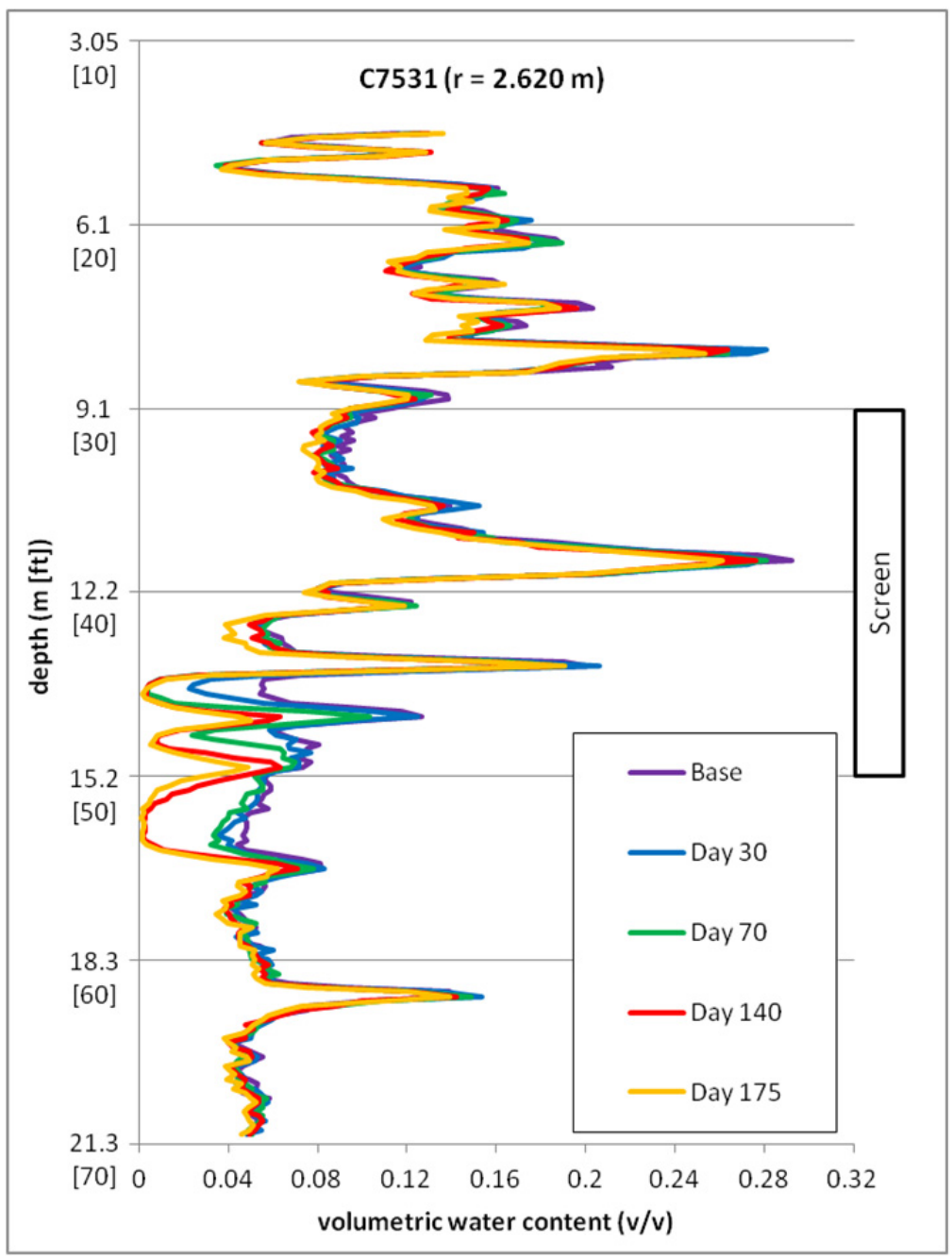

Figure 4.31. Neutron Moisture Probe Response Over Time for Location C7531 (2.620 m from injection well). This location is along the axis between the injection and extraction wells. The base time is a logging event in December 2010, prior to the continuous active desiccation period. Other data are for logging events in nominal days from the start of active desiccation. 


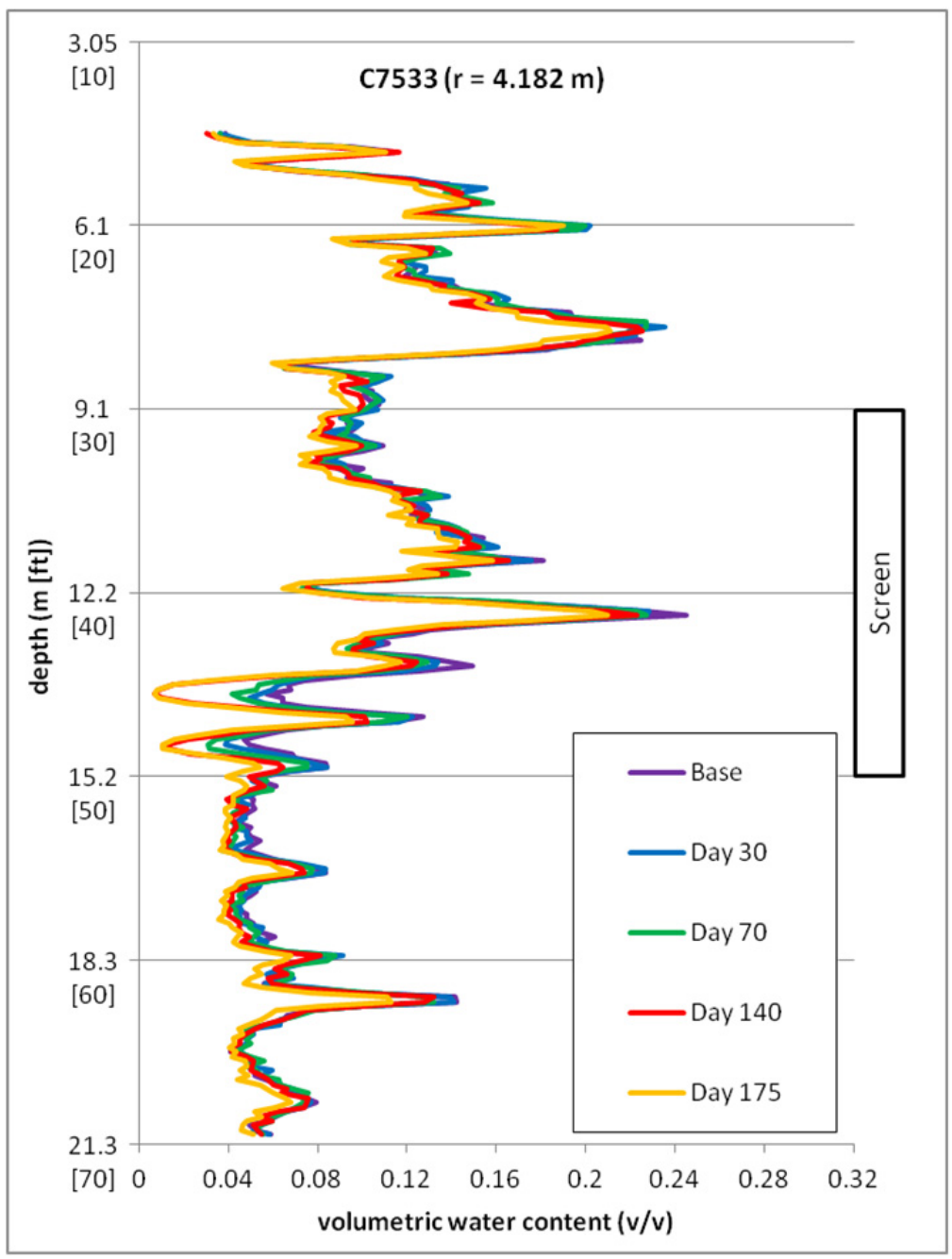

Figure 4.32. Neutron Moisture Probe Response Over Time for Location C7533 (4.182 m from injection well). The base time is a logging event in December 2010, prior to the continuous active desiccation period. Other data are for logging events in nominal days from the start of active desiccation. 


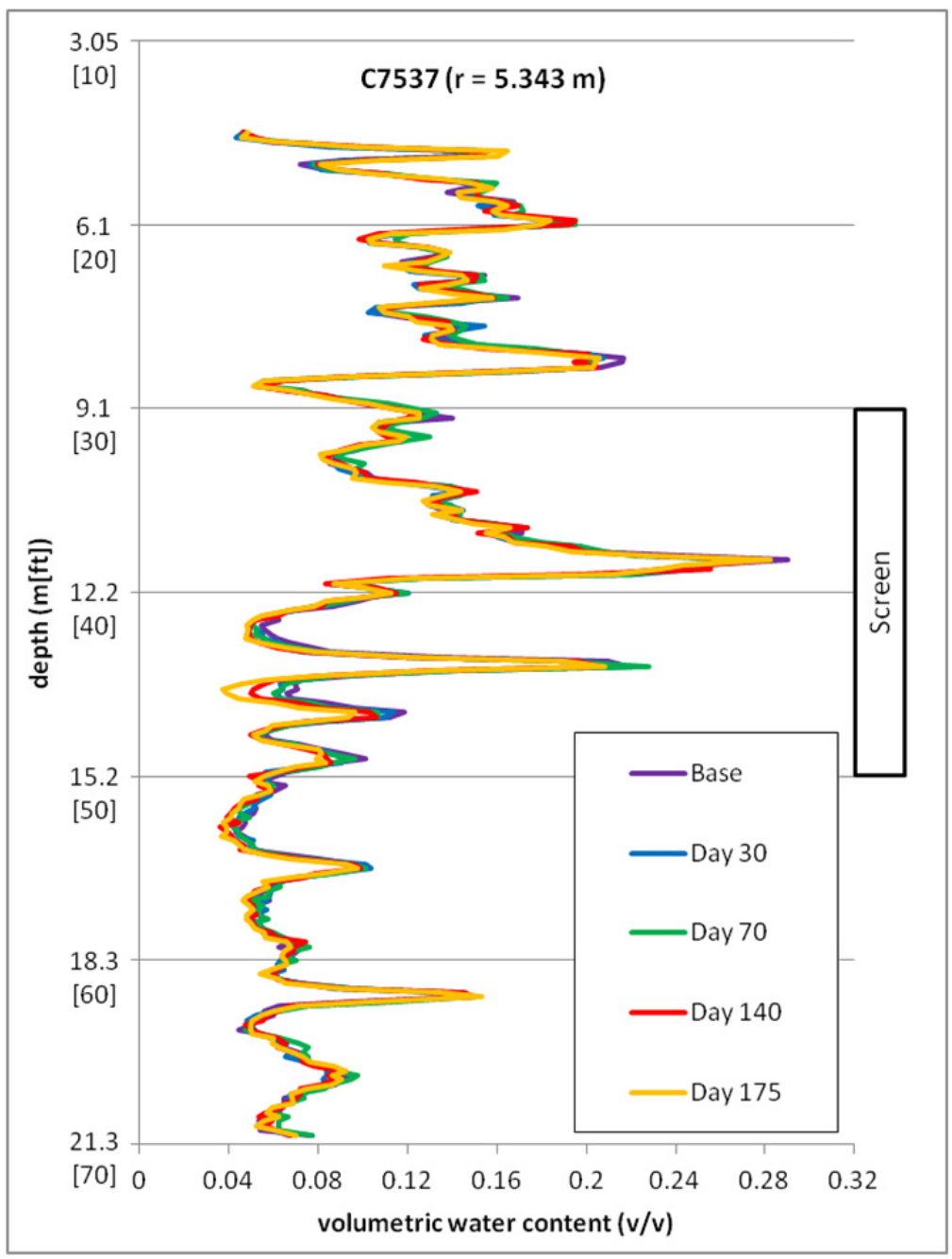

Figure 4.33. Neutron Moisture Probe Response Over Time for Location C7537 (5.343 m from injection well). This location is along the axis between the injection and extraction wells. The base time is a logging event in December 2010, prior to the continuous active desiccation period. Other data are for logging events in nominal days from the start of active desiccation. 

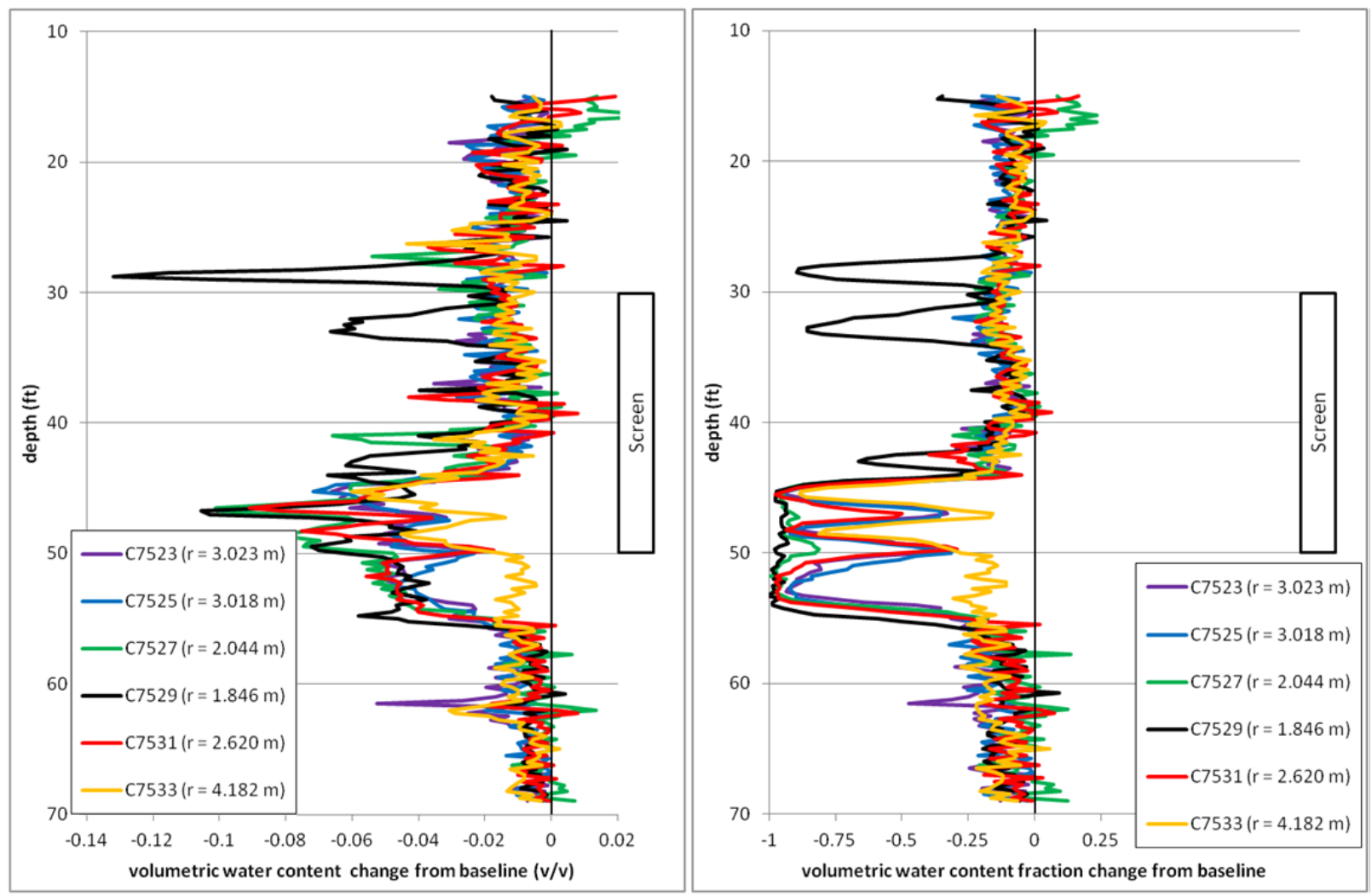

Figure 4.34. Change in Water Content at the End of Active Desiccation (day 175, July 2011) Compared to Pre-Desiccation Baseline (December 2010) Based on Neutron Moisture Probe Data for Locations C7523, C7525, C7527, C7529, C7531, and C7533 

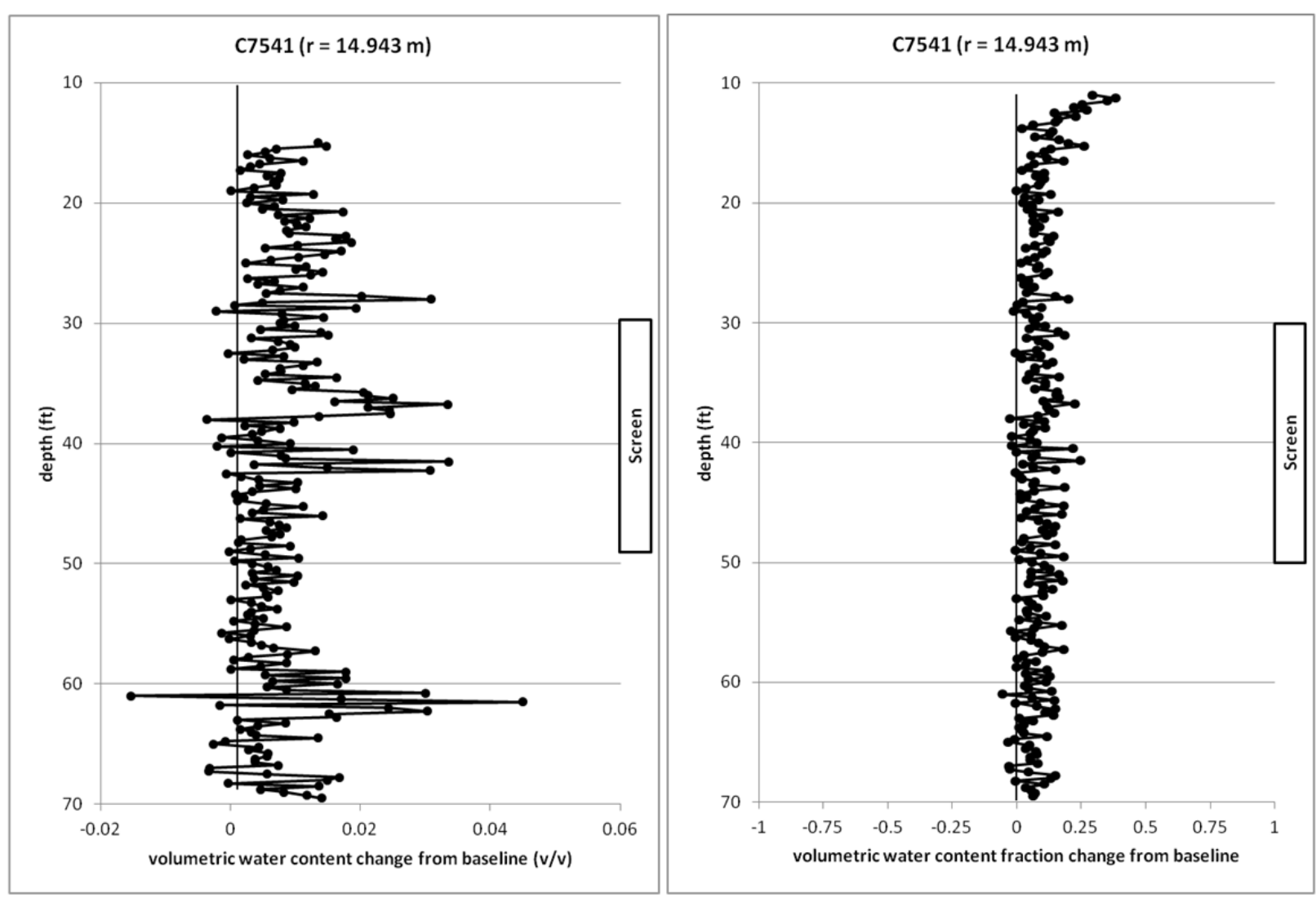

Figure 4.35. Change in Water Content at the End of Active Desiccation (day 175, July 2011) Compared to Pre-Desiccation Baseline (December 2010) Based on Neutron Moisture Probe Data for Location C7541, Near the Extraction Well on the Side Opposite from the Injection Well 

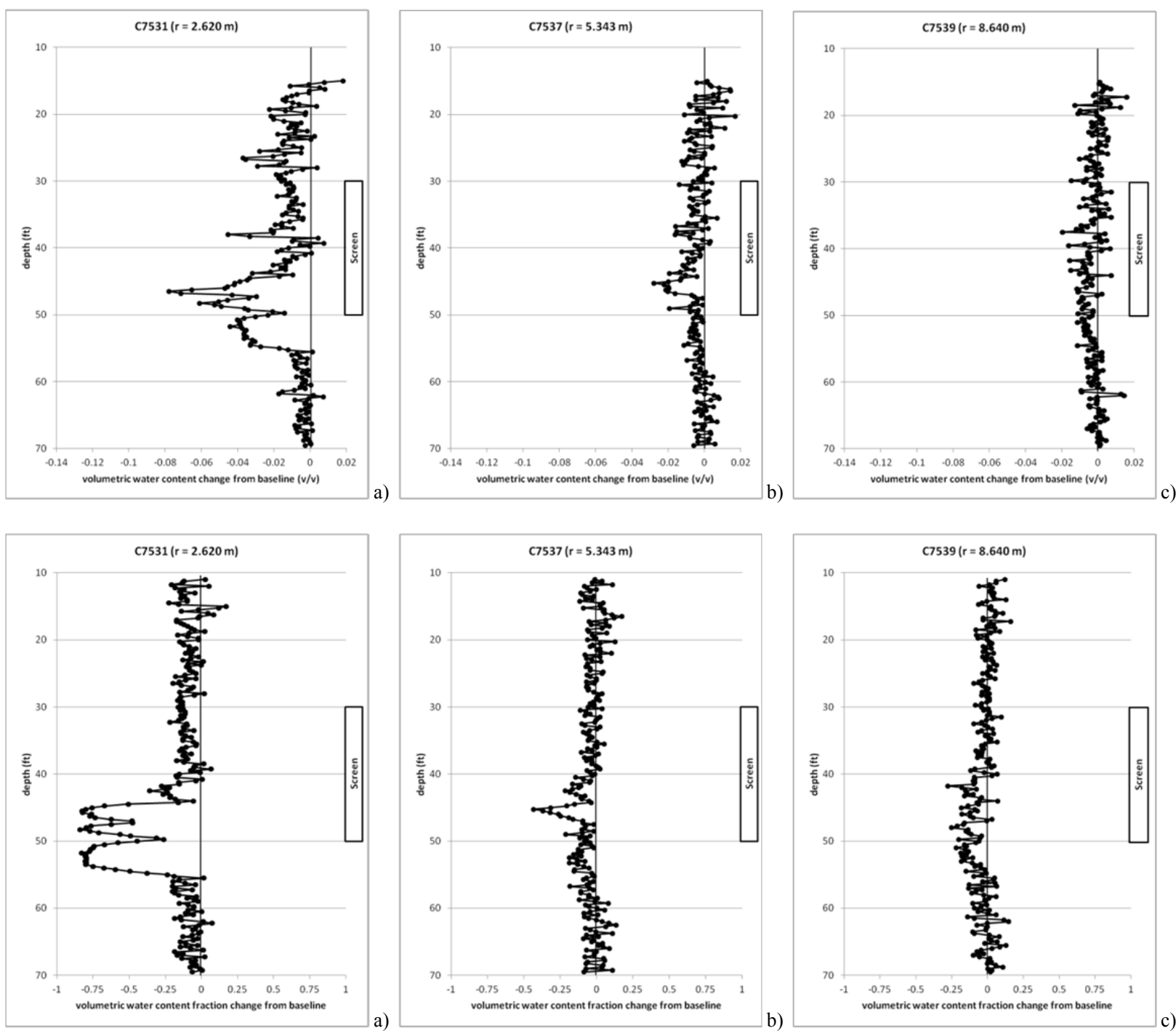

Figure 4.36. Change in Water Content at the End of Active Desiccation (day 175, July 2011) Compared to Pre-Desiccation Baseline (December 2010) Based on Neutron Moisture Probe Data for Locations a) C7531, b) C7537, and c) C7539, Along the Axis Between the Injection and Extraction Wells at Distances of $2.62 \mathrm{~m}, 5.343 \mathrm{~m}$, and $8.64 \mathrm{~m}$ from the Injection Well, Respectively 


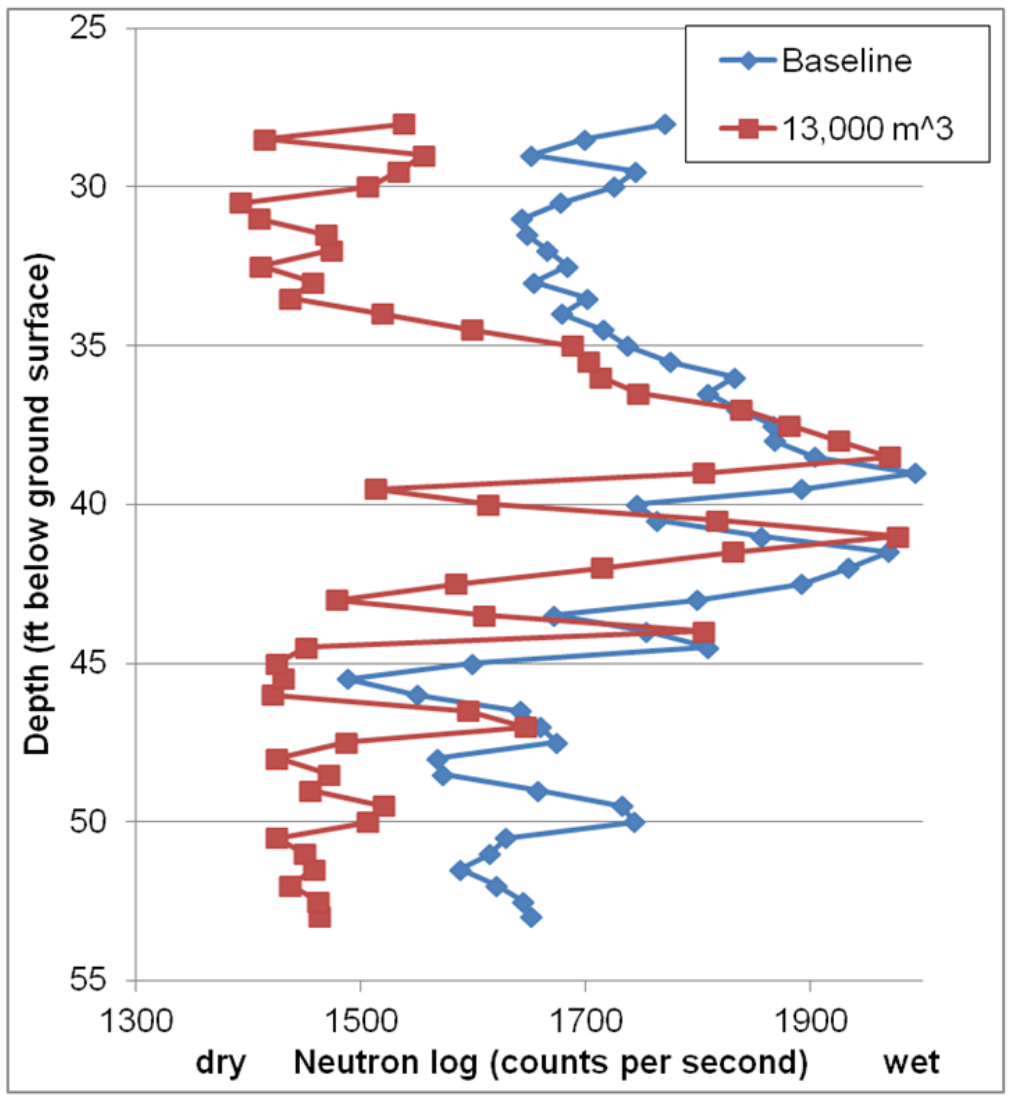

Figure 4.37. Neutron Moisture Log Response in the Injection Well Comparing Pre-Injection (baseline) and After $13,000 \mathrm{~m}^{3}$ of Dry Nitrogen were Injected 
Table 4.2. Post-Desiccation Sediment Core Analysis Results. Data from additional core samples for gravimetric and volumetric moisture content are shown in Appendix A.

\begin{tabular}{|c|c|c|c|c|c|}
\hline $\begin{array}{l}\text { Begin Depth } \\
\text { Feet }\end{array}$ & $\begin{array}{c}\text { End Depth } \\
\text { Feet }\end{array}$ & $\begin{array}{l}\text { Moisture Content } \\
\text { \% by Weight }\end{array}$ & $\begin{array}{c}\text { Tc-99 } \\
\mu \mathrm{g} / \mathrm{g} \text { dry }\end{array}$ & $\begin{array}{c}\text { Tc-99 } \\
\text { pCi/g dry }\end{array}$ & $\begin{array}{l}\text { Nitrate } \\
\mu \mathrm{g} / \mathrm{g} \text { dry }\end{array}$ \\
\hline \multicolumn{6}{|c|}{ Core C8388 } \\
\hline 20.15 & 22.65 & 9.94 & $<3.90 \mathrm{E}-05$ & $<6.63 \mathrm{E}-01$ & $1.48 \mathrm{E}+01$ \\
\hline 22 & 24.5 & 5.78 & $<3.92 \mathrm{E}-05$ & $<6.66 \mathrm{E}-01$ & $8.27 \mathrm{E}+00$ \\
\hline 24 & 26.5 & 6.19 & $<3.90 \mathrm{E}-05$ & $<6.63 \mathrm{E}-01$ & $8.57 \mathrm{E}+00$ \\
\hline 26.9 & 29.4 & 17.3 & $<3.90 \mathrm{E}-05$ & $<6.63 \mathrm{E}-01$ & $5.67 \mathrm{E}+01$ \\
\hline 29.7 & 32.2 & 5.87 & $3.87 \mathrm{E}-04$ & $6.58 \mathrm{E}+00$ & $9.68 \mathrm{E}+02$ \\
\hline 32.58 & 35.08 & 5.93 & $<3.90 \mathrm{E}-05$ & $<6.63 \mathrm{E}-01$ & $7.41 \mathrm{E}+01$ \\
\hline 35.5 & 38 & 6.57 & $2.74 \mathrm{E}-04$ & $4.66 \mathrm{E}+00$ & $4.25 \mathrm{E}+02$ \\
\hline 38.3 & 40.8 & 16.4 & 2.03E-03 & $3.45 \mathrm{E}+01$ & $4.52 \mathrm{E}+03$ \\
\hline 40.5 & 43 & 10.5 & 5.59E-04 & $9.50 \mathrm{E}+00$ & $1.45 \mathrm{E}+03$ \\
\hline 43.08 & 45.58 & 11.7 & $3.76 \mathrm{E}-03$ & $6.39 \mathrm{E}+01$ & $7.77 \mathrm{E}+03$ \\
\hline 45.2 & 47.7 & 0.319 & $9.71 \mathrm{E}-04$ & $1.65 \mathrm{E}+01$ & $2.04 \mathrm{E}+03$ \\
\hline 47.5 & 50 & 0.467 & $1.99 \mathrm{E}-03$ & $3.38 \mathrm{E}+01$ & $3.63 \mathrm{E}+03$ \\
\hline 50.1 & 52.6 & 0.408 & 4.12E-03 & $7.00 \mathrm{E}+01$ & $5.23 \mathrm{E}+03$ \\
\hline 52.5 & 55 & 0.475 & $2.57 \mathrm{E}-03$ & $4.37 \mathrm{E}+01$ & $3.52 \mathrm{E}+03$ \\
\hline 55.6 & 58.1 & 3.03 & $1.60 \mathrm{E}-03$ & $2.72 \mathrm{E}+01$ & $3.00 \mathrm{E}+03$ \\
\hline 58 & 60.5 & 3.15 & $1.93 \mathrm{E}-03$ & $3.28 \mathrm{E}+01$ & $3.59 \mathrm{E}+03$ \\
\hline \multicolumn{6}{|c|}{ Core C8387 } \\
\hline 20 & 23.1 & 5.62 & $<3.90 \mathrm{E}-05$ & $<6.63 \mathrm{E}-01$ & $8.28 \mathrm{E}+00$ \\
\hline 22.3 & 24.8 & 5.07 & $<3.90 \mathrm{E}-05$ & $<6.63 \mathrm{E}-01$ & $5.44 \mathrm{E}+00$ \\
\hline 25 & 27.5 & 12.9 & $<3.90 \mathrm{E}-05$ & $<6.63 \mathrm{E}-01$ & $6.93 \mathrm{E}+01$ \\
\hline 27.5 & 30 & 4.58 & $<3.90 \mathrm{E}-05$ & $<6.63 \mathrm{E}-01$ & $2.36 \mathrm{E}+01$ \\
\hline 30 & 32.6 & 6.52 & $9.91 \mathrm{E}-05$ & $1.68 \mathrm{E}+00$ & $1.39 \mathrm{E}+02$ \\
\hline 32.8 & 35.3 & 6.86 & $<3.90 \mathrm{E}-05$ & $<6.63 \mathrm{E}-01$ & $3.90 \mathrm{E}+01$ \\
\hline 35.2 & 37.7 & 8.48 & $6.62 \mathrm{E}-04$ & $1.13 \mathrm{E}+01$ & $1.26 \mathrm{E}+03$ \\
\hline 37.5 & 40 & 9.02 & $4.10 \mathrm{E}-03$ & $6.97 \mathrm{E}+01$ & $7.45 \mathrm{E}+03$ \\
\hline 39.9 & 42.4 & 6.25 & $4.28 \mathrm{E}-03$ & $7.28 \mathrm{E}+01$ & $5.86 \mathrm{E}+03$ \\
\hline 42.7 & 45.2 & 4.15 & $2.06 \mathrm{E}-03$ & $3.50 \mathrm{E}+01$ & $3.54 \mathrm{E}+03$ \\
\hline 45.3 & 47.8 & 1.5 & 2.64E-03 & $4.49 \mathrm{E}+01$ & $4.20 \mathrm{E}+03$ \\
\hline 47.6 & 50.1 & 2.78 & $9.54 \mathrm{E}-04$ & $1.62 \mathrm{E}+01$ & $3.03 \mathrm{E}+03$ \\
\hline 49.75 & 52.25 & 3.03 & 4.67E-03 & $7.94 \mathrm{E}+01$ & $6.52 \mathrm{E}+03$ \\
\hline 52.8 & 55.3 & 2.24 & $4.18 \mathrm{E}-03$ & $7.11 \mathrm{E}+01$ & $5.61 \mathrm{E}+03$ \\
\hline 55.5 & 58 & 2.57 & $2.75 \mathrm{E}-03$ & $4.68 \mathrm{E}+01$ & $4.53 \mathrm{E}+03$ \\
\hline 58.3 & 60.8 & 3.12 & $2.84 \mathrm{E}-03$ & $4.83 \mathrm{E}+01$ & $4.27 \mathrm{E}+03$ \\
\hline
\end{tabular}

\subsection{Spatial Analysis of Desiccation}

Imaging of the desiccation process in two and three dimensions was also conducting using temperature, neutron, cross-hole ERT, and cross-hole GPR data. The numerous temperature sensors (2-ft vertical interval) at the monitoring boreholes provided a spatially dense set of data for temperature. Thus, temperature data were interpolated to produce two- and three-dimensional depictions of the temperature distribution at selected time points during the desiccation process. The neutron data were collected at frequent intervals $(7.5 \mathrm{~cm})$ during vertical logging at the monitoring boreholes, providing a 
spatially dense set of data. Thus, the neutron moisture data were also interpolated to produce two- and three-dimensional depictions of the volumetric water content distribution at selected time points during the desiccation process. The Electrical Resistivity Tomography (ERT) system enabled collection of cross-hole data twice daily. These data were interpreted to provide a temporal depiction of the two- and three-dimensional change in moisture conditions. Periodically, GPR data were collected from crossborehole pairs and used to interpret moisture content changes for two-dimensional zones between logging locations. These two dimensional responses provided information about moisture content changes between monitoring locations.

Monitoring the progression of desiccation in the subsurface provides information to guide operational decisions such as modification of the injected gas temperature and flow rate. While nominal values for these injection parameters can be selected based on initial site characterization data, the impact of subsurface heterogeneities cannot be fully predicted and monitoring data to assess the impact of these heterogeneities on desiccation performance is needed. Monitoring data are also needed to determine when the size of the desiccated zone and the final moisture content are sufficient to meet the overall goals for the desiccation remedy. For desiccation, the performance in terms of slowing contaminant movement is a function of the final moisture content in relation to the residual moisture content value for the porous medium. When the moisture content is reduced below the residual moisture content value, porous medium water relative permeability is essentially zero and the remaining water cannot migrate as a result of pressure gradients. Additionally, the physical size of the desiccated zone and conditions at the desiccation zone boundaries impact the overall long-term performance of desiccation in reducing the moisture and contaminant flux to groundwater (Truex et al. 2011). The monitoring methods evaluated in the field test have the potential to provide the above type of data as part of implementing a desiccation remedy.

Temperature sensors can provide a means to monitor the progress and distribution of desiccation using an in situ network of sensors. Temperature decreases due to evaporative cooling until the desiccation front reaches the monitoring locations (i.e., the time when the sediment between the injection location and the monitoring location is desiccated). At that time, the temperature at the monitoring location begins to increase toward the temperature of the injected gas because evaporative cooling is no longer occurring in the sediment between the injection location and the monitoring location (Oostrom et al. 2009). There can be multiple inflection points if there are multiple layers that are being desiccated at different rates and these layers are within a region that can impact the temperature at the monitoring location. Figure 4.38 shows two-dimensional interpolations of temperature sensor data during active desiccation at days 20,45, 90, and 164 (the end of dry gas injection) (see Appendix B for additional temperature plots). The progression of cooled zones shown at days 20 and 45 are indicators of desiccation activity and the related dominant injected dry gas flow pattern. By days 90 and 164, localized warming indicates that some zones have been desiccated, while desiccation, as indicated by cooler temperatures continues to occur at other locations.

Temperature variations impact the distribution of desiccation because temperature impacts the waterholding capacity of the gas. Evaporative cooling causes in situ temperature to decrease and the gas passing through the cooled zone evaporates water up to the water-holding capacity for the temperature of that zone. As the gas moves into warmer portions of the subsurface, the water-holding capacity increases and the gas evaporates more water. Thus, the impact of nonuniform temperature is to spatially spread out the evaporation process. In laboratory flow cell tests, very sharp transitions between the zone of 
desiccation and nondesiccated zones were observed when temperature was relatively constant due to fast heat transfer from the flow cell walls that minimized evaporative cooling impact on temperature (Ward et al. 2008; Oostrom et al. 2009).

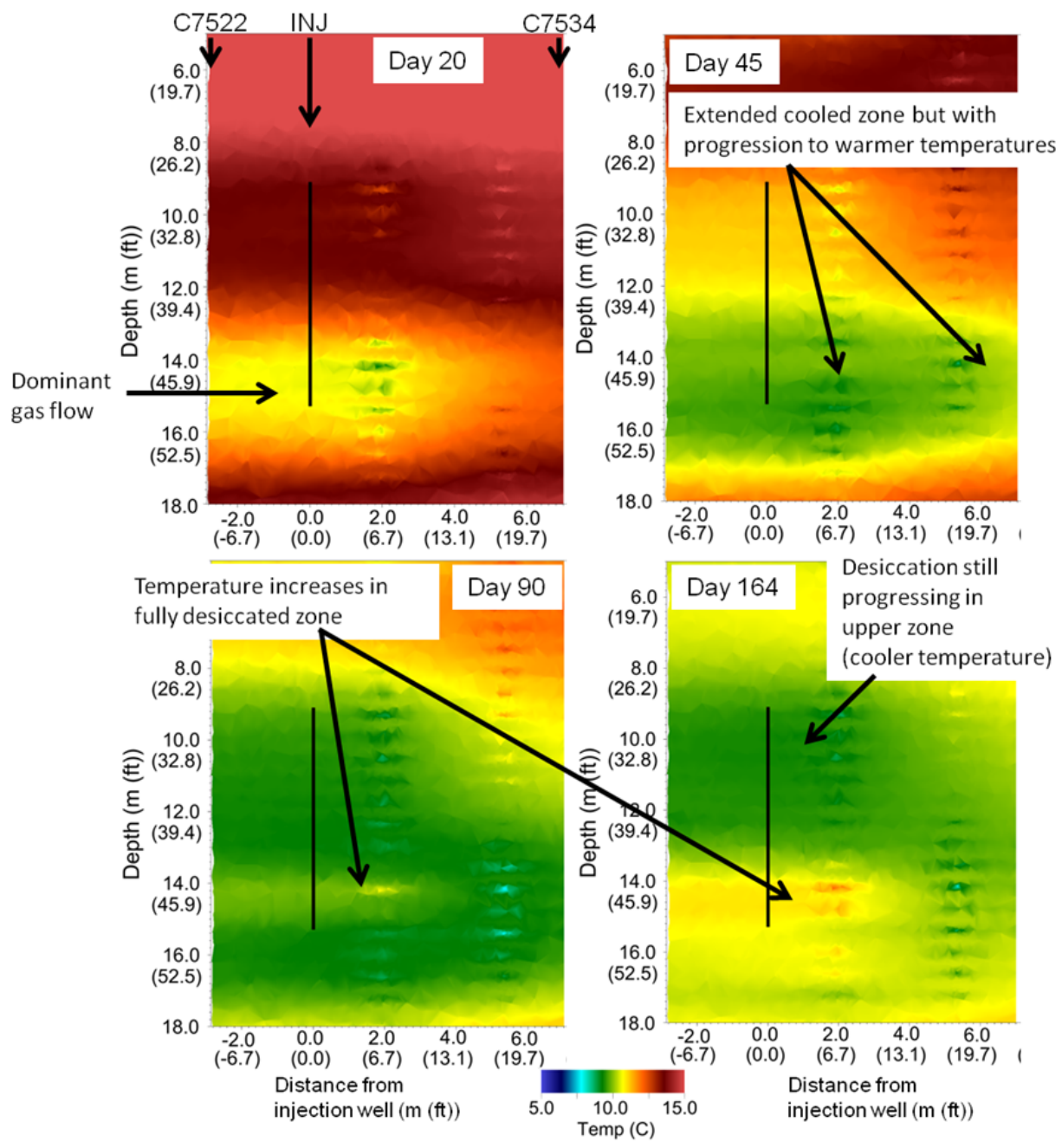

Figure 4.38. Interpolated Temperature Response Along the Axis Between the Injection and Extraction Wells, Indirectly Showing Desiccation Through the Evaporative Cooling Effect.

Temperatures drop while a zone is being desiccated. Once a zone is fully desiccated, there is no more evaporative cooling and temperature rises toward the inlet temperature. Data from sensors at locations C7522-C7534 (Figure 3.4).

Temperature data do not directly enable quantification of moisture content decreases. However, temperature monitoring enables imaging of the nonuniform temperature distribution that affects the desiccation process and temperature inflections from cool to warm that indicate zones of significant desiccation. Temperature correction is also needed for the ERT analyses. Thermistors provide a robust sensor that can be monitored autonomously to provide high temporal and, potentially, high spatial resolution. 
Neutron moisture logging of a borehole is a standard method for obtaining a high resolution vertical profile ( $\sim 7.5 \mathrm{~cm}$ vertical intervals) of volumetric moisture content. These data are a good representation of moisture content at the logging locations within the nominal measurement radius of about $30 \mathrm{~cm}$.

Figure 4.39 shows a two-dimensional interpolation of volumetric moisture content from neutron moisture logging data prior to active desiccation (December 2010) and at the end of active desiccation (see Appendix B for additional neutron moisture interpolation plots). This type of interpolation does not incorporate subsurface conditions that can impact the distribution of desiccation away from the measurement point. Thus, care is needed in interpreting the images with respect to the volumetric distribution of moisture content reduction.

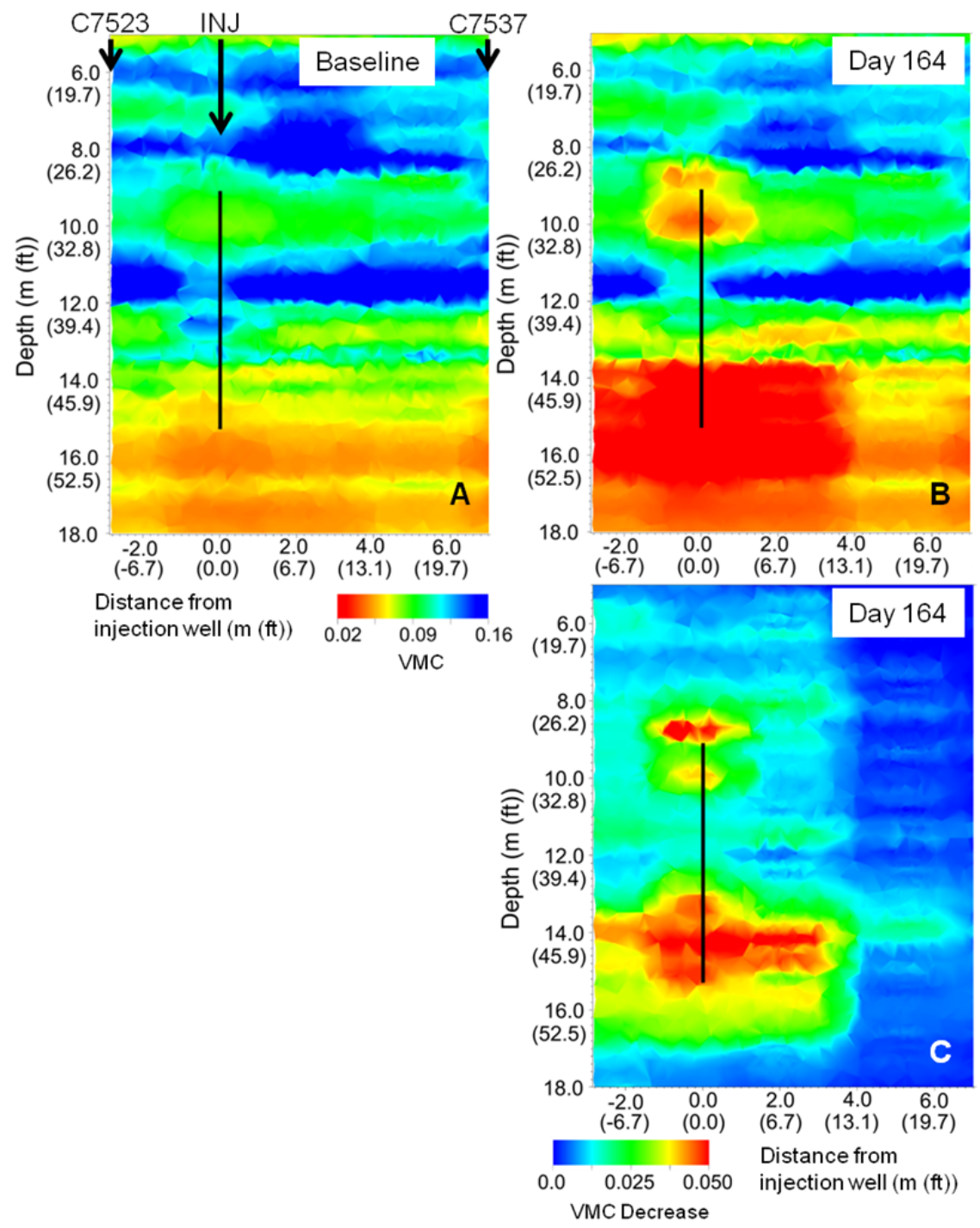

Figure 4.39. Interpolation of Volumetric Moisture Content (VMC) from Neutron Moisture Logging Data Along the Axis Between the Injection and Extraction Wells, Prior to (A) and at the End of Active Desiccation (B). Interpolation of the change in volumetric water content at the end of active desiccation (C) compared to the baseline volumetric moisture content distribution. Neutron moisture data are from logging at locations C7523-C7537 (Figure 3.4). 
Cross-hole ERT reconstructs the electrical conductivity distribution between in situ electrode locations which can be related to the distribution of volumetric moisture content changes (Equation 3.5, Section 3.2.2.3). ERT monitoring can then be used to provide a temporal data set representing the threedimensional distribution of desiccation via moisture content changes that represent conditions throughout the subsurface between electrode locations. The ERT data show changes in the volumetric moisture content expressed as the ratio of volumetric moisture content $\left(\mathrm{VMC}_{\mathrm{t}}\right)$ at the time of the measurement to the baseline volumetric moisture content from an ERT data set collected prior to desiccation $\left(\mathrm{VMC}_{0}\right)$. Thus, a ratio of one designates areas that have not changed from the conditions prior to active desiccation. Ratios lower than one indicate desiccation, for instance, where a ratio of 0.75 means that the volumetric moisture content is 0.75 times what it was prior to desiccation. The progression and distribution of moisture content changes as imaged by ERT is shown in Figure 4.40. These two-dimensional sections were extracted from the three-dimensional ERT images along the transect between the injection and extraction wells. The resolution of the ERT data inversion is on the order of a cubic meter. Thus, the ERT images in Figure 4.40, cannot show sharp contrasts in wetting or drying zones over time, but show a "smoothed" image of how the subsurface is changing. Figure 4.40 shows the impact of non-uniform temperature (Figure 4.38) in the extended, but more moderate moisture content reduction along the path of dominant injection gas flow. There are four time points shown in Figure 4.40, but two ERT data sets were automatically collected each day such that a much higher temporal resolution could be imaged if needed (see Appendix B for additional ERT interpolation plots).

Cross-hole GPR provides means to monitor absolute volumetric moisture content and moisture content changes in two dimensions based on propagation of energy through the subsurface between two logging boreholes. Thus, it provides data for interpretation of volumetric moisture content distribution away from subsurface access points and does not require interpolation between access points like the neutron moisture logging data. However, high electrical conductivity at contaminated sites can severely impact the accuracy of the GPR estimate. When the ground has a high electrical conductivity the lowloss assumption is not valid and the EM velocity is affected by both conductivity and permittivity changes. As shown in Figure 4.41, pre-desiccation GPR moisture content estimates agree well with neutron moisture data above $12 \mathrm{~m}$ bgs where conductivity is low (Figure 4.42). However, below $12 \mathrm{~m}$ bgs, GPR estimates are significantly higher than the neutron moisture data where electrical conductivity is very high (Figure 4.42). In zones where neutron moisture data show significant desiccation by June, the GPR estimates much closer to the neutron moisture data. Figure 4.43 shows the two-dimensional GPR-imaged volumetric moisture content distribution prior to active desiccation (December 2010) and at the end of active desiccation for comparison to the neutron logging data interpolation (Figure 4.39) and ERT image (Figure 4.40). This figure shows volumetric moisture content changes similar to the other methods, although the absolute value of volumetric moisture content is higher by more than double compared to the neutron logging data for the pre-desiccation image and in parts of the post-desiccation image. As shown for the single logging location in Figure 4.41, the offset in Figure 4.43 is likely due to the changes in both electrical permittivity and conductivity that occurred during desiccation and because the low-loss assumption is not valid in some portions of the test site. However, in zones with significant desiccation, the electrical conductivity drops because moisture content decreases. In those zones, as shown in Figure 4.41, GPR moisture content determined through the Equation 3.6 correlation (Section 3.2.2.4) are much closer to those determined by neutron moisture logging. Neutron logging data is expected to be the more accurate localized indicator of volumetric moisture content because of its calibration to physical measurement of moisture content from sediment samples. 


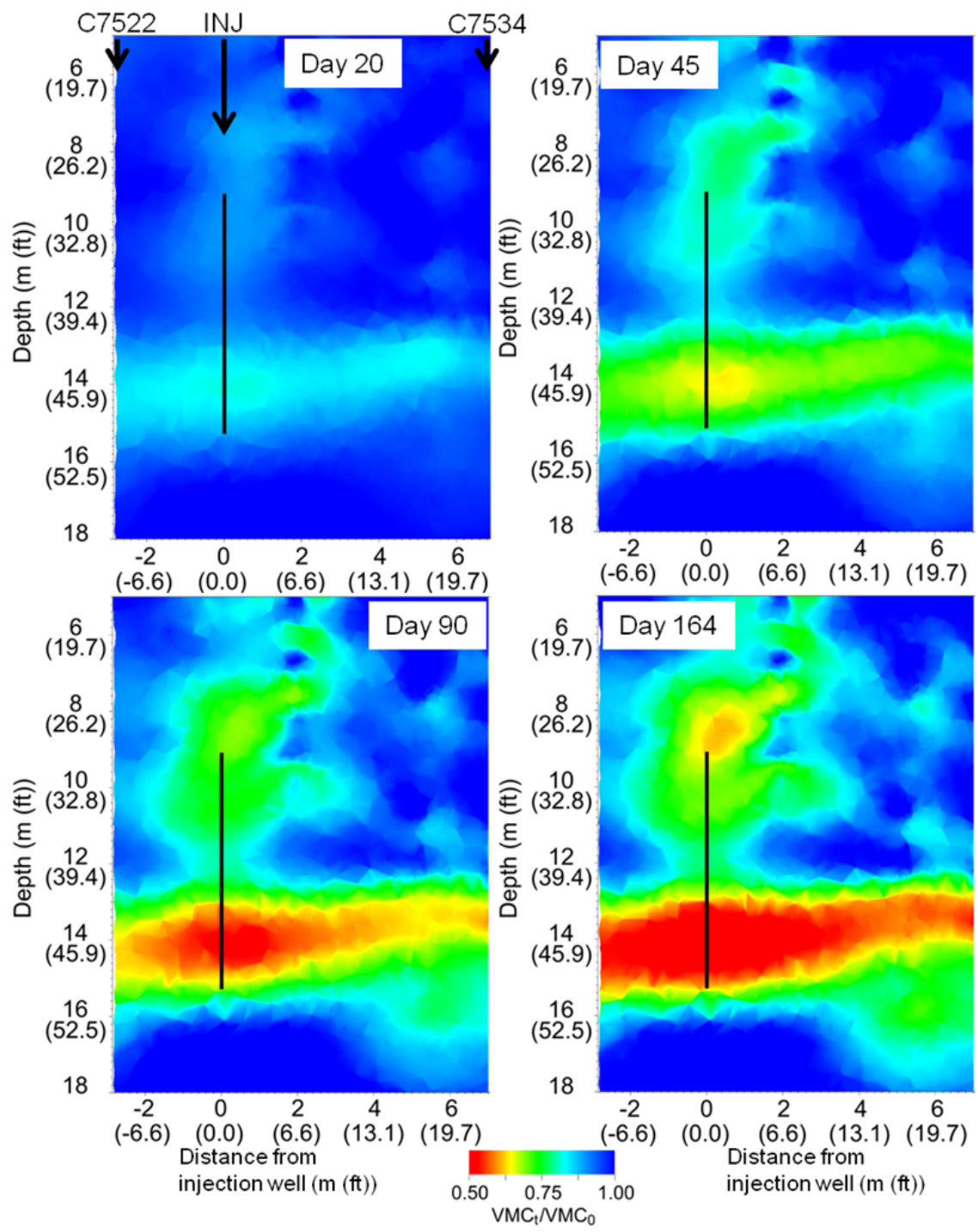

Figure 4.40. Ratio of Volumetric Moisture Content $\left(\mathrm{VMC}_{\mathrm{t}}\right)$ to Pre-desiccation Volumetric Moisture Content $\left(\mathrm{VMC}_{0}\right)$ Over Time Along the Axis Between the Injection and Extraction Wells from Cross-Hole Electrical Resistivity Tomography. ERT data are from sensors at locations C7522-C7534 (Figure 3.4). 


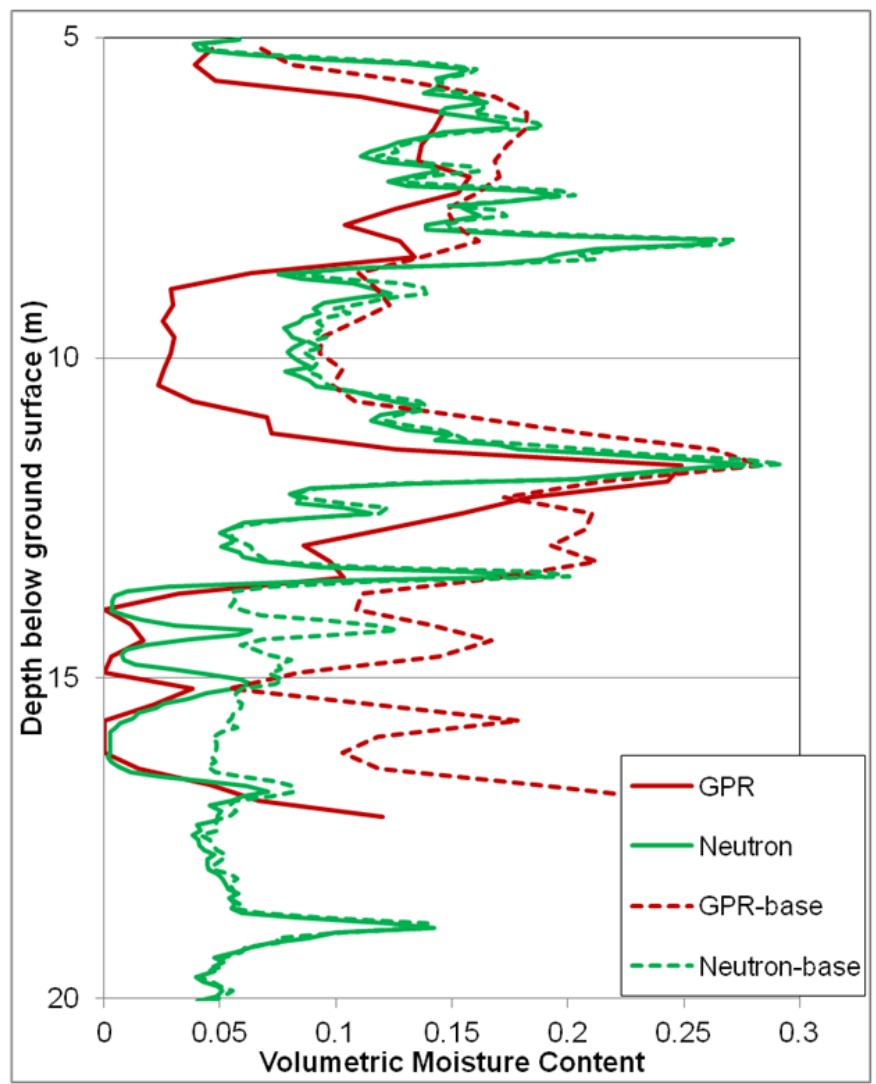

Figure 4.41. Volumetric Moisture Content Data Estimated for Location C7531 Using Neutron Moisture Logging and GPR. Base values are pre-desiccation data collected in December 2010. Neutron data were collected on June 6, 2011 (Day 140 after the start of desiccation). GPR data were collected on June 3, 2011.

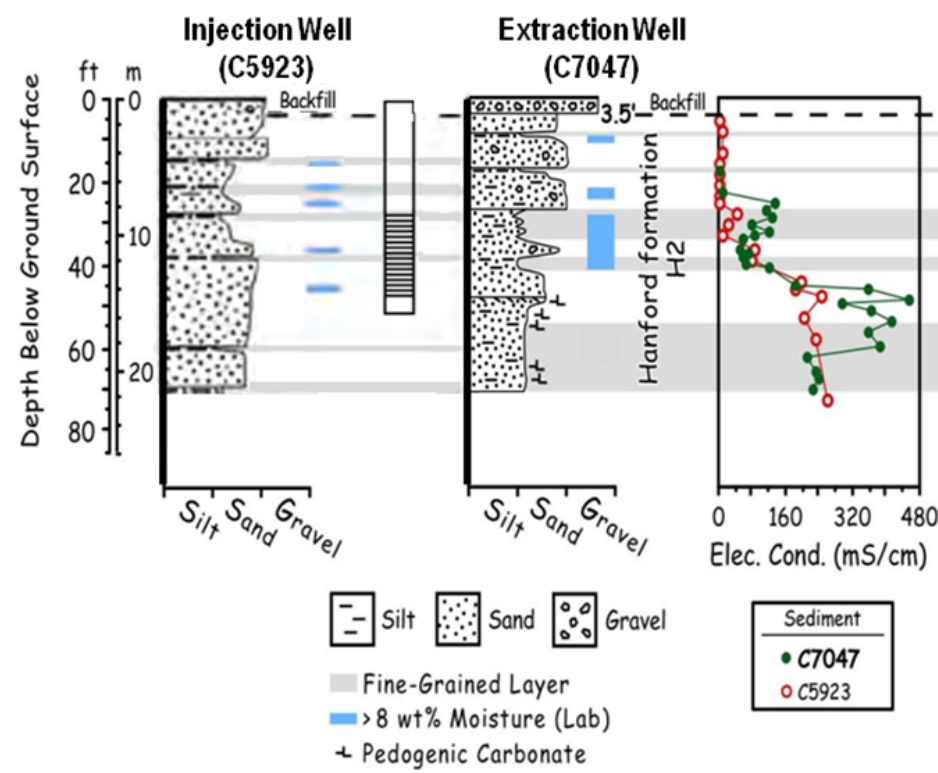

Figure 4.42. Injection and Extraction Well Borehole Data and Well Screened Interval (after DOE 2010a; Serne et al. 2009). Electrical conductivity was measured on pore water extracted from sediment samples. 


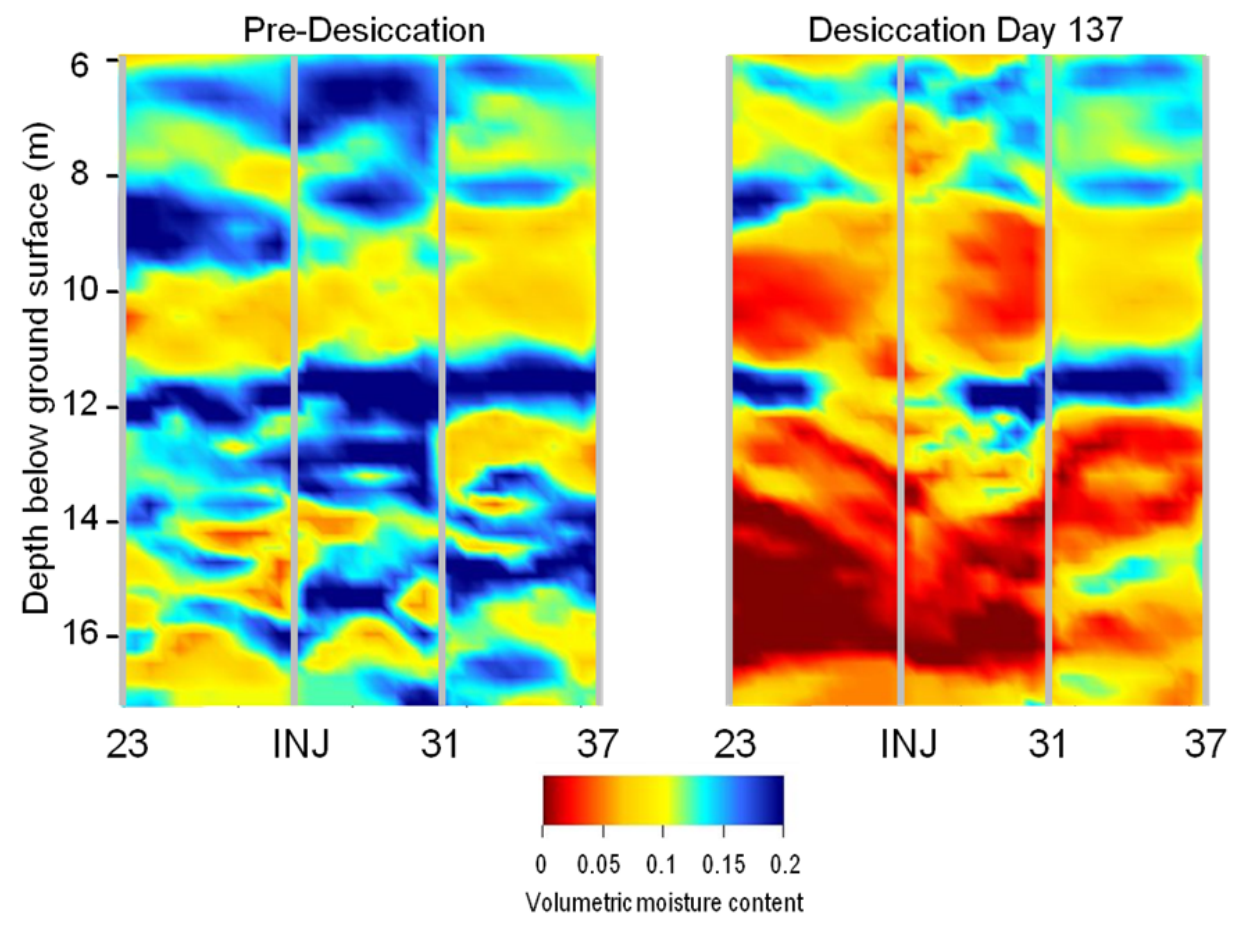

Figure 4.43. 2-D Interpretation of Volumetric Moisture Content from Cross-Hole Ground Penetrating Radar Data Prior to Desiccation (left) and at Day 137 (June 3, 2011) After the Start of Active Desiccation (right)

\subsection{Analysis of Condensate Collected During Active Desiccation}

Condensate from the extracted soil gas was collected and analyzed periodically for Tc-99 and nitrate. These analyses were conducted because initial soil gas extraction testing had shown the potential for contamination to be present in the extraction stream (DOE 2010a). Contamination in condensate was observed for many of the samples collected over the duration of the active desiccation test (Table 4.3), either due to actual extraction of contaminants or due to residual in the extraction system from previous testing (see DOE 2010a). However, full-scale design for desiccation would not require an extraction well and issues associated with contaminant extraction can be avoided.

Table 4.3. Condensate Sampling Results

\begin{tabular}{cccccc}
\hline Sampling Date & Sample No. & Nitrate-N $(\mu \mathrm{g} / \mathrm{L})$ & Tc-99 $(\mathrm{pCi} / \mathrm{L})$ & Gross $\alpha(\mathrm{pCi} / \mathrm{L})$ & Gross $\beta(\mathrm{pCi} / \mathrm{L})$ \\
\hline $12 / 02 / 2010$ & B29M54 & 0.155 & 69 & $\mathrm{U}$ & $\mathrm{U}$ \\
$12 / 02 / 2010$ & B29M59 & 0.162 & 87 & $\mathrm{U}$ & 22 \\
$2 / 03 / 2011$ & B29M55 & $\mathrm{U}$ & $\mathrm{U}$ & $\mathrm{U}$ & 6.4 \\
$6 / 13 / 2011$ & B29M56 & $\mathrm{U}$ & 58 & $\mathrm{U}$ & $\mathrm{U}$ \\
$6 / 13 / 2011$ & B29M56 & - & $99^{(\mathrm{a})}$ & - & $\mathrm{U}^{(\mathrm{b})}$ \\
\hline
\end{tabular}

(a) Sample reanalyzed; laboratory did not consider difference between this result and the original to be significant. (b) Sample reanalyzed. 


\subsubsection{Post-Desiccation Data}

The three primary types of monitoring for the rewetting period included in this report (July 2011 through February 2012) are listed below.

Sensor data. In situ sensor monitoring was continued without interruption after active desiccation was terminated. The figures below (Figures 4.44 through 4.53 ) show the initial responses for those sensor locations where a response was observed during active desiccation.

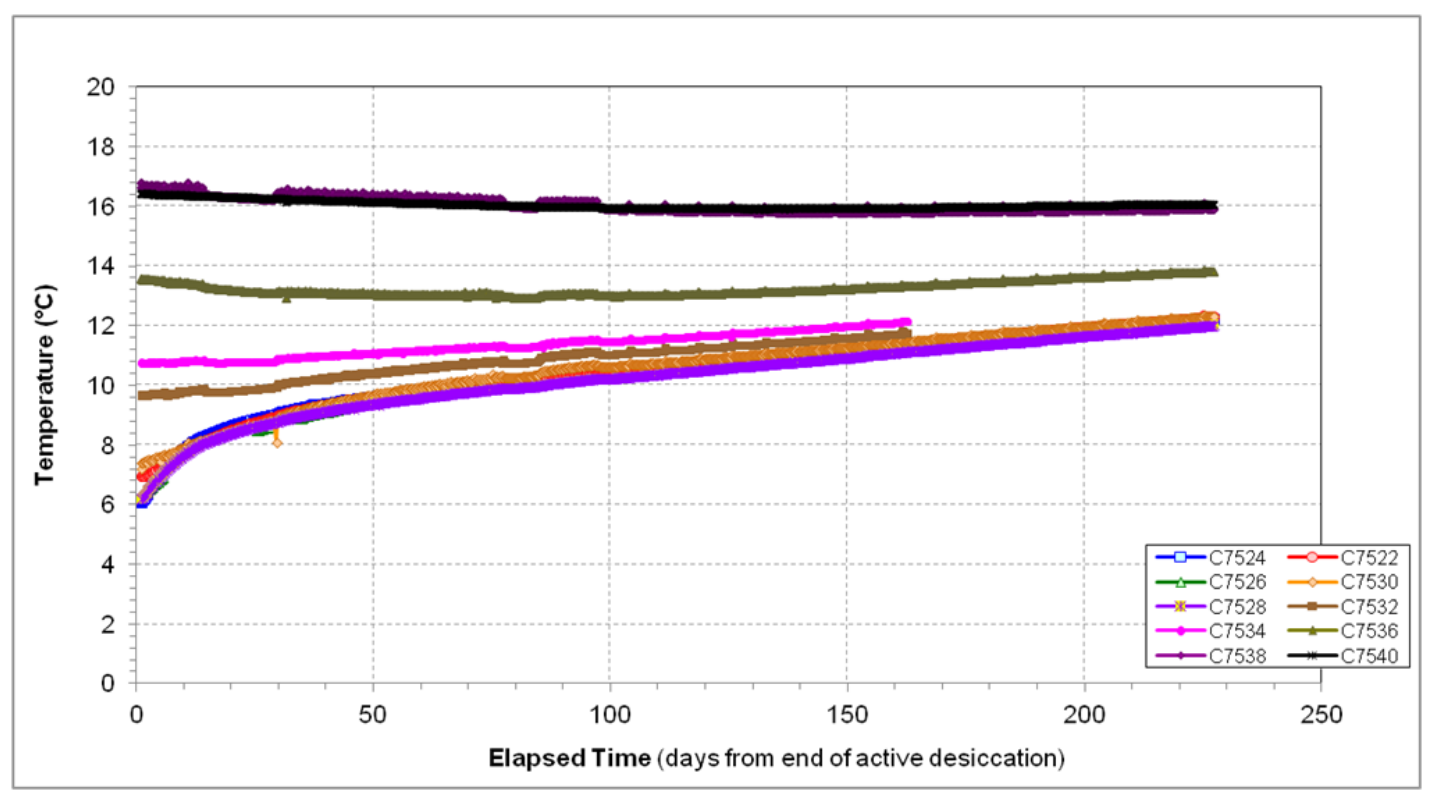

Figure 4.44. Post-Desiccation Temperature Response Over Time for the Sensors at a Depth of $32.5 \mathrm{ft}$ Below Ground Surface

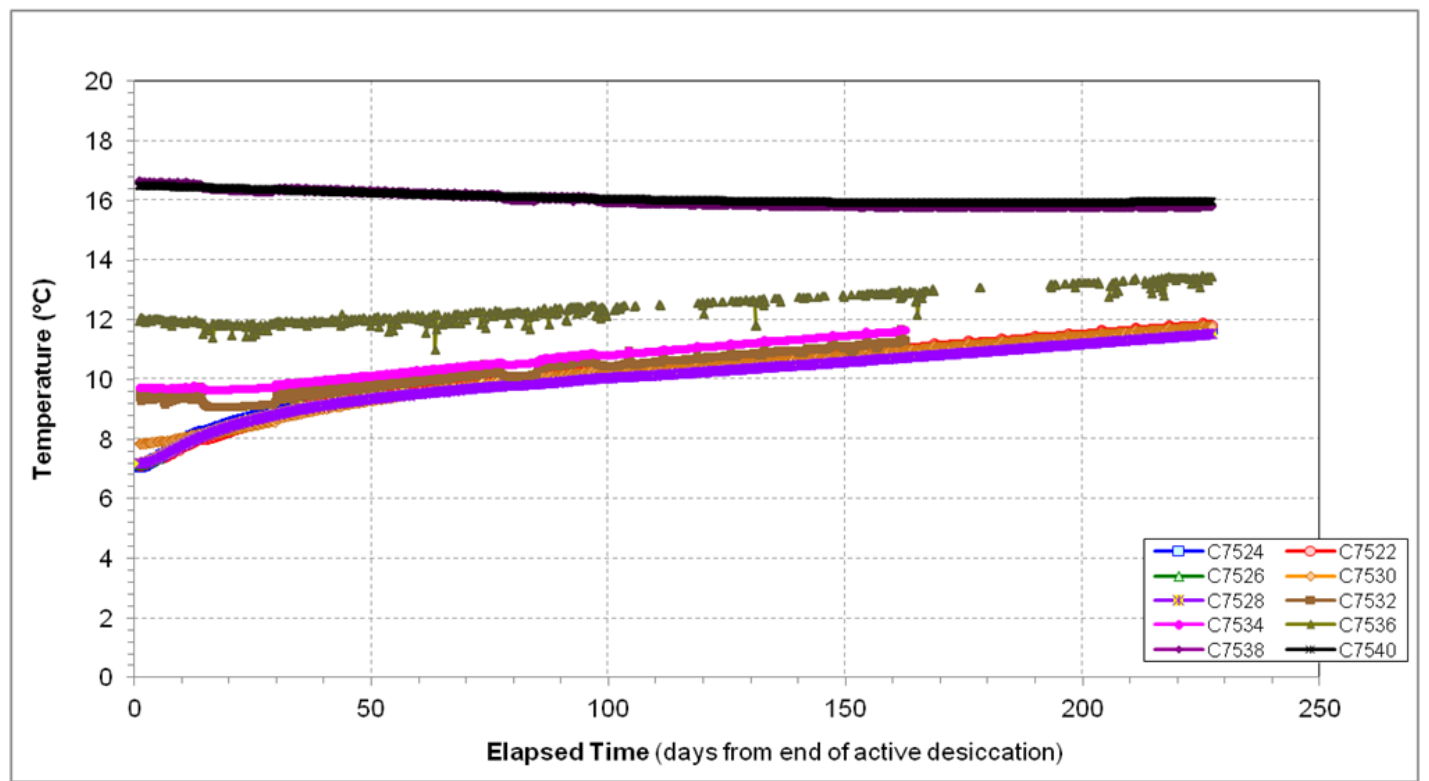

Figure 4.45. Post-Desiccation Temperature Response Over Time for the Sensors at a Depth of $36.5 \mathrm{ft}$ Below Ground Surface 


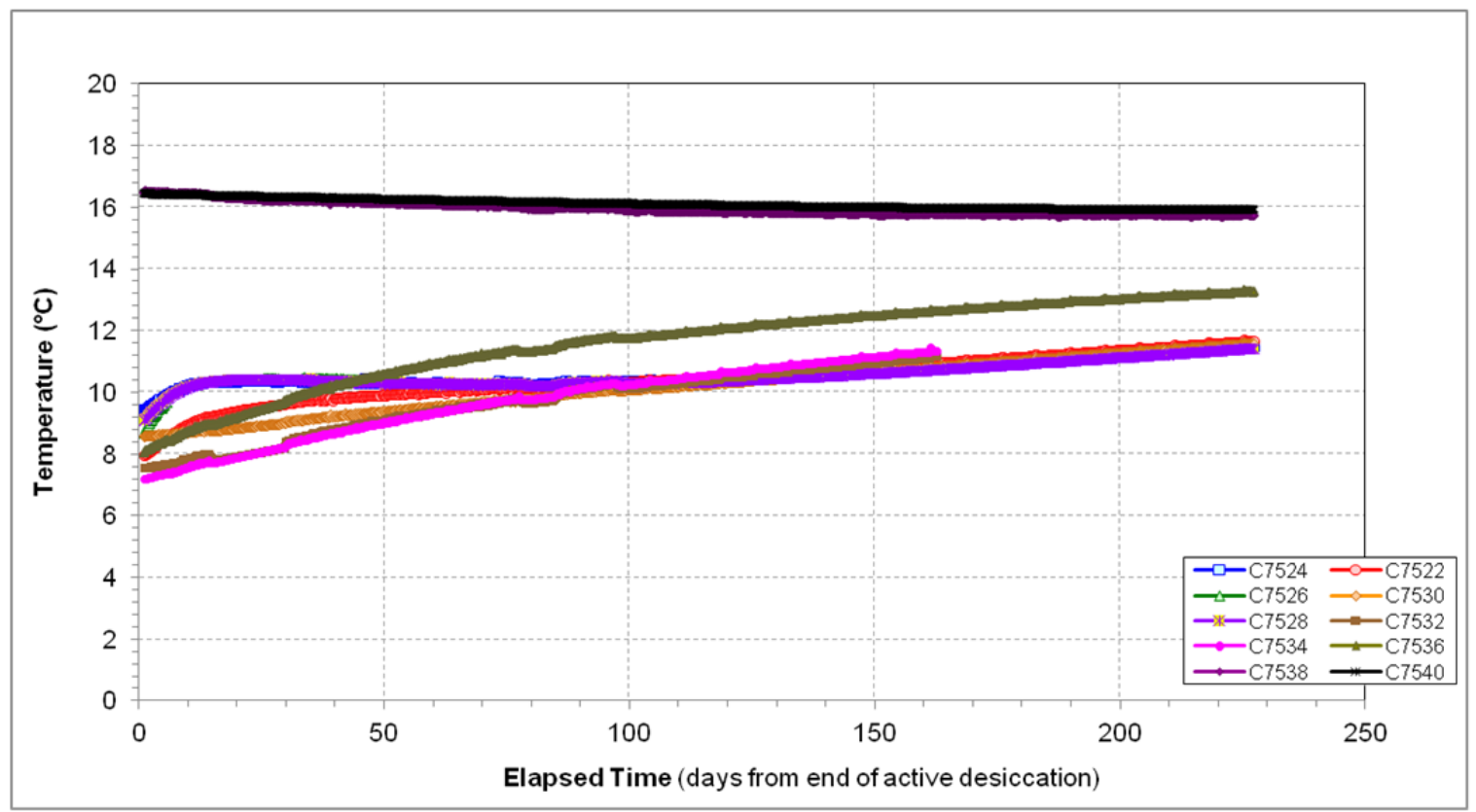

Figure 4.46. Post-Desiccation Temperature Response Over Time for the Sensors at a Depth of $42.5 \mathrm{ft}$ Below Ground Surface

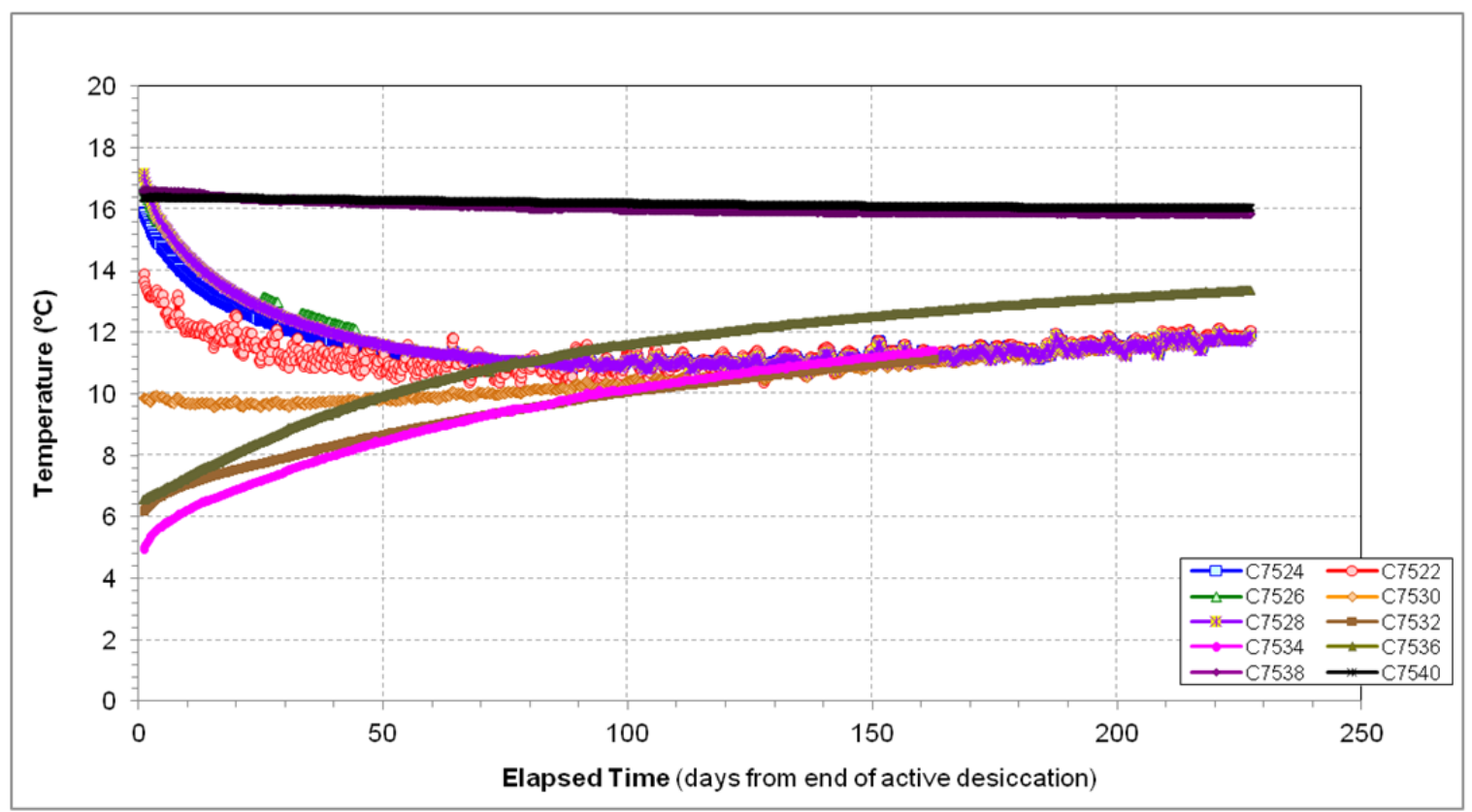

Figure 4.47. Post-Desiccation Temperature Response Over Time for the Sensors at a Depth of $46.5 \mathrm{ft}$ Below Ground Surface 


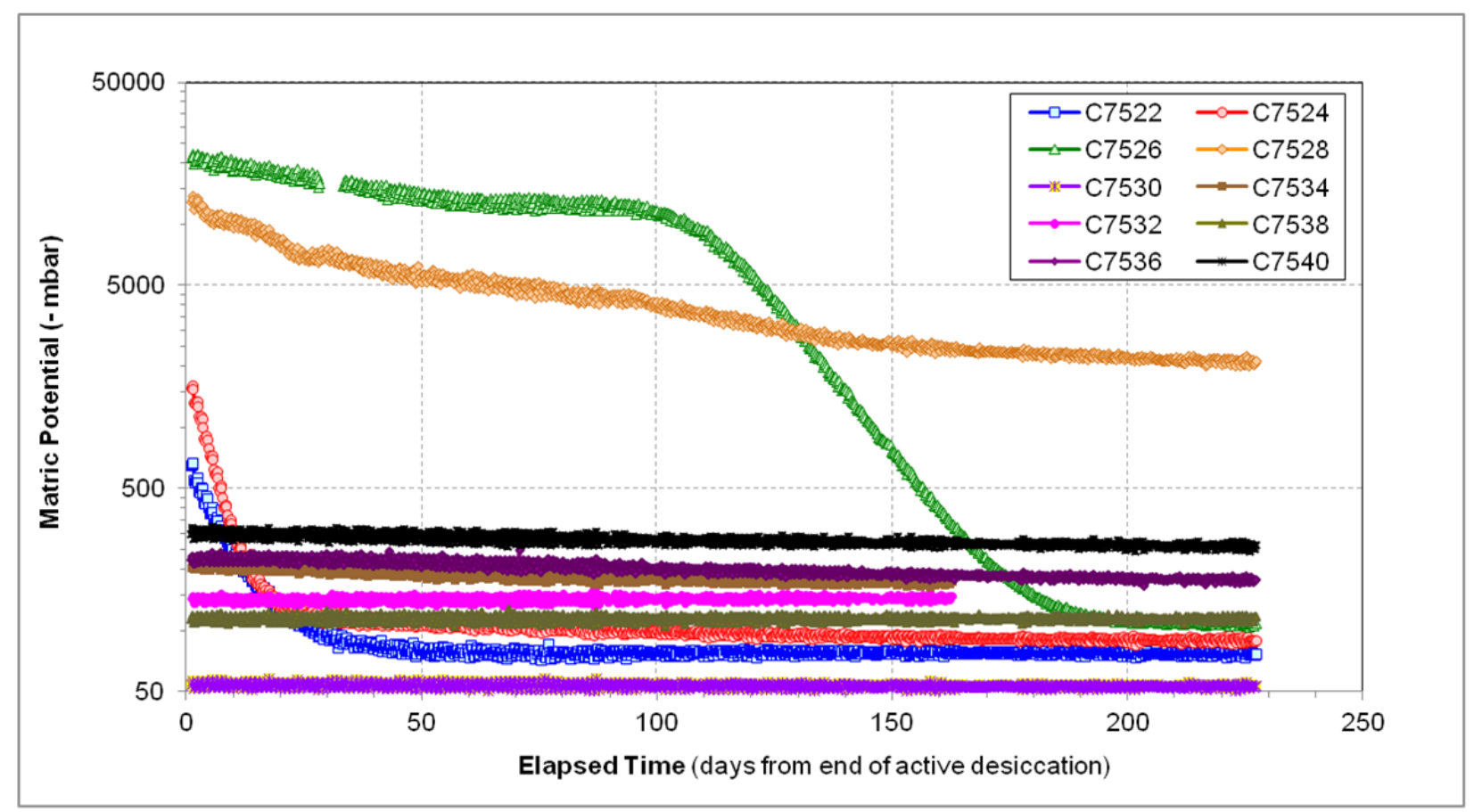

Figure 4.48. Post-Desiccation Heat Dissipation Unit (matric potential) Response Over Time for the Sensors at a Depth of $42.5 \mathrm{ft}$ Below Ground Surface

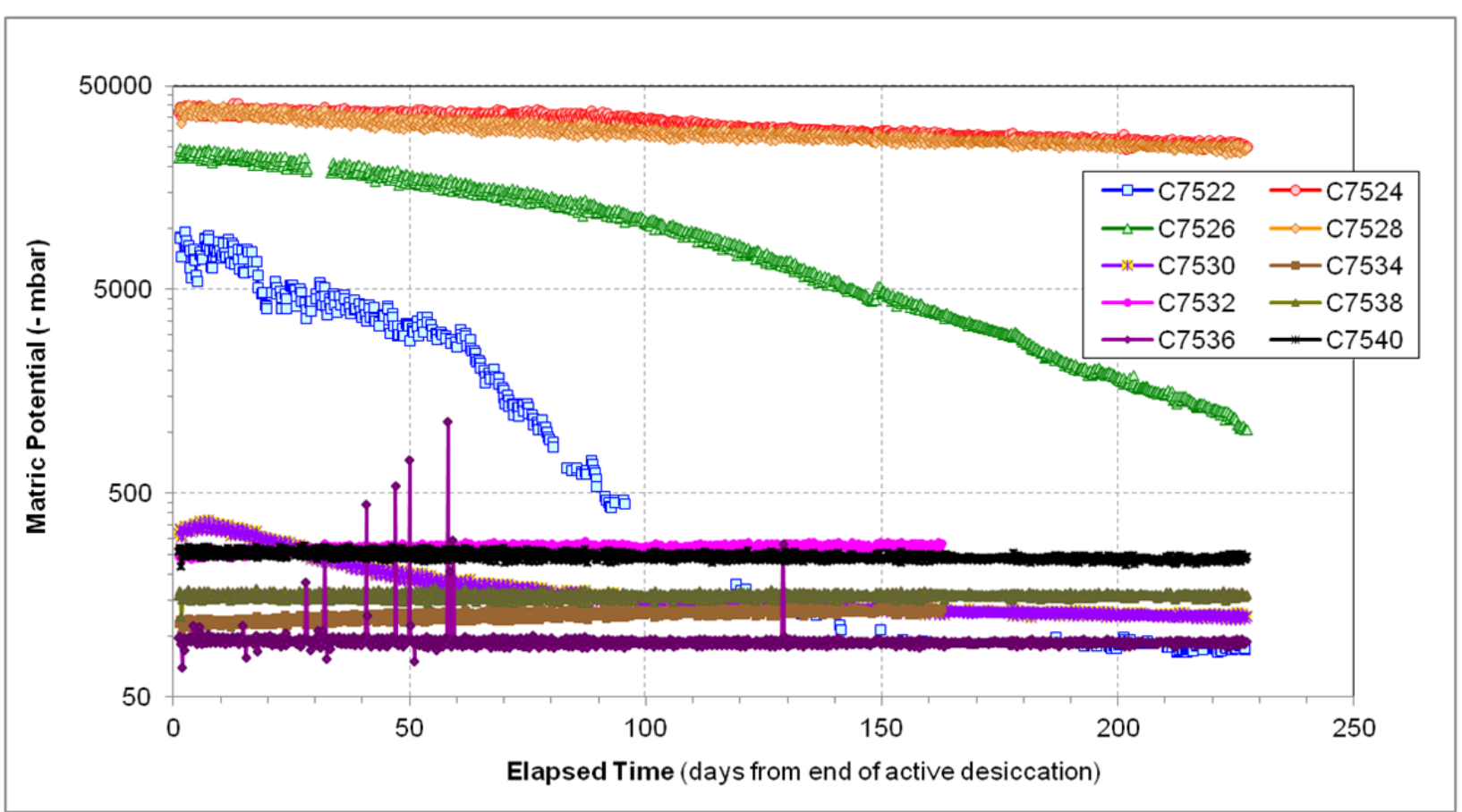

Figure 4.49. Post-Desiccation Heat Dissipation Unit (matric potential) Response Over Time for the Sensors at a Depth of $47.5 \mathrm{ft}$ Below Ground Surface 


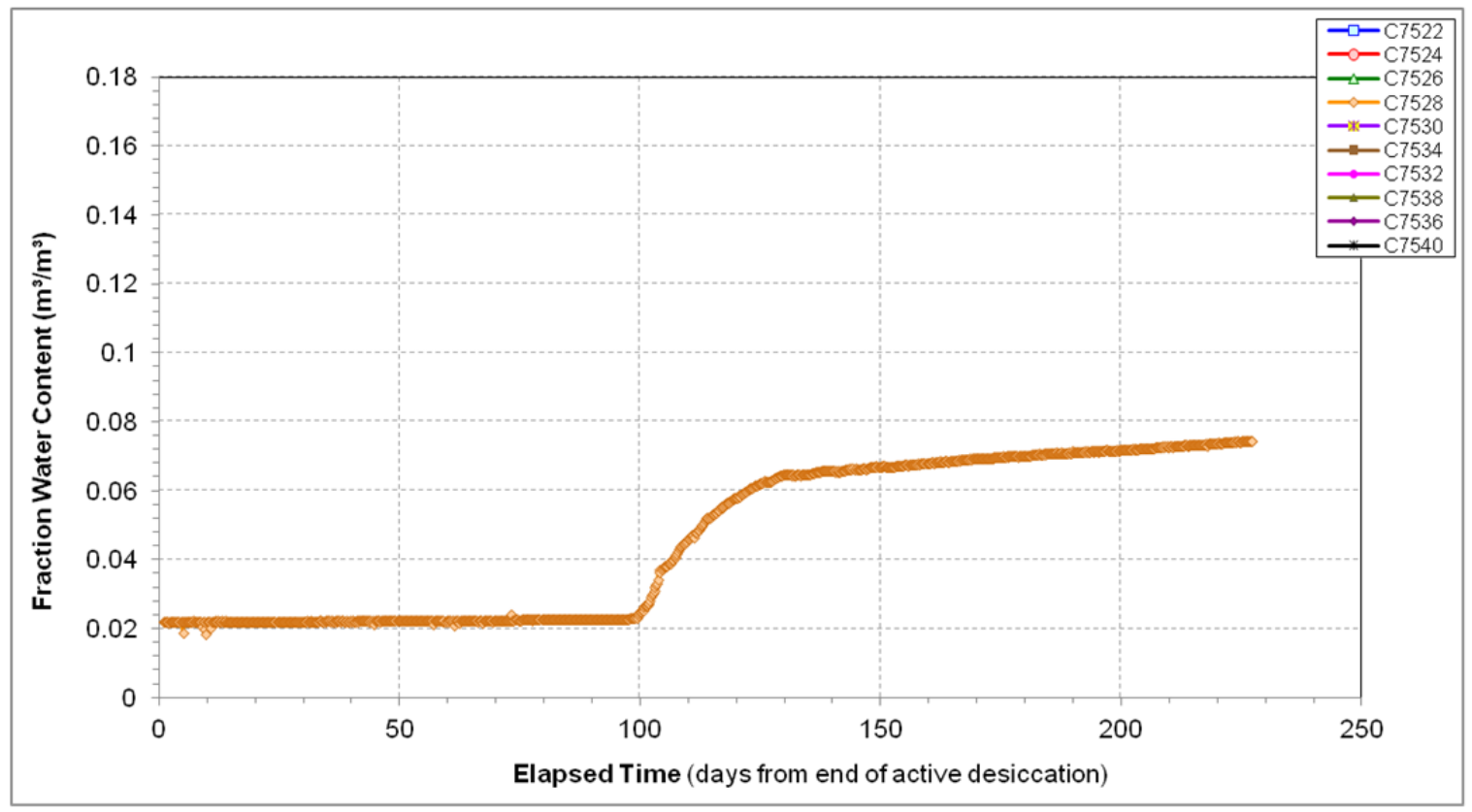

Figure 4.50. Post-Desiccation Dual-Probe Heat-Pulse Sensor (moisture content) Response Over Time for the Sensors at a Depth of $42.5 \mathrm{ft}$ Below Ground Surface

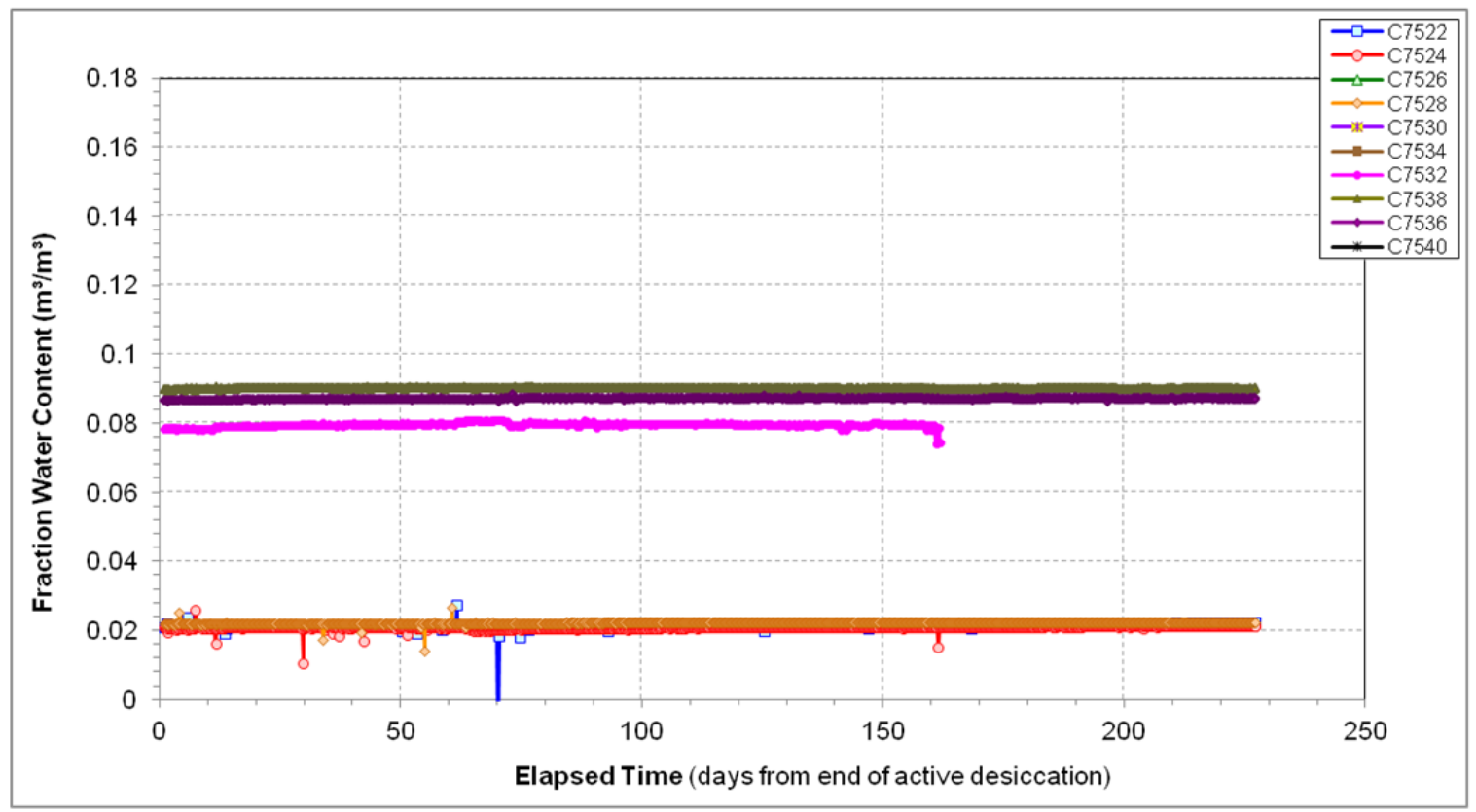

Figure 4.51. Post-Desiccation Dual-Probe Heat-Pulse Sensor (moisture content) Response Over Time for the Sensors at a Depth of $47.5 \mathrm{ft}$ Below Ground Surface 


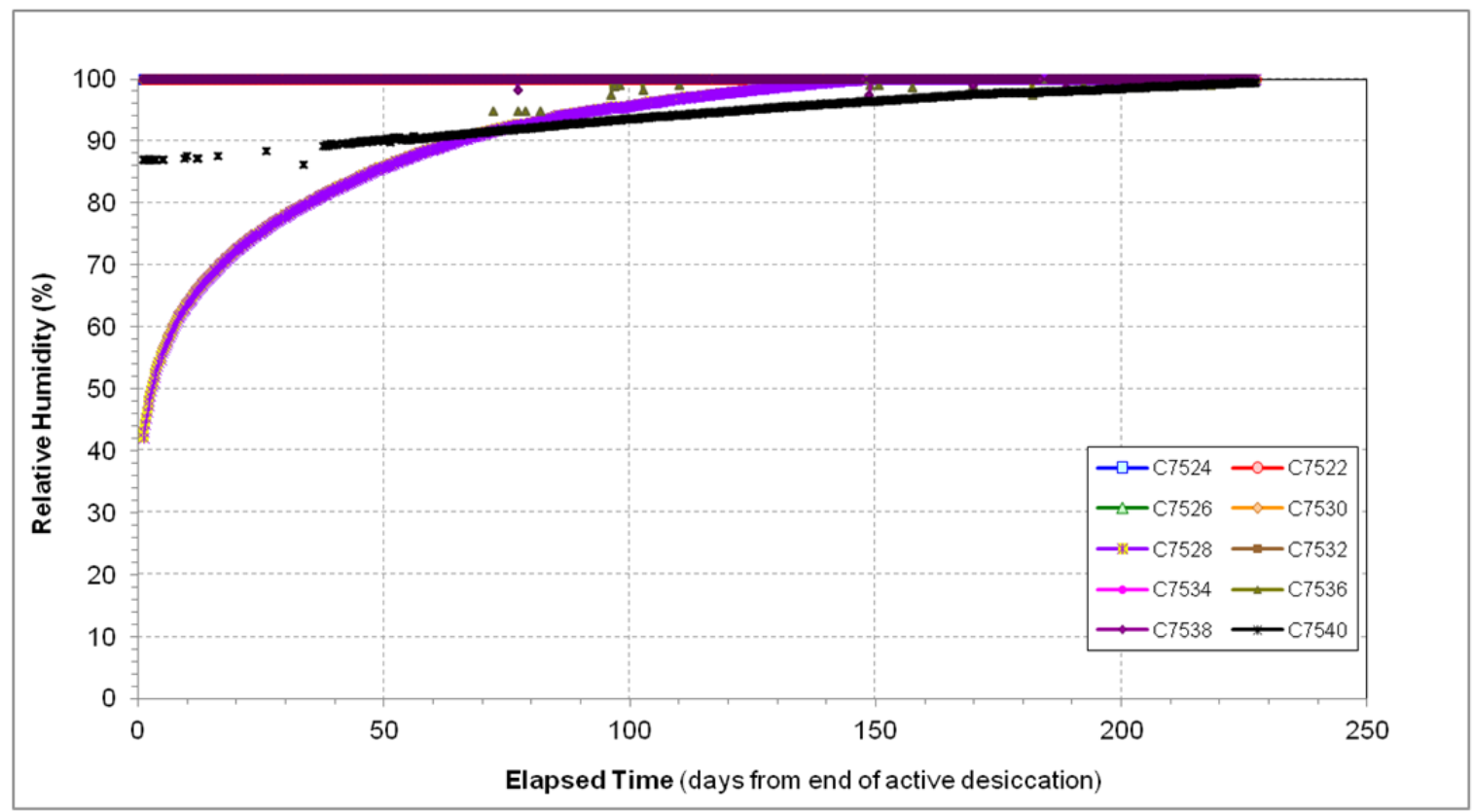

Figure 4.52. Post-Desiccation Relative Humidity Probe Response Over Time for the Sensors at a Depth of $42.5 \mathrm{ft}$ Below Ground Surface

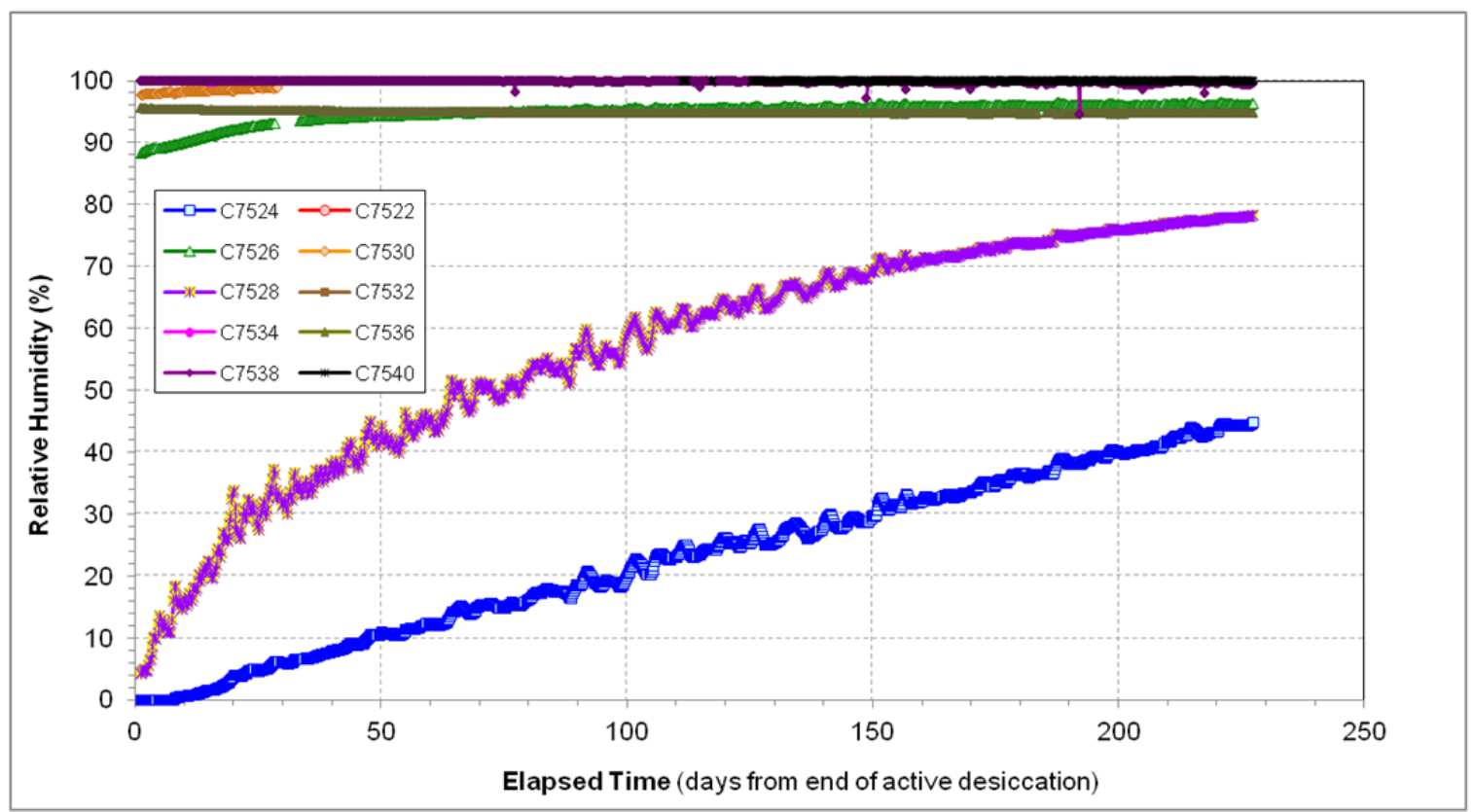

Figure 4.53. Post-Desiccation Relative Humidity Probe Response Over Time for the Sensors at a Depth of $47.5 \mathrm{ft}$ Below Ground Surface

Neutron data. Vertical profiles from neutron moisture logging events conducted in July, August, September, December, and February are plotted in the following figures (Figures 4.54 through 4.60) to depict the relative rewetting that has occurred during this timeframe. 


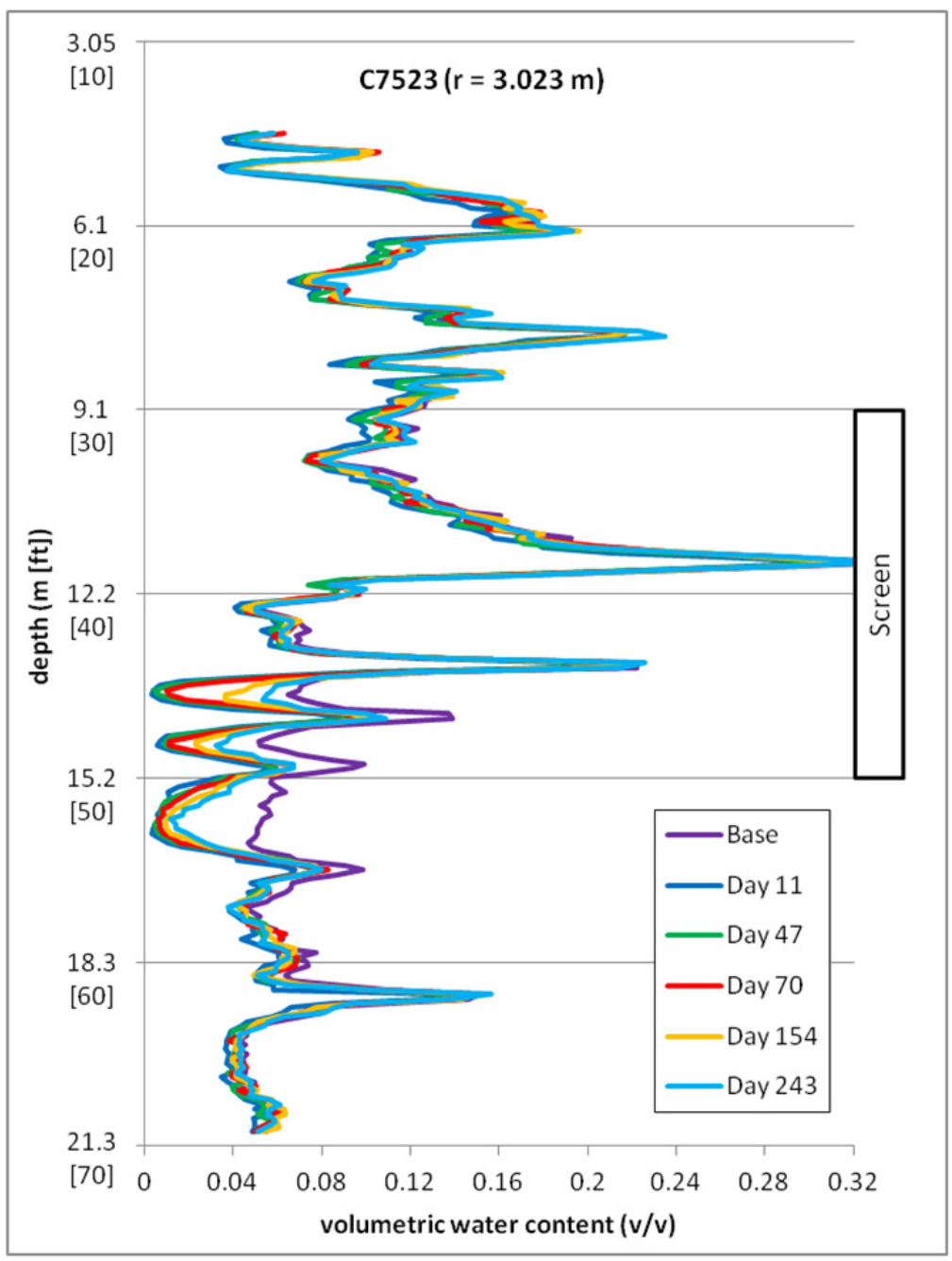

Figure 4.54. Neutron Moisture Probe Response Over Time for Location C7523 (3.023 m from injection well). The base time is a logging event in December 2010, prior to the continuous active desiccation period. Other data are for logging events in nominal days after the end of active desiccation. 


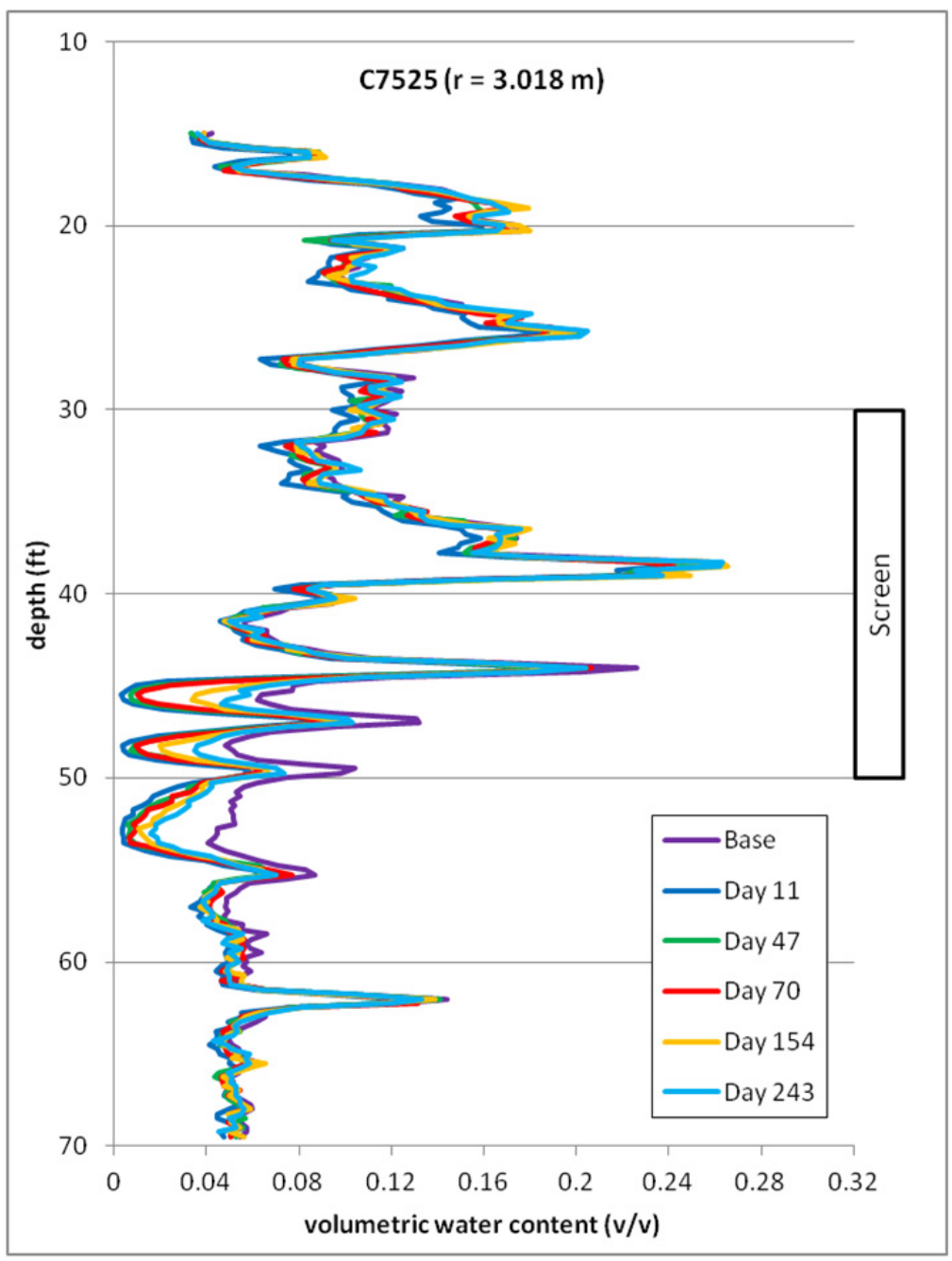

Figure 4.55. Neutron Moisture Probe Response Over Time for Location C7525 (3.018 m from injection well). The base time is a logging event in December 2010, prior to the continuous active desiccation period. Other data are for logging events in nominal days after the end of active desiccation. 


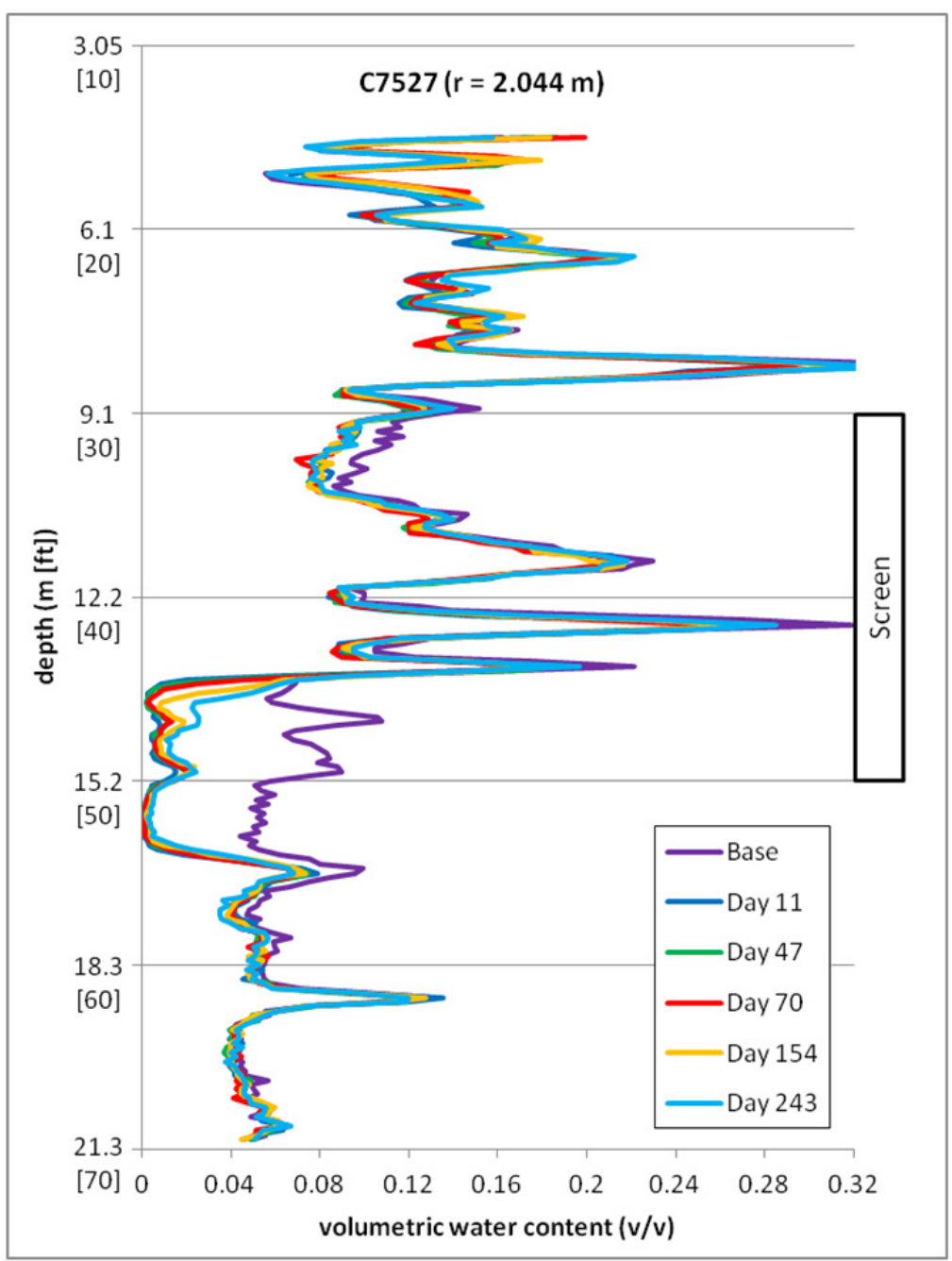

Figure 4.56. Neutron Moisture Probe response Over Time for Location C7527 (2.044 m from injection well). The base time is a logging event in December 2010, prior to the continuous active desiccation period. Other data are for logging events in nominal days after the end of active desiccation. 


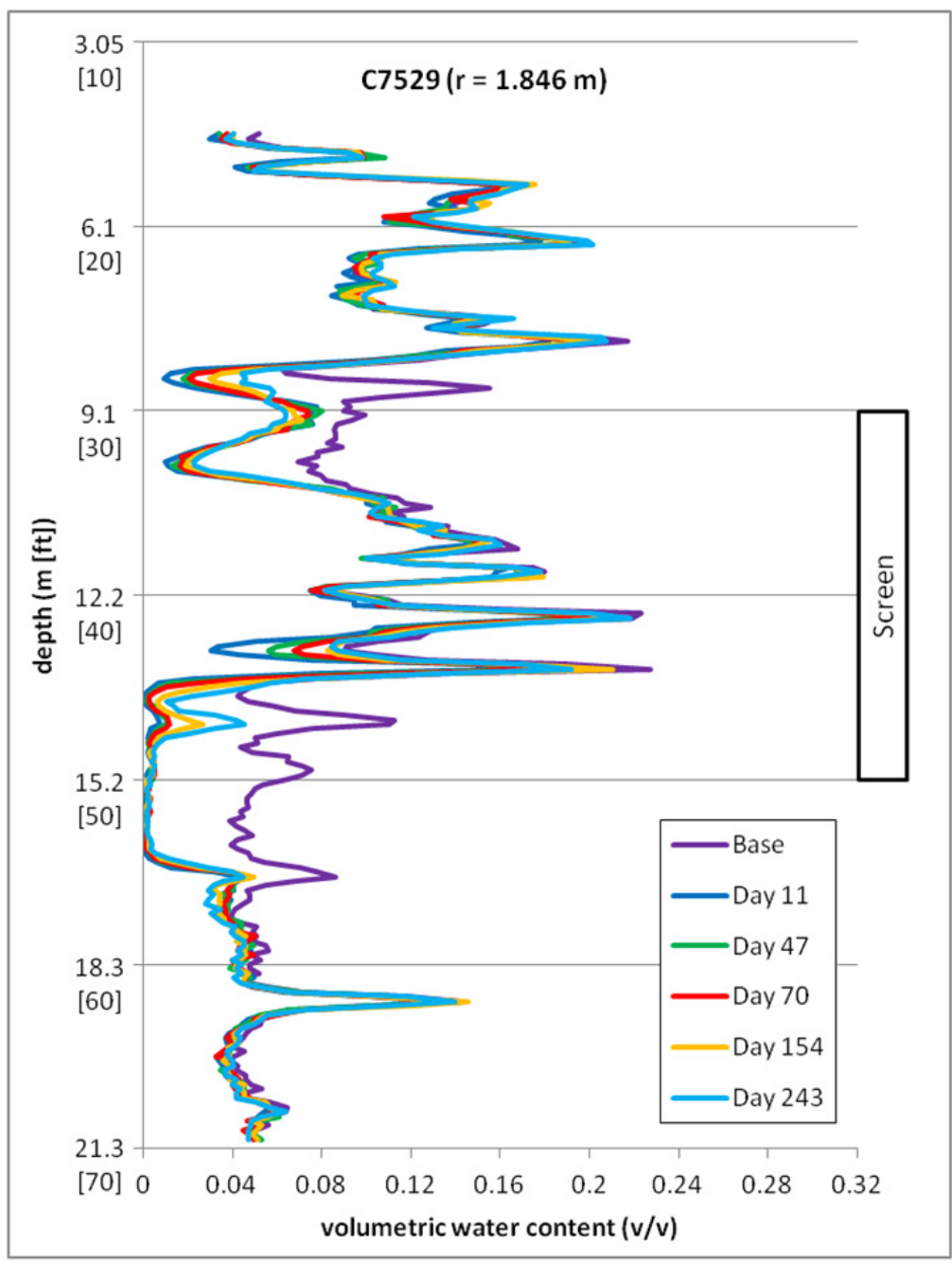

Figure 4.57. Neutron Moisture Probe Response Over Time for Location C7529 (1.846 m from injection well). The base time is a logging event in December 2010, prior to the continuous active desiccation period. Other data are for logging events in nominal days after the end of active desiccation. 


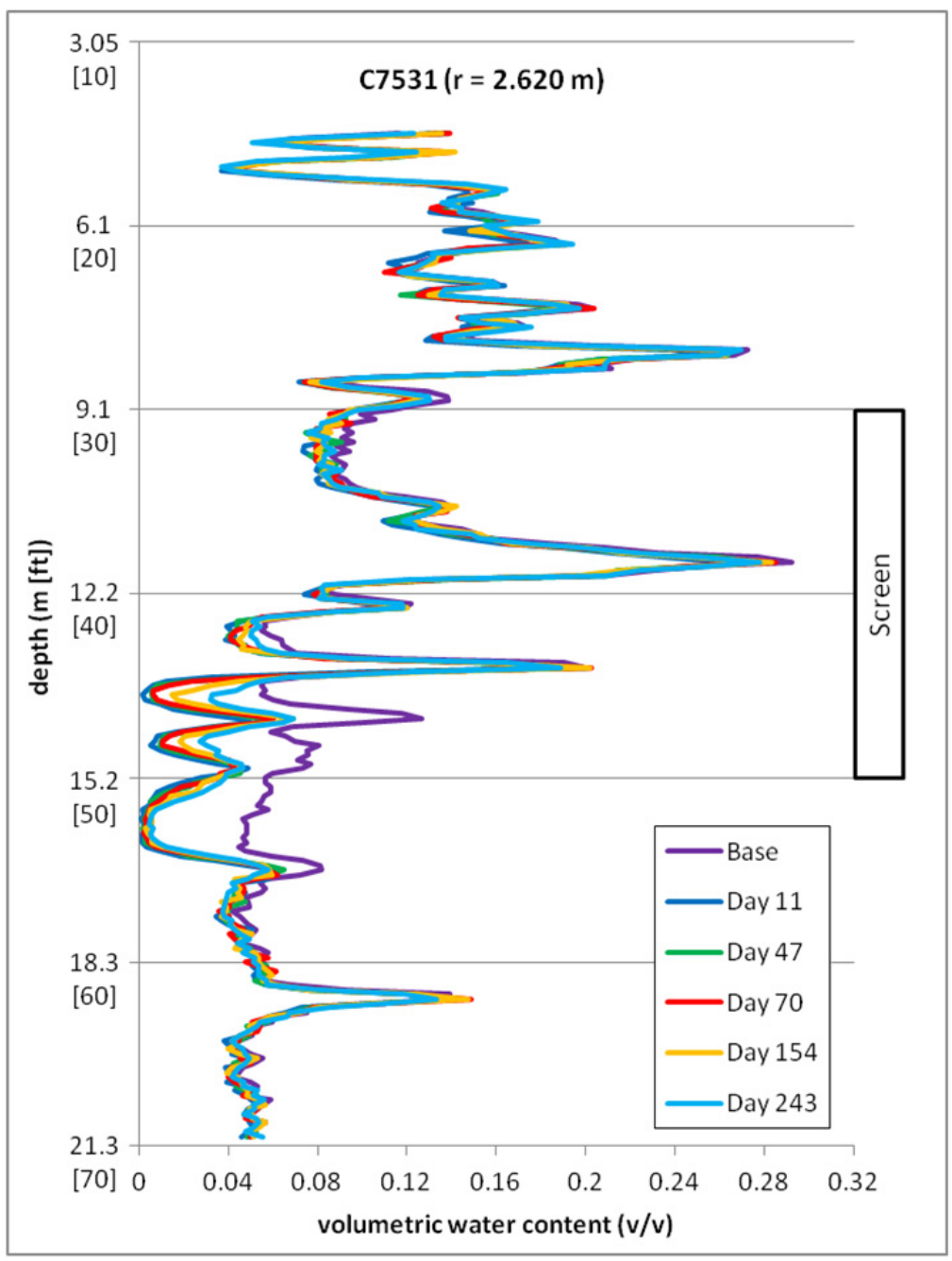

Figure 4.58. Neutron Moisture Probe Response Over Time for Location C7531 (2.620 m from injection well). This location is along the axis between the injection and extraction wells. The base time is a logging event in December 2010, prior to the continuous active desiccation period. Other data are for logging events in nominal days after the end of active desiccation. 


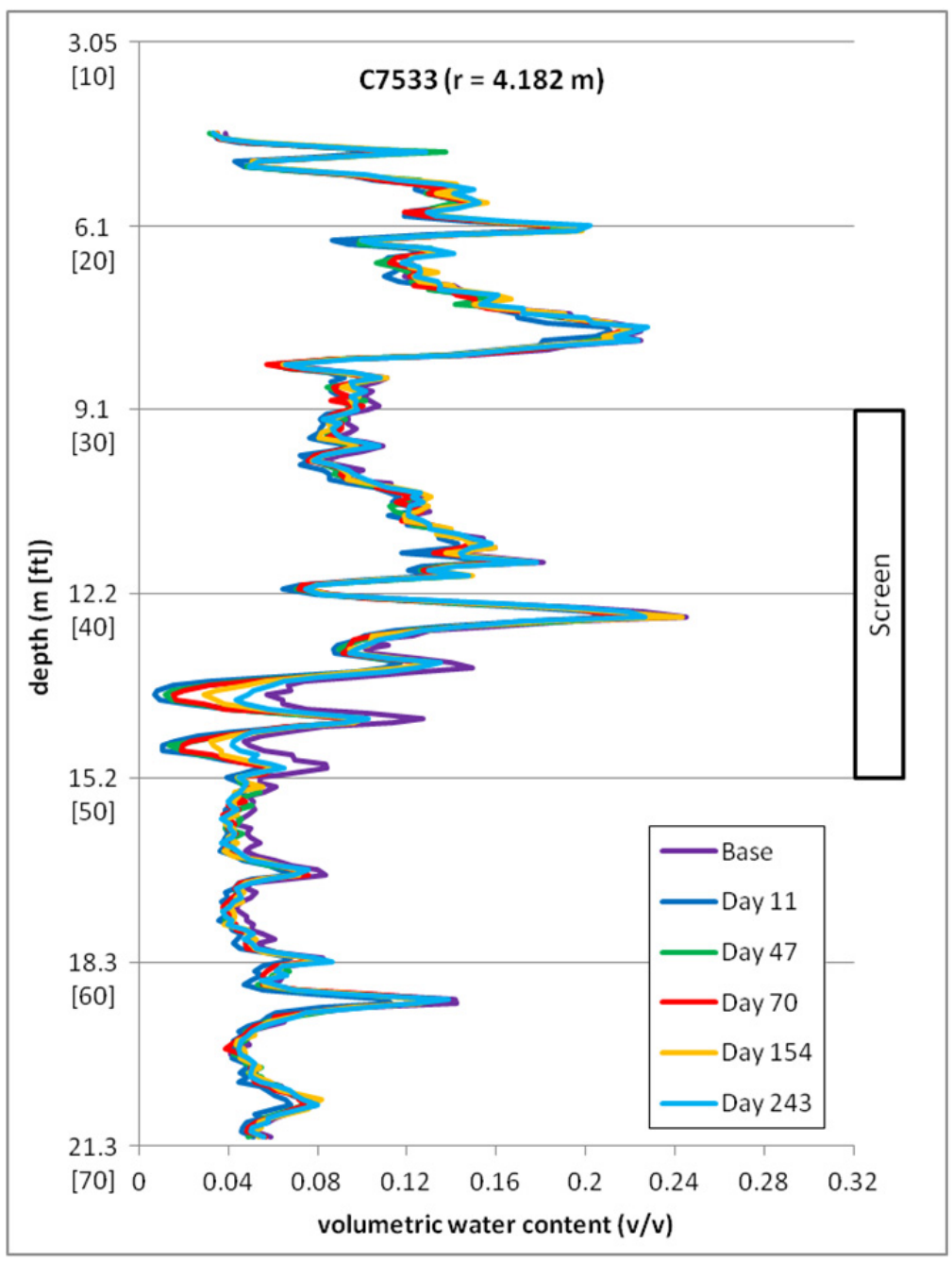

Figure 4.59. Neutron Moisture Probe Response Over Time for Location C7533 (4.182 m from injection well). The base time is a logging event in December 2010, prior to the continuous active desiccation period. Other data are for logging events in nominal days after the end of active desiccation. 


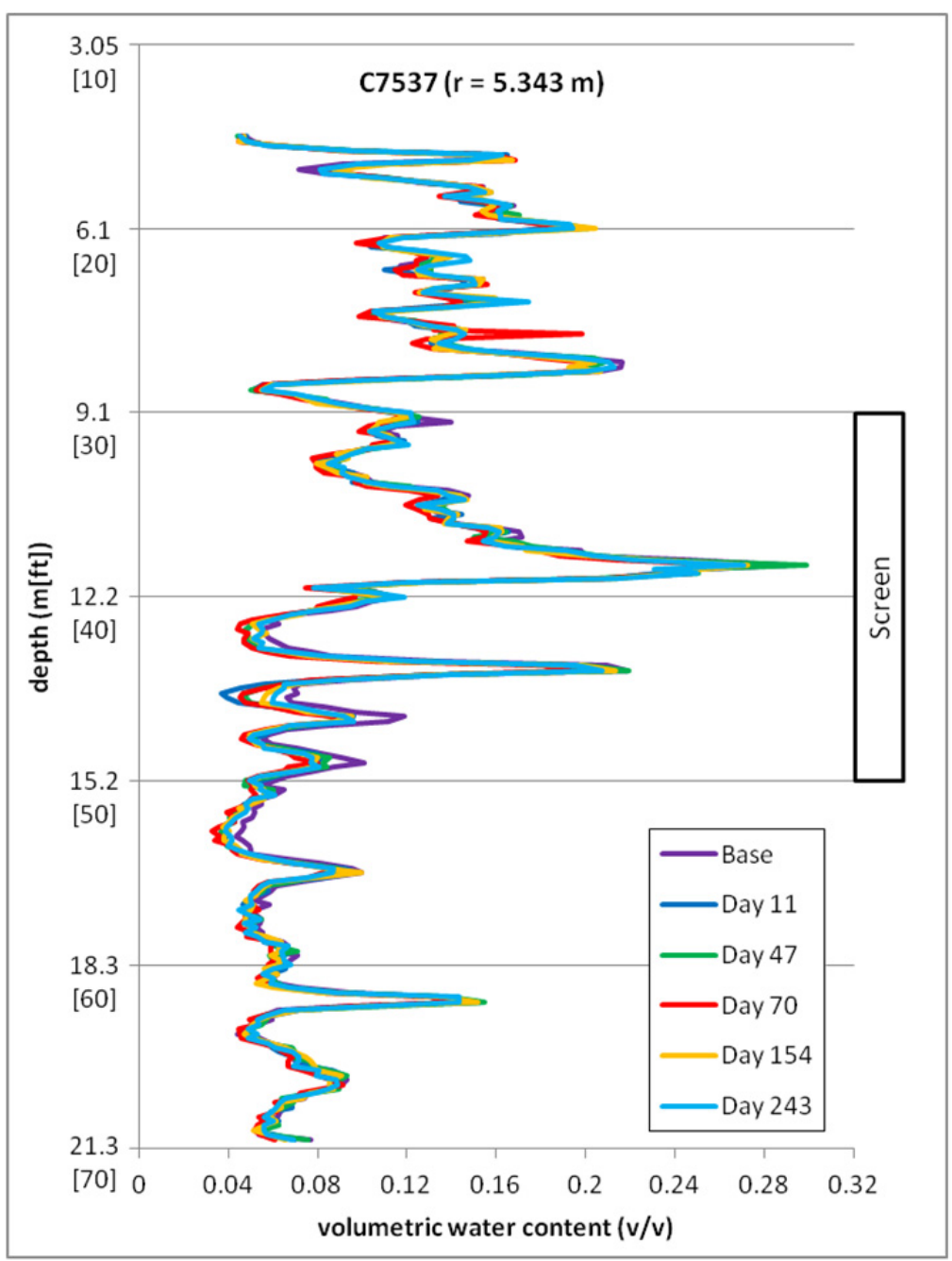

Figure 4.60. Neutron Moisture Probe Response Over Time for Location C7537 (5.343 m from injection well). This location is along the axis between the injection and extraction wells. The base time is a logging event in December 2010, prior to the continuous active desiccation period. Other data are for logging events in nominal days after the end of active desiccation.

Geophysical data. Periodic GPR surveys were collected during post-desiccation monitoring. The GPR-interpreted volumetric moisture content distribution at day 137 during active desiccation and 193 and 265 days after the end of active desiccation are shown in Figure 4.61. Note the GPR data at day 137 during desiccation are prior to the end of active desiccation (e.g., day 164) such that conditions were likely dryer at the onset of the post-desiccation monitoring period. A mix of wetter and dryer conditions are depicted in the GPR data after desiccation compared to during desiccation, particularly evident in the interval between logging locations C7531 and C7537, though also evident in other areas. This type of response would be expected with localized re-equilibration of moisture conditions causing water to move from wetter to dryer regions. The GPR data show that zones with the most significant reduction of moisture content during desiccation have remained dry, although, within the resolution of the GPR analysis, have increased in moisture content after the end of active desiccation. 


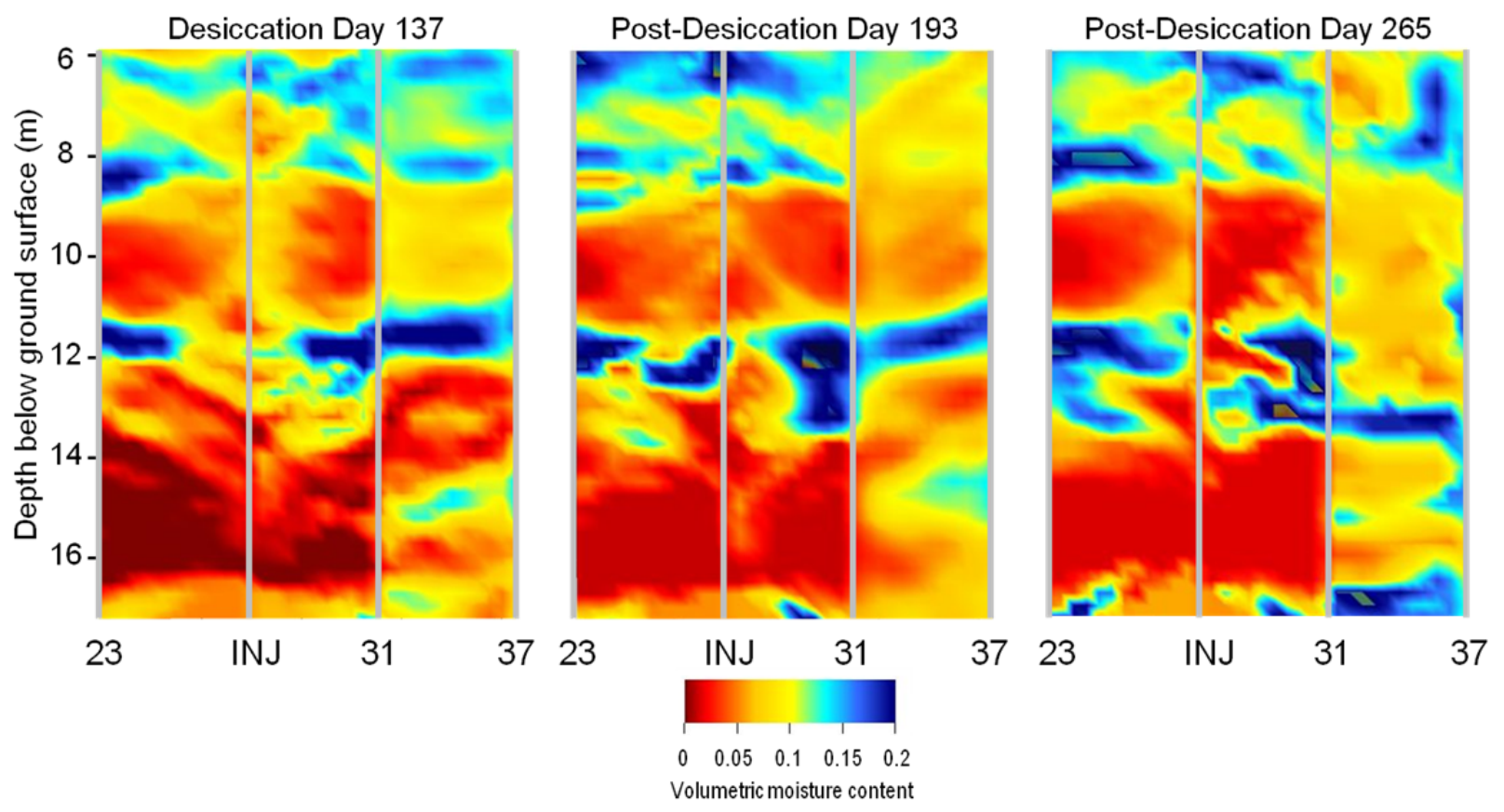

Figure 4.61. 2-D Interpretation of Volumetric Moisture Content from Cross-Hole Ground Penetrating Radar Data During Desiccation (left) at Day 137 (June 3, 2011) and After the End of Active Desiccation (right) at Days 193 and 265.

ERT monitoring was continued without interruption after active desiccation was terminated. Figure 4.62 shows the ERT interpretation of changes in the volumetric moisture content expressed as the ratio of volumetric moisture content $(\mathrm{VMC})$ at the time of the measurement to the volumetric moisture content at the end of active desiccation $\left(\mathrm{VMC}_{0}\right)$. Thus, a ratio of one designates areas that have not changed from the conditions at the end of active desiccation. Ratios higher than one indicate rewetting, for instance, where a ratio of 1.5 means that the volumetric moisture content is 1.5 times higher than it was at the end of active desiccation. Ratios lower than one indicate drying, for instance, a ratio of 0.75 means that the volumetric moisture content is 0.75 times what it was at the end of active desiccation. The resolution of the ERT data inversion is on the order of a cubic meter. Thus, the ERT images in Figure 4.62, cannot show sharp contrasts in wetting or drying zones over time, but show a "smoothed" image of how the subsurface is changing. In Figure 4.62, the image at day 116 of the post-desiccation period shows little change. As time progresses, some regions in the test area get wetter (proceeding from green to yellow to orange in color) with a maximum change to a ratio of about 1.8 compared to conditions at the end of the active desiccation period. The moisture for this rewetting processes is being drawn from adjacent regions as shown by areas that get dryer (getting more dark blue in color).

The GPR and ERT monitoring provide a large-scale volumetric assessment of rewetting that will be most useful over longer periods of time. In particular, ERT data can be collected autonomously as a means to evaluate large-scale changes in the moisture distribution. These ERT data can then guide collection of GPR and neutron data that provide more direct quantification of moisture distribution. 


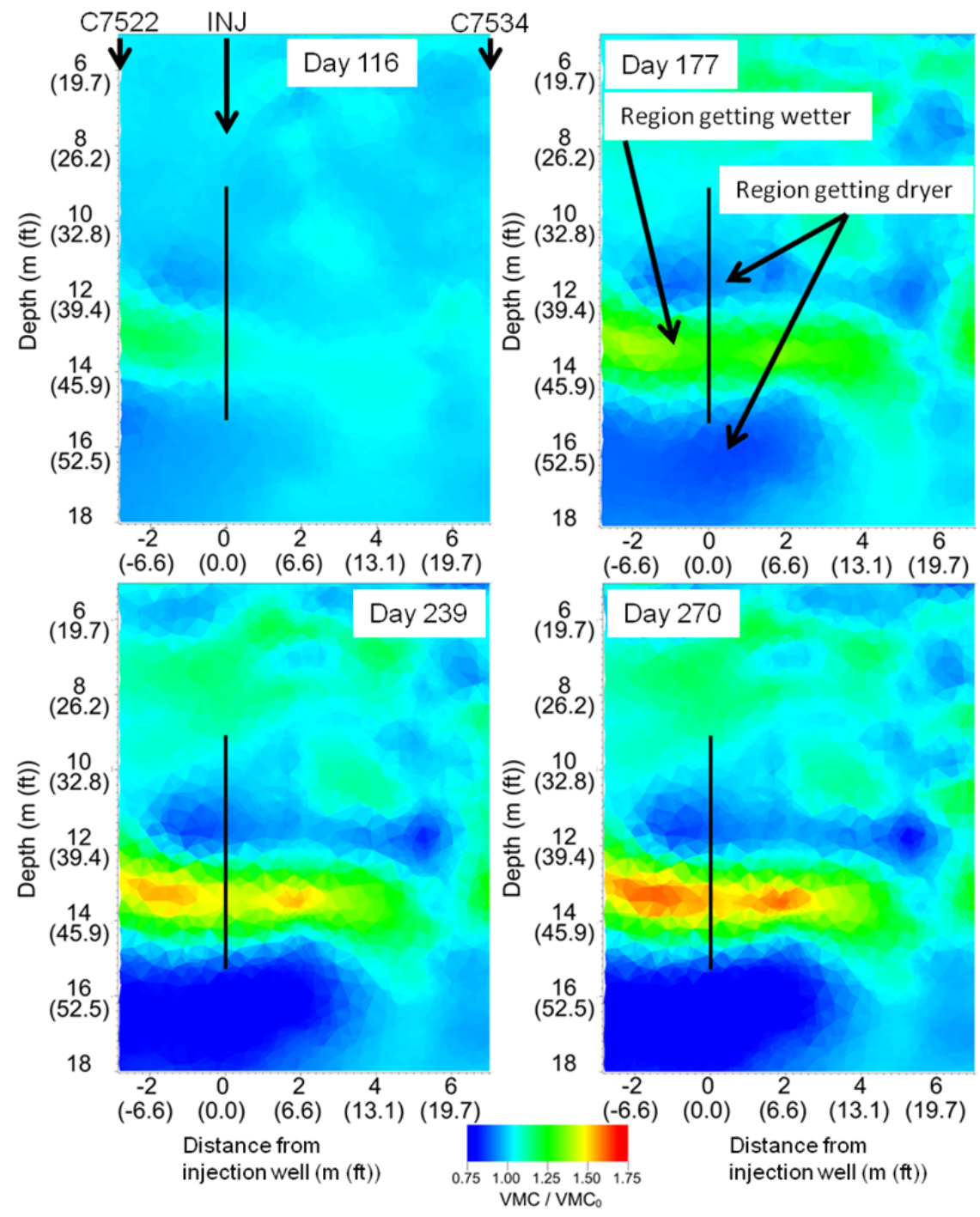

Figure 4.62. Ratio of Volumetric Moisture Content (VMC) to the Volumetric Moisture Content at the End of Active Desiccation $\left(\mathrm{VMC}_{0}\right)$ Over Time Along the Axis Between the Injection and Extraction Wells from Cross-Hole Electrical Resistivity Tomography. ERT data are from sensors at locations C7522-C7534 (Figure 3.4).

\subsection{Data Assessment with Respect to Field Test Objectives}

Field test data and associated laboratory and numerical modeling results are interpreted with respect to each of the field test objectives.

\subsubsection{Design Parameters}

The first section (4.2.1.1) summarizes information collected and applied to support the field design. Specific design features are then discussed in the next section (4.2.1.2). 


\subsubsection{Design Information for the Field Test}

Information supporting the design the desiccation field test was obtained through laboratory studies (4.2.1.1.1), field site characterization (4.2.1.1.2), and numerical modeling (4.2.1.1.3).

\subsection{Laboratory Information Input to Desiccation Design}

A vadose zone technical panel was convened in 2005 to evaluate potential vadose zone technologies, including desiccation (FHI 2006). In their evaluation, panel members provided guidance on the type of uncertainties that need to be resolved before applying desiccation as part of a remedy. This guidance, additional external technical review comments, and subsequent development of data quality objectives for the desiccation field test were used to guide design efforts in support of the desiccation treatability test. The primary conclusions of the laboratory and modeling efforts relevant to desiccation design are described below. These efforts are described in detail in Truex et al. (2011) and the additional reports and manuscripts cited below.

Impact of evaporative cooling on desiccation rate. Evaporative cooling occurs during desiccation at and adjacent to desiccation fronts to an extent that can be accurately quantified based on known processes (Oostrom et al. 2009; Ward et al. 2008; Truex et al. 2011). Temperature decreases due to evaporative cooling until the desiccation front reaches the monitoring locations (i.e., the time when the sediment between the injection location and the monitoring location is desiccated). At that time, the temperature at the monitoring location begins to increase toward the temperature of the injected gas because evaporative cooling is no longer occurring in the sediment between the injection location and the monitoring location (Oostrom et al. 2009). There can be multiple inflection points if there are multiple layers that are being desiccated at different rates and these layers are within a region that can impact the temperature at the monitoring location (Oostrom et al. 2009). The temperature response is less dramatic at larger distances from the injection well as the cooling front extends ahead of the desiccation front.

Temperature variations impact the distribution of desiccation because temperature impacts the waterholding capacity of the gas. Evaporative cooling causes in situ temperature to decrease and the gas passing through the cooled zone evaporates water up to the water-holding capacity for the temperature of that zone. As the gas moves into warmer portions of the subsurface, the water-holding capacity increases and the gas evaporates more water. Thus, the impact of nonuniform temperature is to spatially spread out the evaporation process. In laboratory flow cell tests, very sharp transitions between the zone of desiccation and nondesiccated zones were observed when temperature was relatively constant due to fast heat transfer from the flow cell walls that minimized evaporative cooling impact on temperature (Ward et al. 2008; Oostrom et al. 2009). For field applications, however, evaporative cooling may decrease temperatures over a large area and more significantly impact the desiccation front characteristics.

Impact of solutes on desiccation and the fate of solutes during desiccation: Experiments demonstrated the desiccation rate is not a function of salt concentration. As such, inclusion of salt concentrations in estimates of desiccation rate is not necessary. The experimental results also suggest that for slowly moving desiccation fronts and high solute concentrations $(>100 \mathrm{~g} / \mathrm{L})$, some redistribution of solute may occur in the soil moisture and in the direction of the solute concentration gradient. Because the sediment is relatively dry behind the desiccation front, solute migration will occur in the direction of the desiccation front movement or laterally at the edges of the desiccated area. Maximum concentration factors of about $120 \%$ of the initial concentration were observed in the one-dimensional column 
experiments. This moderate concentration increase does not affect the desiccation process because the desiccation rate is independent of the salt concentration.

Impact of porous media heterogeneity on desiccation. Desiccation rate is a function of soil gas flow rate. Thus, where layers of contrasting permeability are present, desiccation occurs to the greatest extent in higher permeability layers (Oostrom et al. 2009, In Press; Ward et al. 2008). Nonuniform initial moisture conditions impact the desiccation volume because wetter zones require more dry gas contact to become desiccated. For instance, using a water-holding capacity of $14.6 \mathrm{~g}$-water $/ \mathrm{m}^{3}$-gas $\left(17^{\circ} \mathrm{C}\right)$, a porosity of 0.3 , and a bulk density of $1900 \mathrm{~kg} / \mathrm{m}^{3}$, desiccating a porous medium to initially containing $5 \mathrm{wt} \%$ of water requires about 22,000 pore volumes of dry gas, whereas desiccating a porous medium initially containing $7 \mathrm{wt} \%$ of water requires about 30,000 pore volumes of dry gas. Thus, initially wetter zones require more dry gas contact than initially dryer zones and will lead to nonuniform drying even if the gas flow rate through each zone is the same. Nonuniform initial moisture content conditions also lead to relative gas-phase permeability contrasts between wetter and dryer zones that impede gas flow through the wetter zones and further accentuate the nonuniformity of the desiccation process.

Evaluation of rewetting phenomena after desiccation: The rate of rewetting is a function of the porous media properties of both the desiccated zone and the subsurface surrounding this zone and the moisture content distribution at the end of desiccation. After desiccation, the target zone will tend back toward the equilibrium moisture conditions for the porous media properties. Vapor-phase rewetting will occur, but has negligible impact on the overall rewetting process. Advective rewetting strongly depends on the porous media permeability within and surrounding the desiccated zone and the total thickness of the desiccated zone. Thus, targeting thick desiccated zones surrounded by lower permeability porous media will result in slower rewetting and an overall more significant effect on moisture flux toward the groundwater. More detailed discussion of rewetting is provided in Section 4.2.2.2.

Evaluation of gas tracers for use in monitoring desiccation: The application of gas-phase partitioning tracer tests was proposed to estimate initial water volumes and monitor progress of the desiccation process at pilot-test and field sites. Laboratory tracer tests were conducted in porous medium columns with various water saturations with sulfur hexafluoride as the conservative tracer and tricholorofluoromethane and difluoromethane as the water-partitioning tracers. Based on laboratory results, gasphase partitioning tracer tests may be used to determine initial water volumes in sediments, provided the initial water saturations are sufficiently large. However, these tracer tests cannot be used to detect and quantify water in relatively dry or desiccated sediments (Oostrom et al. 2011).

\subsection{Field Input to Desiccation Design}

In addition to the technical data obtained through laboratory experiments, field site characterization information is also used as input to the design for a specific application. At the pilot test site, predesiccation characterization efforts at the test site included the following activities.

- Sediment air permeability of the targeted desiccation depth interval (Serne et al. 2009)

- Sediment air permeability contrast, cone penetrometer tip pressure, and resistivity logging as a function of depth at five locations using the air permeameter technique (DOE 2010a)

- Extracted soil gas humidity, temperature, and pressure at selected volumetric flow rates (DOE 2010a)

- Quantification of contaminants in the extracted soil gas and extracted water (DOE 2010a) 
- Logging and laboratory sediment data that characterizes the heterogeneity, especially in terms of the distribution of sandy and silty layers within the targeted desiccation depth interval (Serne et al. 2009)

- Intrinsic properties of key sediment types from borehole samples (Serne et al. 2009; DOE 2010a)

- Moisture content distribution at borehole locations (Serne et al. 2009; DOE 2010a)

- Permeability-moisture content relationships from borehole samples (Serne et al. 2009)

- Contaminant distribution from borehole samples and inferred from an electrical resistivity survey (Serne et al. 2009; Um et al. 2009, Characterization of Sediments from the Soil Desiccation Pilot Test) (SDPT Site in the BC Cribs and Trenches Area)

- Baseline neutron moisture logging and a GPR survey were conducted to evaluate the initial distribution of moisture content. A baseline ERT survey was also used to evaluate the lithology and contaminant distributions based on the distribution of conductivity.

- Once test infrastructure was installed, a gas tracer test was conducted to evaluate injected gas flow patterns.

- The equilibration of installed sensors to the in situ conditions was also monitored prior to start of active desiccation.

\subsection{Modeling Input to Desiccation Design}

Several types of modeling studies were conducted to provide input to the desiccation field test design. Simulations to estimate the overall performance of an idealized zone of desiccation in the subsurface in terms of slowing moisture and contaminant flux to groundwater were conducted to evaluate the relevant size of a desiccation zone for full-scale application and as a first investigation of the performance in terms of the target extent of moisture reduction during desiccation. Numerical modeling of the field scale desiccation process was also used to evaluate how operational and design factors impact the rate of desiccation and the magnitude of change in monitored parameters. Numerical modeling of the desiccation field test site conditions was also conducted to provide a comparative basis for evaluating field test results. These modeling studies are described in the sections below.

Identification of an appropriate performance target for desiccation. Simulations were used to evaluate the impact of desiccation on contaminant transport to the groundwater (Truex et al. 2011). In conjunction with a surface barrier, desiccation significantly delayed the concentration and arrival time of contaminants to the groundwater. The amount of delay is most impacted by the location and extent of the desiccated zone with respect to the zones of high contaminant and moisture content. Overall, desiccation in conjunction with a surface barrier reduces contaminant migration through the vadose zone more than a barrier alone. Desiccation can also be applied multiple times in the near term to enhance its overall effectiveness in the long term.

Numerical modeling of operational and design factors for the desiccation processes at field scale. Subsurface soil gas flow patterns and related desiccation rates in a homogeneous domain were used initially to evaluate field-test operational conditions. These simulations were targeted at defining appropriate well spacing, airflow, and parameters related to the test layout and equipment for the desiccation demonstration. A series of three-dimensional simulations were conducted using the STOMP simulator (White and Oostrom 2006) to examine different injection and extraction flow rates. Injection 
and extraction flow rates were varied in the range of 100 to $400 \mathrm{cfm}$ for both balanced (e.g., 300/300 cfm injection/extraction) and unbalanced (e.g., 300/100 cfm injection/extraction) conditions.

Unlike a single injection well or a single injection with multiple extraction well configurations, which owing to symmetry, can be simulated two-dimensionally with cylindrical coordinates, a dipole system requires a three-dimensional simulation. Figure 4.63 shows a cross sectional view of the conceptual model for simulating the dipole test. Two vertical wells of diameter $d_{W}$, with a screen from a depth $d$ to a depth $l$, are installed in an effective homogeneous soil above a water table at depth $b$. For these simulations, $d_{W}=0.1524 \mathrm{~m}(0.5 \mathrm{ft}), d=9.7 \mathrm{~m}(30 \mathrm{ft}), l=15.8 \mathrm{~m}(50 \mathrm{ft})$, and $b=103 \mathrm{~m}(338 \mathrm{ft})$. The injection and extraction wells are spaced $12 \mathrm{~m}$ apart.

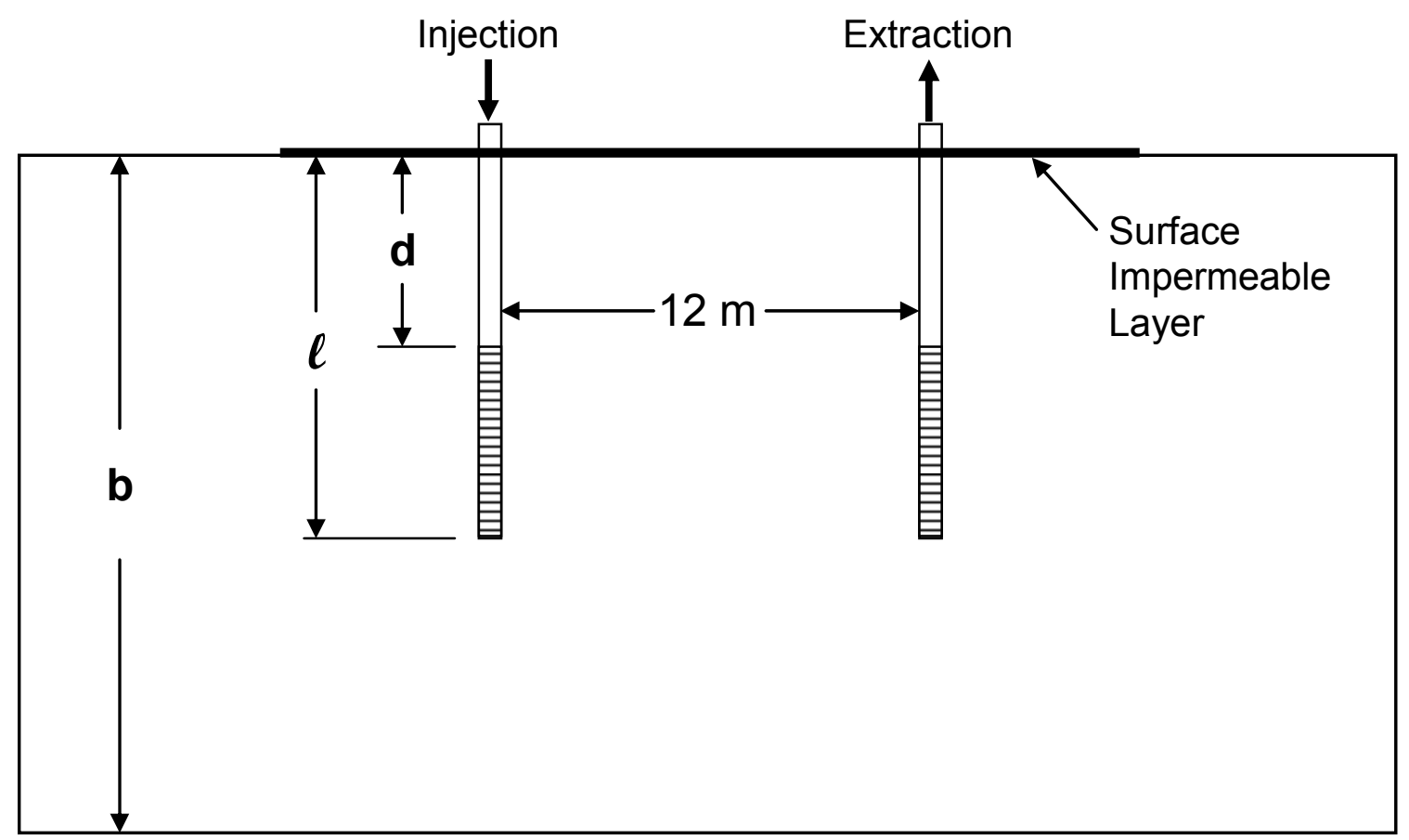

Figure 4.63. Conceptual Model of Well Configuration Used to Simulate Airflow Between Two Wells

Boundary conditions are needed for the aqueous mass, gaseous mass, and energy conservation equations. At the surface (100 by $100 \mathrm{~m}$ ), a no-flow (zero flux) boundary was specified for the aqueous phase across the entire surface. For the gas phase, a no-flow (zero flux) boundary was specified across the areal extent of the surface impermeable layer $(46.95 \mathrm{~m}$ by $46.95 \mathrm{~m})$ whereas the remainder of the surface was held constant at atmospheric pressure, $\mathrm{P}_{\mathrm{atm}}$. For the energy conservation equation, the upper surface is kept at a constant temperature of $23^{\circ} \mathrm{C}$ whereas the initial temperature in the domain is assumed to be $17^{\circ} \mathrm{C}$. Owing to the presence of the water table at the bottom boundary, both the aqueous and gas pressures were held constant at $\mathrm{P}_{\mathrm{atm}}$, corrected for the difference in elevation. Temperature was held constant at groundwater temperature, $T_{g w}$, of $17^{\circ} \mathrm{C}$. The four vertical boundaries of the three-dimensional domain were specified as hydraulic gradient boundaries for the aqueous and gaseous phases $(\delta \mathrm{P} / \delta \mathrm{z}=\mathrm{H})$ and as outflow boundaries for energy.

Simulations used an air inlet temperature of $20^{\circ} \mathrm{C}$ with a $10 \%$ relative humidity, a subsurface initial temperature of $17^{\circ} \mathrm{C}$, and an initial moisture content of $0.11 \mathrm{~m}^{3} / \mathrm{m}^{3}$. Thermal properties are also important 
in modeling the evaporation/condensation processes. Thermal properties of the porous media were estimated from Cass et al. (1981). The porous media pneumatic properties were homogeneous with no anisotropy ratio in the saturated hydraulic conductivity, and set to match the results from the constant rate permeability test. These simulations tend to be somewhat conservative (slow desiccation front movement) with respect to the most permeable portions of the test site because flow is more uniform than is expected in the field. In the field, lower permeability lenses are expected to focus flow in the higher permeability layers such that these would dry more quickly. However, the simulations likely over predict the reduction in moisture content within the dry zone because it does not account for drying of the less permeable lenses.

Under the simplified conditions of the simulations, desiccation volumes with time are similar to scoping calculations. For instance, the volume of desiccation over 100 days was approximately $50 \mathrm{~m}^{3}$-soil observed in simulations with a 300-cfm injection flow rate. A desiccation volume can also be hand-calculated assuming a $13-\mathrm{g} / \mathrm{m}^{3}$ water capacity of air $\left(\right.$ at $\left.\sim 15^{\circ} \mathrm{C}\right)$, a $300-\mathrm{cfm}$ injection flow rate of air with $10 \%$ relative humidity, and a change in moisture content of $0.11 \mathrm{~m}^{3} / \mathrm{m}^{3}$. This hand-calculated value is $\sim 48 \mathrm{~m}^{3}$-soil. Maintaining relatively higher injection rates (e.g., $300 \mathrm{cfm}$ ) provides for a larger desiccation volume within the targeted 6-month operational period. The larger desiccated volume is more favorable for monitoring because the desiccation front will intersect multiple monitoring locations. Lower injection flow rates (e.g., $100 \mathrm{cfm}$ ) require a well spacing likely infeasible for installation in the field (wells too closely spaced for drilling operations), or a longer operational time. For example, the time course of desiccation was simulated for three different injection/extraction conditions: 300/100 cfm (Figure 4.64), 100/100 (Figure 4.65), and 300/300 (Figure 4.66). These figures demonstrate that higher volumes of soil are desiccated at higher injection rates. Extracting at higher rates (e.g., 300/300 cfm) provides less of a benefit, and shows that moisture content is reduced by only a small measure (relative to the $300 / 100 \mathrm{cfm}$ case). Note also that simulations predict some localized condensation near the extraction well due to the lowered subsurface temperature.

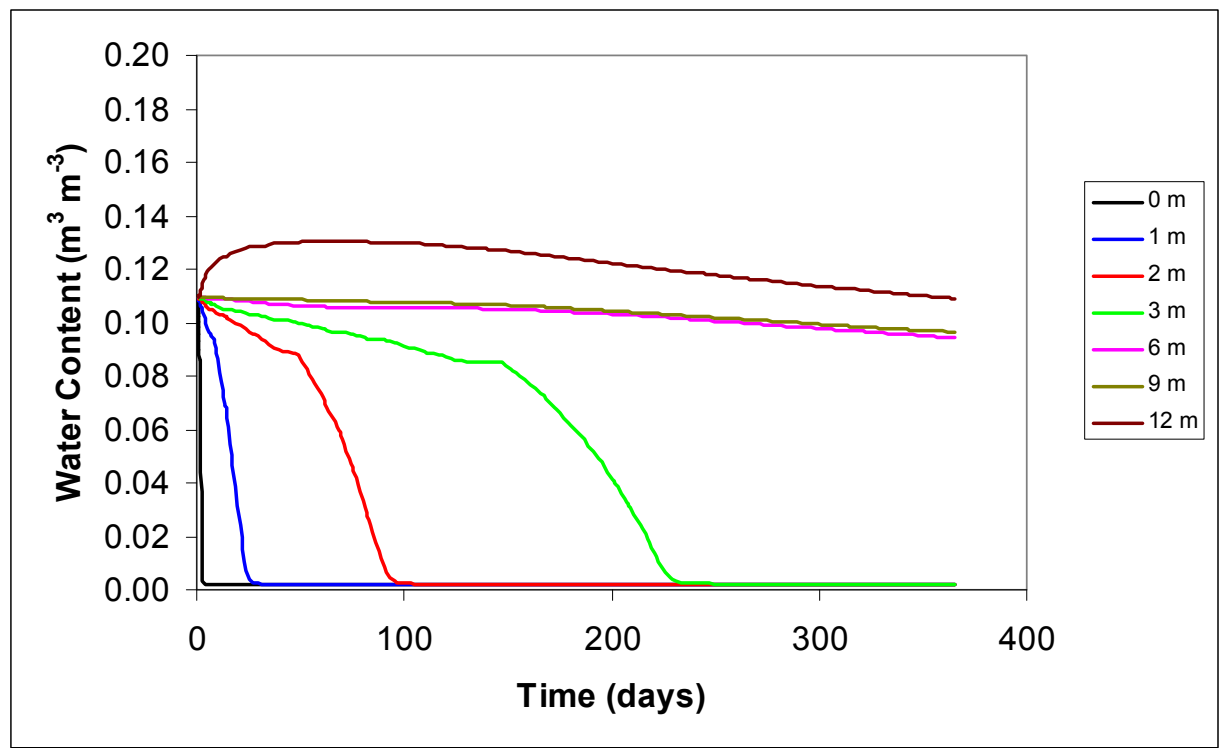

Figure 4.64. Simulated Desiccation (change in water content) Along the Centerline from the Injection to the Extraction Wells (mid-screen depth) for 300/100 cfm Injection/Extraction Flow Rates 


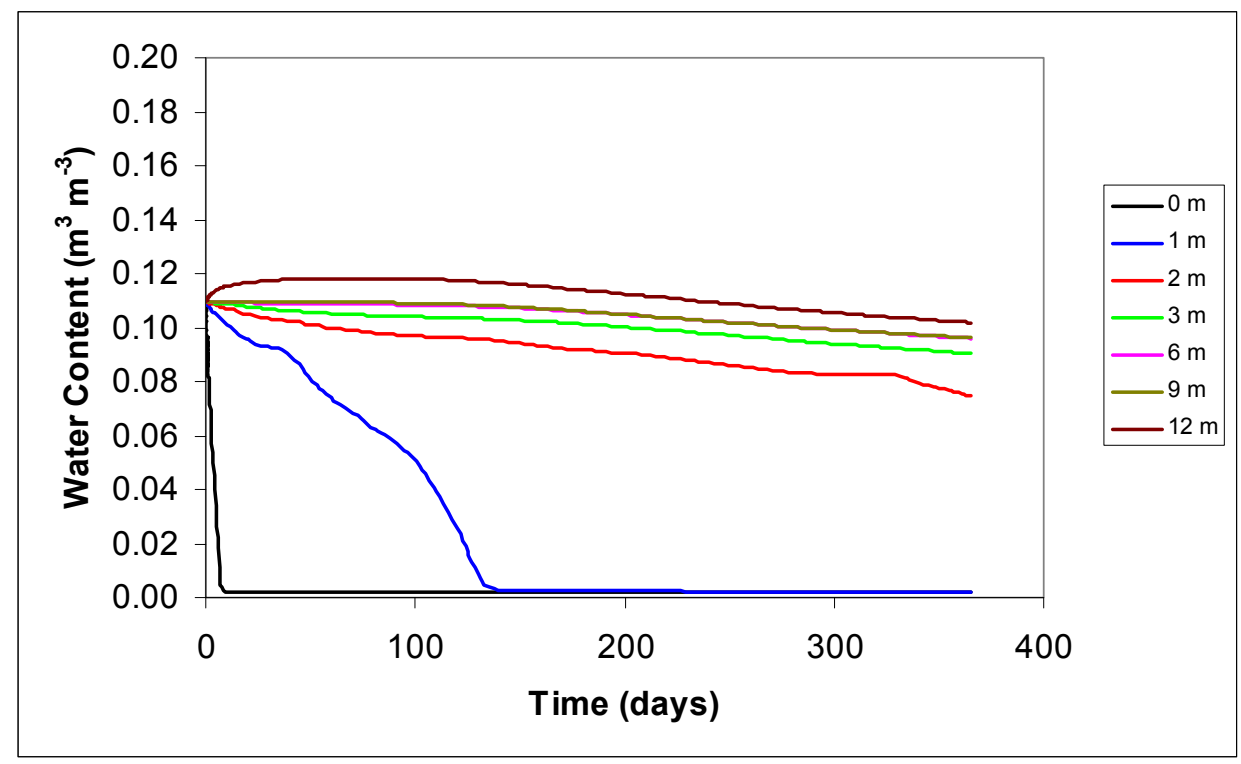

Figure 4.65. Simulated Desiccation (change in water content) Along the Centerline from the Injection to the Extraction Wells (mid-screen depth) for 100/100 cfm Injection/Extraction Flow Rates

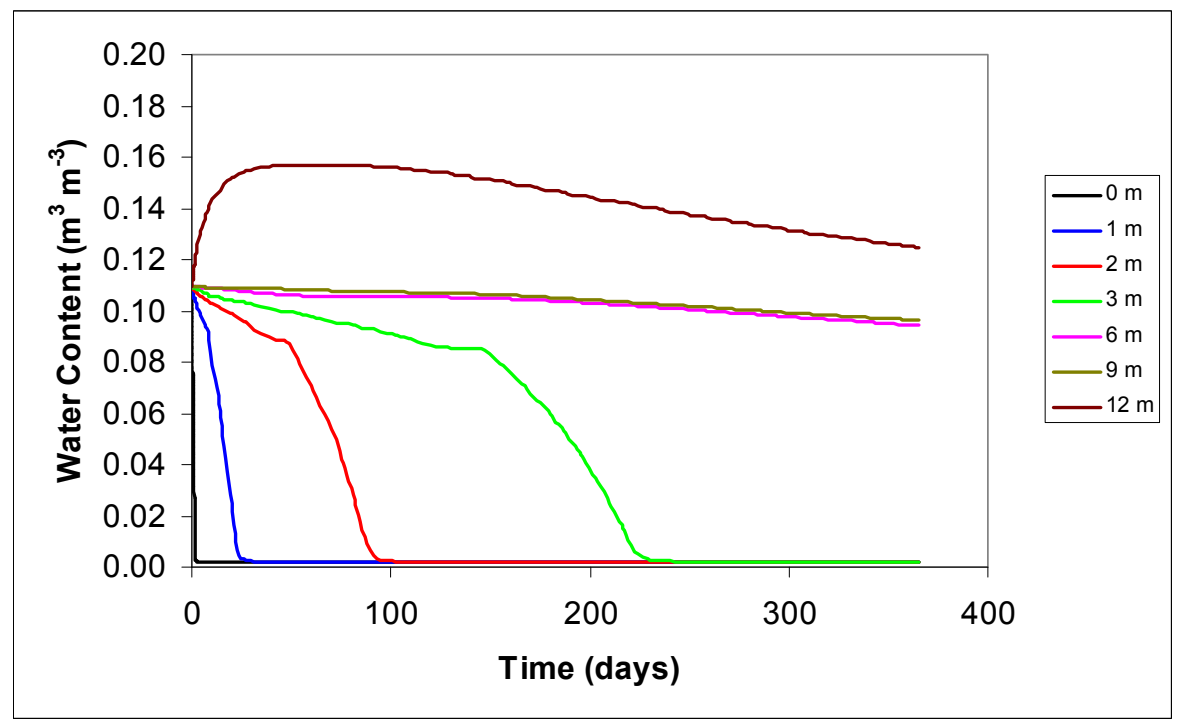

Figure 4.66. Simulated Desiccation (change in water content) Along the Centerline from the Injection to the Extraction Wells (mid-screen depth) for 300/300 cfm Injection/Extraction Flow Rates

Desiccation near the injection well (i.e., within $3 \mathrm{~m}$ ) is primarily controlled by the injection flow rate. As shown in Figure 4.67 for a range of different injection/extraction rates, gas flow is directly proportional to the injection flow rate through a Y-Z plane located between the injection and extraction wells at a distance of $3 \mathrm{~m}$ from the injection well. The extraction rate has only a small impact on the gas flow rate at this distance from the extraction well. Table 4.4 shows the total gas flow rate at this plane for a cross sectional area of $57 \mathrm{~m}^{2}(8.5 \mathrm{~m}$ in the y direction by $6.7 \mathrm{~m}$ in the $\mathrm{z}$ direction) on the centerline between the injection and extraction wells. When the injection rate is $300 \mathrm{cfm}$, the range of flow rates 
varies from 77 to $80 \mathrm{cfm}$, whereas at $100 \mathrm{cfm}$ the volumetric flow rate $3 \mathrm{~m}$ from the injection well is only $21 \mathrm{cfm}$. Due to the dipole arrangement of the wells, only $20 \%-30 \%$ of the injected airflow is captured at this distance from the injection well.

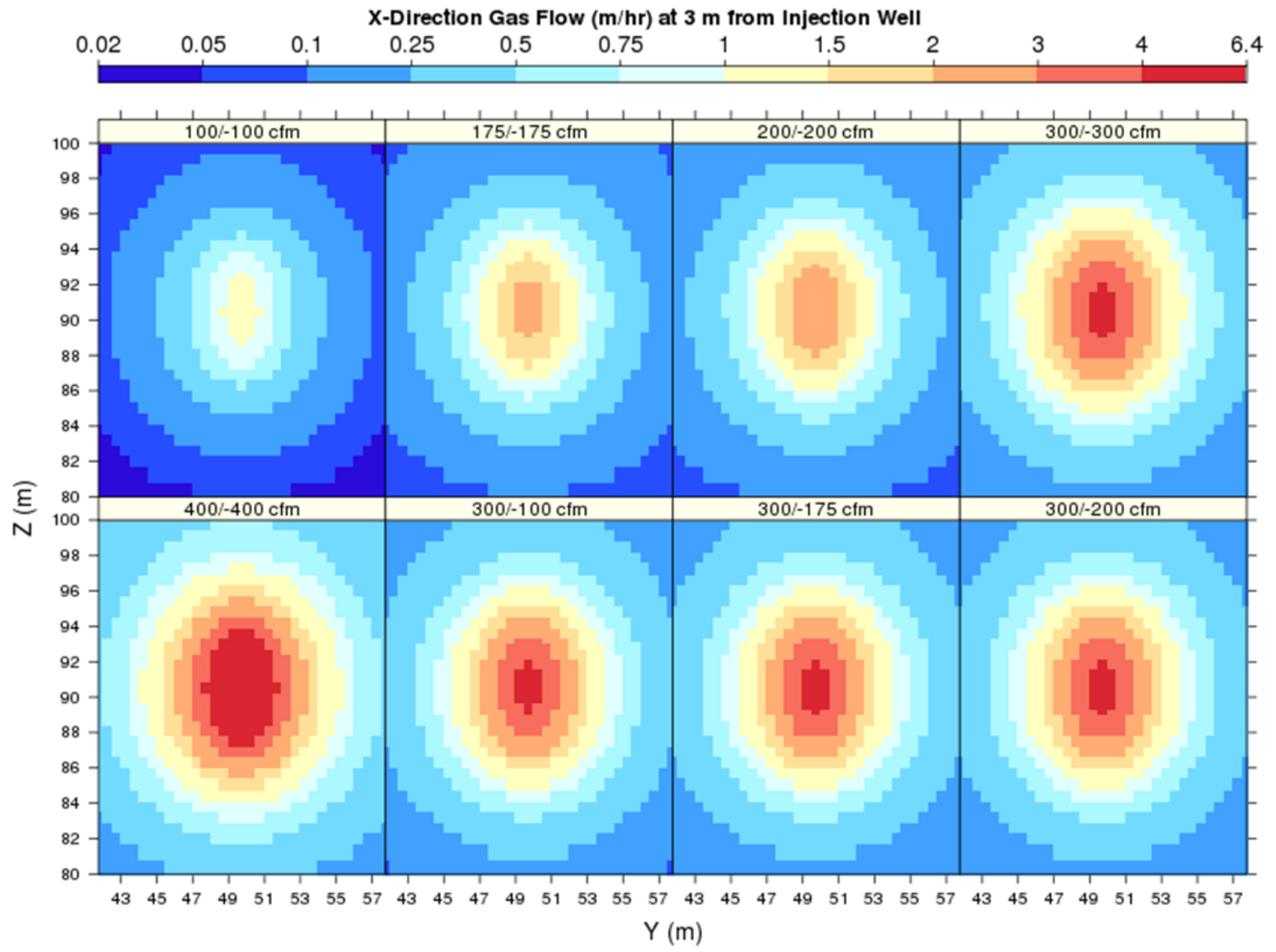

Figure 4.67. Depiction of Gas Flow Rate in a Y-Z Plane Located Between the Injection and Extraction Wells at a Distance of $3 \mathrm{~m}$ from the Injection Well. The extraction well is $12 \mathrm{~m}$ from the injection well. The flow rates are shown as injection/extraction. Note the flow rate through the plane increases with increasing injection flow rate. However, for a fixed injection flow rate of $300 \mathrm{cfm}$, the extraction flow rate has little impact on the flow rate through the plane.

Table 4.4. Simulated Gas Flow Rate Through a Y-Z Plane Located Between the Injection and Extraction Wells at a Distance of $3 \mathrm{~m}$ from the Injection Well in a Cross Sectional Area of $57 \mathrm{~m}^{2}(8.5 \mathrm{~m}$ in the y direction by $6.7 \mathrm{~m}$ in the $\mathrm{z}$ direction) on the Centerline Between the Injection and Extraction Wells

\begin{tabular}{|c|c|c|c|c|c|c|c|c|}
\hline \multirow{3}{*}{$\begin{array}{l}\text { Total gas flow rate through } \\
\text { cross section }(\mathrm{cfm})\end{array}$} & \multicolumn{8}{|c|}{ Injection/Extraction Flow Rates (cfm) } \\
\hline & $100 / 100$ & $175 / 175$ & $200 / 200$ & $300 / 300$ & $400 / 400$ & $300 / 100$ & $300 / 175$ & $300 / 200$ \\
\hline & 21.19 & 40.46 & 47.57 & 79.79 & 116.77 & 77.94 & 78.66 & 78.88 \\
\hline
\end{tabular}

At $9 \mathrm{~m}$ from the injection well, the impact of lower extraction rates on the gas flow rate can be observed (Figure 4.68). When the injection rate is fixed at $300 \mathrm{cfm}$ and the extraction rate is lowered, the primary effect is a reduction in the gas flow rate along the centerline between the injection and extraction 
wells. Note the rate of desiccation is essentially the same for both a $300 \mathrm{cfm} / 100 \mathrm{cfm}$ injection/extraction condition (Figure 4.64) compared to a $300 \mathrm{cfm} / 300 \mathrm{cfm}$ injection/extraction condition (Figure 4.66) within the first $3 \mathrm{~m}$ of the injection well. Use of a dipole arrangement helps focus the soil gas flow to within a targeted monitoring zone and depth interval defined generally by the screened intervals of the wells. The extraction rate can be lower than the injection rate and still direct flow to the monitored test zone. This situation may be preferred for the test because 1) it maintains extraction flow rates lower than the critical velocity that may entrain droplets in the extracted soil gas; and 2) it helps minimize short circuiting between the injection and extraction wells due to the lower induced pressure gradients relative to higher extraction rates.

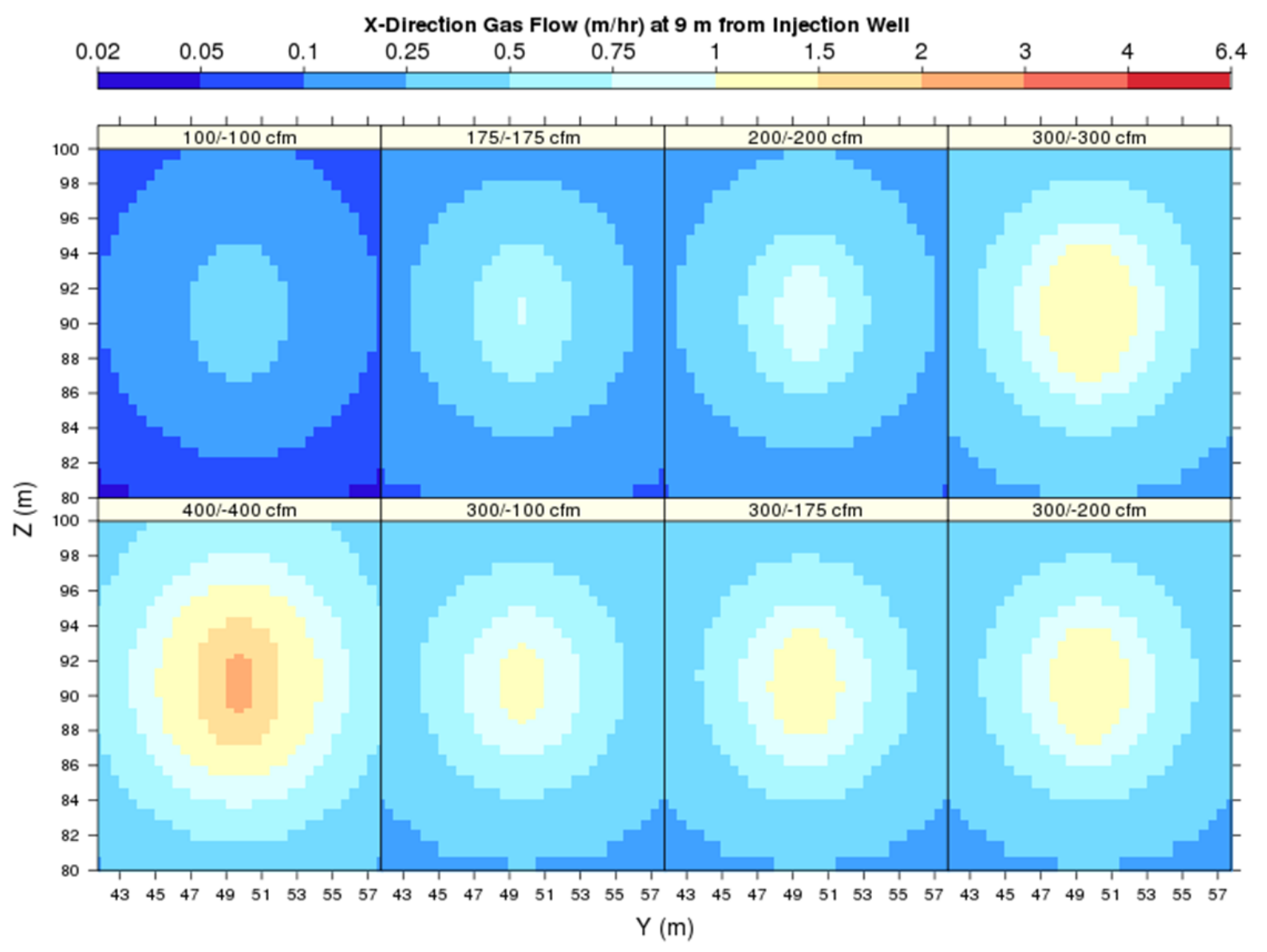

Figure 4.68. Depiction of Gas Flow Rate in a Y-Z Plane Located Between the Injection and Extraction Wells at a Distance of $9 \mathrm{~m}$ from the Injection Well. The extraction well is $12 \mathrm{~m}$ from the injection well. The flow rates are shown as injection/extraction. Note the flow rate through the plane increases with increasing injection flow rate. However, for a fixed injection flow rate of $300 \mathrm{cfm}$, lower extraction flow rates diminish the flow rate through the plane, especially along the centerline between the injection and extraction wells.

Simulations also show a moderate increase in moisture content near the extraction well (see Figures 4.64 through 4.66). While lower pressure tends to decrease relative humidity, the lower temperature induced at the extraction well in the simulations (see Figures 4.69 through 4.71) causes condensation to occur. This condensation is focused around the extraction well because of the higher 
airflow rate through this region and because the extraction well draws soil gas from regions outside the desiccation zone where temperatures are higher compared to near the well.

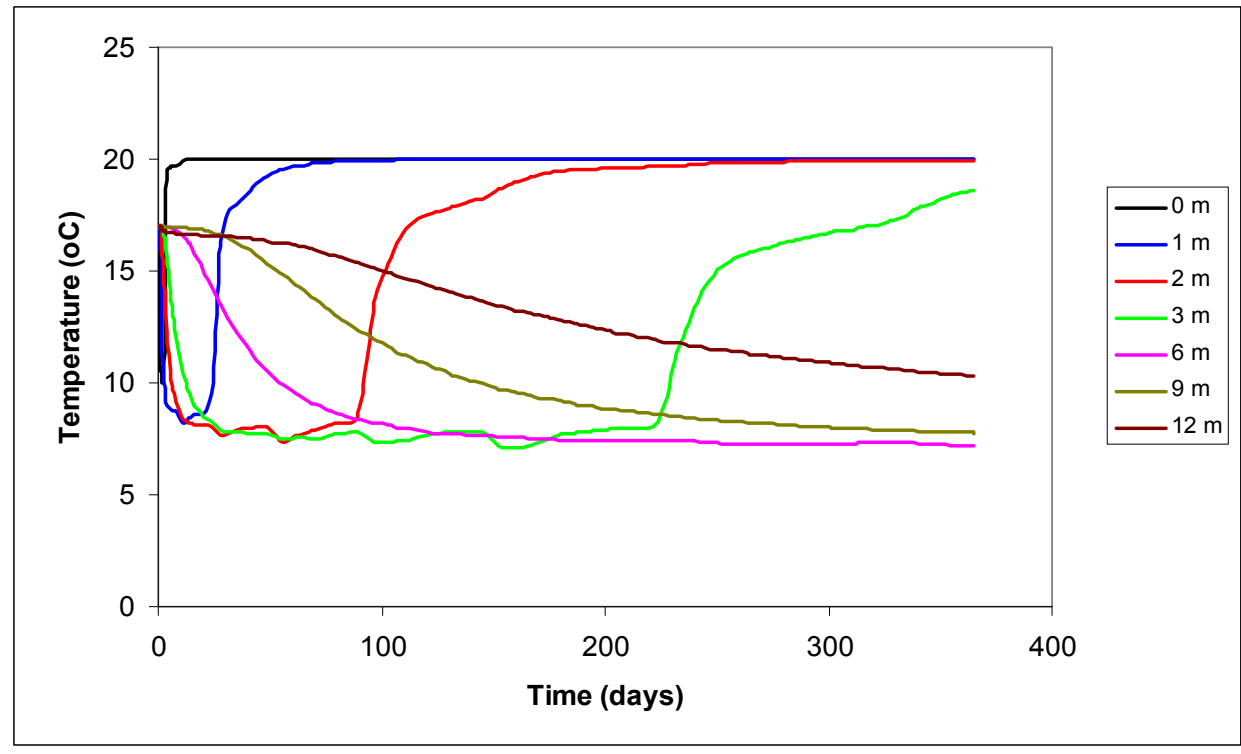

Figure 4.69. Simulated Temperature Profile During Desiccation Along the Centerline from the Injection to the Extraction Wells (mid-screen depth) for 300/100 cfm Injection/Extraction Flow Rates. The injected air temperature is $20^{\circ} \mathrm{C}$.

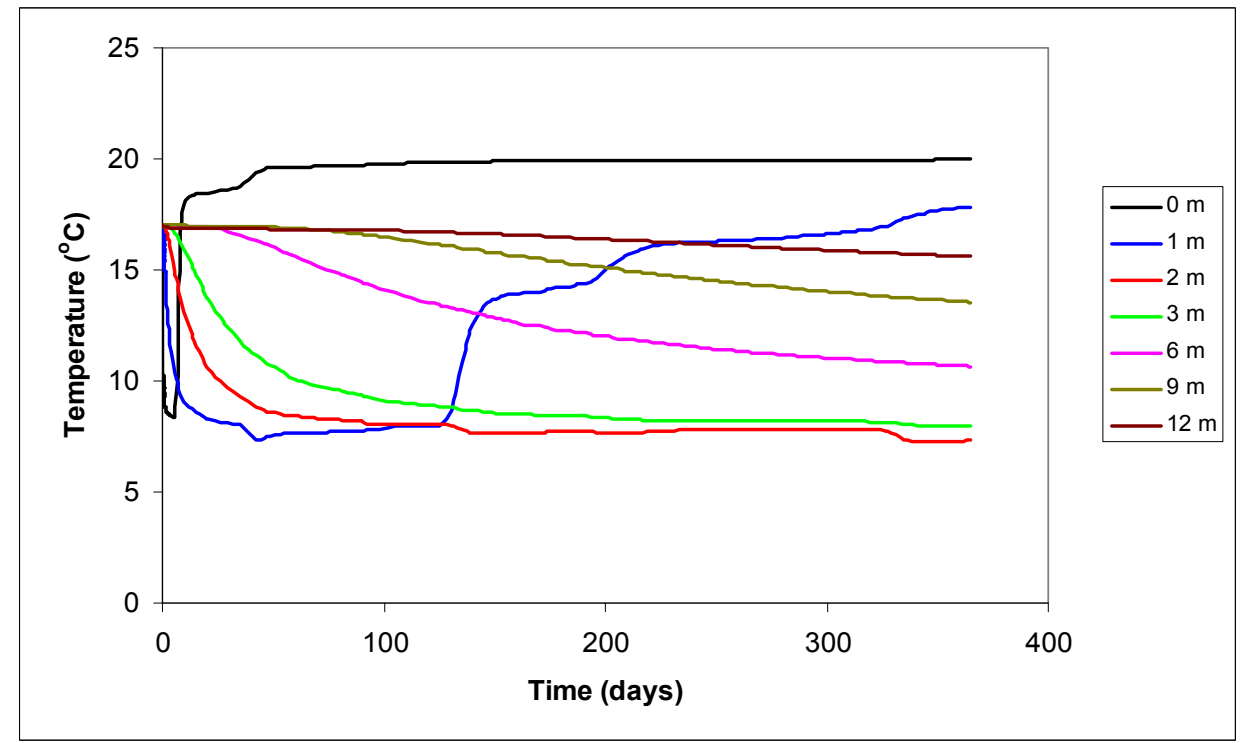

Figure 4.70. Simulated Temperature Profile During Desiccation Along the Centerline from the Injection to the Extraction Wells (mid-screen depth) for 100/100 cfm Injection/Extraction Flow Rates. The injected air temperature is $20^{\circ} \mathrm{C}$. 


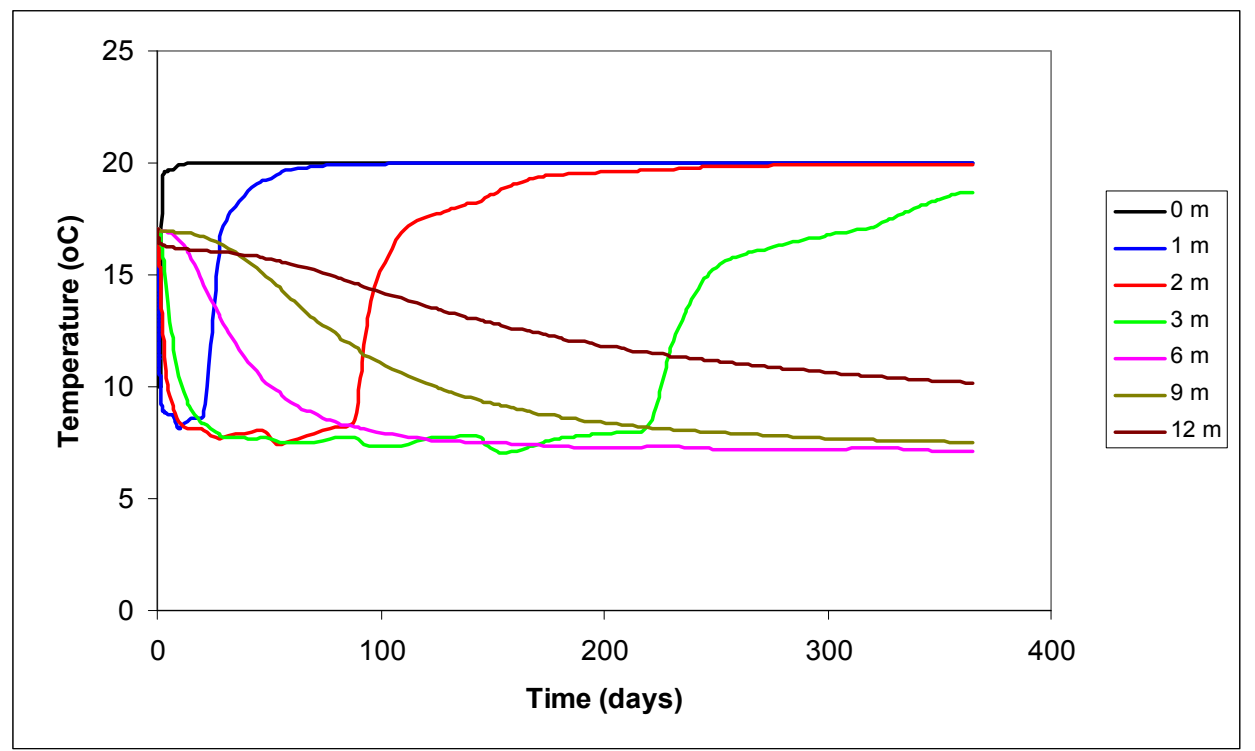

Figure 4.71. Simulated Temperature Profile During Desiccation Along the Centerline from the Injection to the Extraction Wells (mid-screen depth) for 300/300 cfm Injection/Extraction Flow Rates. The injected air temperature is $20^{\circ} \mathrm{C}$.

The simulation results suggest that field operations could be effectively initiated by selecting a desired influent airflow rate (e.g., $300 \mathrm{cfm})$ based on a targeted desiccation volume and test timeframe. The extraction flow rate could then be increased until a desired flow pattern (e.g., as measured by pressure and tracer response) is obtained. Pressure gradients, and therefore the flow field, vary with the selected injection and extraction flow rates. For example, Figures 4.72, 4.73, and 4.74 show the pressure gradients for the 300/100 cfm injection/extraction, the 100/100 cfm injection/extraction, and the $300 / 300 \mathrm{cfm}$ injection/extraction conditions, respectively. Based on previous scoping simulations (Ward et al. 2008), increased injection air temperature could be used to increase the desiccation rate if necessary to reach targeted desiccation volumes within the test timeframe. Because monitoring instrumentation would be impacted by the injected air temperature, only moderate increases in injection air temperature should be considered. 

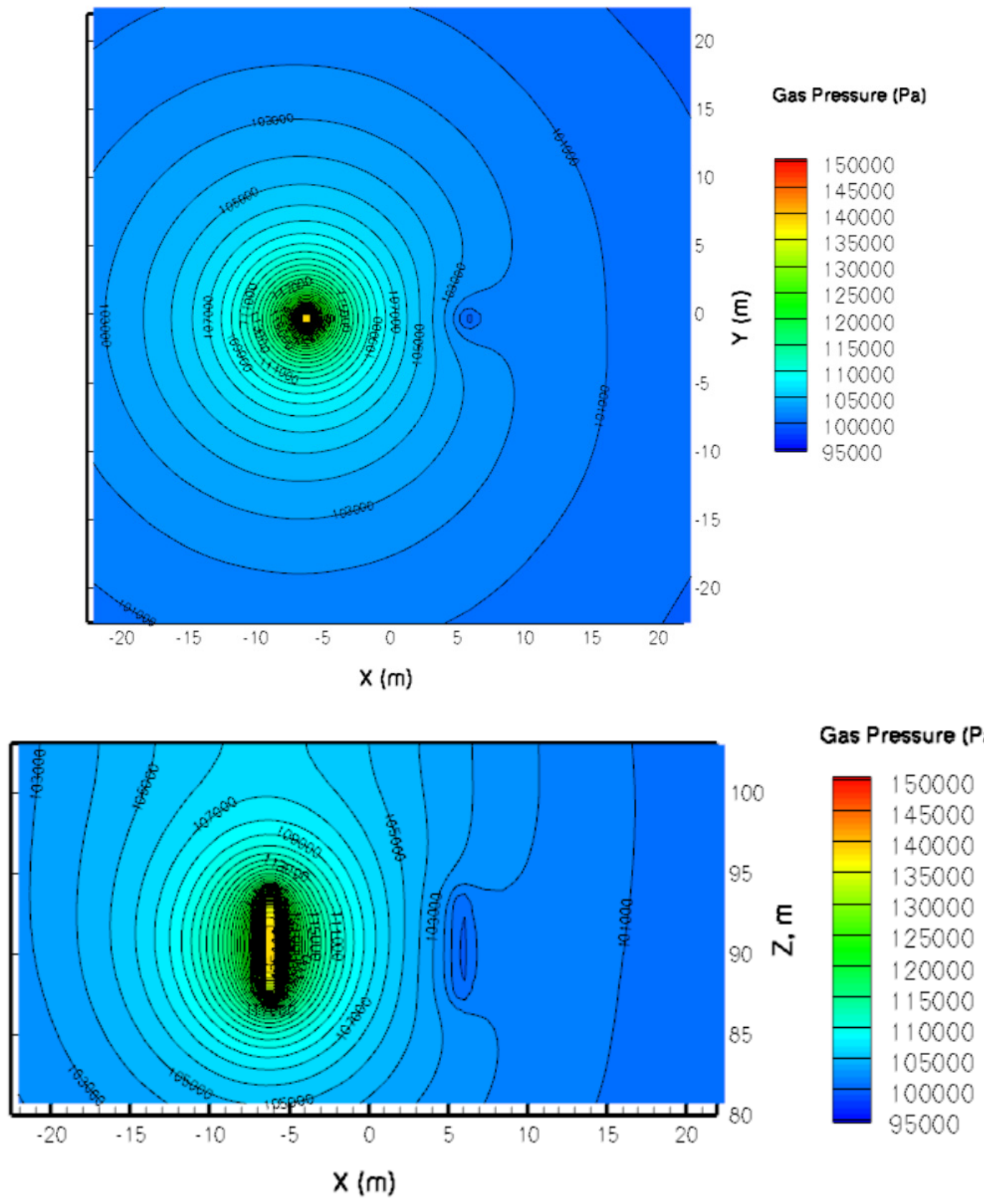

Figure 4.72. Simulated Plan (mid-screen depth) and Cross Sectional Views of the Pressure Gradients for $300 / 100 \mathrm{cfm}$ Injection/Extraction Flow Rates. Injection well is at $-6 \mathrm{~m}$ and the extraction well is at $6 \mathrm{~m}$. 

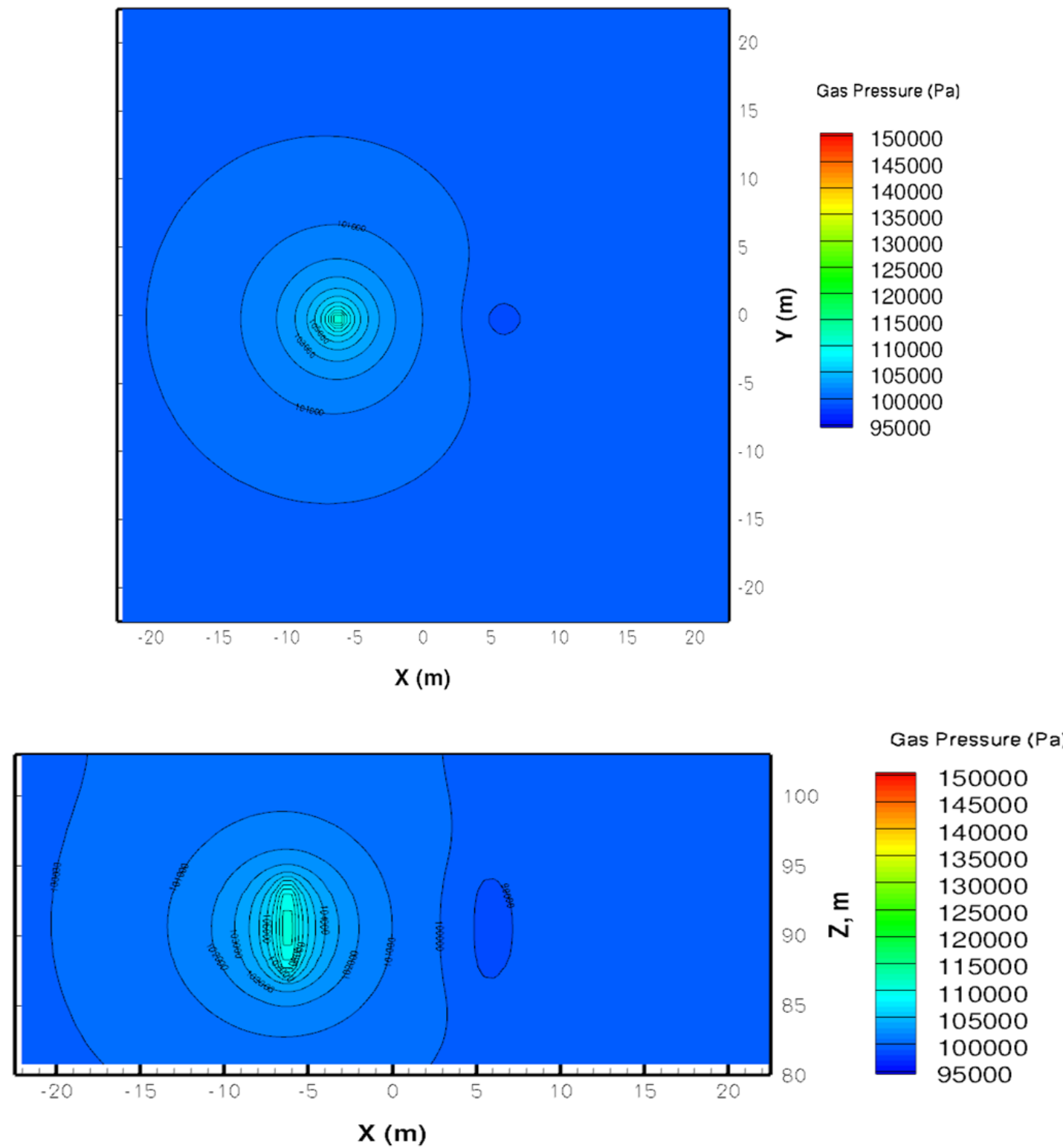

Figure 4.73. Simulated Plan (mid-screen depth) and Cross Sectional Views of the Pressure Gradients for $100 / 100 \mathrm{cfm}$ Injection/Extraction Flow Rates. Injection well is at $-6 \mathrm{~m}$ and the extraction well is at $6 \mathrm{~m}$. 

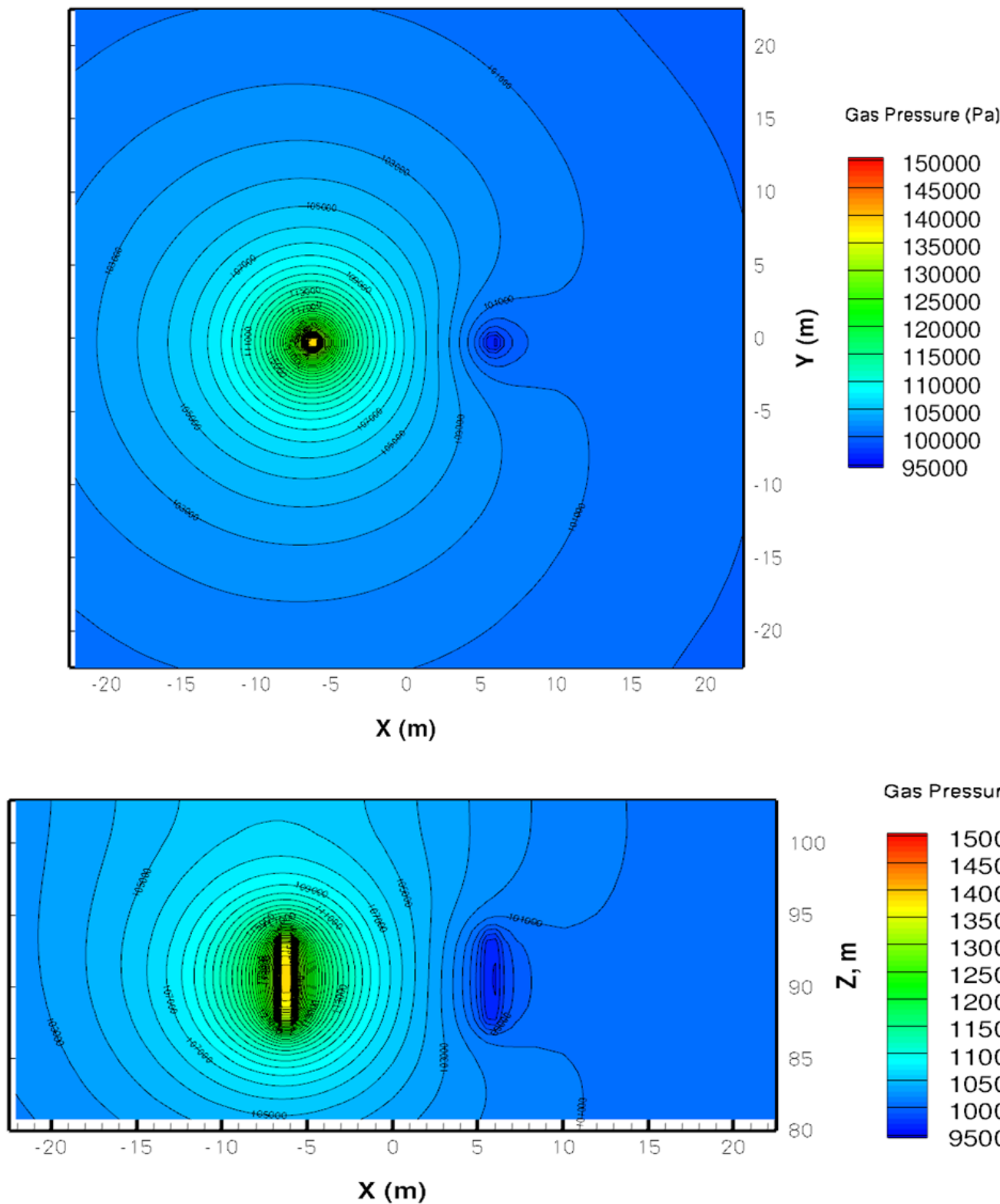

Gas Pressure (Pa)

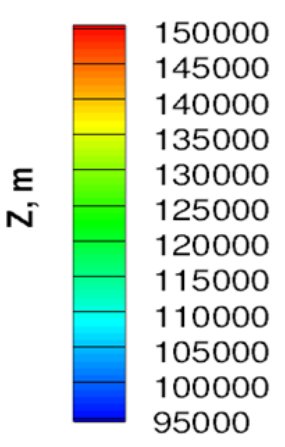

Figure 4.74. Simulated Plan (mid-screen depth) and Cross Sectional Views of the Pressure Gradients for $300 / 300 \mathrm{cfm}$ Injection/Extraction Flow Rates. Injection Well is at $-6 \mathrm{~m}$ and the Extraction Well is at $6 \mathrm{~m}$.

Numerical modeling of the desiccation field test site. Pre-test simulations (above) were conducted using a homogeneous model domain based on the bulk subsurface property information available prior to having test infrastructure in place. Refined field simulations were conducted using the results of gas tracer testing at the test site (Section 4.1) to modify the model domain and account for the large-scale heterogeneity observed from these tracer data. Injected gas flow was significantly higher in the deeper monitored zone at the site compared to the upper zones. Thus, the model domain was modified to include a low permeability zone in the 30 to $40 \mathrm{ft}$ depth interval. Desiccation simulations were conducted using this model domain to provide an estimate for the temporal desiccation response at the site monitoring 
locations for use in comparing to the observed responses. Note that the simulated results do not account for small-scale heterogeneity or lateral heterogeneity, so are expected to represent general, not specific, trends in desiccation progress.

Figures 4.75 through 4.81 show the simulated moisture content, matric potential, humidity, and temperature responses at the monitoring locations. The responses are shown for each of the sensor depth intervals at these locations. Simulated results show desiccation responses occurring at C7522, C7524, C7526, C7528 at the $47.5 \mathrm{ft}$ sensor depth interval within 30 days, similar to the field results (Section 4.1). Within 60 days, the simulations show a desiccation response at C7530 at the $47.5 \mathrm{ft}$ sensor depth interval, also reflected in the field data. The simulations over-predict desiccation progress at C7532 and C7534 and for the 32, 37.5, and $42 \mathrm{ft}$ intervals. However, the extent of over-prediction is not known because the test was stopped after about 150 days of dry gas injection.

(a)

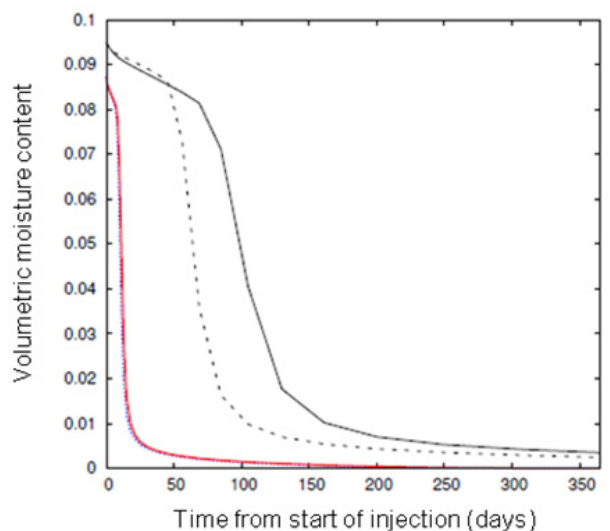

(b)

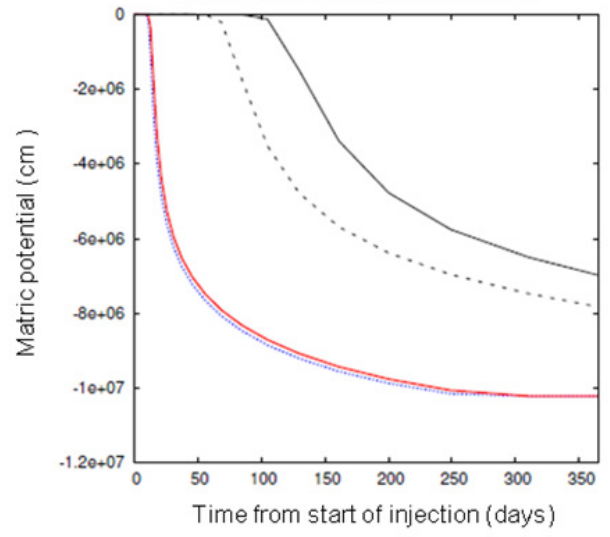

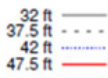

(c)
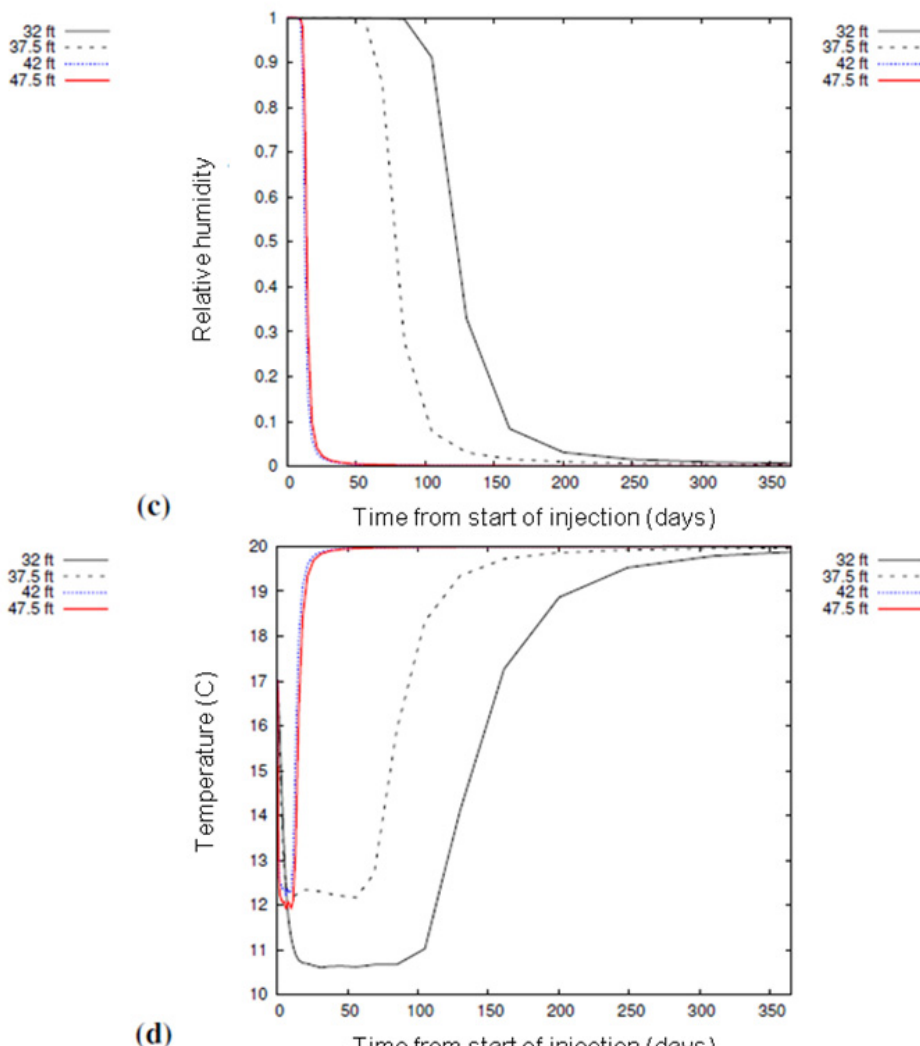

$47.5 \mathrm{th}$

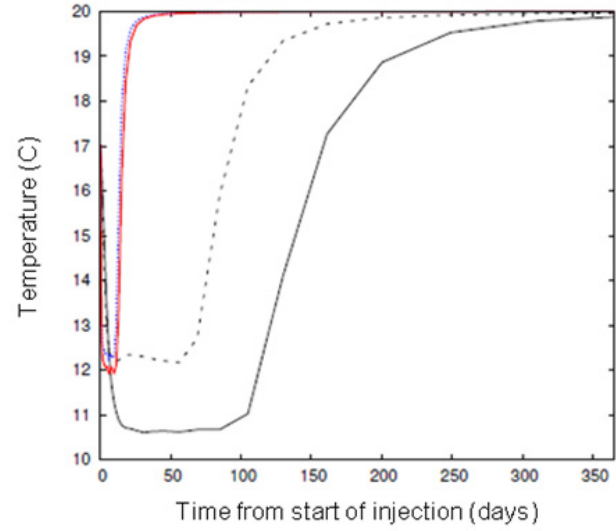

Figure 4.75. Simulated Desiccation Response at Location C7522 for a Layered Model Domain in Terms of a) Volumetric Moisture Content, b) Matric Potential, c) Relative Humidity, and d) Temperature Changes at the Nominal Mid-Depth of the Sensor Intervals for the Field Test $(32,37.5,42$, and $47.5 \mathrm{ft}$ bgs $)$ 
(a)

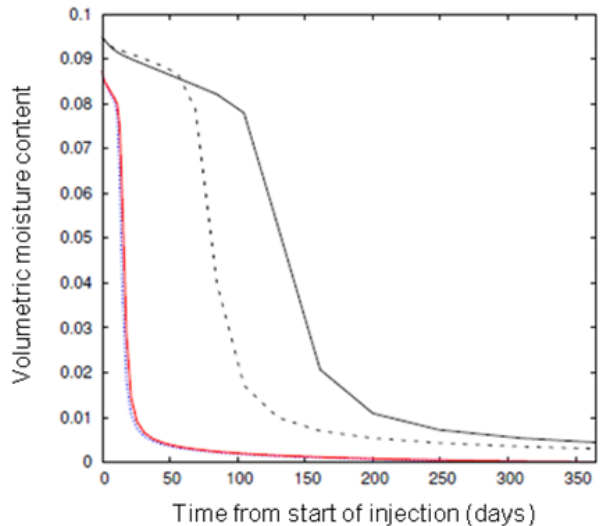

(b)

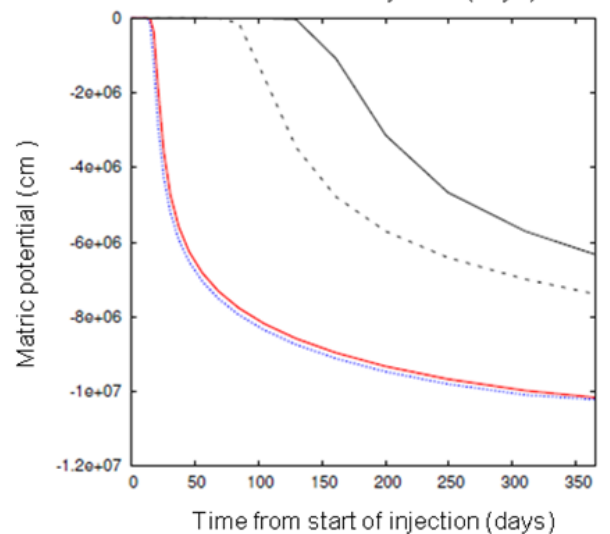

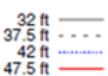
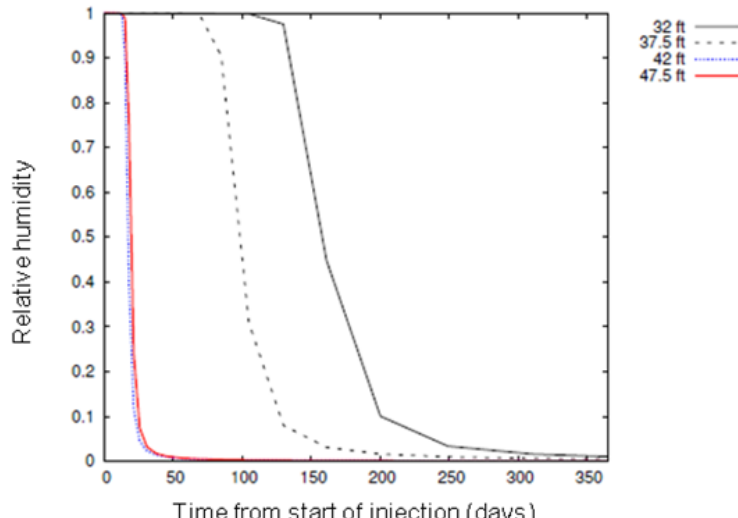

(c)

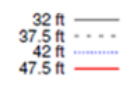

(d)

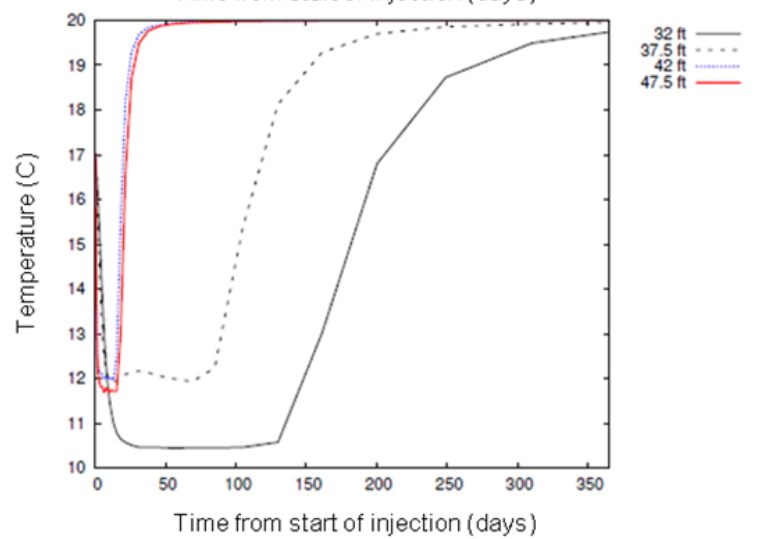

Figure 4.76. Simulated Desiccation Response at Location C 7524 for a Layered Model Domain in Terms of a) Volumetric Moisture Content, b) Matric Potential, c) Relative Humidity, and d) Temperature Changes at the Nominal Mid-Depth of the Sensor Intervals for the Field Test $(32,37.5,42$, and $47.5 \mathrm{ft}$ bgs $)$ 
(a)

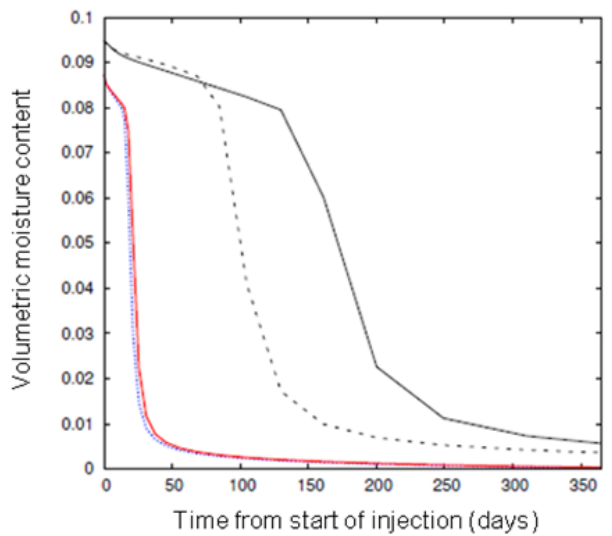

(b)

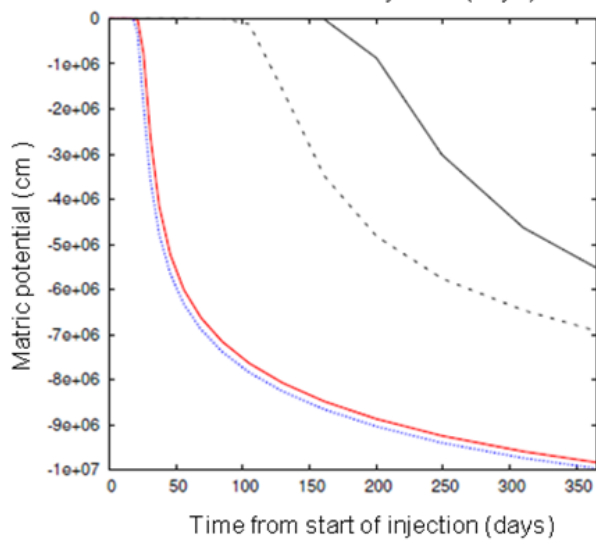

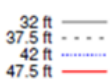

(c)
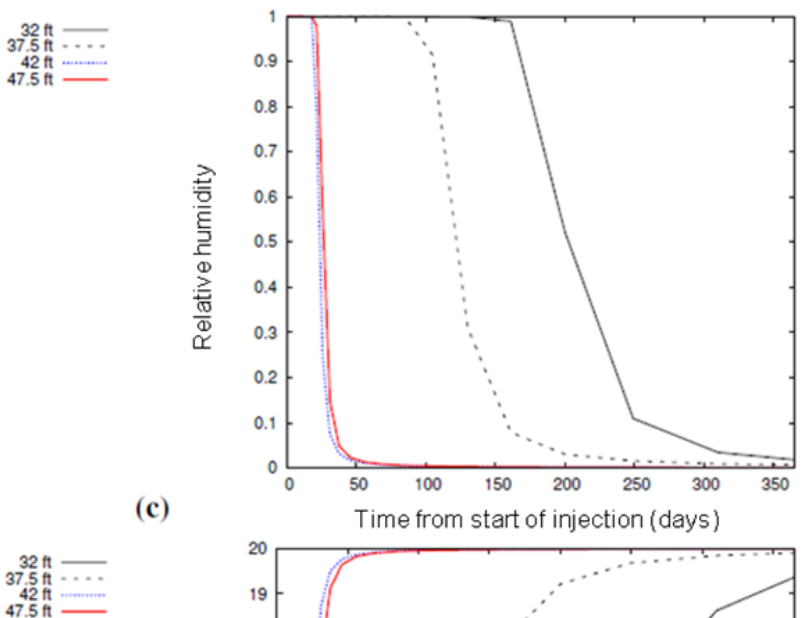

(d)

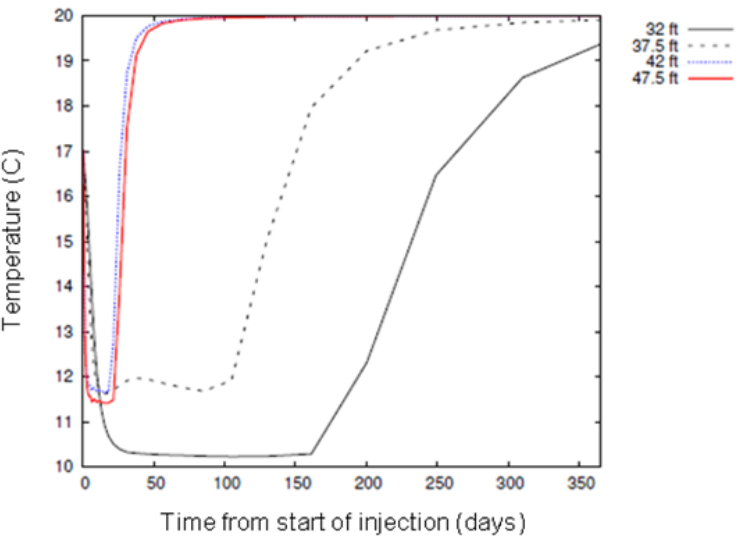

Figure 4.77. Simulated Desiccation Response at Location C7526 for a Layered Model Domain in Terms of a) Volumetric Moisture Content, b) Matric Potential, c) Relative Humidity, and d) Temperature Changes at the Nominal Mid-Depth of the Sensor Intervals for the Field Test $(32,37.5,42$, and $47.5 \mathrm{ft}$ bgs $)$ 
(a)

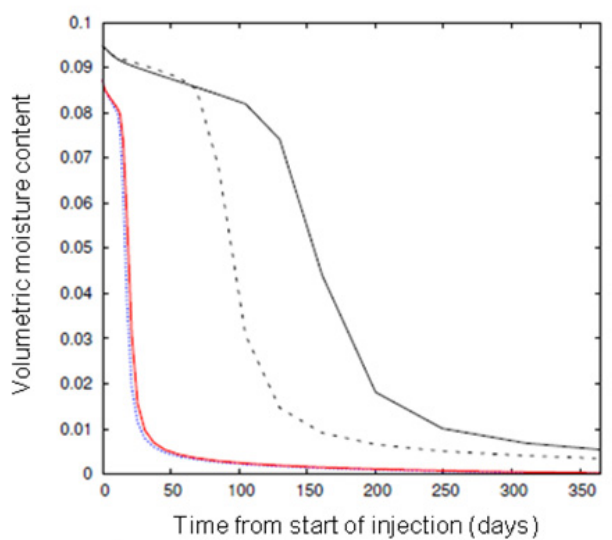

(b)

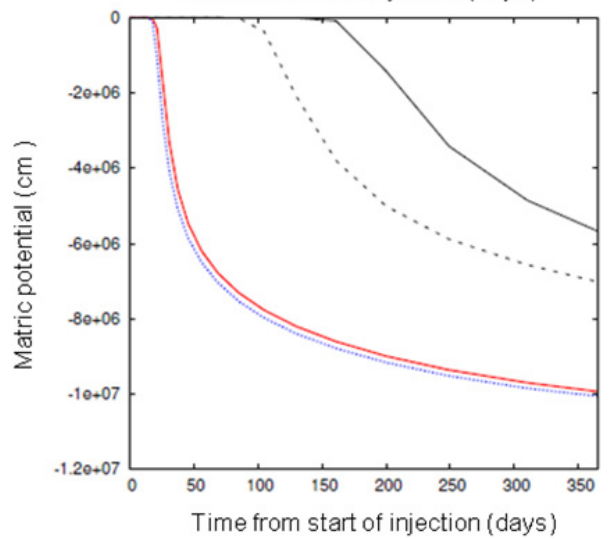

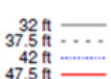

(c)
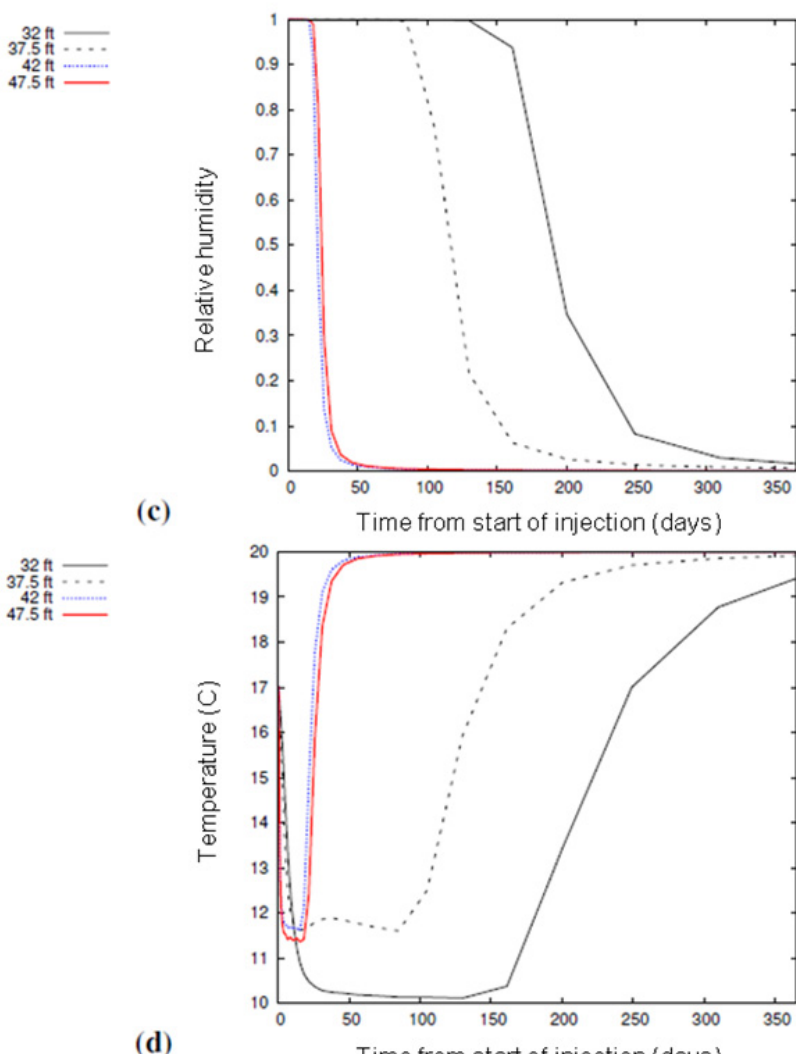
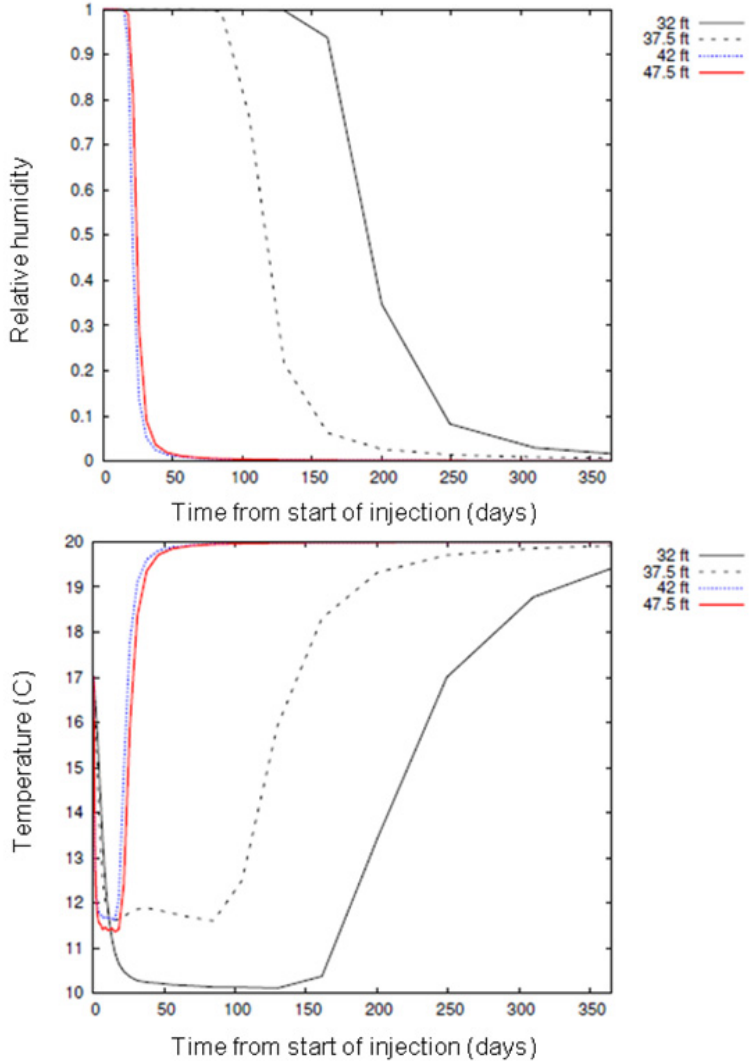

Figure 4.78. Simulated Desiccation Response at Location C7528 for a Layered Model Domain in Terms of a) Volumetric Moisture Content, b) Matric Potential, c) Relative Humidity, and d) Temperature Changes at the Nominal Mid-Depth of the Sensor Intervals for the Field Test $(32,37.5,42$, and $47.5 \mathrm{ft}$ bgs $)$ 
(a)

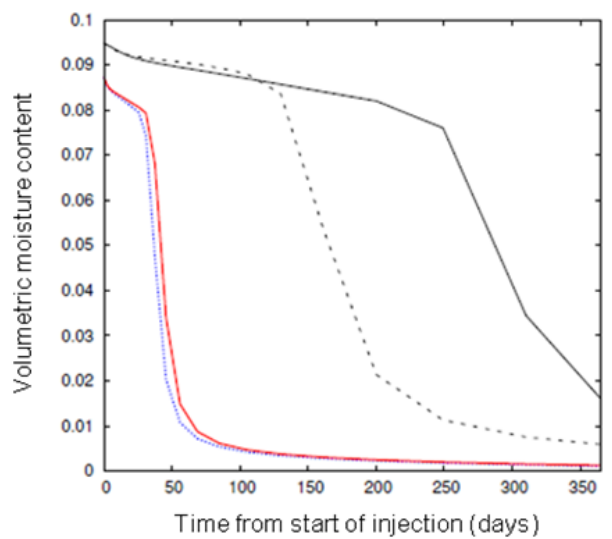

(b)

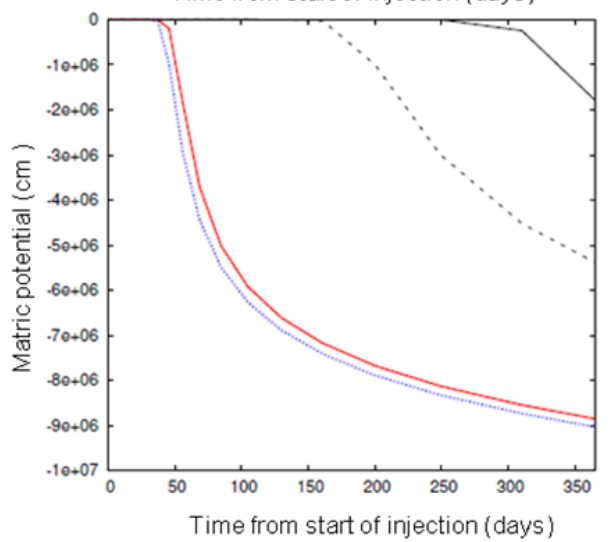

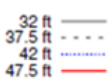

(c)
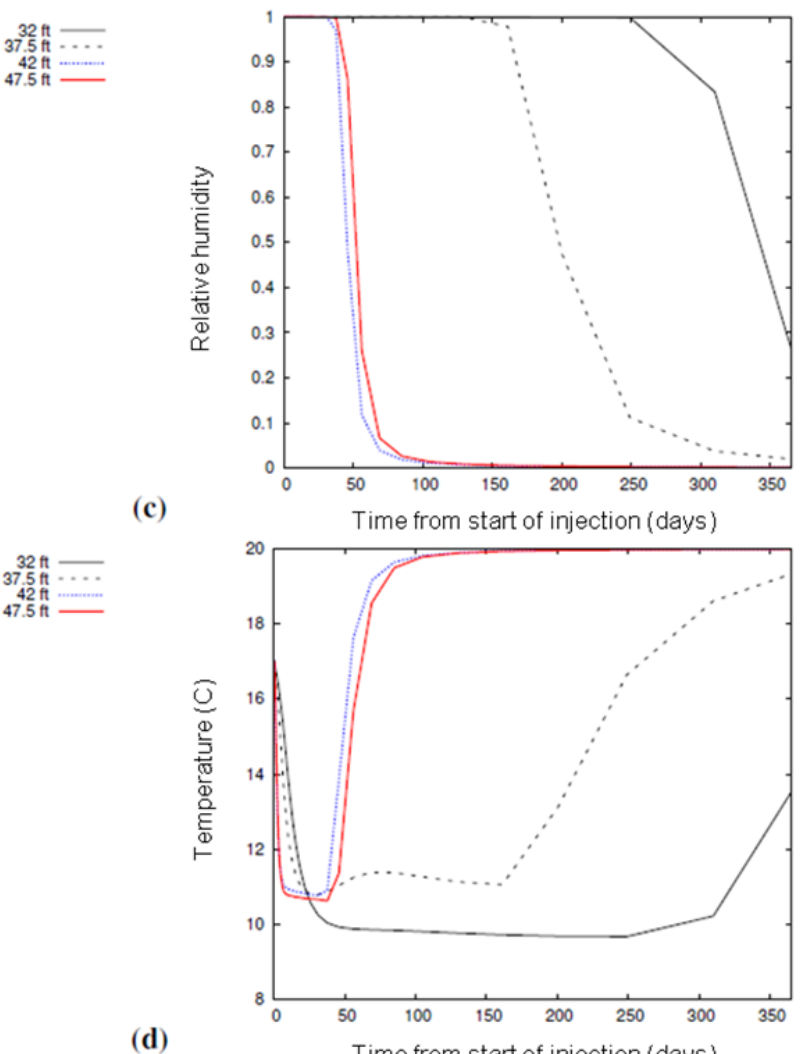

$32 \mathrm{tt}$
$37.5 \mathrm{th}$
$42 \mathrm{tt}$
$47.5 \mathrm{t}$

(d)

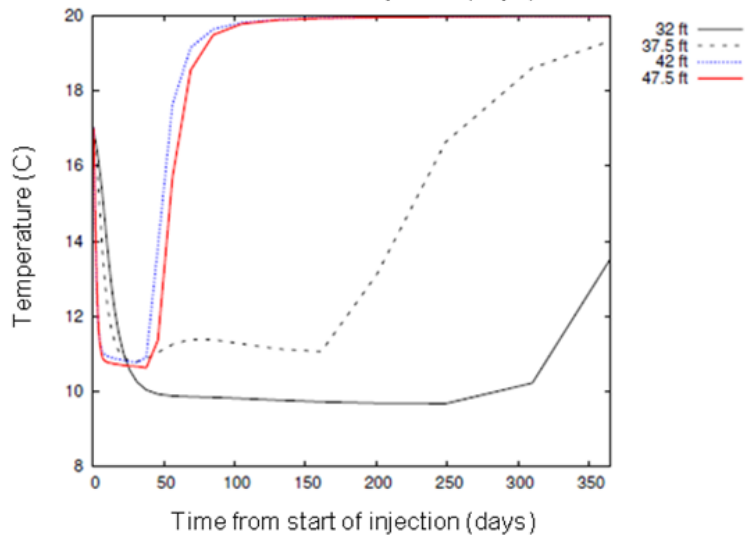

Figure 4.79. Simulated Desiccation Response at Location C7530 for a Layered Model Domain in Terms of a) Volumetric Moisture Content, b) Matric Potential, c) Relative Humidity, and d) Temperature Changes at the Nominal Mid-Depth of the Sensor Intervals for the Field Test $(32,37.5,42$, and $47.5 \mathrm{ft}$ bgs $)$ 
(a)

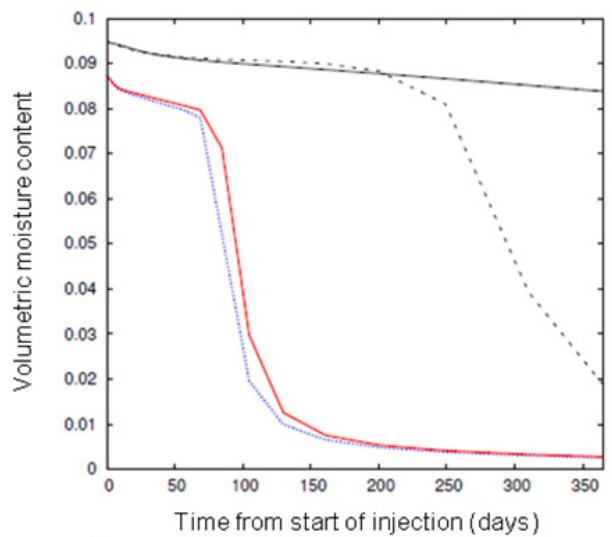

(b)

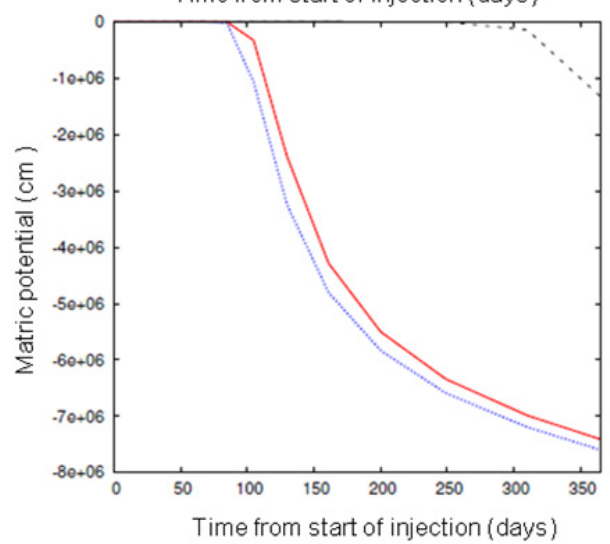

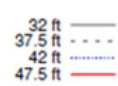

(c)
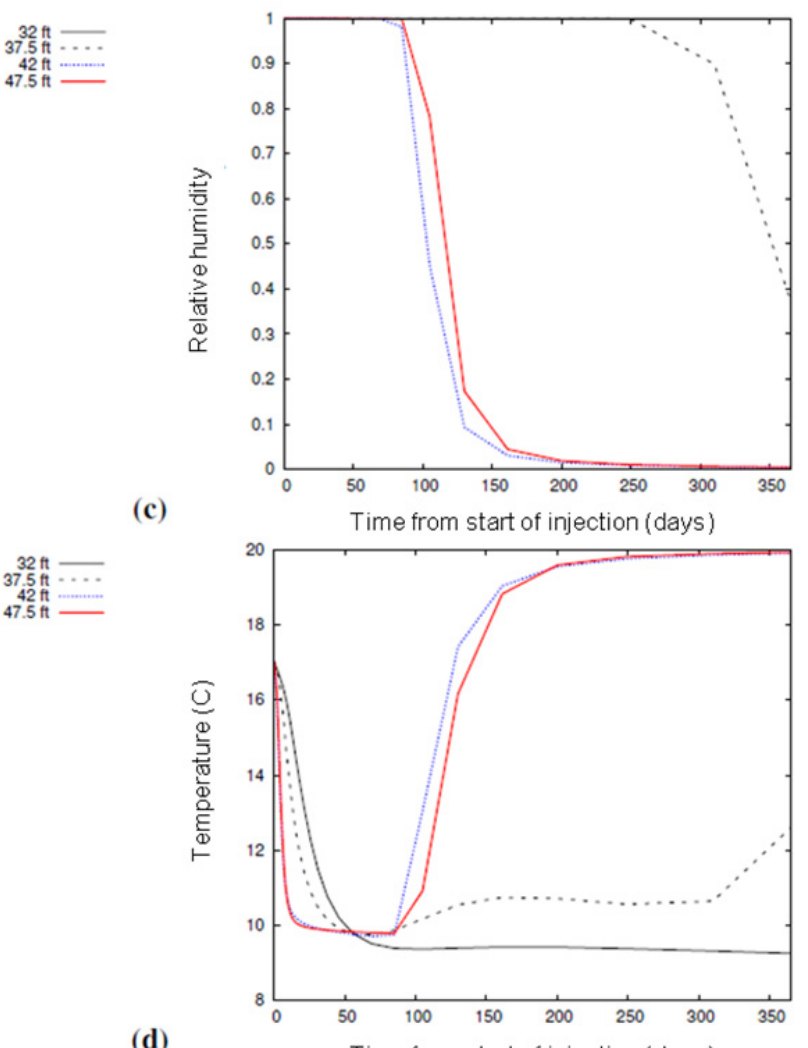

(d)

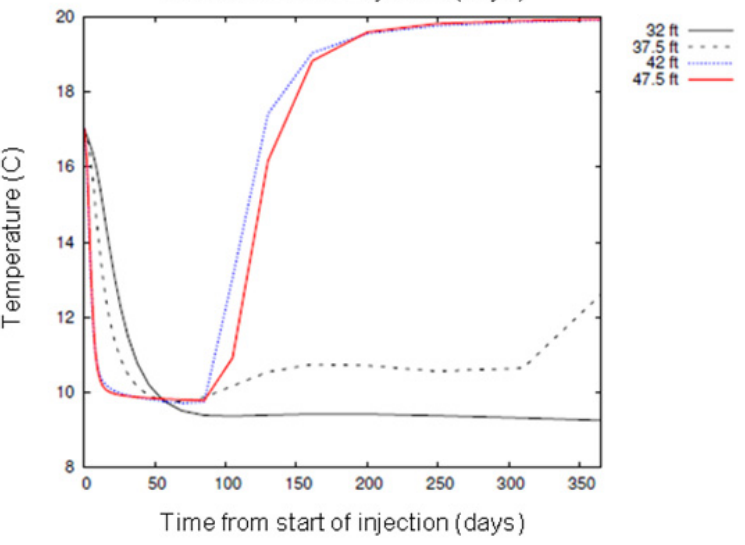

Figure 4.80. Simulated Desiccation Response at Location C7532 for a Layered Model Domain in Terms of a) Volumetric Moisture Content, b) Matric Potential, c) Relative Humidity, and d) Temperature Changes at the Nominal Mid-Depth of the Sensor Intervals for the Field Test $(32,37.5,42$, and $47.5 \mathrm{ft}$ bgs $)$ 
(a)

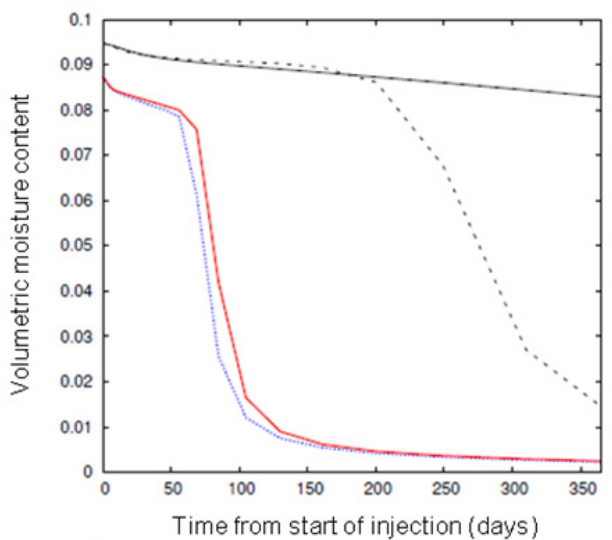

(b)

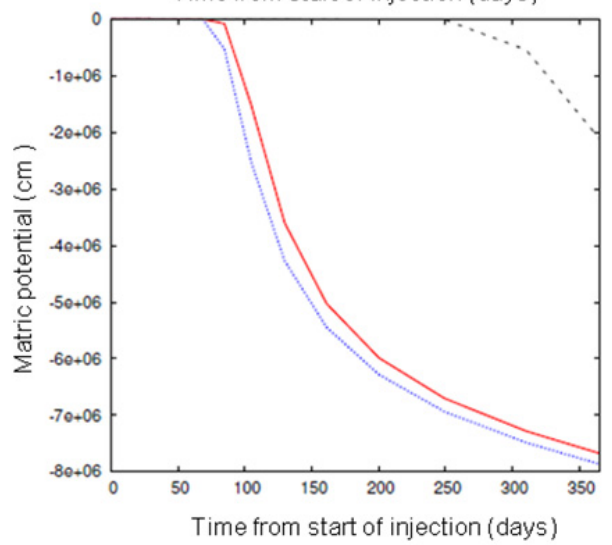

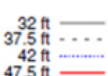

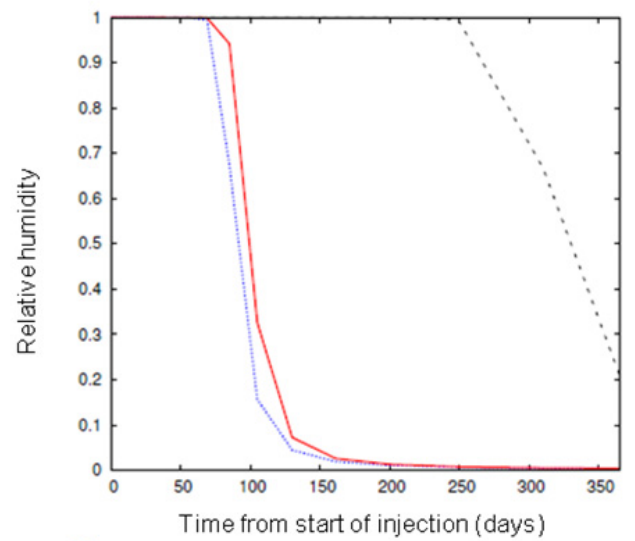
$32 \mathrm{th}$
$37.5 \mathrm{t}$
$42 \mathrm{th}$
$47.5 \mathrm{th}$

(c)

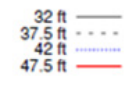

(d)

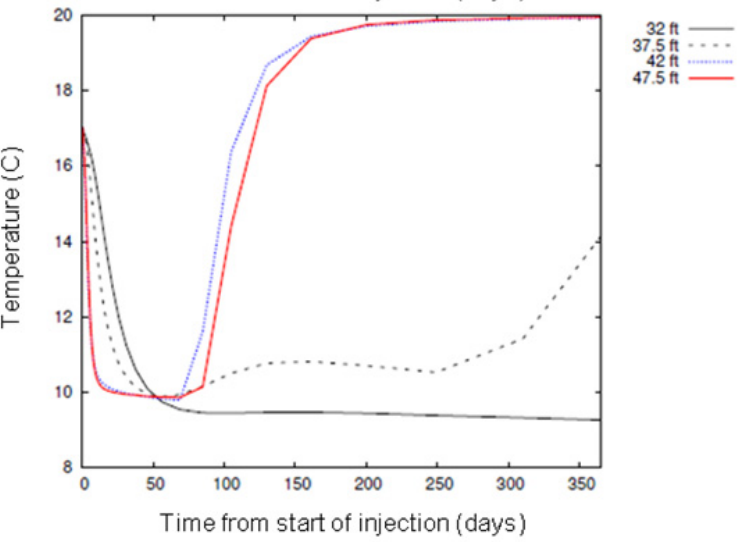

Figure 4.81. Simulated Desiccation Response at Location C7534 for a Layered Model Domain in Terms of a) Volumetric Moisture Content, b) Matric Potential, c) Relative Humidity, and d) Temperature Changes at the Nominal Mid-Depth of the Sensor Intervals for the Field Test $(32,37.5,42$, and $47.5 \mathrm{ft}$ bgs $)$

\subsubsection{Assessment of Desiccation Design Features}

Several elements of the field test design are potentially important for use in a full-scale design for desiccation. The material below summarizes important features related to 1) equipment and monitoring design, and 2) field characterization information.

Equipment and Monitoring Design. The following elements should be considered in the design of the monitoring system for a full-scale application.

- While in situ sensors provided information that was used to interpret desiccation performance during the field test, the only in situ sensors recommended for full-scale are thermistors (temperature sensing) and electrical resistivity electrodes (see Section 4.2.3). Emplacement of these sensors requires an access borehole into which a thermistor cable containing thermistors at a specific interval (e.g., every $0.6 \mathrm{~m}$ ) and an electrical resistivity electrode cable with electrodes at specific intervals (e.g., every $2 \mathrm{~m}$ ). With these cables in the borehole, the borehole should be backfilled with an alternating fill of sand and hydrated bentonite grout such that each individual electrical resistivity electrode is within grout material and there is sand separating each grouted zone from the grout zone above and below. The grout is needed to maintain good electrical contact between the electrode and 
the formation. It should not be continuous, however, so that each electrode acts separately (e.g., is separated by an insulating material [sand]). Thermistors can be within either material.

- Cased wells installed for neutron logging should use the same design as used in the field test.

- The injection well can be designed to enable short term neutron moisture logging characterization of moisture content changes that correlate to injected gas flow. To enable neutron moisture logging, a stilling well can be installed in the injection well that allows access for a small diameter logging probe (see Figure 3.7). The rate of change in moisture at each depth interval during initial injection operations is related to the amount of gas flow within that depth interval.

For full-scale application, key field parameters important to desiccation design and performance evaluation and the associated characterization methodology are listed below. This recommendation assumes an injection-only design.

- Bulk permeability - rough estimate needed with additional quantification through measurements only if permeability may be low enough to cause air injection issues or significantly impact the air injection design.

- Distribution of permeability - estimate based on borehole lithology and vertical neutron probe data may be sufficient with additional information gathered if needed based on the uncertainties in the lateral heterogeneity or nature of permeability contrasts.

- Sediment properties from borehole samples - lithology description, moisture, contaminant, conductivity, and particle size information as a function of depth are needed at minimum to link to field measurements and estimate residual moisture content (used for setting target).

- Initial distribution of moisture and contaminants - sufficient information is needed to target desiccation and select appropriate performance goals (size of desiccated zone and extent of moisture reduction needed).

\subsubsection{Desiccation Field Test Performance}

The field test data can be interpreted with respect to the desiccation performance using the following categories of performance during active desiccation and after active desiccation (rewetting phase).

\subsubsection{Active Desiccation Performance Assessment}

Lateral Extent of Desiccation from Injection Well. Significant desiccation response was observed within the 13.7-16.8 $\mathrm{m}$ bgs (45-55 ft) depth interval out to a lateral extent of about $3 \mathrm{~m}$ from the injection well with a limited desiccation response (desiccation in less than 1-m-thick depth intervals) at 4 to $5.5 \mathrm{~m}$ distance by the end of active desiccation based on sensor and neutron logging data (Section 4.1.2). Specifically, the neutron moisture log data (Section 4.1.2.1) show that the extent of drying depends on the initial moisture content and the distance from the injection well (see also Truex et al. In Press).

Examining the neutron moisture content data over time in the depth interval between 13.7 and $15.2 \mathrm{~m} \mathrm{bgs}$ shows that, at locations C7529 and C7527 within $2 \mathrm{~m}$ of the injection well, the initially dryer zones, correlated to coarser higher permeability zones, dry first. However, with time, the initially wetter zones, correlated to finer-grained, lower permeability zones, are also desiccated. At larger radial distances from the injection well (e.g., locations C7531, C7523, C7525, C7533, and C7537) in this same depth interval, 
moisture content is reduced over time primarily in the initially dryer zones, but by a much smaller extent in the initially wetter zones, especially as radial distance increases. Thus, while the leading edge of desiccation is following preferential flow pathways, the desiccated zone broadens over time and includes initially wetter regions closer to the injection well. This type of pattern of desiccation for adjacent coarseand fine-grained layers has also been observed in laboratory flow cell tests (Oostrom et al. 2009, In Press).

A rough comparison can be made to the expected radial influence calculated based on the amount of dry gas injected. About $1,800,000 \mathrm{~m}^{3}$ of dry nitrogen was injected. This amount of dry gas, at the average temperature during the field test, is sufficient to fully desiccate a cylindrical region with a height of $6.1 \mathrm{~m}$ (screen length) and an initial moisture content of $0.0894 \mathrm{~m}^{3}$-water $/ \mathrm{m}^{3}$-gas (initial average at the test site) to a radius of about $3.4 \mathrm{~m}$.

Volumetric Desiccation Estimate. Quantitative estimates of desiccation volume related to a specific threshold moisture content can be calculated using the neutron moisture logging data and the GPR data (ERT does not provide the necessary moisture content information). Neutron moisture logging data provides the vertical distribution of volumetric moisture content at the logging locations. The volumetric distribution of desiccation can be evaluated based on the volume reduced to below a specified threshold moisture content. Volumes were calculated by first identifying the neutron data locations (corresponding to a depth interval of $7.6 \mathrm{~cm}$ ) along a neutron moisture log vertical profile where the final volumetric moisture content was below the specified threshold. Table 4.5 shows the number of neutron data intervals meeting each specified threshold value. The volume for each threshold location was then computed by multiplying the interval depth by the annular volumes between the monitoring point and the radial extent of the next inner monitoring location (or to the injection well for the innermost monitoring location). Finally, the volumes for each data interval meeting the specified threshold were added to provide the total volume below the specified threshold (Table 4.6). This estimate assumed a radial symmetry for the desiccation zone. Using the same type of calculation procedure for the neutron moisture logging data but with no specified threshold (e.g., all neutron data intervals where final moisture content values were lower than initial moisture content values), moisture content was reduced compared to initial conditions in a volume of $1300 \mathrm{~m}^{3}$. Integrating the neutron data for the portion of the test site out to the radial distance to well C7537, the computed total amount of water removed during desiccation is $18,400 \mathrm{~kg}$. Using a psychometric chart and the average test site temperature during desiccation of $12^{\circ} \mathrm{C}$, the injected gas has a capacity to hold about $10.9 \mathrm{~g}$-water $/ \mathrm{m}^{3}$-gas once it evaporates water and reaches a relative humidity of $100 \%$ at $12^{\circ} \mathrm{C}$. With this water-holding capacity, the amount of water removed during desiccation computed based on the amount of dry gas injected during the test $\left(1.8 \mathrm{E}+6 \mathrm{~m}^{3}\right)$ was $19,600 \mathrm{~kg}$.

Table 4.5. Neutron Moisture Logging Data Showing the Number of 7.6-cm-thick Intervals at or Below the Specified Threshold Volumetric Moisture Content at the End of Active Desiccation

\begin{tabular}{|c|c|c|c|c|c|c|c|}
\hline $\begin{array}{c}\text { Volumetric } \\
\text { Moisture } \\
\text { Content } \\
\text { Threshold } \\
\left(\mathrm{m}^{3} / \mathrm{m}^{3}\right)\end{array}$ & $\begin{array}{c}\mathrm{C} 7529 \\
\mathrm{r}=1.85 \mathrm{~m}\end{array}$ & $\begin{array}{c}\mathrm{C} 7527 \\
\mathrm{r}=2.04 \mathrm{~m}\end{array}$ & $\begin{array}{c}\mathrm{C} 7531 \\
\mathrm{r}=2.62 \mathrm{~m}\end{array}$ & $\begin{array}{c}\mathrm{C} 7525 \\
\mathrm{r}=3.02 \mathrm{~m}\end{array}$ & $\begin{array}{c}\mathrm{C} 7523 \\
\mathrm{r}=3.02 \mathrm{~m}\end{array}$ & $\begin{array}{c}\mathrm{C} 7533 \\
\mathrm{r}=4.18 \mathrm{~m}\end{array}$ & $\begin{array}{c}\mathrm{C} 7537 \\
\mathrm{r}=5.34 \mathrm{~m}\end{array}$ \\
\hline 0.01 & 41 & 33 & 22 & 18 & 15 & 3 & 0 \\
\hline 0.02 & 48 & 38 & 30 & 24 & 24 & 7 & 0 \\
\hline 0.03 & 56 & 44 & 35 & 33 & 30 & 16 & 0 \\
\hline 0.04 & 89 & 54 & 62 & 56 & 62 & 40 & 11 \\
\hline
\end{tabular}


Table 4.6. Computed Volume of Soil Desiccated to at or Below the Specified Threshold Volumetric Moisture Content at the End of Active Desiccation Using the Data from Table 4.5, an Assumption of Radial Symmetry, and the Specified Radial Distances to Each Monitoring Location. Note that because locations $\mathrm{C} 7523$ and C7525 were at essentially the same radial distance, only the data from location C7523 was used in the calculation.

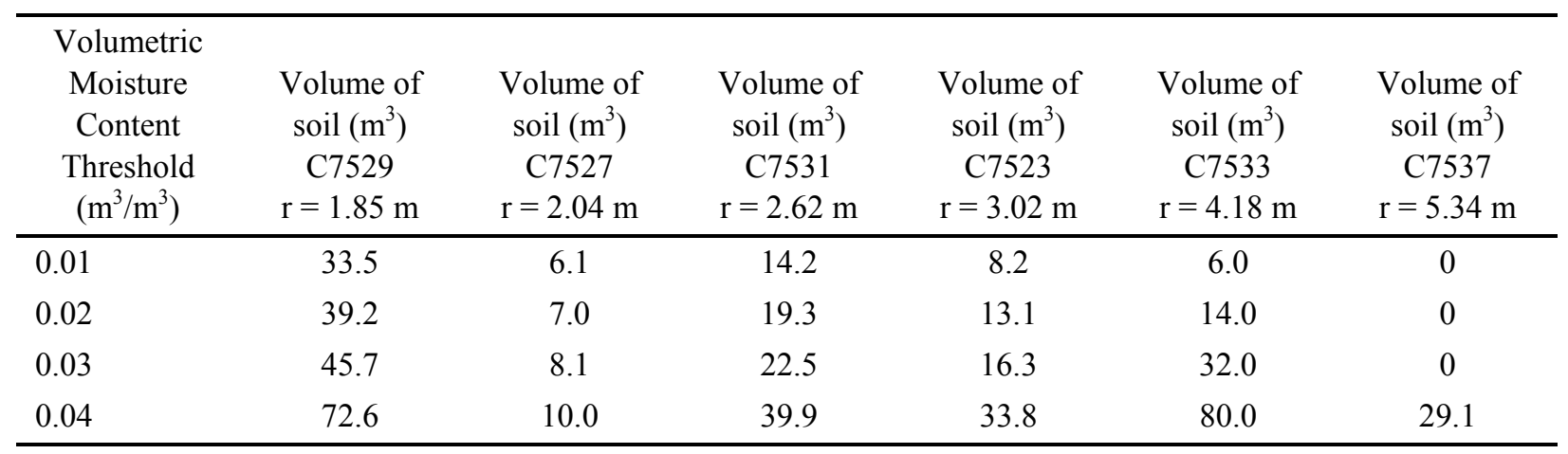

Cross-hole GPR data were collected between the injection well and surrounding logging wells C7523, C7525, C7527, C7529, and C7531 and processed to produce a 2D image of the estimated volumetric moisture content within the plane between the well pairs. For each well pair and at every depth the maximum distance from the injection well with volumetric water content less than a threshold of $0.01 \mathrm{~m}^{3} / \mathrm{m}^{3}$ cutoff was identified. A cylindrically symmetric volume was then calculated from the average distance at each depth from the well pair data. The GPR-based estimate of desiccation volume for desiccation to a volumetric moisture content equal to or less than $0.01 \mathrm{~m}^{3} / \mathrm{m}^{3}$ was $52 \mathrm{~m}^{3}$. For comparison, the data from neutron moisture logging for the portion of the test site out to the radial distance to well C7531 was used to compute a desiccation volume of $62 \mathrm{~m}^{3}$ at the same threshold.

Vertical Distribution of Desiccation. Significant variation in desiccation was observed across the vertical profile of the test site. This variation correlated to the initial moisture content, sediment texture, and amount of dry gas flow through a given vertical zone. The variation is evident in the neutron moisture logging profiles where initially wetter zones (finer materials) dried more slowly. Some of the thinner initially wet zones in the $13.7-16.8 \mathrm{~m}$ bgs (45-55 ft) depth interval dried over time, however, because of the high flow of dry gas adjacent to these zones (see neutron log for C7529, located about $1.8 \mathrm{~m}$ from the injection well). ERT, neutron, and GPR data depict some desiccation vertically above and below the injection well screen interval, likely the result of gas flow spreading in the relatively permeable zones above and below the screened interval.

Desiccation Moisture Endpoint. In zones that were fully desiccated, neutron moisture logging and post-desiccation core analysis show that the volumetric moisture content was reduced to less than $0.01 \mathrm{~m}^{3} / \mathrm{m}^{3}$. Sensors in highly desiccated zones showed matric potential values less than -10 bar. These field measurements are consistent with the extremely dry post-desiccation conditions observed in laboratory tests (Truex et al. 2011; Oostrom et al. 2009, In Press).

Desiccation Rate. The desiccation rate is directly proportional to the rate at which dry gas is injected and the carrying capacity of that gas for water. For the field test, the injection flow rate was maintained at nominally $300 \mathrm{scfm}$ with a relative humidity of zero. Using a psychometric chart and the approximate initial subsurface temperature of $17^{\circ} \mathrm{C}$, the injected gas has a capacity to hold about $14.6 \mathrm{~g}$-water $/ \mathrm{m}^{3}$-gas 
once it evaporates water and reaches a relative humidity of $100 \%$ at $17^{\circ} \mathrm{C}$. Based on this information, the nominal desiccation rate at the field test site would be about $180 \mathrm{~L} / \mathrm{d}$ (water was transferred from the water phase to the gas phase). However, due to evaporative cooling, the average temperature within the field test site desiccation zone was about $12^{\circ} \mathrm{C}$. At the lower temperature, injected gas has a capacity to hold about $10.9 \mathrm{~g}$-water $/ \mathrm{m}^{3}$-gas and a corresponding desiccation rate would be about $130 \mathrm{~L} / \mathrm{d}$. The remainder of the overall capacity $(50 \mathrm{~L} / \mathrm{d})$ would evaporate water from portions of the subsurface further away from the primary desiccation zone as the overall subsurface temperatures warmed toward $17^{\circ} \mathrm{C}$. Maintaining higher and more uniform temperature would make the desiccation front more abrupt (e.g., keep more of the capacity within a target zone). When temperature drops at the desiccation zone, the holding capacity of the air decreases. As the gas moves outward to other areas, temperature increases and the gas picks up additional water. Thus, the transfer of water to gas phase occurs over distance. Keeping the temperature more constant minimizes the "spreading" of the desiccation process over distance.

In controlled laboratory experiments, injection of dry gas into moist homogeneous porous media causes drying to occur with a very sharp transition between the dried porous media (toward the injection location) and the moist porous media. In these conditions, the volume of dried sediment can be calculated using the approach presented above. Factors that make the transition between dried and moist zones occur over a larger distance include evaporative cooling effects (causing a lower water-holding capacity of the gas), and heterogeneity in gas flow (caused by heterogeneity in permeability and moisture content distribution). In the field, both of these conditions were present, and a simple volume calculation to estimate the fully desiccated zone is not directly applicable.

Impact of Evaporative Cooling. Significant evaporative cooling occurs during desiccation as observed both in laboratory tests and the field test. As discussed above, the evaporative cooling can impact the overall desiccation rate within the portion of the vadose zone where temperatures are lowered and tends to spread the desiccation process over distance. For scale-up, evaporative cooling must be considered in terms of the potential to condense water in the subsurface depending on the injected gas temperature and relative humidity and the subsurface temperature. This effect is discussed in Section 4.2.4. While evaporative cooling will always occur with desiccation, its impact can be evaluated and included in the desiccation design.

Operational Performance. System operations were very stable over time with the field test system. For a full-scale system, extraction of soil gas is not recommended, thus simplifying the system further. Injection of ambient air rather than dry nitrogen is recommended for full scale. Thus, operational reliability will be related to the reliability of the blower and air heater components. These are standardized equipment where reliability is expected to be high.

\subsubsection{Post-Desiccation (Rewetting) Performance Assessment}

Desiccation is intended to help meet remediation goals by slowing the movement of contaminated moisture through the vadose zone and thereby reducing the flux of contaminants into the groundwater. The rate at which moisture returns to the desiccated zone, here termed the rewetting rate, is important in the overall long-term performance of desiccation as part of a remedy. Rewetting phenomena and rates have been studied through laboratory and modeling efforts. Data are also being collected at the field test site after active desiccation was terminated. The sections below summarize the information and data available to date. 


\subsection{Laboratory Evaluation of Rewetting}

Laboratory data quantifying the rewetting process was collected and reported in Truex et al. (2011). Key conclusions were that vapor-phase rewetting can occur but rewets the desiccated zone only to a small extent, essentially to a level below the residual moisture content. Rewetting by aqueous transport occurs consistent with standard hydraulic phenomena such that desiccating to very low moisture content and creating very low aqueous phase hydraulic conductivity conditions leads to very low rates of aqueous transport rewetting.

\subsection{Modeling Analysis of Rewetting}

Modeling analyses have been initiated to examine rewetting phenomena as a function of key controlling porous media properties. This information provides a quantitative description of rewetting using example gravel, sand, and silt porous media with well-characterized properties (Carsel and Parrish, 1988; Tokunaga et al. 2002). A sand-gravel system is used for the majority of the investigation to illustrate the type of rewetting responses and the relative rate of rewetting for different conditions. The sand-gravel system responds relatively quickly due to the high permeability of these porous media. Lower permeability porous media systems would respond slower, but have the same character of response, as is discussed through sensitivity analyses below.

After desiccation, rewetting of dried-out zones can potentially take place through two major processes: 1) advection as a result of pressure head gradients in the aqueous phase, and 2) vapor transport as a result of water vapor concentration gradients in the gaseous phase. A series of one-dimensional (1-D) simulations was conducted using three relatively simple configurations to demonstrate the relative magnitude of the two processes and to investigate the effects of hydraulic properties on rewetting through water advection. The three considered configurations are shown in Figure 4.82. Although the simulation configurations are hypothetical, they can be used to demonstrate rewetting phenomena of a relatively thin desiccated layer (Configuration I), a more extensive desiccated layer (Configuration II), and a series of desiccated higher permeability layers, separated by unaffected lower permeability layers (Configuration III). In Configuration I, a 1-m-gravel layer is located in sand. In Configuration II, the gravel layer is 5-m-thick. A total of three 1-m-thick gravel layers, separated by $0.5 \mathrm{~m}$ sand layers, are considered in Configuration III.

All configurations comprise a $30 \mathrm{~m}$ unsaturated zone, from $z=0 \mathrm{~m}$ at the surface to a depth of $30 \mathrm{~m}$ $(z=30 \mathrm{~m})$. The simulations were conducted with the water-air-energy (WAE) mode of the STOMP simulator (White and Oostrom 2006). A listing of the simulations is provided in Table 4.7. The hydraulic properties of the porous media, obtained from Carsel and Parrish (1988) and Tokunaga et al. (2002), are shown in Table 4.8. In the simulations, the Webb (2000) extension is used to allow desiccation of the porous media below the reported residual water saturation. The Webb (2000) extension has been used to simulate desiccation and rewetting in the laboratory experiments described by Truex et al. (2011) and Oostrom et al. (2012, In Press). At the top and bottom of the domain, a zero water flux was imposed. At the top and bottom of the domain, gas pressures of 101,325 and 101,676.3 Pa were used, respectively, to approach a condition without advective gas movement in the porous media by keeping the gas pressure gradient at $11.71 \mathrm{~Pa} / \mathrm{m}$. The temperature of the subsurface was kept at $17^{\circ} \mathrm{C}$. 
The desiccated gravel layers were created by imposing a perturbed moisture content of $0.0044 \mathrm{~m}^{3} / \mathrm{m}^{3}$, which is approximately $10 \%$ of the equilibrium moisture content for simulations using the Base Case hydraulic properties. The perturbed moisture content is in the range where water vapor pressure lowering occurs, resulting in a relative humidity of $\sim 0.4$ and water vapor diffusion from the sand into the gravel layers.

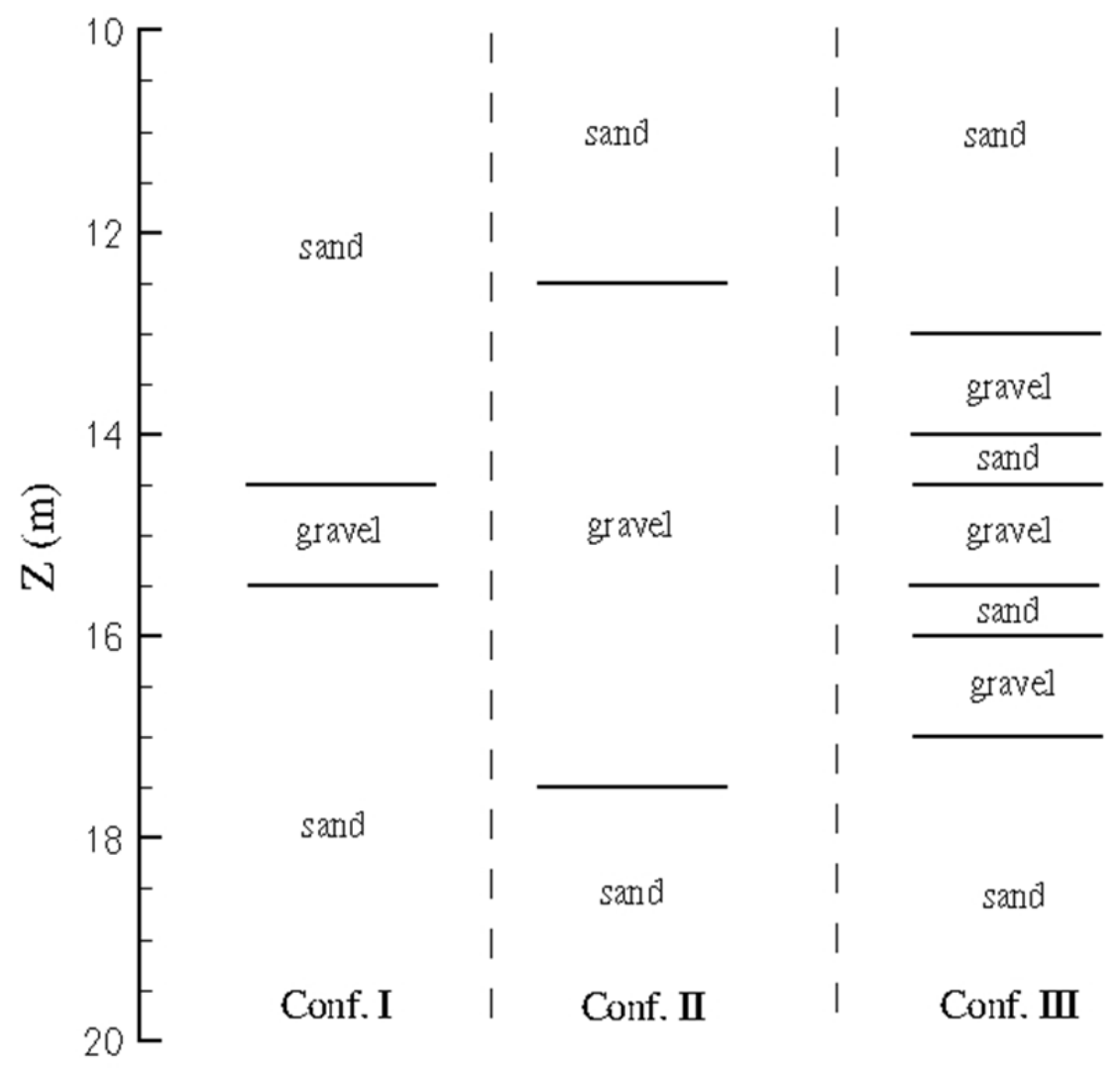

Figure 4.82. Overview of the Three Considered Configurations. The total computational domain for each of the configurations extends from $z=0 \mathrm{~m}$ to $z=30 \mathrm{~m}$, with sand from $z=0 \mathrm{~m}$ to $10 \mathrm{~m}$ and from $z=20 \mathrm{~m}$ to $z=30 \mathrm{~m}$. 
Table 4.7. Overview of the Rewetting Simulations. The three considered configurations are shown in Figure 4.82. The Base Case hydraulic properties are listed in Table 4.8. The imposed change with respect to the Base Case is indicated in the 'Modification' column.

\begin{tabular}{lll}
\hline \multicolumn{1}{c}{ Simulation } & Configuration & \multicolumn{1}{c}{ Modification } \\
\hline I-1 (Base Case) & I & - \\
I-2 & I & Vapor diffusion only \\
I-3 & I & Desiccated gravel layer after 1 year of rewetting of Base Case (I-1) \\
I-4 & I & Gravel $K_{\text {sat }} \times 10$ \\
I-5 & I & Gravel $K_{\text {sat }} / 10$ \\
I-6 & I & Sand $K_{\text {sat }} \times 10$ \\
I-7 & I & Sand $K_{\text {sat }} / 10$ \\
I-8 & I & Gravel van Genuchten $\alpha=0.5 \mathrm{~cm}^{-1}$ \\
I-9 & I & Gravel van Genuchten $\alpha=0.35 \mathrm{~cm}^{-1}$ \\
I-10 & I & Gravel van Genuchten $n=1.5$ \\
I-11 & I & Gravel van Genuchten $n=3.0$ \\
I-12 & I & 1 -m-thick sand layer in otherwise silt subsurface \\
II-1 (Base Case) & II & - \\
II-2 & II & Vapor diffusion only \\
II-3 & II & Desiccated gravel layer after 1 year of rewetting of Base Case (II-1) \\
II-4 & II & Gravel $K_{\text {sat }} \times 10$ \\
III-1 (Base Case) & III & - \\
III-2 & III & Vapor diffusion only \\
III-3a & III & Desiccated gravel layers after 1 year of rewetting of Base Case (III-1) \\
III-3b & III & Desiccated gravel layers after 1 year of rewetting of Case III-3a \\
III-4 & III & Gravel $K_{\text {sat }} \times 10$ \\
\hline
\end{tabular}

Table 4.8. Hydraulic Properties of Porous Media (after Carsel and Parrish 1988; Tokunaga et al. 2002)

\begin{tabular}{lccc}
\hline \multicolumn{1}{c}{ Property } & Sand & Gravel & Silt \\
\hline $\begin{array}{l}\text { Hydraulic conductivity } \\
(\mathrm{cm} / \mathrm{hr})\end{array}$ & 29.7 & $297^{(\mathrm{a})}$ & 0.25 \\
Van Genuchten $\alpha(1 / \mathrm{cm})$ & 0.145 & 0.20 & 0.016 \\
Van Genuchten pore & 2.68 & 2.13 & 1.37 \\
geometry factor, $n$ & & & \\
Porosity & 0.43 & 0.33 & 0.46 \\
Residual water saturation & 0.045 & 0.028 & 0.034 \\
\hline
\end{tabular}

(a) Data not provided by Tokunaga et al. (2002). The gravel hydraulic conductivity was assumed to be $10 \times$ of the sand hydraulic conductivity.

\section{Configuration I}

In Configuration I, rewetting of a 1-m-thick desiccated gravel layers is considered. The initial conditions after desiccation denote a moisture content of $0.093 \mathrm{~m}^{3} / \mathrm{m}^{3}$ and $0.0044 \mathrm{~m}^{3} / \mathrm{m}^{3}$ in the sand and gravel, respectively. The rewetting process, shown in Figure 4.83 , demonstrates an attempt of the system 
to ultimately return to the equilibrium conditions, indicated by the black line in the figure. During the initial rewetting stages, the moisture content in the sand directly adjacent to the gravel layer decreases to approximately $0.07 \mathrm{~m}^{3} / \mathrm{m}^{3}$ as water is pulled into the gravel. During that time, the moisture content in the upper and lower part of the gravel layer increases to $0.035 \mathrm{~m}^{3} / \mathrm{m}^{3}$. These moisture contents near the sandgravel interface remain approximately constant until the moisture content throughout the gravel layer are approximately the same as indicated by the yellow line. At that point in time ( $\sim 2$ years), the moisture contents both in the gravel layer and in the sand adjacent to this layer start to increase again, ultimately approaching the initial equilibrium conditions.

Figure 4.84 shows moisture contents over time for Case I-2 where only water vapor diffusion into the gravel layer is considered by imposing a zero water relative permeability. The moisture content changes from this process are relatively small. Even after 1,000 years of rewetting through vapor diffusion, the moisture contents in the gravel layer have only increased to $0.15 \mathrm{~m}^{3} / \mathrm{m}^{3}$.

For Case I-3, the initial conditions reflect desiccation of the gravel layer after a rewetting period of 1 year following a previous desiccation of the gravel layer. These initial conditions are shown by the dashed red line in Figure 4.85. This case is an example of operations where multiple desiccation periods are used following rewetting episodes. For this particular example, the rewetting of the gravel during the first few years is less than for the Base Case (Figure 4.82). Over a 10-year rewetting period, however, the moisture contents in the gravel layer are similar to what was observed for the Base Case.

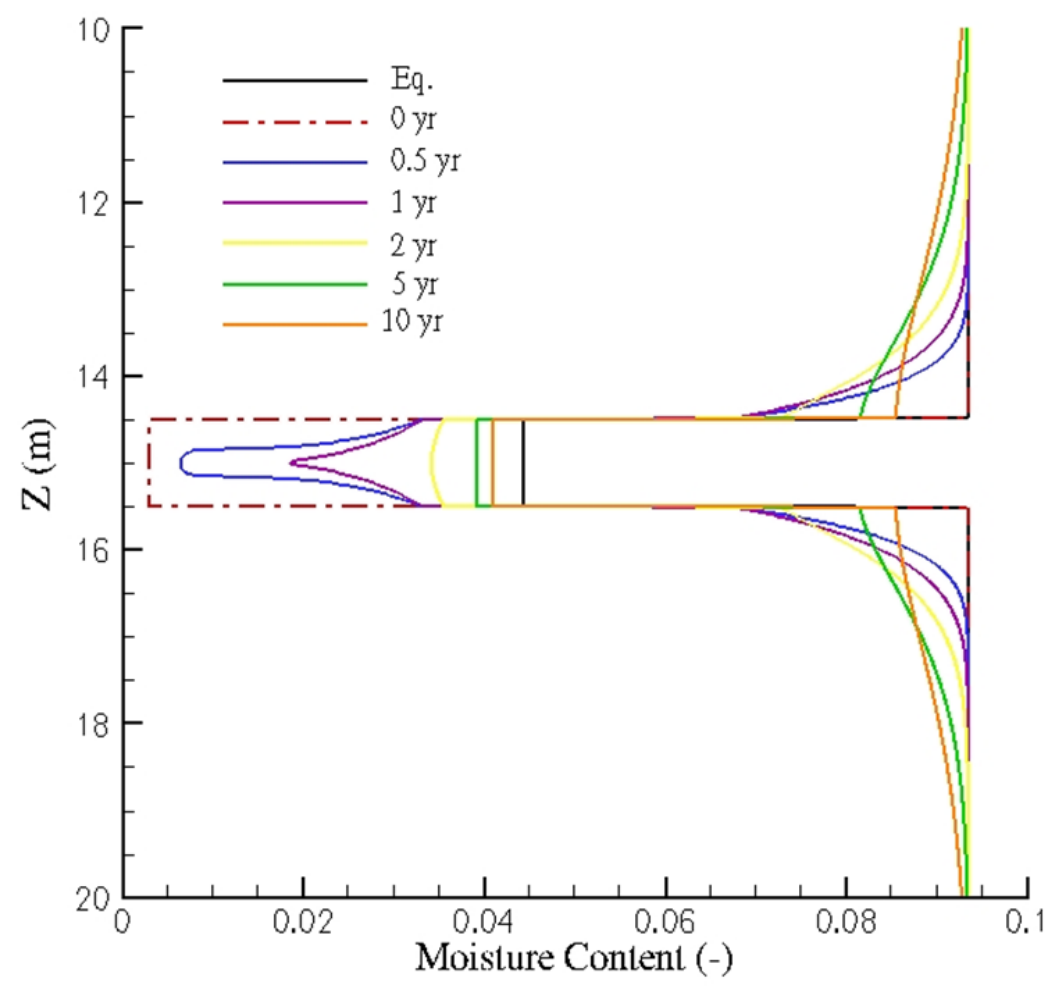

Figure 4.83. Moisture Contents at Various Times during Rewetting for Case I-1 (Base Case). The black line indicates the water content at equilibrium. 


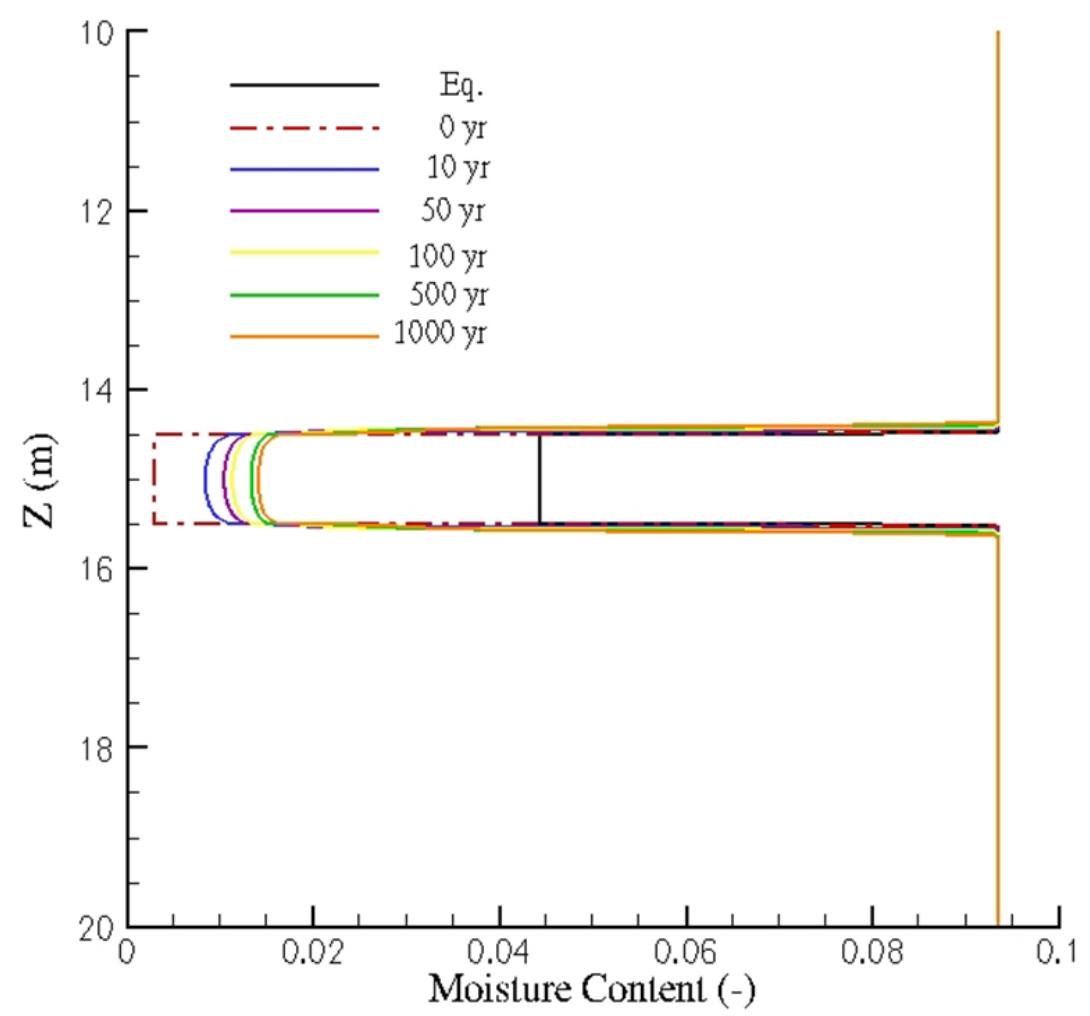

Figure 4.84. Moisture Contents at Various Times during Rewetting for Case I-2 (Vapor diffusion only)

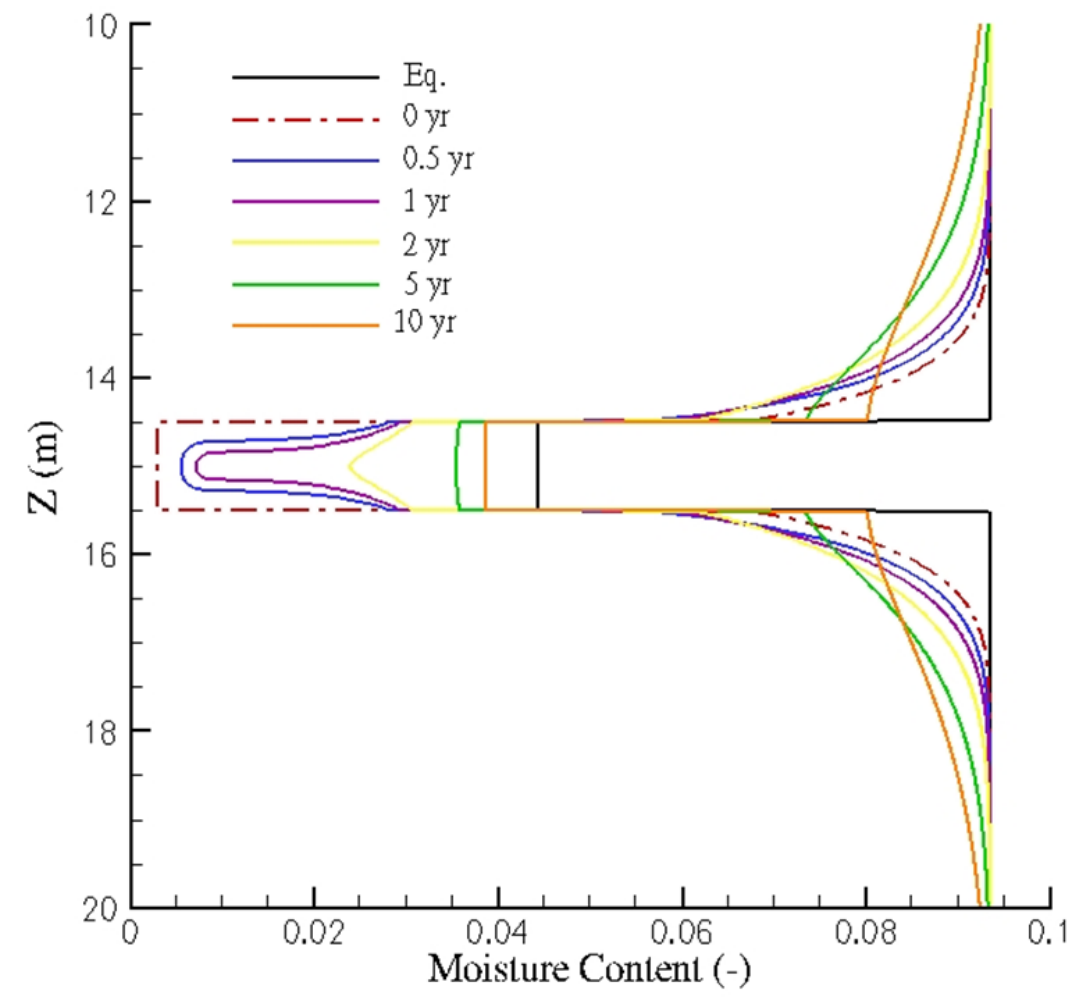

Figure 4.85. Moisture Contents at Various Times during Rewetting for Case I-3 (Desiccated gravel layer after 1 year of rewetting of Base Case) 
The effects of the saturated hydraulic conductivity $\left(K_{\text {sat }}\right)$ of the gravel layer on rewetting are shown in Figures 4.86 and 4.87. Because no representative $K_{\text {sat }}$ of the gravel was provided by Tokunaga et al. (2002), an estimate of $297 \mathrm{~cm} / \mathrm{hr}$, which is 10 times the value for sand, was used for the Base Case simulation. To investigate a wider range of potential values, a $K_{\text {sat }}$ increase and a decrease by a factor of 10 was considered in Case I-4 (Figure 4.86) and Case I-5 (Figure 4.87), respectively. Figure 4.86 shows a much faster initial wetting of the gravel, accompanied by lower moisture contents in the adjacent sand. The moisture content distribution after 10 years of rewetting was again close to what was observed for the base case. A reduction in the gravel $K_{\text {sat }}$ slowed down the rewetting of the gravel for the first years (Figure 4.87) compared to the Base Case. During that stage, the flow rate into the gravel was lower, and the moisture content in the adjacent sand did not decrease as much. However, a rewetting period of 10 years was again sufficient to generate similar moisture content conditions as for the Base Case.

As for Case I-4, fast rewetting was also obtained when the sand $K_{\text {sat }}$ was increased by a factor of 10 (Case I-6). Figure 4.88 shows that after only 1 year of rewetting, moisture contents in the gravel were larger than $0.04 \mathrm{~m}^{3} / \mathrm{m}^{3}$. After a rewetting period of 10 years, near equilibrium conditions were obtained. A reduction of the sand $K_{\text {sat }}$ (Case I-7) resulted in much slower rewetting (Figure 4.89). Under these conditions, it is much harder to deliver water from the sand to the gravel, as indicated by the considerable moisture content gradients near the sand-gravel interfaces.

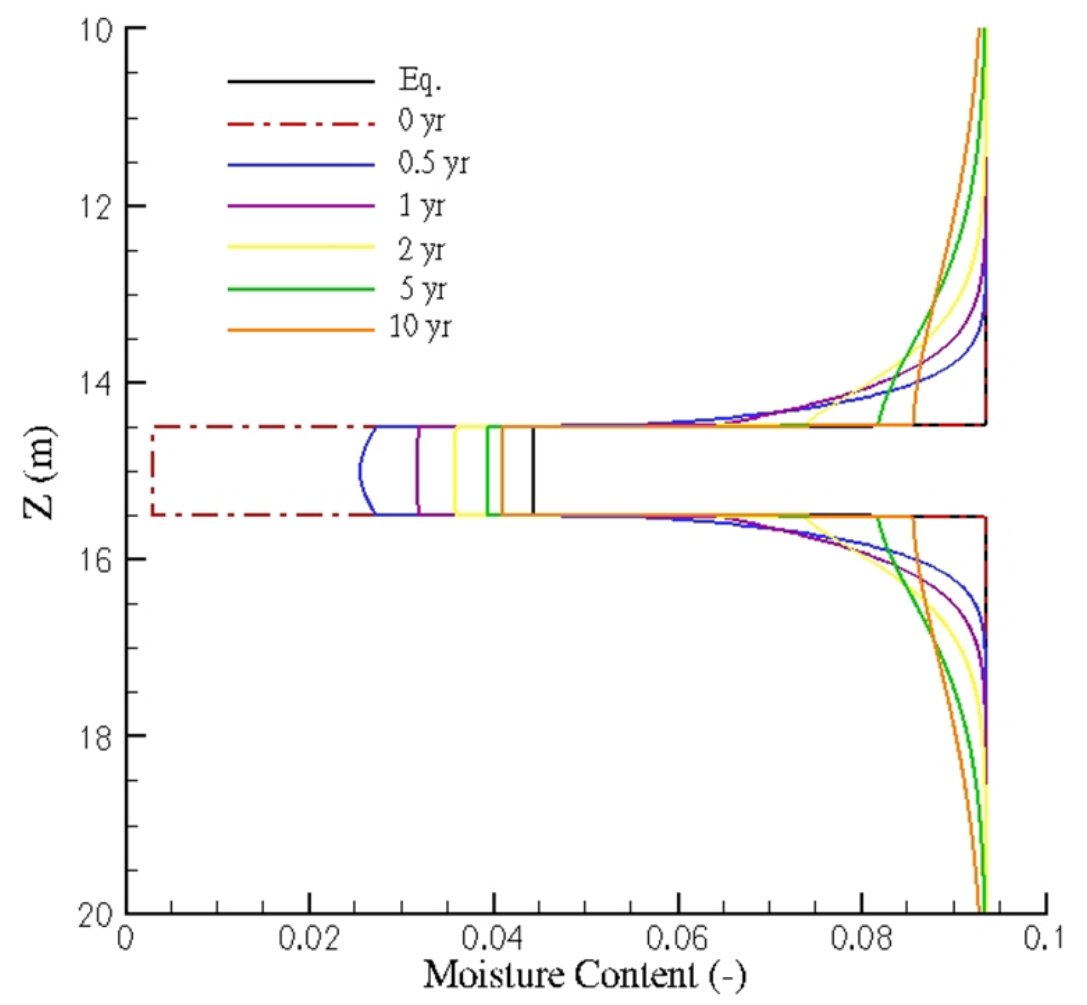

Figure 4.86. Moisture Contents at Various Times during Rewetting for Case I-4 (Gravel $\left.K_{s a t} \times 10\right)$ 


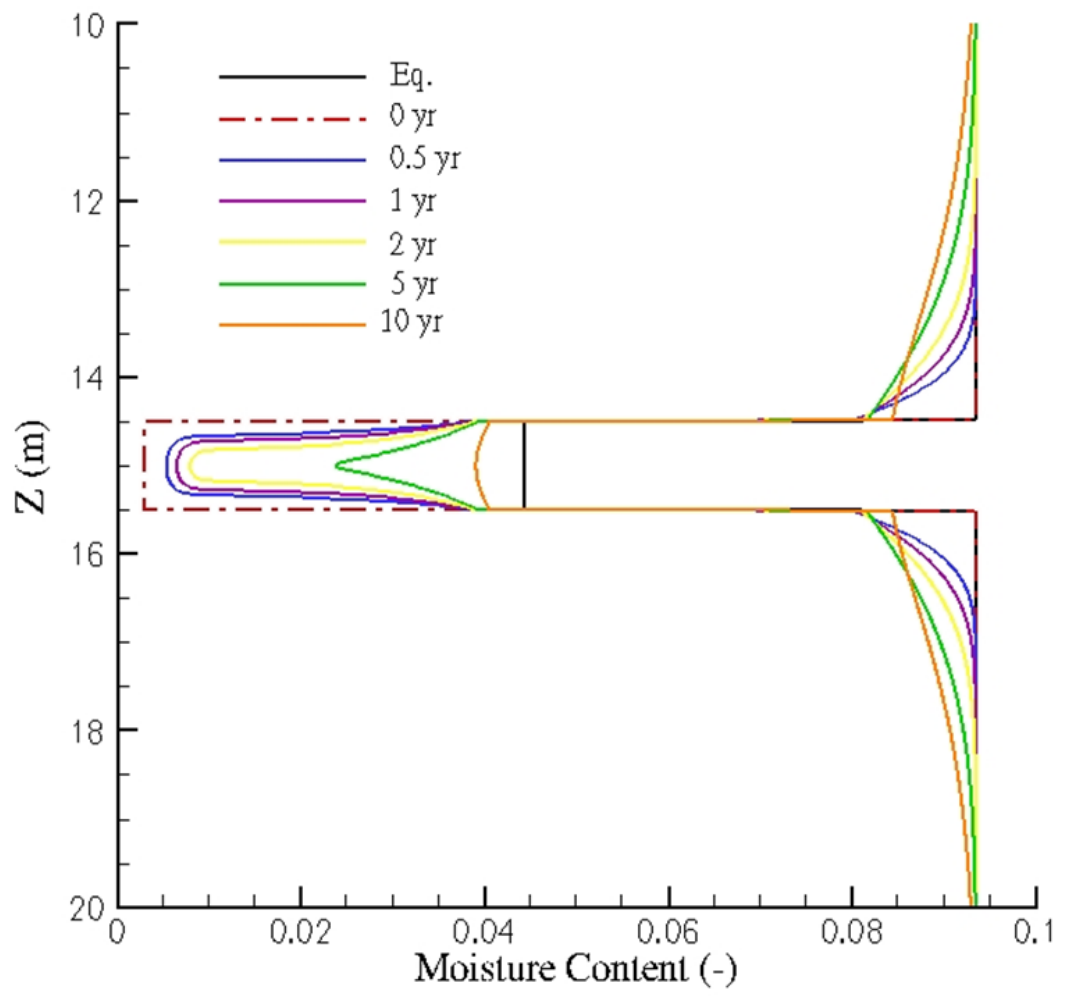

Figure 4.87. Moisture Contents at Various Times during Rewetting for Case I-5 (Gravel $K_{\text {sat }} / 10$ )

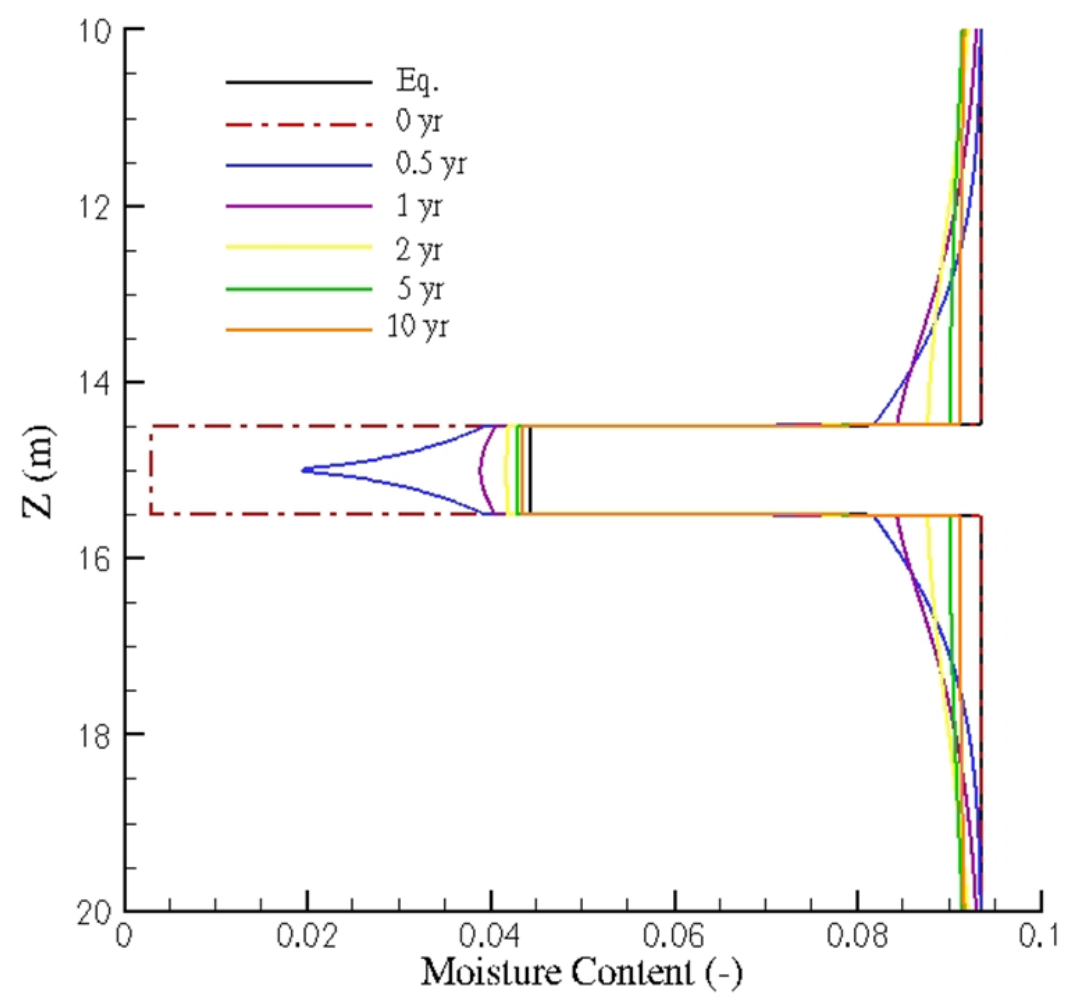

Figure 4.88. Moisture Contents at Various Times during rewetting for Case I-6 (Sand $K_{s a t} \times 10$ ) 


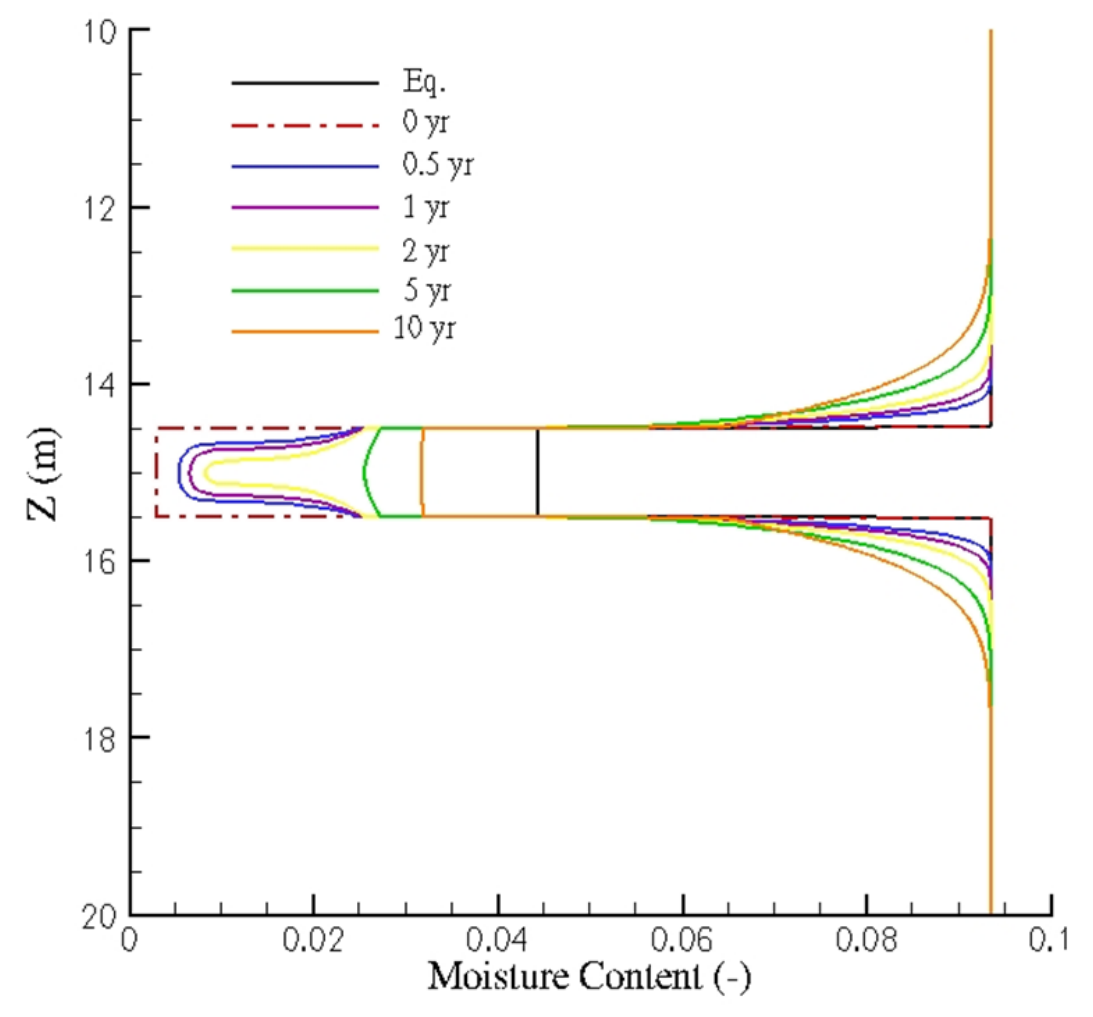

Figure 4.89. Moisture Contents at Various Times during Rewetting for Case I-7 (Sand $K_{\text {sat }} / 10$ )

Van Genuchten $\alpha$ values of 0.5 and $0.35 \mathrm{~cm}^{-1}$ were used in Case I-8 (Figure 4-90) and Case I-9 (Figure 4.91), respectively. The increases in these values, compared to the Base Case, have the overall effect of shifting the capillary pressure - saturation relationship towards the left. In other words, for the same capillary pressure, the moisture content decreases with an increasing $\alpha$ value. The effect of changes in this value exhibits itself in Figures 4.90 and 4.91 by the lower equilibrium values and by the rewetting behavior. In Figure 4.90 with the lowest equilibrium moisture content, rewetting is relatively slow due to the low relative permeability values in the gravel for moisture contents smaller than $0.02 \mathrm{~m}^{3} / \mathrm{m}^{3}$. The water fluxes into the gravel are small and the moisture content reduction during rewetting in the adjacent sand is less than $0.005 \mathrm{~m}^{3} / \mathrm{m}^{3}$. For the intermediate $\alpha$ value in Figure 4.91, the rewetting rate is in between what was observed for the Base Case (Figure 4.83) and Case I-8 (Figure 4.90).

The results of changing the van Genuchten $n$ value to 1.5 (Case I-10) and 3.0 (Case I-11) are shown in Figure 4.92 and 4.93, respectively. An increase in $n$ indicates a more homogeneous pore size distribution and results in a shift to the left for capillary pressure - water content relations. For the same capillary pressure, the moisture content decreases with an increasing $n$ value. As a result, for the lower $n$ value of 1.5 the equilibrium moisture content is relatively high $\left(\sim 0.09 \mathrm{~m}^{3} / \mathrm{m}^{3}\right)$, as shown in Figure 4.92 . For the case with the higher $n$ value, the equilibrium moisture content is reduced to $\sim 0.02 \mathrm{~m}^{3} / \mathrm{m}^{3}$. The large difference in equilibrium moisture contents have a considerable effect on how the gravel layers rewet. For the low $n$ case, rewetting is rapid due to the larger associated water relative permeability value (Figure 4.93). For the high $n$ case, rewetting is much slower because it occurs only at relatively low moisture contents and associated lower water relative permeabilities (Figure 4.93). 


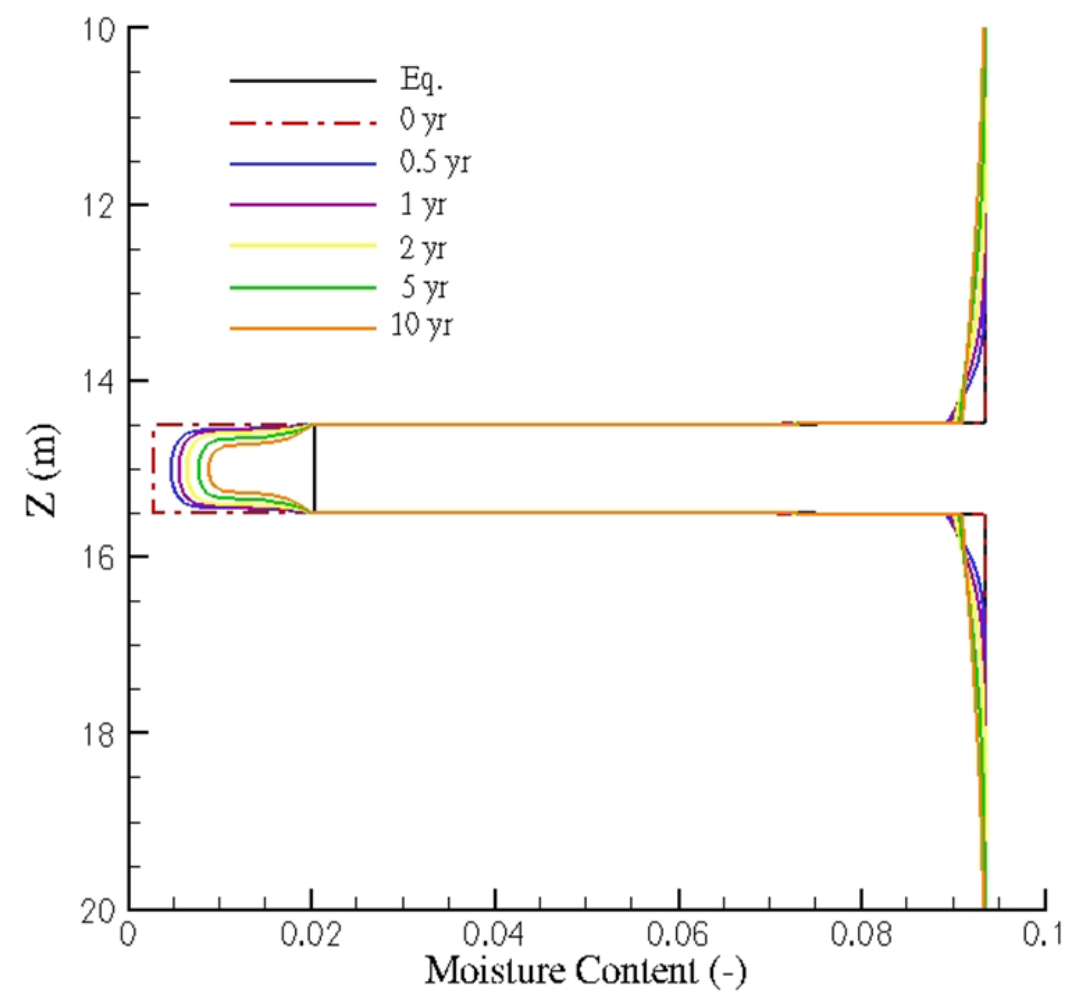

Figure 4.90. Moisture Contents at Various Times during Rewetting for Case I-8 (Gravel van Genuchten $\left.\alpha=0.5 \mathrm{~cm}^{-1}\right)$

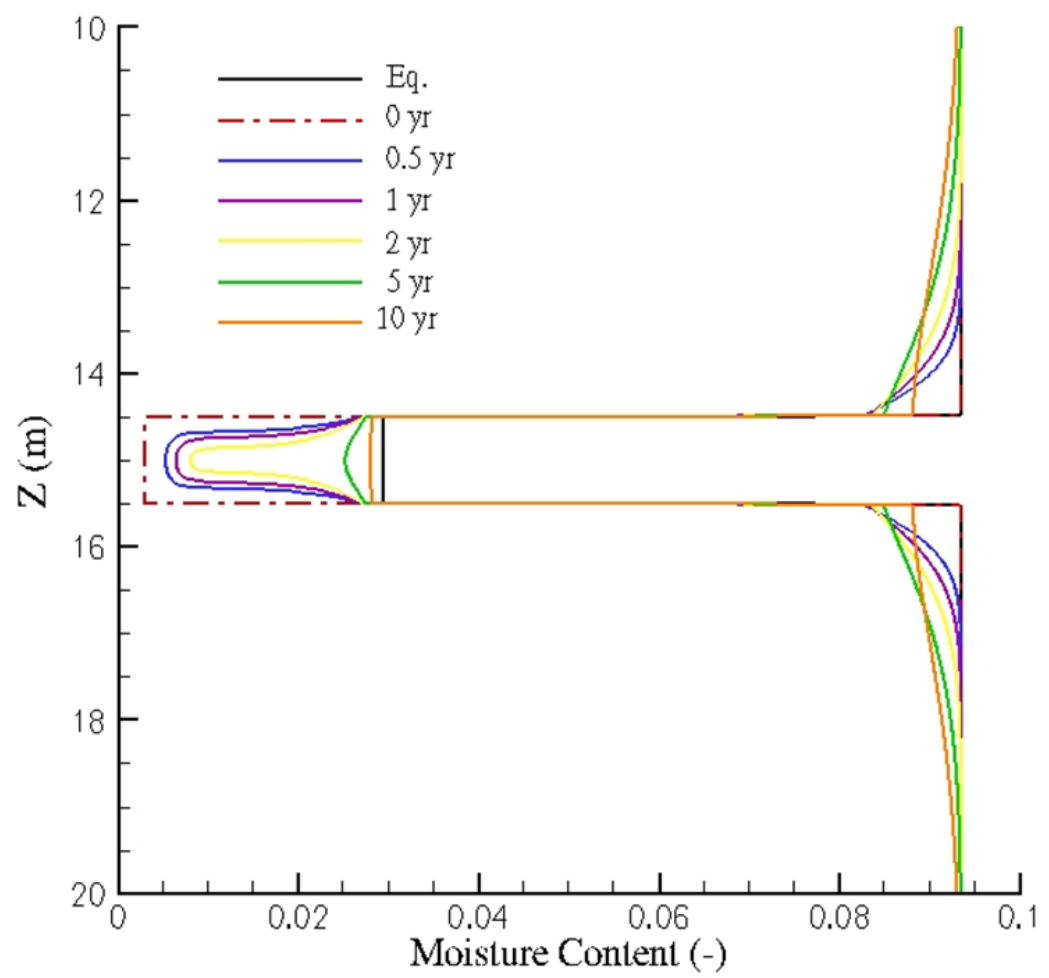

Figure 4.91. Moisture Contents at Various Times during Rewetting for Case I-9 (Gravel van Genuchten $\alpha=0.35 \mathrm{~cm}^{-1}$ ) 


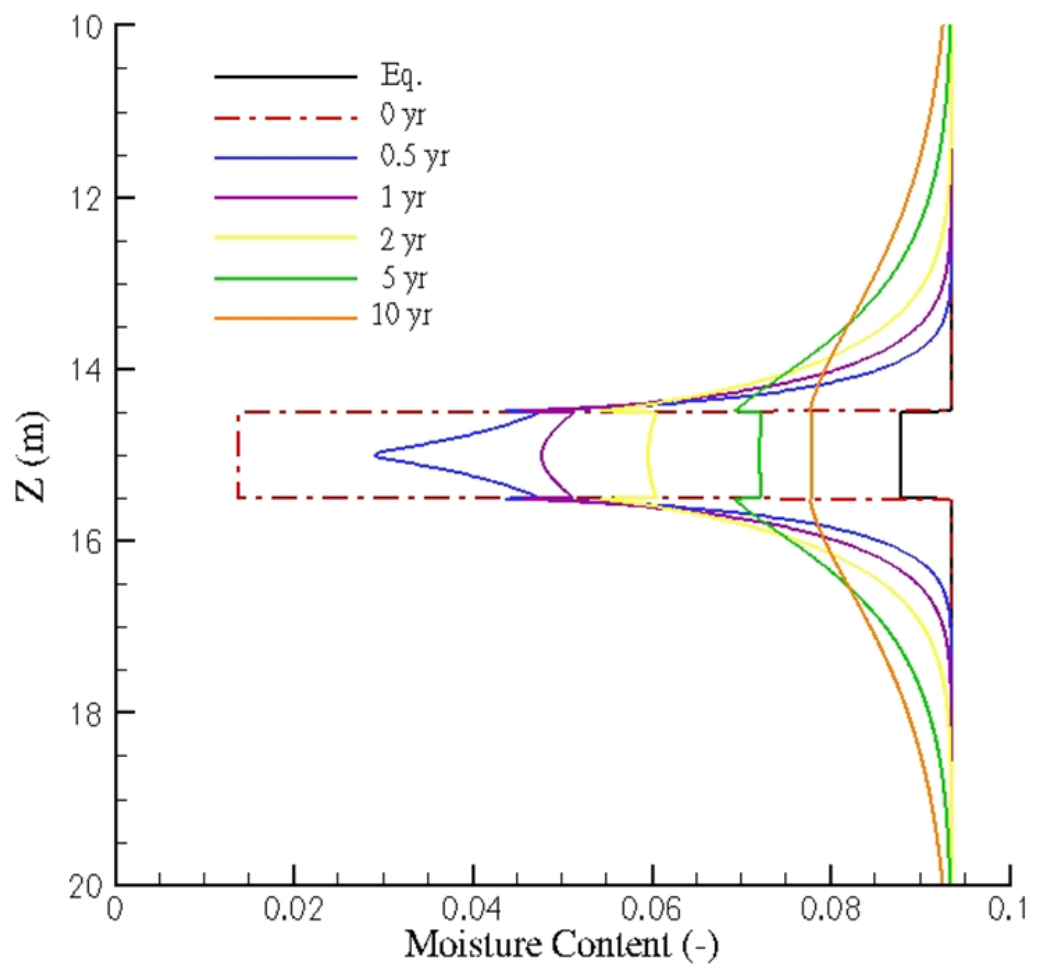

Figure 4.92. Moisture Contents at Various Times during Rewetting for Case I-10 (Gravel van Genuchten $n=1.5$ )

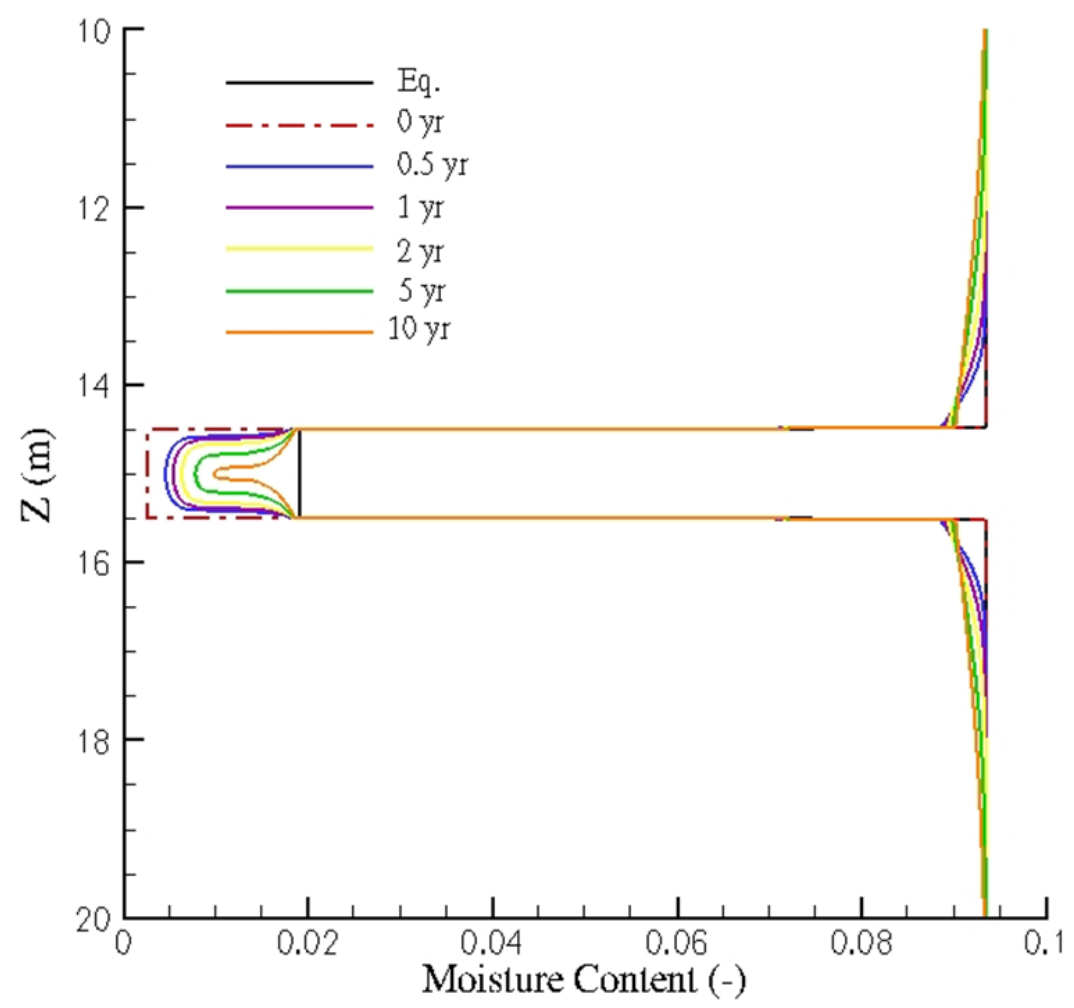

Figure 4.93. Moisture Contents at Various Times during Rewetting for Case I-11 (Gravel van Genuchten $n=3$ ) 
A simulation was conducted using the same configuration to evaluate rewetting of a 1-m-thick sand layer located in a silt subsurface (Case I-12). Primarily due to the hydraulic properties of the silt (Table 4.8), rewetting of a sand layer surrounded by silt would be several orders of magnitude slower than rewetting of a gravel layer with water migrating from adjacent sand. After 100 years of rewetting, the sand layer moisture content would only have increased to approximately $0.02 \mathrm{~m}^{3} / \mathrm{m}^{3}$. This rewetting through advective water movement is approximately one order of magnitude faster than rewetting through water vapor diffusion only. The differences between Figure 4.94 for the sand layer in silt and Figure 4.83 for the gravel layer in sand clearly demonstrate the importance of hydraulic properties contrast between adjacent porous media on rewetting.

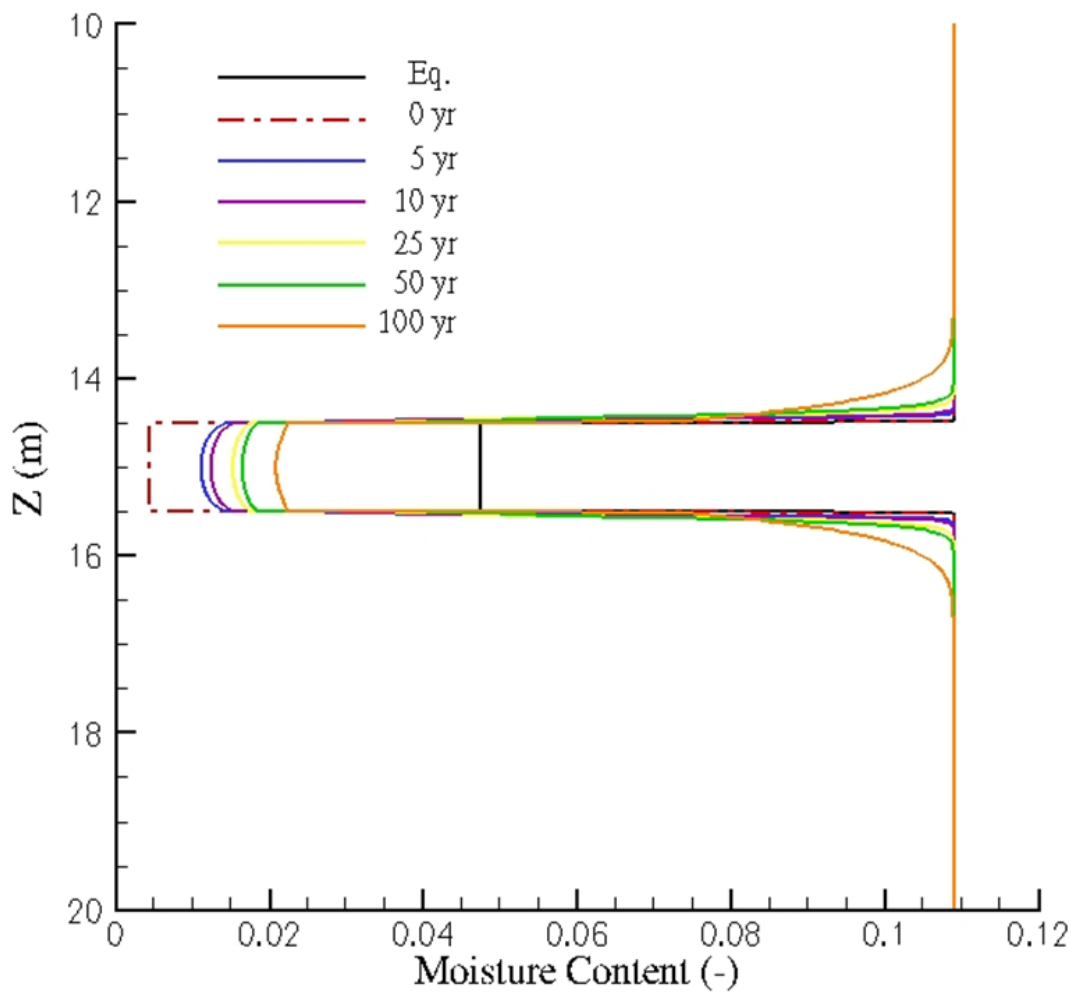

Figure 4.94. Moisture Contents at Various Times during Rewetting for Case I-12 (1-m-thick sand layer in otherwise silt subsurface)

\section{Configuration II}

In Configuration II, the rewetting of a 5-m-thick desiccated gravel layer is considered. The initial conditions after desiccation are similar for Configuration I with a moisture content of $0.093 \mathrm{~m}^{3} / \mathrm{m}^{3}$ in the sand and $0.0044 \mathrm{~m}^{3} / \mathrm{m}^{3}$ in the gravel. The rewetting process for the Base Case properties (Case II-1) again shows an attempt to return to the equilibrium conditions, which are indicated by the black line in Figure 4.95. During the initial phases of rewetting, the moisture content in the upper and lower part of the gravel layer increase to $0.035 \mathrm{~m}^{3} / \mathrm{m}^{3}$ and the moisture content in the sand direct adjacent to the gravel decreases to approximately $0.07 \mathrm{~m}^{3} / \mathrm{m}^{3}$. These values are similar to what was observed for the $1-\mathrm{m}$-thick gravel case. These moisture contents near the sand-gravel interface remain approximately constant for the first 10 years of rewetting as the central 2 meters in the gravel have not been affected by rewetting at that time. 
Figure 4.96 shows moisture contents over time for Case II-2 where only water vapor diffusion into the thick gravel layer is considered. As was observed for Configuration I, the moisture content changes from this process are relatively small. After 1,000 years of rewetting through vapor diffusion, the moisture contents in the gravel layer have only increased to $0.01 \mathrm{~m}^{3} / \mathrm{m}^{3}$, which is smaller than for Configuration I.

For Case II-3, the initial conditions reflect desiccation of the full gravel layer to a moisture content of $0.0044 \mathrm{~m}^{3} / \mathrm{m}^{3}$ after a rewetting period of 1 year following a full previous desiccation of that gravel layer. These initial conditions are shown by the dashed red line in Figure 4.97. For this example of multiple desiccation periods following rewetting, the rewetting of the gravel during the first few years after a second desiccation is less than for the Base Case (Figure 4.95). Over the 10-year rewetting period, however, the moisture contents in the gravel layer are similar to what was observed for the Base Case, demonstrating that for this particular desiccation scenario, the long term benefits are not substantially improved compared to the Base Case (II-1).

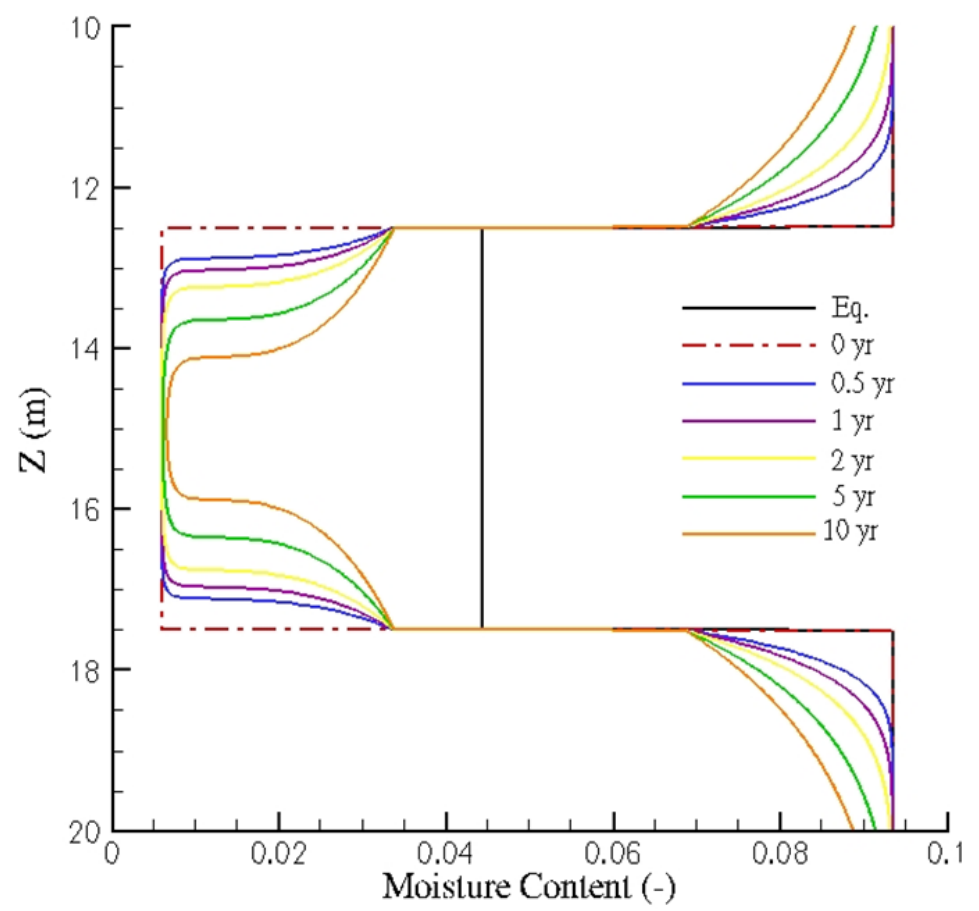

Figure 4.95. Moisture Contents at Various Times during Rewetting for Case II-1 (Base Case). The black line indicates the water content at equilibrium. 


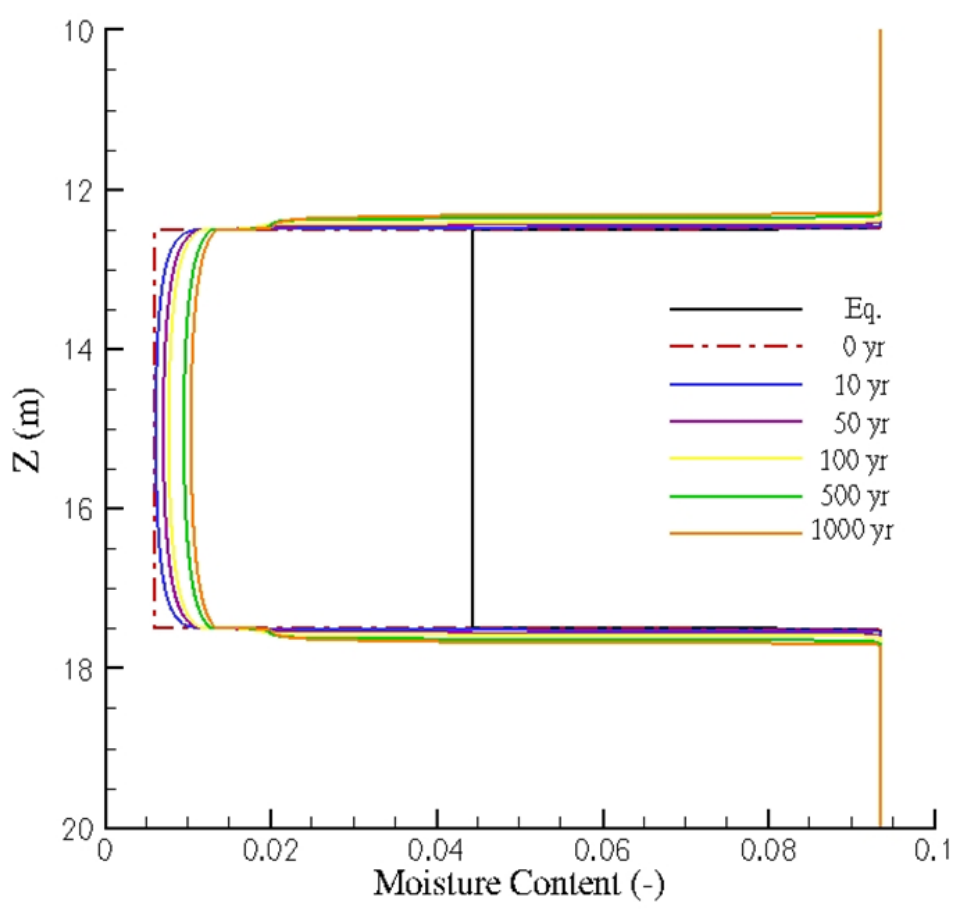

Figure 4.96. Moisture Contents at Various Times during Rewetting for Case II-2 (Vapor diffusion only)

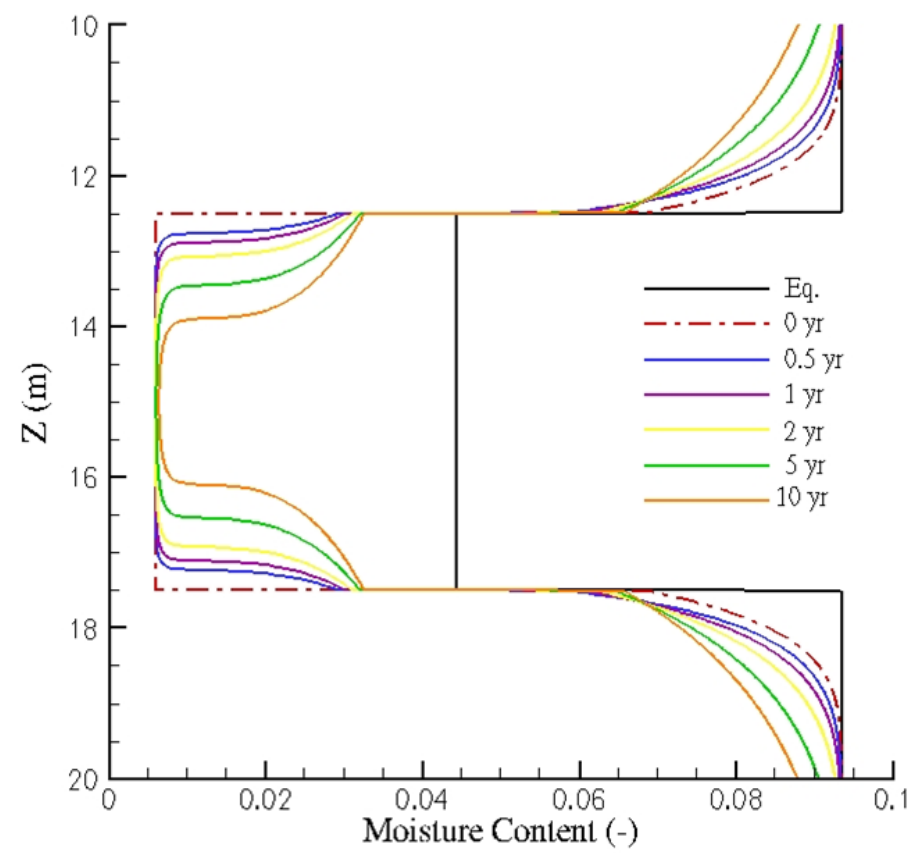

Figure 4.97. Moisture Contents at Various Times during Rewetting for Case II-3 (Desiccated gravel layer after 1 year of rewetting of Base Case)

Finally, the effects of a ten-fold increase in the saturated hydraulic conductivity $\left(K_{\text {sat }}\right)$ of the gravel layer on rewetting are shown in Figure 4-98 for Case II-4. Figure 4-98 shows a faster wetting of the gravel, with penetration of the advected water throughout the gravel and the moisture content distribution 
after ten years of rewetting is almost homogenous as indicated by the orange line. At later times, the moisture contents in the sand adjacent to the gravel will start to increase again.

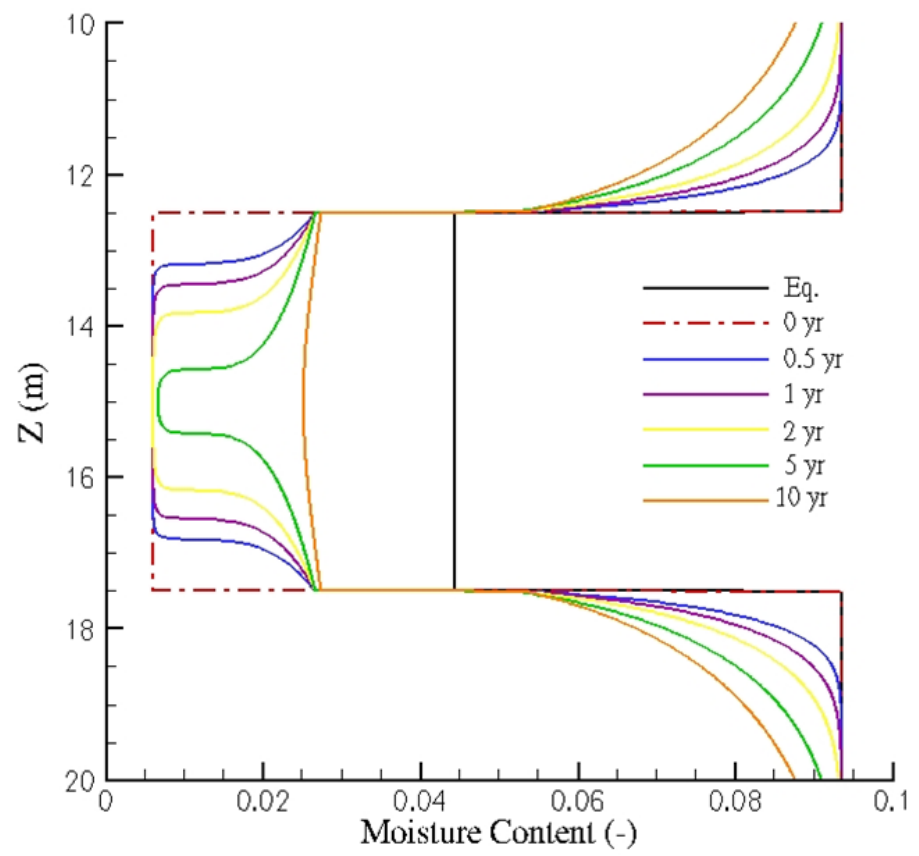

Figure 4.98. Moisture Contents at Various Times during Rewetting for Case II-4 (Gravel $K_{\text {sat }} \times 10$ )

\section{Configuration III}

In Configuration III, rewetting of three desiccated gravel layers is considered (Figure 4.99). The rewetting process for the Base Case (Case III-1) indicate differences in how moisture contents rebound between the thin sand layers between the gravel zones, and the sand directly above the upper gravel layer and the below the lowest gravel layer. In the sand above and below the gravel zones, rewetting looks similar to what happens for Configuration I. In the sand layers between the gravel zones, a rebound in moisture contents is still possible. Interestingly, the water for the rebound in the narrow sand layers actually comes from the gravel, indicating that the gravel layers not only attract water, but also distribute water into the sand layers on the path to a system equilibrium condition. Compared to the upper and lower gravel layer, the middle layer lags somewhat in the rewetting. This result is logical because most of the water entering this layer has to be transported through the narrow sand layers first. 


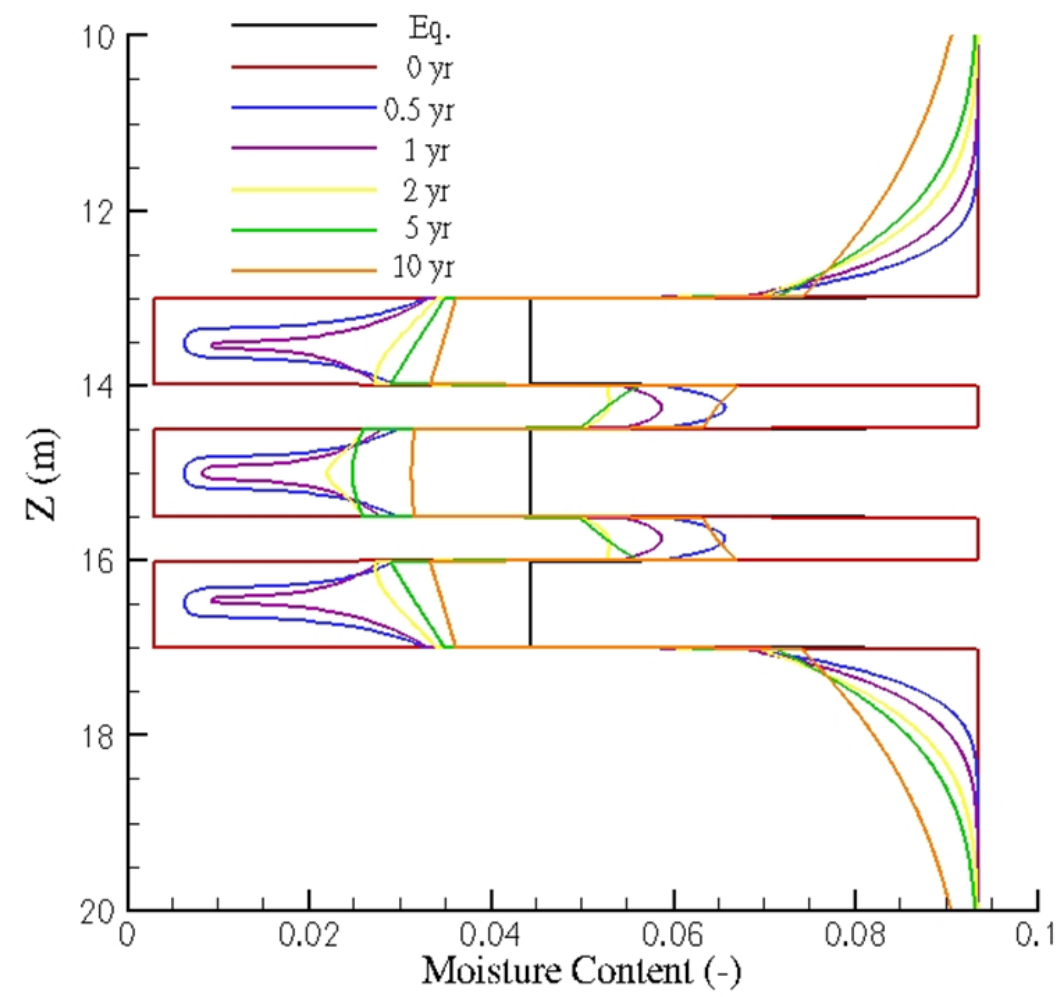

Figure 4.99. Moisture Contents at Various Times during Rewetting for Case III-1 (Base Case). The black line indicates the water content at equilibrium.

Figure 4.100 shows moisture contents over time for Case III-2 where only water vapor diffusion into the three gravel layers is considered. As was observed for the other two configurations, the moisture content changes from this process are small. After 1,000 years of rewetting through vapor diffusion, the water contents in the gravel layers have only increased to $0.015 \mathrm{~m}^{3} / \mathrm{m}^{3}$, which is similar to Configuration I. For all considered cases, water vapor diffusion is a slow process with minor impacts in terms of moisture content changes over time. 


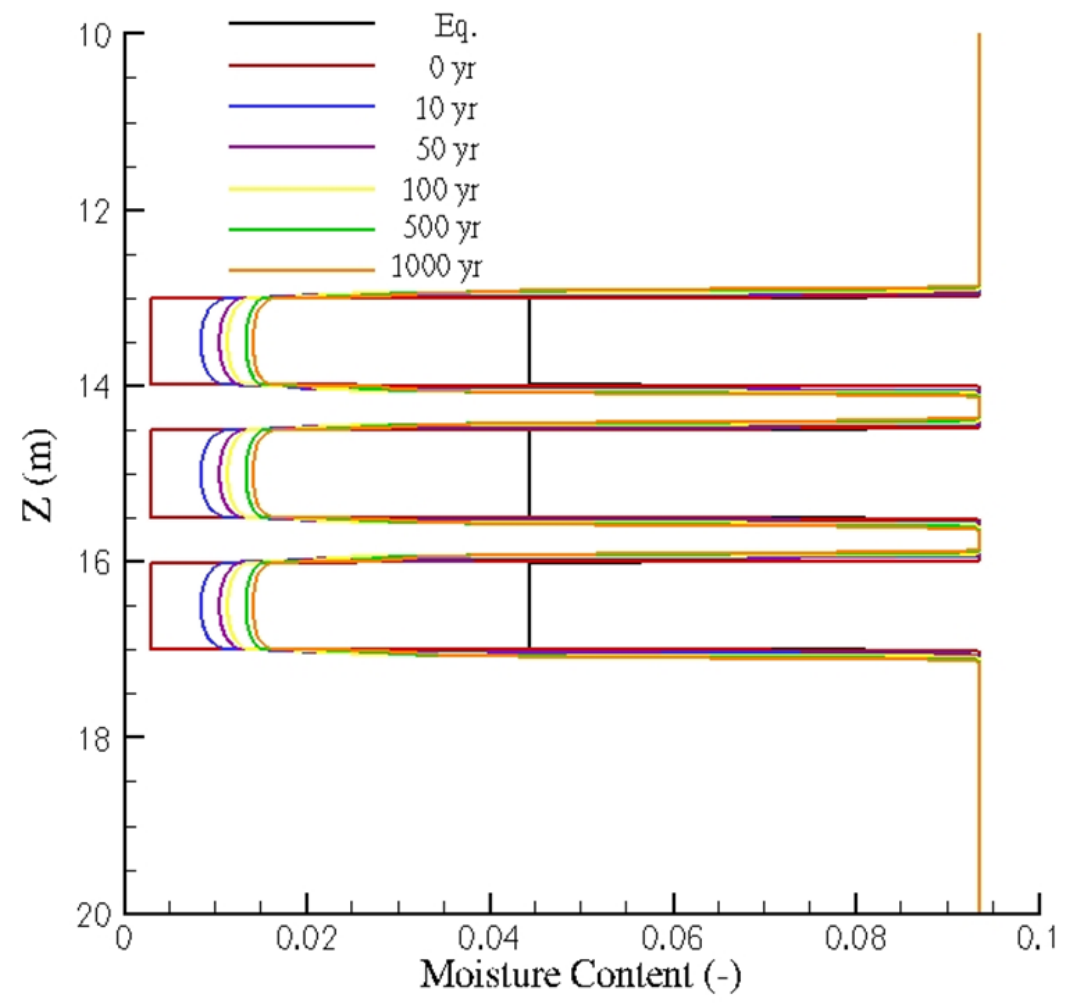

Figure 4.100. Moisture Contents at Various Times during Rewetting for Case III-2 (Vapor diffusion only)

For Case III-3a, the initial conditions reflect desiccation of the three gravel layers to a moisture content of $0.0044 \mathrm{~m}^{3} / \mathrm{m}^{3}$ after a rewetting period of one year following a full previous desiccation of that gravel layer. The rewetting after that perturbation is shown in Figure 4.101. To demonstrate the effects of and additional desiccation after another 1-year rewetting period, subsequent rewetting after that modification is shown in Figure 4.102 for Case III-3b. In both Figure 4.101 and Figure 4.102, the moisture contents after desiccation are indicated by the red line. For this example of multiple desiccation periods following rewetting, the rewetting of the gravel layers slows down after each desiccation perturbation. For this scenario, including a total of three desiccations of the gravel layer, a considerable reduction in rewetting is observed in Figure 4.102 for Case III-3b. For this case, it can be clearly seen that the rewetting of the middle gravel layer is considerably impacted by the subsequent desiccation perturbations. These results are also relevant to desiccation of a target interval containing small lowpermeability lenses where, for a given desiccation time, Figure 4.102 represents conditions that can be induced near the injection well and Figures 4.101 and 4.99 are progressively further from the injection well. As shown in the field test and laboratory experiments (Oostrom et al. 2009, In Press), once high permeability zones are dry, continued passage of dry gas past small, initially wetter lower-permeability zones results in drying of the low-permeability zone over time.

Finally, the effects of a 10-fold increase in the saturated hydraulic conductivity $\left(K_{\text {sat }}\right)$ of the gravel layer on rewetting are shown in Figure 4.103 for Case III-4. As for the other two configurations, the figure shows a faster wetting of the gravel compared to the base case, with penetration of the advected water throughout the gravel layers after only 0.5 year of rewetting. 


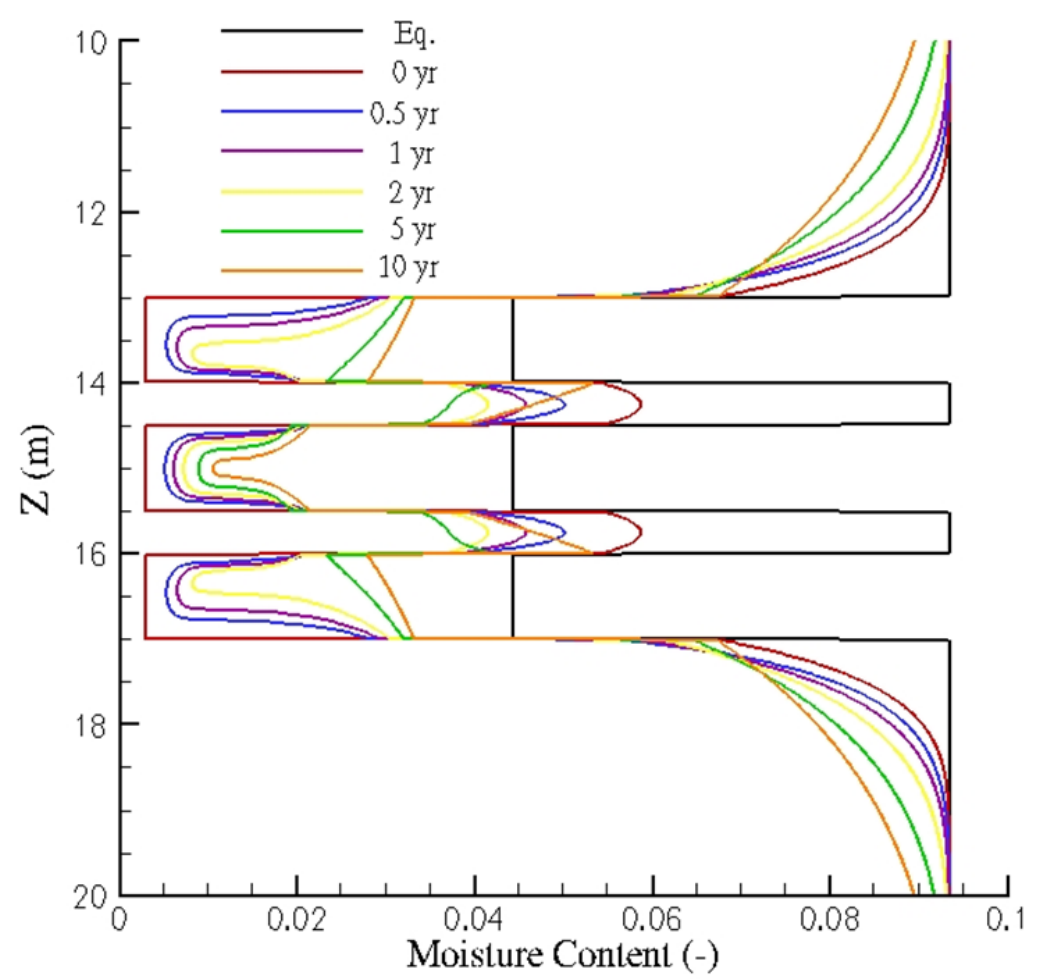

Figure 4.101. Moisture Contents at Various Times during Rewetting for Case III-3a (Desiccated gravel layers after 1 year of rewetting of Base Case)

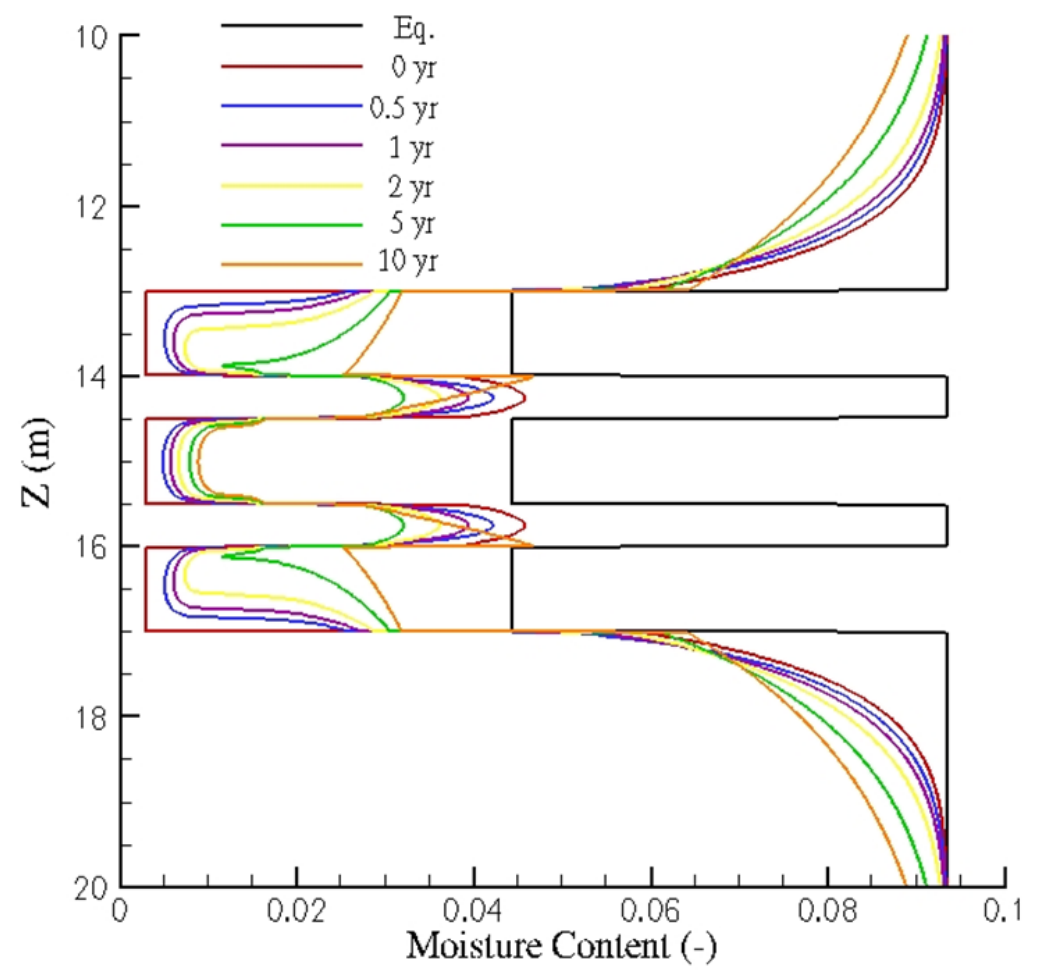

Figure 4.102. Moisture Contents at Various Times during Rewetting for Case III-3b (Desiccated gravel layers after 1 year of rewetting of Case IIIa) 


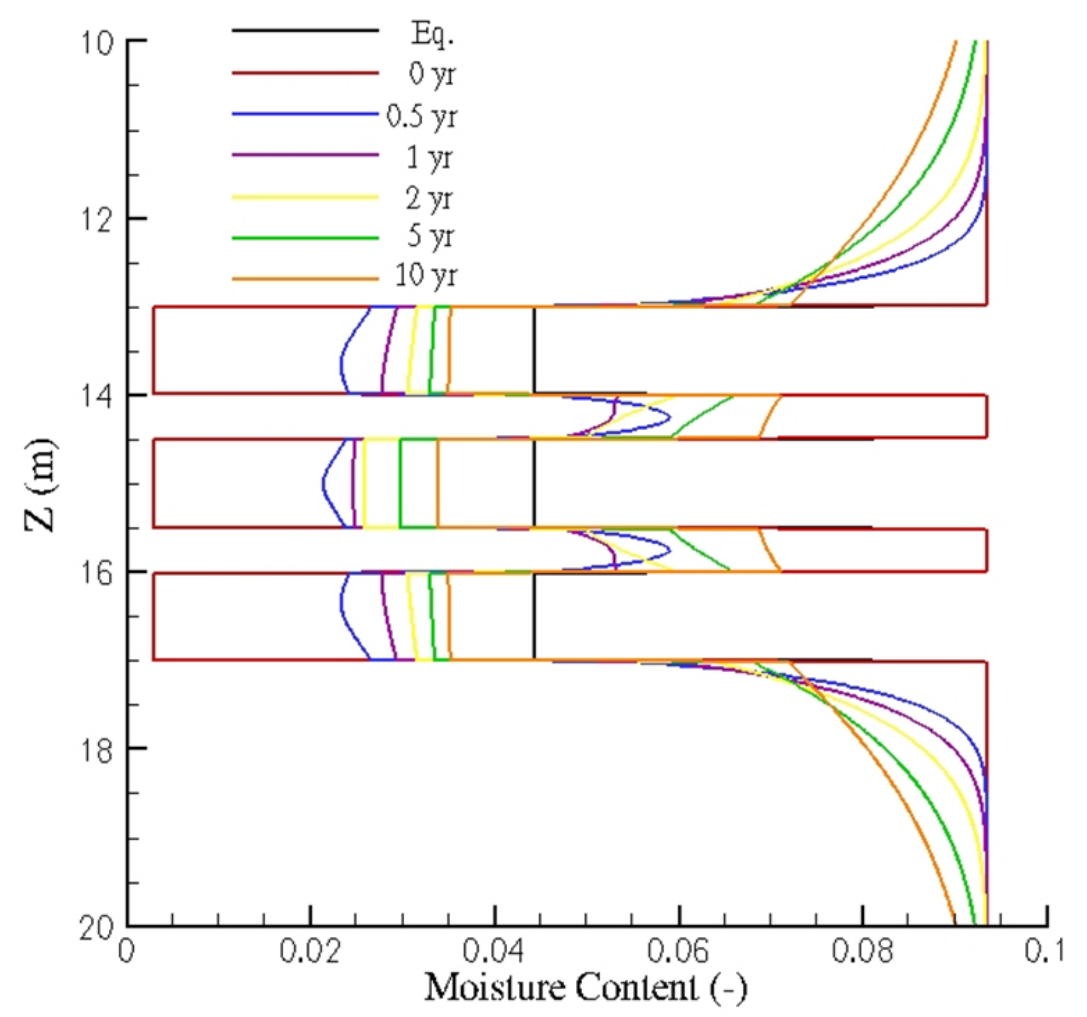

Figure 4.103. Moisture Contents at Various Times during Rewetting for Case II-4 (Gravel $\left.K_{\text {sat }} \times 10\right)$

\section{Rewetting Conclusions from Modeling Assessment}

The rate of rewetting is a function of the porous media properties of both the desiccated zone and the subsurface surrounding this zone, and the moisture content distribution at the end of desiccation. After desiccation, the moisture content distribution in the target zone will trend back toward the equilibrium moisture conditions for the porous media properties. Vapor-phase rewetting will occur, but has negligible impact on the overall rewetting process. Advective rewetting in the aqueous phase strongly depends on the porous media permeability within and surrounding the desiccated zone and the total thickness of the desiccated zone. Thus, targeting thick desiccated zones surrounded by lower permeability porous media will result in slower rewetting and an overall more significant effect on moisture flux toward the groundwater.

When small low-permeability lenses are present within a thicker target desiccation zone, it is useful to either 1) desiccate long enough to also dry these zones, or 2) desiccate the high-permeability zones, allow rewetting for a period of time, and then desiccate again to lower the moisture content of the lowpermeability zones. Note that nearer to the injection well, as shown in the field test, smaller lowpermeability zones will be initially desiccated. Further away from the injection wells, these zones are less likely to be desiccated with limited desiccation time.

To set performance targets for desiccation, porous media properties such as those shown in Table 4.8 are needed. With these properties, the 1-D modeling techniques from this section could be applied to evaluate the target depth interval based on porous media distribution (e.g., layering of silts and sands) and the overall thickness of the desiccated zone to achieve slow rewetting rates and associated goals for 
protection of groundwater. As a further step, the desiccation design target could also be incorporated into 2-D simulations such as those described in Truex et al. (2011) to estimate the impact of desiccation and related remedy components such as a surface infiltration barrier on the contaminant flux to groundwater.

\subsection{Assessment of Initial Field Test Rewetting Data}

Rewetting has occurred to varying degrees in different locations at the field test site within the 8-month monitoring period after the end of active desiccation. This type of mixed response was expected because of variations in the thickness of the desiccated zones, differences in the moisture conditions in zones bordering the desiccated zones, and differences in the extent of moisture content reduction. As described in Section 4.2.2.2.2, these factors, along with the properties of the porous media, impact the rate of rewetting. Continued longer-term monitoring will be necessary to fully evaluate rewetting for the field test. The following assessment of data from monitoring location C7529 highlights the type of rewetting responses that are being observed. Neutron moisture data are used for this initial assessment here, although initial ERT and GPR data from the initial 8-month monitoring period are also presented in Section 4.1.2.2.

Figure 4.57, showing post-desiccation neutron moisture data for monitoring location C7529, provides an example of the variations in rewetting response related to the variations in the thickness of the desiccated zones, differences in the moisture conditions in zones bordering the desiccated zones, and differences in the extent of moisture content reduction. At the $\sim 13 \mathrm{~m}$ bgs depth, where moderate reductions in moisture content occurred during desiccation, moisture content over the 8-month monitoring period has increased back to near pre-desiccation moisture content conditions. This relatively thin depth interval is surrounded above and below by zones of relatively high moisture content. As described in the modeling analysis for rewetting (Section 4.2.2.2.2), relatively quick re-equilibration of moisture would occur under these conditions. In contrast, there is a much thicker desiccated zone where moisture content was reduced to very low levels from about $14 \mathrm{~m}$ bgs to about $17 \mathrm{~m}$ bgs. In the lower portion of this thick desiccated zone, rewetting has been negligible. Moisture content below the desiccated zone is also relatively low such that, in addition to the low aqueous-phase permeability created by significant drying, there is a relatively small driving force for advective rewetting from below. These conditions lead to longer rewetting periods as shown in the modeling analysis for rewetting (Section 4.2.2.2.2). At the upper portion of this thick desiccated zone, more rewetting has occurred over the 8-month monitoring period. Above the desiccated zone, there are relatively high moisture conditions, and therefore a higher driving force for advective rewetting. Note that in this high-moisture zone above the desiccated zone the moisture content has decreased over time as water has moved into desiccated regions above and below the high-moisture zone. As described in the modeling analysis for rewetting (Section 4.2.2.2.2), this type of re-equilibration is expected, but with re-application of desiccation, the rewetting phenomena gets progressively slower as the moisture in both the higher and lower permeability regions (i.e., desiccated and adjacent higher moisture zones) is reduced.

As discussed in the modeling analysis for rewetting (Section 4.2.2.2.2), overall performance of desiccation depends on the porous media properties, the thickness of the desiccated zone, and the moisture conditions surrounding the desiccated zone. For a full-scale application, the design should consider these performance factors in selecting the desiccation target interval and in evaluating the potential for successive applications of desiccation to reach conditions that create a slow rewetting rate. 


\subsubsection{Instrumentation and Monitoring Assessment}

In situ remediation of the deep vadose zone for nonvolatile contaminants is largely in the developmental and demonstration stage. Thus, techniques for monitoring of remediation performance have not been fully evaluated. Desiccation, similarly to some other in situ remedies, imposes significant changes to subsurface conditions over a relatively short timeframe. Several types of instruments are available that monitor the type of properties affected by the desiccation process, but have not been previously used for monitoring desiccation. Candidate sensors were tested in the laboratory using a twodimensional flow cell with imposed desiccation and rewetting conditions. These same sensors were also installed at the field test site. The sections below summarize the information and data available to date and interpret the sensor performance with respect to monitoring the desiccation process and subsequent rewetting of the desiccated zone.

\subsubsection{Laboratory Evaluation of Instrumentation}

Laboratory testing of in situ sensors was conducted and reported in Truex et al. (2011) and Oostrom et al. (2012). In summary, the sensors installed at the desiccation field-test site were tested with respect to monitoring desiccation and rewetting in a laboratory flow cell. The thermistors, heat dissipation units, and humidity probes provided useful information for both desiccation and rewetting. Thermocouple psychrometers and DPHP instruments detected passage of the desiccation front, but were not useful thereafter. All instruments detect only very localized conditions, and changes in parameters must occur at the instrument location for the instrument to detect or quantify a change in conditions.

\subsubsection{Field Test Information for Instrumentation}

Sensor performance was also evaluated based on the data obtained during desiccation field testing. The results were generally consistent with the laboratory testing of the sensors. Using the neutron data as an indicator of where significant desiccation occurred, strong sensor responses would be expected at the $47 \mathrm{ft}$ bgs sensor intervals within $3 \mathrm{~m}$ of the injection well and moderate responses at the $42 \mathrm{ft}$ bgs sensor interval for the same wells. The heat dissipation units and thermistors showed responses at the expected locations. Note that the thermistors were placed every 2 feet between 10 and $70 \mathrm{ft}$ bgs. As such, the thermistors provided a good vertical indication of desiccation activity based on the evaporative cooling response. Some responses were observed for humidity and moisture content sensors, but not for every location where a change in these parameters would be expected.

Reliability of sensors was also evaluated based on the number of sensors that stopped functioning or did not respond when a response was expected. Based on this assessment, the heat dissipation units and thermistors were reliable with $100 \%$ of the thermistors and 39 of 40 HDU remaining functional throughout the test. Almost half of the humidity probes failed during the test (19/40) and 29 of 40 DPHP sensors failed. None of the thermocouple psychrometers provided meaningful data and 20 of 40 sensors completely failed (no signal).

Neutron moisture logging of a borehole is a standard method for obtaining a high resolution vertical profile ( $\sim 7.5 \mathrm{~cm}$ vertical intervals) of volumetric moisture content. These data are a good representation of moisture content at the logging locations within the nominal measurement radius of about $30 \mathrm{~cm}$. Measurement is manual, which may lead to lower temporal resolution than for methods that can operate 
autonomously. Interpolation of volumetric moisture content from neutron moisture logging data can be used to generate a three-dimensional image of moisture conditions. This type of interpolation does not incorporate subsurface conditions away from the measurement point that can impact the distribution of desiccation. The neutron moisture logging data provide robust information but over a small volumetric extent. Interpolation is impacted by the location of the drying front. For instance if drying has occurred at one location, but not yet at another location, interpolation cannot effectively project the extent of drying past the first location. A neutron logging image can show sharp moisture content contrasts that may not be physically accurate away from the logging locations. Thus, care is needed in interpreting the images with respect to the volumetric distribution of moisture content reduction.

Cross-hole ERT senses the electrical conductivity distribution between in situ electrode locations. As described in Equation 3.5 (Section 3.2.2.3), changes in the electrical conductivity distribution are related to changes in the volumetric moisture content distribution. While ERT measures only the change, not the absolute volumetric moisture content, the ERT data can be used to provide a temporal data set representing the distribution of desiccation via moisture content changes. These data are in response to conditions between electrodes, not just at the electrodes.

Overall, several factors impact the ERT estimate. Decreases in temperature and moisture content occur during desiccation, both of which cause a decrease in electrical conductivity. Thus, in order to quantitatively estimate the moisture content change using ERT, a temperature correction is necessary. This correction is moisture content dependent, but in practice, a constant temperature correction factor is applied in the data inversion. In addition, increasing fluid conductivity with decreasing moisture content is expected to dampen the ERT response and impact moisture content change estimates. With ERT, the resolution of the data inversion averages moisture content changes over a volume and the distribution of spatial moisture content change is depicted with lower contrast than actually exist, appearing as a smoothed or blurred representation of actual changes. Imaging resolution is related to electrode distribution which can also change over time if electrodes have to be dropped from the network because of electrical coupling issues as the porous medium is desiccated. In the field test, maintaining electrical coupling was difficult in heavily desiccated zones, likely due to bentonite contraction and subsequent separation from electrodes. Full-scale applications would need to consider improved wetting capability or nonshrinkable grout around electrodes to maintain adequate coupling (e.g., neat Portland cement).

Cross-hole ERT is implemented using robust in situ electrodes that can be monitored autonomously to provide high temporal resolution. Spatial resolution is related to the electrode distribution and proximity to the desiccation zone, and can be selected to be appropriate for the scale of the desiccation target and the resolution needed based on the monitoring goals. For instance, the ERT applied at the test site imaged a zone about 12-m long by 6-m wide by 55-m thick with about 100 electrodes at 9 lateral locations. A volume twice as large could have been imaged using the same number of electrodes with a correspondingly scaled electrode spacing in the same number of lateral locations. In that case, image rendering would essentially look the same as shown in Figure 4.40, but the scale would be twice as large. For larger volumetric applications, neutron moisture logging could also be applied, although larger interpolation distances may misrepresent moisture content changes between logging locations, especially if there is significant heterogeneity, and there would be longer durations for desiccation to propagate from one logging location to the next. Thus, it may be advantageous at larger sites to use ERT imaging even through image resolution would need to be considered in interpreting the distribution and extent of moisture content reduction. 
Cross-hole GPR provides means to monitor absolute volumetric moisture content and moisture content changes in two dimensions based on propagation of energy through the subsurface between two logging boreholes. Thus, it provides data for interpretation of volumetric moisture content distribution away from subsurface access points and does not require interpolation between access points like the neutron moisture logging data. However, high electrical conductivity at contaminated sites can severely impact the accuracy of the GPR estimate. When the ground has a high electrical conductivity the lowloss assumption is not valid and the EM velocity is affected by both electrical conductivity and permittivity changes. However, in zones with significant desiccation, the electrical conductivity drops because moisture content decreases. In those zones, GPR moisture content determined through the Equation 3.3 correlation are much closer to those determined by neutron moisture logging.

GPR provides a 2-D image of the subsurface moisture content using manual measurements, which may lead to lower temporal resolution than for methods that can operate autonomously. GPR logging borehole spacing is constrained by energy propagation and generally needs to be less than $10 \mathrm{~m}$ for the vadose zone and even much smaller for areas with high electrical conductivity (about $3 \mathrm{~m}$ at the desiccation test site). However, while the absolute value of moisture content is not accurate in areas of high electrical conductivity, GPR does image the location of moisture content changes and can provide accurate estimates of moisture content in highly desiccated zones, even when initial electrical conductivity is high. Thus, the GPR data may be suitable for identifying the distribution of highly desiccated zones and estimating the moisture content in these zones. Additionally, GPR can also be deployed to include measurement between the injection well (through the use of stilling well) and surrounding wells. ERT and neutron logging cannot effectively include data collection at the injection well because 1) the injection well configuration is not conducive to neutron logging or placement of ERT electrodes and 2) the subsurface adjacent to the injection well dries rapidly and creates conditions that are not suitable for ERT electrode operation (i.e., electrical coupling between the electrodes and the porous media is poor at low moisture content).

In summary, traditional moisture content monitoring through neutron moisture logging is well established and provides detailed vertical profile information at discrete logging locations. Interpolation of multiple logging locations is possible, but must be applied with caution because interpolation does not account for subsurface heterogeneities away from the logging locations and becomes less representative as the distance between logging locations increases. ERT implementation is readily scalable to larger sites. ERT data can be collected autonomously for good temporal resolution and can provide estimates of moisture content changes in three dimensions. GPR scaling is limited by the need for relatively closely spaced subsurface access for logging. While moisture content estimates are impacted by high electrical conductivity, estimates in low conductivity and significantly desiccated zones appear to be similar to neutron moisture data. GPR also provides the ability to monitor directly surrounding the dry-gas injection well and may be useful for assessing near-well patterns of desiccation that relate to gas flow and are important for operational decisions. Interestingly, interpolation of temperature data, due to the evaporative cooling effect of desiccation, also provided useful three-dimensional information about the progress of desiccation and is a robust method for vadose zone implementation. 


\subsubsection{Scale-Up Assessment}

The following sections address scale-up of desiccation with respect to design requirements, setting performance requirements, design calculations, and assessment of desiccation with respect to CERCLA feasibility study requirements.

\subsubsection{Ambient Air Injection Assessment}

The Water-Air-Energy mode of the STOMP simulator (White and Oostrom 2000; 2006) was used to simulate the desiccation process induced by injection of ambient air under a range of temperature $\left(0^{\circ} \mathrm{C}\right.$ to $\left.30^{\circ} \mathrm{C}\right)$ and relative humidity $(0 \%$ to $90 \%)$ conditions. Simulation results were evaluated in terms of desiccation efficiency and the potential for condensation of water within the subsurface as a function of the ambient air conditions.

\subsection{Approach}

A two-dimensional cylindrical coordinate system was used for the simulations (Figure 4.104). The 6-m-long injection well was located at the center of the 100-m thick domain, starting at $30 \mathrm{~m}$ below ground surface (bgs). Using symmetry, the simulations were conducted in two-dimensions with the injection well at the left edge of a domain consisting of a 45-degree wedge within the cylinder. Unlike the field test, no extraction well was used in the simulations, only injection of ambient air which was allowed to exit the right side of the domain. The water table was located at $100 \mathrm{~m}$ below the surface, as represented by the bottom boundary of the domain.

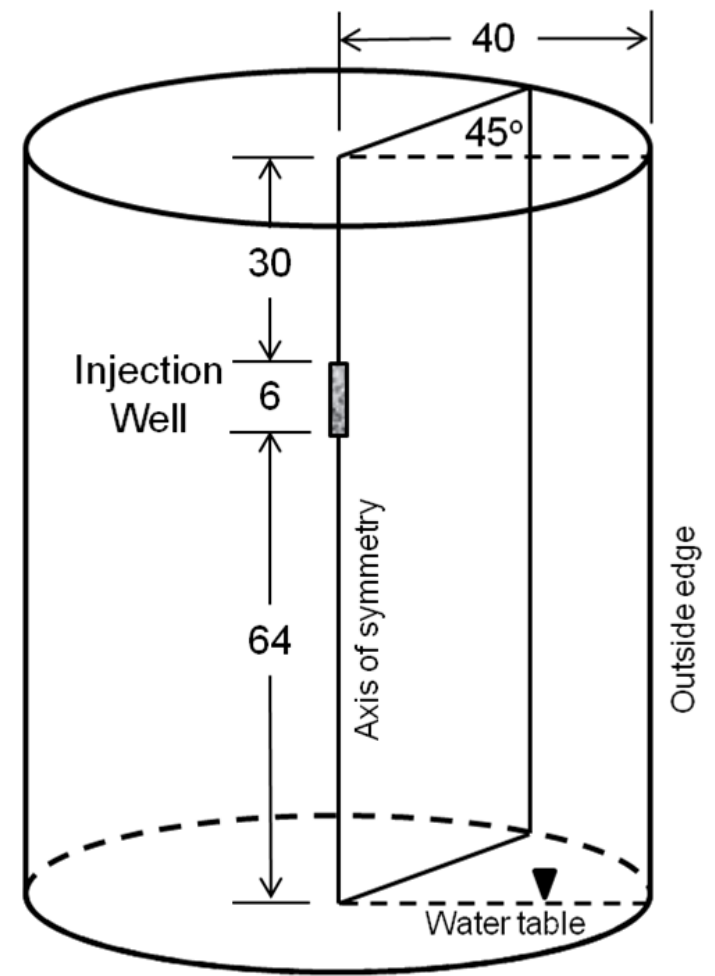

Figure 4.104. Schematic of Cylindrical Domain Used to Simulate Injection of Ambient Air. Dimensions are in meters. 
Grid convergence tests were performed to obtain the discretization used in the scoping simulations. The $40-\mathrm{m}$ by $100-\mathrm{m}$ domain was discretized into 60 nodes in the horizontal, and 400 nodes in the vertical, yielding a total of 24,000 nodes in the domain. The domain was discretized with variable horizontal spacing $(0.25$ to $1.0 \mathrm{~m})$, which was refined near the injection well, but increased with distance from the injection well.

Boundary conditions were set for the top, bottom, and outside edge of the domain. For the gas phase, zero-flux boundaries were established at the top and bottom, representing use of a gas-impermeable barrier at ground surface and the water table, respectively. The outside edge boundary condition accounted for the weight of air along the vertical boundary using a gas pressure of $102494.5363 \mathrm{~Pa}$ at the lowest cell. For the aqueous phase, a zero-flux boundary was set at the top of the domain. At the bottom, a fixed (Dirichlet) pressure (102496.0000 Pa) was set to represent the water table (relative to an atmospheric pressure of $101325 \mathrm{~Pa}$ at the top of the domain). At the outside edge boundary, similar to the gas phase boundary condition, a hydrostatic condition was set that accounted for the weight of the water column, with the aqueous pressure at the lowest cell set at $101269.7945 \mathrm{~Pa}$. For energy transport, a fixed temperature of $17^{\circ} \mathrm{C}$ was assumed for the top, bottom, and outside edge boundaries. At the injection well axis boundary, no flow conditions outside of the injection well were assumed because this boundary represented the axis of symmetry.

The domain was assumed to be homogeneous with hydraulic properties associated with a welldrained sand (Table 4.9). A homogeneous domain was used so that impacts of desiccation and condensation could be readily identified without confounding factors that could be attributed to subsurface heterogeneities. The Webb extension (Webb 2000) was used in conjunction with the van Genuchten equation (1980) to describe the pressure-saturation relationship for dry regions. Water retention relations such as the van Genuchten (1980) equation have a limitation at low aqueous saturations because they use residual or irreducible water saturation parameters (Webb 2000). When the irreducible water saturation (residual moisture content) is approached, the aqueous phase relative permeability approaches zero and the capillary pressure approaches infinity. This behavior of the capillary pressure-saturation curve can cause numerical problems at saturations near the irreducible water saturation (residual moisture content). The approach of using a finite irreducible saturation typically fails when the saturation drops below this value. The method by Webb (2000) extends the capillary pressure curves to zero liquid saturations, but does not necessitate refitting or experimental data for the van Genuchten portion of the curves. The details of the extension are discussed in Webb (2000).

Table 4.9. Hydraulic Properties of the Porous Medium

\begin{tabular}{ll}
\hline Saturated Hydraulic Conductivity $\left(\mathrm{cm} \mathrm{s}^{-1}\right)$ & $2.270 \times 10^{-3}$ \\
van Genuchten alpha $\left(\mathrm{cm}^{-1}\right)$ & 0.061 \\
van Genuchten $n$ & 2.031 \\
Residual Saturation & 0.080 \\
\hline
\end{tabular}

Using the Webb extension with the van Genuchten equation for capillary pressure, three different sets of simulations were performed with continuous injection of ambient air for a period one year. Prior to injection of gas, an approximate steady-state condition was obtained by allowing the soil to drain for 1 year without desiccation and infiltration, yielding an initial water saturation of $\sim 7 \%$. The use of the 
Webb extension to the van Genuchten equation permits the saturation to drop slightly below the residual moisture content for the porous medium. In the first set of simulations (Case 1), ambient air was injected into the subsurface at a rate of 300 cubic feet per minute $(\mathrm{cfm})$, the rate used in the desiccation field test. In the second set of simulations (Case 2), the same injection rate was used, but the initial saturation of the porous medium was set to $16 \%$ so that the effectiveness of desiccation and the potential for condensation could be observed at higher starting water saturation. In the third set of simulations (Case 3), the initial saturation of the domain was the same as for Case 1, but the injection rate was doubled to $600 \mathrm{cfm}$.

For all three cases, ambient air was injected at five different temperatures: $0^{\circ} \mathrm{C}, 10^{\circ} \mathrm{C}, 17^{\circ} \mathrm{C}, 20^{\circ} \mathrm{C}$, and $30^{\circ} \mathrm{C}$. At each temperature, the air was injected at 10 different relative humidity values: $0 \%, 10 \%$, $20 \%, 30 \%, 40 \%, 50 \%, 60 \%, 70 \%, 80 \%$, and $90 \%$. Simulation results were analyzed primarily by examining trends in water saturation, temperature, relative humidity, and matric potential at an observation point located $5 \mathrm{~m}$ laterally from the injection well at a depth aligned with the midpoint of the injection screen.

\subsection{Assessment Results}

The same basic variation in responses for water saturation, temperature, relative humidity, and matric potential as a function of influent gas temperature and relative humidity were observed for each of the three cases simulated. Figures 4.105 through 4.108 show the series of responses for different temperature and relative humidity combinations under Case 1 conditions. Each set of plots represent the response for a given temperature of the injected ambient air. Lines plotted in each set of plots represent the relative humidity of the injected air. In the plots below, several abbreviated axis legends are used. The legend "Aq Saturation" is the soil moisture saturation (volume water/volume pore space). The legend "Aq matric potential, bar" is the matric potential in the soil in units of pressure (bar) where higher negative values equate to higher capillary pressures. 
(a)
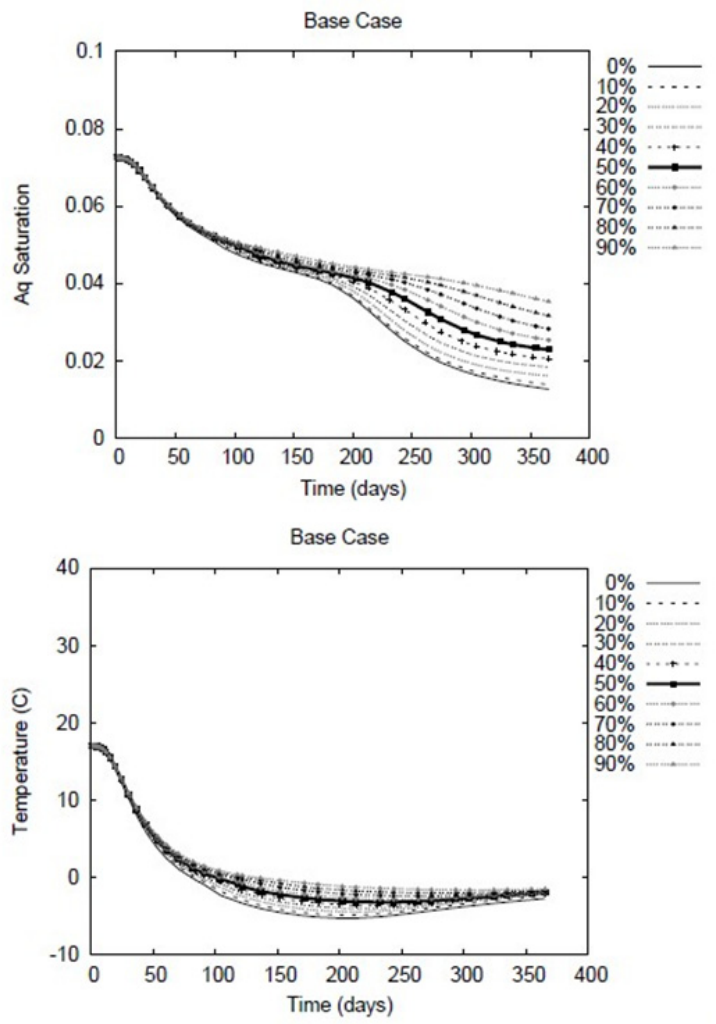
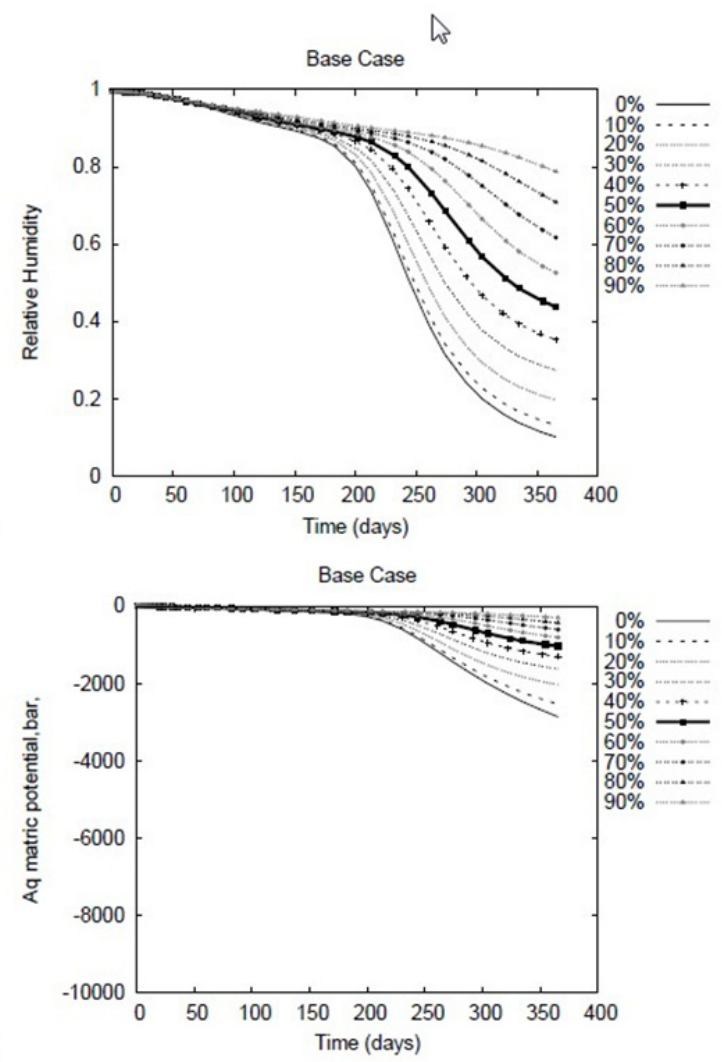

Figure 4.105. Ambient Air Desiccation as a Function of Injected Gas Relative Humidity for an Injected Gas Temperature of $0^{\circ} \mathrm{C}$ 
(a)
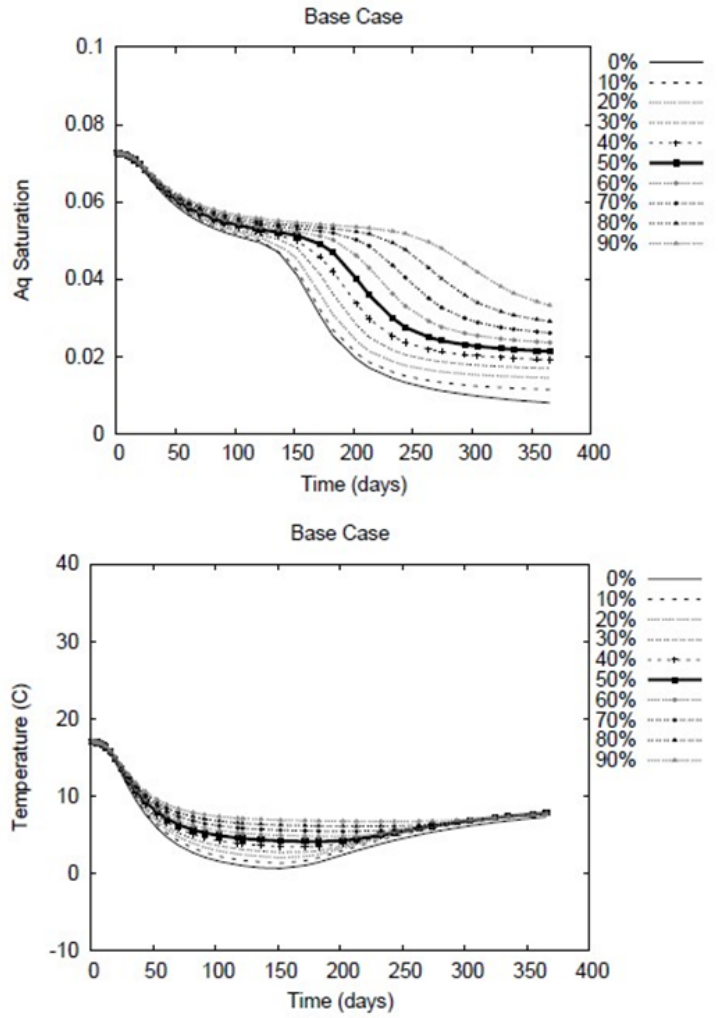

(c)
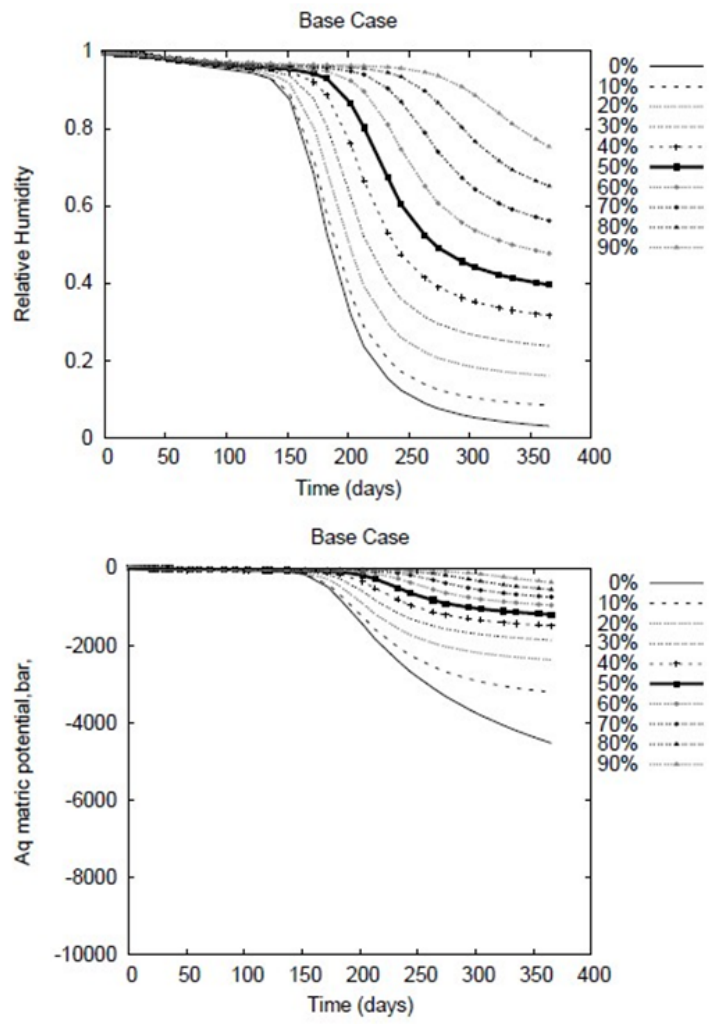

Figure 4.106. Ambient Air Desiccation as a Function of Injected Gas Relative Humidity for an Injected Gas Temperature of $10^{\circ} \mathrm{C}$ 
(a)
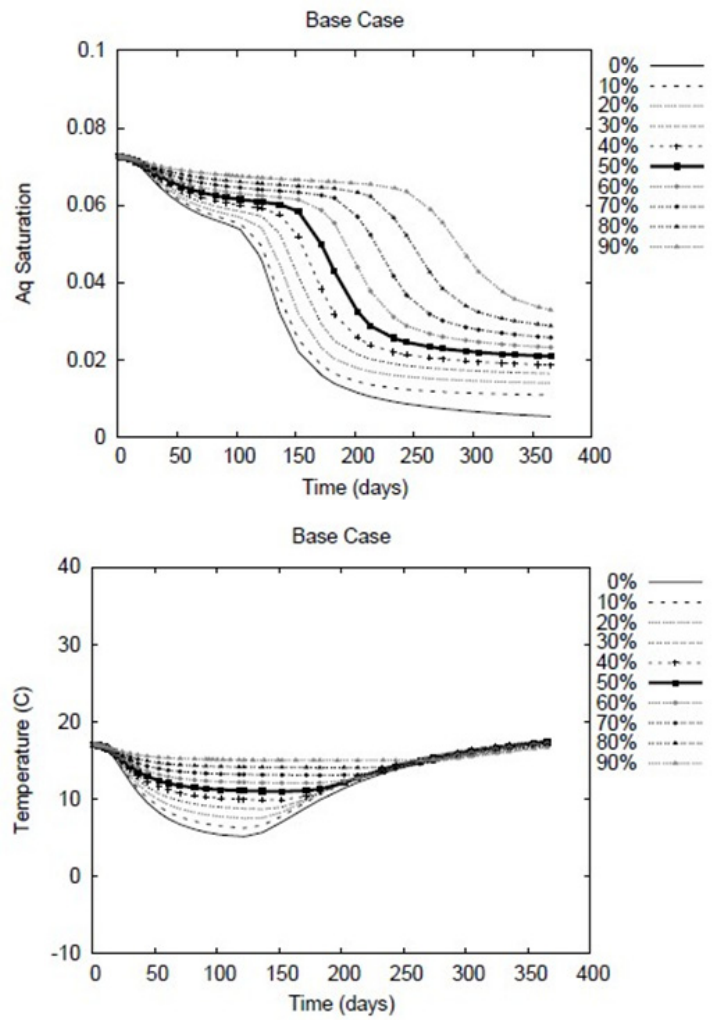
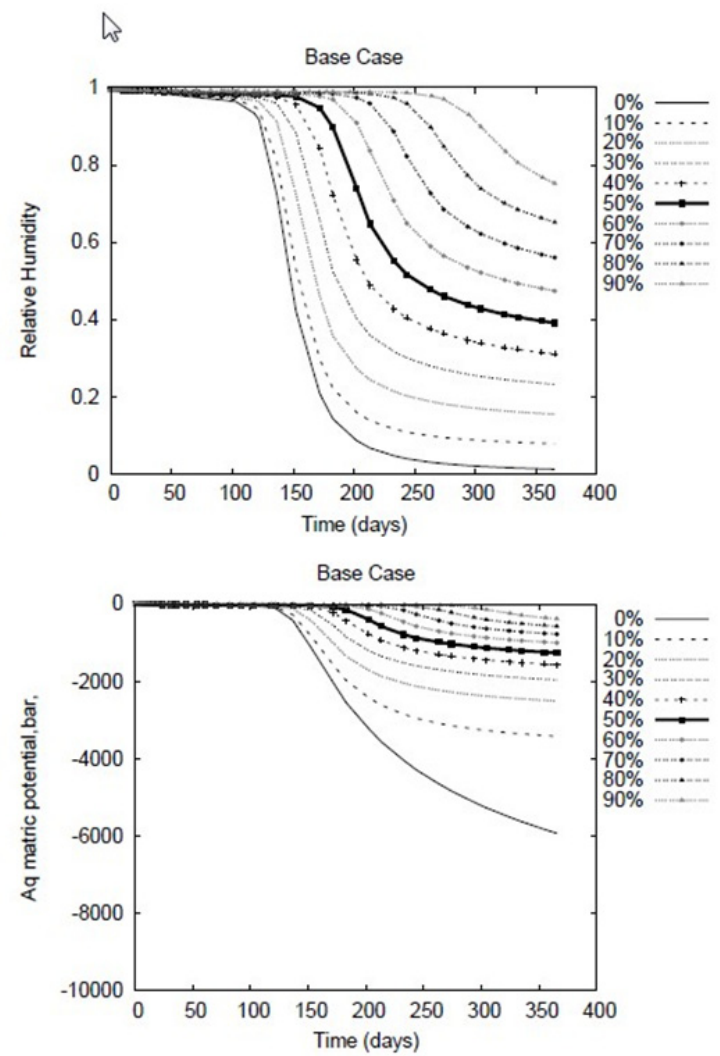

Figure 4.107. Ambient Air Desiccation as a Function of Injected Gas Relative Humidity for an Injected Gas Temperature of $20^{\circ} \mathrm{C}$ 
(a)

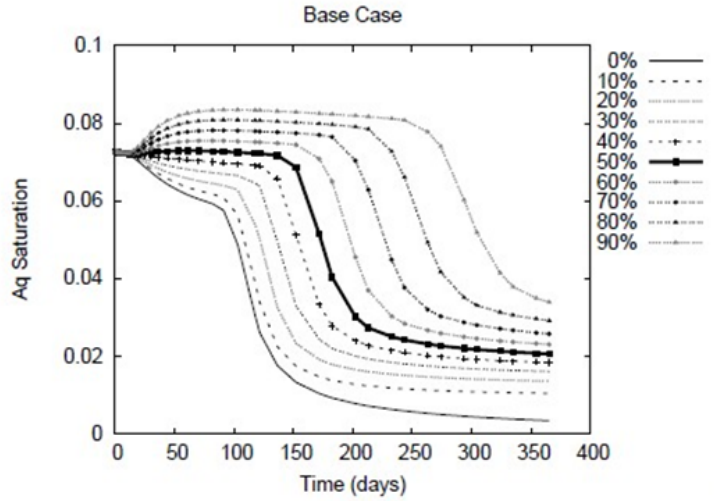

(b)

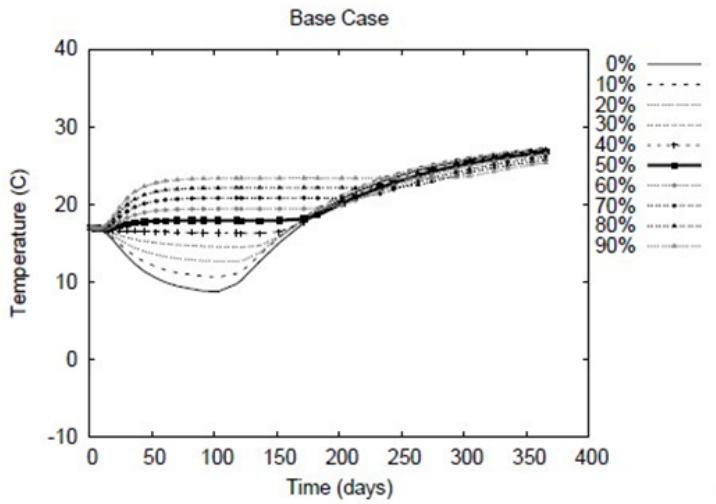

(c)

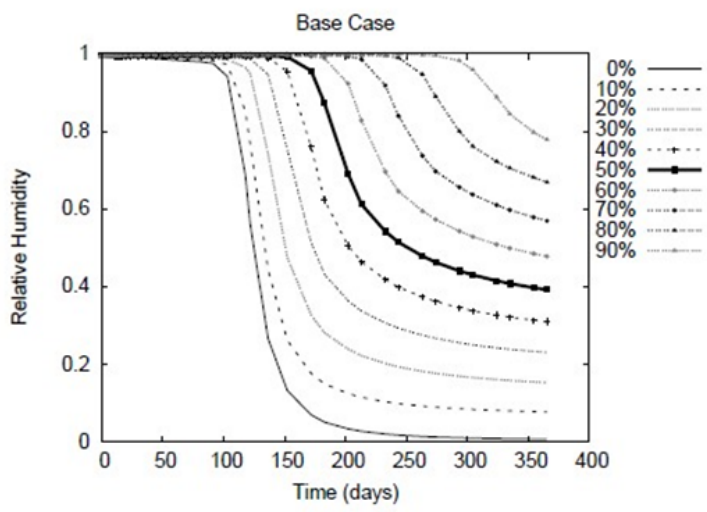

(d)

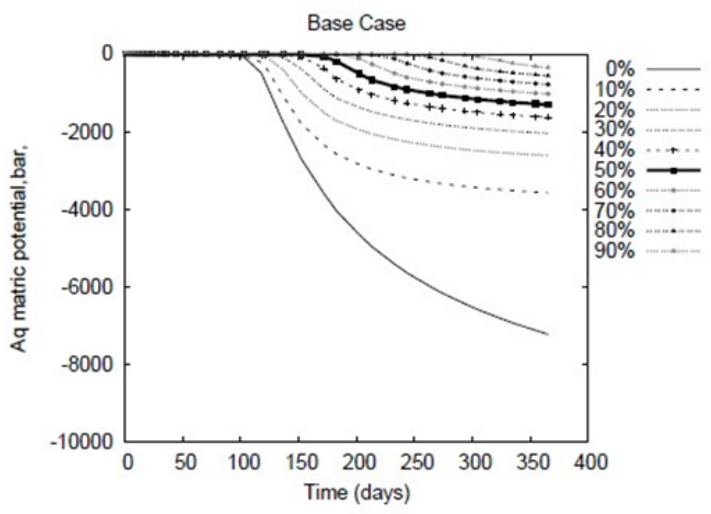

Figure 4.108. Ambient Air Desiccation as a Function of Injected Gas Relative Humidity for an Injected Gas Temperature of $30^{\circ} \mathrm{C}$

Lower temperatures produce slower desiccation rates but did not generate conditions causing condensation of water in the subsurface. Higher temperatures result in quicker desiccation, but lead to the potential for condensation in the subsurface (as evidenced by temporary increased water saturations) at higher relative humidity values (e.g., above about $50 \%$ ). The condensation is a temporary phenomena that occurs until the temperature at the monitored point increases to where condensation does not occur. The temperature increase is from the heat in the influent gas and therefore, occurs slowly. The simulations showed moderate increases in water saturation until that time. However, potential issues caused by condensation and the amount of saturation increase for a specific site would need to be evaluated in the site-specific design to define an upper limit for relative humidity at higher influent gas temperatures.

The extent of desiccation is a function of the influent gas relative humidity. Note that in Figures 4.105 through 4.108 , the simulated water saturation is progressively higher as the relative humidity increases from $0 \%$ to $90 \%$. The variation between water saturation is greater at higher temperatures. For a given site, the targeted water saturation endpoint should be considered in selecting appropriate ambient air conditions for desiccation operations. This pattern of water saturation is also evident in Figures 4.109 through 4.113, which groups plots by the relative humidity of the injected ambient air. Lines plotted in each set of plots represent the temperature of the injected air. 
(a)
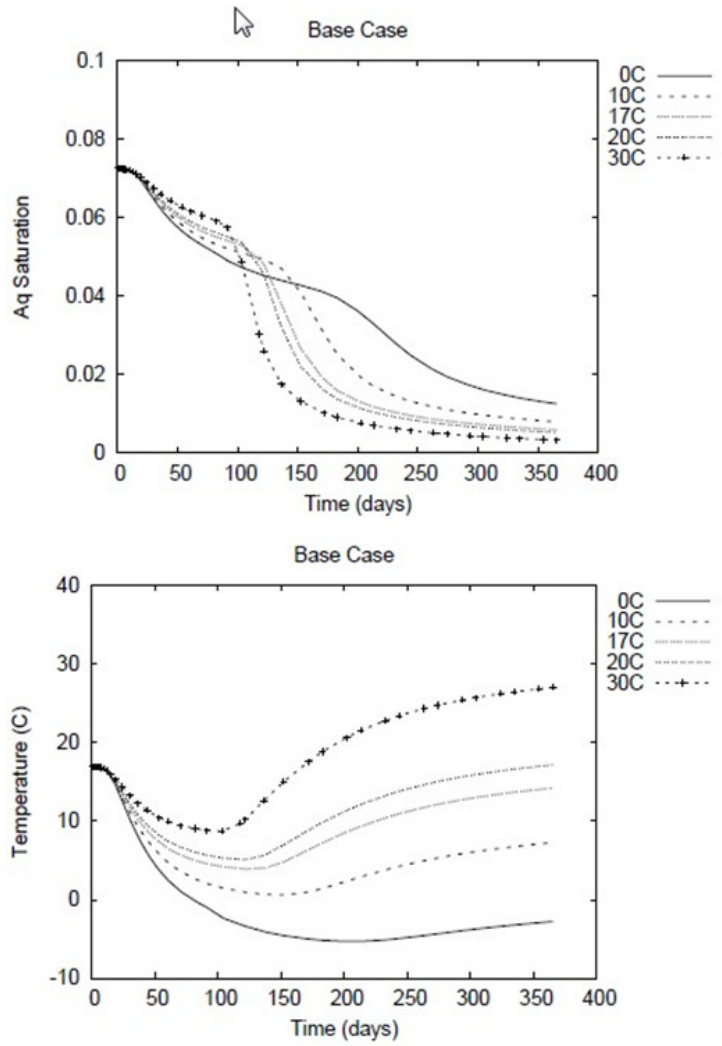
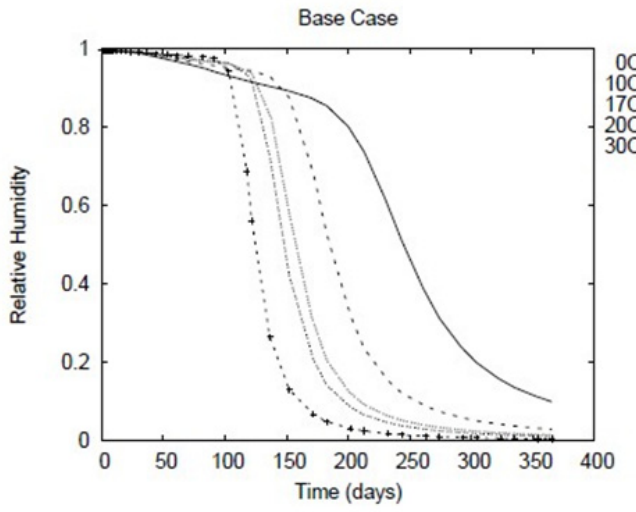

(1)

$20 \mathrm{C}$

C $\cdots+$.

(c)

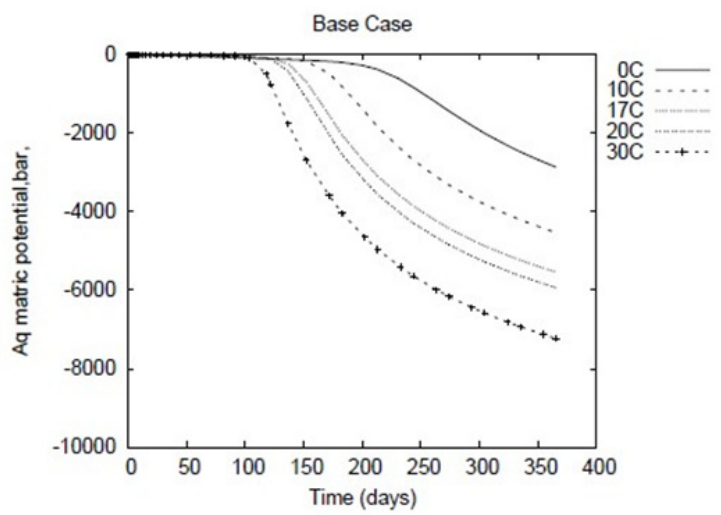

Figure 4.109. Ambient Air Desiccation as a Function of Injected Gas Temperature for an Injected Gas Relative Humidity of $0 \%$ 
(a)
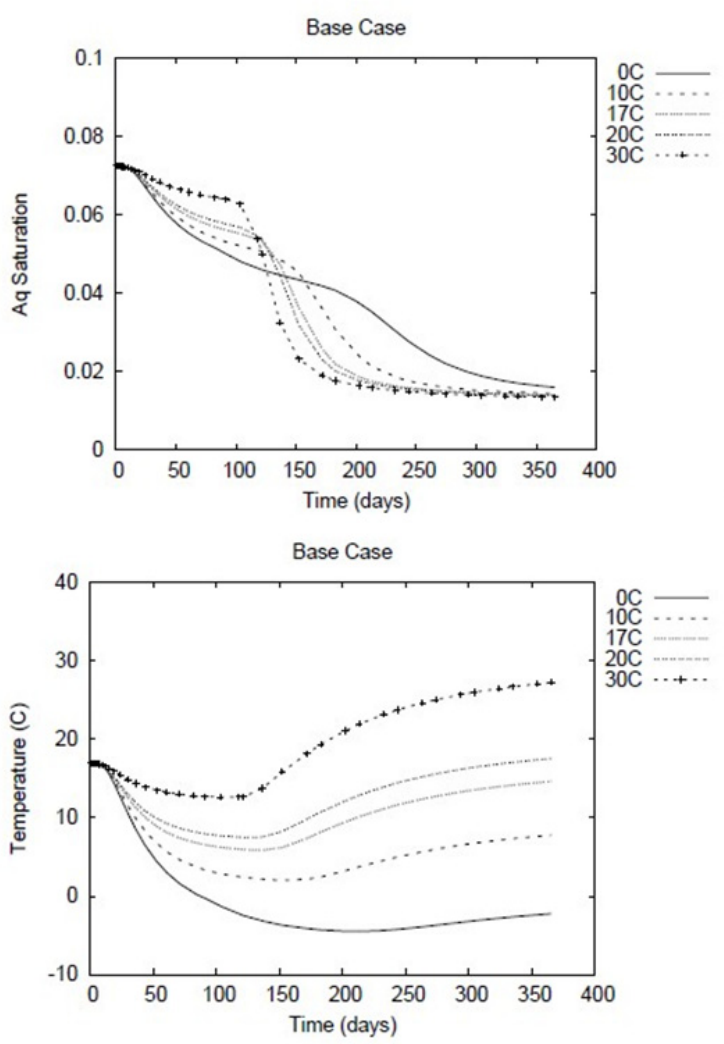

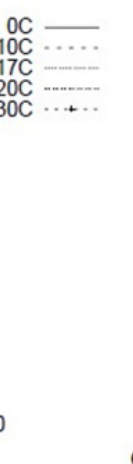

(c)
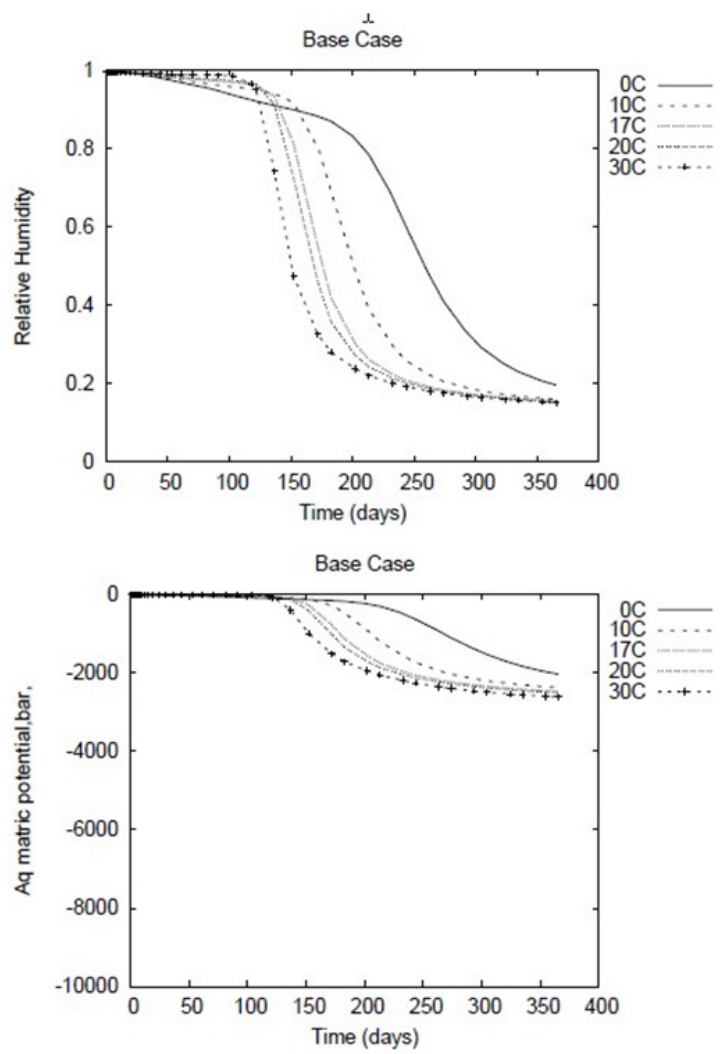

Figure 4.110. Ambient Air Desiccation as a Function of Injected Gas Temperature for an Injected Gas Relative Humidity of $20 \%$ 
(a)
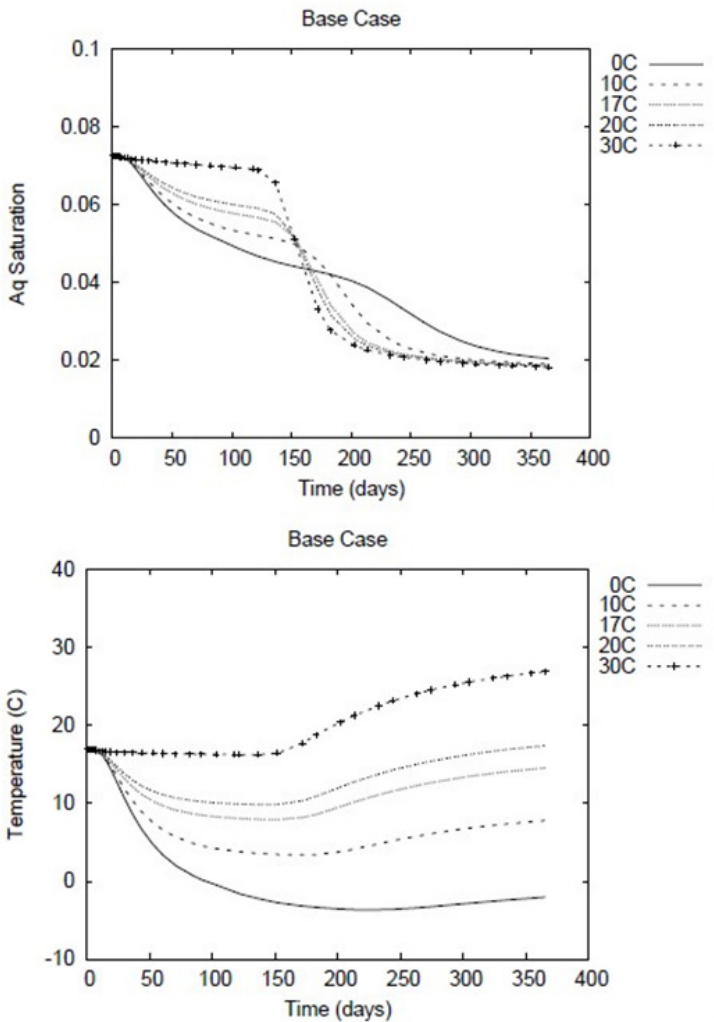

(c)
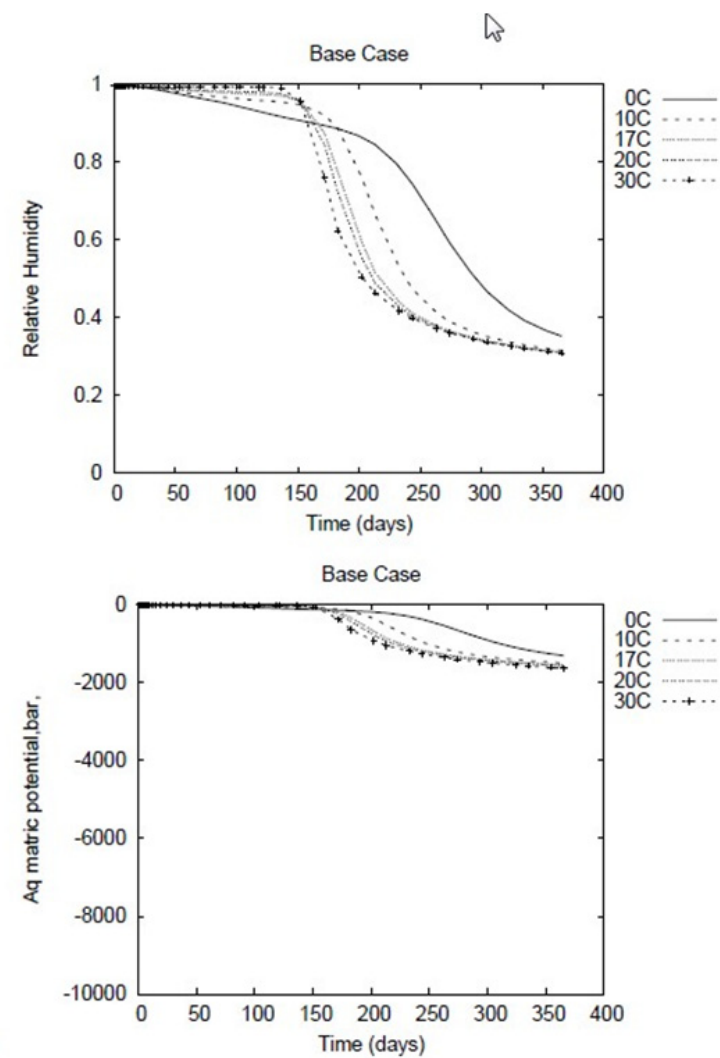

Figure 4.111. Ambient Air Desiccation as a Function of Injected Gas Temperature for an Injected Gas Relative Humidity of $40 \%$ 
(a)
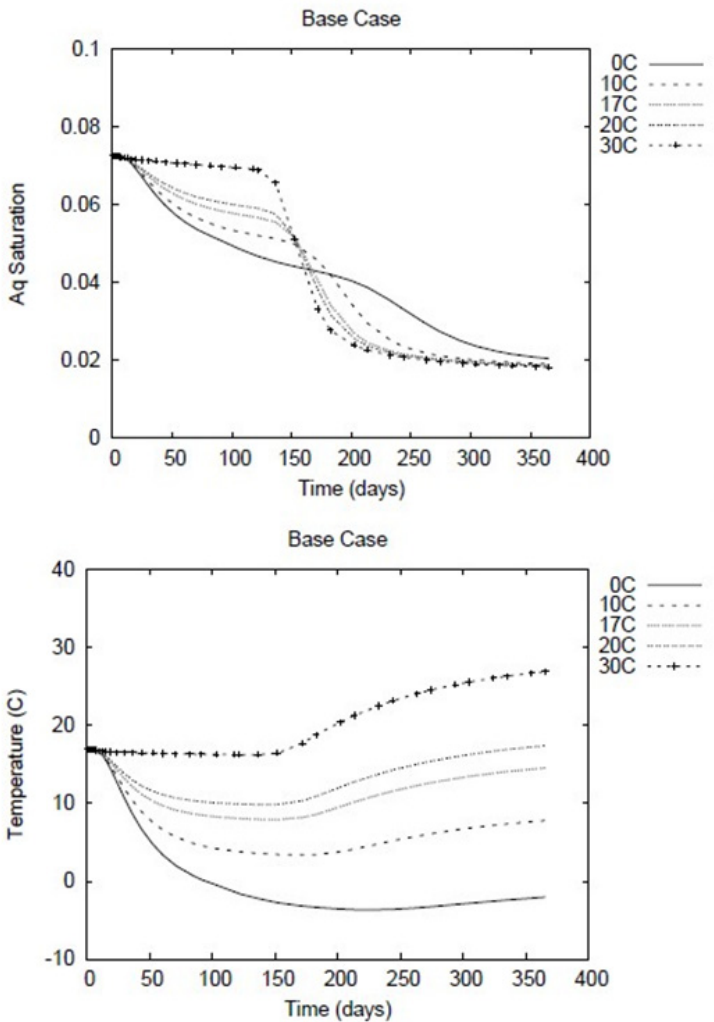

(c)
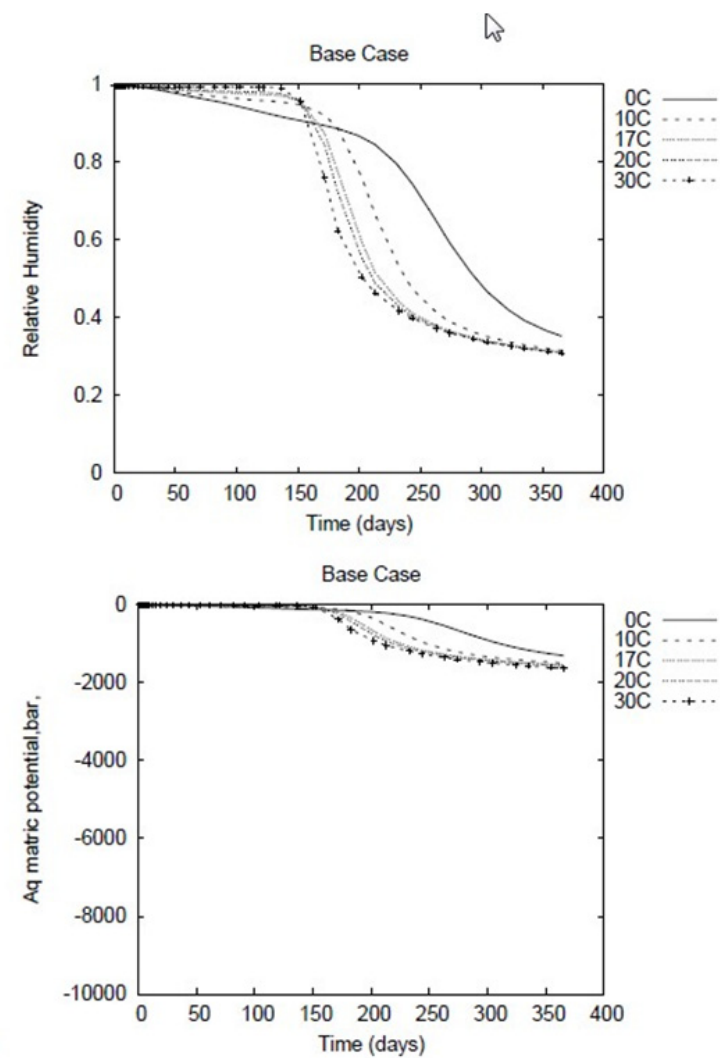

Figure 4.112. Ambient Air Desiccation as a Function of Injected Gas Temperature for an Injected Gas Relative Humidity of $60 \%$ 
(a)
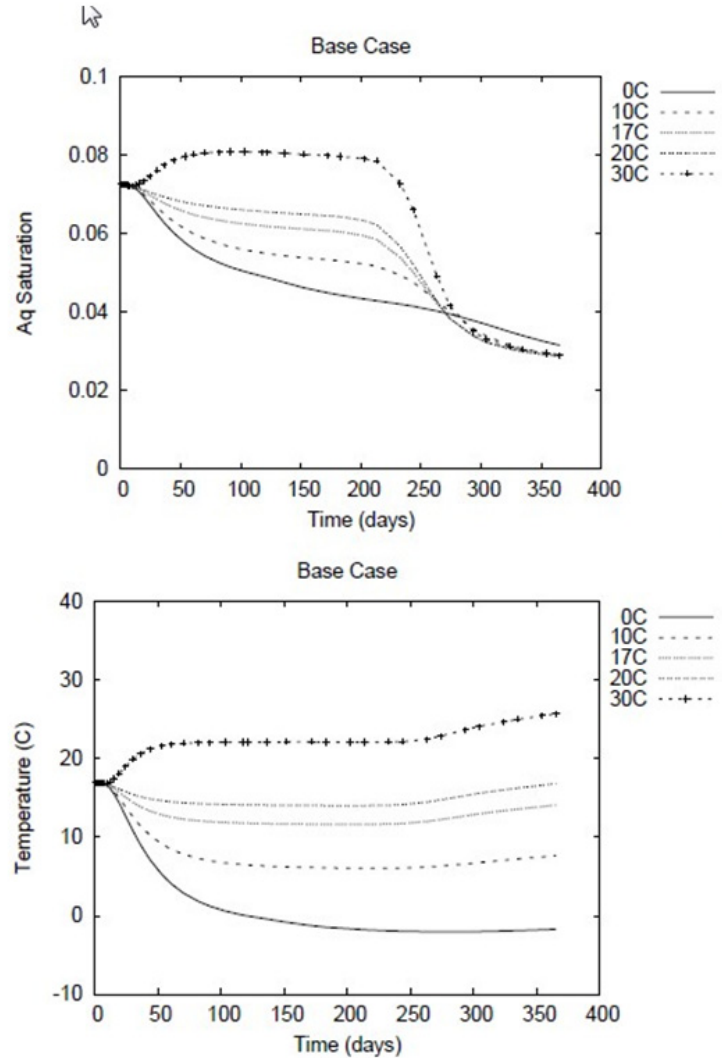

(c)

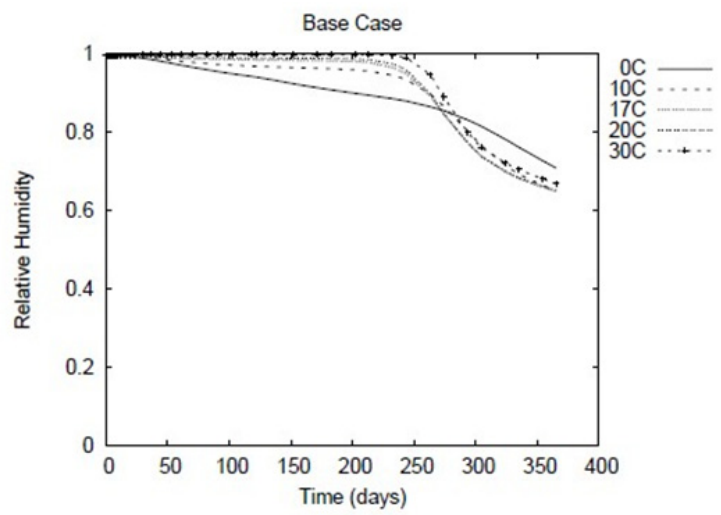

(d)

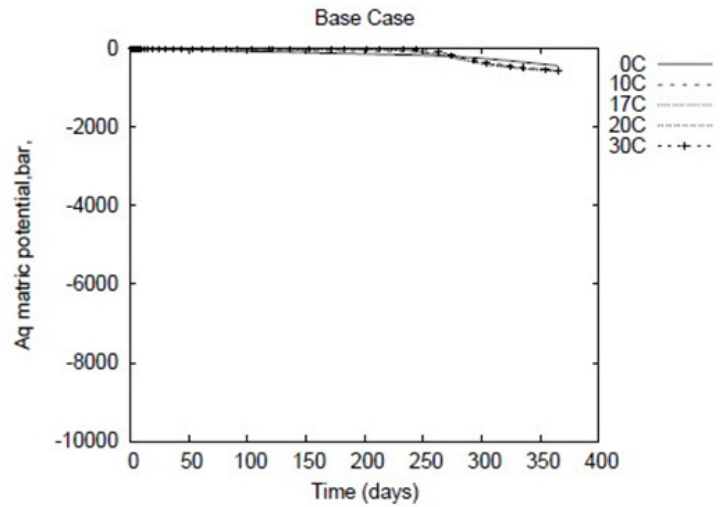

Figure 4.113. Ambient Air Desiccation as a Function of Injected Gas Temperature for an Injected Gas Relative Humidity of $80 \%$

The same pattern of response to higher temperature and relative humidity were observed for Cases 2 and 3 (Figures 4.114 through 4.121, respectively), but the duration and extent of relative water saturation change are different, as expected. 
(a)
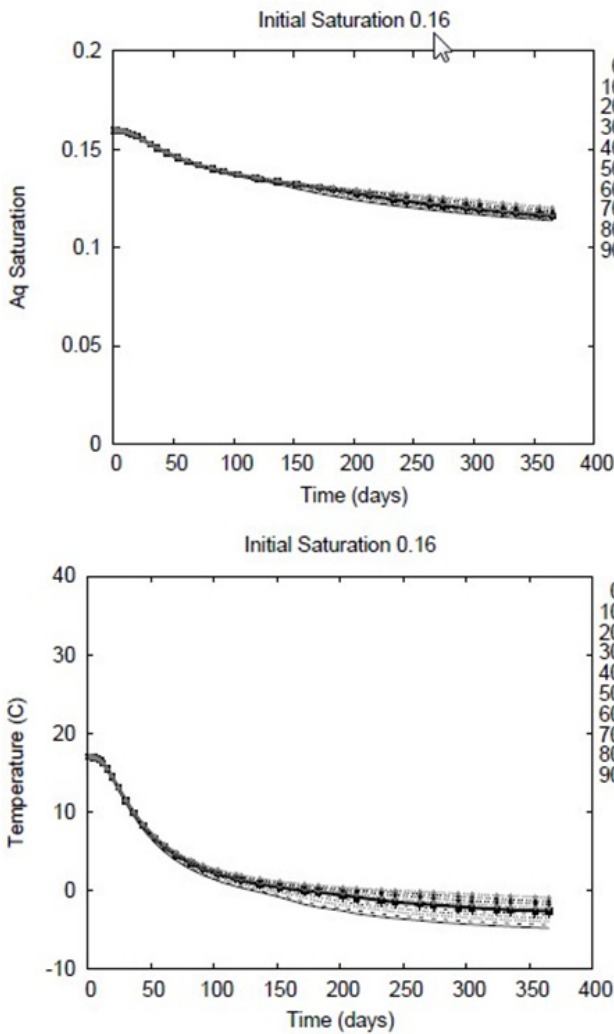

(c)
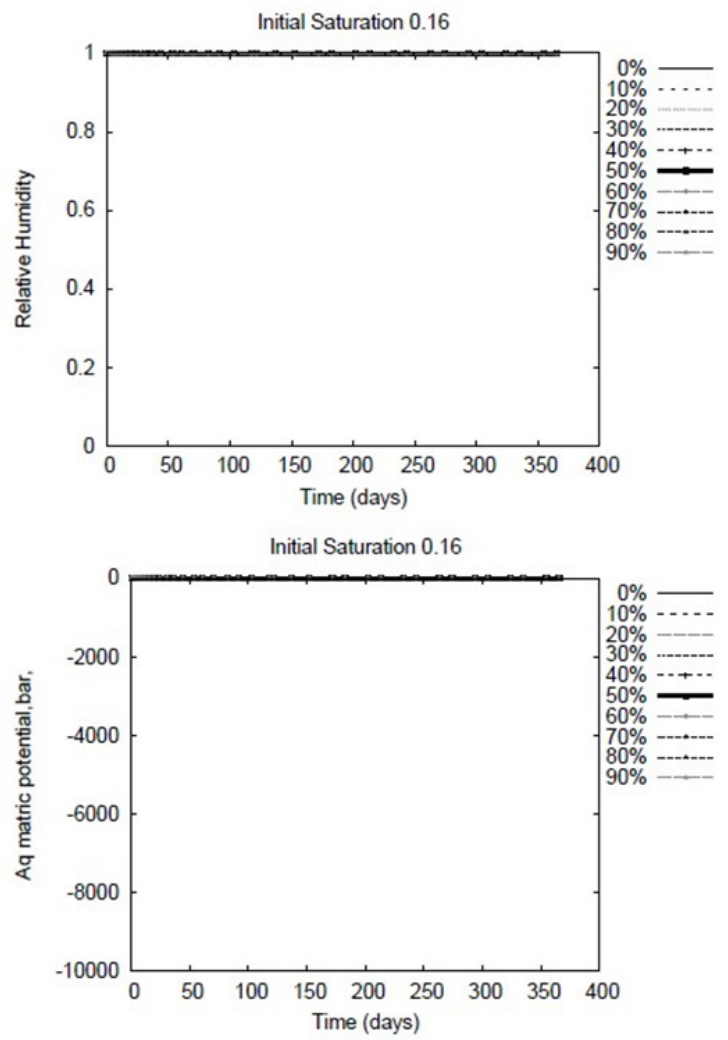

Figure 4.114. Ambient Air Desiccation as a Function of Injected Gas Relative Humidity for an Injected Gas Temperature of $0^{\circ} \mathrm{C}$, High Initial Saturation Condition 


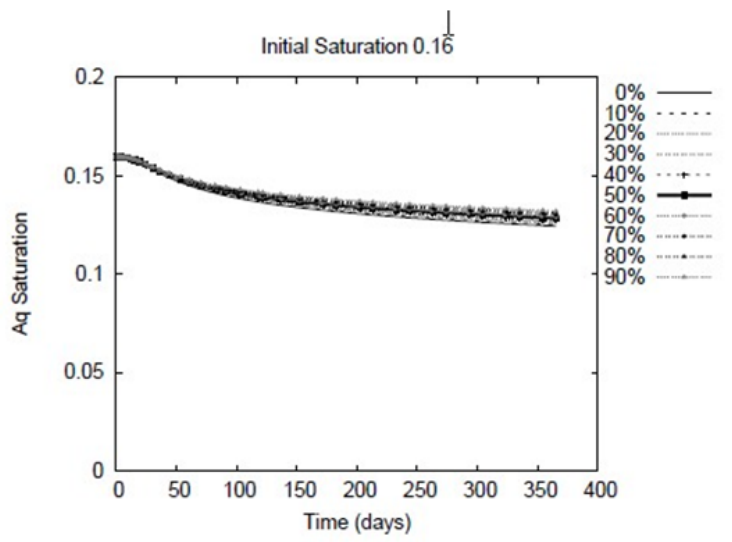

(a)

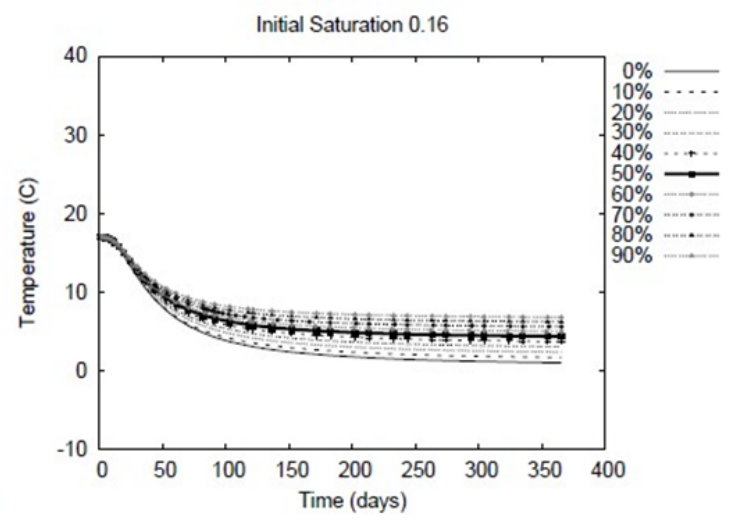

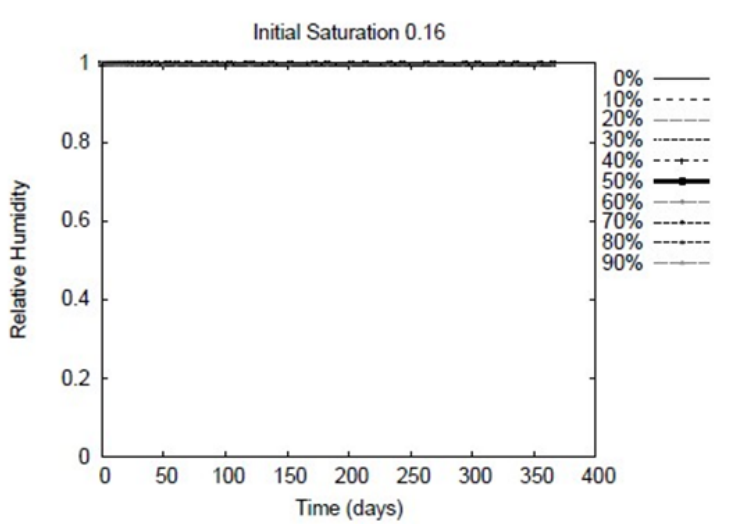

(c)

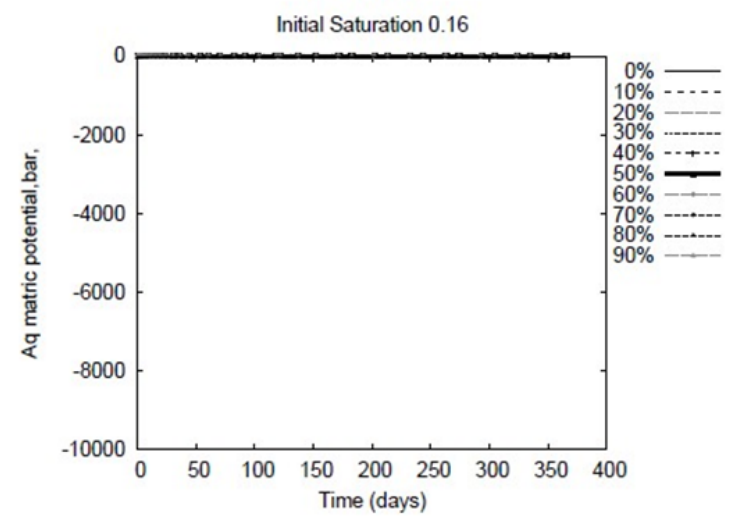

Figure 4.115. Ambient Air Desiccation as a Function of Injected Gas Relative Humidity for an Injected Gas Temperature of $10^{\circ} \mathrm{C}$, High Initial Saturation Condition. 

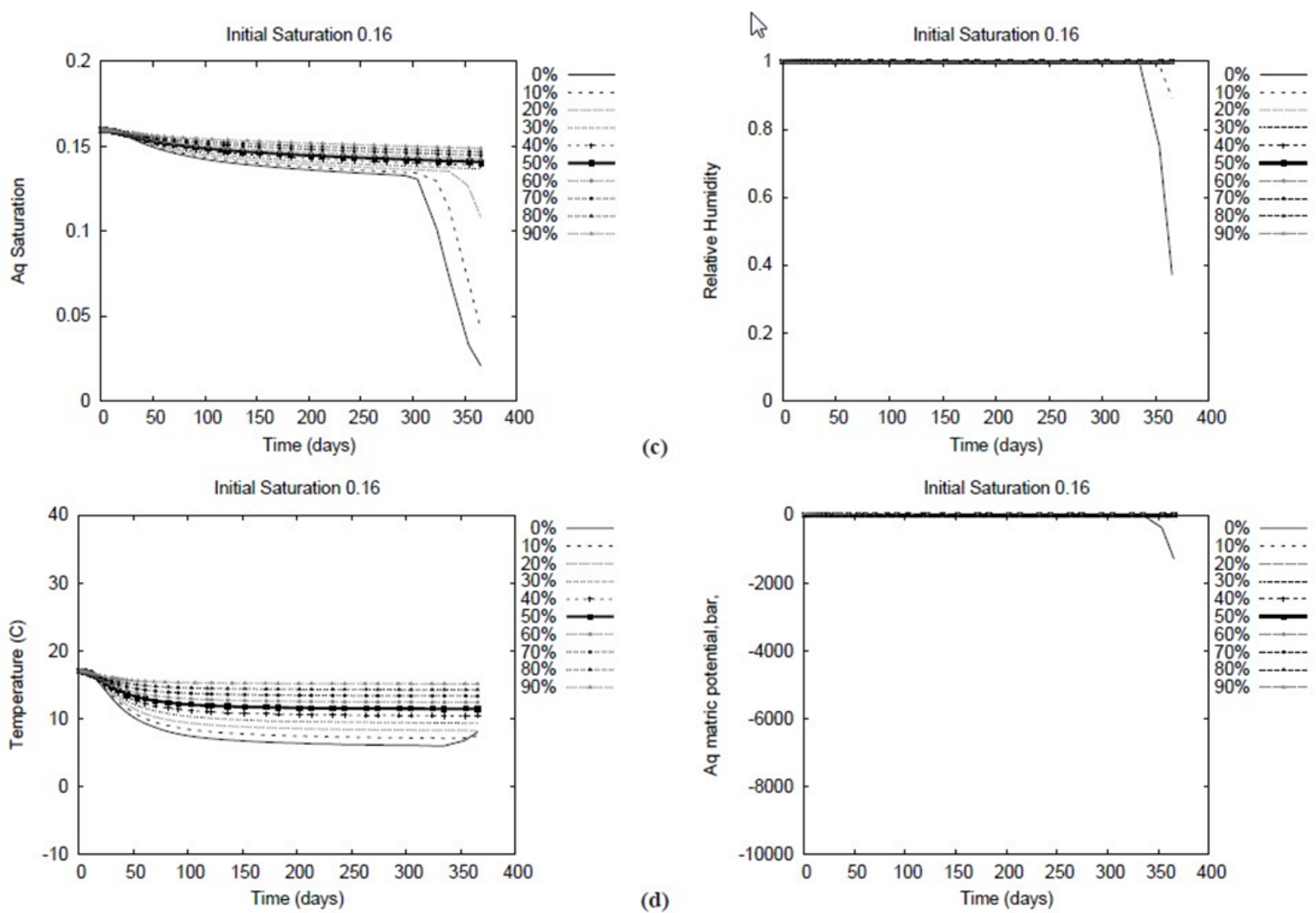

Figure 4.116. Ambient Air Desiccation as a Function of Injected Gas Relative Humidity for an Injected Gas Temperature of $20^{\circ} \mathrm{C}$, High Initial Saturation Condition 
(a)
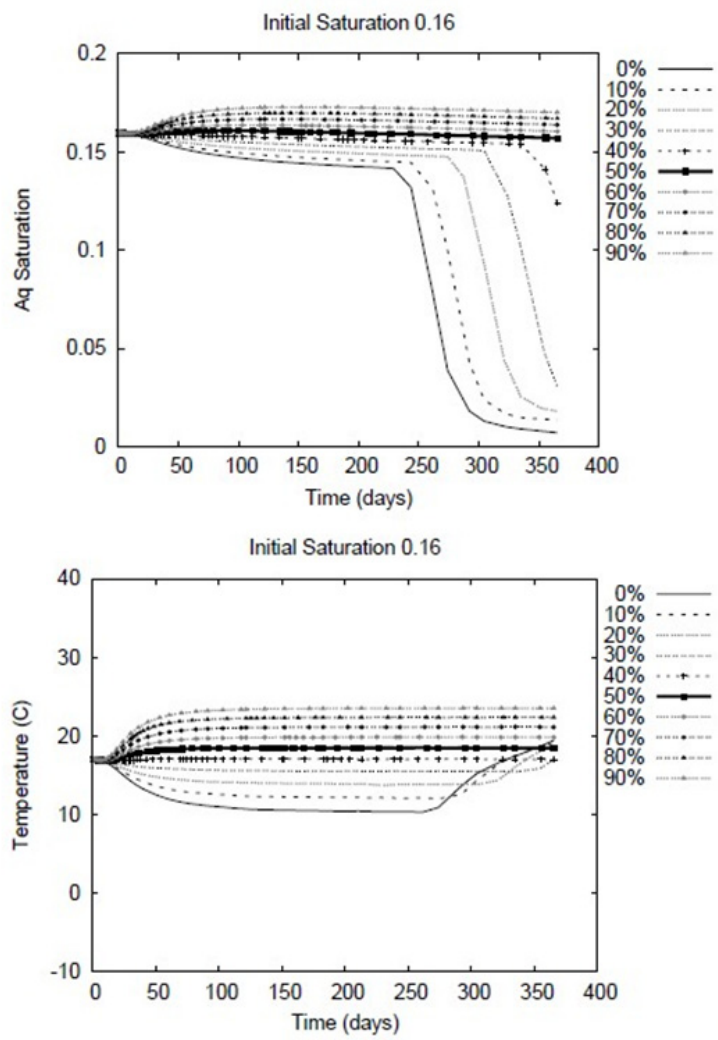

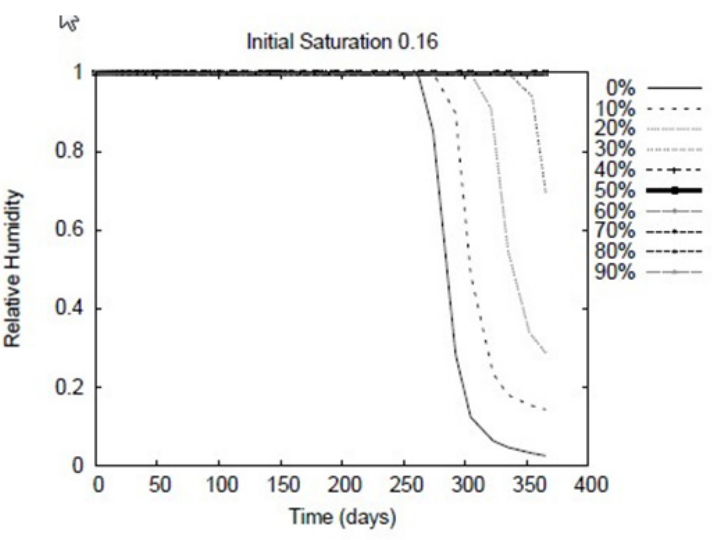

(c)

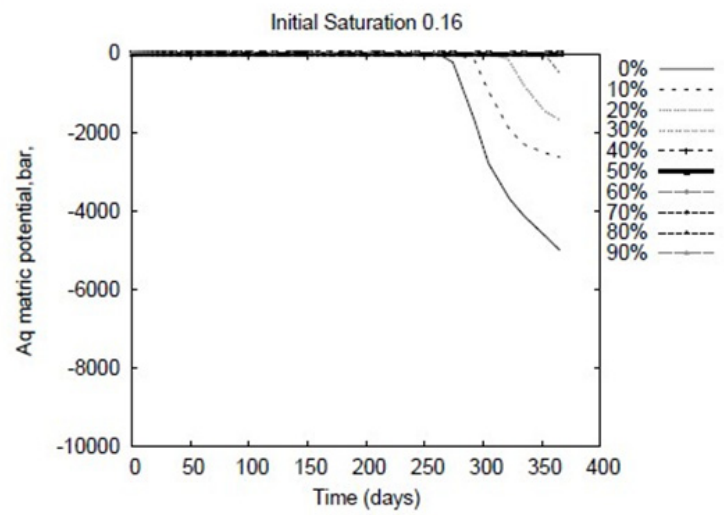

Figure 4.117. Ambient Air Desiccation as a Function of Injected Gas Relative Humidity for an Injected Gas Temperature of $30^{\circ} \mathrm{C}$, High Initial Saturation Condition 


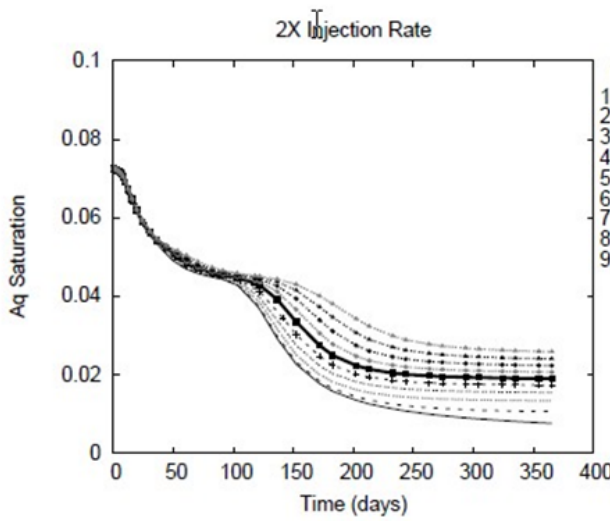

(a)

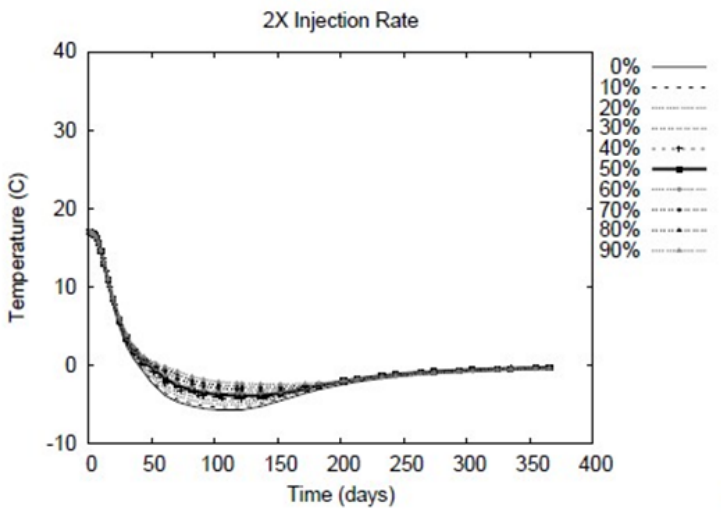

(c)
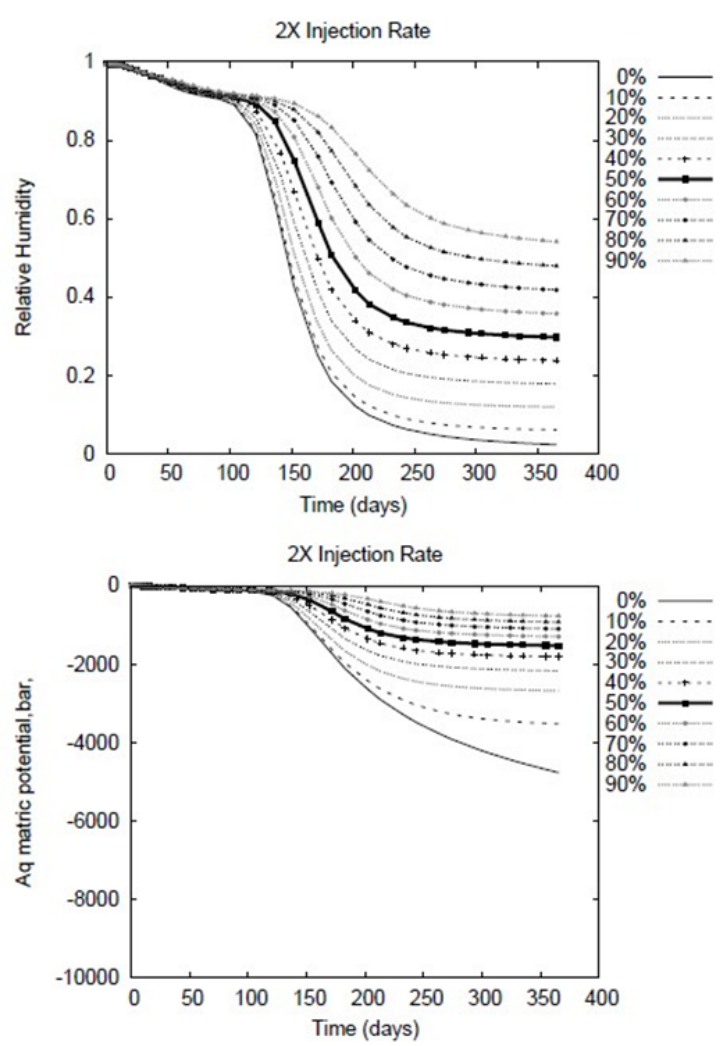

Figure 4.118. Ambient Air Desiccation as a Function of Injected Gas Relative Humidity for an Injected Gas Temperature of $0^{\circ} \mathrm{C}$, High Injection Rate Condition 
(a)
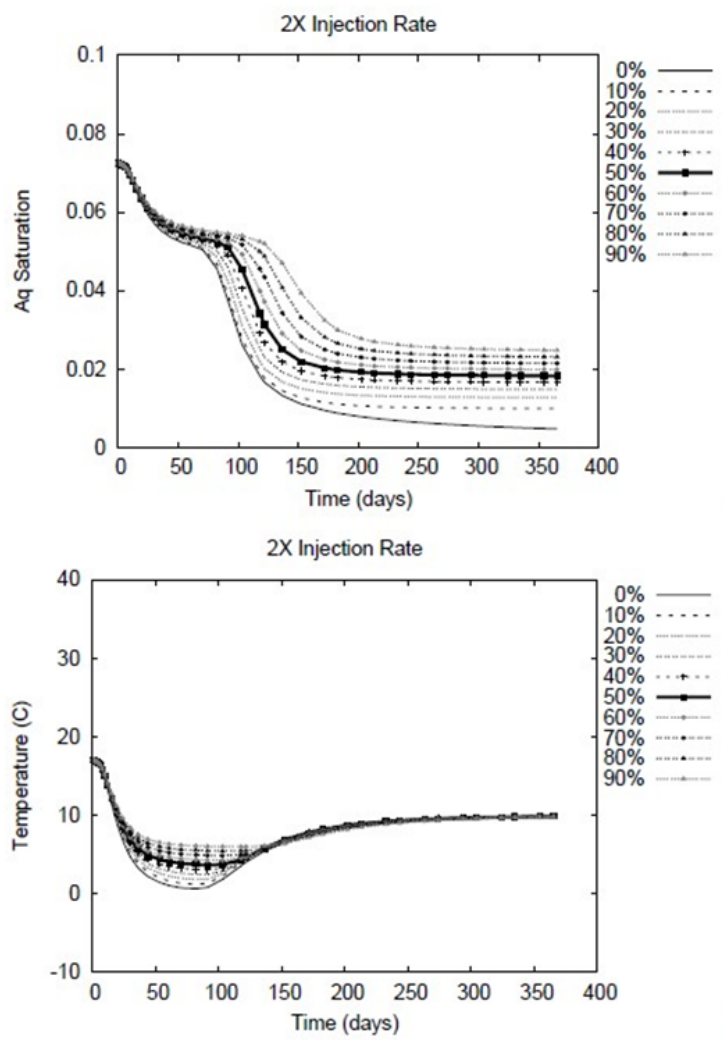

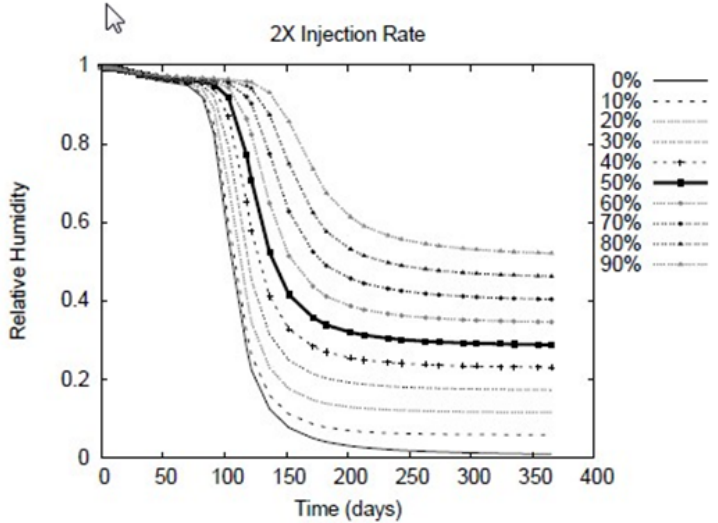

(c)

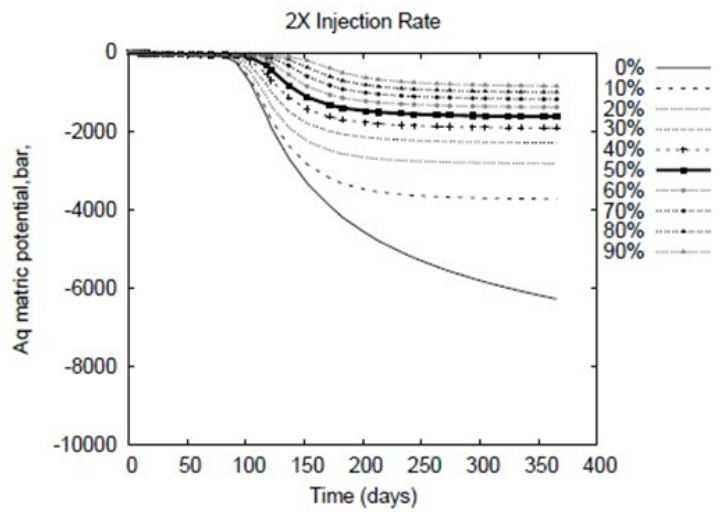

Figure 4.119. Ambient Air Desiccation as a Function of Injected Gas Relative Humidity for an Injected Gas Temperature of $10^{\circ} \mathrm{C}$, High Injection Rate Condition 
(a)
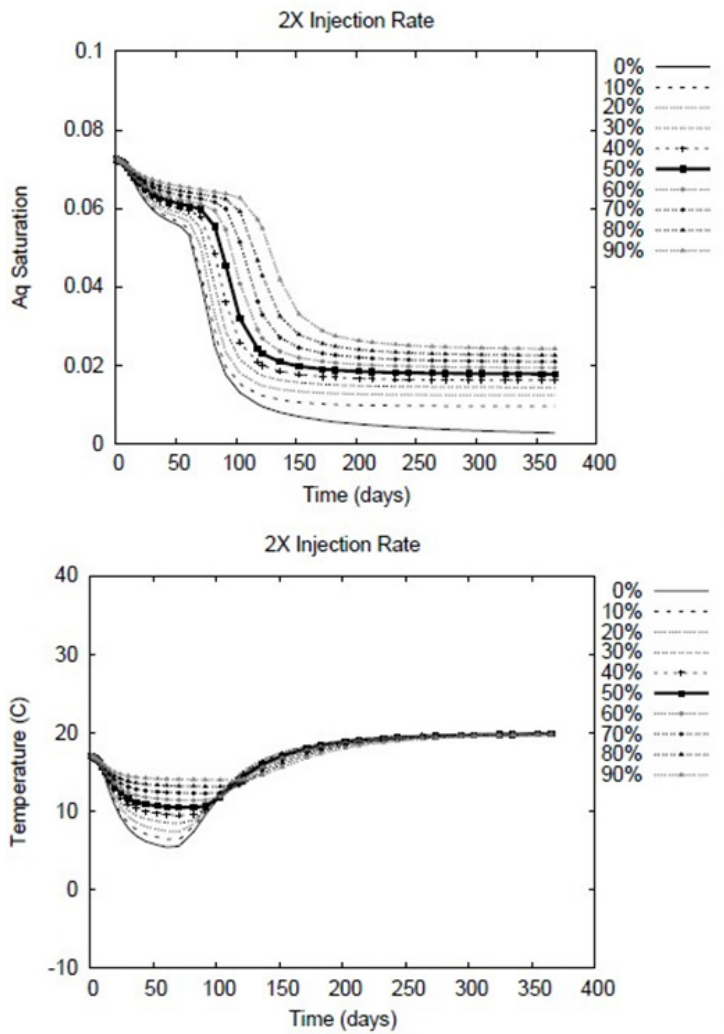

(c)
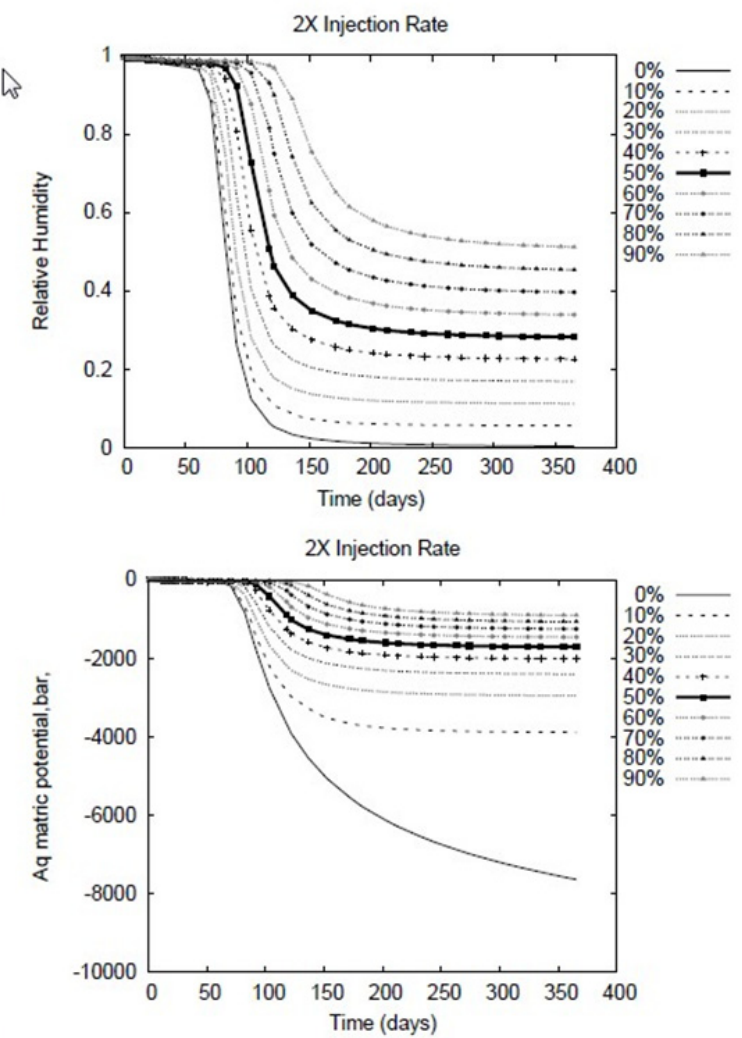

Figure 4.120. Ambient Air Desiccation as a Function of Injected Gas Relative Humidity for an Injected Gas Temperature of $20^{\circ} \mathrm{C}$, High Injection Rate Condition 
(a)
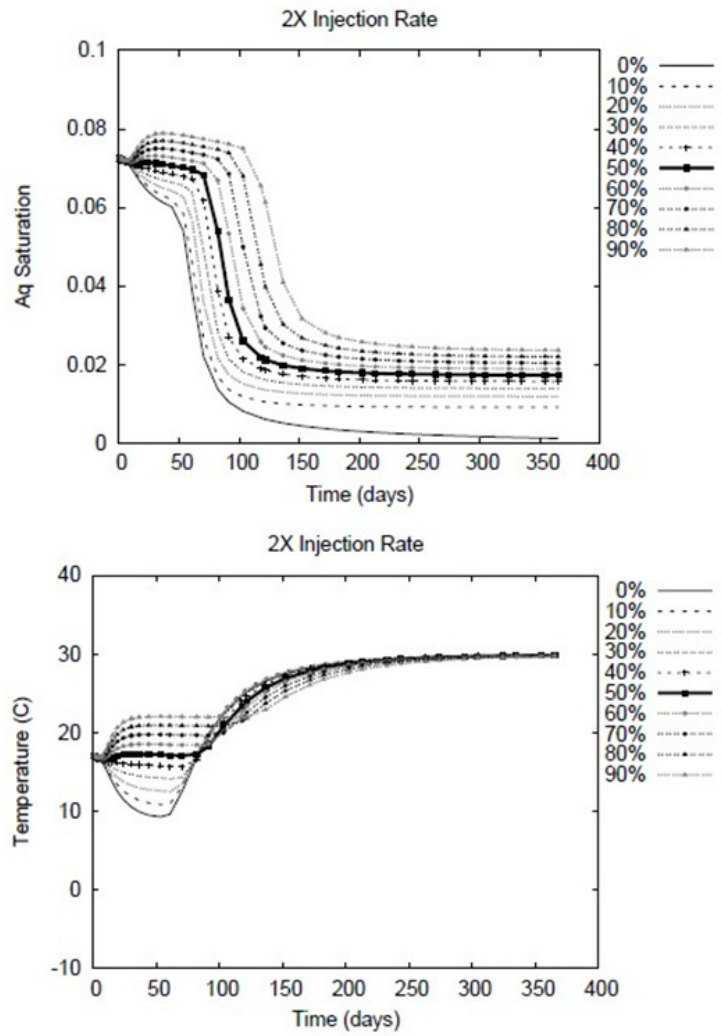

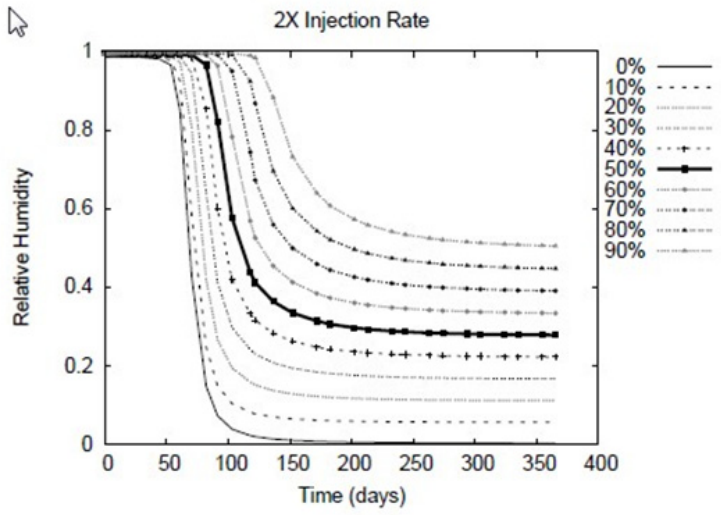

(c)

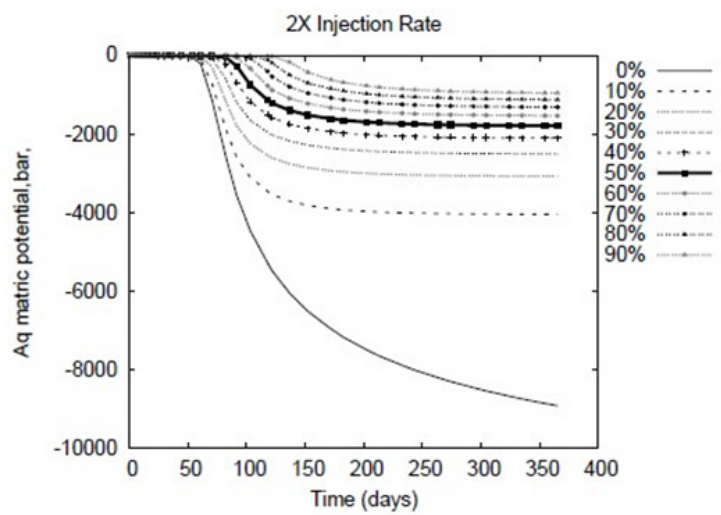

Figure 4.121. Ambient Air Desiccation as a Function of Injected Gas Relative Humidity for an Injected Gas Temperature of $30^{\circ} \mathrm{C}$, High Injection Rate Condition

\subsection{Ambient Air Assessment Conclusions}

The simulation results suggest that ambient air under a wide range of temperature and relative humidity conditions could be used for desiccation. It appears that for Hanford, an injection process that enables heating of the influent air would enhance desiccation rate with ambient air. In that case, fall, spring, and winter air could be heated to reach an effective combination of temperature and relative humidity that increases the desiccation rate without risking condensation. Under a limited set of higher humidity, cooler temperature conditions, injection of air may need to be ceased until conditions change back to a favorable range. In the summer, heating would likely not be needed. However, a control to cease injection during higher humidity periods would be needed.

While the ambient air assessment results are for a generic homogeneous domain, the results along with meteorological data may be useful for designing desiccation based on use of ambient air at a level of detail appropriate for a feasibility study.

\subsubsection{Assessment of Injection-Only Desiccation Operations}

Simulations were conducted to evaluate the injected gas flow and resultant subsurface desiccation distribution as a function of depth for implementation of desiccation using an injection-only design. Desiccation occurs as a result of injection of dry gas that has the capacity to evaporate water from the 
subsurface. An extraction well can be used to help direct gas flow within the subsurface, but extraction of soil gas does not directly cause any desiccation. Thus, if injection of dry gas can be effectively delivered to desiccate the targeted region, no extraction is needed.

Injected dry gas evaporates water until it reaches $100 \%$ relative humidity. This humid gas is then pushed outward from the injection point and would only release water back to the subsurface if temperature decreased and the related water-holding capacity of the gas thereby decreased. Because evaporative cooling occurs during desiccation, the injected gas flow is generally from cooler to warmer temperature after it has evaporated water from the subsurface. As such, the desiccation process tends to prevent condensation adjacent to the desiccation zone. Temperature changes may occur near the ground surface, however, due to seasonal weather conditions. Thus, it is of interest to understand the gas flux induced at the surface from an injection-only design because if the near-surface is cooler than deeper in the vadose zone, condensation may occur as gas is pushed upward.

The distribution of the desiccation zone and soil gas flux at the ground surface were simulated under several scenarios as part of evaluating an injection-only design. Figure 4.122 shows the model domain, although radial geometry and symmetry were used to simplify the simulations. Table 4.10 shows the simulation matrix.

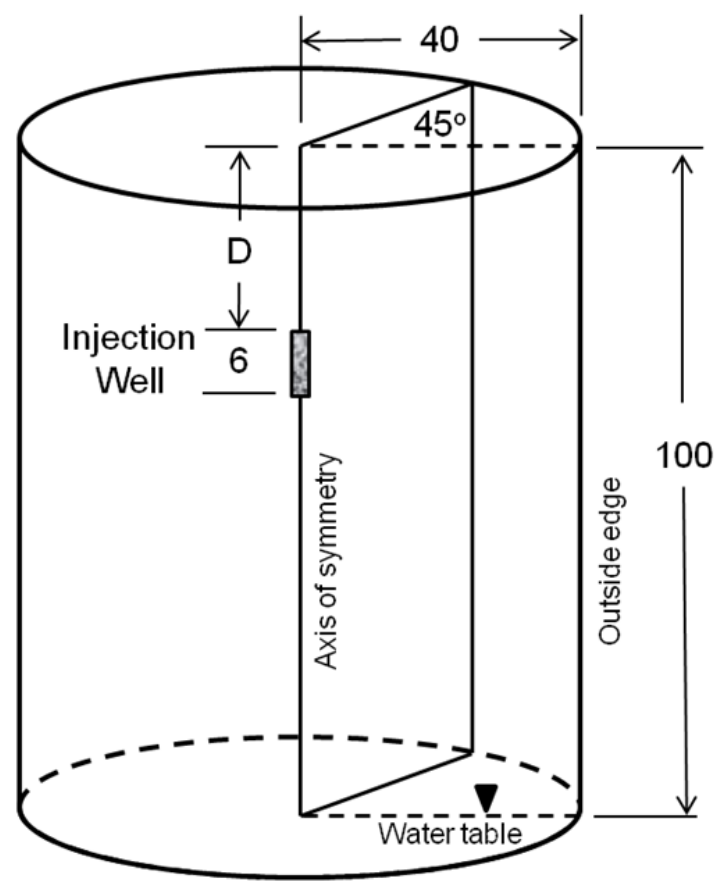

Figure 4.122. Model Domain 
Table 4.10. Simulation Matrix

\begin{tabular}{ccccc}
\hline Simulation & Depth $(\mathrm{D})(\mathrm{m})$ & $\begin{array}{c}\text { Injection Flow Rate } \\
(\mathrm{cfm})\end{array}$ & Anisotropy & $\begin{array}{c}\text { No-flux surface } \\
\text { (cover) }\end{array}$ \\
\hline 1 & 10 & 300 & $10: 1$ & no \\
2 & 20 & 300 & $10: 1$ & no \\
3 & 30 & 300 & $10: 1$ & no \\
4 & 10 & 600 & $10: 1$ & no \\
5 & 20 & 600 & $10: 1$ & no \\
6 & 30 & 600 & $10: 1$ & no \\
7 & 10 & 300 & $1: 1$ & no \\
8 & 20 & 300 & $1: 1$ & no \\
9 & 30 & 300 & $1: 1$ & no \\
10 & 10 & 300 & $10: 1$ & yes \\
11 & 20 & 300 & $10: 1$ & yes \\
12 & 30 & 300 & $10: 1$ & Yes \\
\hline
\end{tabular}

Figure 4.123 shows the simulation results in terms of the distribution of the desiccated zone after 1 year of desiccation. Note that the distribution of the desiccated zone is essentially the same at all simulated injection well screen depths. Thus, the proximity of the surface for the simulated scenarios, even without use of a barrier to gas flow, does not impact injected gas flow and skew the desiccated zone at shallower depths. Anisotropy and injection flow rate have predictable impact on the desiccation distribution. Table 4.11 shows the gas flux at ground surface for each of the cases. Shallower injection wells have greater gas flux out of the ground surface and cold-weather-induced condensation would need to be considered in the desiccation design. The gas flux decreases with the depth of injection well screen, especially in the presence of moderate anisotropy.

While these simulations use a very generalized domain, the results suggest that an injection onlydesign is viable. For a specific site, consideration of the injection well screen depth and anisotropy can be used to evaluate the need for a barrier to gas flow at the surface. 


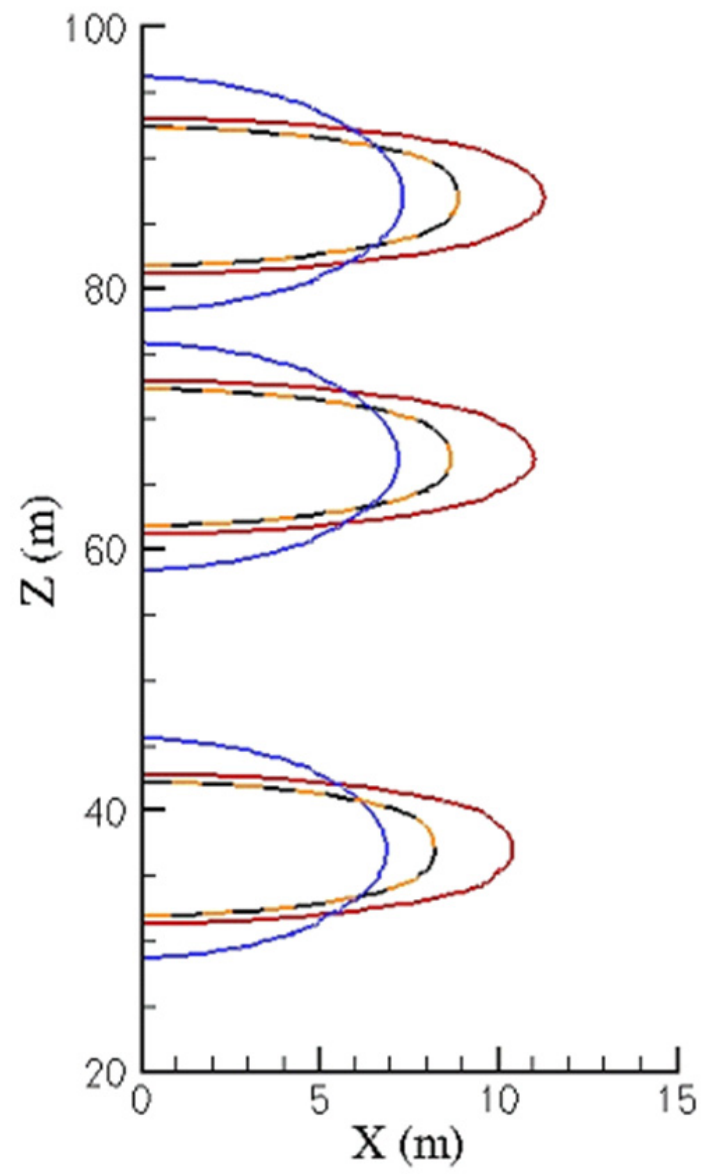

Figure 4.123. $3 \%$ Saturation Contour After 1 Year of Desiccation. The initial saturation was $\sim 7 \%$. Black lines: Base Case (300 cfm; 10:1 anisotropy; no surface cover); Red lines: $600 \mathrm{cfm}$; Blue lines: Isotropic; Orange dashed lines: Surface cover. Note that the orange dashed and black lines are coincident.

Table 4.11. Gas Flow Rate Out of the Top Domain Surface

\begin{tabular}{|c|c|c|}
\hline $\mathrm{D}(\mathrm{m})$ & Variable & $\begin{array}{l}\text { Flux Out of Top Surface } \\
(\mathrm{L} / \mathrm{min})\end{array}$ \\
\hline 10 & base case & 140.9 \\
\hline 10 & $600 \mathrm{cfm}$ & 276.3 \\
\hline 10 & isotropic & 616.9 \\
\hline 10 & cover & 0 \\
\hline 30 & base case & 4.4 \\
\hline 30 & $600 \mathrm{cfm}$ & 9.0 \\
\hline 30 & isotropic & 227.0 \\
\hline 30 & cover & 0 \\
\hline 60 & base case & 0 \\
\hline 60 & $600 \mathrm{cfm}$ & 0 \\
\hline 60 & isotropic & 35.9 \\
\hline 60 & cover & 0 \\
\hline
\end{tabular}




\subsubsection{Performance Requirements Based on Permeability Reduction and Rewetting}

In zones that achieved considerable desiccation, the volumetric moisture content was reduced from values of up to $0.10 \mathrm{~m}^{3} / \mathrm{m}^{3}$ down to values near $0.01 \mathrm{~m}^{3} / \mathrm{m}^{3}$. The impact of reducing moisture content to this low level on the vertical movement of water and contaminants to groundwater is related to the change in water relative permeability caused by the moisture reduction. While sediment properties throughout the test site are not known, based on sediment characterization data, some of these sediments are similar in grain size to the 100-mesh sand installed in the sensor zones and to a well-characterized Hanford lysimeter sand used in desiccation flow cell experiments (Oostrom et al. 2012, In Press). The Hanford lysimeter sand is a mixture of sands obtained from several Hanford locations and is considered to be representative of typical Hanford sand (Rockhold et al. 1988). Using the van Genuchten (1980) $n$ and the residual moisture content values for the lysimeter sand, water relative permeability values as a function of moisture content can be computed using a relationship combining the Mualem (1976) relative permeability model with the van Genuchten (1980) pressure-saturation relation. The relative permeability relation for moisture contents ranging from the residual moisture content value up to $0.1 \mathrm{~m} / \mathrm{m}^{3}$ is plotted in Figure 4.124 as the gray line. The curve indicates that, theoretically, the water permeability approaches zero when the moisture content is reduced to the residual value of $0.042 \mathrm{~m}^{3} / \mathrm{m}^{3}$. If the moisture content is reduced below the residual moisture content value as a result of desiccation, the actual water relative permeability is essentially zero and the remaining water cannot migrate as a result of pressure gradients. Given that the residual moisture content is a fitting parameter and is not typically directly measured, the water relative permeability behavior for three additional residual moisture contents has also been included in Figure 4.124. The additional curves indicate that an endpoint moisture content of $0.01 \mathrm{~m}^{3} / \mathrm{m}^{3}$, as obtained for this field test, will have a non-zero water relative permeability only if the actual residual moisture content of the porous media is smaller than $0.01 \mathrm{~m}^{3} / \mathrm{m}^{3}$. Even for the most extreme case, with an imposed residual moisture content of zero, the relative permeability at a moisture content of $0.01 \mathrm{~m}^{3} / \mathrm{m}^{3}$ has been reduced to $\sim 1.0 \mathrm{E}-5$, representing a reduction of more than three orders of magnitude compared to the relative permeability for a moisture content of $0.1 \mathrm{~m}^{3} / \mathrm{m}^{3}$ (Figure 4.124).

In zones with less significant moisture reduction, rewetting from adjacent moist zones is expected to occur relatively quickly because the water relative permeability of the drier zone has not been significantly reduced. A range of moisture content reduction was observed at the desiccation field test site and moisture content is being monitored over the next few years to evaluate rewetting rates. In addition to rewetting from aqueous-phase movement, rewetting can also occur through movement of vapor-phase moisture (humid soil gas). Truex et al. (2011) demonstrated that vapor-phase rewetting can increase the moisture content to near the residual moisture content of tested porous media. However, the vapor-phase rewetting process is also very slow without soil gas advection because of the relatively low moisture content of soil gas and slow diffusion-driven movement of the humid gas.

The above phenomena are discussed in the context of rewetting processes in Section 4.2.2.2.2. While it is important to target moisture content reductions that result in low post-desiccation moisture content in relation to the residual moisture content for the porous media, it is also important to consider the overall porous media properties within and surrounding the desiccation zone. As shown in the rewetting analysis, the porous media permeability distribution and the overall thickness of the desiccated zone significantly impact the rewetting rate. Thus, site-specific performance targets must be developed considering the properties and the site heterogeneity. 


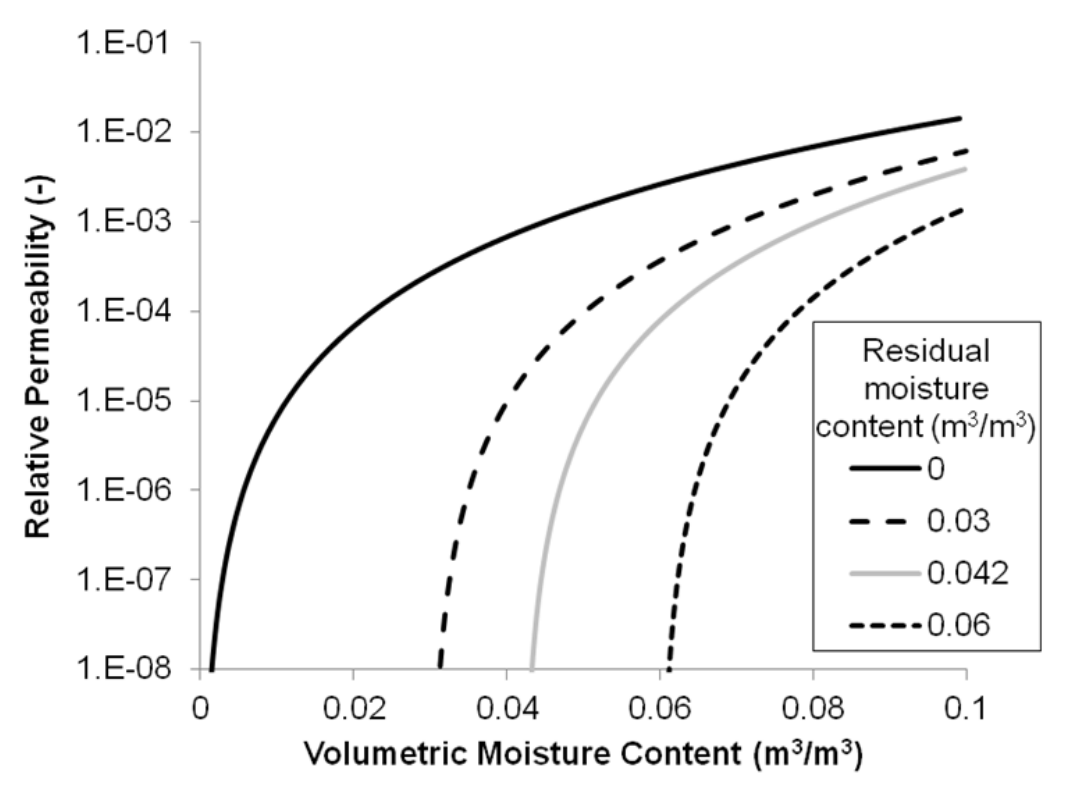

Figure 4.124. Relative Permeability (Mualem 1976) as a Function of Moisture Content, Using a van Genuchten (1980) $n$ value of 3.64 and Residual Moisture Contents of 0, 0.03, 0.42, and 0.06 . The van Genuchten $n$ Value of 3.64 and residual moisture content of 0.42 (gray line) were derived from laboratory retention properties for the Hanford lysimeter sand (Oostrom et al. 2012).

\subsubsection{Design Calculations}

Like many in situ technologies, numerical simulations provide a primary means to evaluate and select designs based on 1) flow and physical/chemical processes during implementation (e.g., injection of dry gas) and 2) predicted performance as a function of design. As shown in this report and previous studies (Truex et al. 2011; Ward et al. 2008), models are available for use in this design process. However there are also scoping-level calculations that can be used to support design of a desiccation system. Scoping calculations for desiccation are based on calculation of the water-holding capacity of injected gas and relating this factor to moisture removal in the subsurface. Results of laboratory tests and modeling have shown that desiccation processes can be reasonably represented by this type of calculation (Truex et al. 2011; Oostrom et al. 2009, 2012, In Press).

The water-holding capacity of the injected gas is a function of its temperature and starting relative humidity. The temperature of the subsurface has been shown to vary significantly during desiccation due to evaporative cooling. For scoping purposes, the temperature used in the analysis could be selected as the starting subsurface temperature (e.g., $\sim 17^{\circ} \mathrm{C}$ for Hanford) to define a maximum amount of moisture that will be removed. While temperature variation occurs in the vicinity of the zone that is being desiccated, injected gas will move into portions of the vadose zone that are at the starting temperature. Thus, in a more diffuse zone, the total water removed is related to the starting vadose zone temperature. A more conservative approach would be to use a lower temperature such as $12^{\circ} \mathrm{C}$ (observed average temperature in the field test site during desiccation). This lower temperature would represent the waterholding capacity within a more focused desiccation zone where it is more likely that significant reduction in moisture content will occur. Using the lower temperature is conservative in that the water-holding 
capacity will be lower and the scoping calculations will estimate that a longer period of injection is needed to reach a specified moisture removal goal. For use of ambient air injection, the temperature and relative humidity of the injected gas will vary over time. In scoping calculations, meteorological data can be used to select a representative temperature and relative humidity for the design that is suitable for estimating the average water-holding capacity over a 1-year timeframe.

With the selected subsurface temperature and representative injected gas temperature and relative humidity, the water-holding capacity of the injected gas can be determined using a psychometric chart as the humidity ratio $\left(\mathrm{kg}_{\text {water }} / \mathrm{kg}_{\text {air }}\right)$ at $100 \%$ relative humidity and the subsurface temperature minus the humidity ratio $\left(\mathrm{kg}_{\text {water }} / \mathrm{kg}_{\text {air }}\right)$ at the injected gas relative humidity and temperature (dry bulb). This computation provides the water-holding capacity of the injected gas in mass of water per mass of air units. The ideal gas law can be used to compute the density of the influent air to convert the waterholding capacity to units of mass of water per volume of air (e.g., kg-water $/ \mathrm{m}^{3}$-gas). Desiccation volume in the subsurface is related to the water-holding capacity of the injected gas, the amount of gas injected (flow rate and duration of injection), and the amount of water per volume of soil (soil moisture content). A useful parameter for scoping level design at a site is the desiccation capacity of the injected gas in units of volume of soil desiccated per volume of gas injected. As shown in field and laboratory testing, desiccation will reduce soil moisture content to very low levels. Thus, the amount of water that will be removed from a target volume can be estimated as the average starting moisture content in the volume (e.g., $\mathrm{kg}$-water $/ \mathrm{m}^{3}$-soil). By dividing the water-holding capacity of the injected gas by the gravimetric water content, a desiccation capacity can be computed in units of volume of soil desiccated per volume of gas injected (e.g., $\mathrm{m}^{3}$-soil $/ \mathrm{m}^{3}$-gas). The desiccation capacity can then be used to estimate the total volume of gas that needs to be injected (product of the flow rate and duration) to reach a target desiccation volume. For an actual application, heterogeneity in the subsurface will cause variations in the starting moisture content and overall distribution of the desiccated zone. However, the scoping calculation reflects the physical linkage between the capacity of the injected gas to evaporate and carry away water and the amount of water that needs to be removed, and is therefore useful to assess the approximate duration of treatment for a given injection gas flow rate.

An example computation is shown below.

- Water-holding capacity of air at a relative humidity of $100 \%$ for $17^{\circ} \mathrm{C}$ subsurface temperature $=$ $0.012 \mathrm{~kg}$-water $/ \mathrm{kg}$-air (psychometric chart)

- Water-holding capacity of air at an assumed average relative humidity of $20 \%$ for an assumed average ambient air temperature of $15^{\circ} \mathrm{C}=0.002 \mathrm{~kg}$-water $/ \mathrm{kg}$-air (psychometric chart)

- Water-holding capacity of injected gas $=0.012-0.002=0.01 \mathrm{~kg}$-water $/ \mathrm{kg}$-air

- Density of air at $17^{\circ} \mathrm{C}$ using the ideal gas law $=1.22 \mathrm{~kg}$-air $/ \mathrm{m}^{3}$-air

- Water-holding capacity of injected gas $=0.01 \times 1.22=0.0122 \mathrm{~kg}$-water $/ \mathrm{m}^{3}$-air

- Average moisture content in target zone $=90 \mathrm{~kg}$-water $/ \mathrm{m}^{3}$-soil (volumetric moisture content of 0.09)

- Desiccation capacity of injected gas $=0.0122 / 90=1.36 \mathrm{E}-4 \mathrm{~m}^{3}$-soil $/ \mathrm{m}^{3}$-air

- The desiccation capacity can be used to estimate a desiccation volume for a selected flow rate and duration. For instance, injecting ambient air at $30 \mathrm{~m}^{3} / \mathrm{min}(\sim 1000 \mathrm{cfm})$ for 1 year is $1.58 \mathrm{E}+7 \mathrm{~m}^{3}$-air. Using the desiccation capacity above, the desiccated volume $=1.36 \mathrm{E}-4 \times 1.58 \mathrm{E}+7=\sim 2000 \mathrm{~m}^{3}$. 


\subsubsection{Assessment with Respect to CERCLA Feasibility Study Criteria}

It will be necessary for the feasibility study author to evaluate soil desiccation using the seven CERCLA criteria, i.e., protectiveness of human health and the environment, compliance with applicable or relevant and appropriate requirements (ARARs); long-term effectiveness and permanence; reduction of toxicity, mobility, or volume; short-term effectiveness; implementability; and cost. The following section summarizes the information collected during the treatability test and how they relate to the CERLCA criteria.

\section{Threshold Criteria: Protectiveness and ARARs}

Numerical modeling will be a key tool in evaluating whether desiccation can meet remediation goals associated with the Comprehensive Environmental Response, Compensation, and Liability Act (CERCLA) feasibility study threshold criteria of 1) protection of human health and environment and 2) ARARs. Satisfying the CERCLA protectiveness criterion requires that groundwater not be contaminated above the defined groundwater remediation goals by future contaminant migration. The criteria determining remediation goals are the ARARs that define groundwater standards. It is expected that assessment of performance for evaluation purposes in the FS will rely on fate and transport modeling. The treatability test collected data to improve the technical basis for this modeling and thereby increase site, regulator, and stakeholder confidence in the model results. Table 4.12 lists modeling and supporting laboratory information that were collected in the treatability test that relate to the threshold criteria.

Table 4.12. Information to Support Threshold Criteria

\begin{tabular}{|c|c|}
\hline Element & Supporting Information \\
\hline Model developed for application to desiccation & $\begin{array}{l}\text { Desiccation design modeling code enhancements to address } \\
\text { very dry conditions obtained by desiccation have been } \\
\text { developed and applied as part of the field test (Truex et al. } \\
\text { 2011; Section 4.2; Oostrom et al. 2009, 2012, In Press) } \\
\text { - Numerical modeling of overall desiccation performance } \\
\text { with respect to impact on groundwater has been conducted } \\
\text { and provides a template for how this type of modeling can } \\
\text { be applied in the future (Truex et al. 2011) } \\
\text { - Laboratory tests have been conducted to support the model } \\
\text { development and evaluate modeling performance (Truex } \\
\text { et al. 2011; Oostrom et al. 2009, 2012, In Press) }\end{array}$ \\
\hline $\begin{array}{l}\text { Description and quantification of rewetting } \\
\text { process }\end{array}$ & $\begin{array}{l}\text { - Laboratory tests have been conducted to quantify and } \\
\text { describe vapor-phase and aqueous-phase rewetting (Oostrom } \\
\text { et al. In Press; Truex et al. 2011) } \\
\text { - An assessment of rewetting rate as a function of desiccation } \\
\text { end point and surrounding conditions has been conducted } \\
\text { (Section 4.2.2.2) } \\
\text { - Short term rewetting data ( } 8 \text { months of rewetting) have been } \\
\text { collected at the field site with plans to continue this data } \\
\text { collection (Section 4.1.2.2) }\end{array}$ \\
\hline
\end{tabular}




\section{Long-Term Effectiveness and Permanence}

With respect to information from the treatability test, long-term effectiveness and permanence considers the magnitude of residual risk to human and ecological receptors (Table 4.13). Soil desiccation is not expected to remove contamination, but leave it relatively immobilized in the vadose zone. Over time, "rewetting" of the desiccation zone following treatment will occur. The rate of rewetting is important with respect to the contaminant flux to the groundwater and resultant groundwater contaminant concentrations.

Table 4.13. Information to Support Long-Term Effectiveness and Permanence Criterion

\begin{tabular}{ll}
\hline \multicolumn{1}{c}{ Element } & \multicolumn{1}{c}{ Supporting Information } \\
\hline $\begin{array}{l}\text { What desiccation conditions mitigate vertical } \\
\text { transport of water/solutes? }\end{array}$ & $\begin{array}{l}\text { The relationship between porous media properties, } \\
\text { desiccation extent, and rewetting rate have been quantified } \\
\text { (Section 4.2.2.2) }\end{array}$ \\
$\begin{array}{ll}\text { Description and quantification of rewetting } \\
\text { process and how it relates to the longevity of the } \\
\text { desiccation effect on contaminant migration to } \\
\text { groundwater }\end{array}$ & $\begin{array}{l}\text { Laboratory tests have been conducted to quantify and } \\
\text { describe vapor-phase and aqueous-phase rewetting (Oostrom } \\
\text { et al. In Press; Truex et al. 2011) }\end{array}$ \\
& $\begin{array}{l}\text { An assessment of rewetting rate as a function of desiccation } \\
\text { end point and surrounding conditions has been conducted } \\
\text { (Section 4.2.2.2) }\end{array}$ \\
& $\begin{array}{l}\text { Short term rewetting data (8 months of rewetting) have been } \\
\text { collected at the field site with plans to continue this data } \\
\text { collection (Section 4.1.2.2) }\end{array}$ \\
$\begin{array}{ll}\text { In a heterogeneous environment, how dry do the } \\
\text { low permeability zones need to be and how does } \\
\text { this correlate to future water migration? }\end{array}$ & $\begin{array}{l}\text { An assessment of rewetting rate as a function of desiccation } \\
\text { end point and surrounding conditions has been conducted } \\
\text { based on field data in heterogeneous portions of the test site } \\
\text { (Section 4.2.2.2) }\end{array}$ \\
\hline
\end{tabular}

\section{Reduction of Volume, Mobility, or Toxicity}

By intent, soil desiccation will reduce the mobility of otherwise quite mobile contaminants (Tc-99 and nitrate). Desiccation does not address the volume or toxicity of the contamination. Ultimately, mobility is controlled by the rate of rewetting after desiccation (Table 4.14).

Table 4.14. Information to Support Reduction of Toxicity, Mobility, or Volume Criterion

\begin{tabular}{ll}
\hline \multicolumn{1}{c}{ Element } & \multicolumn{1}{c}{ Supporting Information } \\
\hline $\begin{array}{l}\text { What desiccation conditions mitigate vertical } \\
\text { transport of water/solutes? }\end{array}$ & $\begin{array}{l}\text { The relationship between porous media properties, } \\
\text { desiccation extent, and rewetting rate have been quantified } \\
\text { (Section 4.2.2.2) }\end{array}$ \\
$\begin{array}{ll}\text { Description and quantification of rewetting } \\
\text { process and related impact on mobility }\end{array}$ & $\begin{array}{l}\text { Laboratory tests have been conducted to quantify and } \\
\text { describe vapor-phase and aqueous-phase rewetting (Oostrom } \\
\text { et al. In Press; Truex et al. 2011) }\end{array}$ \\
& $\begin{array}{l}\text { An assessment of rewetting rate as a function of desiccation } \\
\text { end point and surrounding conditions has been conducted }\end{array}$ \\
& $\begin{array}{l}\text { (Section 4.2.2.2) } \\
\text { Short term rewetting data (8 months of rewetting) have been } \\
\text { collected at the field site with plans to continue this data } \\
\text { collection (Section 4.1.2.2) }\end{array}$ \\
\hline
\end{tabular}




\section{Short-Term Effectiveness}

Short-term effectiveness considers potential effects on human health and the environment during the implementation phase of the remedy, and the time required to achieve the remedial action objectives (Table 4.15). Extraction of soil gas, as applied for the field test, could expose workers and/or the public (if it is contaminated); however, extraction of soil gas is not recommended for the full-scale design and is therefore not considered as part of short-term effectiveness. Another attribute of this criterion is the rate of desiccation in terms of the remediation timeframe.

Table 4.15. Information to Support Short-Term Effectiveness Criterion

\begin{tabular}{cl}
\hline Element & \multicolumn{1}{c}{ Supporting Information } \\
\hline Quantification of desiccation rate & Laboratory tests have quantified the desiccation rate (Truex et al. \\
& 2011 ; Oostrom et al. 2009, 2012, In Press) \\
& - Field test data were evaluated with respect to the desiccation rate \\
& (Section 4.2) \\
$\bullet$ & Desiccation design information includes information related to \\
& estimating the desiccation rate (Section 4.2) \\
\hline
\end{tabular}

\section{Implementability}

Implementability includes technical and administrative feasibility, and availability of services and materials. The only pertinent element of this criterion for the treatability test is technical feasibility (Table 4.16).

Table 4.16. Information to Support Implementability Criterion

\begin{tabular}{ll}
\hline \multicolumn{1}{c}{ Element } & \multicolumn{1}{c}{ Supporting Information } \\
\hline Design information & Desiccation design modeling code enhancements to address very dry \\
conditions obtained by desiccation have been developed and applied as part of & the field test (Truex et al. 2011; Section 4.2; Oostrom et al. 2009, 2012, In \\
& Press) \\
- & Numerical modeling of overall desiccation performance with respect to impact \\
& on groundwater has been conducted and provides a template for how this type \\
& of modeling can be applied in the future (Truex et al. 2011) \\
- & Laboratory tests have been conducted to support the model development and \\
& evaluate modeling performance (Truex et al. 2011; Oostrom et al. 2009,2012, \\
& In Press) \\
- & The relationship between porous media properties, desiccation extent, and \\
& rewetting rate have been quantified (Section 4.2.2.2) \\
- & Desiccation design information was generated from the treatability test, \\
& including use of ambient air and injection-only designs (Sections 2.2 and \\
& $4.2 .4)$ \\
- & Field test equipment has been described, although some aspects of the field \\
& test design are not recommended as part of full-scale implementation (Section \\
& 3.2 ) \\
- Desiccation design information was generated from the treatability test, \\
including use of ambient air and injection-only designs (Sections 2.2 and \\
4.2.4)
\end{tabular}


Table 4.16. (contd)

\begin{tabular}{|c|c|}
\hline Element & Supporting Information \\
\hline $\begin{array}{l}\text { Subsurface property ranges and } \\
\text { heterogeneity for implementing } \\
\text { desiccation }\end{array}$ & $\begin{array}{l}\text { - Desiccation design modeling code enhancements to address very dry } \\
\text { conditions obtained by desiccation have been developed and applied as part of } \\
\text { the field test (Truex et al. 2011; Section 4.2; Oostrom et al. 2009, 2012, In } \\
\text { Press) } \\
\text { - Numerical modeling of overall desiccation performance with respect to impact } \\
\text { on groundwater has been conducted and provides a template for how this type } \\
\text { of modeling can be applied in the future (Truex et al. 2011) } \\
\text { - Laboratory tests have been conducted to support the model development and } \\
\text { evaluate modeling performance (Truex et al. 2011; Oostrom et al. 2009, 2012, } \\
\text { In Press) }\end{array}$ \\
\hline
\end{tabular}

\section{Cost}

Cost elements are needed to develop relative cost estimates for use in feasibility studies (Table 4.17). Historical data relating to Hanford well drilling/completion exists to estimate the cost of specific wells to be used for gas injection. Cost of air handling equipment to inject ambient air and providing monitoring capability can be obtained from engineering handbooks/vendors. No specialized equipment is necessary to implement desiccation.

Table 4.17. Information Supporting Estimating Cost for Desiccation

\begin{tabular}{|c|c|}
\hline Element & Supporting Information \\
\hline Design & $\begin{array}{l}\text { Field test equipment has been described, although some } \\
\text { aspects of the field test design are not recommended as part } \\
\text { of full-scale implementation (Section 3.2) } \\
\text { - Desiccation design information was generated from the } \\
\text { treatability test, including use of ambient air and injection- } \\
\text { only designs (Sections } 2.2 \text { and } 4.2 .4 \text { ) }\end{array}$ \\
\hline Operating timeframe & $\begin{array}{l}\text { - Desiccation design information includes information related } \\
\text { to estimating the desiccation rate (Section 4.2) } \\
\text { - Desiccation design modeling include code enhancements to } \\
\text { address very dry conditions obtained by desiccation has been } \\
\text { developed and applied as part of the field test (Truex et al. } \\
\text { 2011; Section 4.2; Oostrom et al. 2009, 2012, In Press) } \\
\text { - Laboratory tests have quantified the desiccation rate (Truex } \\
\text { et al. 2011; Oostrom et al. 2009, 2012a, b) } \\
\text { - Field test data were evaluated with respect to the desiccation } \\
\text { rate (Section 4.2) }\end{array}$ \\
\hline $\begin{array}{l}\text { Surface barrier needs in conjunction with } \\
\text { desiccation }\end{array}$ & $\begin{array}{l}\text { Numerical modeling of overall desiccation performance with } \\
\text { respect to impact on groundwater have been conducted and } \\
\text { provide a template for how this type of modeling can be } \\
\text { applied in the future, including consideration of surface } \\
\text { barriers (Truex et al. 2011) }\end{array}$ \\
\hline
\end{tabular}




\subsection{Quality Assurance Results}

The Data Quality Objectives Summary Report for the Soil Desiccation Pilot Test (CHPRC 2009) defines principle study questions (PSQ) for the treatability test. Below are those questions and brief discussions of how each has been met.

PSQ \#1: Will soil desiccation result in significant reduction of the sediment moisture content?

Desiccation reduced sediment moisture content to nearly zero in a significant portion of the zone targeted by the test (see Section 4.2.2.1, Active Desiccation Performance Assessment). While desiccation proceeded initially in strata having higher permeability, adjacent strata with lower permeability began to dry as well.

PSQ \#2: Will a significant rate of sediment desiccation be accomplished during the test?

Desiccation proceeded as expected, correlating directly with the rate of dry gas injected (see Section 4.2.2.1, Active Desiccation Performance Assessment).

PSQ \#3: Can soil desiccation be performed cost effectively?

Extrapolation of test results to a proposed remediation indicates that cost is limited to drilling injection wells, a comparable quantity of monitoring boreholes, blowers to inject ambient air, and heaters to condition the ambient air, as appropriate, for the duration required to desiccate the target region (see Section 2.0 Conclusions and Recommendations, Section 6.0, Cost and Schedule, and Section 4.2.4.5 Assessment with Respect to CERCLA Feasibility Study Criteria). All aspects of the remedy utilize readily available technology and robust equipment.

PSQ \#4: Can soil desiccation be accomplished such that it is effective in protecting groundwater in the long term?

Numerical simulations were performed that show desiccation, in combination with a surface barrier designed to minimize recharge, will protect groundwater from mobile vadose zone contamination (Truex et al. 2011).

Data collection and evaluation, and laboratory sample analysis were conducted in accordance with the methods and specifications described in the Sampling and Analysis Plan for the Soil Desiccation Pilot Test (DOE 2010c). A data quality assessment will be provided in a future revision of this test report that includes description of how the quality control limits were met for detection limits, accuracy, and precision (i.e., Table 1-2 and in accordance with Sections 2.3 and 2.4 of the Sampling and Analysis Plan for the Soil Desiccation Pilot Test [DOE 2010c]). 


\subsection{Cost and Schedule}

Overall cost of the desiccation pilot test, beginning October 2008 to conduct a data quality objectives (DQO) process for the characterization phase and continuing through design, construction, and implementation of the desiccation test to March 2012, was nearly \$5.9 million. Major cost elements and associated expenditures are shown in Table 6.1.

Table 6.1. Costs for Treatability Test Activities

\begin{tabular}{lr}
\hline \multicolumn{1}{c}{ Treatability Test Activity } & $\$(\mathrm{~K})$ \\
\hline Characterization phase DQO and sampling \& analysis plan (permitting documentation) & 208 \\
Characterization equipment (design/procurement/installation) & 270 \\
Characterization phase borehole and extraction well drilling & 414 \\
Characterization phase data collection (sample collection \& analysis, in situ sediment & 638 \\
permeability) & \\
Characterization testing reporting & 55 \\
Desiccation Field Test Plan and Sampling \& Analysis Plan & 102 \\
Laboratory testing \& numerical simulations (support test design) & 1,372 \\
Monitoring borehole drilling & 340 \\
Test site preparation (electric power, surface geomembrane installation) & 198 \\
Equipment/instrument design, procurement and installation & 366 \\
Conduct active portion of test & 406 \\
Nitrogen supply & 595 \\
Post-desiccation borehole drilling and sampling & 161 \\
Post-desiccation monitoring (rewetting, 1 year) & 301 \\
Data evaluation \& reporting & 445 \\
\hline Total & $\mathbf{5 , 8 7 2}$ \\
\hline
\end{tabular}

Costs shown above are not representative of what it would cost to implement a desiccation remedy. As discussed in Section 2 and Section 4.2.4 of this report, the design would be simplified due to the focus being remedy implementation rather than data collection related to evaluation of the desiccation process. For example, ambient air is recommended rather than dry nitrogen and desiccation progress monitoring would be accomplished with fewer instruments/sensors/geophysical methods and in a manner that maximizes autonomous data collection. Note also that a desiccation remedy would likely be combined with a permanent surface barrier, such as an evapotranspiration barrier, to limit recharge. 


\subsection{References}

Archie GE. 1942. "The Electrical Resistivity Log as an Aid in Determining Some Reservoir Characteristics." Petroleum Transactions of AIME 146:54-62.

Basinger JM, GJ Kluitenberg, JM Ham, JM Frank, PL Barnes, and MB Kirkham. 2003. "Laboratory Evaluation of the Dual-Probe Heat-Pulse Method for Measuring Soil Water Content." Vadose Zone Journal 2:389-399.

Bilskie J, R Clawson, and J Ritter. 2007. "Calibration of Heat Pulse Sensors for Soil Water Matric Potential.” In Annual Meetings Abstracts [CD] ASA, CSSA, and SSSA, Madison, Wisconsin.

Binley A, G Cassiani, R Middleton, and P Winship. 2002. "Vadose Zone Model Parameterisation Using Cross-Borehole Radar and Resistivity Imaging." Journal of Hydrology 267(3-4):147-159.

Brown RW and DL Bartos. 1982. A Calibration Model for Screen-Caged Peltier Thermocouple Psychrometers. Research Paper INT-293, U.S. Department of Agriculture Research, Forest Service, Intermountain Forest and Range Experimental Station, Ogden, Utah.

Carsel RF and RS Parrish. 1988. "Developing Joint Probability Distributions of Soil Water Retention Characteristics." Water Resources Research 24(5):755-769.

Campbell GS, C Calissendorif, and JH Williams. 1991. "Probe for Measuring Soil Specific Heat Using a Heat-Pulse Method.” Soil Science Society of America Journal 55:(29):1-293.

Cass A, GS Campbell, and TL Jones. 1981. Hydraulic and Thermal Properties of Soil Samples from the Buried Waste Test Facility. PNL-4015, Pacific Northwest Laboratory, Richland, Washington.

CHPRC. 2009. Data Quality Objectives Summary Report for the Soil Desiccation Pilot Test. SGW-41327, Rev. 0, CH2M HILL Plateau Remediation Company, Richland, Washington.

Corbin RA, BC Simpson, MJ Anderson, WF Danielson III, JG Field, TE Jones, and CT Kincaid. 2005. Hanford Soil Inventory Model Rev. 1. RPP-26744, Rev. 0, CH2M HILL Hanford Group, Inc., Richland Washington.

Daily W and E Owen. 1991. "Cross-Borehole Resistivity Tomography.” Geophysics 56:1228-1235.

Day-Lewis FD, JM Harris, and SM Gorelick. 2002. "Time-lapse Inversion of Crosswell Radar Data." Geophysics 67:1740-1752.

Dresel PE, DM Wellman, KJ Cantrell, and MJ Truex. 2011. "Review: Technical and Policy Challenges in Deep Vadose Zone Remediation of Metals and Radionuclides." Environmental Science \& Technology 45(10):4207-4216.

DOE. 2008a. Deep Vadose Zone Treatability Test Plan for the Hanford Central Plateau.

DOE/RL-2007-56, Rev. 0, U.S. Department of Energy Richland Office, Richland, Washington. 
DOE. 2008b. Sampling and Analysis Plan for Characterization of the Soil Desiccation Pilot Test Site. DOE/RL-2008-67, Rev. 0, U.S. Department of Energy Richland Office, Richland, Washington.

DOE. 2009. BC Cribs and Trenches Excavation-Based Treatability Test Report, Rev. 1 Reissue. DOE/RL-2009-36, U.S. Department of Energy, Richland Operations Office, Richland, Washington.

DOE. 2010a. Characterization of the Soil Desiccation Pilot Test Site. DOE/RL-2009-119, Rev. 0, U.S. Department of Energy Richland Office, Richland, Washington.

DOE. 2010b. Field Test Plan for the Soil Desiccation Pilot Test. DOE/RL-2010-04, Rev. 0, U.S. Department of Energy Richland Office, Richland, Washington.

DOE. 2010c. Sampling and Analysis Plan for the Soil Desiccation Pilot Test. DOE/RL-2010-83, Rev. 0, U.S. Department of Energy Richland Office, Richland, Washington.

Evett SR. 2005. International Soil Moisture Sensor Comparison. In Irrigation Insights No. 1, Second Edition, Soil Water Monitoring. P Charlesworth (ed.), Land \& Water Australia, Braddon, Australia, pp. 68-71.

EPA. 1992. Guidance for Conducting Treatability Studies under CERCLA. EPA/540/R-92/071a, U.S. Environmental Protection Agency, Washington, D.C.

FHI. 2006. Evaluation of Vadose Zone Treatment Technologies to Immobilize Technetium-99. WMP-27397, Rev. 1, Fluor Hanford, Inc., Richland, Washington.

Flint AL, GS Campbell, KM Ellett, and C Calissendorff. 2002. "Calibration and Temperature Correction of Heat Dissipation Matric Potential Sensors.” Soil Science Society of America Journal 66:1439-1445.

Friedman SP. 2005. "Soil Properties Influencing Apparent Electrical Conductivity: A Review." Computers and Electronics in Agriculture 46:47-50.

Greacen EL, RL Correll, RB Cunningham, OC Johns, and KD Nichols. 1981. "Calibration.” In Soil Water Assessment by the Neutron Method, pp. 50-78, CSIRO, Melbourne, Australia.

Hamamoto S, P Moldup, K Kawamoto, T Komatsu. 2010. “Excluded-Volume Expansion of Archie's Law for Gas and Solute Diffusivities and Electrical and Thermal Conductivities in Variably Saturated Porous Media." Water Resources Research,46, doi:10.1029/2099WR00842r.

Han M, S Youssef, E Rosenberg, M Fleury, P Levitz. 2009. "Deviation from Archie's Law in Partially Saturated Porous Media: Wetting Film Versus Disconnectedness of the Conducting Phase." Physical Review E, 79,doi:10.1103/PhysRevE.79.031127.

Hignett C and SR Evett. 2002. "Neutron Thermalization.” In Methods of Soil Analysis. Part 4Physical Methods. JH Dane and G Clarke Topp (eds.), pp. 501-521, Soil Science Society of America, Madison, Wisconsin. 
Hubbard SS, JE Peterson, EL Majer, PT Zawislanski, J Roberts, KH Williams, and F Wobber. 1997. "Estimation of Permeable Pathways and Water Content Using Tomographic Radar Data." The Leading Edge of Exploration 16(11):1623-1628.

Huisman JA, C Sperl, W Bouten, and JM Verstraten. 2001. "Soil Water Content Measurements at Different Scales: Accuracy of Time Domain Reflectometry and Ground-Penetrating Radar." Journal of Hydrology 245:48-58.

Jackson MJ and DR Tweeton. 1994. MIGRATOM - Geophysical Tomography Using Wavefront Migration and Fuzzy Constraints. Bureau of Mines Report of Investigations 9497, 35 pp., Pittsburgh, Pennsylvania.

Johnson TC, RJ Versteeg, A Ward, FD Day-Lewis, and A Revil. 2010. “Improved Hydrogeophysical Characterization and Monitoring Through Parallel Modeling and Inversion of Time-Domain Resistivity and Induced Polarization Data." Geophysics 75(4):WA27-WA41.

Ledieu J, P De Ridder, P De Clerck, and S Dautrebande. 1986. "A Method of Measuring Soil Moisture by Time-Domain Reflectometry." Journal of Hydrology 88:319-328.

Li, J., DW Smith, SG Fityus, and DC Sheng. 2003. "The Numerical Analysis of Neutron Moisture Probe Measurements." ASCE International Journal of Geomechanics 3(1):11-20.

Mualem Y. 1976. "A New Model for Predicting the Hydraulic Conductivity of Unsaturated Porous Media. Water Resources Research 12:513-522.

Oostrom M, TW Wietsma, JH Dane, MJ Truex, and AL Ward. 2009. "Desiccation of Unsaturated Porous Media: Intermediate-Scale Experiments and Numerical Simulation." Vadose Zone Journal $8: 643-650$.

Oostrom M, GD Tartakovsky, TW Wietsma, MJ Truex, and JH Dane. 2011. "Determination of Water Saturation in Relatively Dry and Desiccated Porous Media Using Gas-Phase Partitioning Tracer Tests." Vadose Zone Journal 10:1-8; doi:10.2136/vzj2010.0101.

Oostrom M, TW Wietsma, CE Strickland, VL Freedman, and MJ Truex. 2012. "Instrument Testing During Desiccation and Rewetting at the Intermediate Laboratory Scale." Vadose Zone Journal doi:10.2136/vzj2011.0089.

Oostrom M, VL Freedman, TW Wietsma, and MJ Truex. In Press. "Effects of Porous Medium Heterogeneity on Vadose Zone Desiccation: Intermediate-Scale Laboratory Experiments and Simulations." Vadose Zone Journal.

Ruijun M, A McBratney, B Whelan, B Minasny, and M Short. 2011. "Comparing Temperature Correction Models for Soil Electrical Conductivity Measurement." Precision Agriculture 12:55-66, doi:10.1007/s11119-009-9156-7. 
Serne RJ, AL Ward, W Um, BN Bjornstad, DF Rucker, DC Lanigan, and MW Benecke. 2009. Electrical Resistivity Correlation to Vadose Zone Sediment and Pore-Water Composition for the BC Cribs and Trenches Area. PNNL-17821, Pacific Northwest National Laboratory, Richland, Washington.

Slater LD and DP Lesmes. 2002. "Electrical-Hydraulic Relationships Observed for Unconsolidated Sediments. Water Resources Research 38:1213-1225.

Tokunaga TK, J Wan, and KR Olson. 2002. “Saturation-Matric Potential Relations in Gravel.” Water Resources Research 38(10):1214, doi:10.1029/2001WR001242.

Topp GC and PA (Ty) Ferré. 2002. "Water Content." In Methods of Soil Analysis Part 4, Physical Methods, SSSA Book Series No. 5, JH Dane and GC Topp (eds.), Section 3.1, pp. 417-545, Soil Science Society of America, Inc., Madison, Wisconsin.

Truex MJ, M Oostrom, VL Freedman, CE Strickland, and AL Ward. 2011. Laboratory and Modeling Evaluations in Support of Field Testing for Desiccation at the Hanford Site. PNNL-20146, Pacific Northwest National Laboratory, Richland, Washington.

Truex MJ, M Oostrom, CE Strickland, GB Chronister, MW Benecke, and CD Johnson. In Press. "FieldScale Assessment of Desiccation Implementation for Deep Vadose Zone Contaminants." Vadose Zone Journal.

Um W, RJ Serne, MJ Truex, AL Ward, MM Valenta, CF Brown, C Iovin, KN Geiszler, IV Kutnyakov, ET Clayton, H-S Chang, SR Baum, and DM Smith. 2009. Characterization of Sediments from the Soil Desiccation Pilot Test (SDPT) Site in the BC Cribs and Trenches Area. PNNL-18800, Pacific Northwest National Laboratory, Richland, Washington.

van Genuchten M Th. 1980. "A Closed-Form Equation for Predicting the Hydraulic Conductivity of Unsaturated Soils." Soil Science Society of America Journal 44:892-898.

Van Overmeeren R, S Sariowan, and J Geherls. 1997. "Ground Penetrating Radar for Determining Volumetric Soil Water Content: Results of Comparative Measurements at Two Test Sites." Journal of Hydrology 197:316-338.

Ward AL, GW Gee, ZF Zhang, and JM Keller. 2004. Vadose Zone Contaminant Fate and Transport Analysis for the 216-B-26 Trench. PNNL-14907, Pacific Northwest National Laboratory, Richland, Washington.

Ward AL, M Oostrom, and DH Bacon. 2008. Experimental and Numerical Investigations of Soil Desiccation for Vadose Zone Remediation: Report for Fiscal Year 2007. PNNL-17274, Pacific Northwest National Laboratory, Richland, Washington.

Ward AL and RS Wittman. 2009. Calibration of a Neutron Hydroprobe for Moisture Measurements in Small-Diameter Steel-Cased Boreholes. PNNL-18539, Pacific Northwest National Laboratory, Richland, Washington. 
Webb SW. 2000. "A Simple Extension of Two-Phase Characteristic Curves to Include the Dry Region." Water Resources Research 36:1425-1430.

White I and SJ Zegelin. 1995. "Electric and Dielectric Methods for Monitoring Soil-Water Content." In Handbook of Vadose Zone Characterization and Monitoring, LG Wilson, LG Everett, and S Cullen (eds.), Chapter 22, A. F. Lewis, New York.

White MD and M Oostrom. 2006. STOMP Subsurface Transport Over Multiple Phases, Version 4.0, User's Guide. PNNL-15782, Pacific Northwest National Laboratory, Richland, Washington.

White MD and M Oostrom. 2000. STOMP Subsurface Transport Over Multiple Phase: Theory Guide. PNNL-11216, Pacific Northwest National Laboratory, Richland, Washington.

Yao T, PJ Wierenga, AR Graham, and SP Neuman. 2004. "Neutron Probe Calibration in a Vertically Stratified Vadose Zone.” Vadose Zone Journal 3:1400-1406. 


\section{Appendix A}

Analytical Data Report for Sediment Samples Collected from Post-Desiccation Boreholes C8387 and C8388 


\section{Appendix A}

\section{Analytical Data Report for Sediment Samples Collected from Post-Desiccation Boreholes C8387 and C8388}

Two boreholes were installed after the end of active desiccation in the locations shown in Figure 3.4 of the main text. Samples were collected and analyzed for soil moisture and selected pore water chemistry as described in the detailed laboratory report shown below. Additional samples were analyzed to provide a more complete profile of the soil moisture distribution in the two boreholes than the more limited set of samples that were analyzed for soil moisture and selected pore water chemistry. These additional sample analyses used the same procedures as described in the laboratory report. Table A.1 and Table A. 2 provide the results of these additional analyses. 
Table A.1. BC Crib Borehole C8387

\begin{tabular}{|c|c|c|c|c|c|c|c|c|c|c|}
\hline $\begin{array}{c}\text { Shoe } \\
\text { depth } \\
\text { (ft bgs) }\end{array}$ & $\begin{array}{c}\text { Interval } \\
\quad \#\end{array}$ & Liner & $\begin{array}{l}\text { Core Depth } \\
\text { (ft) }\end{array}$ & $\begin{array}{l}\text { Gravimetric Soil } \\
\text { (gSoil/gTotal) }\end{array}$ & $\begin{array}{c}\text { Gravimetric } \mathrm{H}_{2} 0 \\
\left(\mathrm{gH}_{2} \mathrm{O} / \mathrm{gSoil}\right)\end{array}$ & $\begin{array}{c}\text { Gravimetric } \mathrm{H}_{2} 0 \\
\left(\mathrm{gH}_{2} \mathrm{O} / \mathrm{gTotal}\right)\end{array}$ & $\begin{array}{c}\text { Core Soil } \\
\text { Weight (g) }\end{array}$ & $\begin{array}{c}\text { Bulk } \\
\text { Density } \\
\left(\mathrm{g} / \mathrm{cm}^{3}\right)\end{array}$ & $\begin{array}{c}\text { Volumetric } \\
\text { Moisture } \\
\text { Content }\end{array}$ & Liner \\
\hline \multirow[t]{4}{*}{23.1} & 242 & D & 21.1 & 0.9756 & 0.0250 & 0.0244 & 2021.853 & 1.739 & 0.0434 & S.S \\
\hline & 242 & $\mathrm{C}$ & 21.6 & 0.9468 & 0.0562 & 0.0532 & 2011.353 & 1.686 & 0.0947 & S.S \\
\hline & 242 & B & 22.1 & 0.9288 & 0.0767 & 0.0712 & 1927.571 & 1.649 & 0.1264 & S.S \\
\hline & 242 & A & 22.6 & 0.9480 & 0.0549 & 0.0520 & 1639.336 & 1.737 & 0.0953 & S.S \\
\hline \multirow[t]{4}{*}{24.8} & 243 & D & 22.8 & 0.9318 & 0.0732 & 0.0682 & 2135.929 & 1.850 & 0.1354 & S.S \\
\hline & 243 & $\mathrm{C}$ & 23.3 & 0.9517 & 0.0507 & 0.0483 & 2025.542 & 1.742 & 0.0884 & S.S \\
\hline & 243 & B & 23.8 & 0.9397 & 0.0642 & 0.0603 & 2142.795 & 1.862 & 0.1195 & S.S \\
\hline & 243 & A & 24.3 & 0.9283 & 0.0773 & 0.0717 & 1606.192 & 1.730 & 0.1337 & S.S \\
\hline \multirow[t]{4}{*}{27.5} & 244 & D & 25.5 & 0.8667 & 0.1538 & 0.1333 & 1816.046 & 1.586 & 0.2439 & S.S \\
\hline & 244 & $\mathrm{C}$ & 26 & 0.8861 & 0.1285 & 0.1139 & 1778.685 & 1.530 & 0.1966 & S.S \\
\hline & 244 & B & 26.5 & 0.9056 & 0.1042 & 0.0944 & 1801.553 & 1.552 & 0.1618 & S.S \\
\hline & 244 & A & 27 & 0.9275 & 0.0782 & 0.0725 & 1454.546 & 1.577 & 0.1234 & S.S \\
\hline \multirow[t]{4}{*}{30} & 245 & D & 28 & 0.9501 & 0.0525 & 0.0499 & 2129.560 & 1.838 & 0.0964 & S.S \\
\hline & 245 & $\mathrm{C}$ & 28.5 & 0.9562 & 0.0458 & 0.0438 & 2159.482 & 1.851 & 0.0847 & S.S \\
\hline & 245 & B & 29 & 0.9379 & 0.0662 & 0.0621 & 1969.866 & 1.715 & 0.1136 & S.S \\
\hline & 245 & A & 29.5 & 0.9489 & 0.0539 & 0.0511 & 1520.408 & 1.708 & 0.0920 & S.S \\
\hline \multirow[t]{4}{*}{32.6} & 246 & D & 30.6 & 0.9418 & 0.0618 & 0.0582 & 1976.165 & 1.735 & 0.1073 & S.S \\
\hline & 246 & $\mathrm{C}$ & 31.1 & 0.9388 & 0.0652 & 0.0612 & 1884.380 & 1.621 & 0.1057 & S.S \\
\hline & 246 & B & 31.6 & 0.9523 & 0.0500 & 0.0477 & 1900.233 & 1.648 & 0.0825 & S.S \\
\hline & 246 & A & 32.1 & 0.9451 & 0.0581 & 0.0549 & 1563.495 & 1.642 & 0.0954 & S.S \\
\hline \multirow[t]{4}{*}{35.3} & 247 & D & 33.3 & 0.9457 & 0.0575 & 0.0543 & 1419.735 & 1.620 & 0.0931 & S.S \\
\hline & 247 & $\mathrm{C}$ & 33.8 & 0.9358 & 0.0686 & 0.0642 & 1836.318 & 1.590 & 0.1091 & S.S \\
\hline & 247 & B & 34.3 & 0.9393 & 0.0647 & 0.0607 & 1797.091 & 1.559 & 0.1008 & S.S \\
\hline & 247 & A & 34.8 & 0.9218 & 0.0848 & 0.0782 & 1705.674 & 1.558 & 0.1321 & S.S \\
\hline
\end{tabular}


Table A.1. (contd)

\begin{tabular}{|c|c|c|c|c|c|c|c|c|c|c|}
\hline $\begin{array}{l}\text { Shoe } \\
\text { depth } \\
\text { (ft bgs) }\end{array}$ & $\begin{array}{c}\text { Interval } \\
\#\end{array}$ & Liner & $\begin{array}{l}\text { Core Depth } \\
(\mathrm{ft})\end{array}$ & $\begin{array}{c}\text { Gravimetric Soil } \\
\text { (gSoil/gTotal) }\end{array}$ & $\begin{array}{c}\text { Gravimetric } \\
\text { H20 } \\
\text { (gH2O/gSoil) }\end{array}$ & $\begin{array}{c}\text { Gravimetric H20 } \\
(\mathrm{gH} 2 \mathrm{O} / \mathrm{g} \text { Total })\end{array}$ & $\begin{array}{l}\text { Core Soil } \\
\text { Weight (g) }\end{array}$ & $\begin{array}{c}\text { Bulk } \\
\text { Density } \\
(\mathrm{g} / \mathrm{cm} 3)\end{array}$ & $\begin{array}{c}\text { Volumetric } \\
\text { Moisture } \\
\text { Content }\end{array}$ & Liner \\
\hline \multirow[t]{4}{*}{37.7} & 248 & $\mathrm{D}$ & 35.7 & 0.9183 & 0.0890 & 0.0817 & 1855.367 & 1.679 & 0.1495 & lexan \\
\hline & 248 & $\mathrm{C}$ & 36.2 & 0.9219 & 0.0848 & 0.0781 & 1807.339 & 1.622 & 0.1374 & lexan \\
\hline & 248 & B & 36.7 & 0.9216 & 0.0850 & 0.0784 & 1709.177 & 1.613 & 0.1371 & lexan \\
\hline & 248 & A & 37.2 & 0.9190 & 0.0882 & 0.0810 & 1491.020 & 1.679 & 0.1481 & lexan \\
\hline \multirow[t]{4}{*}{40} & 249 & $\mathrm{D}$ & 38 & 0.8369 & 0.1949 & 0.1631 & 1769.562 & 1.615 & 0.3149 & lexan \\
\hline & 249 & $\mathrm{C}$ & 38.5 & 0.9172 & 0.0902 & 0.0828 & 2065.194 & 1.869 & 0.1686 & lexan \\
\hline & 249 & B & 39 & 0.8616 & 0.1607 & 0.1384 & 1811.489 & 1.694 & 0.2722 & lexan \\
\hline & 249 & A & 39.5 & 0.9508 & 0.0518 & 0.0492 & 1845.906 & 1.872 & 0.0970 & lexan \\
\hline \multirow[t]{4}{*}{42.4} & 250 & $\mathrm{D}$ & 40.4 & 0.9631 & 0.0384 & 0.0369 & 2183.568 & 1.921 & 0.0737 & S.S \\
\hline & 250 & $\mathrm{C}$ & 40.9 & 0.9412 & 0.0625 & 0.0588 & 2151.414 & 1.854 & 0.1159 & S.S \\
\hline & 250 & B & 41.4 & 0.9582 & 0.0437 & 0.0418 & 2128.379 & 1.882 & 0.0822 & S.S \\
\hline & 250 & A & 41.9 & 0.9620 & 0.0395 & 0.0380 & 1716.586 & 1.818 & 0.0717 & S.S \\
\hline \multirow[t]{4}{*}{45.2} & 251 & $\mathrm{D}$ & 43.2 & 0.9635 & 0.0379 & 0.0365 & 2200.939 & 1.946 & 0.0737 & S.S \\
\hline & 251 & $\mathrm{C}$ & 43.7 & 0.9602 & 0.0415 & 0.0398 & 2212.550 & 1.846 & 0.0766 & S.S \\
\hline & 251 & B & 44.2 & 0.9535 & 0.0487 & 0.0465 & 2079.005 & 1.797 & 0.0876 & S.S \\
\hline & 251 & A & 44.7 & 0.9366 & 0.0677 & 0.0634 & 1657.068 & 1.828 & 0.1239 & S.S \\
\hline \multirow[t]{4}{*}{47.8} & 252 & $\mathrm{D}$ & 45.8 & 0.9884 & 0.0117 & 0.0116 & 1785.630 & 1.747 & 0.0204 & lexan \\
\hline & 252 & $\mathrm{C}$ & 46.3 & 0.9852 & 0.0150 & 0.0148 & 1846.856 & 1.721 & 0.0258 & lexan \\
\hline & 252 & B & 46.8 & 0.9748 & 0.0259 & 0.0252 & 1889.609 & 1.698 & 0.0440 & lexan \\
\hline & 252 & A & 47.3 & 0.9590 & 0.0427 & 0.0410 & 1504.271 & 1.727 & 0.0737 & lexan \\
\hline \multirow[t]{4}{*}{50.1} & 253 & $\mathrm{D}$ & 48.1 & 0.9811 & 0.0193 & 0.0189 & 1926.402 & 1.913 & 0.0369 & lexan \\
\hline & 253 & $\mathrm{C}$ & 48.6 & 0.9729 & 0.0278 & 0.0271 & 2105.944 & 1.942 & 0.0540 & lexan \\
\hline & 253 & B & 49.1 & 0.9783 & 0.0222 & 0.0217 & 2216.295 & 1.985 & 0.0441 & lexan \\
\hline & 253 & A & 49.6 & 0.9794 & 0.0211 & 0.0206 & 1802.544 & 2.017 & 0.0425 & lexan \\
\hline \multirow[t]{4}{*}{52.25} & 254 & $\mathrm{D}$ & 50.25 & 0.9759 & 0.0247 & 0.0241 & 2144.630 & 1.938 & 0.0478 & lexan \\
\hline & 254 & $\mathrm{C}$ & 50.75 & 0.9705 & 0.0303 & 0.0295 & 1986.242 & 1.826 & 0.0554 & lexan \\
\hline & 254 & B & 51.25 & 0.9823 & 0.0180 & 0.0177 & 2025.038 & 1.823 & 0.0328 & lexan \\
\hline & 254 & A & 51.75 & 0.9803 & 0.0201 & 0.0197 & 1719.977 & 1.824 & 0.0366 & lexan \\
\hline
\end{tabular}


Table A.1. (contd)

\begin{tabular}{|c|c|c|c|c|c|c|c|c|c|c|}
\hline $\begin{array}{c}\text { Shoe } \\
\text { depth } \\
\text { (ft bgs) }\end{array}$ & $\begin{array}{c}\text { Interval } \\
\#\end{array}$ & Liner & $\begin{array}{l}\text { Core Depth } \\
\text { (ft) }\end{array}$ & $\begin{array}{c}\text { Gravimetric Soil } \\
\text { (gSoil/gTotal) }\end{array}$ & $\begin{array}{c}\text { Gravimetric } \\
\text { H20 } \\
\text { (gH2O/gSoil) }\end{array}$ & $\begin{array}{c}\text { Gravimetric H20 } \\
\text { (gH2O/gTotal) }\end{array}$ & $\begin{array}{c}\text { Core Soil } \\
\text { Weight (g) }\end{array}$ & $\begin{array}{c}\text { Bulk } \\
\text { Density } \\
(\mathrm{g} / \mathrm{cm} 3)\end{array}$ & $\begin{array}{l}\text { Volumetric } \\
\text { Moisture } \\
\text { Content }\end{array}$ & Liner \\
\hline \multirow[t]{4}{*}{55.3} & 255 & D & 53.3 & 0.9791 & 0.0213 & 0.0209 & 1875.504 & 1.849 & 0.0394 & lexan \\
\hline & 255 & $\mathrm{C}$ & 53.8 & 0.9781 & 0.0224 & 0.0219 & 1939.036 & 1.746 & 0.0391 & lexan \\
\hline & 255 & B & 54.3 & 0.9815 & 0.0189 & 0.0185 & 1954.603 & 1.754 & 0.0331 & lexan \\
\hline & 255 & A & 54.8 & 0.9751 & 0.0255 & 0.0249 & 1606.498 & 1.775 & 0.0453 & lexan \\
\hline \multirow[t]{4}{*}{58} & 256 & D & 56 & 0.9754 & 0.0252 & 0.0246 & 1858.719 & 1.773 & 0.0446 & lexan \\
\hline & 256 & $\mathrm{C}$ & 56.5 & 0.9749 & 0.0257 & 0.0251 & 1905.450 & 1.721 & 0.0443 & lexan \\
\hline & 256 & B & 57 & 0.9806 & 0.0198 & 0.0194 & 1884.272 & 1.747 & 0.0345 & lexan \\
\hline & 256 & A & 57.5 & 0.9793 & 0.0211 & 0.0207 & 1682.015 & 1.784 & 0.0377 & lexan \\
\hline \multirow[t]{4}{*}{60.8} & 257 & $\mathrm{D}$ & 58.8 & 0.9712 & 0.0297 & 0.0288 & 1896.229 & 1.825 & 0.0542 & lexan \\
\hline & 257 & $\mathrm{C}$ & 59.3 & 0.9697 & 0.0312 & 0.0303 & 1911.856 & 1.736 & 0.0542 & lexan \\
\hline & 257 & B & 59.8 & 0.9775 & 0.0230 & 0.0225 & 1913.514 & 1.726 & 0.0397 & lexan \\
\hline & 257 & A & 60.3 & 0.9744 & 0.0263 & 0.0256 & 1661.784 & 1.810 & 0.0476 & Lexan \\
\hline
\end{tabular}


Table A.2. BC Crib Borehole C8388

\begin{tabular}{|c|c|c|c|c|c|c|c|c|c|c|}
\hline $\begin{array}{c}\text { Shoe } \\
\text { depth } \\
\text { (ft bgs) }\end{array}$ & $\begin{array}{c}\text { Interval } \\
\#\end{array}$ & Liner & $\begin{array}{l}\text { Core Depth } \\
\text { (ft) }\end{array}$ & $\begin{array}{c}\text { Gravimetric } \\
\text { Soil } \\
\text { (gSoil/gTotal) }\end{array}$ & $\begin{array}{c}\text { Gravimetric } \\
\text { H20 } \\
\text { (gH2O/gSoil) }\end{array}$ & $\begin{array}{c}\text { Gravimetric H20 } \\
(\mathrm{gH} 2 \mathrm{O} / \mathrm{gT} \text { Total })\end{array}$ & $\begin{array}{c}\text { Core Soil } \\
\text { Weight (g) }\end{array}$ & $\begin{array}{c}\text { Bulk } \\
\text { Density } \\
(\mathrm{g} / \mathrm{cm} 3)\end{array}$ & $\begin{array}{c}\text { Volumetric } \\
\text { Moisture } \\
\text { Content }\end{array}$ & Liner \\
\hline \multirow[t]{4}{*}{22.65} & $3 \mathrm{~K} 3$ & $\mathrm{D}$ & 20.65 & 0.9385 & 0.0656 & 0.0615 & 2142.053 & 1.952 & 0.1280 & lexan \\
\hline & $3 \mathrm{~K} 3$ & $\mathrm{C}$ & 21.15 & 0.9096 & 0.0994 & 0.0904 & 2006.969 & 1.813 & 0.1803 & lexan \\
\hline & $3 \mathrm{~K} 3$ & B & 21.65 & 0.9408 & 0.0629 & 0.0592 & 1999.706 & 1.819 & 0.1144 & lexan \\
\hline & $3 \mathrm{~K} 3$ & A & 22.15 & 0.9002 & 0.1109 & 0.0998 & 1647.762 & 1.840 & 0.2041 & lexan \\
\hline \multirow[t]{4}{*}{24.5} & $3 \mathrm{~K} 4$ & $\mathrm{D}$ & 22.5 & 0.9405 & 0.0632 & 0.0595 & 2079.084 & 1.945 & 0.1229 & lexan \\
\hline & $3 \mathrm{~K} 4$ & $\mathrm{C}$ & 23 & 0.9454 & 0.0578 & 0.0546 & 2126.613 & 1.883 & 0.1088 & lexan \\
\hline & $3 \mathrm{~K} 4$ & $\mathrm{~B}$ & 23.5 & 0.9508 & 0.0518 & 0.0492 & 1956.198 & 1.849 & 0.0958 & lexan \\
\hline & $3 \mathrm{~K} 4$ & A & 24 & 0.9476 & 0.0553 & 0.0524 & 1973.296 & 1.792 & 0.0992 & lexan \\
\hline \multirow[t]{4}{*}{26.5} & $3 \mathrm{~K} 5$ & $\mathrm{D}$ & 24.5 & 0.9326 & 0.0723 & 0.0674 & 2127.653 & 1.949 & 0.1409 & lexan \\
\hline & $3 \mathrm{~K} 5$ & $\mathrm{C}$ & 25 & 0.9417 & 0.0619 & 0.0583 & 2049.586 & 1.887 & 0.1169 & lexan \\
\hline & $3 \mathrm{~K} 5$ & B & 25.5 & 0.9229 & 0.0836 & 0.0771 & 1970.841 & 1.867 & 0.1560 & lexan \\
\hline & $3 \mathrm{~K} 5$ & A & 26 & 0.9253 & 0.0808 & 0.0747 & 1578.073 & 1.758 & 0.1420 & lexan \\
\hline \multirow[t]{4}{*}{29.4} & $3 \mathrm{~K} 6$ & $\mathrm{D}$ & 27.4 & 0.8724 & 0.1463 & 0.1276 & 1873.455 & 1.734 & 0.2537 & lexan \\
\hline & $3 \mathrm{~K} 6$ & $\mathrm{C}$ & 27.9 & 0.8522 & 0.1734 & 0.1478 & 1808.040 & 1.653 & 0.2866 & lexan \\
\hline & $3 \mathrm{~K} 6$ & B & 28.4 & 0.8900 & 0.1237 & 0.1100 & 1649.540 & 1.562 & 0.1932 & lexan \\
\hline & $3 \mathrm{~K} 6$ & A & 28.9 & 0.9617 & 0.0398 & 0.0383 & 1696.923 & 1.786 & 0.0711 & lexan \\
\hline \multirow[t]{4}{*}{32.2} & $3 \mathrm{~K} 7$ & $\mathrm{D}$ & 30.2 & 0.9454 & 0.0577 & 0.0546 & 1915.942 & 1.749 & 0.1009 & lexan \\
\hline & $3 \mathrm{~K} 7$ & $\mathrm{C}$ & 30.7 & 0.9446 & 0.0587 & 0.0554 & 1805.548 & 1.648 & 0.0967 & lexan \\
\hline & $3 \mathrm{~K} 7$ & B & 31.2 & 0.9387 & 0.0653 & 0.0613 & 1679.898 & 1.541 & 0.1006 & lexan \\
\hline & $3 \mathrm{~K} 7$ & A & 31.7 & 0.9429 & 0.0605 & 0.0571 & 1495.053 & 1.739 & 0.1052 & lexan \\
\hline \multirow[t]{4}{*}{35.08} & $3 \mathrm{~K} 8$ & $\mathrm{D}$ & 33.08 & 0.9532 & 0.0491 & 0.0468 & 1730.562 & 1.593 & 0.0782 & lexan \\
\hline & $3 \mathrm{~K} 8$ & $\mathrm{C}$ & 33.58 & 0.9440 & 0.0593 & 0.0560 & 1717.657 & 1.549 & 0.0919 & lexan \\
\hline & $3 \mathrm{~K} 8$ & B & 34.08 & 0.9512 & 0.0513 & 0.0488 & 1758.257 & 1.597 & 0.0820 & lexan \\
\hline & $3 \mathrm{~K} 8$ & A & 34.58 & 0.9392 & 0.0648 & 0.0608 & 1407.363 & 1.605 & 0.1040 & lexan \\
\hline
\end{tabular}


Table A.2. (contd)

\begin{tabular}{|c|c|c|c|c|c|c|c|c|c|c|}
\hline $\begin{array}{c}\text { Shoe } \\
\text { depth } \\
\text { (ft bgs) }\end{array}$ & $\begin{array}{c}\text { Interval } \\
\quad \#\end{array}$ & Liner & $\begin{array}{l}\text { Core Depth } \\
\quad(\mathrm{ft})\end{array}$ & $\begin{array}{c}\text { Gravimetric } \\
\text { Soil } \\
\text { (gSoil/gTotal) }\end{array}$ & $\begin{array}{c}\text { Gravimetric } \\
\mathrm{H}_{2} \mathrm{O} \\
\left(\mathrm{gH}_{2} \mathrm{O} / \mathrm{gSoil}\right)\end{array}$ & $\begin{array}{c}\text { Gravimetric } \mathrm{H}_{2} 0 \\
\left(\mathrm{gH}_{2} \mathrm{O} / \mathrm{g} \text { Total }\right)\end{array}$ & $\begin{array}{c}\text { Core Soil } \\
\text { Weight }(\mathrm{g})\end{array}$ & $\begin{array}{l}\text { Bulk } \\
\text { Density } \\
\left(\mathrm{g} / \mathrm{cm}^{3}\right)\end{array}$ & $\begin{array}{l}\text { Volumetric } \\
\text { Moisture } \\
\text { Content }\end{array}$ & Liner \\
\hline \multirow[t]{4}{*}{38} & $3 \mathrm{~K} 9$ & $\mathrm{D}$ & 36 & 0.9334 & 0.0714 & 0.0666 & 1722.603 & 1.614 & 0.1152 & lexan \\
\hline & $3 \mathrm{~K} 9$ & $\mathrm{C}$ & 36.5 & 0.9383 & 0.0657 & 0.0617 & 1781.458 & 1.599 & 0.1050 & lexan \\
\hline & $3 \mathrm{~K} 9$ & B & 37 & 0.9310 & 0.0741 & 0.0690 & 1759.204 & 1.597 & 0.1183 & lexan \\
\hline & $3 \mathrm{~K} 9$ & A & 37.5 & 0.9158 & 0.0920 & 0.0842 & 1435.497 & 1.662 & 0.1529 & lexan \\
\hline \multirow[t]{4}{*}{40.8} & $3 \mathrm{~L} 0$ & $\mathrm{D}$ & 38.8 & 0.8791 & 0.1375 & 0.1209 & 1827.191 & 1.706 & 0.2347 & lexan \\
\hline & $3 \mathrm{~L} 0$ & $\mathrm{C}$ & 39.3 & 0.8591 & 0.1641 & 0.1409 & 1751.187 & 1.579 & 0.2591 & lexan \\
\hline & $3 \mathrm{~L} 0$ & B & 39.8 & 0.9640 & 0.0373 & 0.0360 & 1807.990 & 1.642 & 0.0613 & lexan \\
\hline & $3 \mathrm{~L} 0$ & $\mathrm{~A}$ & 40.3 & 0.9532 & 0.0491 & 0.0468 & 2059.347 & 1.839 & 0.0903 & lexan \\
\hline \multirow[t]{4}{*}{43} & $3 \mathrm{~L} 1$ & $\mathrm{D}$ & 41 & 0.9204 & 0.0865 & 0.0796 & 2123.792 & 1.906 & 0.1648 & lexan \\
\hline & $3 \mathrm{~L} 1$ & $\mathrm{C}$ & 41.5 & 0.9049 & 0.1051 & 0.0951 & 2017.399 & 1.907 & 0.2005 & lexan \\
\hline & $3 \mathrm{~L} 1$ & B & 42 & 0.8751 & 0.1428 & 0.1249 & 2026.234 & 1.818 & 0.2596 & lexan \\
\hline & $3 \mathrm{~L} 1$ & A & 42.5 & 0.9244 & 0.0818 & 0.0756 & 1718.685 & 1.582 & 0.1295 & lexan \\
\hline \multirow[t]{4}{*}{45.58} & $3 \mathrm{~L} 2$ & $\mathrm{D}$ & 43.58 & 0.9582 & 0.0436 & 0.0418 & 2034.541 & 1.809 & 0.0789 & S.S \\
\hline & $3 \mathrm{~L} 2$ & $\mathrm{C}$ & 44.08 & 0.8951 & 0.1172 & 0.1049 & 1862.052 & 1.661 & 0.1947 & S.S \\
\hline & $3 \mathrm{~L} 2$ & B & 44.58 & 0.9720 & 0.0288 & 0.0280 & 2188.209 & 1.796 & 0.0518 & S.S \\
\hline & $3 \mathrm{~L} 2$ & A & 45.08 & 0.9785 & 0.0220 & 0.0215 & 1514.024 & 1.772 & 0.0390 & S.S \\
\hline \multirow[t]{4}{*}{47.7} & $3 \mathrm{~L} 3$ & $\mathrm{D}$ & 45.7 & 0.9914 & 0.0087 & 0.0086 & 2054.515 & 1.866 & 0.0162 & S.S. \\
\hline & $3 \mathrm{~L} 3$ & $\mathrm{C}$ & 46.2 & 0.9968 & 0.0032 & 0.0032 & 1878.524 & 1.887 & 0.0060 & lexan \\
\hline & $3 \mathrm{~L} 3$ & B & 46.7 & 0.9957 & 0.0043 & 0.0043 & 1883.157 & 1.745 & 0.0076 & S.S \\
\hline & $3 \mathrm{~L} 3$ & A & 47.2 & 0.9942 & 0.0059 & 0.0058 & 1407.065 & 1.706 & 0.0100 & S.S \\
\hline \multirow[t]{4}{*}{50} & $3 \mathrm{~L} 4$ & $\mathrm{D}$ & 48 & 0.9947 & 0.0053 & 0.0053 & 1861.472 & 2.014 & 0.0107 & S.S. \\
\hline & $3 \mathrm{~L} 4$ & $\mathrm{C}$ & 48.5 & 0.9954 & 0.0047 & 0.0046 & 2039.802 & 1.859 & 0.0087 & S.S. \\
\hline & $3 \mathrm{~L} 4$ & B & 49 & 0.9964 & 0.0036 & 0.0036 & 2085.788 & 1.803 & 0.0065 & S.S. \\
\hline & $3 \mathrm{~L} 4$ & A & 49.5 & 0.9833 & 0.0170 & 0.0167 & 1553.909 & 1.831 & 0.0311 & S.S. \\
\hline \multirow[t]{3}{*}{52.6} & $3 \mathrm{~L} 5$ & $\mathrm{D}$ & 50.6 & 0.9934 & 0.0066 & 0.0066 & 1850.101 & 1.869 & 0.0123 & S.S. \\
\hline & $3 \mathrm{~L} 5$ & $\mathrm{C}$ & 51.1 & 0.9959 & 0.0041 & 0.0041 & 2137.602 & 1.897 & 0.0077 & S.S. \\
\hline & $3 \mathrm{~L} 5$ & B & 51.6 & 0.9996 & 0.0004 & 0.0004 & 1697.700 & 1.719 & 0.0006 & S.S. \\
\hline
\end{tabular}


Table A.2. (contd)

\begin{tabular}{|c|c|c|c|c|c|c|c|c|c|c|}
\hline $\begin{array}{c}\text { Shoe } \\
\text { depth } \\
\text { (ft bgs) }\end{array}$ & $\begin{array}{c}\text { Interval } \\
\quad \#\end{array}$ & Liner & $\begin{array}{l}\text { Core Depth } \\
\text { (ft) }\end{array}$ & $\begin{array}{c}\text { Gravimetric } \\
\text { Soil } \\
\text { (gSoil/gTotal) }\end{array}$ & $\begin{array}{c}\text { Gravimetric } \\
\mathrm{H}_{2} \mathrm{O} \\
\left(\mathrm{gH}_{2} \mathrm{O} / \mathrm{gSoil}\right)\end{array}$ & $\begin{array}{c}\text { Gravimetric } \mathrm{H}_{2} 0 \\
\left(\mathrm{gH}_{2} \mathrm{O} / \mathrm{g} \text { Total }\right)\end{array}$ & $\begin{array}{c}\text { Core Soil } \\
\text { Weight (g) }\end{array}$ & $\begin{array}{c}\text { Bulk } \\
\text { Density } \\
\left(\mathrm{g} / \mathrm{cm}^{3}\right)\end{array}$ & $\begin{array}{l}\text { Volumetric } \\
\text { Moisture } \\
\text { Content }\end{array}$ & Liner \\
\hline & $3 \mathrm{~L} 5$ & A & 52.1 & 0.9996 & 0.0004 & 0.0004 & 1441.798 & 1.703 & 0.0006 & S.S. \\
\hline \multirow[t]{4}{*}{55} & 3L6 & D & 53 & 0.9891 & 0.0110 & 0.0109 & 1556.227 & 1.702 & 0.0187 & S.S. \\
\hline & $3 \mathrm{~L} 6$ & $\mathrm{C}$ & 53.5 & 0.9953 & 0.0047 & 0.0047 & 1891.339 & 1.743 & 0.0083 & S.S. \\
\hline & $3 \mathrm{~L} 6$ & B & 54 & 0.9986 & 0.0014 & 0.0014 & 1796.795 & 1.739 & 0.0024 & S.S. \\
\hline & $3 \mathrm{~L} 6$ & A & 54.5 & 0.9989 & 0.0011 & 0.0011 & 1658.533 & 1.794 & 0.0019 & S.S. \\
\hline \multirow[t]{4}{*}{58.1} & $3 \mathrm{~L} 7$ & D & 56.1 & 0.9778 & 0.0227 & 0.0222 & 2019.425 & 1.746 & 0.0397 & S.S. \\
\hline & $3 \mathrm{~L} 7$ & $\mathrm{C}$ & 56.6 & 0.9706 & 0.0303 & 0.0294 & 1962.817 & 1.682 & 0.0510 & S.S. \\
\hline & $3 \mathrm{~L} 7$ & B & 57.1 & 0.9774 & 0.0231 & 0.0226 & 1972.768 & 1.697 & 0.0392 & S.S. \\
\hline & $3 \mathrm{~L} 7$ & A & 57.6 & 0.9785 & 0.0219 & 0.0215 & 1624.707 & 1.789 & 0.0392 & S.S. \\
\hline \multirow[t]{4}{*}{60.5} & $3 \mathrm{~L} 8$ & D & 58.5 & 0.9709 & 0.0300 & 0.0291 & 2119.794 & 1.801 & 0.0540 & S.S. \\
\hline & $3 \mathrm{~L} 8$ & $\mathrm{C}$ & 59 & 0.9695 & 0.0315 & 0.0305 & 2033.248 & 1.752 & 0.0552 & S.S. \\
\hline & $3 \mathrm{~L} 8$ & B & 59.5 & 0.9756 & 0.0251 & 0.0244 & 1962.153 & 1.682 & 0.0421 & S.S. \\
\hline & $3 \mathrm{~L} 8$ & A & 60 & 0.9717 & 0.0291 & 0.0283 & 1508.434 & 1.698 & 0.0494 & S.S. \\
\hline
\end{tabular}




\section{A.1 Introduction}

Between September 1, 2011, and September 14, 2011, sediment samples were received from postdesiccation boreholes and a subset of these samples were analyzed as described herein.

\section{A.1.1 Analytical Results/Methodology}

The analyses for this project were performed at the 331 Building in the 300 Area of the Hanford Site. Analyses were performed according to Pacific Northwest National Laboratory (PNNL) approved procedures and/or nationally recognized test procedures. The data sets include the sample identification numbers, analytical results, estimated quantification limits (EQL), and quality control data.

\section{A.1.2 Quality Control}

The preparatory and analytical quality control requirements, calibration requirements, acceptance criteria, and failure actions are defined in the online quality assurance plan, Conducting Analytical Work in Support of Regulatory Programs (PNNL 2010). This QA plan implements the Hanford Analytical Services Quality Assurance Requirements Documents (DOE/RL 2007 [HASQARD]) for PNNL.

\section{A.1.3 Definitions}

Dup Duplicate

RPD Relative Percent Difference

NR No Recovery (percent recovery less than zero)

ND Non-Detectable

$\%$ REC Percent Recovery

\section{A.1.4 Sample Receipt}

Samples were received with a chain of custody (COC) and analyzed according to the sample identification numbers supplied by the client. All samples were refrigerated upon receipt until prepared for analysis. All samples were received with custody seals intact unless noted in the case narrative.

\section{A.1.5 Holding Times}

Holding time is defined as the time from sample preparation to the time of analyses. The prescribed holding times were met for all analytes unless noted in the case narrative.

\section{A.1.6 Analytical Results}

All reported analytical results meet the requirements of the CAW or client-specified statement of work unless noted in the case narrative. 


\section{A.2 Case Narrative Report}

\section{Hold Time}

Due to the requirements of the statement of work and sampling events in the field, the 28 day and the $48 \mathrm{hr}$ requirements could not be met. The statement of work requires samples to be selected at the completion of the borehole. It is not always possible to complete a borehole and have the samples shipped to the laboratory within the hold time requirements.

\section{Preparation Blank (PB)}

No discrepancies noted.

\section{Duplicate (DUP)}

No discrepancies noted.

\section{Laboratory Control Samples (LCS)}

No discrepancies noted.

\section{Post Spike (PS)}

No discrepancies noted.

\section{Matrix Spike (MS)}

Not Applicable

\section{Other QC Criteria}

No discrepancies noted.

\section{A.3 References}

DOE/RL 2007. 2007. Hanford Analytical Services Quality Assurance Requirements Document. DOE/RL-96-68, Rev. 3, U.S. Department of Energy, Richland Operations Office, Richland, Washington.

PNNL. 2010. Conducting Analytical Work in Support of Regulatory Programs. PNNL-SA-63118, Pacific Northwest National Laboratory, Richland, Washington. 


\section{Samples Included in this Report}

200-BC-1 Soil Desiccation Pilot Test

\begin{tabular}{|c|c|c|c|c|c|c|}
\hline \multirow{2}{*}{$\frac{\text { Date Received }}{\text { B2H3K3 }}$} & \multirow{2}{*}{$\frac{\text { Date Collected }}{1109002-01}$} & \multirow{2}{*}{$\frac{\text { Matrix }}{\text { Soil }}$} & \multicolumn{2}{|c|}{ Laboratory ID } & \multicolumn{2}{|c|}{ HEIS No. } \\
\hline & & & $8 / 30 / 11$ & 09:40 & $9 / 1 / 11$ & $13: 05$ \\
\hline B2H3K4 & $1109002-02$ & Soil & $8 / 30 / 11$ & $10: 35$ & 9/1/11 & $13: 05$ \\
\hline В2Н3К5 & $1109002-03$ & Soil & $8 / 30 / 11$ & $13: 40$ & $9 / 1 / 11$ & 13:05 \\
\hline B2H3K6 & $1109002-04$ & Soil & $8 / 31 / 11$ & $08: 35$ & $9 / 6 / 11$ & $14: 10$ \\
\hline В2H3K7 & $1109002-05$ & Soil & $8 / 31 / 11$ & 09:45 & $9 / 6 / 11$ & $14: 10$ \\
\hline В2Н3К8 & 1109002-06 & Soil & $8 / 31 / 11$ & 11:00 & $9 / 6 / 11$ & $14: 10$ \\
\hline В2Н3К9 & $1109002-07$ & Soil & $8 / 31 / 11$ & $13: 30$ & $9 / 6 / 11$ & $14: 10$ \\
\hline B2H3L0 & 1109002-08 & Soil & $8 / 31 / 11$ & $14: 30$ & $9 / 6 / 11$ & $14: 10$ \\
\hline B2H3L1 & 1109002-09 & Soil & $9 / 1 / 11$ & 09:05 & $9 / 7 / 11$ & 11:06 \\
\hline B2H3L2 & $1109002-10$ & Soil & $9 / 1 / 11$ & 09:55 & $9 / 7 / 11$ & 11:06 \\
\hline B2H3L3 & $1109002-11$ & Soil & $9 / 1 / 11$ & $11: 25$ & $9 / 7 / 11$ & 11:06 \\
\hline B2H3L4 & $1109002-12$ & Soil & $9 / 2 / 11$ & 09:25 & 9/9/11 & $13: 20$ \\
\hline B2H3L5 & $1109002-13$ & Soil & $9 / 2 / 11$ & $10: 15$ & 9/9/11 & $13: 20$ \\
\hline B2H3L6 & $1109002-14$ & Soil & $9 / 2 / 11$ & $12: 50$ & 9/9/11 & $13: 20$ \\
\hline B2H3L7 & $1109002-15$ & Soil & $9 / 2 / 11$ & $13: 55$ & 9/9/11 & $13: 20$ \\
\hline B2H3L8 & $1109002-16$ & Soil & $9 / 2 / 11$ & $14: 35$ & 9/9/11 & $13: 20$ \\
\hline B2H242 & $1109002-17$ & Soil & $9 / 8 / 11$ & 09:18 & $9 / 14 / 11$ & $13: 30$ \\
\hline B2H243 & $1109002-18$ & Soil & $9 / 8 / 11$ & 10:10 & $9 / 14 / 11$ & $13: 30$ \\
\hline B2H 244 & 1109002-19 & Soil & $9 / 8 / 11$ & $11: 10$ & $9 / 14 / 11$ & $13: 30$ \\
\hline B2H 245 & $1109002-20$ & Soil & $9 / 8 / 11$ & $13: 20$ & $9 / 14 / 11$ & $13: 30$ \\
\hline B2H246 & $1109002-21$ & Soil & $9 / 8 / 11$ & $14: 20$ & $9 / 14 / 11$ & $13: 30$ \\
\hline B2H247 & $1109002-22$ & Soil & 9/9/11 & 08:05 & $9 / 14 / 11$ & $13: 30$ \\
\hline B2H248 & $1109002-23$ & Soil & $9 / 9 / 11$ & 09:20 & $9 / 14 / 11$ & $13: 30$ \\
\hline В2H249 & $1109002-24$ & Soil & 9/9/11 & $10: 15$ & $9 / 14 / 11$ & $13: 30$ \\
\hline $\mathrm{B} 2 \mathrm{H} 250$ & $1109002-25$ & Soil & $9 / 9 / 11$ & 11:17 & $9 / 14 / 11$ & $13: 30$ \\
\hline B2H251 & $1109002-26$ & Soil & $9 / 9 / 11$ & $13: 40$ & $9 / 14 / 11$ & $13: 30$ \\
\hline B2H252 & $1109002-27$ & Soil & 9/9/11 & $14: 45$ & $9 / 14 / 11$ & $13: 30$ \\
\hline B2H 253 & $1109002-28$ & Soil & $9 / 12 / 11$ & $08: 35$ & $9 / 14 / 11$ & $13: 30$ \\
\hline B2H254 & $1109002-29$ & Soil & $9 / 12 / 11$ & 09:45 & $9 / 14 / 11$ & $13: 30$ \\
\hline B2H 255 & $1109002-30$ & Soil & $9 / 12 / 11$ & $10: 50$ & $9 / 14 / 11$ & $13: 30$ \\
\hline B2H256 & $1109002-31$ & Soil & $9 / 12 / 11$ & $13: 15$ & $9 / 14 / 11$ & $13: 30$ \\
\hline B2H257 & $1109002-32$ & Soil & $9 / 12 / 11$ & $14: 30$ & $9 / 14 / 11$ & $13: 30$ \\
\hline В2H258 & $1109002-33$ & Soil & 9/9/11 & $13: 40$ & $9 / 14 / 11$ & $13: 30$ \\
\hline
\end{tabular}




\section{Samples Analyzed in this Report}

The following analyses were performed on the following samples included in this report:

Anions by Ion Chromatography

Moisture Content

Tc_U 1:1 DI Water Extract by ICPMS

\begin{tabular}{|c|c|c|c|c|c|c|}
\hline \multirow{2}{*}{$\begin{array}{l}\text { Date Received } \\
\text { B2H3K3 }\end{array}$} & \multirow{2}{*}{$\begin{array}{c}\text { Date Collected } \\
1109002-01\end{array}$} & \multirow{2}{*}{$\frac{\text { Matrix }}{\text { Soil }}$} & \multicolumn{2}{|c|}{ Laboratory ID } & \multicolumn{2}{|c|}{ HEIS No. } \\
\hline & & & $8 / 30 / 11$ & 09:40 & $9 / 1 / 11$ & $13: 05$ \\
\hline B2H3K4 & 1109002-02 & Soil & $8 / 30 / 11$ & $10: 35$ & $9 / 1 / 11$ & $13: 05$ \\
\hline В2H3К5 & $1109002-03$ & Soil & $8 / 30 / 11$ & $13: 40$ & $9 / 1 / 11$ & $13: 05$ \\
\hline В2H3К6 & $1109002-04$ & Soil & $8 / 31 / 11$ & $08: 35$ & $9 / 6 / 11$ & $14: 10$ \\
\hline В2H3К 7 & $1109002-05$ & Soil & $8 / 31 / 11$ & 09:45 & $9 / 6 / 11$ & $14: 10$ \\
\hline В2Н3К 8 & $1109002-06$ & Soil & $8 / 31 / 11$ & 11:00 & $9 / 6 / 11$ & $14: 10$ \\
\hline В2H3К9 & 1109002-07 & Soil & $8 / 31 / 11$ & $13: 30$ & $9 / 6 / 11$ & $14: 10$ \\
\hline B2H3L0 & $1109002-08$ & Soil & $8 / 31 / 11$ & $14: 30$ & $9 / 6 / 11$ & $14: 10$ \\
\hline B2H3L1 & 1109002-09 & Soil & $9 / 1 / 11$ & 09:05 & $9 / 7 / 11$ & 11:06 \\
\hline B2H3L2 & $1109002-10$ & Soil & $9 / 1 / 11$ & 09:55 & $9 / 7 / 11$ & 11:06 \\
\hline B2H3L3 & $1109002-11$ & Soil & $9 / 1 / 11$ & $11: 25$ & $9 / 7 / 11$ & 11:06 \\
\hline B2H3L4 & $1109002-12$ & Soil & $9 / 2 / 11$ & 09:25 & 9/9/11 & $13: 20$ \\
\hline B2H3L5 & $1109002-13$ & Soil & $9 / 2 / 11$ & $10: 15$ & 9/9/11 & $13: 20$ \\
\hline B2H3L6 & $1109002-14$ & Soil & $9 / 2 / 11$ & $12: 50$ & 9/9/11 & $13: 20$ \\
\hline B2H3L 7 & $1109002-15$ & Soil & $9 / 2 / 11$ & $13: 55$ & 9/9/11 & $13: 20$ \\
\hline B2H3L8 & $1109002-16$ & Soil & $9 / 2 / 11$ & $14: 35$ & 9/9/11 & $13: 20$ \\
\hline B2H242 & $1109002-17$ & Soil & 9/8/11 & 09:18 & $9 / 14 / 11$ & $13: 30$ \\
\hline В2H243 & $1109002-18$ & Soil & 9/8/11 & 10:10 & $9 / 14 / 11$ & $13: 30$ \\
\hline B2H244 & 1109002-19 & Soil & 9/8/11 & $11: 10$ & $9 / 14 / 11$ & $13: 30$ \\
\hline B2H245 & $1109002-20$ & Soil & $9 / 8 / 11$ & $13: 20$ & $9 / 14 / 11$ & $13: 30$ \\
\hline В2H246 & $1109002-21$ & Soil & 9/8/11 & $14: 20$ & $9 / 14 / 11$ & $13: 30$ \\
\hline В2H247 & $1109002-22$ & Soil & 9/9/11 & 08:05 & $9 / 14 / 11$ & $13: 30$ \\
\hline B2H248 & $1109002-23$ & Soil & 9/9/11 & 09:20 & $9 / 14 / 11$ & $13: 30$ \\
\hline B2H249 & $1109002-24$ & Soil & 9/9/11 & $10: 15$ & $9 / 14 / 11$ & $13: 30$ \\
\hline B2H250 & $1109002-25$ & Soil & 9/9/11 & $11: 17$ & $9 / 14 / 11$ & $13: 30$ \\
\hline В2H251 & $1109002-26$ & Soil & 9/9/11 & $13: 40$ & $9 / 14 / 11$ & $13: 30$ \\
\hline B2H 252 & $1109002-27$ & Soil & 9/9/11 & $14: 45$ & $9 / 14 / 11$ & $13: 30$ \\
\hline В2H253 & $1109002-28$ & Soil & $9 / 12 / 11$ & $08: 35$ & $9 / 14 / 11$ & $13: 30$ \\
\hline B2H254 & $1109002-29$ & Soil & $9 / 12 / 11$ & 09:45 & $9 / 14 / 11$ & $13: 30$ \\
\hline В2H255 & $1109002-30$ & Soil & $9 / 12 / 11$ & $10: 50$ & $9 / 14 / 11$ & $13: 30$ \\
\hline B2H256 & $1109002-31$ & Soil & $9 / 12 / 11$ & $13: 15$ & $9 / 14 / 11$ & $13: 30$ \\
\hline B2H257 & $1109002-32$ & Soil & $9 / 12 / 11$ & $14: 30$ & $9 / 14 / 11$ & $13: 30$ \\
\hline B2H258 & $1109002-33$ & Soil & 9/9/11 & $13: 40$ & $9 / 14 / 11$ & $13: 30$ \\
\hline
\end{tabular}




\section{Wet Chemistry}

Moisture Content (\% by Weight) by AGG-WC-001

\begin{tabular}{|c|c|c|c|c|c|}
\hline Lab ID & HEIS No. & Results & EQL & Analyzed & Batch \\
\hline 1109002-01 & В2H3К3 & $9.94 \mathrm{E} 0$ & $\mathrm{~N} / \mathrm{A}$ & $9 / 15 / 11$ & $1 \mathrm{II} 2001$ \\
\hline 1109002-02 & B2H3K4 & $5.78 \mathrm{E} 0$ & N/A & $9 / 15 / 11$ & $1 \mathrm{II} 12001$ \\
\hline 1109002-03 & В2H3К5 & $6.19 \mathrm{E} 0$ & N/A & $9 / 15 / 11$ & $1 \mathrm{II} 12001$ \\
\hline 1109002-04 & В2H3K6 & $1.73 \mathrm{E} 1$ & N/A & $9 / 15 / 11$ & $1 \mathrm{II} 12001$ \\
\hline 1109002-05 & B2H3K7 & $5.87 \mathrm{E} 0$ & N/A & $9 / 15 / 11$ & $1 \mathrm{II} 12001$ \\
\hline 1109002-06 & $\mathrm{B} 2 \mathrm{H} 3 \mathrm{~K} 8$ & $5.93 \mathrm{E} 0$ & N/A & $9 / 15 / 11$ & $1 \mathrm{II} 12001$ \\
\hline 1109002-07 & В2H3К 9 & $6.57 \mathrm{E} 0$ & N/A & $9 / 15 / 11$ & $1 \mathrm{II} 2001$ \\
\hline $1109002-08$ & $\mathrm{~B} 2 \mathrm{H} 3 \mathrm{~L} 0$ & $1.64 \mathrm{E} 1$ & N/A & $9 / 15 / 11$ & $1 \mathrm{II} 12001$ \\
\hline 1109002-09 & B2H3L1 & $1.05 \mathrm{E} 1$ & $\mathrm{~N} / \mathrm{A}$ & $9 / 15 / 11$ & $1 \mathrm{II} 12001$ \\
\hline $1109002-10$ & B2H3L2 & $1.71 \mathrm{E} 1$ & $\mathrm{~N} / \mathrm{A}$ & $9 / 15 / 11$ & $1 \mathrm{II} 12001$ \\
\hline $1109002-11$ & B2H3L3 & $3.19 \mathrm{E}-1$ & N/A & $9 / 15 / 11$ & $1 \mathrm{II} 2001$ \\
\hline $1109002-12$ & B2H3L4 & $4.67 \mathrm{E}-1$ & N/A & $9 / 15 / 11$ & $1 \mathrm{II} 12001$ \\
\hline $1109002-13$ & B2H3L5 & $4.08 \mathrm{E}-1$ & N/A & $9 / 15 / 11$ & $1 \mathrm{II} 12001$ \\
\hline 1109002-14 & B2H3L6 & $4.75 \mathrm{E}-1$ & N/A & $9 / 15 / 11$ & $1 \mathrm{II} 12001$ \\
\hline $1109002-15$ & B2H3L 7 & $3.03 \mathrm{E} 0$ & N/A & $9 / 15 / 11$ & $1 \mathrm{II} 12001$ \\
\hline $1109002-16$ & B2H3L8 & $3.15 \mathrm{E} 0$ & N/A & $9 / 15 / 11$ & $1 \mathrm{II} 2001$ \\
\hline $1109002-17$ & B2H 242 & $5.62 \mathrm{E} 0$ & N/A & 9/19/11 & $1 \mathrm{II} 15002$ \\
\hline $1109002-18$ & B2H 243 & $5.07 \mathrm{E} 0$ & N/A & $9 / 19 / 11$ & $1 \mathrm{II} 15002$ \\
\hline $1109002-19$ & B2H244 & $1.29 \mathrm{E} 1$ & $\mathrm{~N} / \mathrm{A}$ & $9 / 19 / 11$ & $1 \mathrm{I} 15002$ \\
\hline $1109002-20$ & B2H245 & $4.58 \mathrm{E} 0$ & N/A & $9 / 19 / 11$ & $1 \mathrm{II} 15002$ \\
\hline $1109002-21$ & B2H246 & $6.52 \mathrm{E} 0$ & $\mathrm{~N} / \mathrm{A}$ & 9/19/11 & $1 \mathrm{II} 15002$ \\
\hline $1109002-22$ & B2H247 & $6.86 \mathrm{E} 0$ & N/A & $9 / 19 / 11$ & $1 \mathrm{II} 15002$ \\
\hline $1109002-23$ & B2H248 & $8.48 \mathrm{E} 0$ & N/A & 9/19/11 & $1 \mathrm{II} 15002$ \\
\hline $1109002-24$ & B2H249 & $9.02 \mathrm{E} 0$ & N/A & 9/19/11 & $1 \mathrm{II} 15002$ \\
\hline $1109002-25$ & $\mathrm{~B} 2 \mathrm{H} 250$ & $6.25 \mathrm{E} 0$ & N/A & 9/19/11 & $1 \mathrm{II} 15002$ \\
\hline $1109002-26$ & B2H251 & $4.15 \mathrm{E} 0$ & N/A & 9/19/11 & $1 \mathrm{II} 15002$ \\
\hline $1109002-27$ & В2H 252 & $1.50 \mathrm{E} 0$ & N/A & $9 / 19 / 11$ & $1 \mathrm{II} 15002$ \\
\hline $1109002-28$ & B2H 253 & $2.78 \mathrm{E} 0$ & N/A & 9/19/11 & $1 \mathrm{II} 15002$ \\
\hline $1109002-29$ & B2H 254 & $3.03 \mathrm{E} 0$ & $\mathrm{~N} / \mathrm{A}$ & $9 / 19 / 11$ & $1 \mathrm{I} 15002$ \\
\hline $1109002-30$ & B2H 255 & $2.24 \mathrm{E} 0$ & N/A & $9 / 19 / 11$ & $1 \mathrm{II} 15002$ \\
\hline $1109002-31$ & B2H256 & $2.57 \mathrm{E} 0$ & $\mathrm{~N} / \mathrm{A}$ & $9 / 19 / 11$ & $1 \mathrm{II} 15002$ \\
\hline $1109002-32$ & B2H257 & $3.12 \mathrm{E} 0$ & N/A & 9/19/11 & $1 \mathrm{II} 15002$ \\
\hline $1109002-33$ & B2H258 & 3.92E0 & N/A & $9 / 19 / 11$ & $1 \mathrm{II} 15002$ \\
\hline
\end{tabular}


Anions by Ion Chromatography

\begin{tabular}{|c|c|c|c|c|c|c|c|}
\hline CAS \# & Analyte & Results & Units & EQL & Analyzed & Batch & Method \\
\hline HEIS No. & В2H3K3 & \multicolumn{3}{|c|}{ Lab ID: $\quad$ 1109002-01 } & & & \\
\hline $14797-55-8$ & Nitrate & $1.48 \mathrm{E} 1$ & $\mu \mathrm{g} / \mathrm{g}$ dry & $5.00 \mathrm{E} 0$ & $9 / 21 / 11$ & $1 \mathrm{I} 21001$ & AGG-IC-001 \\
\hline HEIS No. & B2H3K4 & \multicolumn{3}{|c|}{ Lab ID: $\quad$ 1109002-02 } & & & \\
\hline $14797-55-8$ & Nitrate & $8.27 \mathrm{E} 0$ & $\mu \mathrm{g} / \mathrm{g}$ dry & $5.02 \mathrm{E} 0$ & $9 / 21 / 11$ & 1I21001 & AGG-IC-001 \\
\hline HEIS No. & В2H3K5 & \multicolumn{3}{|c|}{ Lab ID: $\quad$ 1109002-03 } & & & \\
\hline $14797-55-8$ & Nitrate & $8.57 \mathrm{E} 0$ & $\mu \mathrm{g} / \mathrm{g}$ dry & $5.00 \mathrm{E} 0$ & $9 / 21 / 11$ & $1 \mathrm{I} 21001$ & AGG-IC-001 \\
\hline HEIS No. & В2Н3К6 & \multicolumn{3}{|c|}{ Lab ID: $\quad$ 1109002-04 } & & & \\
\hline $14797-55-8$ & Nitrate & $5.67 \mathrm{E} 1$ & $\mu \mathrm{g} / \mathrm{g}$ dry & $5.00 \mathrm{E} 0$ & $9 / 21 / 11$ & $1 \mathrm{I} 21001$ & AGG-IC-001 \\
\hline HEIS No. & B2H3K7 & \multicolumn{3}{|c|}{ Lab ID: $\quad$ 1109002-05 } & & & \\
\hline $14797-55-8$ & Nitrate & $9.68 \mathrm{E} 2$ & $\mu \mathrm{g} / \mathrm{g}$ dry & $5.00 \mathrm{E} 1$ & $9 / 23 / 11$ & $1 \mathrm{I} 21001$ & AGG-IC-001 \\
\hline HEIS No. & В2H3K8 & \multicolumn{3}{|c|}{ Lab ID: $\quad$ 1109002-06 } & & & \\
\hline $14797-55-8$ & Nitrate & 7.41E1 & $\mu \mathrm{g} / \mathrm{g}$ dry & $5.00 \mathrm{E} 0$ & $9 / 21 / 11$ & $1 \mathrm{I} 21001$ & AGG-IC-001 \\
\hline HEIS No. & В2Н3К9 & \multicolumn{3}{|c|}{ Lab ID: $\quad$ 1109002-07 } & & & \\
\hline $14797-55-8$ & Nitrate & $4.25 \mathrm{E} 2$ & $\mu \mathrm{g} / \mathrm{g}$ dry & $5.00 \mathrm{E} 0$ & $9 / 21 / 11$ & $1 \mathrm{I} 21001$ & AGG-IC-001 \\
\hline HEIS No. & B2H3LO & \multicolumn{3}{|c|}{ Lab ID: $\quad$ 1109002-08 } & & & \\
\hline $14797-55-8$ & Nitrate & $4.52 \mathrm{E} 3$ & $\mu \mathrm{g} / \mathrm{g}$ dry & $5.00 \mathrm{E} 1$ & $9 / 23 / 11$ & $1 \mathrm{I} 21001$ & AGG-IC-001 \\
\hline HEIS No. & B2H3L1 & \multicolumn{3}{|c|}{ Lab ID: $\quad 1109002-09$} & & & \\
\hline $14797-55-8$ & Nitrate & $1.45 \mathrm{E} 3$ & $\mu \mathrm{g} / \mathrm{g}$ dry & $5.00 \mathrm{E} 1$ & $9 / 23 / 11$ & $1 \mathrm{I} 21001$ & AGG-IC-001 \\
\hline HEIS No. & B2H3L2 & \multicolumn{3}{|c|}{ Lab ID: $\quad$ 1109002-10 } & & & \\
\hline $14797-55-8$ & Nitrate & 7.77E3 & $\mu \mathrm{g} / \mathrm{g}$ dry & $5.00 \mathrm{E} 1$ & $9 / 23 / 11$ & $1 \mathrm{I} 21001$ & AGG-IC-001 \\
\hline HEIS No. & B2H3L3 & \multicolumn{3}{|c|}{ Lab ID: $\quad$ 1109002-11 } & & & \\
\hline $14797-55-8$ & Nitrate & $2.04 \mathrm{E} 3$ & $\mu \mathrm{g} / \mathrm{g}$ dry & $5.00 \mathrm{E} 1$ & $9 / 23 / 11$ & $1 \mathrm{I} 21001$ & AGG-IC-001 \\
\hline HEIS No. & B2H3L4 & \multicolumn{3}{|c|}{ Lab ID: $\quad$ 1109002-12 } & & & \\
\hline $14797-55-8$ & Nitrate & $3.63 \mathrm{E} 3$ & $\mu \mathrm{g} / \mathrm{g}$ dry & $5.00 \mathrm{E} 1$ & $9 / 23 / 11$ & $1 \mathrm{I} 21001$ & AGG-IC-001 \\
\hline HEIS No. & B2H3L5 & \multicolumn{3}{|c|}{ Lab ID: $\quad$ 1109002-13 } & & & \\
\hline $14797-55-8$ & Nitrate & $5.23 \mathrm{E} 3$ & $\mu \mathrm{g} / \mathrm{g}$ dry & $5.00 \mathrm{E} 1$ & $9 / 23 / 11$ & $1 \mathrm{I} 21001$ & AGG-IC-001 \\
\hline HEIS No. & B2H3L6 & \multicolumn{3}{|c|}{ Lab ID: $\quad$ 1109002-14 } & & & \\
\hline $14797-55-8$ & Nitrate & $3.52 \mathrm{E} 3$ & $\mu \mathrm{g} / \mathrm{g}$ dry & $5.00 \mathrm{E} 1$ & $9 / 23 / 11$ & $1 \mathrm{I} 21001$ & AGG-IC-001 \\
\hline HEIS No. & B2H3L7 & \multicolumn{3}{|c|}{ Lab ID: $\quad$ 1109002-15 } & & & \\
\hline $14797-55-8$ & Nitrate & $3.00 \mathrm{E} 3$ & $\mu \mathrm{g} / \mathrm{g}$ dry & $5.00 \mathrm{E} 1$ & $9 / 23 / 11$ & $1 \mathrm{I} 21001$ & AGG-IC-001 \\
\hline HEIS No. & B2H3L8 & \multicolumn{3}{|c|}{ Lab ID: $\quad$ 1109002-16 } & & & \\
\hline $14797-55-8$ & Nitrate & $3.59 \mathrm{E} 3$ & $\mu \mathrm{g} / \mathrm{g}$ dry & $5.00 \mathrm{E} 1$ & $9 / 23 / 11$ & $1 \mathrm{I} 21001$ & AGG-IC-001 \\
\hline HEIS No. & B2H242 & \multicolumn{3}{|c|}{ Lab ID: $\quad 1109002-17$} & & & \\
\hline $14797-55-8$ & Nitrate & $8.28 \mathrm{E} 0$ & $\mu \mathrm{g} / \mathrm{g}$ dry & $5.00 \mathrm{E} 0$ & $9 / 22 / 11$ & $1 \mathrm{I} 21002$ & AGG-IC-001 \\
\hline HEIS No. & B2H243 & \multicolumn{3}{|c|}{ Lab ID: $\quad$ 1109002-18 } & & & \\
\hline $14797-55-8$ & Nitrate & $5.44 \mathrm{E} 0$ & $\mu \mathrm{g} / \mathrm{g}$ dry & $5.00 \mathrm{E} 0$ & $9 / 22 / 11$ & $1 \mathrm{I} 21002$ & AGG-IC-001 \\
\hline HEIS No. & В2H244 & \multicolumn{3}{|c|}{ Lab ID: $\quad$ 1109002-19 } & & & \\
\hline $14797-55-8$ & Nitrate & $6.93 \mathrm{E} 1$ & $\mu \mathrm{g} / \mathrm{g}$ dry & $5.00 \mathrm{E} 0$ & $9 / 22 / 11$ & $1 \mathrm{I} 21002$ & AGG-IC-001 \\
\hline HEIS No. & B2H245 & \multicolumn{3}{|c|}{ Lab ID: 1109002} & & & \\
\hline $14797-55-8$ & Nitrate & $2.36 \mathrm{E} 1$ & $\mu \mathrm{g} / \mathrm{g}$ dry & $5.00 \mathrm{E} 0$ & $9 / 22 / 11$ & $1 \mathrm{I} 21002$ & AGG-IC-001 \\
\hline HEIS No. & В2H246 & \multicolumn{3}{|c|}{ Lab ID: 1109} & & & \\
\hline $14797-55-8$ & Nitrate & $1.39 \mathrm{E} 2$ & $\mu \mathrm{g} / \mathrm{g}$ dry & $5.00 \mathrm{E} 0$ & $9 / 22 / 11$ & $1 \mathrm{I} 21002$ & AGG-IC-001 \\
\hline
\end{tabular}




\begin{tabular}{|c|c|c|c|c|c|c|c|}
\hline CAS \# & Analyte & Results & Units & EQL & Analyzed & Batch & Method \\
\hline HEIS No. & В2H247 & \multicolumn{3}{|c|}{ Lab ID: $\quad 1109002-22$} & & & \\
\hline $14797-55-8$ & Nitrate & $3.90 \mathrm{E} 1$ & $\mu \mathrm{g} / \mathrm{g}$ dry & $5.00 \mathrm{E} 0$ & $9 / 22 / 11$ & $1 \mathrm{I} 21002$ & AGG-IC-001 \\
\hline HEIS No. & В2H248 & \multicolumn{3}{|c|}{ Lab ID: $\quad 1109002-23$} & & & \\
\hline $14797-55-8$ & Nitrate & $1.26 \mathrm{E} 3$ & $\mu \mathrm{g} / \mathrm{g}$ dry & $5.00 \mathrm{E} 1$ & $9 / 23 / 11$ & $1 \mathrm{I} 21002$ & AGG-IC-001 \\
\hline HEIS No. & В2H249 & \multicolumn{3}{|c|}{ Lab ID: $\quad 1109002-24$} & & & \\
\hline $14797-55-8$ & Nitrate & $7.45 \mathrm{E} 3$ & $\mu \mathrm{g} / \mathrm{g}$ dry & $5.00 \mathrm{E} 1$ & $9 / 23 / 11$ & $1 \mathrm{I} 21002$ & AGG-IC-001 \\
\hline HEIS No. & B2H250 & \multicolumn{3}{|c|}{ Lab ID: $\quad 1109002-25$} & & & \\
\hline $14797-55-8$ & Nitrate & $5.86 \mathrm{E} 3$ & $\mu \mathrm{g} / \mathrm{g}$ dry & $5.00 \mathrm{E} 1$ & $9 / 23 / 11$ & $1 \mathrm{I} 21002$ & AGG-IC-001 \\
\hline HEIS No. & В2H251 & \multicolumn{3}{|c|}{ Lab ID: $\quad 1109002-26$} & & & \\
\hline $14797-55-8$ & Nitrate & $3.54 \mathrm{E} 3$ & $\mu \mathrm{g} / \mathrm{g}$ dry & $5.00 \mathrm{E} 1$ & $9 / 23 / 11$ & $1 \mathrm{I} 21002$ & AGG-IC-001 \\
\hline HEIS No. & В2H252 & \multicolumn{3}{|c|}{ Lab ID: $\quad 1109002-27$} & & & \\
\hline $14797-55-8$ & Nitrate & $4.20 \mathrm{E} 3$ & $\mu \mathrm{g} / \mathrm{g}$ dry & $5.00 \mathrm{E} 1$ & $9 / 23 / 11$ & $1 \mathrm{I} 21002$ & AGG-IC-001 \\
\hline HEIS No. & В2H253 & \multicolumn{3}{|c|}{ Lab ID: $\quad 1109002-28$} & & & \\
\hline $14797-55-8$ & Nitrate & 3.03E3 & $\mu \mathrm{g} / \mathrm{g}$ dry & $5.03 \mathrm{E} 1$ & $9 / 24 / 11$ & $1 \mathrm{I} 21002$ & AGG-IC-001 \\
\hline HEIS No. & В2H254 & \multicolumn{3}{|c|}{ Lab ID: $\quad 1109002-29$} & & & \\
\hline $14797-55-8$ & Nitrate & $6.52 \mathrm{E} 3$ & $\mu \mathrm{g} / \mathrm{g}$ dry & $5.00 \mathrm{E} 1$ & $9 / 24 / 11$ & $1 \mathrm{I} 21002$ & AGG-IC-001 \\
\hline HEIS No. & B2H255 & \multicolumn{3}{|c|}{ Lab ID: $\quad 1109002-30$} & & & \\
\hline $14797-55-8$ & Nitrate & $5.61 \mathrm{E} 3$ & $\mu \mathrm{g} / \mathrm{g}$ dry & $5.00 \mathrm{E} 1$ & $9 / 24 / 11$ & $1 \mathrm{I} 21002$ & AGG-IC-001 \\
\hline HEIS No. & В2H256 & \multicolumn{3}{|c|}{ Lab ID: $\quad 1109002-31$} & & & \\
\hline $14797-55-8$ & Nitrate & $4.53 \mathrm{E} 3$ & $\mu \mathrm{g} / \mathrm{g}$ dry & $5.00 \mathrm{E} 1$ & $9 / 24 / 11$ & 1121002 & AGG-IC-001 \\
\hline HEIS No. & В2H257 & \multicolumn{3}{|c|}{ Lab ID: $\quad 1109002-32$} & & & \\
\hline $14797-55-8$ & Nitrate & 4.27E3 & $\mu \mathrm{g} / \mathrm{g}$ dry & $5.00 \mathrm{E} 1$ & $9 / 24 / 11$ & $1 \mathrm{I} 21002$ & AGG-IC-001 \\
\hline HEIS No. & В2H258 & \multicolumn{3}{|c|}{ Lab ID: $\quad 1109002-33$} & & & \\
\hline $14797-55-8$ & Nitrate & $3.78 \mathrm{E} 3$ & $\mu \mathrm{g} / \mathrm{g}$ dry & $5.47 \mathrm{E} 1$ & $9 / 24 / 11$ & $1 \mathrm{I} 21002$ & AGG-IC-001 \\
\hline
\end{tabular}


Radionuclides by ICP-MS/1:1 Water Extract

\begin{tabular}{|c|c|c|c|c|c|c|c|}
\hline CAS \# & Analyte & Results & Units & EQL & Analyzed & Batch & Method \\
\hline HEIS No. & В2H3K3 & \multicolumn{3}{|c|}{$1109002-01$} & & & \\
\hline 14133-76-7 & Technetium-99 & $<3.90 \mathrm{E}-5$ & $\mu \mathrm{g} / \mathrm{g}$ dry & $3.90 \mathrm{E}-5$ & $9 / 22 / 11$ & 1I22001 & PNNL-AGG-415 \\
\hline HEIS No. & B2H3K4 & \multicolumn{3}{|c|}{ Lab ID: $\quad$ 1109002-02 } & & & \\
\hline 14133-76-7 & Technetium-99 & $<3.92 \mathrm{E}-5$ & $\mu \mathrm{g} / \mathrm{g}$ dry & $3.92 \mathrm{E}-5$ & $9 / 22 / 11$ & $1 \mathrm{I} 22001$ & PNNL-AGG-415 \\
\hline HEIS No. & B2H3K5 & \multicolumn{3}{|c|}{ Lab ID: $\quad$ 1109002-03 } & & & \\
\hline 14133-76-7 & Technetium-99 & $<3.90 \mathrm{E}-5$ & $\mu \mathrm{g} / \mathrm{g}$ dry & $3.90 \mathrm{E}-5$ & $9 / 22 / 11$ & $1 \mathrm{I} 22001$ & PNNL-AGG-415 \\
\hline HEIS No. & В2Н3К6 & \multicolumn{3}{|c|}{ Lab ID: $\quad$ 1109002-04 } & & & \\
\hline $14133-76-7$ & Technetium-99 & $<3.90 \mathrm{E}-5$ & $\mu \mathrm{g} / \mathrm{g}$ dry & $3.90 \mathrm{E}-5$ & $9 / 22 / 11$ & 1I 22001 & PNNL-AGG-415 \\
\hline HEIS No. & В2H3K7 & \multicolumn{3}{|c|}{ Lab ID: $\quad$ 1109002-05 } & & & \\
\hline 14133-76-7 & Technetium-99 & $3.87 \mathrm{E}-4$ & $\mu \mathrm{g} / \mathrm{g}$ dry & $3.90 \mathrm{E}-5$ & $9 / 22 / 11$ & $1 \mathrm{I} 22001$ & PNNL-AGG-415 \\
\hline HEIS No. & В2H3K8 & \multicolumn{3}{|c|}{ Lab ID: $\quad$ 1109002-06 } & & & \\
\hline 14133-76-7 & Technetium-99 & $<3.90 \mathrm{E}-5$ & $\mu \mathrm{g} / \mathrm{g}$ dry & $3.90 \mathrm{E}-5$ & $9 / 22 / 11$ & $1 \mathrm{I} 22001$ & PNNL-AGG-415 \\
\hline HEIS No. & В2H3К9 & \multicolumn{3}{|c|}{ Lab ID: $\quad$ 1109002-07 } & & & \\
\hline 14133-76-7 & Technetium-99 & $2.74 \mathrm{E}-4$ & $\mu \mathrm{g} / \mathrm{g}$ dry & $3.91 \mathrm{E}-5$ & $9 / 22 / 11$ & 1I22001 & PNNL-AGG-415 \\
\hline HEIS No. & B2H3LO & \multicolumn{3}{|c|}{ Lab ID: $\quad$ 1109002-08 } & & & \\
\hline 14133-76-7 & Technetium-99 & $2.03 \mathrm{E}-3$ & $\mu \mathrm{g} / \mathrm{g}$ dry & $3.90 \mathrm{E}-5$ & $9 / 22 / 11$ & $1 \mathrm{I} 22001$ & PNNL-AGG-415 \\
\hline HEIS No. & B2H3L1 & \multicolumn{3}{|c|}{ Lab ID: $\quad$ 1109002-09 } & & & \\
\hline 14133-76-7 & Technetium-99 & $5.59 \mathrm{E}-4$ & $\mu \mathrm{g} / \mathrm{g}$ dry & $3.90 \mathrm{E}-5$ & $9 / 22 / 11$ & $1 \mathrm{I} 22001$ & PNNL-AGG-415 \\
\hline HEIS No. & B2H3L2 & \multicolumn{3}{|c|}{ Lab ID: $\quad 1109002-10$} & & & \\
\hline 14133-76-7 & Technetium-99 & $3.76 \mathrm{E}-3$ & $\mu \mathrm{g} / \mathrm{g}$ dry & $3.90 \mathrm{E}-5$ & $9 / 22 / 11$ & $1 \mathrm{I} 22001$ & PNNL-AGG-415 \\
\hline HEIS No. & B2H3L3 & \multicolumn{3}{|c|}{ Lab ID: $\quad$ 1109002-11 } & & & \\
\hline 14133-76-7 & Technetium-99 & $9.71 \mathrm{E}-4$ & $\mu \mathrm{g} / \mathrm{g}$ dry & $3.90 \mathrm{E}-5$ & $9 / 22 / 11$ & 1I22001 & PNNL-AGG-415 \\
\hline HEIS No. & B2H3L4 & \multicolumn{3}{|c|}{ Lab ID: $\quad$ 1109002-12 } & & & \\
\hline 14133-76-7 & Technetium-99 & $1.99 \mathrm{E}-3$ & $\mu \mathrm{g} / \mathrm{g}$ dry & $3.90 \mathrm{E}-5$ & $9 / 22 / 11$ & $1 \mathrm{I} 22001$ & PNNL-AGG-415 \\
\hline HEIS No. & B2H3L5 & \multicolumn{3}{|c|}{ Lab ID: $\quad 1109002-13$} & & & \\
\hline 14133-76-7 & Technetium-99 & $4.12 \mathrm{E}-3$ & $\mu \mathrm{g} / \mathrm{g}$ dry & $3.90 \mathrm{E}-5$ & $9 / 22 / 11$ & $1 \mathrm{I} 22001$ & PNNL-AGG-415 \\
\hline HEIS No. & B2H3L6 & \multicolumn{3}{|c|}{ Lab ID: $\quad$ 1109002-14 } & & & \\
\hline 14133-76-7 & Technetium-99 & $2.57 \mathrm{E}-3$ & $\mu \mathrm{g} / \mathrm{g}$ dry & $3.90 \mathrm{E}-5$ & $9 / 22 / 11$ & $1 \mathrm{I} 22001$ & PNNL-AGG-415 \\
\hline HEIS No. & B2H3L7 & \multicolumn{3}{|c|}{ Lab ID: $\quad 1109002-15$} & & & \\
\hline 14133-76-7 & Technetium-99 & $1.60 \mathrm{E}-3$ & $\mu \mathrm{g} / \mathrm{g}$ dry & $3.90 \mathrm{E}-5$ & $9 / 22 / 11$ & 1I22001 & PNNL-AGG-415 \\
\hline HEIS No. & B2H3L8 & \multicolumn{3}{|c|}{ Lab ID: 110} & & & \\
\hline $14133-76-7$ & Technetium-99 & $1.93 \mathrm{E}-3$ & $\mu \mathrm{g} / \mathrm{g}$ dry & $3.90 \mathrm{E}-5$ & $9 / 22 / 11$ & $1 \mathrm{I} 22001$ & PNNL-AGG-415 \\
\hline HEIS No. & В2H242 & \multicolumn{3}{|c|}{ Lab ID: $\quad 110$} & & & \\
\hline 14133-76-7 & Technetium-99 & $<3.90 \mathrm{E}-5$ & $\mu \mathrm{g} / \mathrm{g}$ dry & $3.90 \mathrm{E}-5$ & $9 / 22 / 11$ & 1I22001 & PNNL-AGG-415 \\
\hline HEIS No. & В2H243 & \multicolumn{3}{|c|}{ Lab ID: $\quad 110$} & & & \\
\hline 14133-76-7 & Technetium-99 & $<3.90 \mathrm{E}-5$ & $\mu \mathrm{g} / \mathrm{g}$ dry & $3.90 \mathrm{E}-5$ & $9 / 22 / 11$ & $1 \mathrm{I} 22001$ & PNNL-AGG-415 \\
\hline HEIS No. & B2H244 & \multicolumn{3}{|c|}{ Lab ID: $\quad 1109002-19$} & & & \\
\hline 14133-76-7 & Technetium-99 & $<3.90 \mathrm{E}-5$ & $\mu \mathrm{g} / \mathrm{g}$ dry & $3.90 \mathrm{E}-5$ & $9 / 22 / 11$ & $1 \mathrm{I} 22001$ & PNNL-AGG-415 \\
\hline HEIS No. & B2H245 & \multicolumn{3}{|c|}{ Lab ID: $\quad 1109002-20$} & & & \\
\hline 14133-76-7 & Technetium-99 & $<3.90 \mathrm{E}-5$ & $\mu \mathrm{g} / \mathrm{g}$ dry & $3.90 \mathrm{E}-5$ & $9 / 22 / 11$ & $1 \mathrm{I} 22001$ & PNNL-AGG-415 \\
\hline HEIS No. & B2H246 & \multicolumn{2}{|c|}{ Lab ID: 11} & $2-21$ & & & \\
\hline 14133-76-7 & Technetium-99 & $9.91 \mathrm{E}-5$ & $\mu \mathrm{g} / \mathrm{g}$ dry & $3.90 \mathrm{E}-5$ & $9 / 22 / 11$ & $1 \mathrm{I} 22002$ & PNNL-AGG-415 \\
\hline
\end{tabular}




\begin{tabular}{|c|c|c|c|c|c|c|c|}
\hline CAS \# & Analyte & Results & Units & EQL & Analyzed & Batch & Method \\
\hline HEIS No. & B2H247 & \multicolumn{3}{|c|}{ Lab ID: $\quad 1109002-22$} & & & \\
\hline $14133-76-7$ & Technetium-99 & $<3.90 \mathrm{E}-5$ & $\mu \mathrm{g} / \mathrm{g}$ dry & $3.90 \mathrm{E}-5$ & $9 / 22 / 11$ & $1 \mathrm{I} 22002$ & PNNL-AGG-415 \\
\hline HEIS No. & В2H248 & \multicolumn{2}{|c|}{ Lab ID: 11} & $1109002-23$ & & & \\
\hline 14133-76-7 & Technetium-99 & $6.62 \mathrm{E}-4$ & $\mu \mathrm{g} / \mathrm{g}$ dry & $3.90 \mathrm{E}-5$ & $9 / 22 / 11$ & $1 \mathrm{I} 22002$ & PNNL-AGG-415 \\
\hline HEIS No. & В2H249 & \multicolumn{3}{|c|}{ Lab ID: $\quad$ 1109002-24 } & & & \\
\hline 14133-76-7 & Technetium-99 & $4.10 \mathrm{E}-3$ & $\mu \mathrm{g} / \mathrm{g}$ dry & $3.90 \mathrm{E}-5$ & 9/22/11 & $1 \mathrm{I} 22002$ & PNNL-AGG-415 \\
\hline HEIS No. & B2H250 & \multicolumn{3}{|c|}{ Lab ID: $\quad$ 1109002-25 } & & & \\
\hline $14133-76-7$ & Technetium-99 & $4.28 \mathrm{E}-3$ & $\mu \mathrm{g} / \mathrm{g}$ dry & $3.90 \mathrm{E}-5$ & $9 / 22 / 11$ & $1 \mathrm{I} 22002$ & PNNL-AGG-415 \\
\hline HEIS No. & B2H251 & \multicolumn{3}{|c|}{ Lab ID: $\quad 1109002-26$} & & & \\
\hline $14133-76-7$ & Technetium-99 & $2.06 \mathrm{E}-3$ & $\mu \mathrm{g} / \mathrm{g}$ dry & $3.90 \mathrm{E}-5$ & $9 / 22 / 11$ & $1 \mathrm{I} 22002$ & PNNL-AGG-415 \\
\hline HEIS No. & B2H252 & \multicolumn{3}{|c|}{ Lab ID: $\quad 1109002-27$} & & & \\
\hline 14133-76-7 & Technetium-99 & $2.64 \mathrm{E}-3$ & $\mu \mathrm{g} / \mathrm{g}$ dry & $3.90 \mathrm{E}-5$ & $9 / 22 / 11$ & $1 \mathrm{I} 22002$ & PNNL-AGG-415 \\
\hline HEIS No. & В2H253 & \multirow{2}{*}{\multicolumn{2}{|c|}{$\begin{array}{l}\text { Lab ID: } \\
9.54 \mathrm{E}-4 \quad \mu \mathrm{g} / \mathrm{g} \text { dry }\end{array}$}} & $2-28$ & & & \\
\hline 14133-76-7 & Technetium-99 & & & $3.90 \mathrm{E}-5$ & $9 / 22 / 11$ & $1 \mathrm{I} 22002$ & PNNL-AGG-415 \\
\hline HEIS No. & В2H254 & \multicolumn{2}{|c|}{ Lab ID: $\quad 110$} & $2-29$ & & & \\
\hline 14133-76-7 & Technetium-99 & $4.67 \mathrm{E}-3$ & $\mu \mathrm{g} / \mathrm{g}$ dry & $3.90 \mathrm{E}-5$ & $9 / 22 / 11$ & $1 \mathrm{I} 22002$ & PNNL-AGG-415 \\
\hline HEIS No. & B2H255 & \multicolumn{3}{|c|}{ Lab ID: $\quad 1109002-30$} & & & \\
\hline 14133-76-7 & Technetium-99 & $4.18 \mathrm{E}-3$ & $\mu \mathrm{g} / \mathrm{g}$ dry & $3.90 \mathrm{E}-5$ & $9 / 22 / 11$ & $1 \mathrm{I} 22002$ & PNNL-AGG-415 \\
\hline HEIS No. & B2H256 & \multicolumn{3}{|c|}{ Lab ID: $\quad 1109$} & & & \\
\hline 14133-76-7 & Technetium-99 & $2.75 \mathrm{E}-3$ & $\mu \mathrm{g} / \mathrm{g}$ dry & $3.90 \mathrm{E}-5$ & $9 / 22 / 11$ & $1 \mathrm{I} 22002$ & PNNL-AGG-415 \\
\hline HEIS No. & В2H257 & \multicolumn{2}{|c|}{ Lab ID: $\quad 11$} & $2-32$ & & & \\
\hline $14133-76-7$ & Technetium-99 & $2.84 \mathrm{E}-3$ & $\mu \mathrm{g} / \mathrm{g}$ dry & $3.90 \mathrm{E}-5$ & $9 / 22 / 11$ & $1 \mathrm{I} 22002$ & PNNL-AGG-415 \\
\hline HEIS No. & В2H258 & \multicolumn{2}{|c|}{ Lab ID: 11} & $2-33$ & & & \\
\hline $14133-76-7$ & Technetium-99 & $2.19 \mathrm{E}-3$ & $\mu \mathrm{g} / \mathrm{g}$ dry & $4.27 \mathrm{E}-5$ & $9 / 22 / 11$ & $1 \mathrm{I} 22002$ & PNNL-AGG-415 \\
\hline
\end{tabular}




\section{Wet Chemistry - Quality Control}

Environmental Science Laboratory

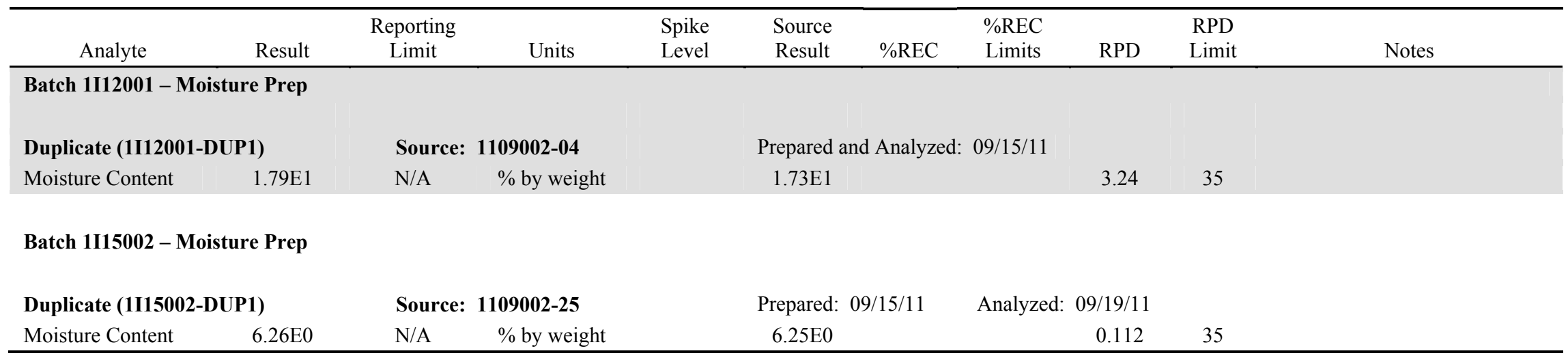




\section{Anions by Ion Chromatography - Quality Control}

\section{Environmental Science Laboratory}

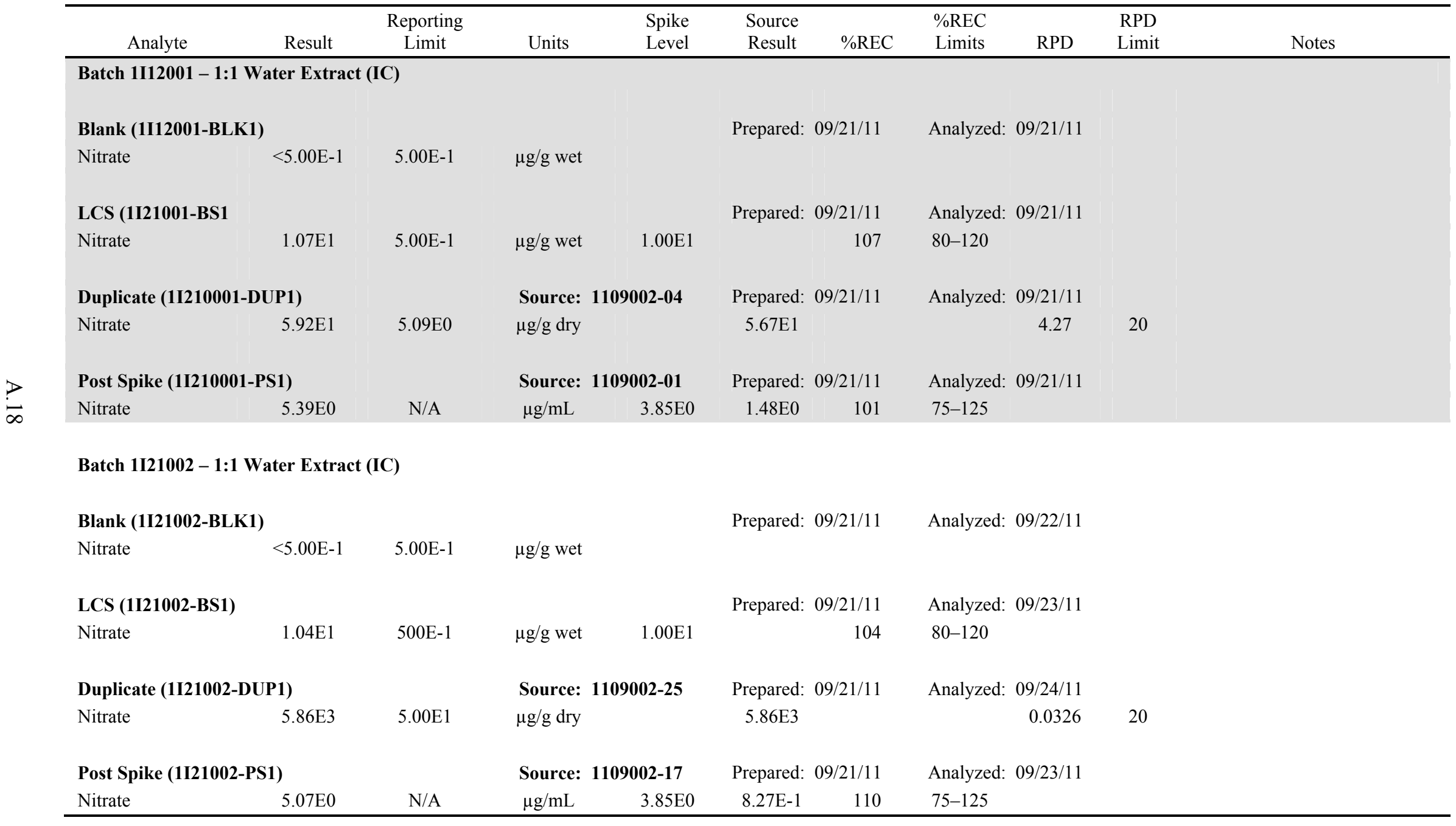




\section{Radionuclides by ICP-MS/1:1 Water Extract - Quality Control}

\section{Environmental Science Laboratory}

\begin{tabular}{|c|c|c|c|c|c|c|c|c|c|c|}
\hline Analyte & Result & $\begin{array}{c}\text { Reporting } \\
\text { Limit }\end{array}$ & Units & $\begin{array}{l}\text { Spike } \\
\text { Level }\end{array}$ & $\begin{array}{l}\text { Source } \\
\text { Result }\end{array}$ & $\%$ REC & $\begin{array}{l}\% \text { REC } \\
\text { Limits }\end{array}$ & RPD & $\begin{array}{l}\text { RPD } \\
\text { Limit }\end{array}$ & Notes \\
\hline \multicolumn{11}{|c|}{ Batch 1I22001 - 1:1 Water Extract (ICP/ICPMS) } \\
\hline \multicolumn{5}{|c|}{ Blank (1I22001-BLK1) } & \multirow{2}{*}{\multicolumn{4}{|c|}{ Prepared and Analyzed: 09/22/11 }} & & \\
\hline Technetium-99 & $<3.90 \mathrm{E}-5$ & $3.90 \mathrm{E}-5$ & $\mu \mathrm{g} / \mathrm{g}$ wet & & & & & & & \\
\hline \multicolumn{3}{|c|}{ Duplicate (1I220001-DUP1) } & \multicolumn{2}{|c|}{ Source: 1109002-04 } & \multicolumn{4}{|c|}{ Prepared and Analyzed: 09/22/11 } & & \\
\hline Technetium-99 & $<3.97 \mathrm{E}-5$ & $3.97 \mathrm{E}-5$ & $\mu \mathrm{g} / \mathrm{g}$ dry & & ND & & & & 35 & \\
\hline \multicolumn{3}{|c|}{ Post Spike (1I220001-PS1) } & \multicolumn{2}{|c|}{ Source: 1109002-01 } & \multicolumn{4}{|c|}{ Prepared and Analyzed: 09/22/11 } & & \\
\hline Technetium-99 & 1.09E0 & N/A & $\mu \mathrm{g} / \mathrm{L}$ & $1.09 \mathrm{E} 0$ & $1.40 \mathrm{E}-3$ & 101 & $75-125$ & & & \\
\hline \multicolumn{11}{|c|}{ Batch 1I22002 - 1:1 Water Extract (ICP/ICPMS) } \\
\hline \multicolumn{5}{|c|}{ Blank (1I22002-BLK1) } & \multirow{2}{*}{\multicolumn{4}{|c|}{ Prepared and Analyzed: 09/22/11 }} & & \\
\hline Technetium-99 & $<3.90 \mathrm{E}-5$ & $3.90 \mathrm{E}-5$ & $\mu \mathrm{g} / \mathrm{g}$ wet & & & & & & & \\
\hline \multicolumn{3}{|c|}{ Duplicate (1I22002-DUP1) } & \multicolumn{2}{|c|}{ Source: 1109002-25 } & \multicolumn{4}{|c|}{ Prepared and Analyzed: 09/22/11 } & & \\
\hline Technetium-99 & $3.35 \mathrm{E}-5$ & $3.90 \mathrm{E}-5$ & $\mu \mathrm{g} / \mathrm{g}$ dry & & $4.28 \mathrm{E}-3$ & & & 24.3 & 35 & \\
\hline
\end{tabular}




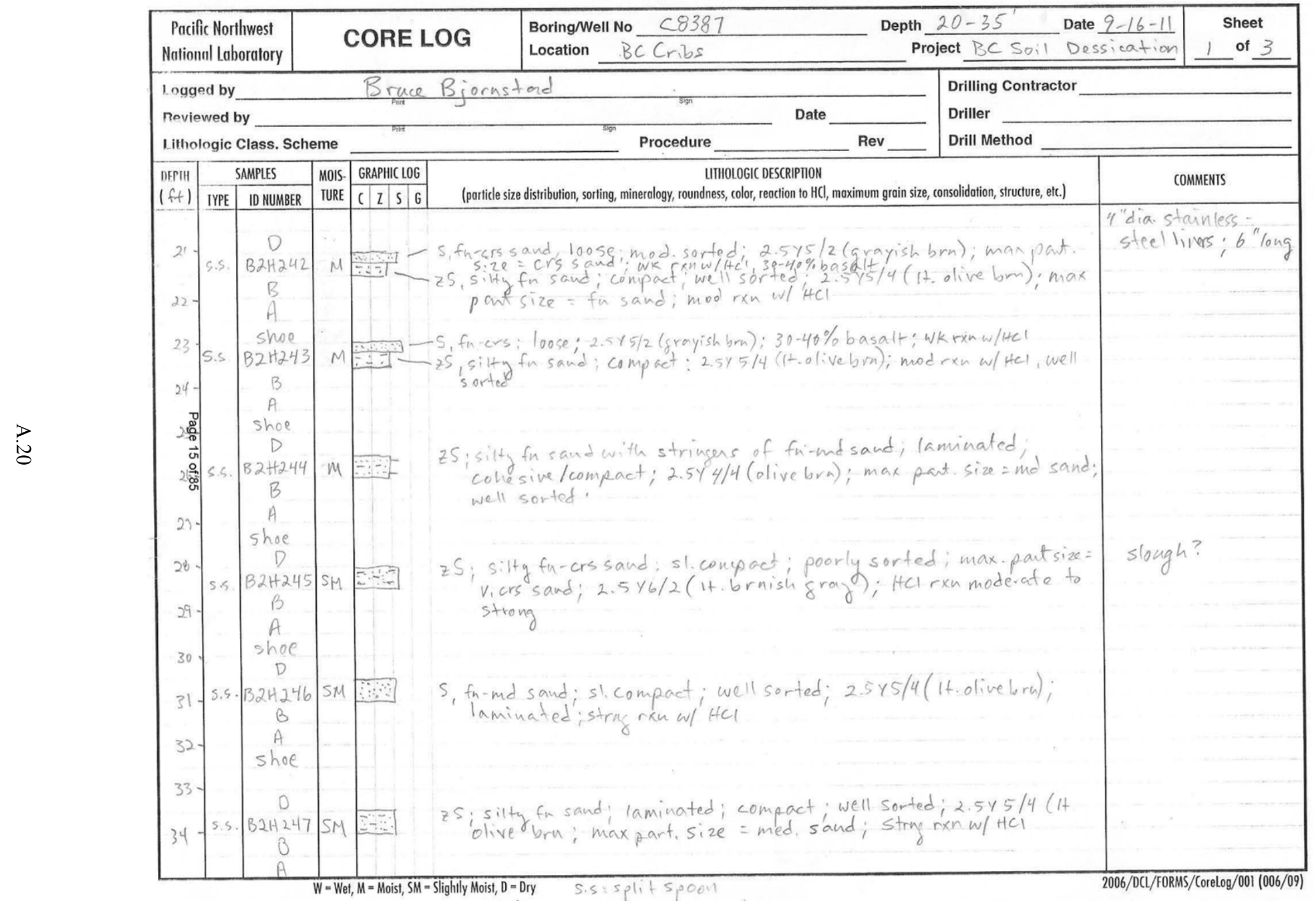




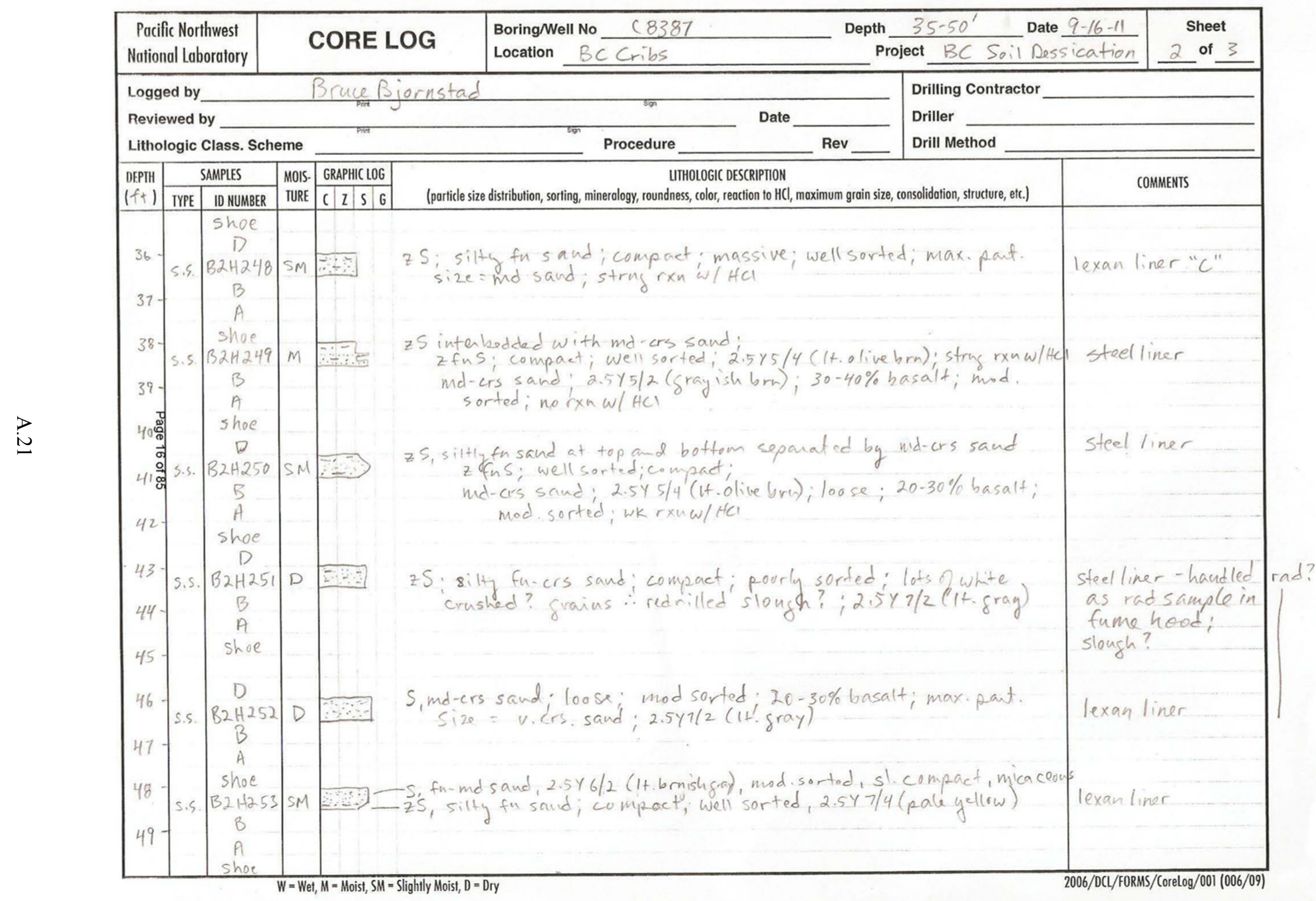




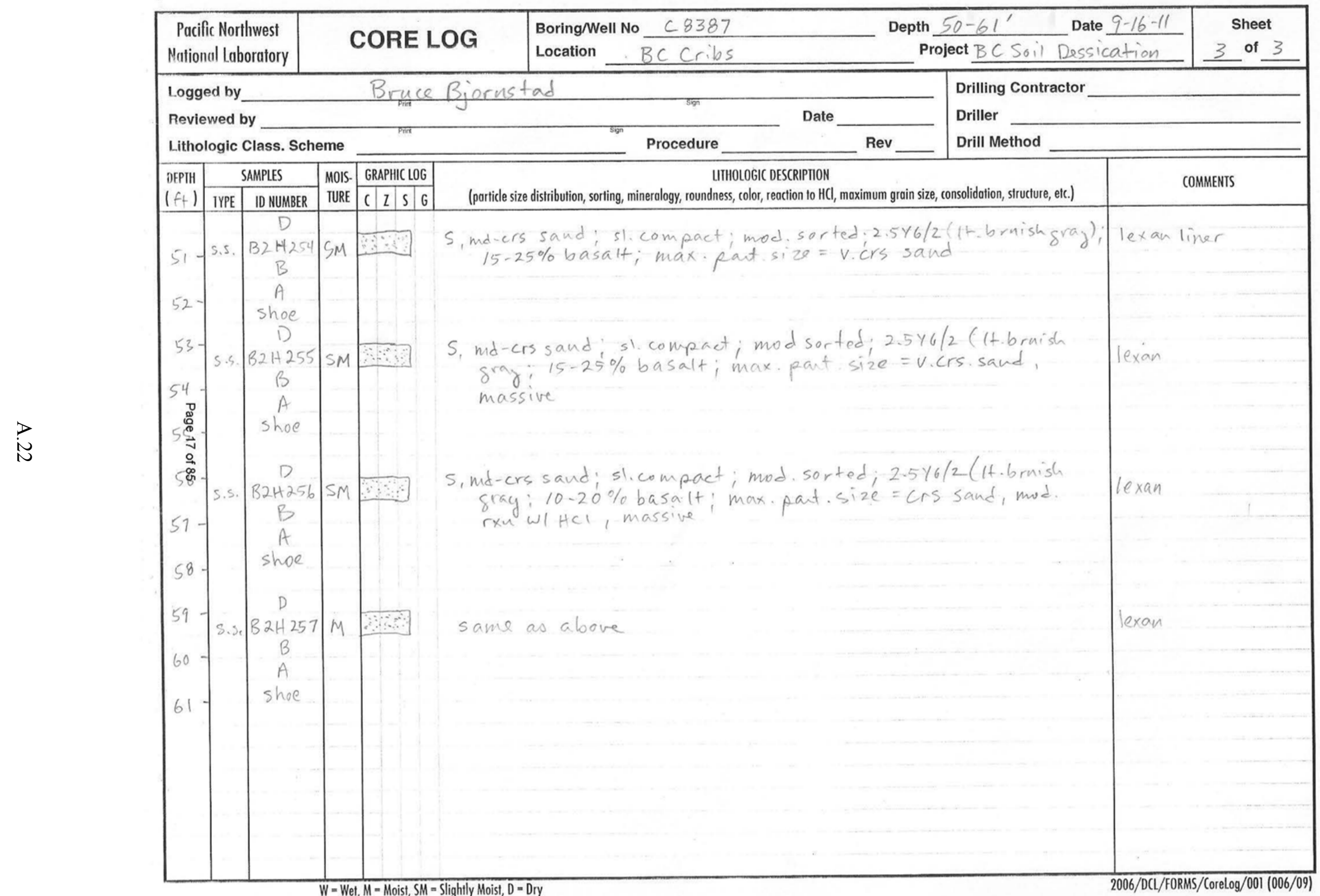




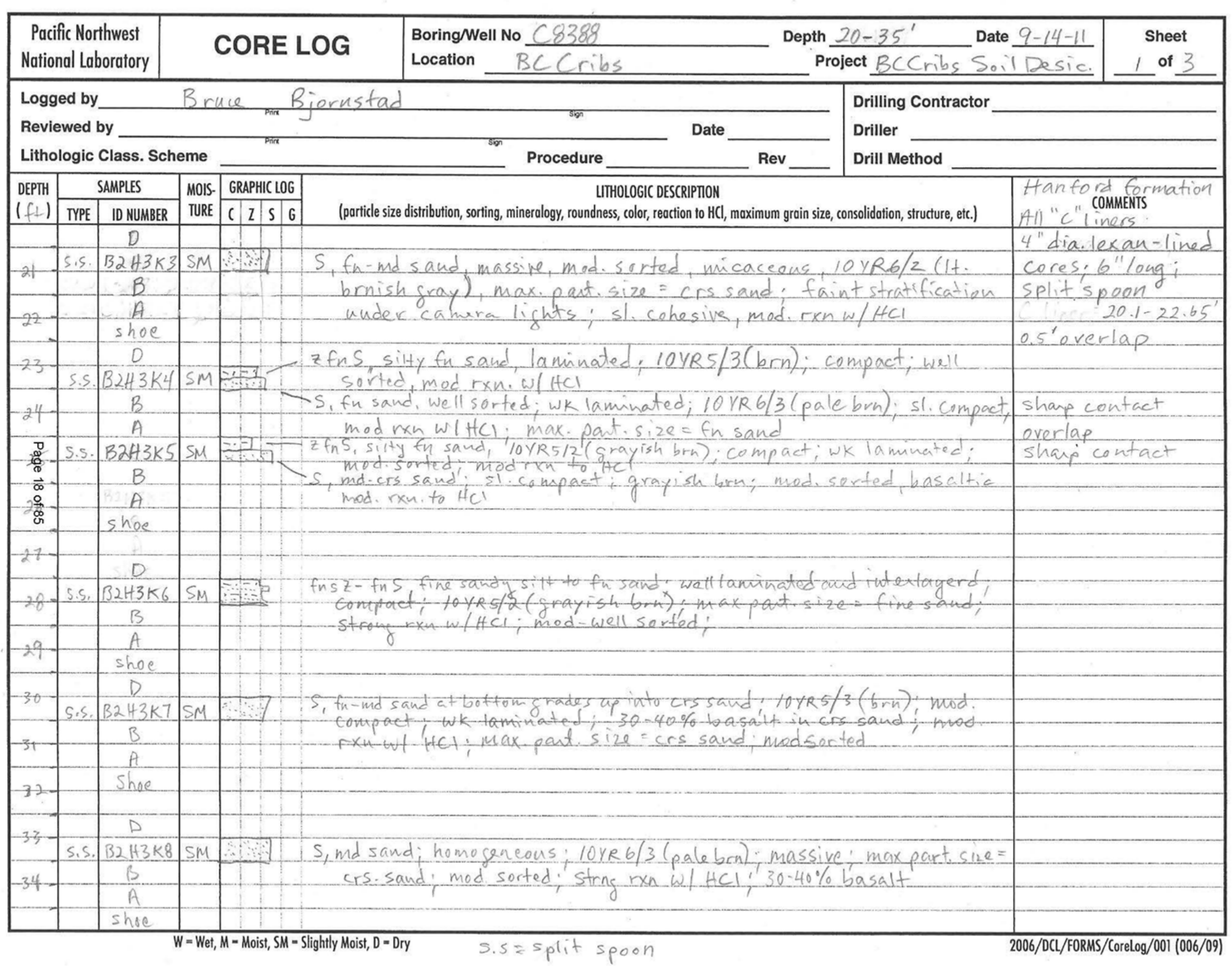




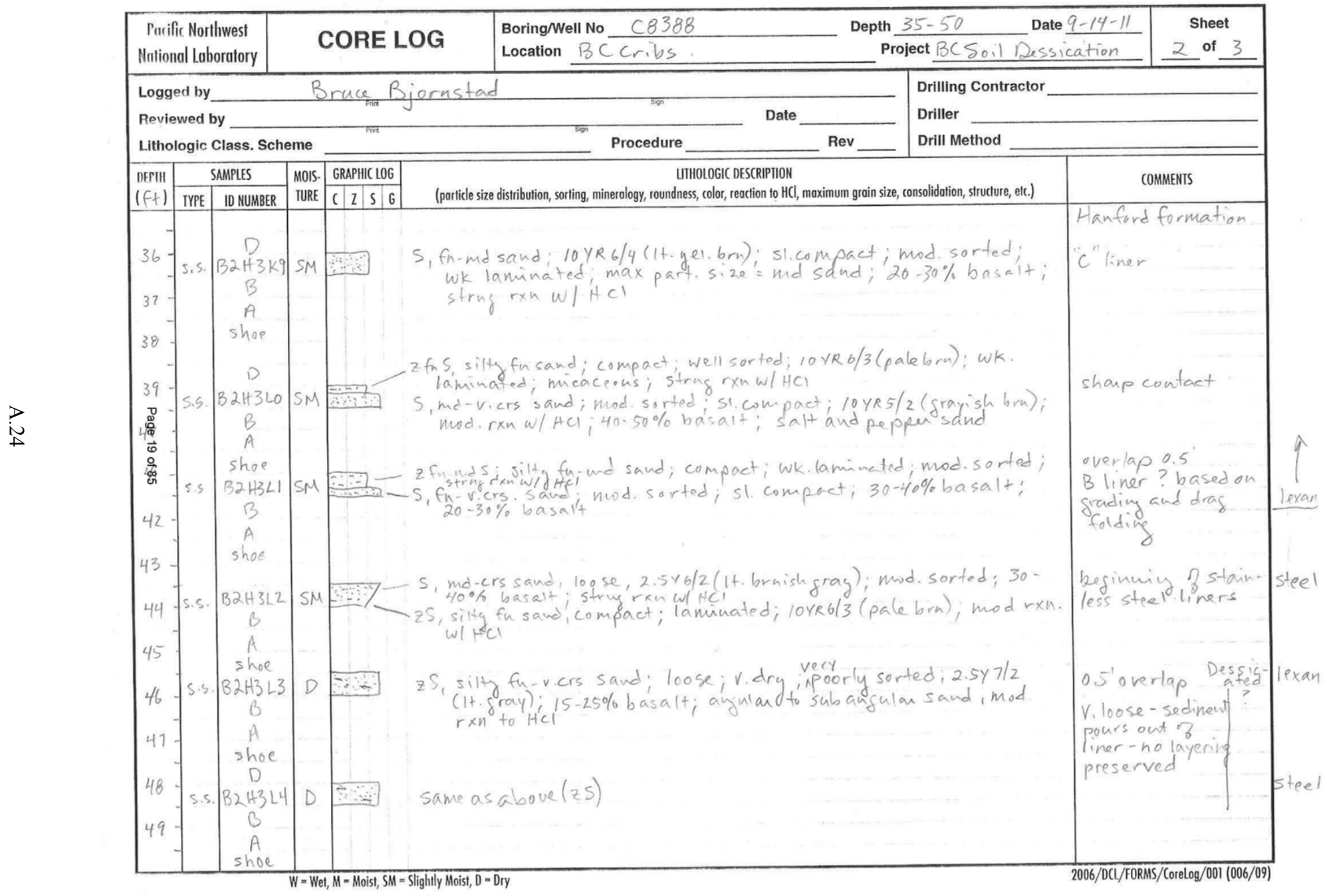




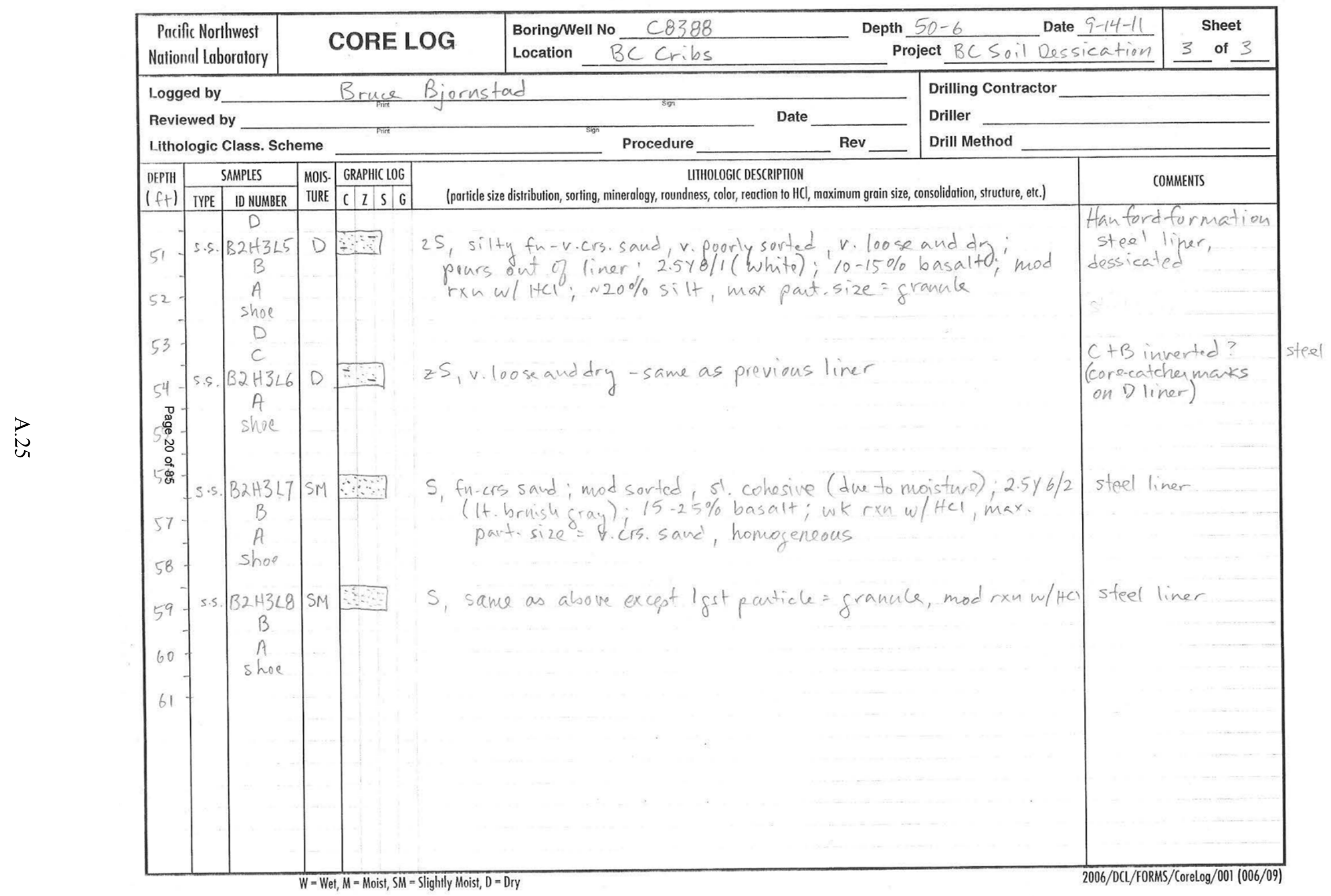



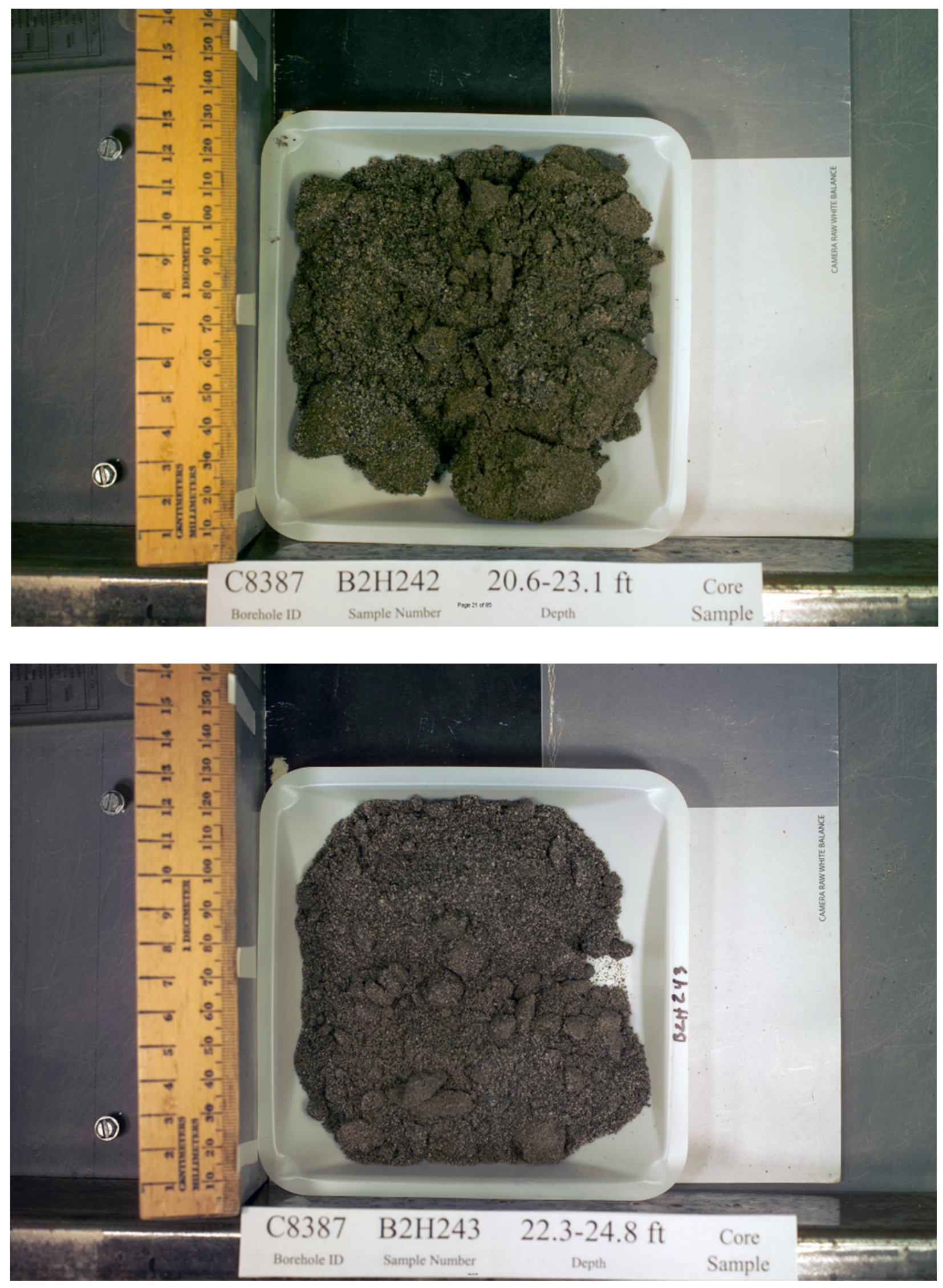

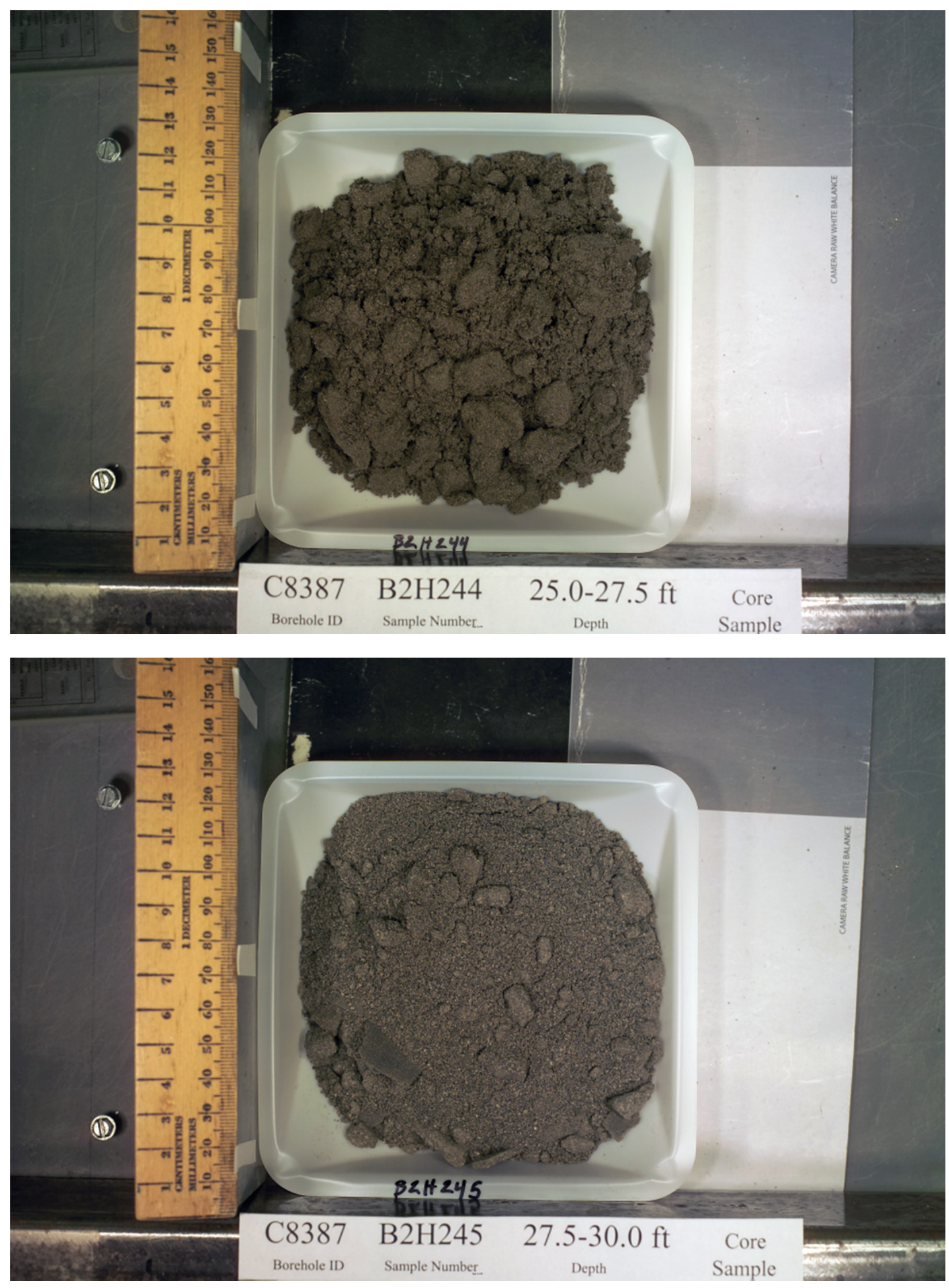

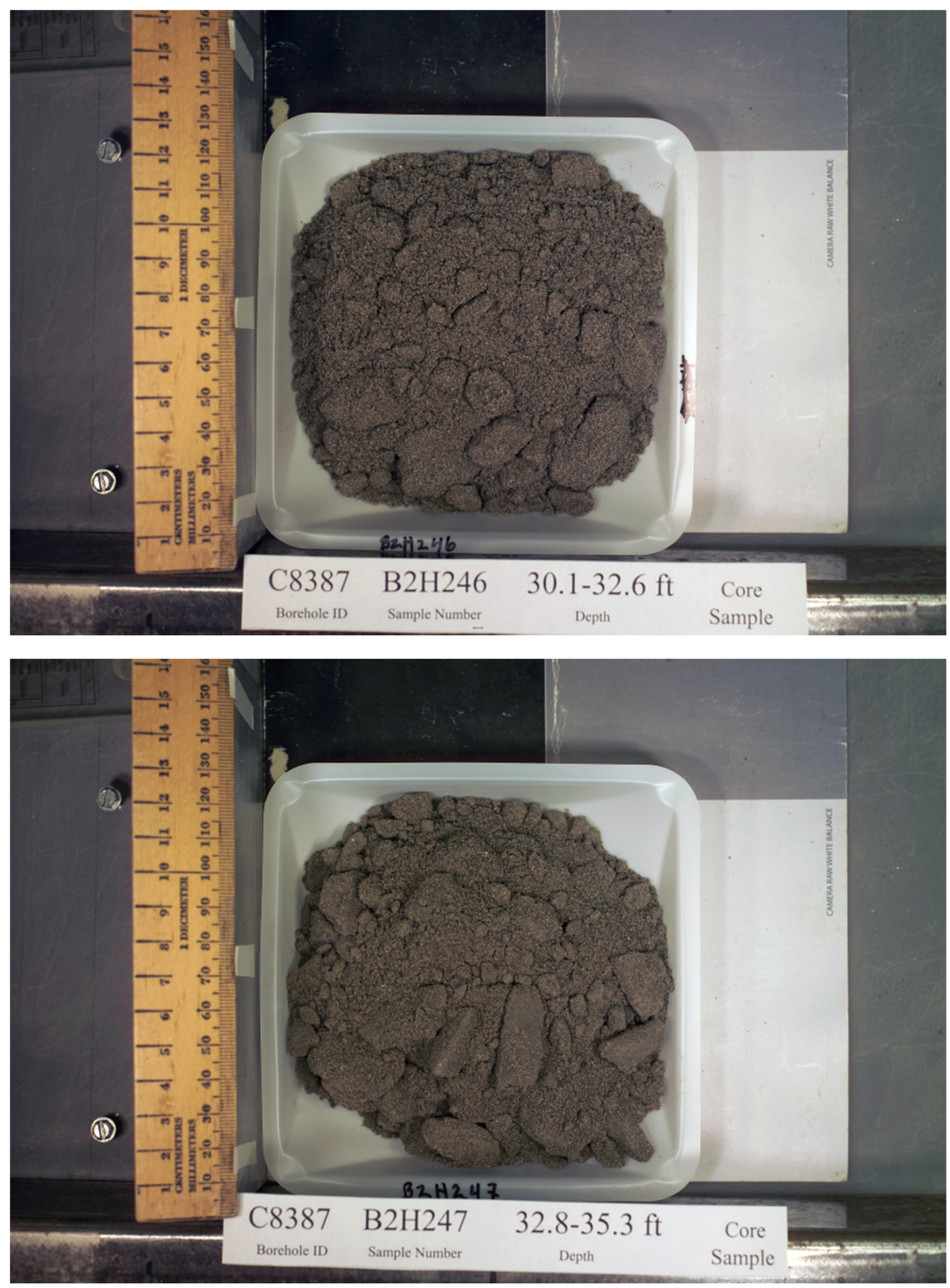

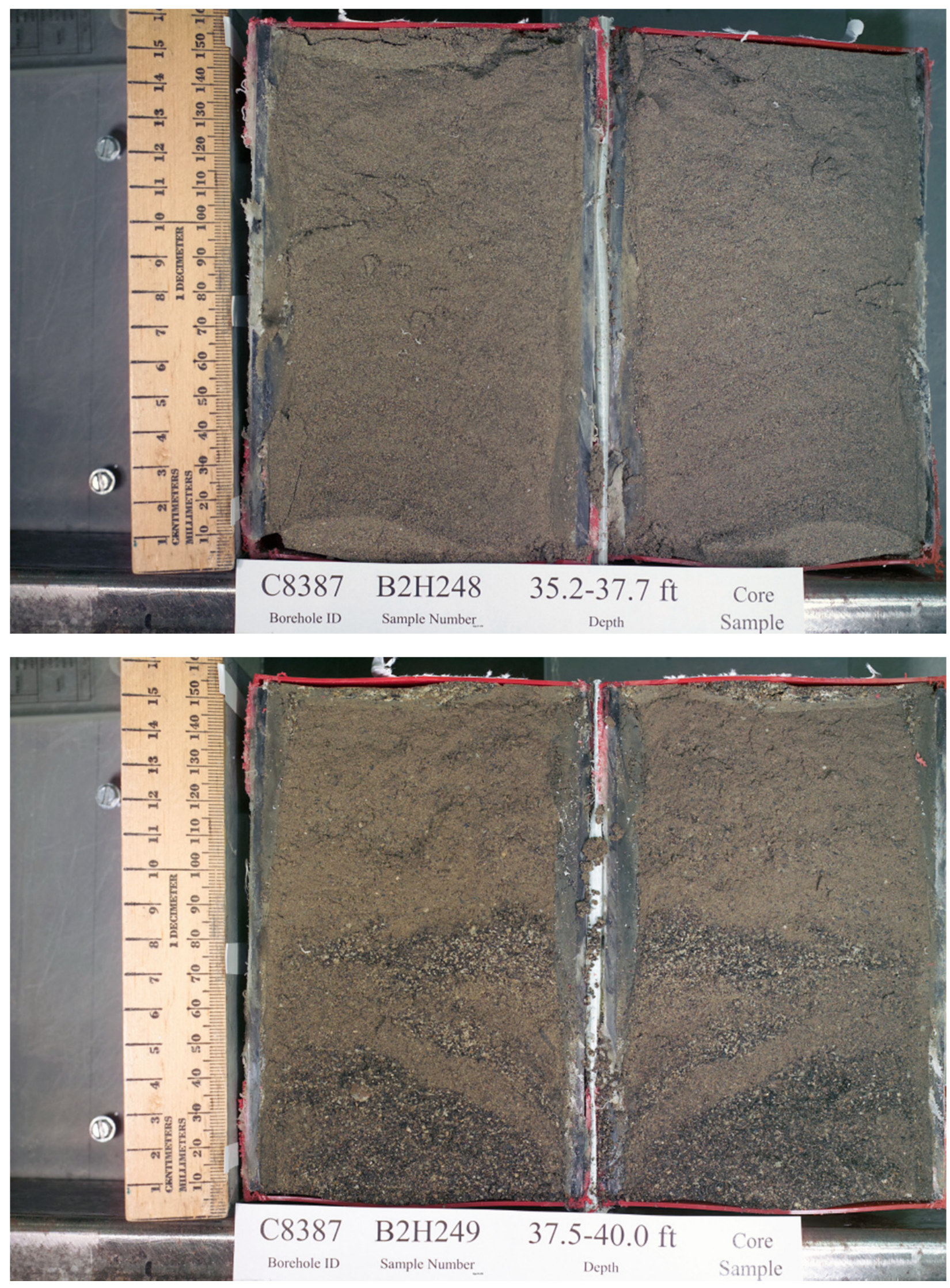

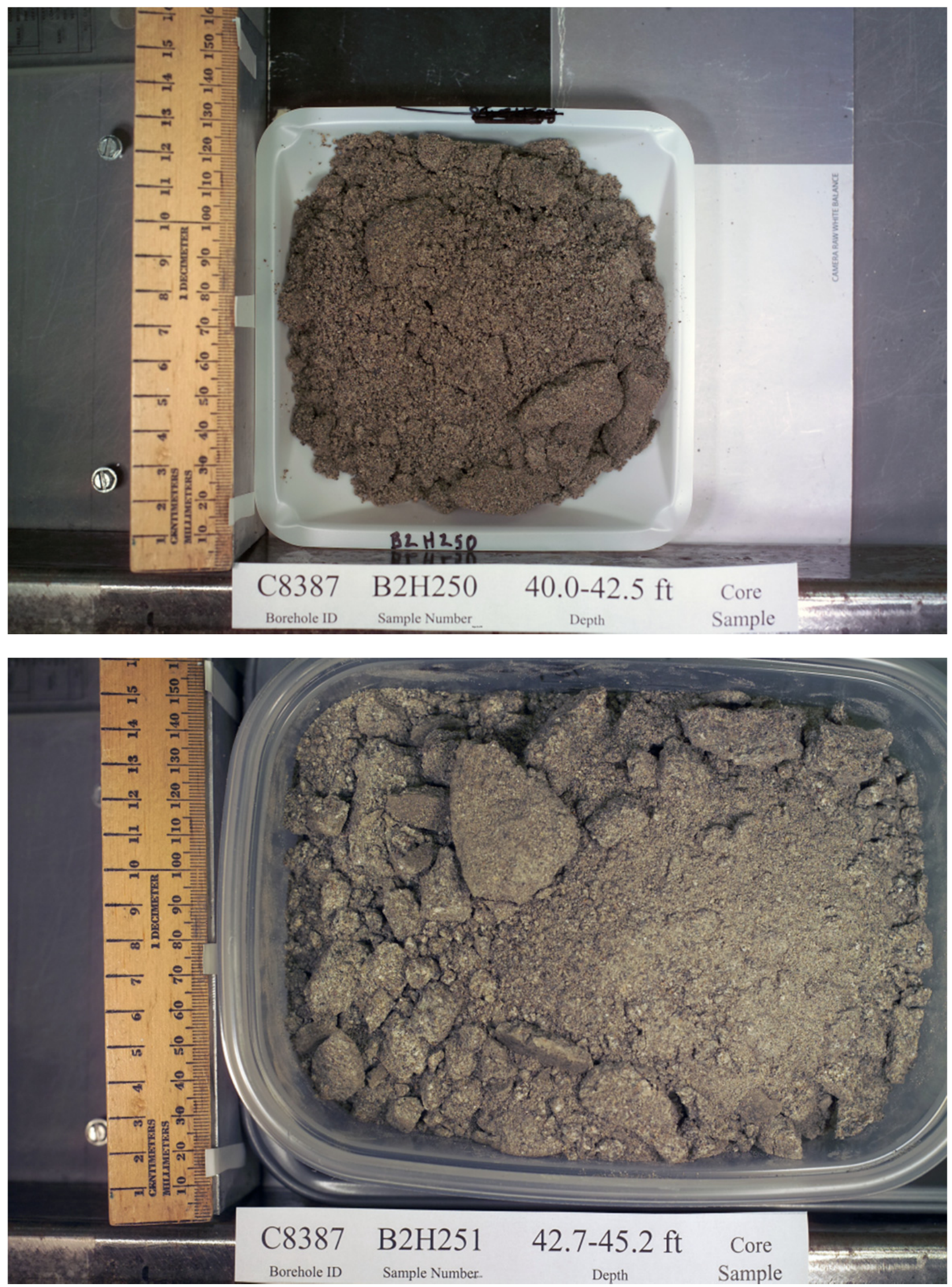

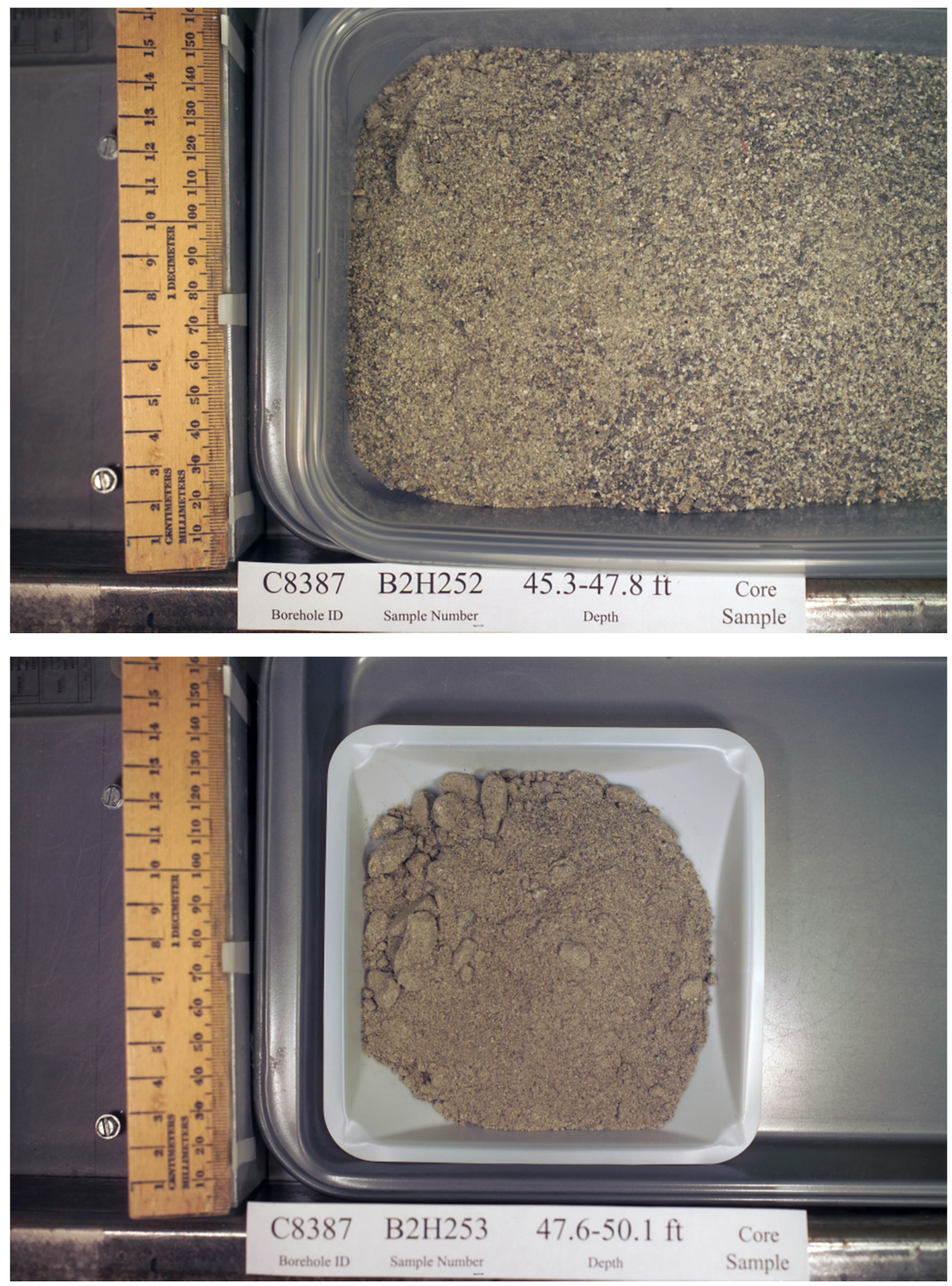

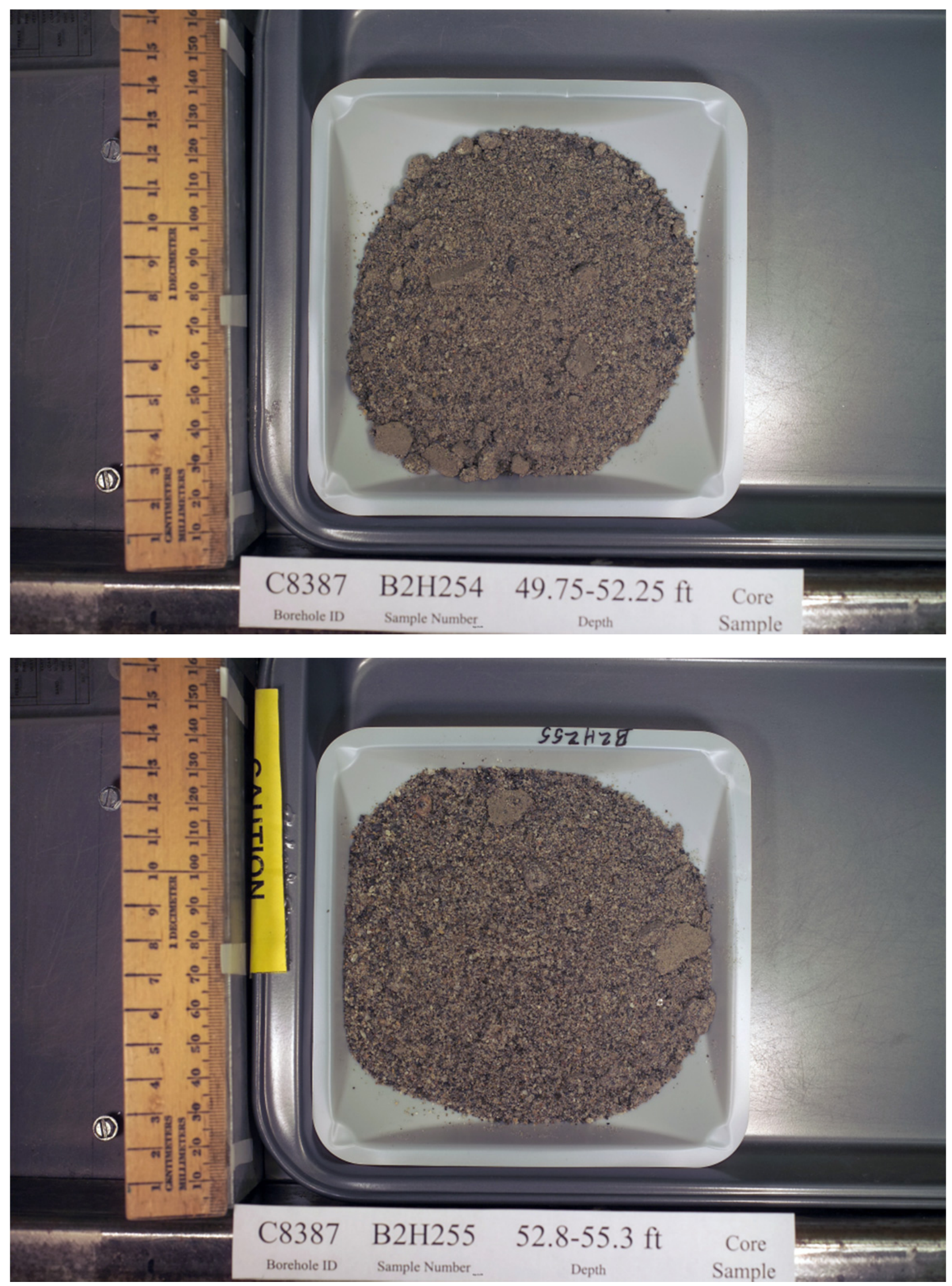

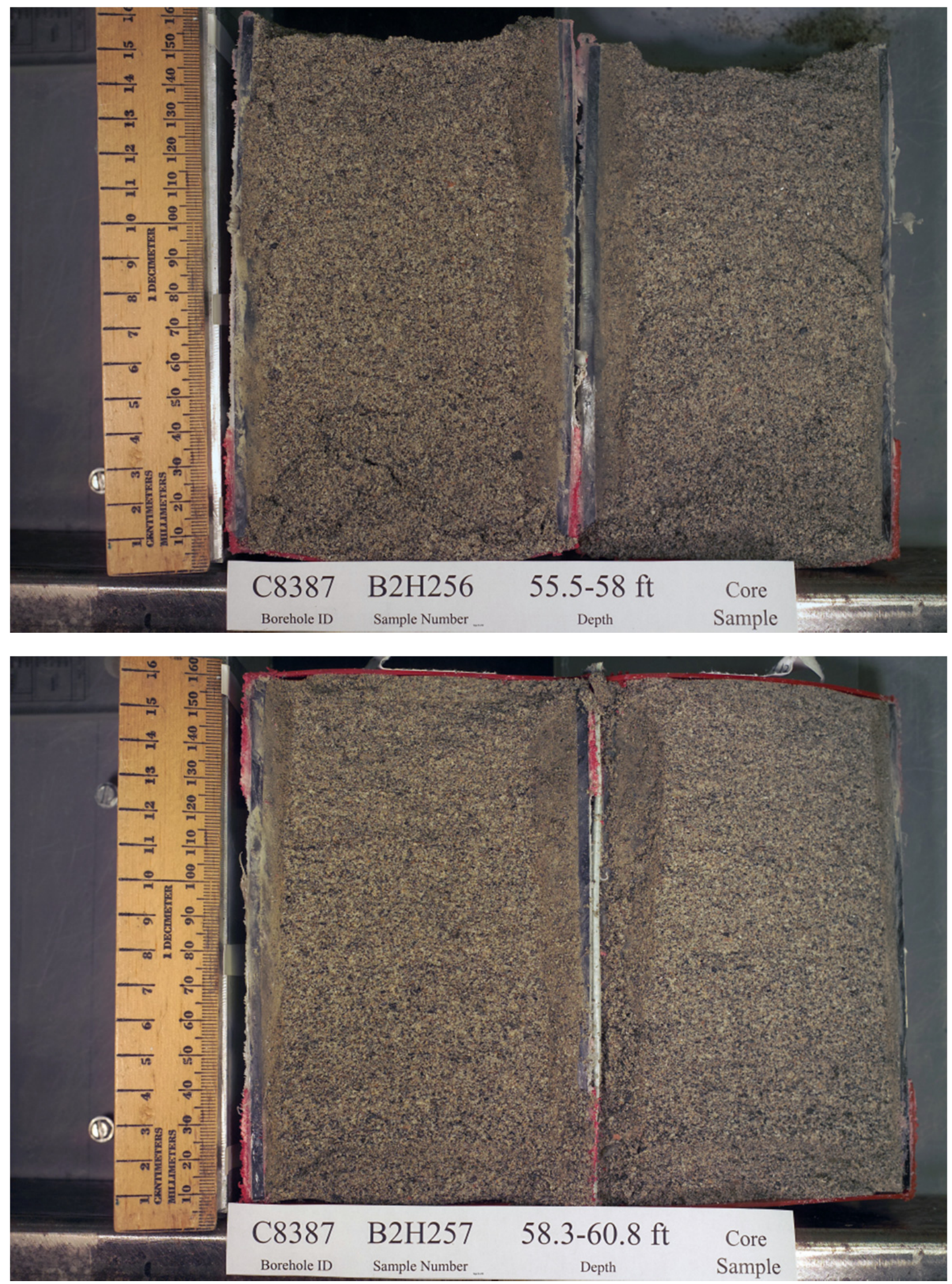

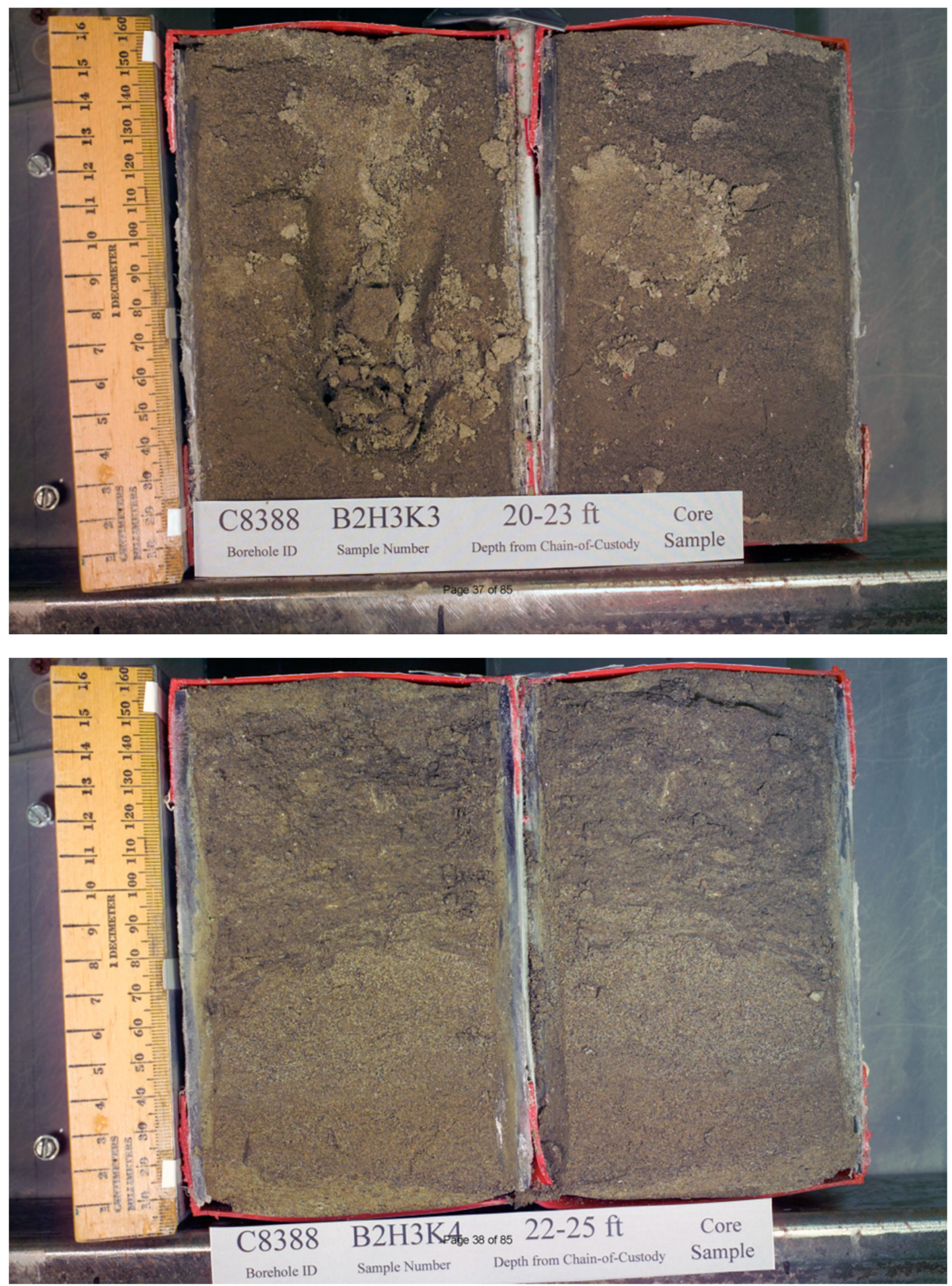

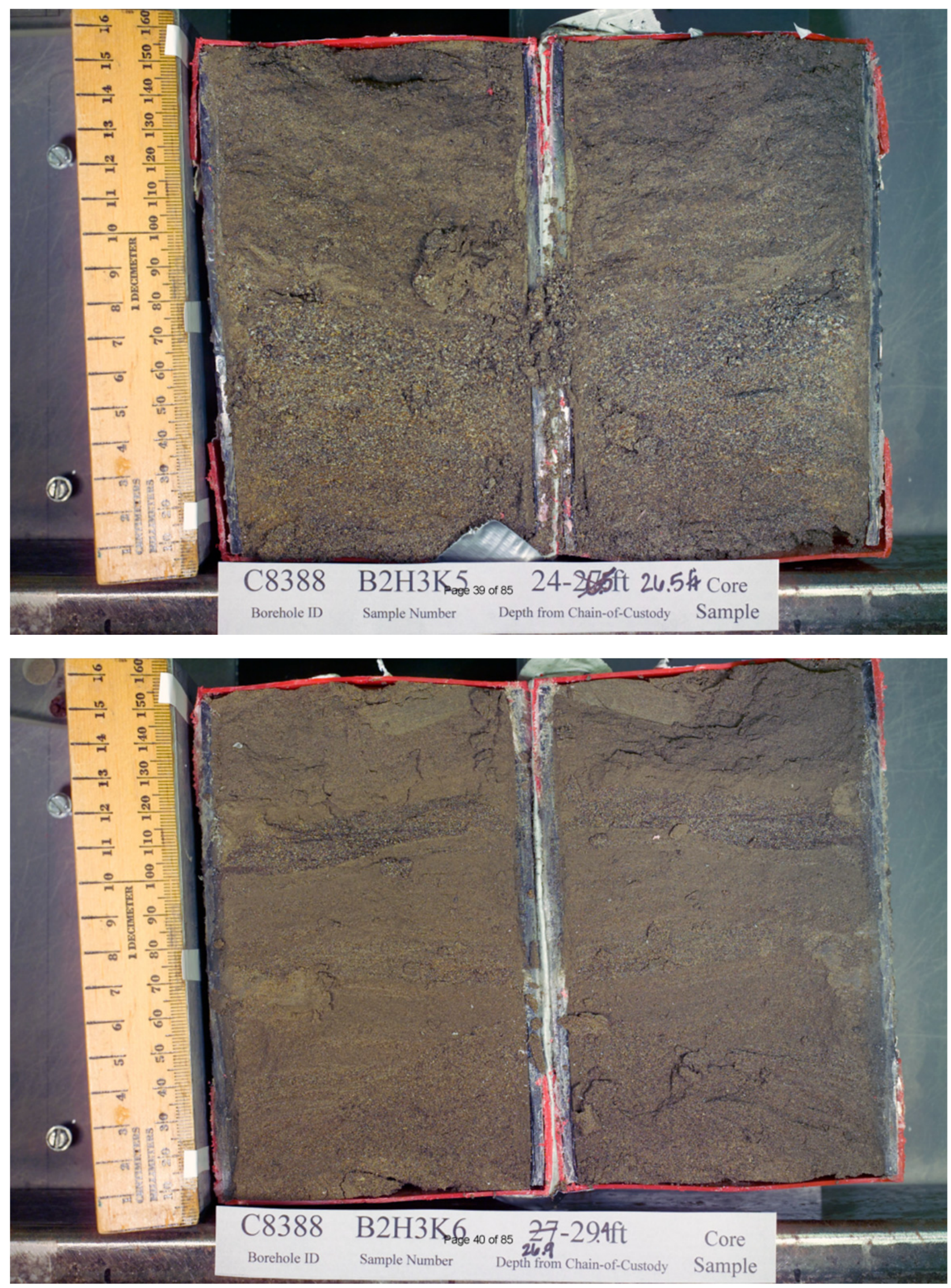

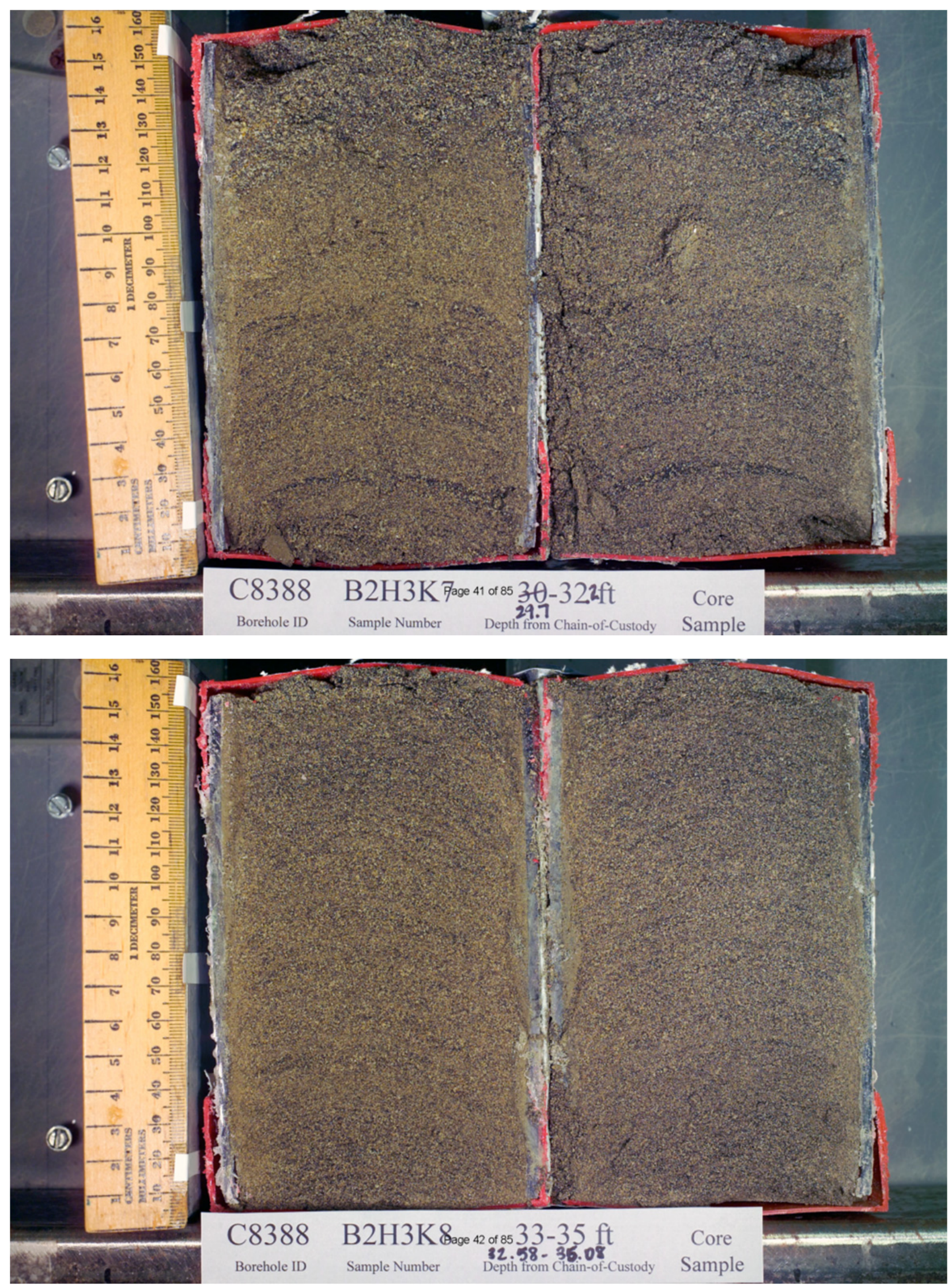

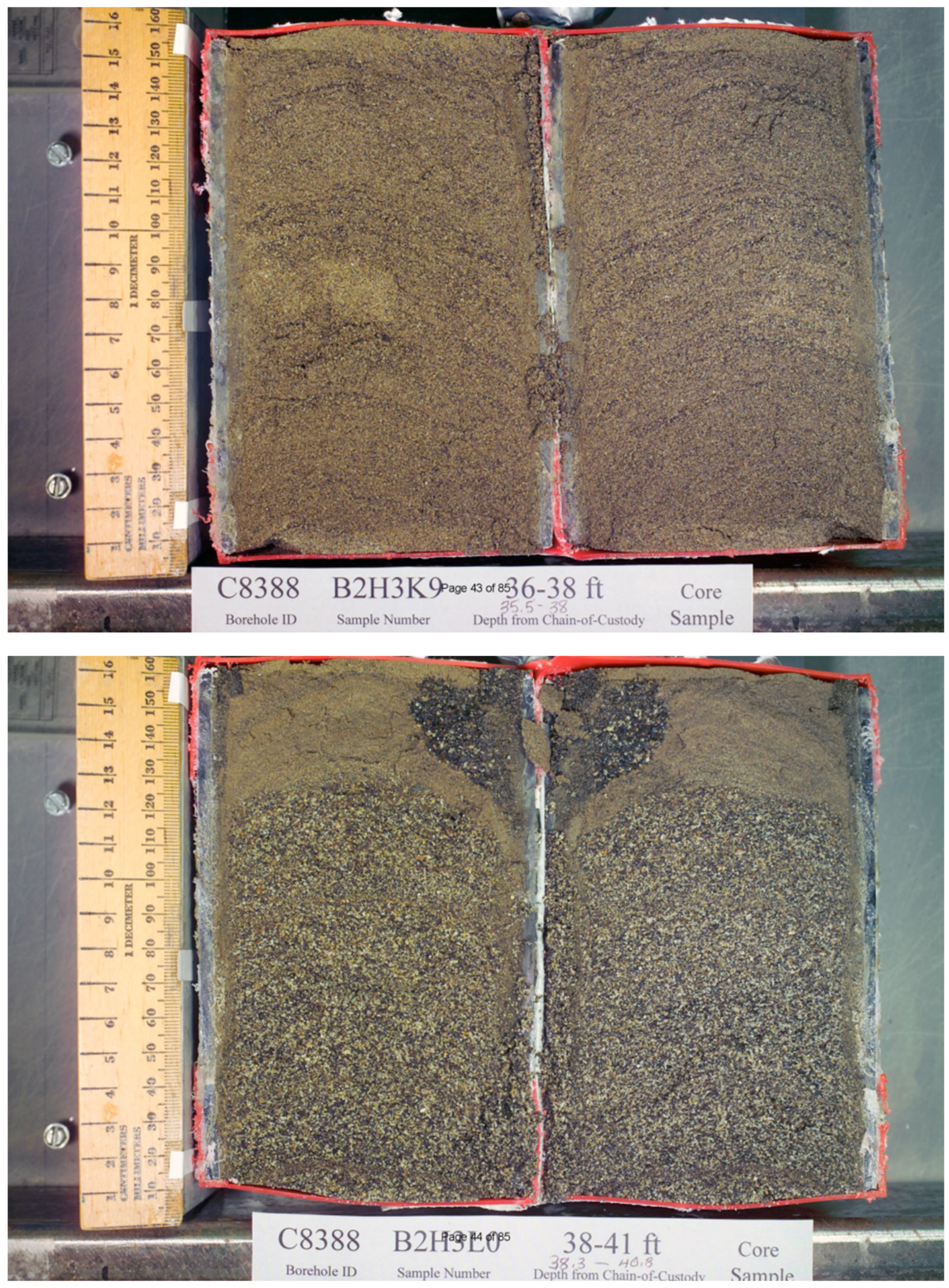

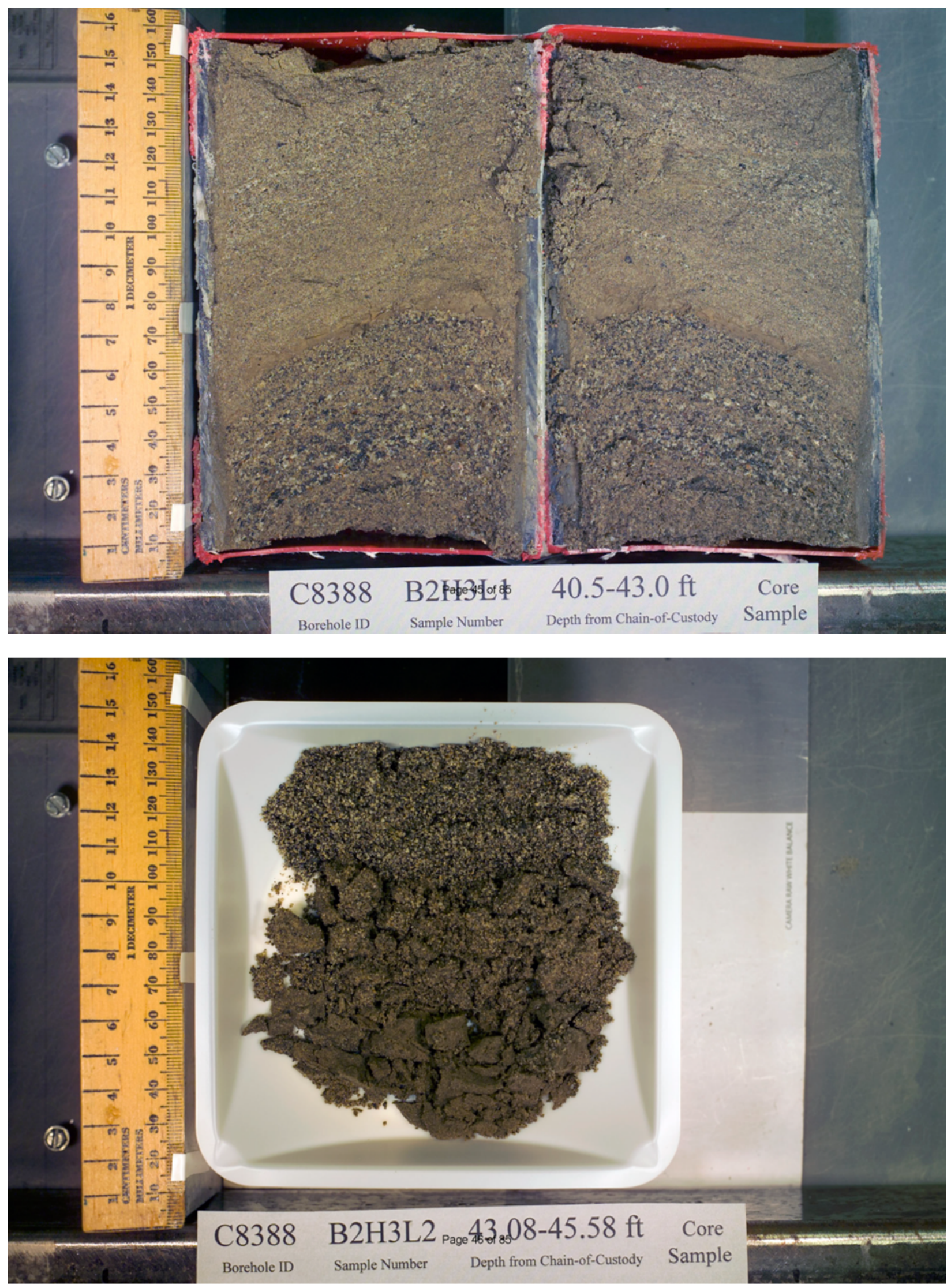

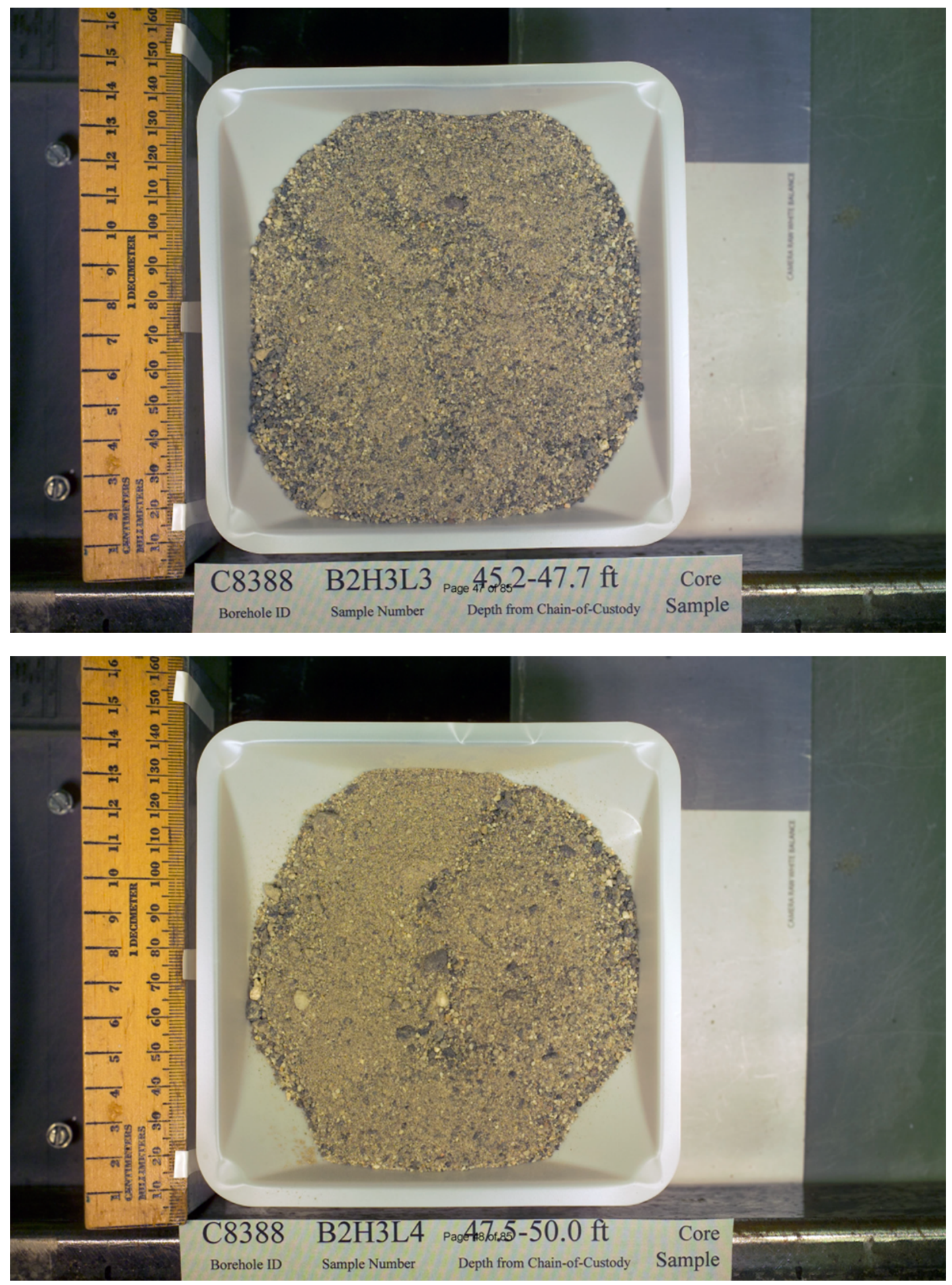

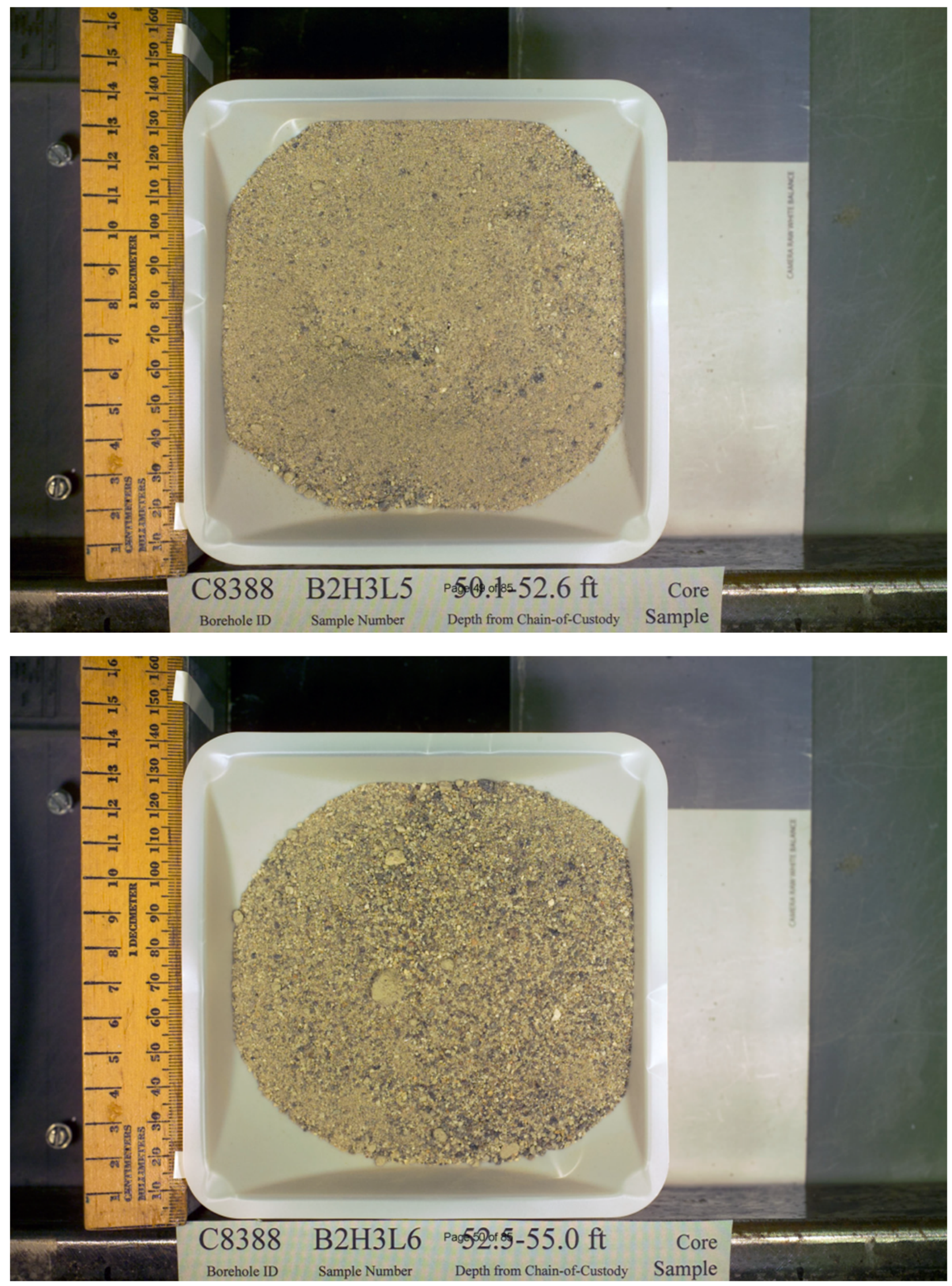

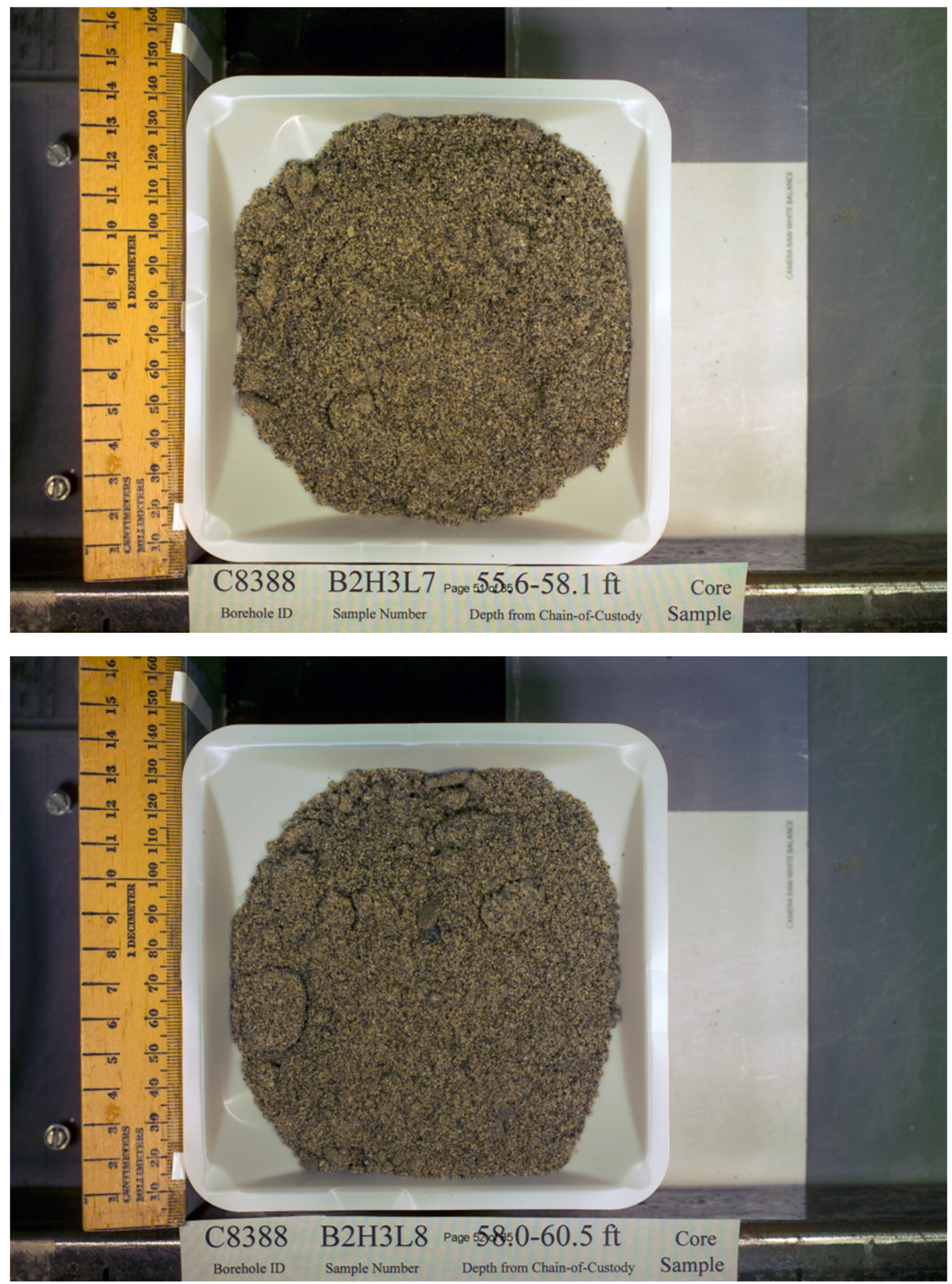


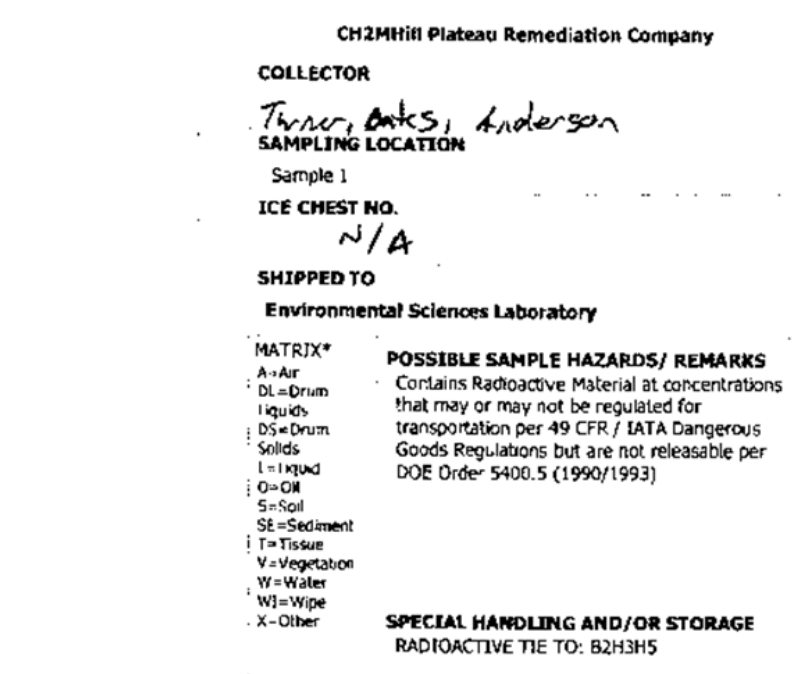

$\frac{P}{N}$

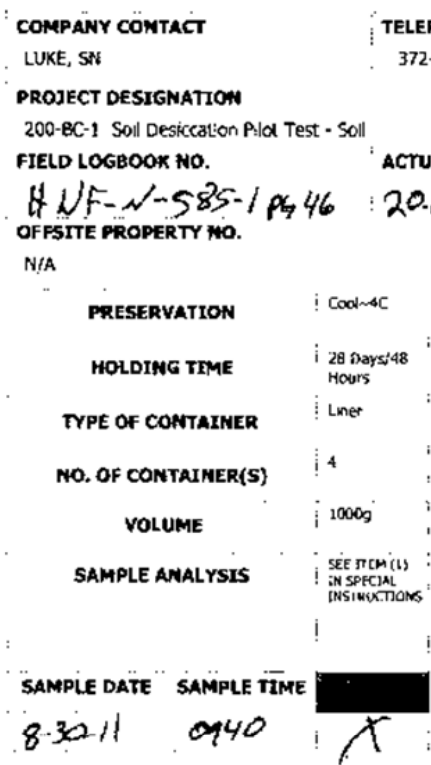

CHAIN OF POSSESSION

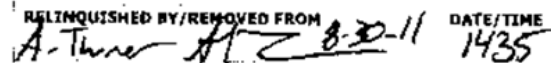

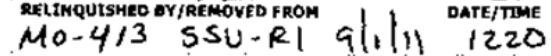
RELINQUISHED OY /REMOVED FROM

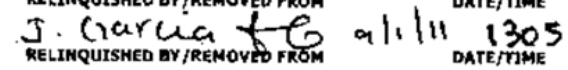

\section{RELIMQUUISHED BY/REMOVED FROH}

RELIMQUISHED BY/REMOVED FROM

DATE/TIME

RELINQUISHED BY/REMOVED FROH

DATE/TIME

DATE/TIME

LABORATORY
SECTION

final sample

FINAL SAMPLE
DISPOSTITON

PRTNTRD ON $8 / 24 / 2011$
SIGN/ PRINT MAMES

RECAIVED QY/STORED 3

MOL/3556 R) 8-30-1/ 1435

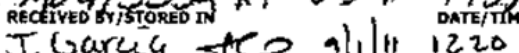
RECEIVED AY/STORED IN TCO Alill

Theo in

Ainanda Lawter andeglilition

RECETYED Bi /STORED IN

DATE/TM

DATE/THM DATE/THE

\section{CHAN OF CUSTODY/SAMPLE AMALYSIS REQUES}

$$
\begin{aligned}
& \text { TELEPHONE NO. } \\
& \text { 372-1657 }
\end{aligned}
$$

GTUAL SAMPLE DEPTH

20.15-27.65 ft

arsis 48

\begin{tabular}{|c|c|c|c|c|c|}
\hline \multicolumn{3}{|c|}{ CHAIN Of CUSTODY/SAMPLE AMALYSIS REQUEST } & \multicolumn{2}{|l|}{ F11-155-063 } & PAGE 1 OF 1 \\
\hline $\begin{array}{l}\text { COMPANY CONTACT } \\
\text { LUKE, SN }\end{array}$ & $\begin{array}{l}\text { TELEPHONE NO. } \\
\text { 372-1567 }\end{array}$ & $\begin{array}{l}\text { PROJECT COORDINATOR } \\
\text { LKE, SN }\end{array}$ & PRICE CODE & $8 \mathbf{H}$ & $\begin{array}{l}\text { DATA } \\
\text { TURMAROUND }\end{array}$ \\
\hline $\begin{array}{l}\text { PROJECT DESIGNATION } \\
\text { 200-EC-1 SOll Desiccation P:Id Test - Soll }\end{array}$ & & $\begin{array}{l}\text { SAF พO. } \\
\text { F11.155 }\end{array}$ & AIR QUALITY & I- & $\begin{array}{c}30 \text { Days / } 30 \\
\text { Days }\end{array}$ \\
\hline IELD LOGBOOK NO. & ACTUAL SAMPLE DEPTH & $C O A$ & METHOD OF SH & MENT & \\
\hline
\end{tabular}

(1)

301405ES10 GOVERMMENT VEHTIL

BILL OF LADING/AIR B̈ILL NO.

N/A

\section{ORIGINAL}

SPECIAL INSTRUCTIONS

** The CACN for all analyticai work at ESL iaboratory is $301405 E S 20$

(under Contract 00036402 Release 00045)

** ESL will perform all anaiyses as outlined on the Field Sampling

Requirements from the material of the liner selected from the four liners of each sleeve that they will be receiving.

** The 200 Area S\&GRP Characterization and Monitoring Sampling and Analysis GKI applies to this SAF.

(1) IC Anions - 9056 \{Nitrate\}; Moisture Content - D2216 \{Percent

moisture (wet sample)\}; TC-99 by ICPMS \{Technetium-99\};

\section{$3 R M \# 13564$}

IITLE

DATE/TIME

DISPOSED or

DATE/TMME 


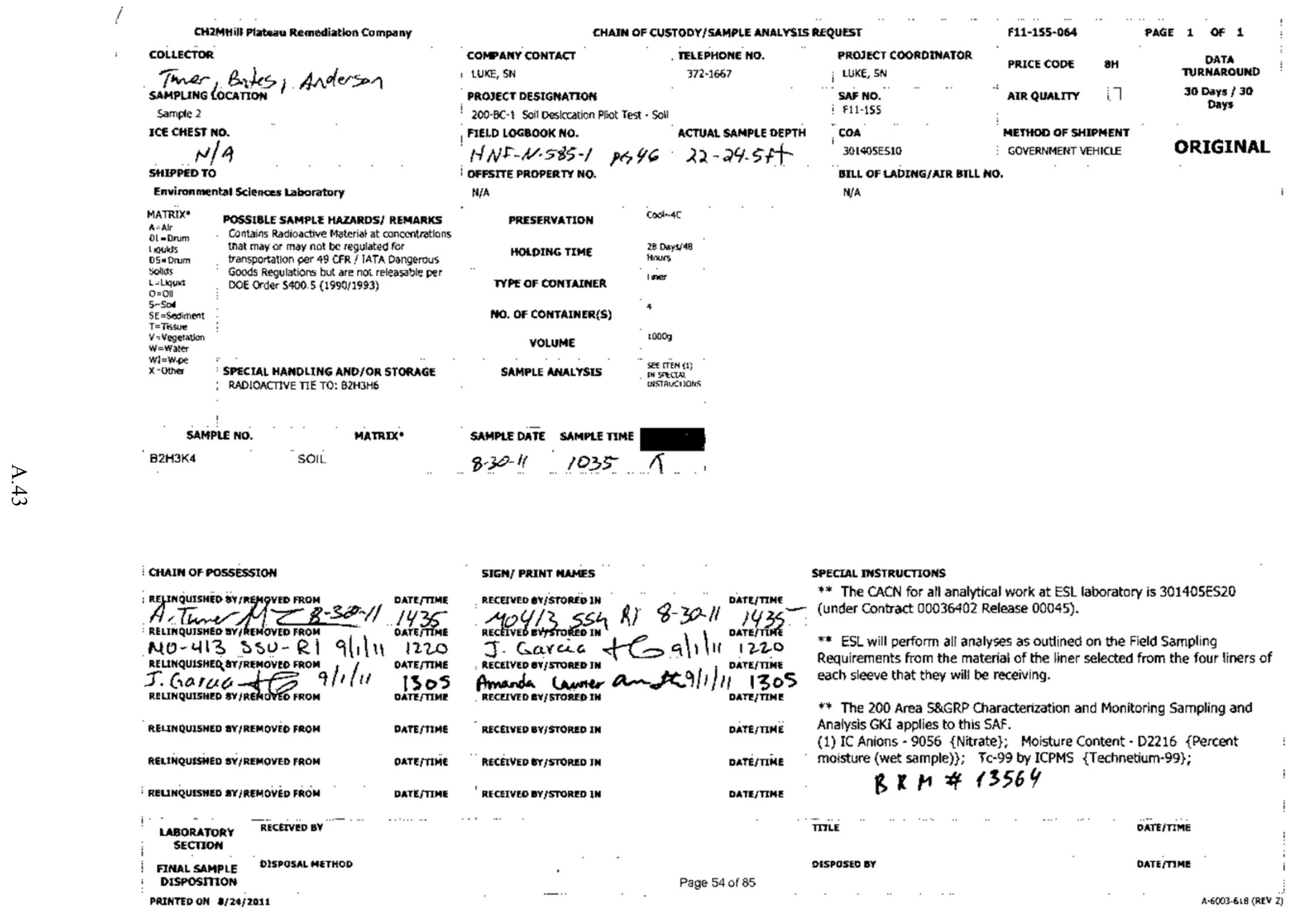




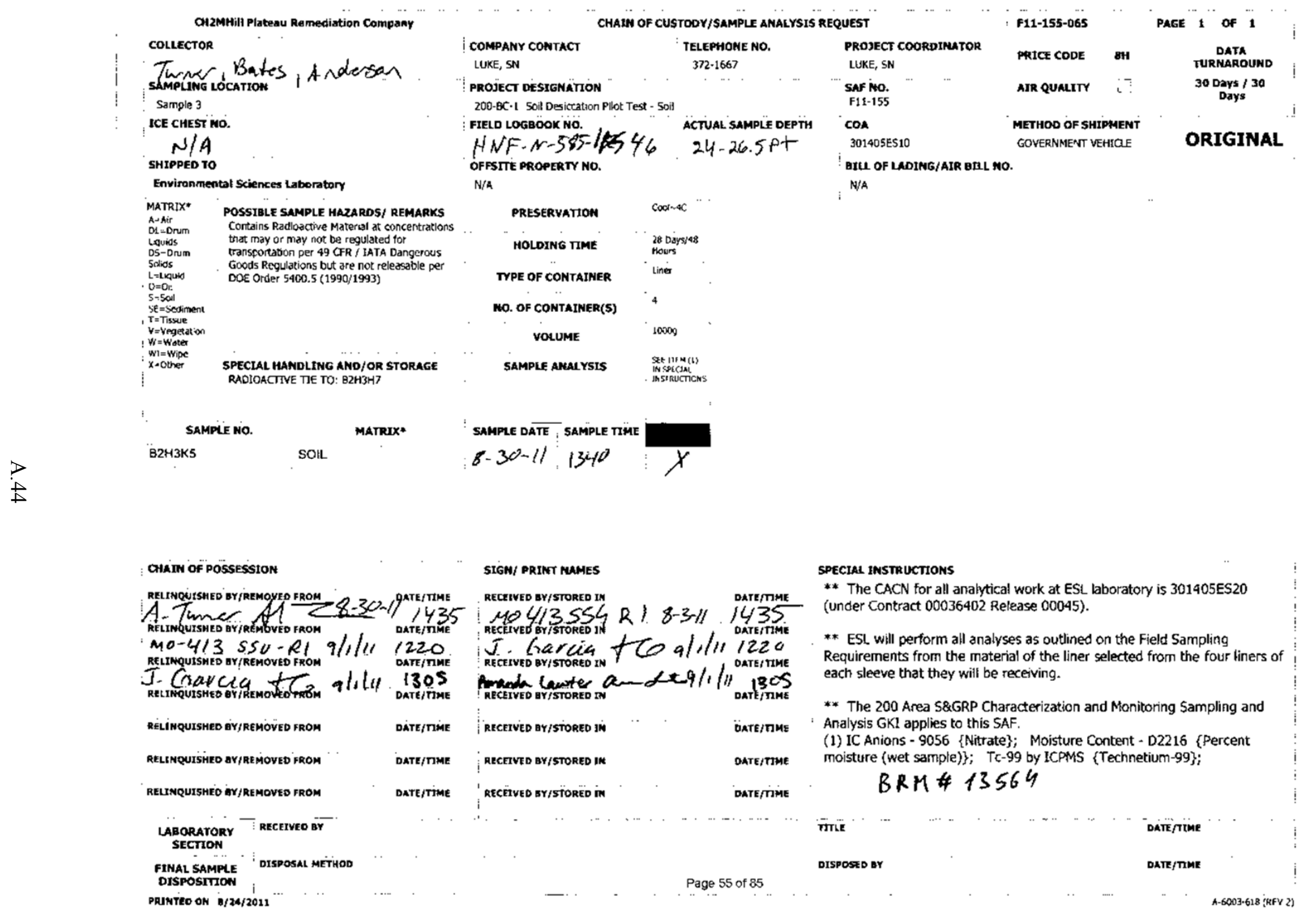




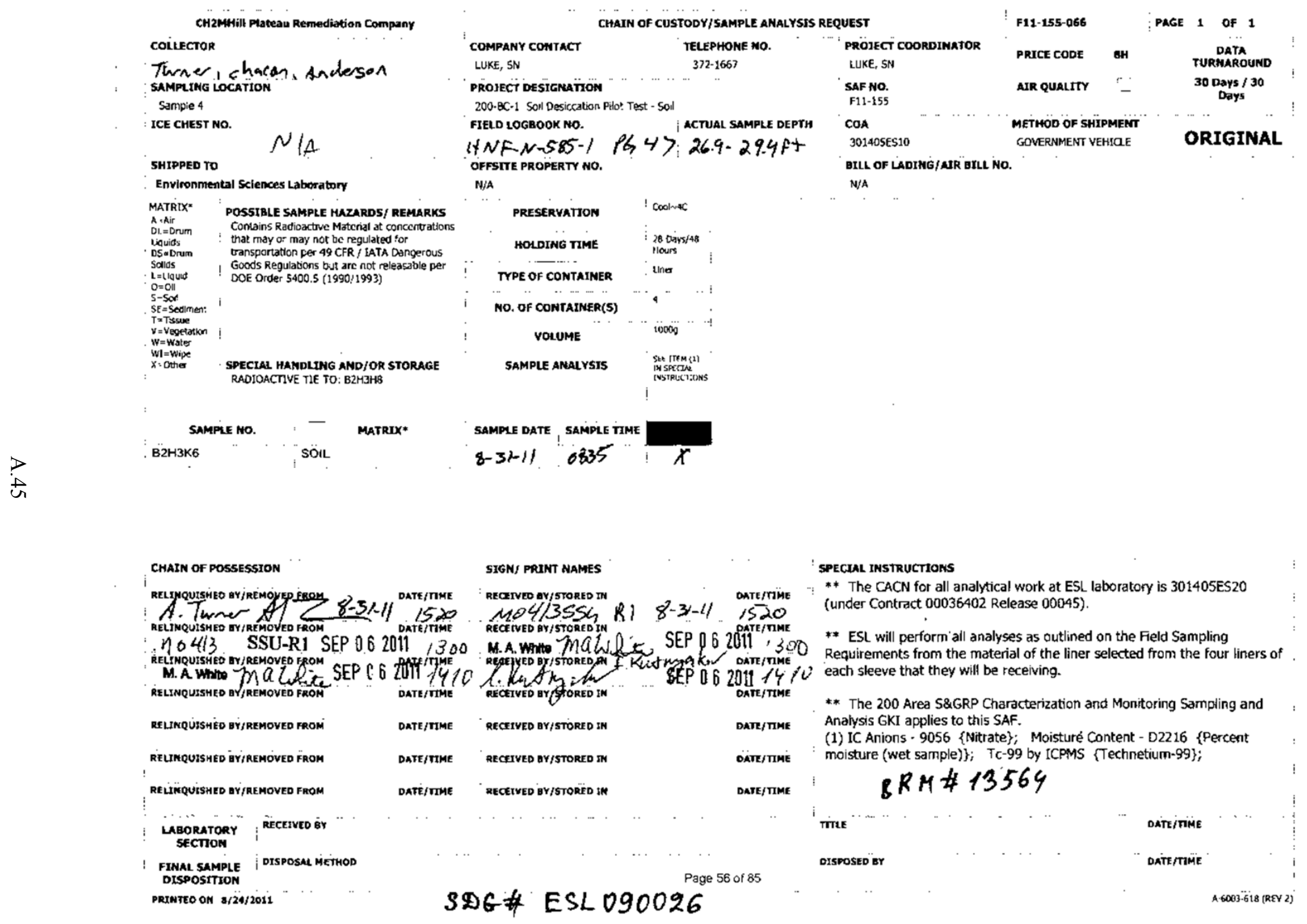




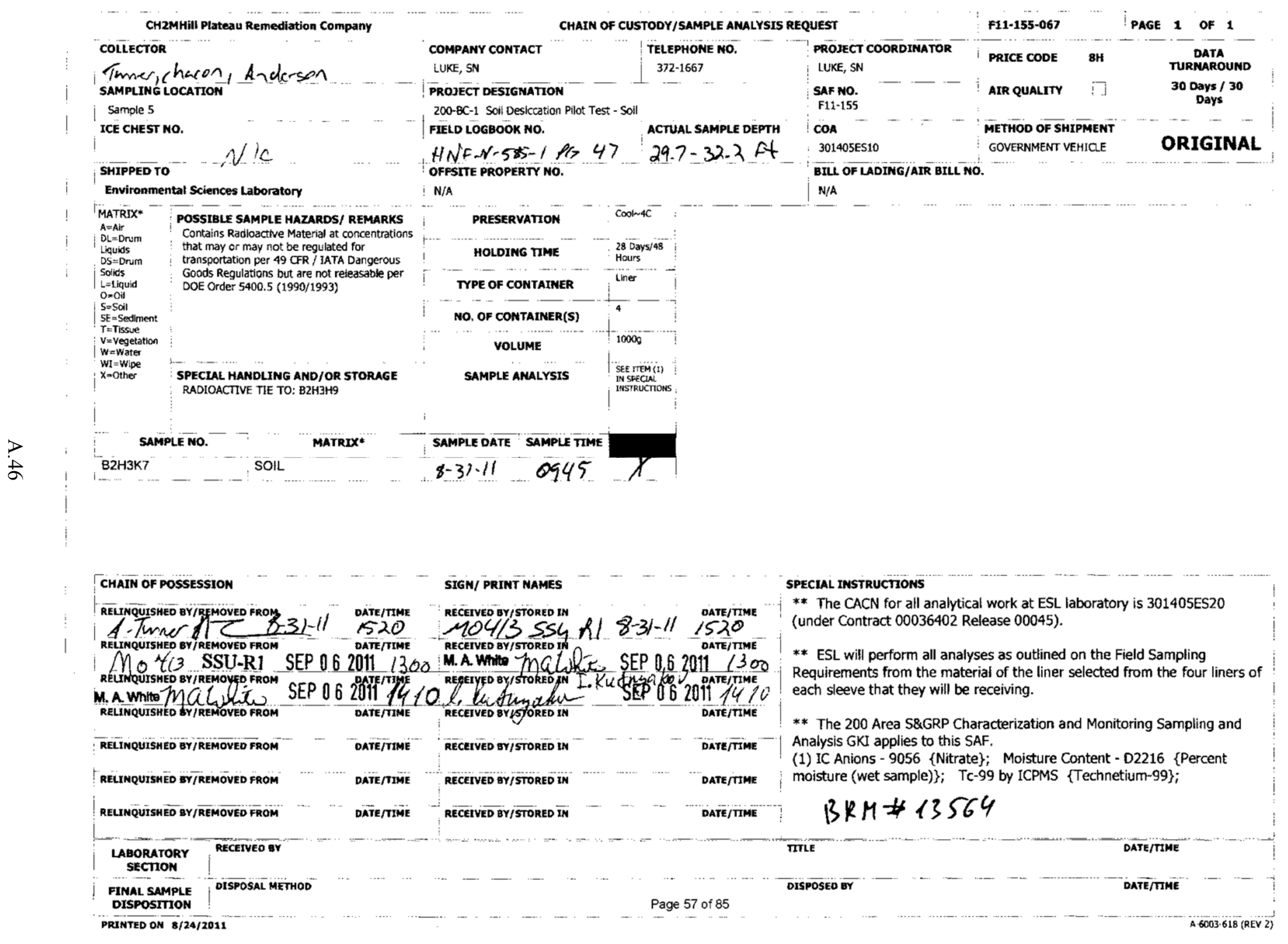


CH2MHill Platoau Remrediation Company

\section{COLLECTON}

Tumer rharen, anderson

Sample 6

ICE CMEST NO.

SHIPped To NIA

MATRIX POSSTBLE SAMPLE HAZARDS/ REMARKS

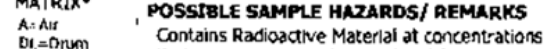

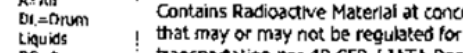

transportation per 49 CFR / IATA Dangerous

Goods Regulations but are nox releasable per

DOE Order 5400.5 (1990/1993)

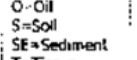

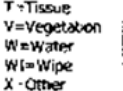

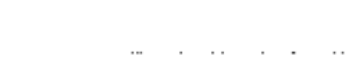

DLING AND/OR STORAGE

RADIOACTIVE TIE TO: A2H3JO SAMPLE NO

MATRIX*
CHAIN OF CUSTODY/SAMPLE ANALYYSIS REQUEST

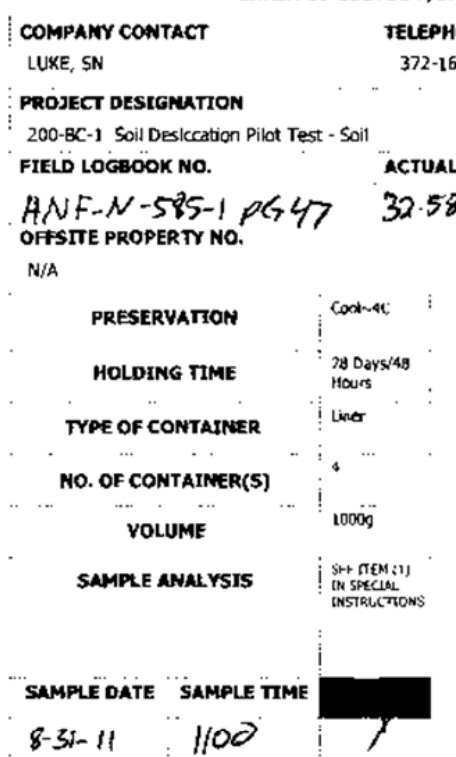

$8-3 i-11$

1100
F11-155-068

PROJECT COOROINATOR

LUKE, SN

SAF NO.

con

301405ES10

N/A
PRUCE CODE $\quad$ BH

AIR QUALITY ".

METHOD OF SHIPMEMT GOVERNMENT VEHICLE
PAGE 1 OF 1
DATA
TURNAROUNO
30 DaYs / 30
DaYs
ORIGINAL

\section{SIGN/ PRINT NAMMES}

CHAIN OF POSSESSION RELSWQUISHED BY $/$ REMOVED FROM $2-31-11$ DATE/TIME

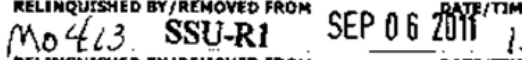
MELINQUESHED BY/REMOVED FROM

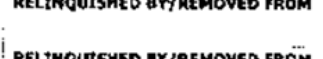
SEP 06 2011 14

RELINQUTSHED BY/REMOVED FROM
RELITQUISHED BY/REMOVED FROM Date/TIME

RELTQUUSHEO BY/REMOVED FROM

DATE/TIME

DATE/TIME

DATETTME

LABORATORY

Recervet ar

FINAL SAMPLE OJSPOSAL METHOD

PRTNTED on 0/24/201

RECEIVED BY/STORED IN ME $4 / 35 S G \mathrm{KI} .831-11$ DATE/TIME

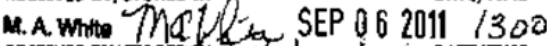

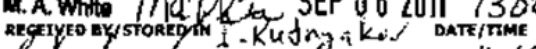

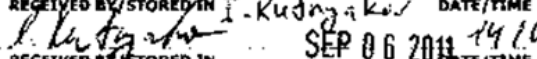

EECINEO EV/STORED IIM

RECRIED BY/STORED IM

RECEIVEO BY/STTORED iN
DATE/TJME

DATE/TMME

DATE/TME
PECCUL INSTRUCTIONS

** The CACN for all analyticai work at ESL laboratory is $301405 E S 20$ (under Contract 00036402 Release 00045).

** ESL will perform all analyses as outlined on the Fieid Sampling Requirements from the material of the liner selected from the four liners of each sleeve that they will be receiving.

** The 200 Area S\&GRP Characterization and Monitoring Sampling and Analysis GKI applies to this SAF.

(1) IC Anions - 9056 (Nitrate\}; Moisture Content - D2216 \{Percent moisture (wet sample)\}; TC-99 by ICPMS \{Technetium-99\};

$$
\text { BR.M } \$ 13564
$$

OATE/TIME
OATi/TIME 
C격ill Plateau Remediation Company COLLECTOR

Twner crow, Andersan

Sample 7

ICE CHEST NO.

$$
\text { NIA }
$$

SHIPPED TO

Environmental Sciences Laboratory

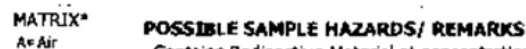

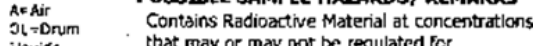
rat may or may not be reg. Goods Regulations but are not chascoble per DOE Order $\$ 400.5$ (1990/1993)

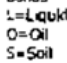

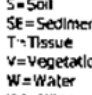

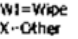

SPECIAL HANDLING AND/OR STORAGE RADTOACTIVE TEE TO: BZH3):

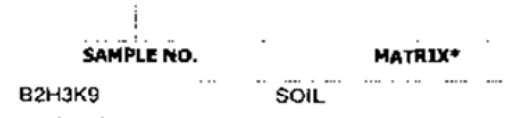

$83 \mid-11$

1330

CHAIN OF CUSTOOY/SAMPLE ANALYSIS REQUEST

COMPANY CONTACT
LUKE, SN

$$
\begin{aligned}
& \text { TELEPHONE NO. } \\
& \text { 372-1667 }
\end{aligned}
$$

PROJECT DESIGNATHON

200-BC-1 Soll Desiccation Pllot Test - Soll

FIELD LOGBOOK NO.

ACTUAL SAMPLE DEPTM

if NF-N-S85-1 PC 47 35.5-36 FT

OFFSIIE PROPERTY WO.

PHOJECT COORDINATOR

UKE, SN

SAF NO

COA

\begin{tabular}{|c|c|}
\hline PRESERYATION & $\cos \sqrt{2} \times c$ \\
\hline HOLOING TIME & $\begin{array}{l}280 \text { Dayss/48 } \\
\text { Hours }\end{array}$ \\
\hline TYPE OF CONTAINER & Loner \\
\hline YO. OF CONTA & \\
\hline & 20008 \\
\hline
\end{tabular}

BIL OF LADING/AIR BTLL NO.

N/A

SAMPLE ANALYSIS

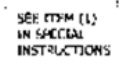

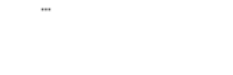

\section{CHAIN OF POSSESSION}

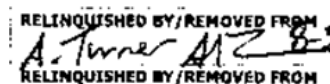
IMU. 40 SSU-R1 SEP 06 20II U. 4 (3 SSU-R1 SEP O 6 2011) 38 RER

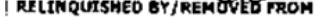

\section{RELINQUISHED QY/REMOVED FROOH}

RELINQUUISHED QY YREMOVED FROM

RELINQUISHEO QY'/REMÓVED FROM

\section{LABORATOR}

SECTION

FINAL SAMPLE
DISPOSITION

PRINTED ON B/24/201

\section{SIGN/ PRINT NAMES}

\section{RECEIVED BY/STORED IN}

DATejtime 1520 mo4/3 SS4 $x$ D... 1520

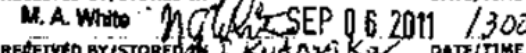
1410

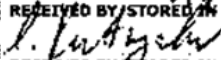

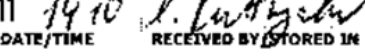

SEP O 6011.1410 DATE/TIME RECENEO BYLTORED WN DATE/TMME OATE/TIME RECEIVEO BY/STORED IN DATE/TIME

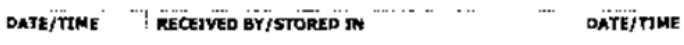
DATE/TIME
DATETMME
RECEIVED BY/STORED IN

\section{SPECLL INSTRUCTIONS}

** The CACN for all analytical work at ESL laboratory is $301405 E S 20$ (under Contract 00036402 Release 00045).

** ESL will perform all analyses as outlined on the Fieid Sampling Requirements from the material of the liner selected from the four liners of each sleeve that they will be receiving.

** The 200 Area S\&GRP Characterization and Monitoring Sampling and Analysis GKI applies to this SAF.

(1) IC Anions - 9056 \{Nitrate\}; Moisture Content - D2216 \{Percent moisture (wet sample)\}; Tc-99 by ICPMS \{Technetium-99\};

\section{$B R M \# 13564$}

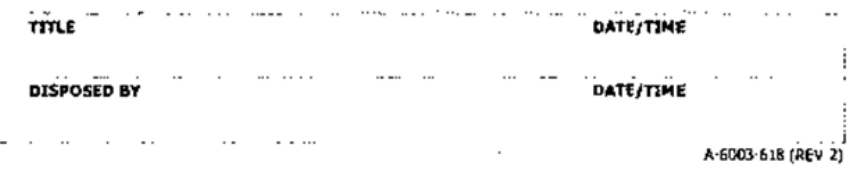


CH2MHill Platesu Remediation Company COLLECTOR

Trunerknow, Anoterson

SAMPLING LOCATION

Sample 8

ICE CHEST NO.

SHIPPED TO $-N \mid A$

Environmental sciences Laboratory

MATRIX* POSSIBLE SAMPIE RAZARDS/ REMARKS

$\begin{aligned} & A=A x \\ & Q\end{aligned}=0$ Num $\quad$ Contains Radioactive Material at concentralions that may or may no be regulated to Goods Regulations but are not releasable per DOE Order 5400.5 (1990/1993)

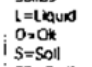

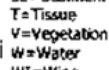

$X=O$ the

SPECLAL HANOLING NAD/OR STORAGE RADIOACTIVE TIE TO: B2H332

\section{SAMPLE No.}

B2H3Lї

SOAL

MATRIX*

\section{CHATN OF POSSESSION}

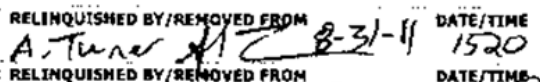

MO 413 SSU-R1 SEP O 1 DATE/TMME MO YI 3 SSU-R1

SEP 06 DATE/TMME 2011 ORO

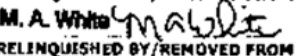

SEP O 6 2011

Dofit 141

! Retrelisteo or

int....

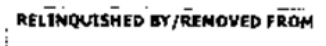

DATE/TïME

SIGN/ PRINT NAMES

CHAIN OF CUSTODY/SAMPLE ANALYSIS REQUEST

F11-155-070

COMPANY CONTACT

LUKE, SN

200-BC-1 Soil Descccation Pildok Test - So

TELEPHONE NO

CO-BC-1 Soil Desiccation

SAF NO.

PRICE CODE

PAGE 1 OF 1

actual SAMPLE DEPTH

HNF-N.585.1 P6.47 $38.3-40.8 \mathrm{ft}$

OFFSTIE PROPERTY MO.

$\mathrm{N} / \mathrm{A}$

PRESERVATION ! COONMC

HOLDING IIME i Hours

TYPE OF CONTAINER tiner

NO. OF CONTAINER(S)

VOLUME

$+10003$

SAMPLF ANALYSIS

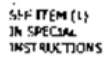

DATE SAMPLE TIME

\&3-1

1430

$104 / 3 \leq x_{1}$ Rा $8-31-11$

OAFETTME
1520

SPECC̈AL INSTRUCTIONS

METHOD OF SHIPMENT

$301405 E S 10$

I GOVERNMENT VEMICLE

BILL OF LADING/AIR BIL NO

(under Contract 00036402 Release 00045).

** ESL will perform all analyses as outlined on the field Sampling

Requirements from the material of the liner selected from the four liners of each sleeve that they will be receiving.

* The 200 Area S\&GRP Characterization and Monitoring Sampling and Analysis GKI applies to this SAF.

(1) IC Anions - 9056 \{Nitrate\}; Moisture Content-D2216 \{Percent

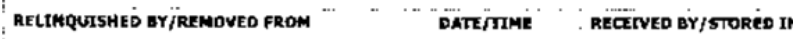

RELINQUISHED QY/REMÖVED FRÖH

DATEMTHE

RECEIVED BŸ̈TTORED IN

LABORATORY AEcEiveó oY

SECTION

Final SAMPLE Disposal method

PÁNTED ON B/24/201
DATE/TRME

DATE/TIME

QAT̄E/TIME molsture (wet sample)\}; Tc-99 by ICPMS \{Technetium-99\};
DATA

Days / 30

ORIGINAL 


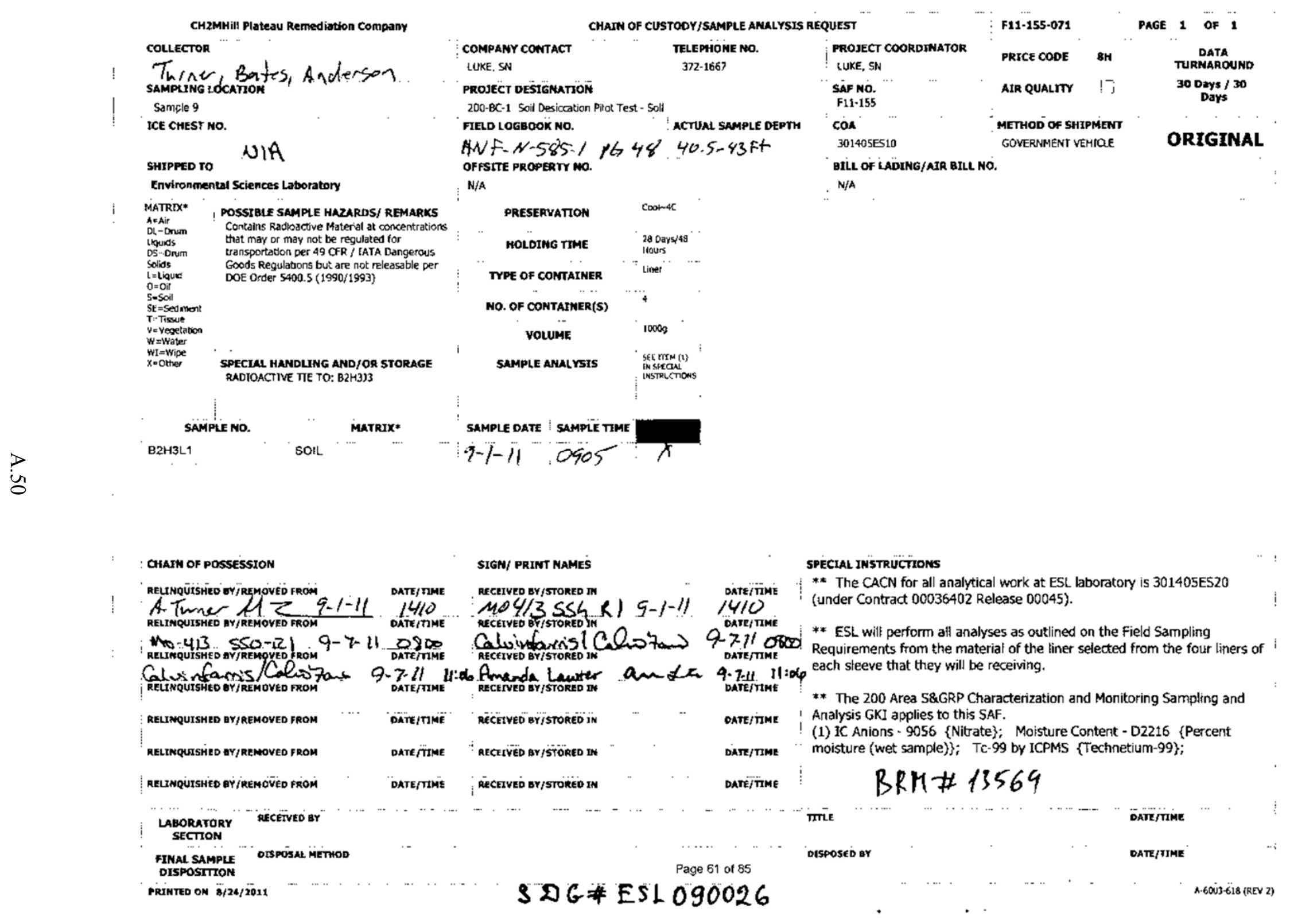




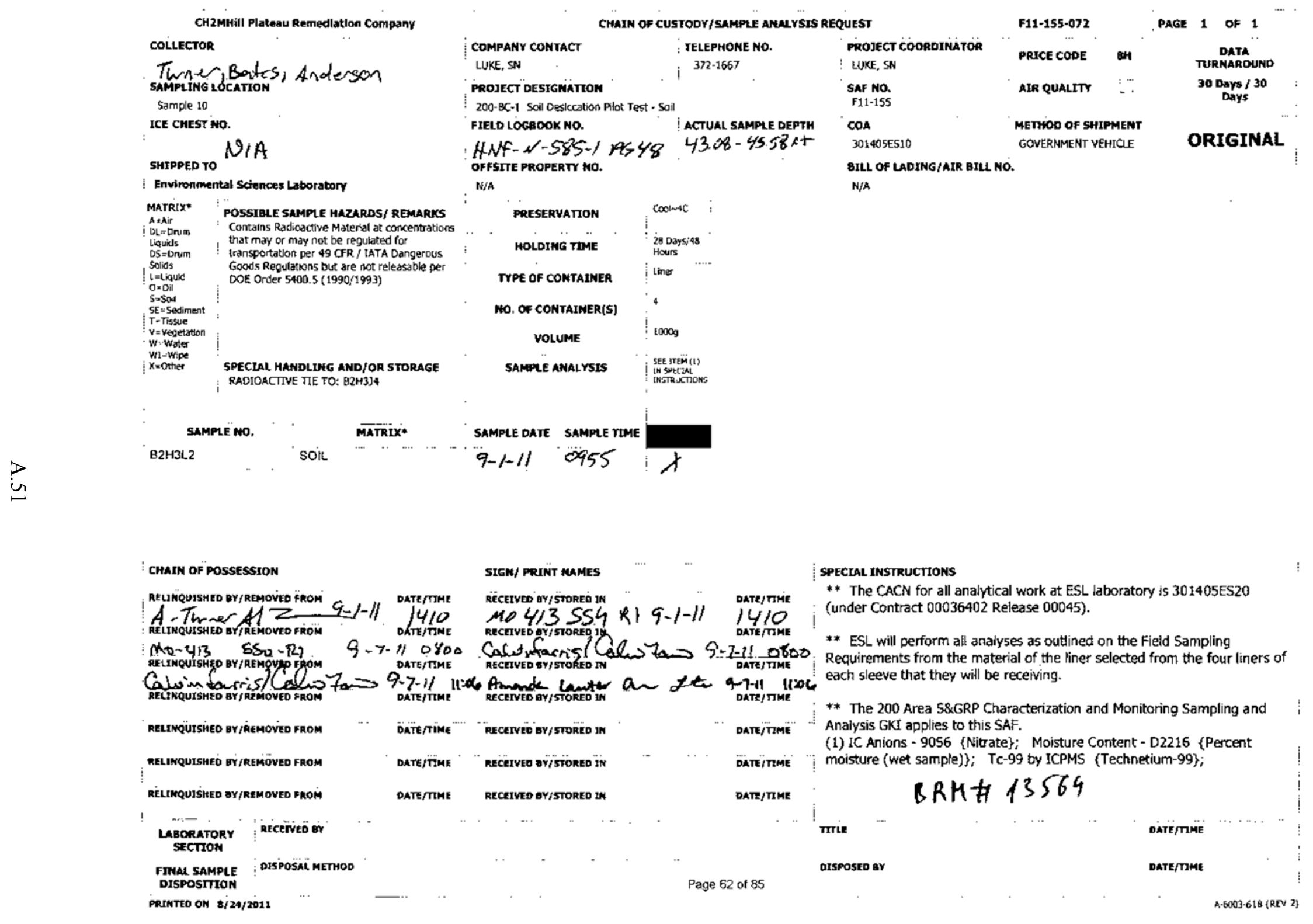




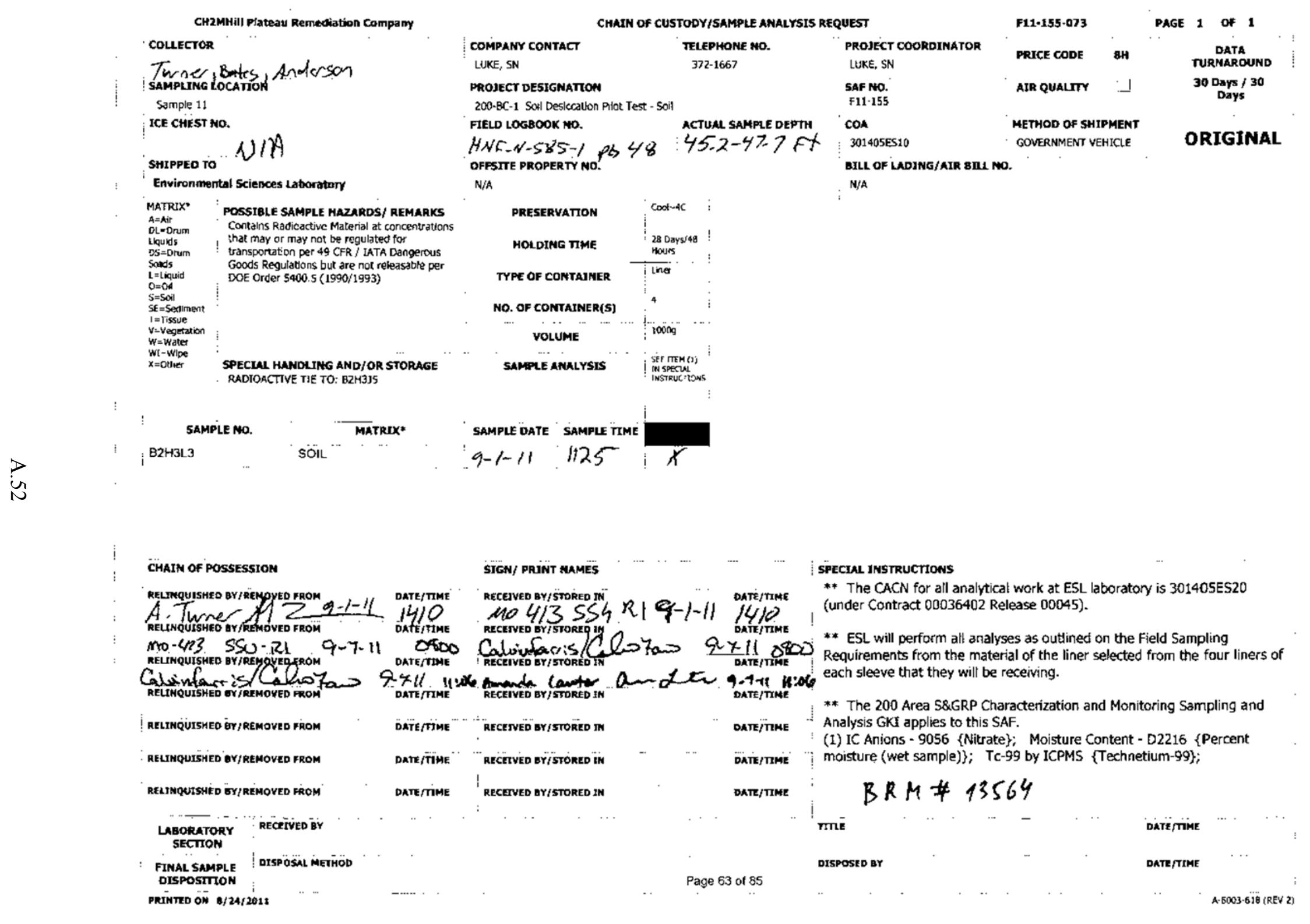


CH2MHill Plabeau Remediation Company

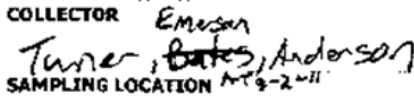

Sample 12

ICE CHEST NO.

SHIPPED TO NIA

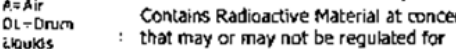
transportation per 49 CFR / IATA Dangerous
Godsts Regulautons but are not releasabte De DOE Order 5400.5 (1990/1993)

PECLAL HANDLING AND/OR STORAGE RADIOACTVE TIE TO: 82 H336
MATRIX* POSSIBLE SAMPLE HAZARDS/ REMARKS

CHAIN OF CUSTODY/SAMPLE ANALYSIS REQUEST

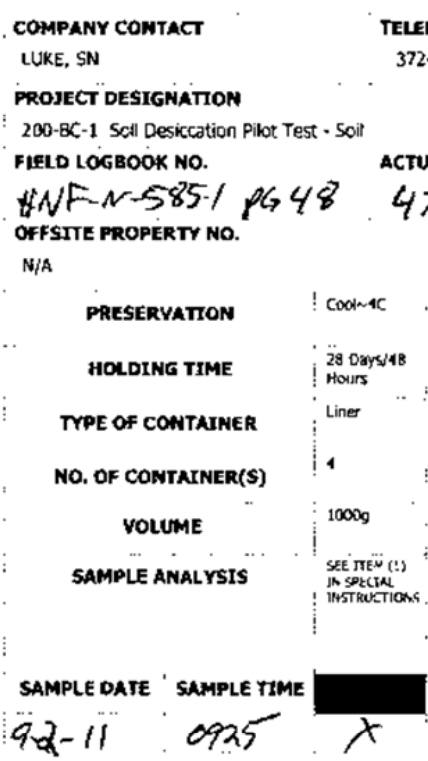

CHAIN OF POSSESSION

RELIMQUISHED BY/REFOUED RROM $\alpha 2=1 / 1500$

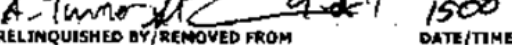

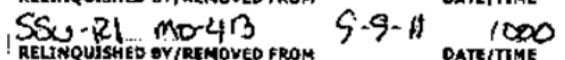

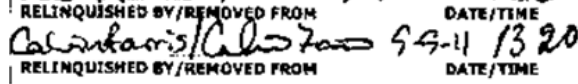

SIGN/ PRINTT NAMESS

RELINQUTSHEO EY/REMOÜED FROM

RELINQUISHED BY/RRMOVED FROM

DATE/TIME

SSU-R1 1 - 2 - $2-11$ ELEPHONE NO.

$372-1667$
PROJECT
SAE

SAF wo.

ACTUAL SAMPLE DePTH

con

301405ES10

BIL OF LADING/AIR BILL NO.

N/A

$\begin{array}{ll}\text { FI1-15S-074 } & \\ \text { PRICE CODE } & \text { BH } \\ \text { AIR QUALTTY } & - \\ \text { METHOD OF SHIPMENT } \\ \text { GOVERNMENT VEHICLE }\end{array}$

PAGE 1 OF 1

DATA

30 Days / 30

Days

ORIGINAL

RECEIVED OY/STORED IM

NECIVED ar/STORED IN 1500

SPECULL INSTRUCYIONS

** The CACN for all analytical work at ESL laboratory is $301405 E S 20$ (under Contract 00036402 Release 00045).

** ESL will perform all analyses as outlined on the Field Sampling

Requirements from the material of the liner selected from the four liners of each sleeve that they will be receiving.

** The 200 Area S\&:GRP Characterization and Monitoring Sampling and Analysis GKI applies to this SAF.

(1) IC Anions - 9056 \{Nitrate); Moisture Content - D2216 (Percent

moisture (wet sample)\}; Tc- 99 by ICPMS \{Technetium-99\};

DATE/TMM

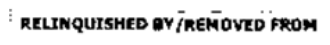

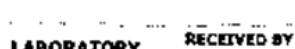

DATE/TIME ' RECTNED BY/STOREO TW

\section{BRM\# 13564}

\section{SECTION}

FINAL SAMPLE DISPOSAL METHOD

PAUNTED ON B/24/201

-... -

TRTE

Datertume

DISPOSED AY

DATE/TME 
CH2MHill Plateau Remediation Company COLLECTOR

Thimer, Emersan, Andorsan

Sample 13

ICE CHEST NO.

SHIPPED TO

NiA

Environmental Sciences Loboratory

MATRIX* POSSIale SAMPLE HAZARDSi REMARKS

AnAir
D $L=0$ rum

that may or may not be regulated for

transportation per 49 CFR / IATA Dangerous

Goods Regulations but are not rele
DOE Order $5400.5(1990 / 1993)$

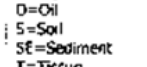

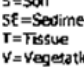

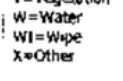

SPECIAL HANDING AND/OR STORAGE

RADTOACTVE TIE TO: B2H33?

SAMPLE NO.- MATRIX*

$$
\text { SOL }
$$

.

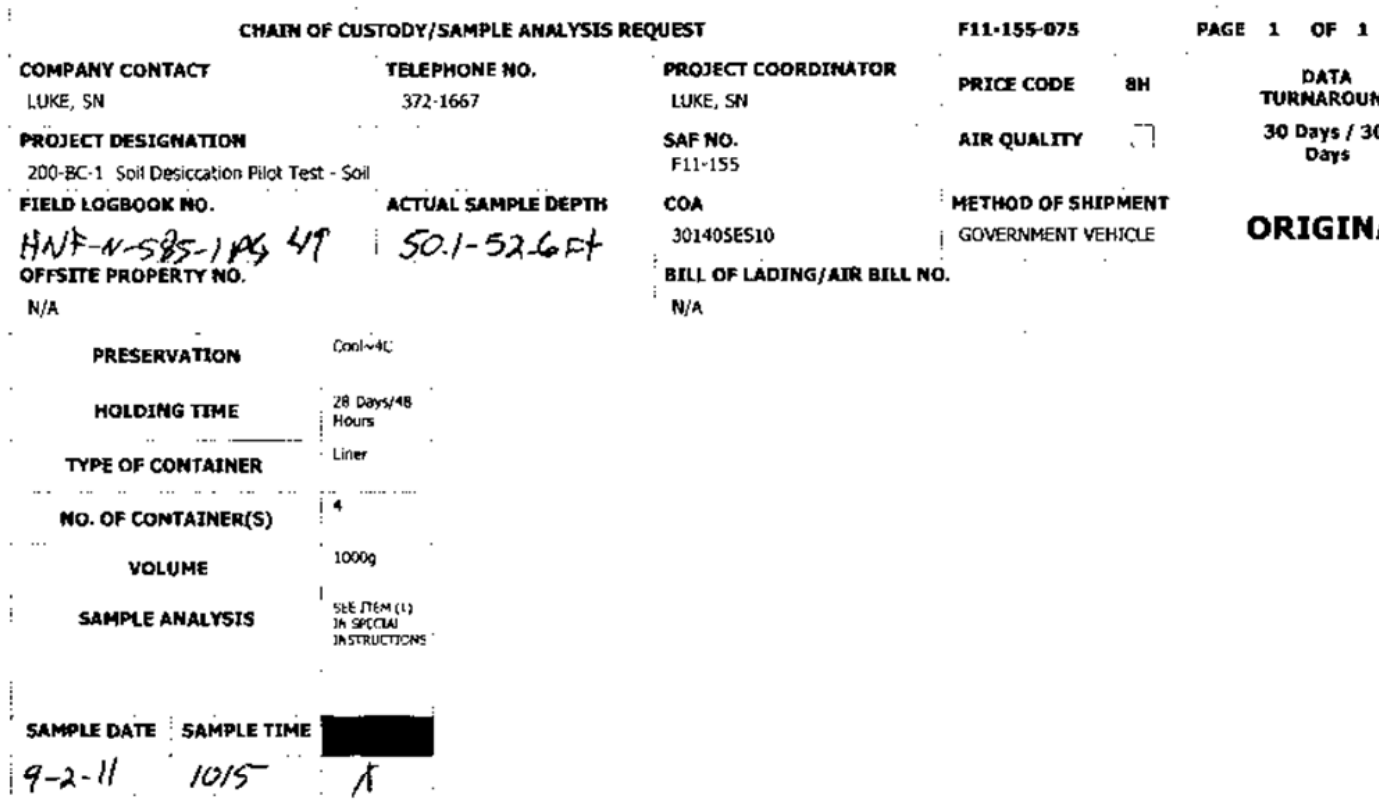

CMAIN Of POSSESSION

SIGN/ PRINT MAMES

REIMQUISHED BY/REM GVED FROM 2 DATE/TIME

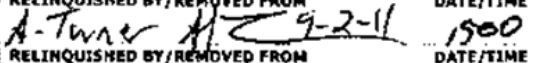
Mo-4l] SSURl R- R-ll 1000 REIINQUISHED BY/REMGVED FROM $9-9-11$ DATE/TME 1320

DATE/TIME

RELUMQUISKËD B̈T/REM̄ONED FROM

DATE/TIME

RECRIVED aY/STOKED aN

RELIMQUISHED BY/REMÖVED FRON

OATE/TIME

LABORATORY RECEIVED BY

SECTION

FIMAL SAMPLE

DRINTED ON $\$$ /24/2011

DATE/TIME

\section{SPECIAL INSTRUCTIONS}

** The CACN for all analytical work at ESL laboratory is 301405 ES20 (under Contract 00036402 Release 00045).

** ESL. will perform all analyses as outlined on the Field Sampling

Requirements from the material of the liner selected from the four liners of each sleeve that they will be receiving.

** The 200 Area S\&GRP Characterization and Monitoring Sampling and Analysis GKI applies to this SAF.

(1) IC Anions - 9056 \{Nitrate\}; Moisture Content-02216 \{Percent

Datejitime moisture (wet sample)\}; Tc. 99 by ICPMS \{Technetium-99\};

DATE/TME : BRM\# 13564

Titre

DATEJTIME

OISPOSED BY

DATEUTIME

Page 65 of 85 
CH2MHill Plateau Remedietion Company COLLECTOR

Throer Emersan, Aindosan

Sample 14

ICE CHEST NO.

$N H A$

SHIPPED TO

Environmental Sciences Laboraton

MATRIX- POSSIBLE SAMPLE HAZARDS/ REMARIS

A-Air
DL=Drum

Goods Regulations but are not releassable per

DOE Order 5400.5 (1990/1993)

$S=$ Soll
$S E=$ Sediment.

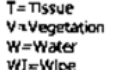

$x=$ OUhE SPECLAL HANOLING AND/OR STORAGE RADIOACTIVE TTE TO: B2H3:8

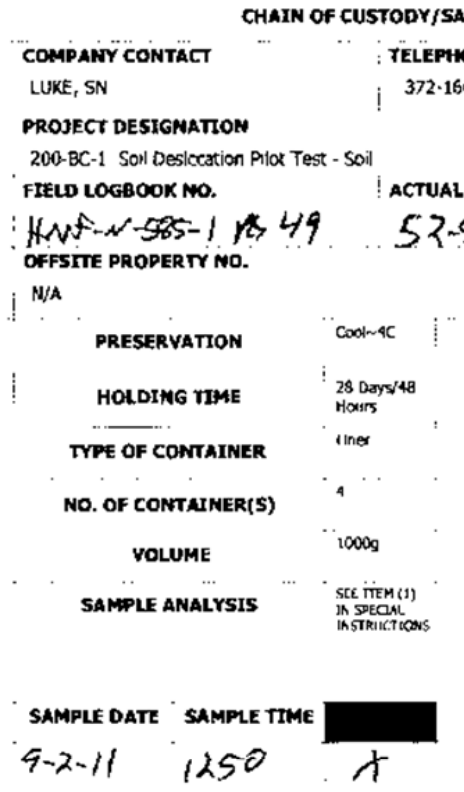

CHAIN OF POSSESSION

REJNQUISHED BY/REMOVEO FROM Mo-413 SSu-21 $59-111000$

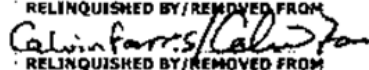
RELIMQUISSIED BY /REMOVED FRON

RELINQUISHED BY / REHOVEDE FROM

, RELINQUTSHED BY/REMOVED FROM

aEcetried BY
STGMI PRINT MAMES DOROM DATE/TIME RELTNQUSSHED EY/REMOWED FROM TYOO s. $9-111320$

AECEYED GYSTORED IN Mo-413SSU-R1 $9-2-1$
saln?

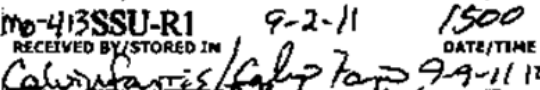
$9-9-1 / 100$ 1320 DATE/TIME OATE/TTME RECEIVED BYGSORED IM

DATE/RAME

\section{OATEfTIME}

RECRIVED BY STTORED IN

DATË/TIME

RECEIVED BY/STORED IM

RECEIVED BY Y TSORED iN
DATE/TIME

Dare/TME

\section{SPECIAL INSTRUCTIONS}

** The CACN for all analytical work at ESL laboratory is $3014058 S 20$ (under Contract 00036402 Release 00045).

** ESL will perform all analyses as outlined on the Field Sampling Requirements from the material of the liner selected from the four liners of each sleeve that they will be receiving.

** The 200 Area S\&GRP Characterization and Monitoring Sampling and Analysis GKI applies to this SAF.

(1) IC Anions - 9056 \{Nitrate\}; Moisture Content-D2216 \{Percent

moisture (wet sample)\}; Tc-99 by ICPMS \{Technetium-99\};

\section{$B R M \# 13564$}

गास्थ

DATE/TME

SECTAOA Disposal METHo

DISPOSITION

Page 66 of 85
DAṪE/TIME 
CH2MHill Plateau Remeciation Company COLLECTOR

Thner Anderson, Enerson
sampLING Lodation
Sample 15
ICE CHEST No.
SHIPPED ro

\section{Enviranmental Sciences Laboratory}

MATRIX* POSSIBLE SAMPLE HAZARDS/ REMARKS

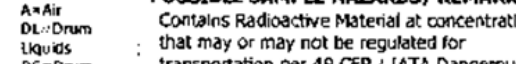

Goods Regulations but are not releasable per

DOE Order 5400.5 (1990/1993)

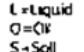

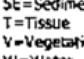

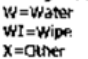

SPECLAL HANDUING AND/OR STORAGE RADIOACTIVE TEE TO: B2H3PA

$\begin{array}{l:l}\text { SAMPLE NO. } & \\ \text { B2H3L̈ } & \text { MÄLTRE* }\end{array}$$$
\text { . }
$$$$
\text { soll }
$$

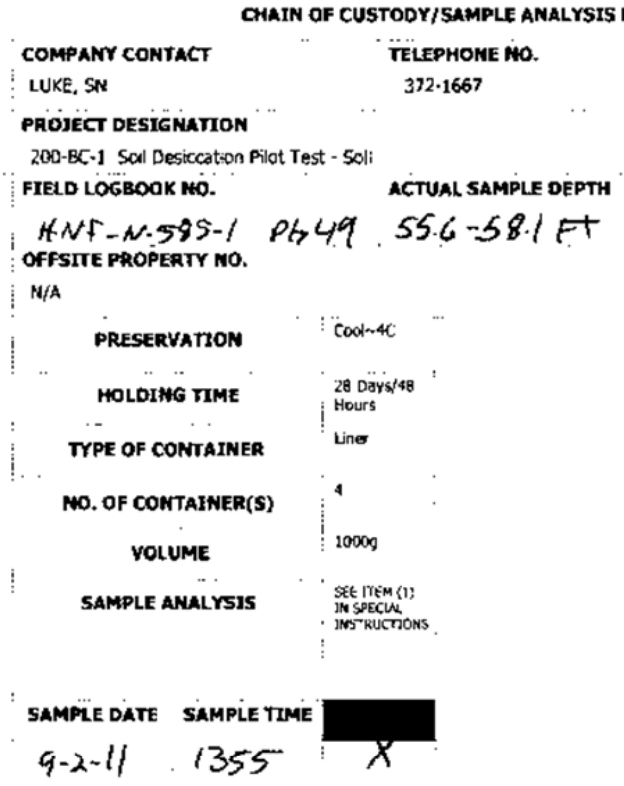$$
9-2-11
$$$$
1355
$$

F11-155-077

PROJECT COOROINATOR

LUKE, SN

SAF NO.

cö

30140SES10

BtLL OF LADING/AIR BILL NO.

PRICE CODE

AIR OUALTY .

METHOD ÖF SHIIPMENT

GOVERNMENT VEHIOE
PAGE 1 OF 1
Data
TURNakound
30 Days $/ 30$
Doys

ORIGINAL

\section{CHAJN OF POSSESSION}

REINQUISHED QYYREHOVED FROM

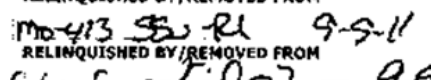

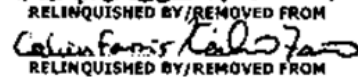

RELIMQUISHED QY/REMOVED FŔOM

\begin{abstract}
"." RELLINQUISHẼ BY /REMOVED FROM
\end{abstract}
RELTRQÜISHEO EY JREMOMVED FROM

LARORATORY RECËIVED QŸ LABORATORY
SECTION

Final SAMPLE DISPOSAC METHAOO
DISPOSJTION

PReNTted on B/24/2011

\section{SIGN/ PRINT NAMES}

DATE/TIME

1500

NT/TIME

RECEIVED OYYSTORED iN

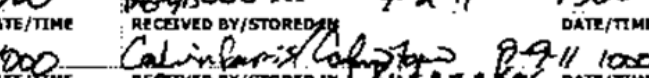

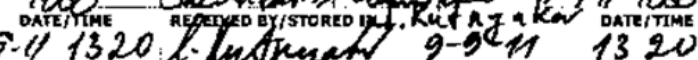

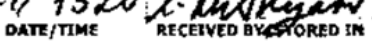

ONTE/TIME RECEIVED BYISTORED IM

DATE/TIME " RECETVED BYYSTORED IN

OATE/THE " RECTIVED BY/STCRED IN
DATE/TIME

DATE/TIME

DATE/TIME

DATE/TIME
SPECIAL INSTRUVCTIONS

** The CACN for all analytical work at ESL laboratory is 301405ES20 (under Contract 00036402 Release 00045).

** ESL will perform all analyses as outlined on the Field Sampling Requirements from the material of the liner selected from the four liners of each sleeve that they will be receiving.

** The 200 Area S\&GRP Characterization and Monitoring Sampling and Analysis GKI applies to this SAF.

(1) IC Anions - 9056 \{Nitrate\}; Maisture Content - D2216 \{Percent moisture (wet sample)); Tc-99 by ICPMS \{Technetium-99\};

\section{BRM \# 13564}

True

Dare/nime

DISPOSED BY

DATE/TME 
CH2MHill Plateau Remediation Company

\section{COLIECTOR}

Thure, Emersan

SAMPUNG LóCATION

Sample 16

ICE CHEST NO.

$$
\text { NIA }
$$

SHIPPED TO

Environmental Sciences Laboratory

MATRIX* POSSTBLE SAMPLE HRZARDS/ REMARKS

- AAAir DixOrum Contains Radioadtive Material at concentrations

that may or may not be reguiated for DOE Order 5400.5 (1990;1993)

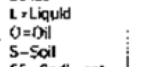

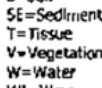

$W 1=$ Whe
$x=0$ the

SPECLAL HANDLING AND/OR STORAGE RADIOACTIVE TTE TO: B2H3KO

$$
\text { SAMPLE NO. }
$$

B2H3LB

No.

$$
\text { soll }
$$

\begin{tabular}{|c|c|c|c|c|c|}
\hline \multicolumn{3}{|c|}{ CHAIN OF CUSTODY/SAMPLE ANALYSIS REQUEST } & \multicolumn{2}{|l|}{ F11-155-078 } & DAGE 1 OF $x$ \\
\hline & $\begin{array}{l}\text { TEIEPHONONE NOO. } \\
\text { 372-1657 }\end{array}$ & $\begin{array}{l}\text { PROJECT COORDINATOR } \\
\text { LUKE, SN }\end{array}$ & PRICE CODE & 8H & $\begin{array}{l}\text { DATA } \\
\text { TURNAROUND }\end{array}$ \\
\hline In Pllot Test - 5011 & & $\begin{array}{l}\text { SAF NO. } \\
\text { F11-155 }\end{array}$ & NR QUALTTY & L. $\vdots$ & $\begin{array}{l}30 \text { Days / } 30 \\
\text { Days }\end{array}$ \\
\hline$p 649$ & $\begin{array}{l}\text { ACTUAL SNMPLE DEPTH } \\
58-60-5 \%{ }^{-}\end{array}$ & COA & $\begin{array}{l}\text { METHOD OF SH } \\
\text { GOYERHMENT V }\end{array}$ & $\begin{array}{l}\text { MENT } \\
\text { IICLE }\end{array}$ & ORIGINAL \\
\hline
\end{tabular}

Matrix
BILL
Gacpss Regulatitan 49 OFR / 1ATA Dangerous

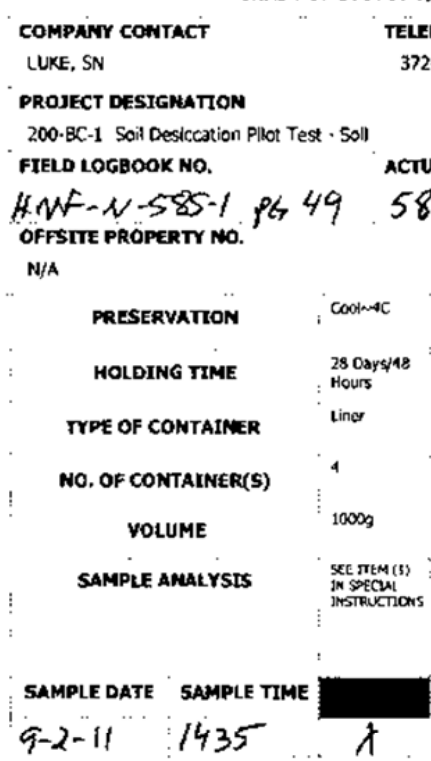

SIGN/ PRXNT NAMES

CHAIN OF POSSESSTON

RELingursHEO BY/REHOUED RROM $q-z-1$

DATËTITME

1500

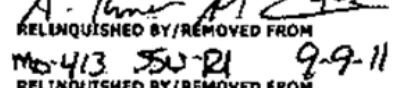

MOL 413 SU DU Calinfarris. alliotar

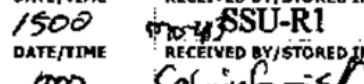

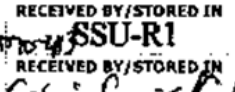

9-2-11

$9.9 .1 / 1320$

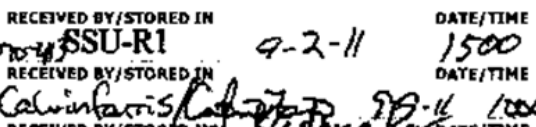

RELSQQUTSHEO QY/REEMOYËD FROM

". RELINQUTSHEO GY/REMOVED FROÖ.

I RELÜ̈QUTSHEO AY/REWOVED FROM

LABORATORY RECERED BY

LABORRTORY
SECTION

FIMAL SAMPLE DISPOSN METHOD

DISPOSITION

PRINTED ON $\mathrm{a} / 24 / 2011$
DATE/TINE RECEVEOEISTORED IN 9-9-11 1320

DATE IITME RECEVED QY/STORED IM

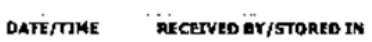

DATE/TINE - ' RECETVED QYYTSTOREO IN
DATE/TIME

DATE/Time

DATETHE
SPECIAL INSTRUCTIONS

* The CACN for all analytical work at ESL laboratory is $301405 E S 20$ (under Contract 00036402 Release 00045).

** ESL will perform all analyses as outlined on the Field Sampling

Requirements from the material of the liner selected from the four liners of each sleeve that they will be receiving.

** The 200 Area S\&GRP Characterization and Monitoring Sampling and Analysis GKI applies to this SAF.

(1) IC Anions - 9056 \{Nitzate\}; Moisture Content - 02216 \{Percent moisture (wet sample)\}; Tc-99 by ICPMS \{Technetium-99\};

$$
\text { BRM } \$ 13564
$$

Page 68 of 85
TIRE

ôispostu er

DATE/TIME

DATÉrTME 


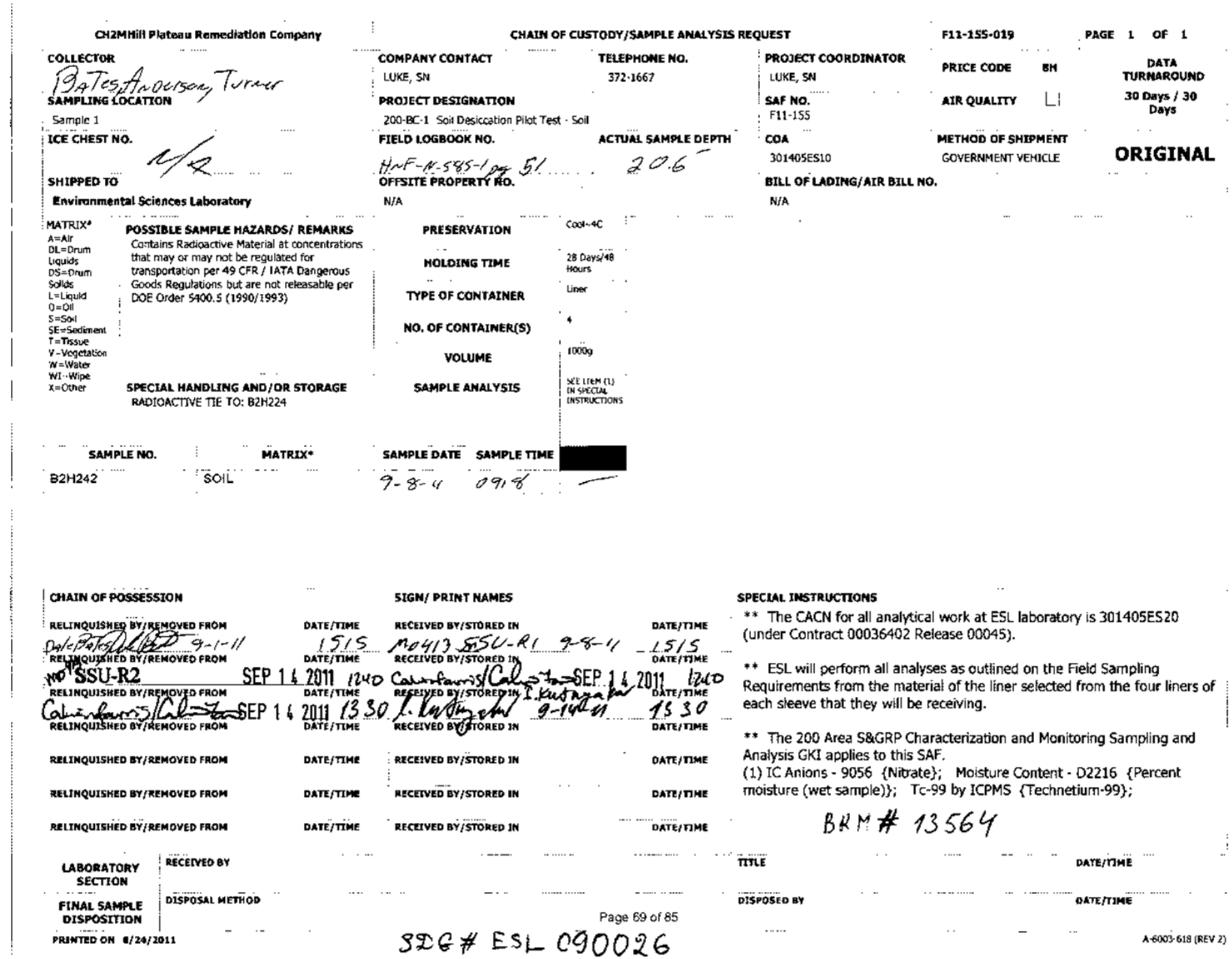


CH2m+rill Platesu Remediation Compony

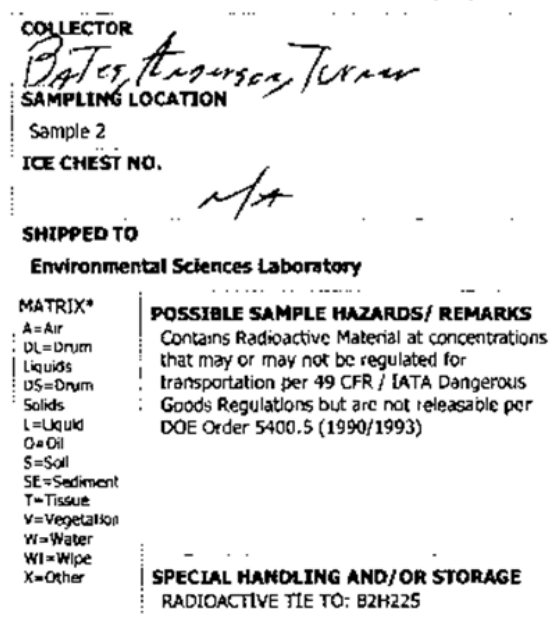

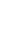

\begin{tabular}{|c|c|}
\hline $\begin{array}{l}\text { COOMPANY CONTACT } \\
\text { LUKE, SN }\end{array}$ & $\begin{array}{l}\text { TELEPHOME NO. } \\
\text { 372-1667 }\end{array}$ \\
\hline \multicolumn{2}{|l|}{ PROJECT DESIGNATION } \\
\hline \multicolumn{2}{|c|}{ 200-BC-1 Soll Desiccation Pilox Test - Soll } \\
\hline \multirow{2}{*}{\multicolumn{2}{|c|}{$\begin{array}{l}\text { HNF-N-SSS } 5 \text {, } \\
\text { OFSITE PROPERTYAO } \\
\text { N/A }\end{array}$}} \\
\hline & \\
\hline PRESERVATION & Coolatec \\
\hline HQLDING TIME & $\begin{array}{l}28 \text { anys } \\
\text { Hours }\end{array}$ \\
\hline TYPE OF CONTAIMER & Liner \\
\hline NO. OF CONTAINER(S) & 4 \\
\hline VOLUME & $10000^{\circ}$ \\
\hline SAMPLE ANALYYSIS & 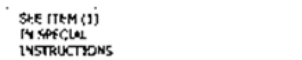 \\
\hline
\end{tabular}

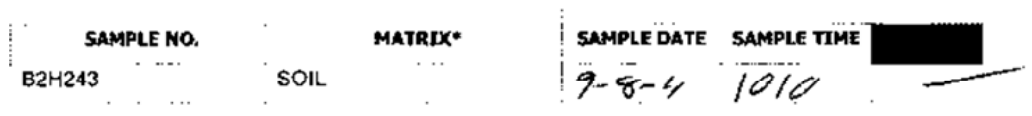

\section{: CHAIM OF POSSESSION}

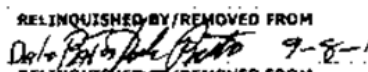
Mo-413 MSU/13

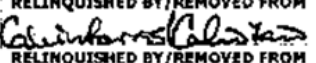

RELINQUISHED BY/REMMOVED FROM

\section{RELIRQUISHED BY /REMOVED FROM}

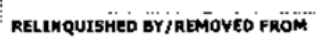

\begin{tabular}{l|l} 
LABORATORY & RECENVED oY
\end{tabular}

SECTION

FIMAL SAMPLE

DISPOSITION

PRINTED ON A/24/2014

\section{SIGW/ PRINT MUMES}

DATT/TIME | RECEVED OY/STORED IN ISIS $\rightarrow 413 \quad 55 \mathrm{U}-12$

SEP $1 \frac{1}{6}$ ZOTII

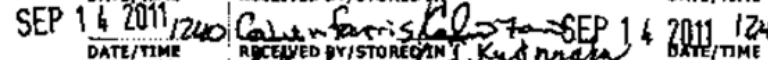

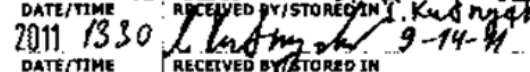

\section{OAT̈Ё̈TME}

RECETṼED BY/STOREO IN

DATE/TIME

DATE/TTME
RECESVED QY/STORED IN

RECEIVED BY /STORED IN

$-$

DATE/TIMI

DATE/TRME

DATE/TIME

- OATE/TTME

\section{SPECIAL INSTRUCTIONS}

** The CACN for all analytical work at ESL laboratory is $301405 E S 20$ (under Contract 00036402 Release 00045)

** ESL will perform ali analyses as outlined on the Field Sampling Requirements from the material of the liner selected from the four liners of each sleeve that they will be receiving.

** The 200 Area S\&GRP Characterization and Monitoring Sampling and Analysis GKI applies to this SAF.

(1) IC Anions - 9056 \{Nitrate\}; Moistufe Content - D2216 \{Percent moisture (wet sample)\}; Tc-99 by ICPMS \{Technetium-99\};

$$
\text { BRM } \# 13564
$$

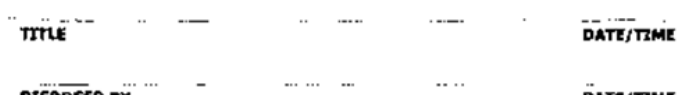

Page 70 of 85

OTSPOSFE

DATE/TIME 


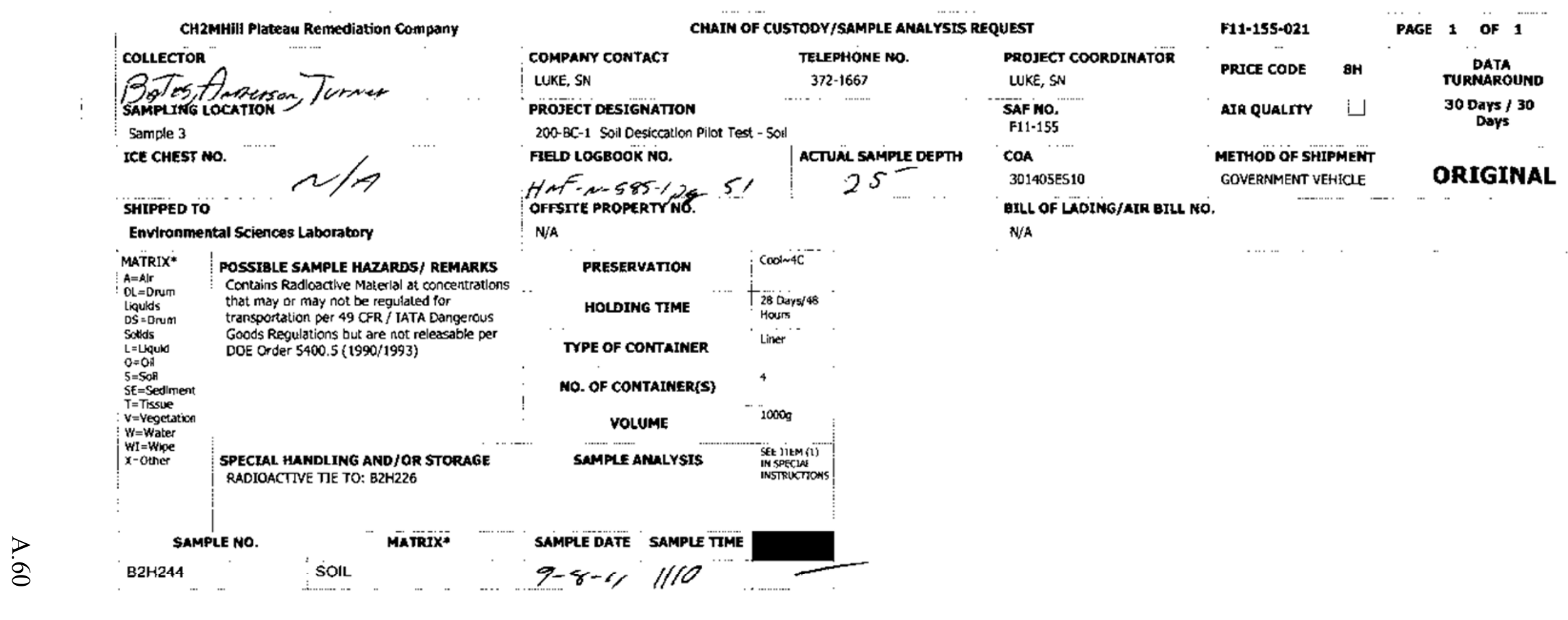

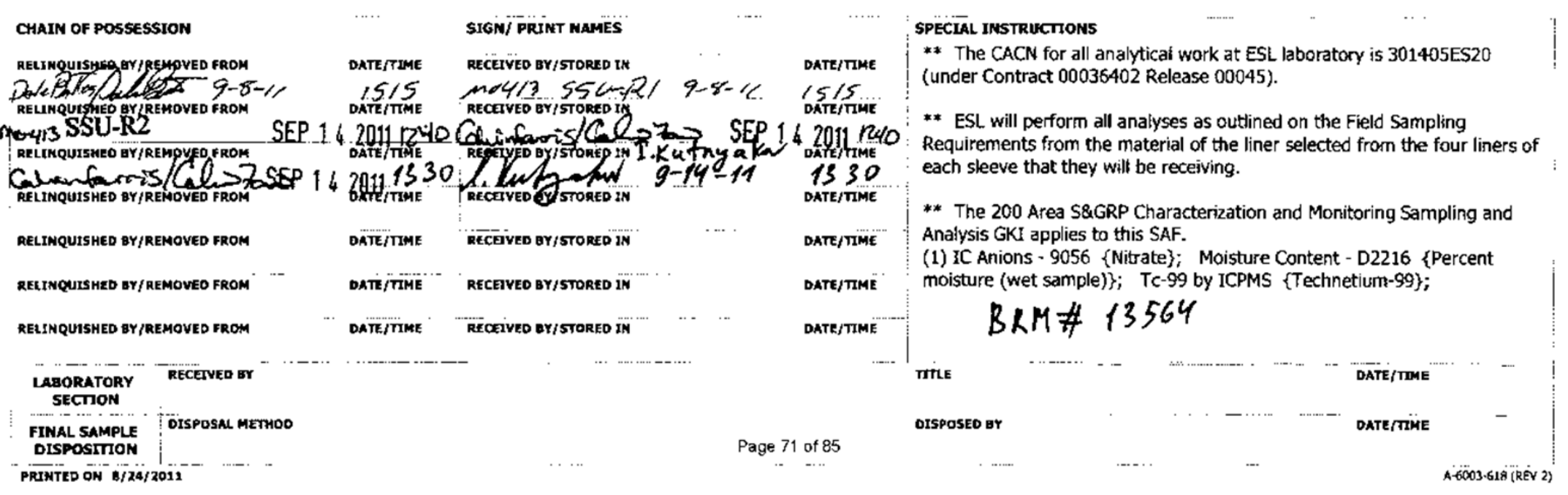




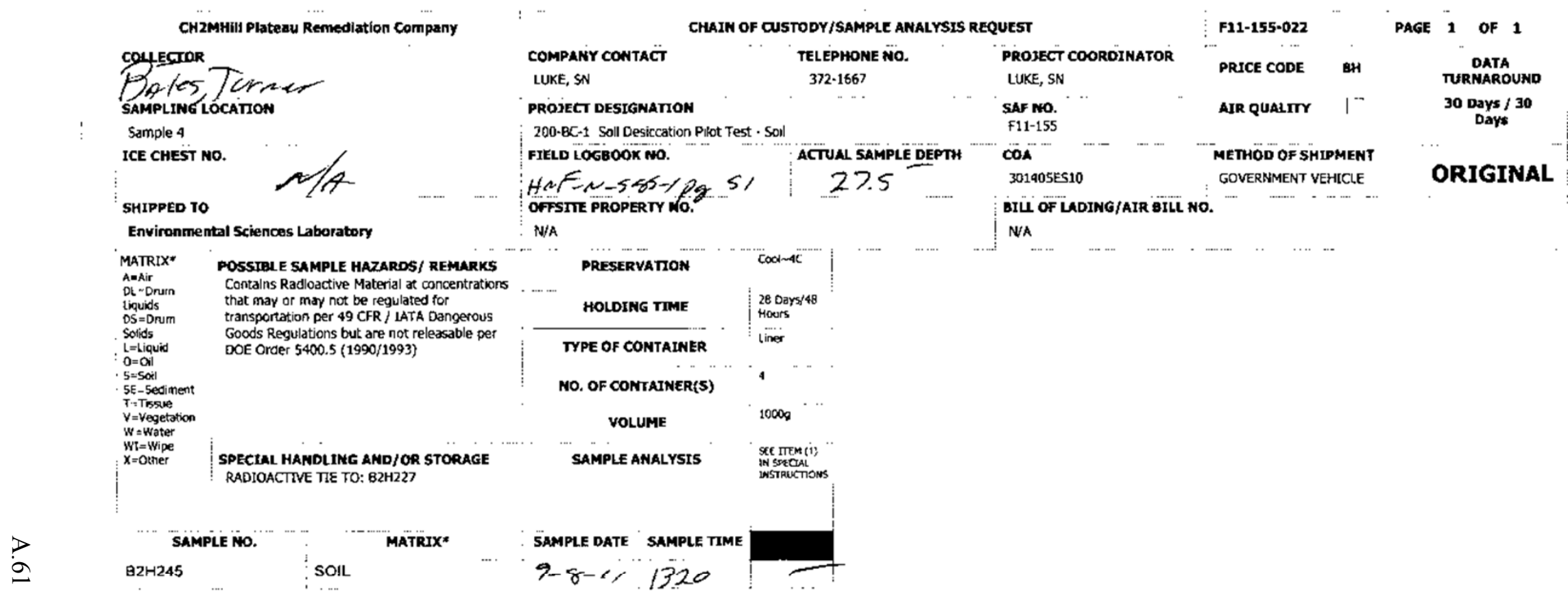

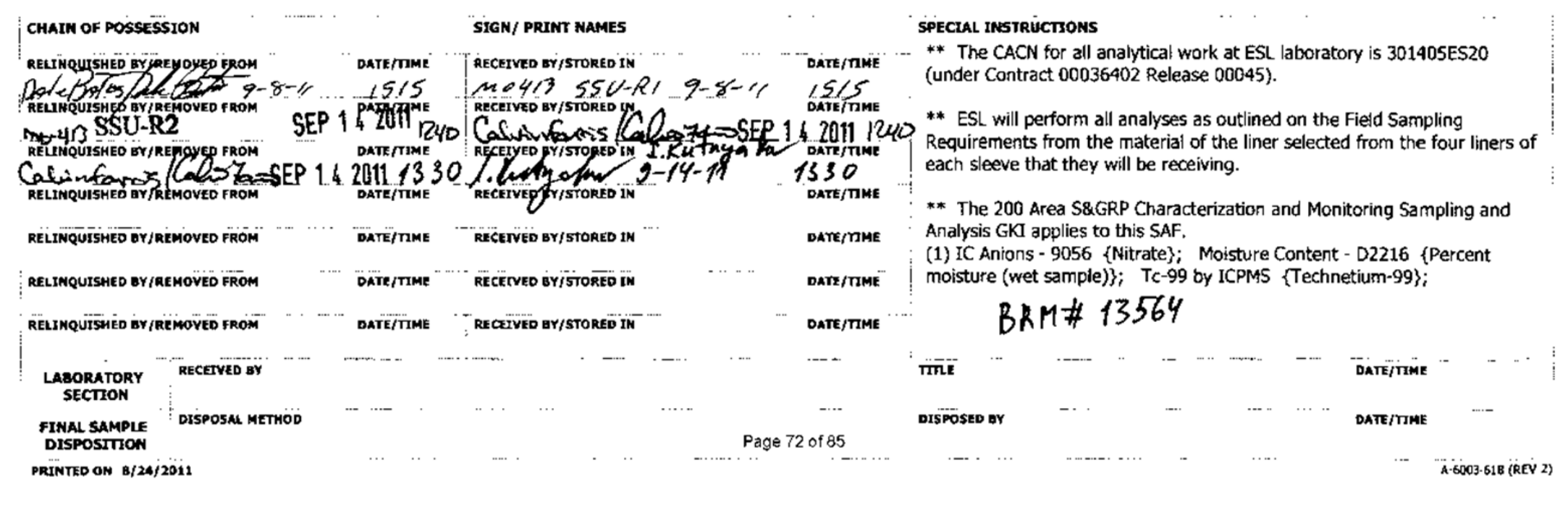




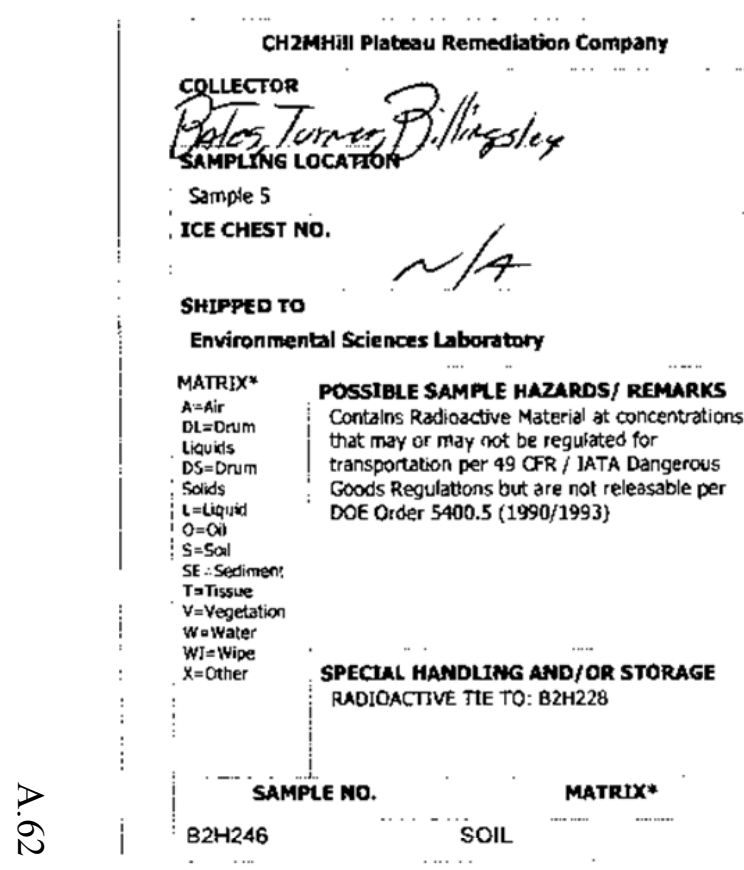

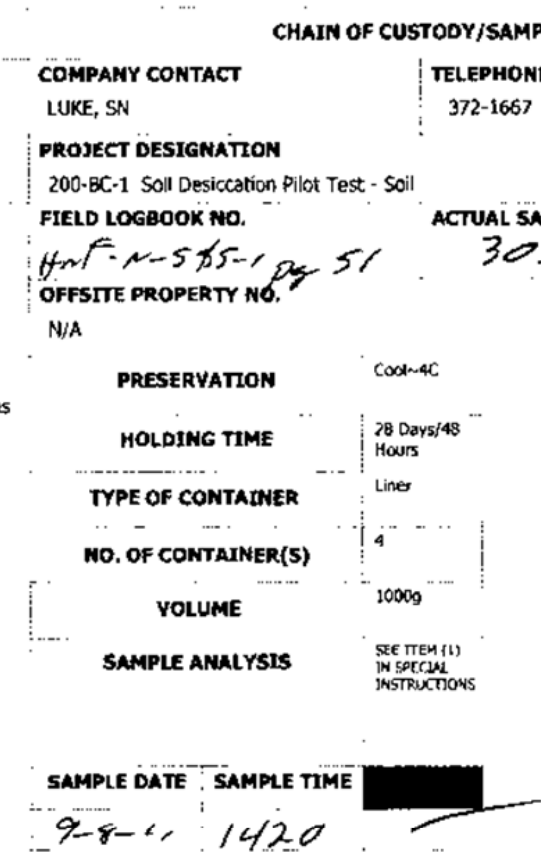

CHAIN OF POSSESSION

RELINUUISHEY OYJPEMOVED FROM

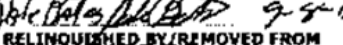
movis SSO-R2 RELINQUISHED BY/BEMgVED FRON RELINQUISHED BY/REMOVED FROM

RELUNQUISHED QY /REMONED FROM

RELUNQUISHED QYYREATOVED FROM

RELINQUISHEED QY /REMOVED FRÖM

\section{LABORATORY}

FIMAL SAMPLE
DISPOSITION

PRINTED ON B/24/20
RECEIVED BY

DISPOSAL METHOOD

11

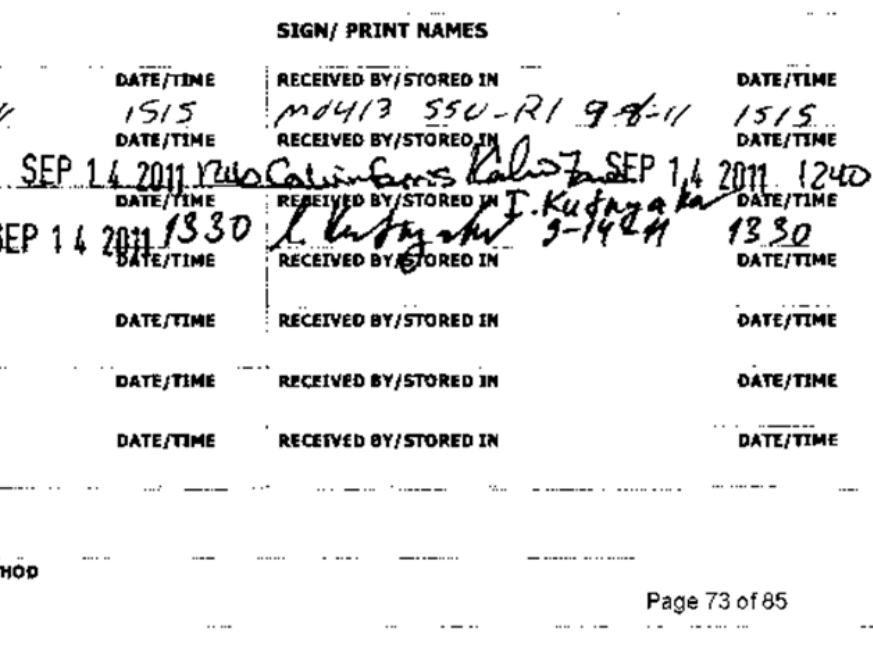

SPECIAL INSTRUCHONS

** The CACN for all analytical work at ESL. laboratory is $301405 E S 20$

(under Contract 00036402 Release 00045)

** ESL will perform all analyses as outlined on the Field Sampling

Requirements from the material of the liner selected from the four liners of each sleeve that they will be receiving.

** The 200 Area S\&GRP Characterization and Monitoring Sampling and Analysis GKI applies to this SAF.

(1) IC Anions - 9056 \{Nitrate\}; Moisture Content - D2216 \{Percent

moisture (wet sample)\}; Tc-99 by ICPMS \{Technetium-99\};

\section{BRM\#13564}

TILE - NATE/TMË

DISPOSED AY DYTE/TIEE
DATA

Days / 30

Days

ORIGINAL 


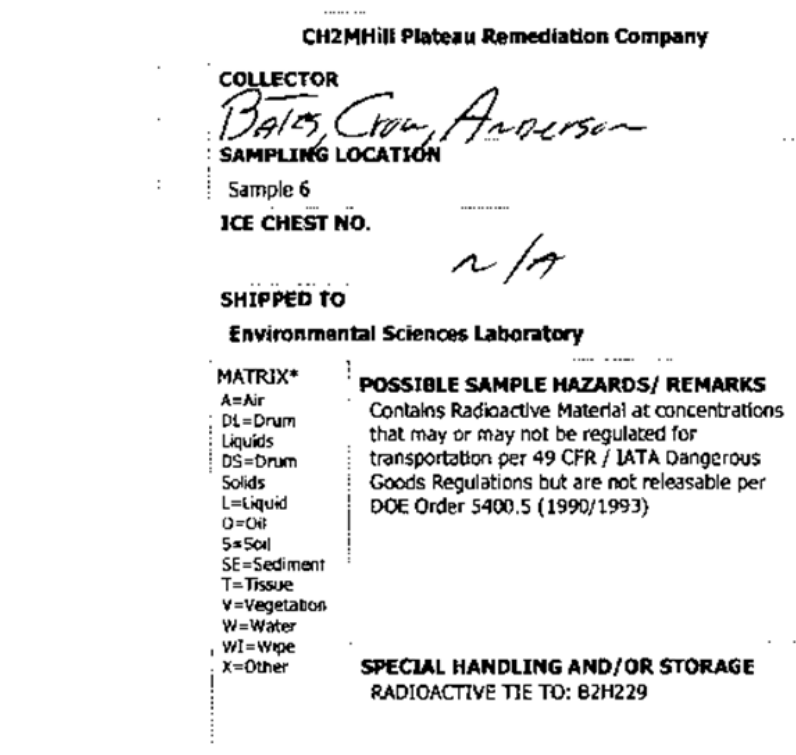

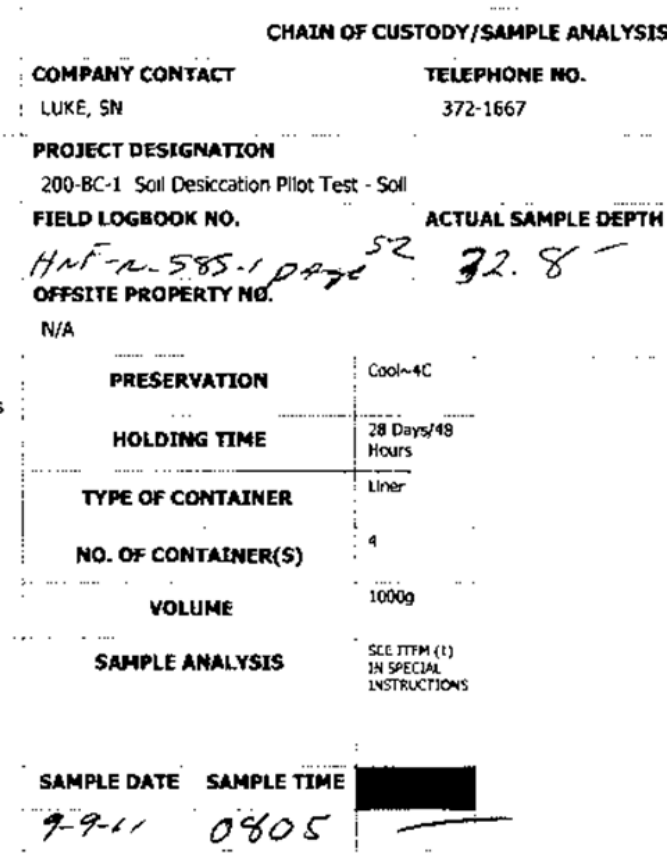

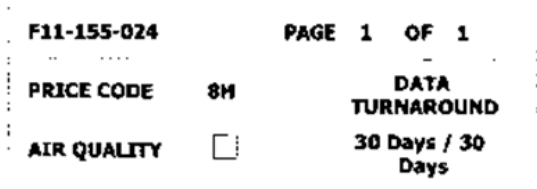

LUKE, SN

SAF NO.

COA

301405ES10

METHOD OF SHIPMENT

GOVERNMENT VEHICL

oiLi of Lading/air BILL No.

N/A

ORIGINAL

MATRIX*

$7-9-6$

0805

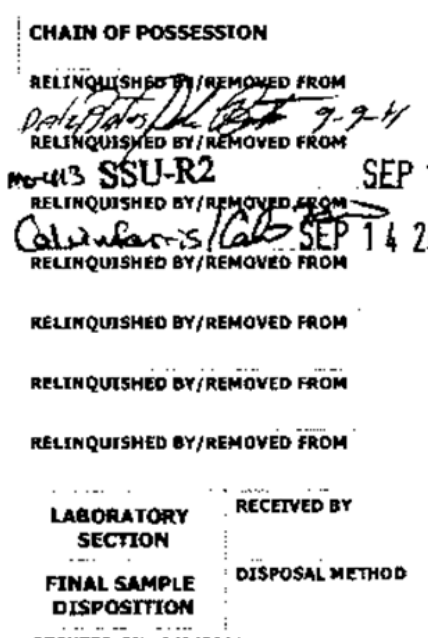

PRINTED ON $9 / 6 / 201$

\section{SIGN/ PRINT NAMES}

\section{DATE/TIME RECETVED BY/STORED IN}

1520

OATE/TIME

SEP 142011 1240

oxt: trme

1330

RECEIVED BY/STORED IN 9 SSU-R1 $9-9-1$

Cauintarris 9-9-1/ I S20

SPECIAL INSTRUCTIONS

** The CACN for all analyticai work at ESL laboratory is 301405ES20

(under Contract 00036402 Release 00045).

** ESL will perform all analyses as outlined on the Field Sampling

Requirements from the material of the liner selected from the four liners of

** The 200 Area S\&GRP Characterization and Monitoring Sampling and

DATE/TMME RECEIVED BY/STORED IN

DXTE/TMAE RECEYVED BY/STOREO IM

DATE/TMAE RECENED BY/STORED IN each sleeve that they will be receiving.

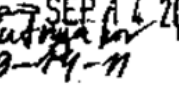

1350

DATE/TIME Analysis GKI applies to this SAF.

(1) IC Anions - 9056 \{Nitrate\}; Moisture Content - D2216 \{Percent moisture (wet sample)\}; TC-99 by ICPMS \{Technetium-99\};

\section{BRM\# 13564}


CH2MHill Ptateau Remediation Company

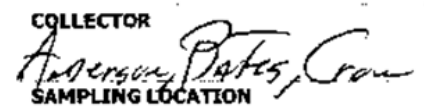

Sample?

ICE CHEST NO.

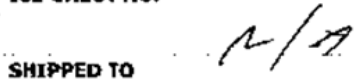

Environmental Sciences Laboratory

\begin{tabular}{l|l} 
MATRIX* & POSSIBLE SAMPLL HAZARDS/ REMARKS \\
A Ait \\
DL=Drum
\end{tabular}

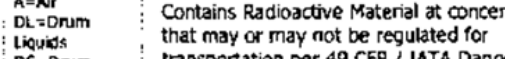

Goods Regulations but are hot releasabic per

DOE Order 5400.5 (1990/1993)

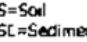

$T=$ Tissue
$V=$ Vegetation

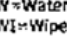

$x=0$ tis

SPECLAL HANDLING AND/OR STORAGE RADIOACTIVE TIE TO: $82 \mathrm{H} 230$
CHAIN OF CUSTODY/SAMPLF ANALYSIS REQUEST

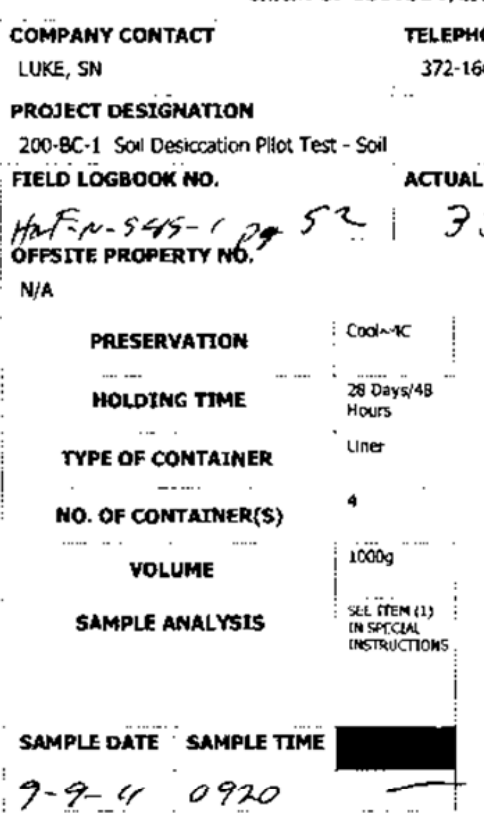

F11-155-02S

PROJECT COORDIMATOR

UKE, SN

SAF NO.

F11-155

$\cos$

301405Es10

BHLL OF LADING/ATR BTLL NO

N/A
PRTCE CODE BH

NIR QUALTTY

METHOD OF SHIPMENT GOVERNMENT VEHICLE
PAGE 1 OF 1 TURATA 30 Days / 30 Days

\section{ORIGINAL}

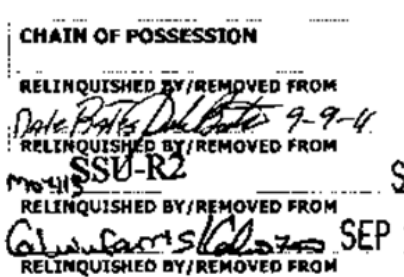

RELTNQUTSHEO QY/REMOVED ERO

RELINQUUISHED EY/REMOVEO YROM

RELINQUISHED BY/REMTOUVED FROM̈

REIINQUTSHED EY/REMOVED FROM

LABORATORY

SECTON

FINAL SAMPLE

DISPOSITton

OTPOSAL METHOD

PRINTEO ON $8 / 24 / 2011$
SIGN/ PRINT NAMES

\section{DATE/TIME RECEIVED BY/STORED}

1520

Moh/3 SSC-R

RECEIVED YY/STOREQ I

SEP 142011 LESO 2011 is 30

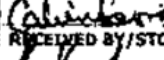
chincoris 2011 is 30 DATE/TIME

OATE/TIME

RECEIVED BY/STORED IM

OATE/TIME

OATE/TIME

RECEIVEO BY/STORED IM

RECENEEO BY/STORED IN

$9-9-11$ OATE/TIME 2019 DATE 240 1330 DATEITIME

Dater

DATE/TIME

DАTE/TIME DATE/TIME
SPECIAL INSTRUCTIONS

** The CACN for all analytical work at ESL laboratory is 301405 ES20

(under Contract 00036402 Release 00045).

** ESL will perform all analyses as outlined on the Field Sampling

Requirements from the material of the liner selected from the four liners of each sleeve that they will be receiving.

** The 200 Area S\&GRP Characterization and Monitoring Sampling and Analysis GKI applies to this SAF.

(1) IC Anions - 9056 \{Nitrate\}; Moisture Content - D2216 \{Percent

moisture (wet sample)\}; Tc-99 by ICPMS \{Technetium-99\};

\section{BRM\# 13564}

DRTE/TIME

Date/Tiné 
CH2mHill Plateau Remediation Company

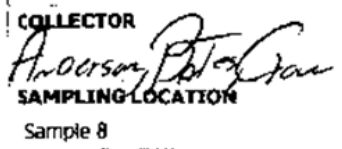

MATRIX*

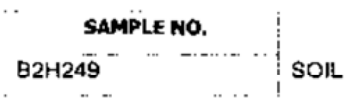

MATRIX

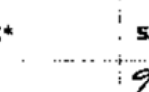

\begin{tabular}{|c|c|c|}
\hline \multicolumn{3}{|c|}{ 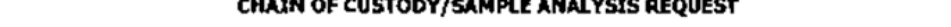 } \\
\hline COMPANY CONTACT & TELEPHONE NO. & PROJECT COORDINATOR \\
\hline LUKE, SN & $372-1667$ & LUKE, SN \\
\hline PROJECT DESIGNATION & & SAF NO. \\
\hline 200-BC-1 Soil Desiccation Pibot Test - Soil & & F11-155 \\
\hline FIED LOGBOOK MO. & ACTUALL SAMPLE DEPTH & $\cos$ \\
\hline
\end{tabular}

HaF Fe.s85-1pg $52 \quad 37.5^{\text {ACTUAL SAMPLE DEPTH }}$

OFFSTTE PROPERTY NO.

N/A

PAESERVATION

MOLING TIME 280 Dars 48 Rours

TYPE OF CONTAINER

NO. OF CONTAINER(S)

VOLUME

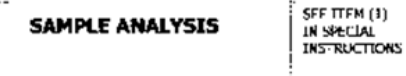

10009

q-9-1r 1015

\section{F11-155-026 \\ PAGE 1 OF 1 \\ PRTCE CODE

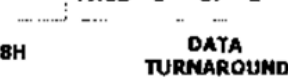 \\ Days}

METHOD OF SHIPMENT

BIL OF LADING/a BR BILL No.

N/A

\section{ORIGINAL}

CHAIN OF POSSESSION

RELINQUISHË DYJ REMOVEO Frö

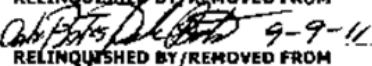
vor/3SSU-R2 REITKQUISHED BY/FFMOVED FROM

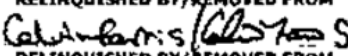

RELINQUISHED BY / KEMOVED FROM

RELINQUISHED QY/REMOYED FROM

REUNQUISHED BY/RËMOUVED FROM

REITQUISHED GY/REMOYED FROM̈

\section{LABORATORY \\ RECEIVED aY}

SECTION

FIMAL SAMPLE

PRINTED ON Bj/24/2011
SIGN/ PRINT NAMES

DATE/TTME RECEVED EY/STORED IN

1520

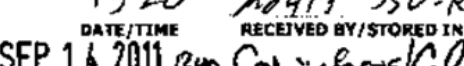

DATE/TIME

20111330

REgrived ay/sToked

RECEVEO BYS SORED

OATE/TIME

DATETTIME

DATE/TIME

RECEIVED BY/STORED IN

(.. $\quad \cdots \cdots \cdots$

$-$

(n............ - -

-........

Page 76 of 85

SPECTAL INSTRUICTIONS

** The CACN for all analytical work at ESL taboratory is $301405 E S 20$

(under Contract 00036402 Release 00045)

** ESL will perform all analyses as outlined on the Field Sarnpling

Requirements from the material of the liner selected from the four liners of each sleeve that they will be receiving.

** The 200 Area S\&GRP Characterization and Monitoring Sarnpling and Analysis GKI applies to this SAF.

(1) IC Anions - 9056 (Nitrate\}; Moisture Content - D2216 \{Percent

DATETTME

moisture (wet sample)\}; Tc-99 by ICPMS \{Technetium-99\},

DARESTME :

Tार

DATE/TIME

DISPOSEO OY

DATE/TIME

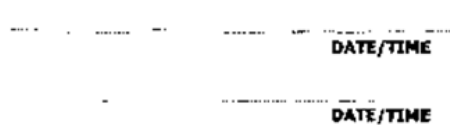




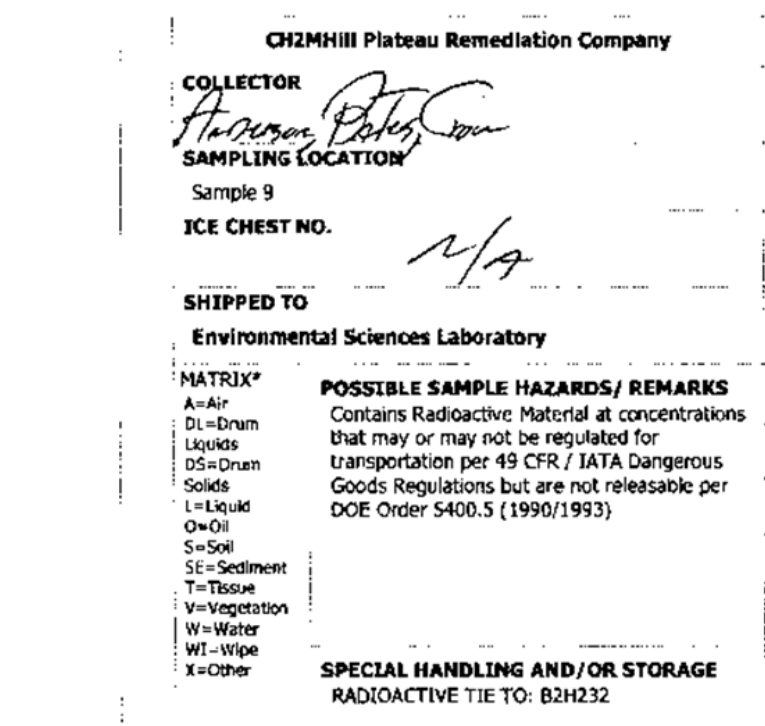

$\stackrel{p}{a}$

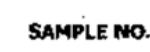

solk

MATRIX*

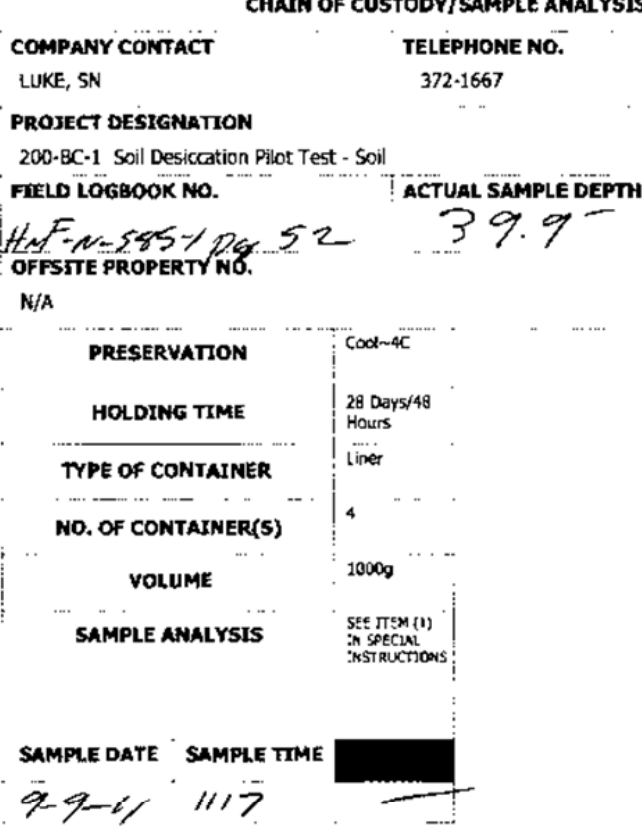

aquil 117

\section{ORIGINAL}

\section{CHAIN Of POSSESSION}

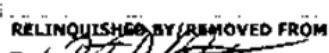
Dele bate a 2

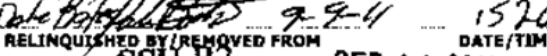
moris SSU-R2 RELINQUISHED QY ZREM VVED FROM SEP 14 2011 RW DATEYTIE Calinfmons 6loparse 1420111330

RELINQUTSHËD EYT $/$ REMOVED RROM DATE/TIME RELNQUUISHED BY/REMOVẼ FROM DATE/TIME RELINQUISHED BY/REMOVED FRŌM DATE/TIME LAGORATORY RECENED QY

\section{SIGN/ PRINT NAMES}

RECESTEEO BY/STOREO iN mo $4 / 3$ SSU-R/ 9-7.6

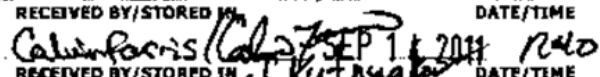

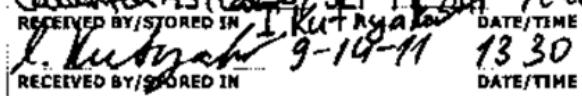

RECEUVËE BY/STORED IN DATE/TMME

RECETVEO BY /STORED IN RECEEVED BY/STORED IN
DATE/TIME

DATE/THE

DATE/TIME

$$
\text { - . - .... }
$$

SPECLAL INSTRUCTIONS

** The CACN for all analytical work at ESL laboratory is 301405ES20 (under Contract 00036402 Release 00045).

** ESL will perform all analyses as outlined on the Field Sampling Requirements from the material of the liner selected from the four liners of each sleeve that they will be receiving.

** The 200 Area S\&GRP Characterization and Monitoring Sampling and Analysis GKI applies to this SAF.

(1) IC Anions - 9056 \{Nitrate\}; Moisture Content - D2216 \{Percent moisture (wet sample)\}; Te-99 by ICPMS \{Technetium-99\},

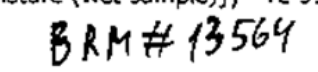

DISPOSED är

DATE/TIME 


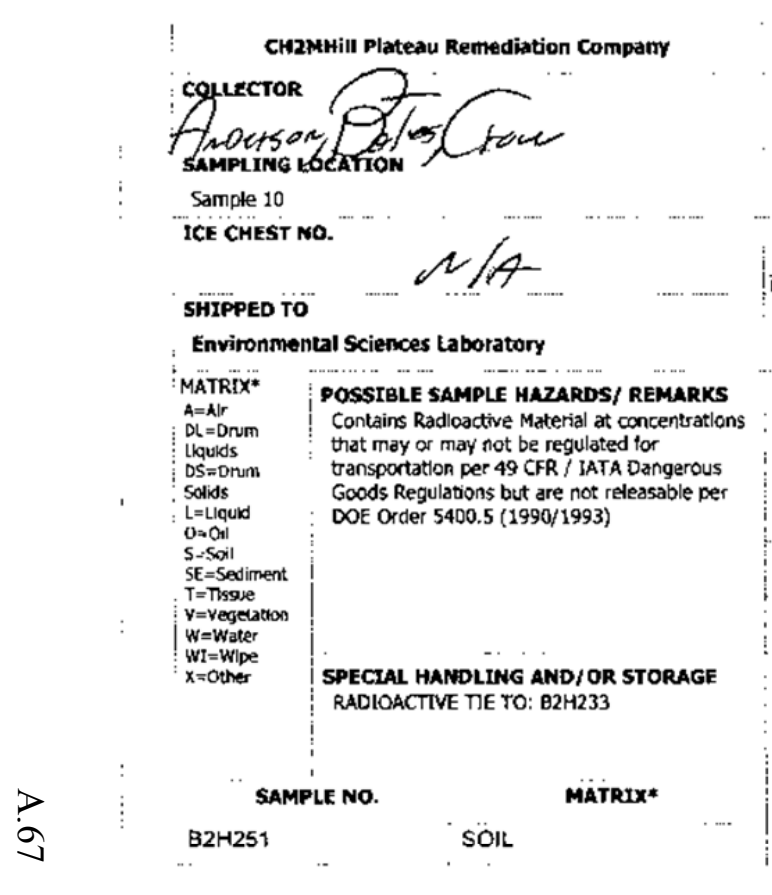

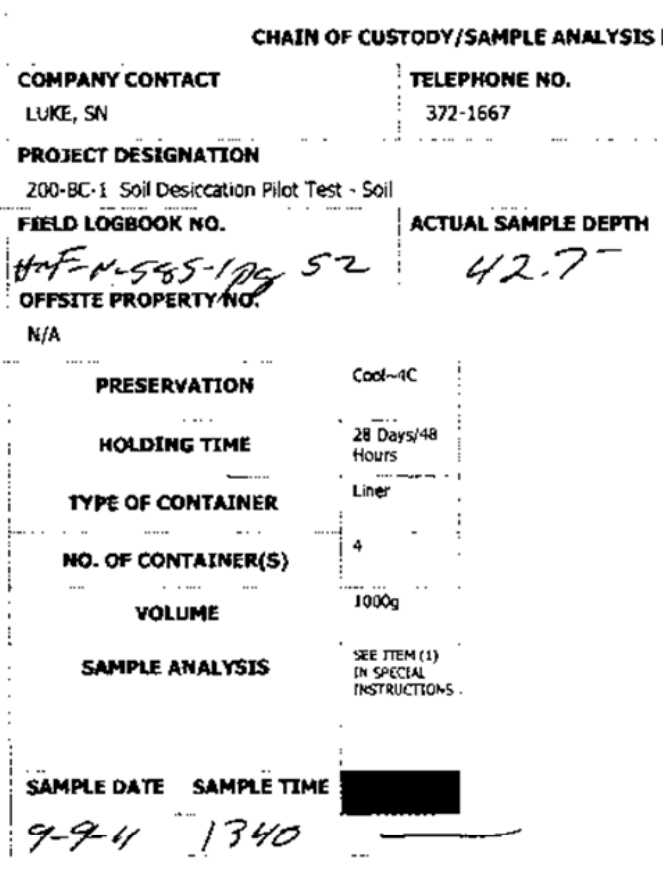

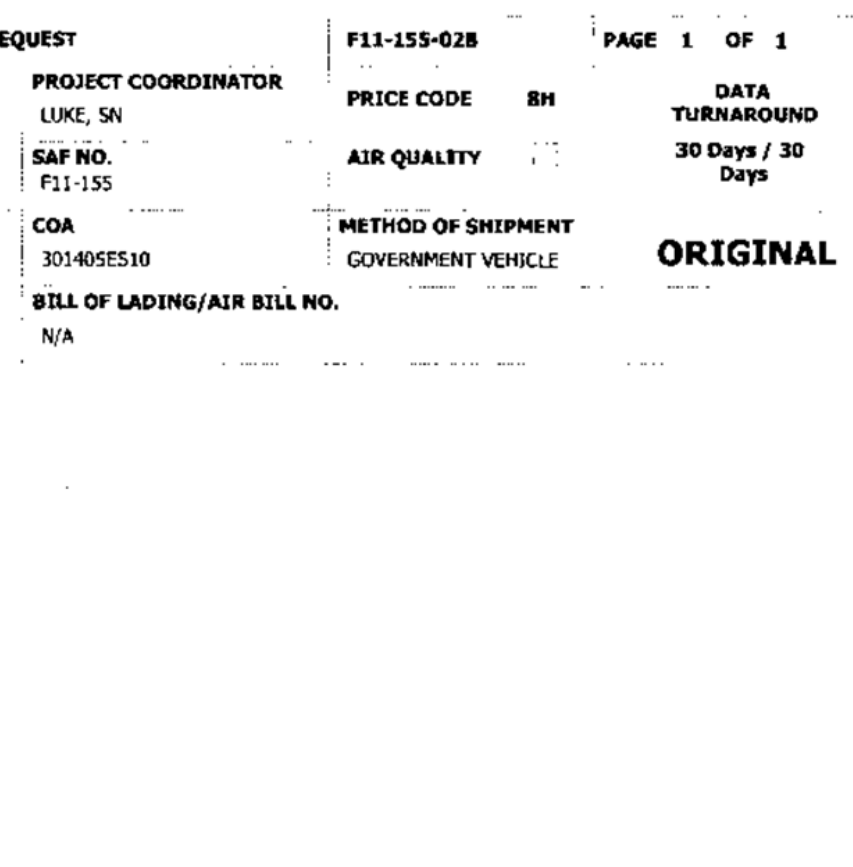

CHAIN OF POSSESSION

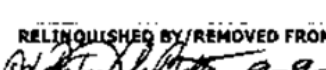

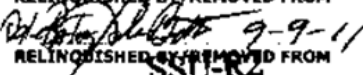
Mo 4 B REUMQUISHED QY / TSMOYED FROA

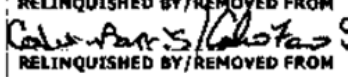

RELINQUISHED B̈YREROVEO FRON

RELUNQUISHED QY/REMOVED FROM

RELINQUTSHED BYYTREMOVED FROM

LABORATORY RECENED BY SECTION

FINAL SAMPLF

DISPOSÄ METHOD

PRUNTED ON $8 / 24 / 2011$

\section{SIGN/ PRINT MAMES}

DATE/TIME

1S20 MOLI 3 SSU-R,

moyi $3.554-2,9-9-1$

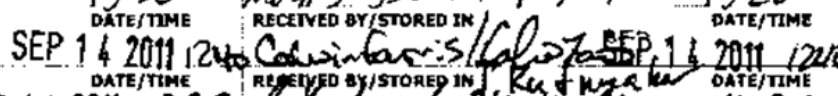

** The CACN for all analytical work at ESL. iaboratory is $301405 E S 20$

(under Contract 00036402 Release 00045).

** ESL will perform all analyses as outined on the Field Sampling

Requirements from the material of the liner selected from the four liners of each sleeve that they will be receiving.

** The 200 Area S\&GRP Characterization and Monitoring Sampling and Analysis GKI applies to this SAF.

(1) IC Anions - 9056 \{Nitrate\}; Moisture Content - 02216 PPercent

DATE/TIME RECEIVED BY/STORED IN

DATEITIME

DATE/TIME RECEIVED BY/STORED IN

DATE/TIME RECEIVED BY/STORED IN

DATE/TIME

DATE /TME

\section{BRM \# 13564}

DISPOSED aY

\section{DATE/TIME}

OATE/TIME 


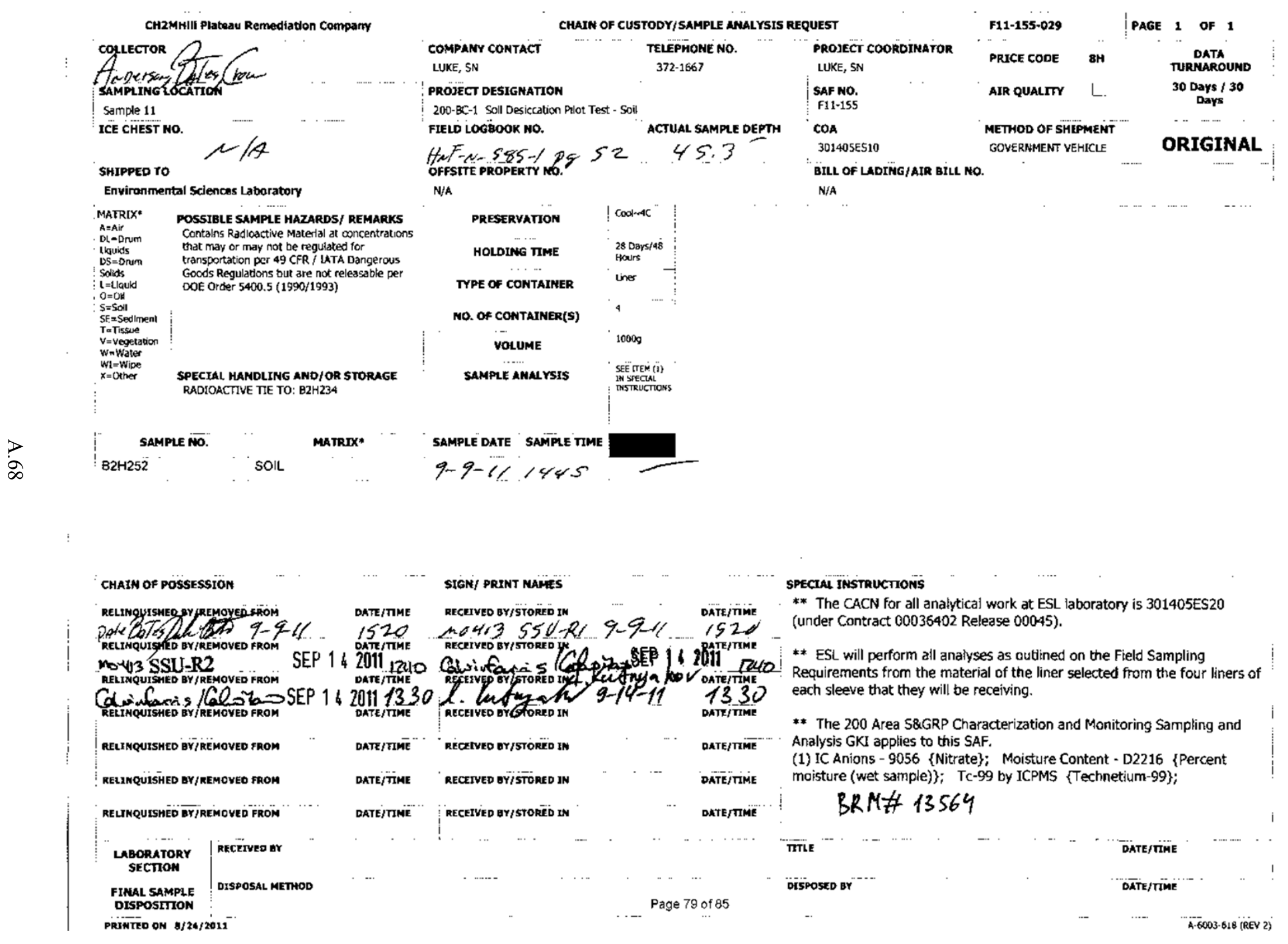


CH2MHII! Plateau Remedlation Company COLECTO Timer Anderson, wallace

Sample 12

ICE CHEST NO.

SHIPEO TO NIA

Environmental Sciences Laboratory

MATRJX* ' POSSIBLE SAMPLE MAZARDS/ REMARKS

\begin{tabular}{l|l}
$A=A i$ & POSSIBLE SAMPLE MAZARDS/ REMARKS \\
Contains Radioactive Material at concentration
\end{tabular}

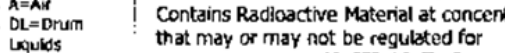

that may or may not be regulated for
uansportation per 49 OFR / IATA Dangerous DOE Order 5400.5 (1990/1993)

MATRIX*
CHAIN OF CUSTODY/SAMPLE ANALYSIS REQUEST

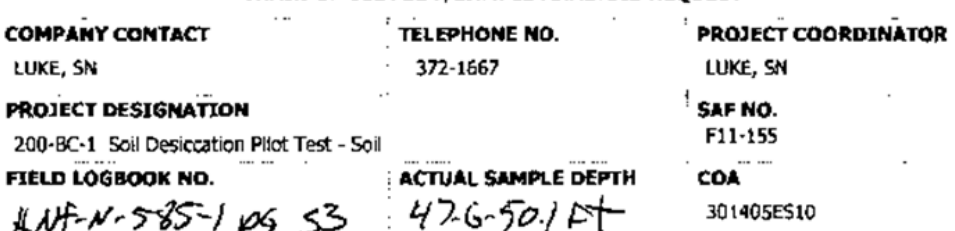

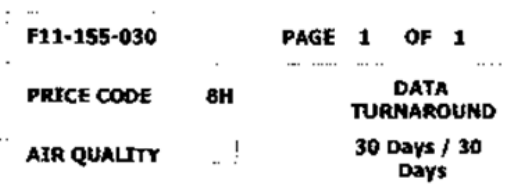

METHOD OF SHIPMËN GOVERNMENT VEHICLE

BIL OF LAOING JATR BIU NO.

N/A

\section{ORIGINAL}

\section{N/A} Goods Regulabions but are not releasable per

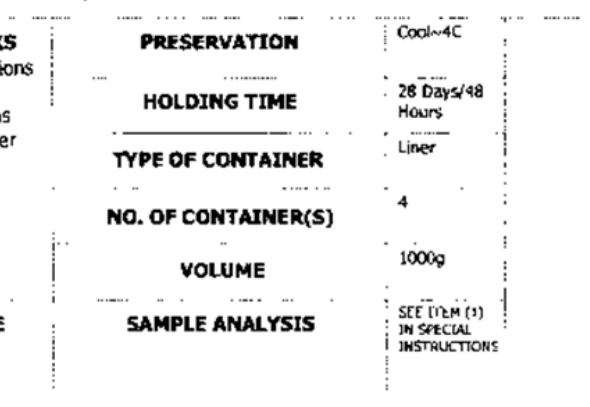

PECIAL HANDLING AND/OR STORAGE RADIOACTIVE TIE TO: B2H235

SAMPLE DATE SAMPLE TIME $9 \pi / 2-11 \quad 0835$

CHAIN OF POSSESSION

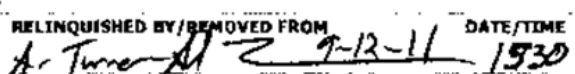
A. Twrer A $7-12-11$

REceiveto ay STrogén it

RECENED BYjSTORERI

SEP 12

SEP 122011 DATE/MME

SPECUAL INSTRUCTIONS

** The CACN for all analytical work at ESL laboratory is $301405 E S 20$

(under Contract 00036402 Release 00045).

** ESL will perform all analyses as outlined on the Field Sampling

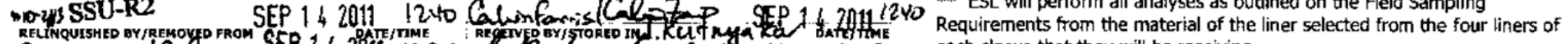

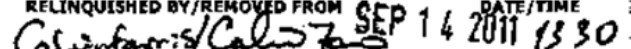
Calinfaroris Cal DATERE

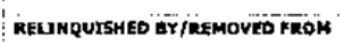
DATEFTIME

RECENYEO BY/STORED IN

RELINQUTSHED AY/REMOUED FROM

DNTE/TIME

RELURQUISHED BY /REMOVED FROM DATEFTIME

RECEIVED BY/STORED IN

RECEIVEË BY/STORED IN
1330

\section{Datem}

DATE/TIME

DATE/TIME

DATE/TIME sleeve that they will be receiving.

** The 200 Area S\&GRP Characterization and Monitoring Sampling and Analysis GKI applies to this SAF.

(1) IC Anions - 9056 \{Nitrate\}; Moisture Content - D2216 \{Percent moisture (wet sample)\}; TC-99 by ICPMS \{Technetium-99\};

\section{BRM\# 13564}

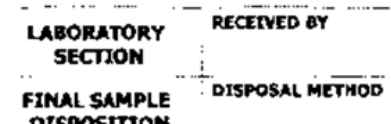

Disposal metToD

TrTe

DATE TIME

-

Page 80 of 85

Disposeto or

DATE/TIME 


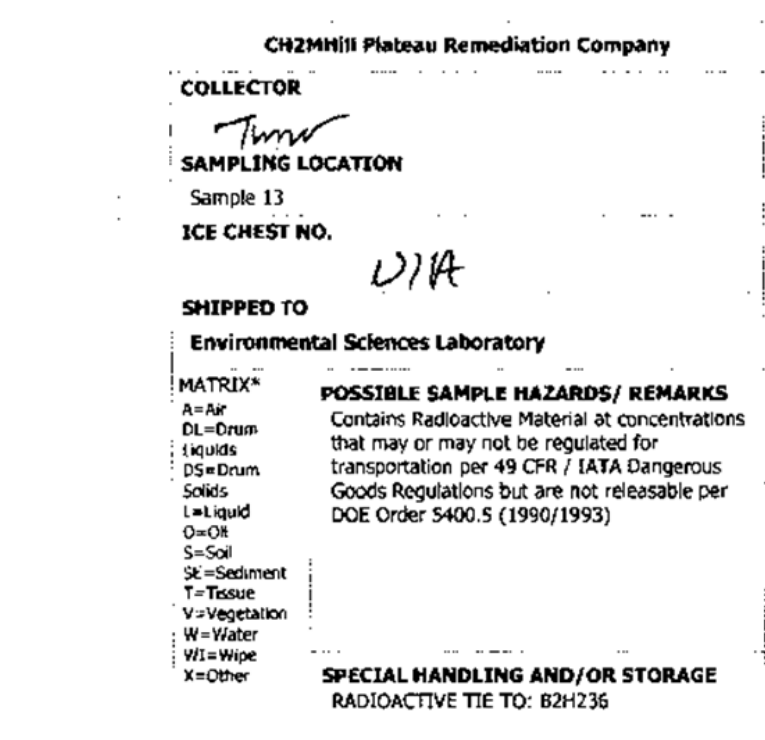

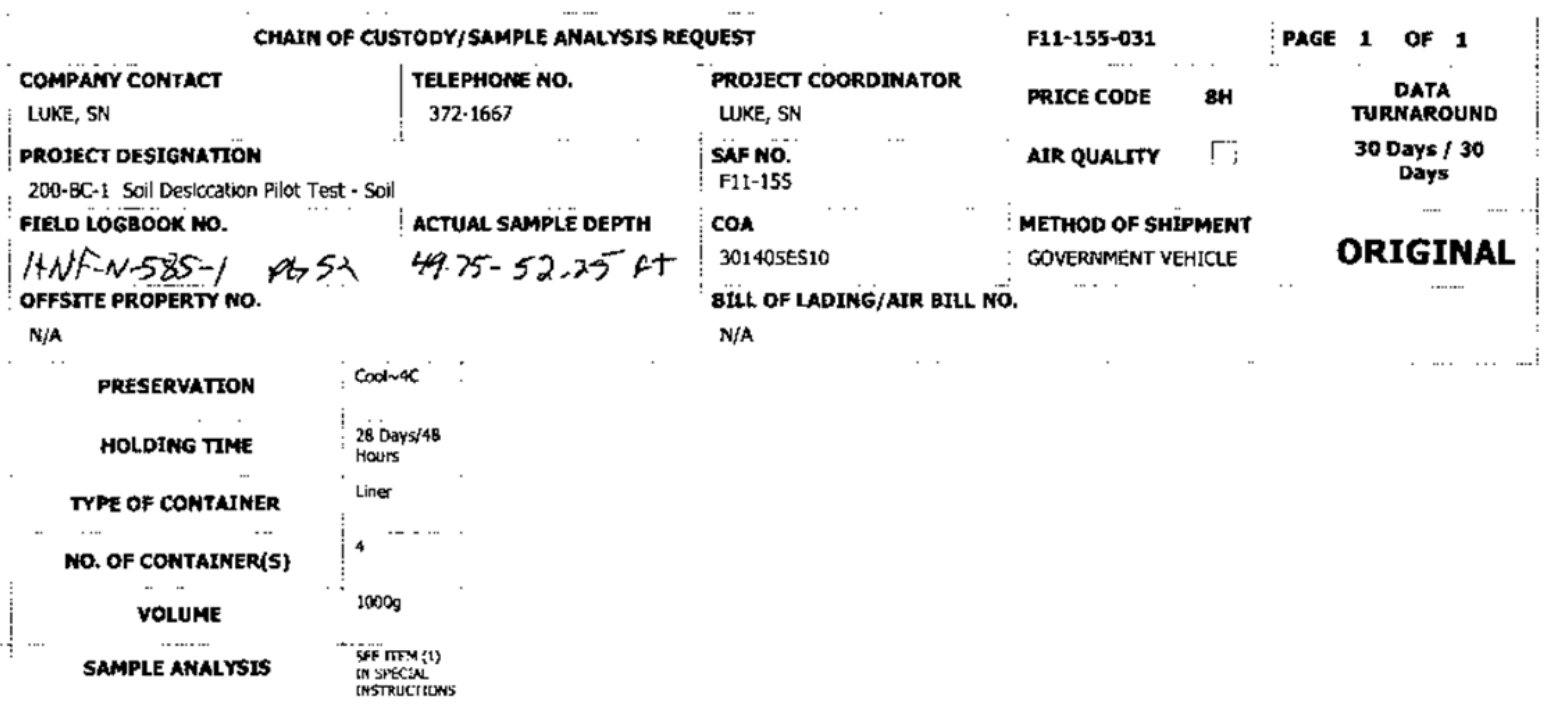

CHAIN OF POSSESSION

RELUNQUISHED OY /WEMOVIED FROM DATE/THA

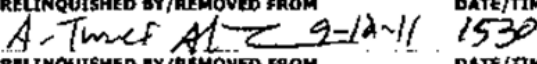

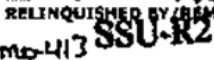
MELUNQUISHED BY/REMOYED FROM

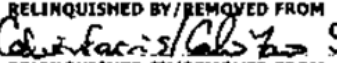
SEP $19^{\wedge}$ Tht RELINQUISHED EY/REMOVED FROM

RELUNQUISHED Ë/RËMOVED FROM DATE/TIME

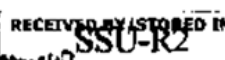

\section{SEP \\ SEP 122011} RECEIVED EY/STOREP IN

DATE/TIME Dare/tTME 2011 r. 240 OATE/TIME
1330

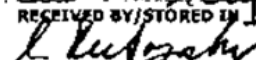

REIINQUISHALD OY/REMOVED FROM DATE/TIME

DATE/TIME

DATE/TIME

RELINQUISHEO GY/REMOVED FROM

DATE/TIME

LABORATORY
SECTON

Fimal Sample RECEIVED BY DATE/TIME DISPOSAL METHOD

-

RECIVED BY/STORED IN

DATE/TME

DATE/TIME

\section{RECETVED EY / STORED IN}

TECEIVED BY/STORED IN

PRTivted on a/26/201

DATEJTME

Page 81 of 85
SPECIAL INSTRUCTIONS

** The CACN for all analytical work at ESL laboratory is 301405ES20

(under Contract 00036402 Release 00045).

** ESL. will perform all analyses as outlined on the Field Sampling

Requirements from the material of the liner selected from the four liners of each sleeve that the $y$ will be receiving.

** The 200 Area S\&GRP Characterization and Monitoring Sampling and Analysis GKI applies to this SAF.

(1) IC Anions - 9056 \{Nitrate\}; Moisture Content - 02216 \{Percent

moisture (wet sample)\}; Tc-99 by ICPMS \{Technetium-99\};

\section{BRM\# 13564}

$\operatorname{int}$

DATE/TIME

DISPOSED G

DATE/TIME 


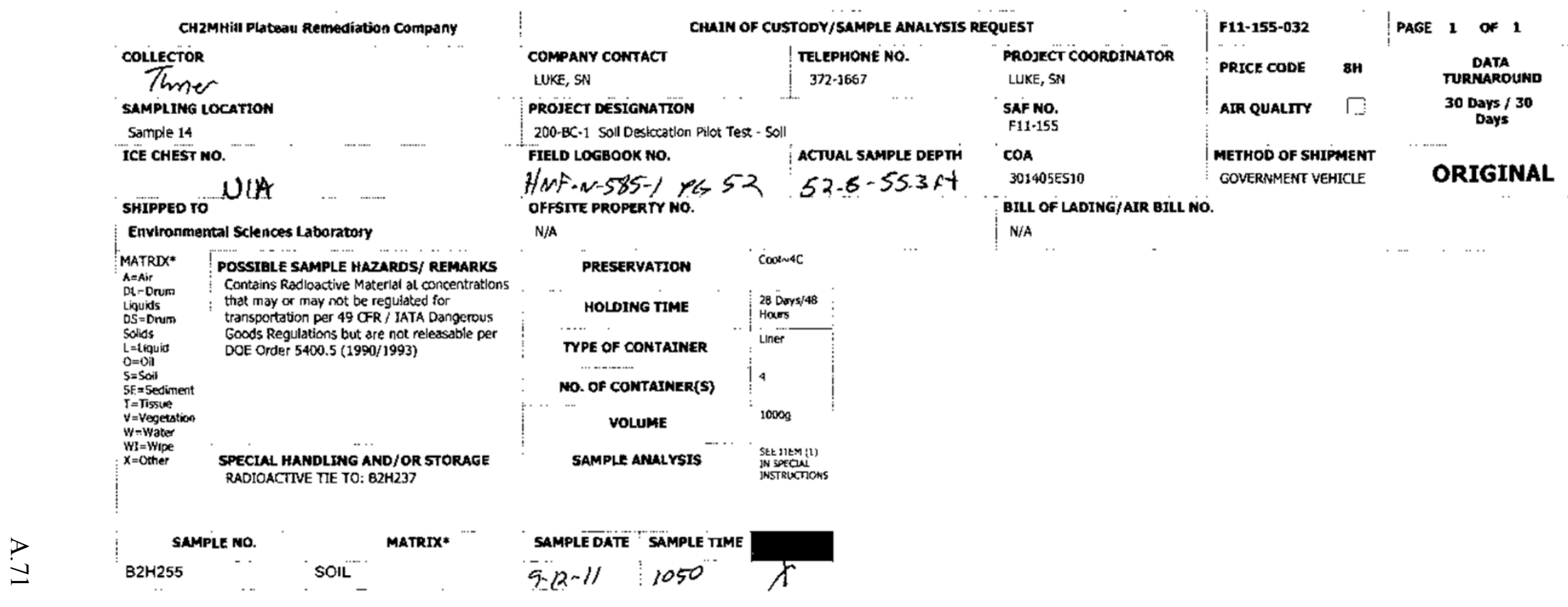

CHAIN OF POSSESSION

REUNQUUSGSEO BY/REMOYEG FROM

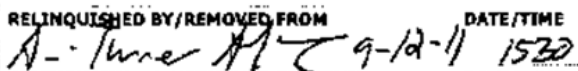

MOLII 3 SSU-R2

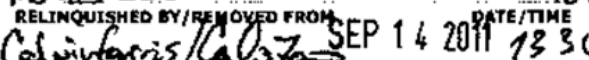

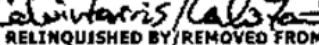

RELINQUISHEO BY/REMOVED FROM

RELINQUISHED QY / REMONEO FROM

RELUMQUISHED BY/REMOVED FROM

$\begin{array}{l:l}\text { LABORATORY } & \text { RECEVED EY } \\ \text { SECTONK } & \\ \text { FINAL SAMPLE } & \text { DISPOSAL MEETHOD } \\ \text { DISPOSMIMON } & \end{array}$

Disposing
DATE/TIME

DATE/TIMË

\section{SIGN/ PRINT NAM̈ES}

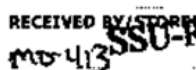

MOU 413

Mo 413 Rerived ay/sTogery

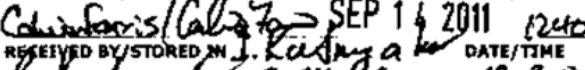

RECEIVED BY FTORED IN

RECEIVED BY/STOAEE IM

OATËTIME

DATEITIME
RECEYEO BY/STORED IN

RECEVED QY/STORED IN

\section{DATE TIME}

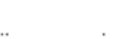

DATE/TIME

DATR TTMME

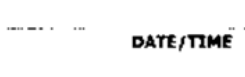

SPECIAL INSTRUCTIONS

** The CACN for all analytical work at ESL laboratory is 301405ES20

(under Contract 00036402 Release 00045).

** ESL will perform all analyses as outlined on the Field Sampling

Requirements from the material of the liner selected from the four liners of each sleeve that they will be receiving.

** The 200 Area S\&GRP Characterization and Monitoring Sampling and Analysis GKI applies to this SAF.

(1) IC Anions - 9056 \{Nitrate\}; Moisture Content - 02216 \{Percent

moisture (wet sample)\}; Tc-99 by ICPMS \{Technetium-99\};

\section{BRM\# 13564}

TiTh

OATE/TIME

DISPOSED or

DATE/TIME 


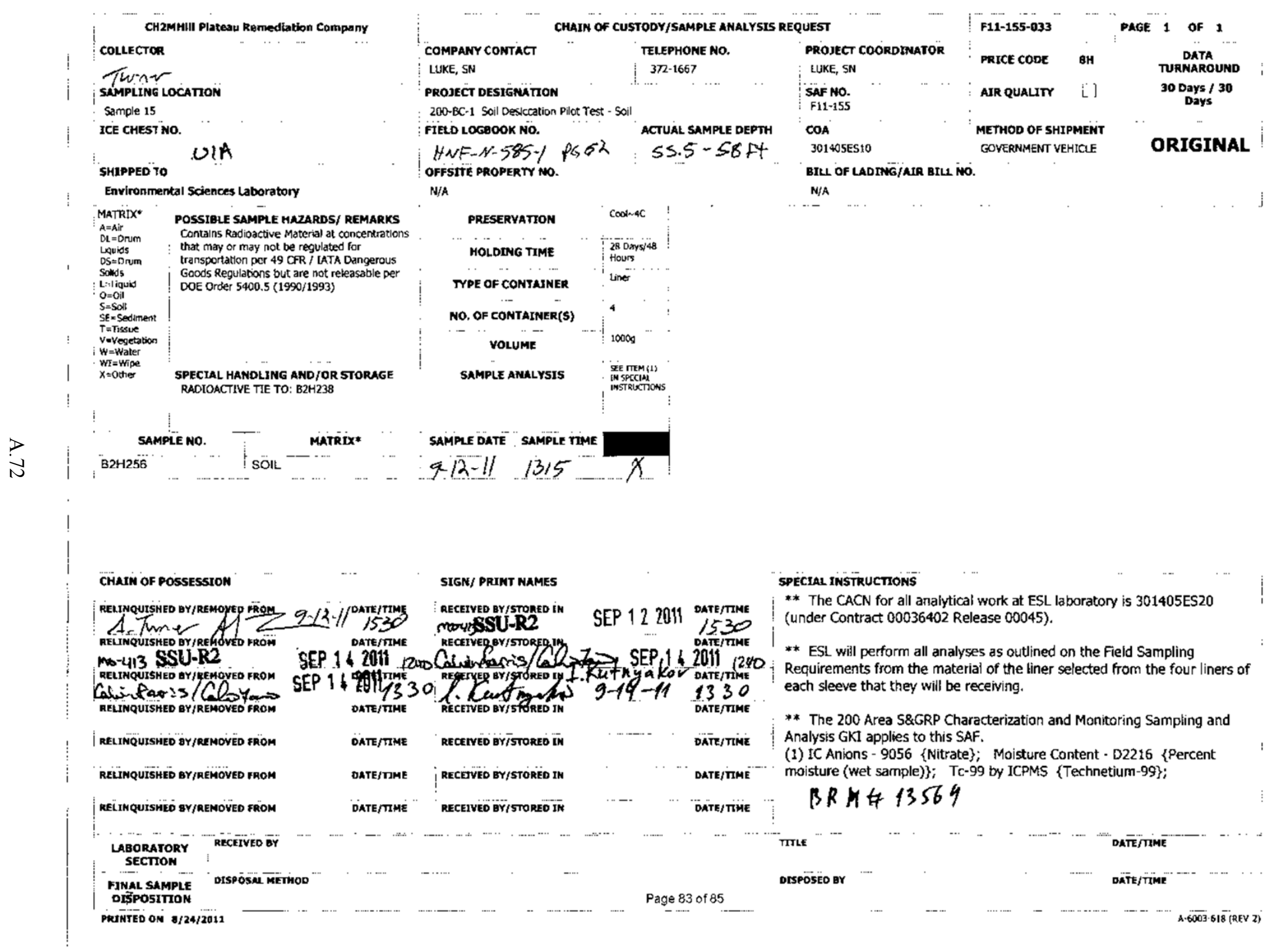




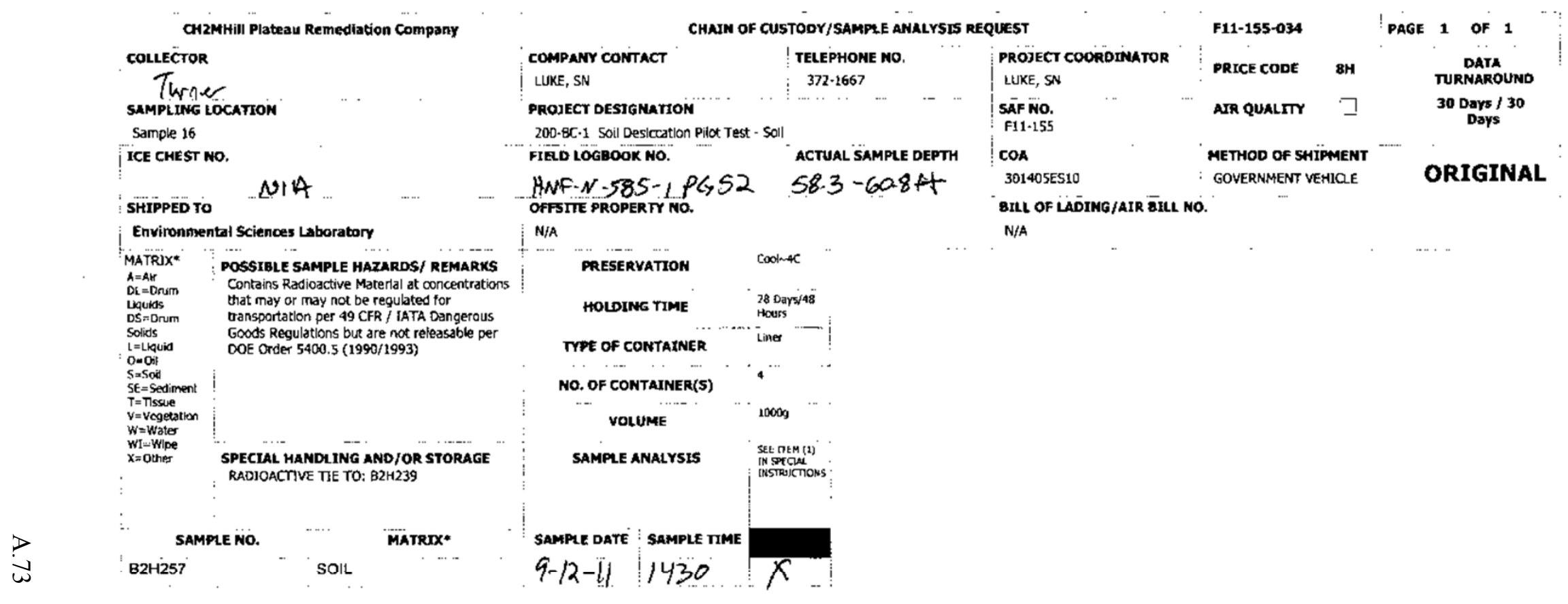

CHAIN OF POSSESS̈ION cheiring of possession

SIGN/ PRINT NAMES

Recerveo BYYSTroke

$9 \cdot(2-1)^{\text {Da }} 1530$

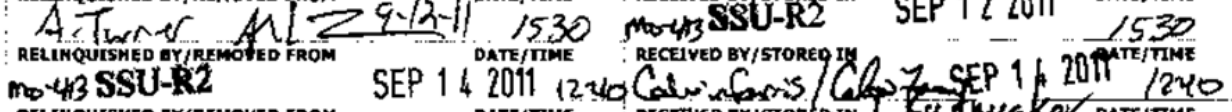
REUTRUISHED BYIREMOUED FROM Cadvinforis Clotar SEP 1 \& 2011133

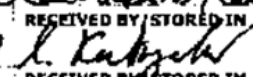
PEcerved ons

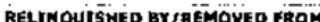

-.- "DATE/TIME

RELINQUTSHED BY /REMOVEOT RROM

- ... DRTE/TMME

RELINQUTSSHED BY/REMONED FR̈OM

LABORATORY RECEIVED

$$
\text { SECTION }
$$

FINAL SAMPLE DISPOSAL METHOD

PRTMTED ON A/24/2011
RECENED BY/STORED IN

D... Date/TIME

RECEIVED EY/STORED IM

RECEYED BV/STORED IN

…... .

.... . .

n...

$\ldots$

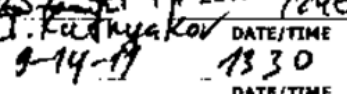

DATE/TINE

DATE/TIME"-

- Date/rime

SPECTAL INSTRUCTIONS

** The CACN for all analytical work at ESL laboratory is $301405 E S 20$

(under Contract 00036402 Release 00045)

** ESL will perform all analyses as outlined on the Field Sampling

Requirements from the material of the liner selected from the four liners of each sleeve that they will be receiving.

** The 200 Area S\&GRP Characterization and Monitoring Sampling and Analysis GKI applies to this SAF.

(1) IC Anions - 9056 \{Nitrate\}; Moisture Content - D2216 \{Percent

moisture (wet sample)\}; TC-99 by ICPMS \{Tectinetium-99\};

\section{BRP\#13564}

TMLE $-\cdots$

DATE/TIME

DisPosed or

DATE/TIME 
CHzMHill Platesu Remediation Company COLLETTOR

$$
\text { Crow }
$$

Sample 17

ICE CHEST NO.

SHIP NED TH

Environmental Sctiences Laboratory

MATRIX" POSSIQLLE SAMPLE MAZARDS/ REMARKS

\begin{tabular}{l|l}
$A=$ Air \\
DL=Drum
\end{tabular} that may or may not be regulated for

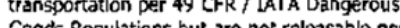
DOE Order $5400.5(1990 / 1993)$

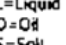

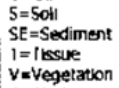

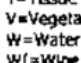

$\underset{x \rightarrow \text { Cther }}{W}$$$
\text { sp }
$$

SPECIAL HANDLING ANO/OR STORAGE RADIOACTIVE TIE TO: B2H233

\begin{abstract}
$$
\text { MATRIX* }
$$$$
\text { " sampieno. MATrix* }
$$

B2H258 SOIL
\end{abstract}

\section{CHAIN OF POSSESSION}

RELINQUISHED OTISREMOVED FROM RCrow R Cnow MO-LI3 SSU-R2 RELTNQUTSHED BYIREESOYEO FROM

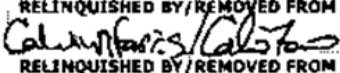
RELINQUISHED BYTREMOVED FROM

RELINQUISHED BY/REMOVED FROM

RELTNQUISHED GY/REMOVED FROM

RELINQUISHED BY/REMOVED FROM

LABORATORY TREETVED DY SECTION

FINAL SAMPLE

DISPOSITION

PRINTED on B/2A/2011

\section{CHATN OF CUSTODY/SAMPLE AMALYSTS REQUEST}

COMPANY CONTACT

LUKE, SN

TELEPHONE NO

$372-1667$

PROJECT DESIGNATION

200-BC-1 Soll Desccation Pliot Test - Soll

FIELD LOGBOOK NO.

ACTUAL SAMPLE DEPTH

HNF-N-585-1 $\quad 42.7^{\prime}$ OFFSTIE PROPERTY NO.

N/A

PRESERVATION

Cood $\sim 4 \mathrm{C}$

HOLOING TIME

28 Dars 48
Hours

TYPE OF CONTATMER

NO. OF CONTAINER(S) $\quad \mathrm{C}_{K S} 8 / 24 / 11$

volume 10000

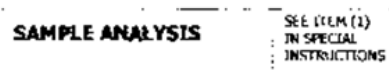

SNMPLE DATE SAMPLE TIME

$9-9-1$

Lits

git $\left.\right|^{2}\left(x^{2}\right)$

1340

SIGN/ PRINT MAMES

RECEIVED BY/STORED IN

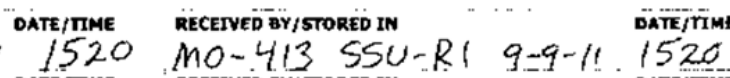
OATE/TRME RECHVED GY/STORED IN A DATE/TIME

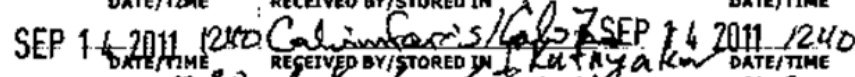

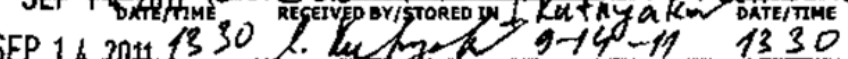

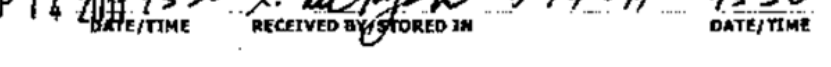

DATE/TIME "

RECCIVED BY $\overline{\text { STSORED JN }}$

N.......... DATE/TIME

$$
\text { -... DATE/TTME ". RECTIVED BY/STORED IN }
$$

DATERTIME"

DRIE/TIME TECETVED BY $/$ STIORED EN

DATEjTIME-

DISPOSAL METHOD -

...

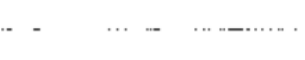

(n-..-

Page 85 of 85 \# $\mathrm{B} 2 \mathrm{H} 258$.

inte

DisPosed BY
PROJECT COORDINATOR

LUKE, SN

SAF NO.

F11-155

301405ES10

BILL Of LADING/ATR BILL NO

N/A

\section{F11-155-035 \\ PRICE CODE \\ AIR QUALITY \\ PAGE 1 OF 1 \\ DATA
TURMAROUND \\ 30 Days / 30}

METHOD OF SHIPMENT

GOVERNMENT VEMICLE GOVER
ORIGINAL

** The CACN for all analytical work at ESL laboratory is $301405 E S 20$ (under Contract 00036402 Release 00045).

** ESL is to prepare this sample as a duplicate of Sample 10 and use HEIS

The 200 Area S\&GRP Characterization and Monitoring Sampling and Analysis GKI applies to this SAF.

(1) IC Anions - 9056 \{Nitrate\}; Moisture Content - D2216 \{Percent moisture (wet sample)\}; Tc-99 by ICPMS \{Technetium-99\};

\section{BRMA 13564}

DATE/TIME

DATE/TIME 


\section{Appendix B}

Supplemental Temperature, Neutron Moisture Log, Electrical Resistivity Tomography, and Ground

Penetrating Radar Data Plots 


\section{Appendix B}

\section{Supplemental Temperature, Neutron Moisture Log, Electrical Resistivity Tomography, and Ground Penetrating Radar Data Plots}

This appendix contains supplemental data plots for temperature, neutron moisture log, electrical resistivity tomography, and ground penetrating radar data collected during active desiccation. These plots expand on those presented in the main text of the report by providing additional time points or three-dimensional images. Discussion for these types of data is provided in Section 4.1.2.1.2 of the main text. 
Temperature Data Interpolation Plots

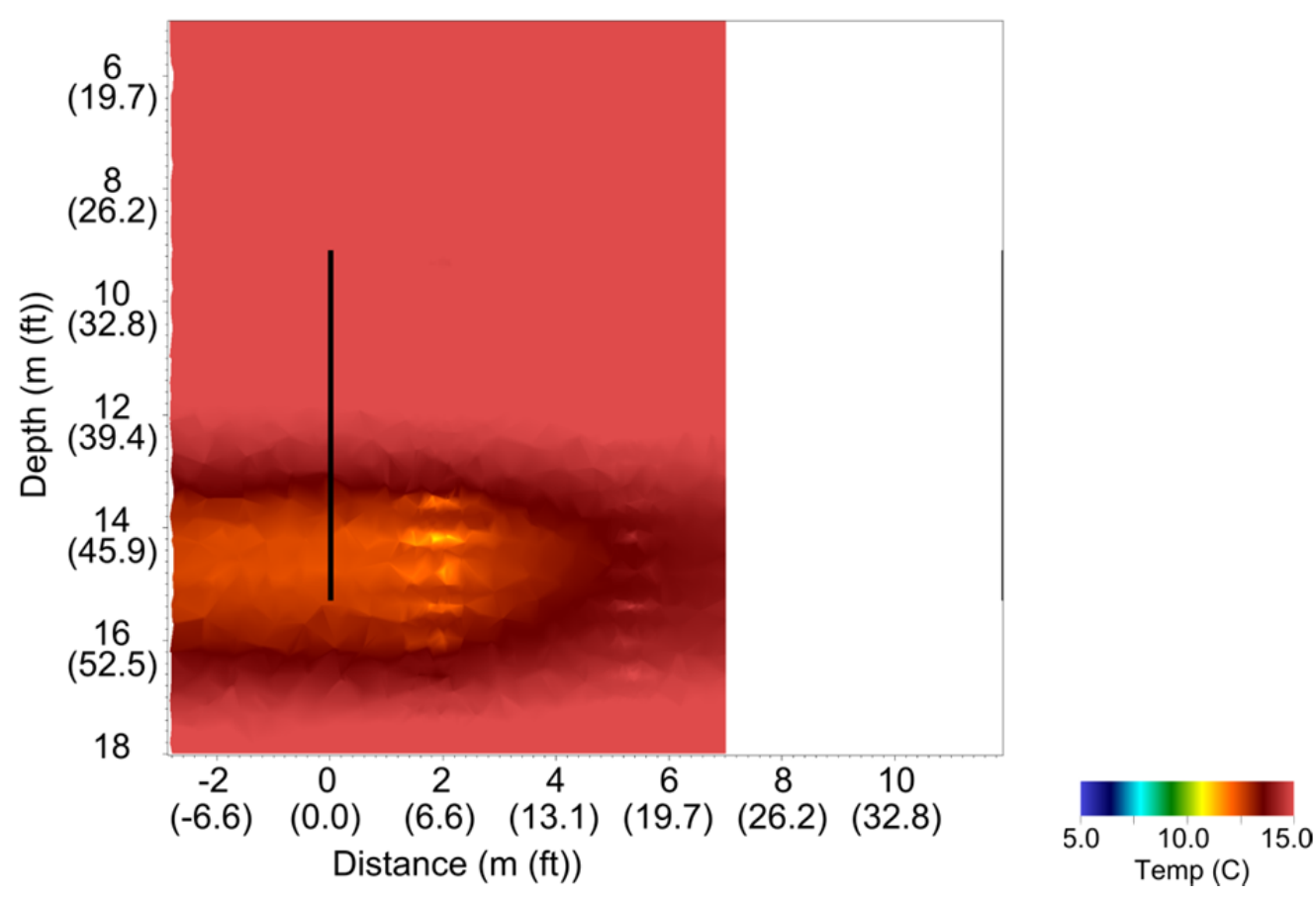

January 31, 2011 (Desiccation Day 14)

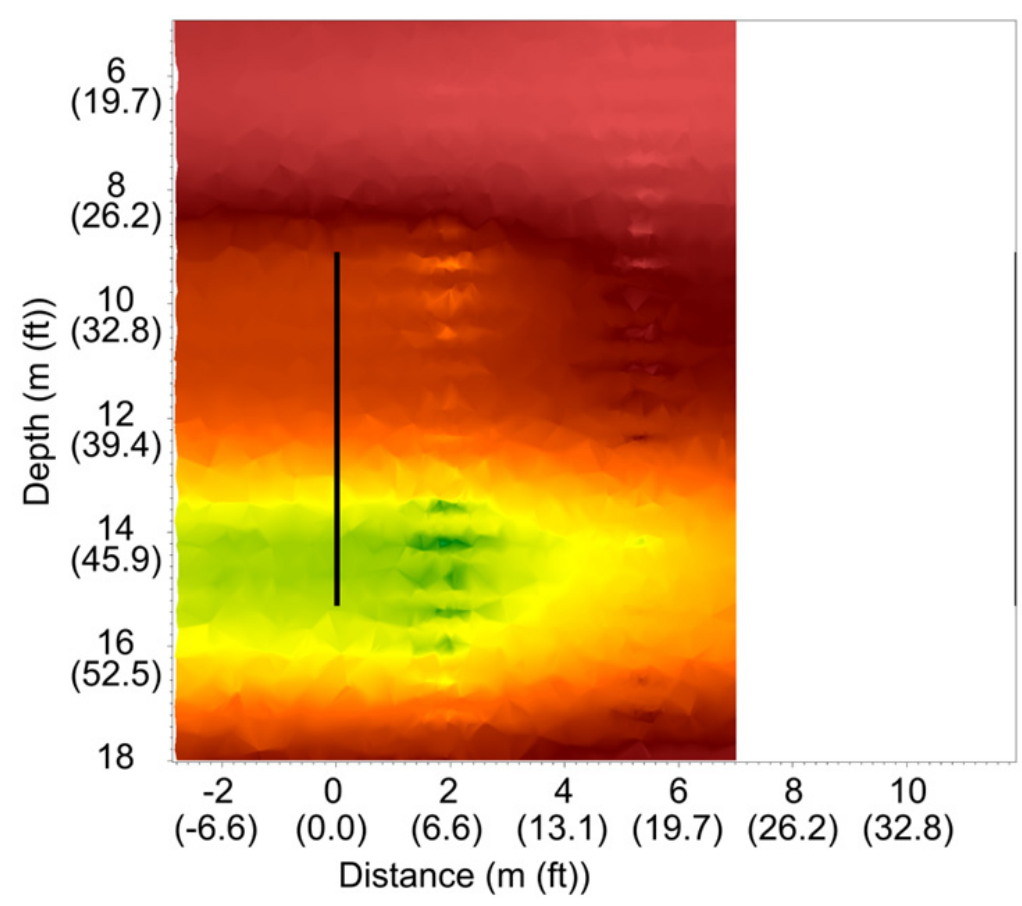

February 14, 2011 (Desiccation Day 28) 


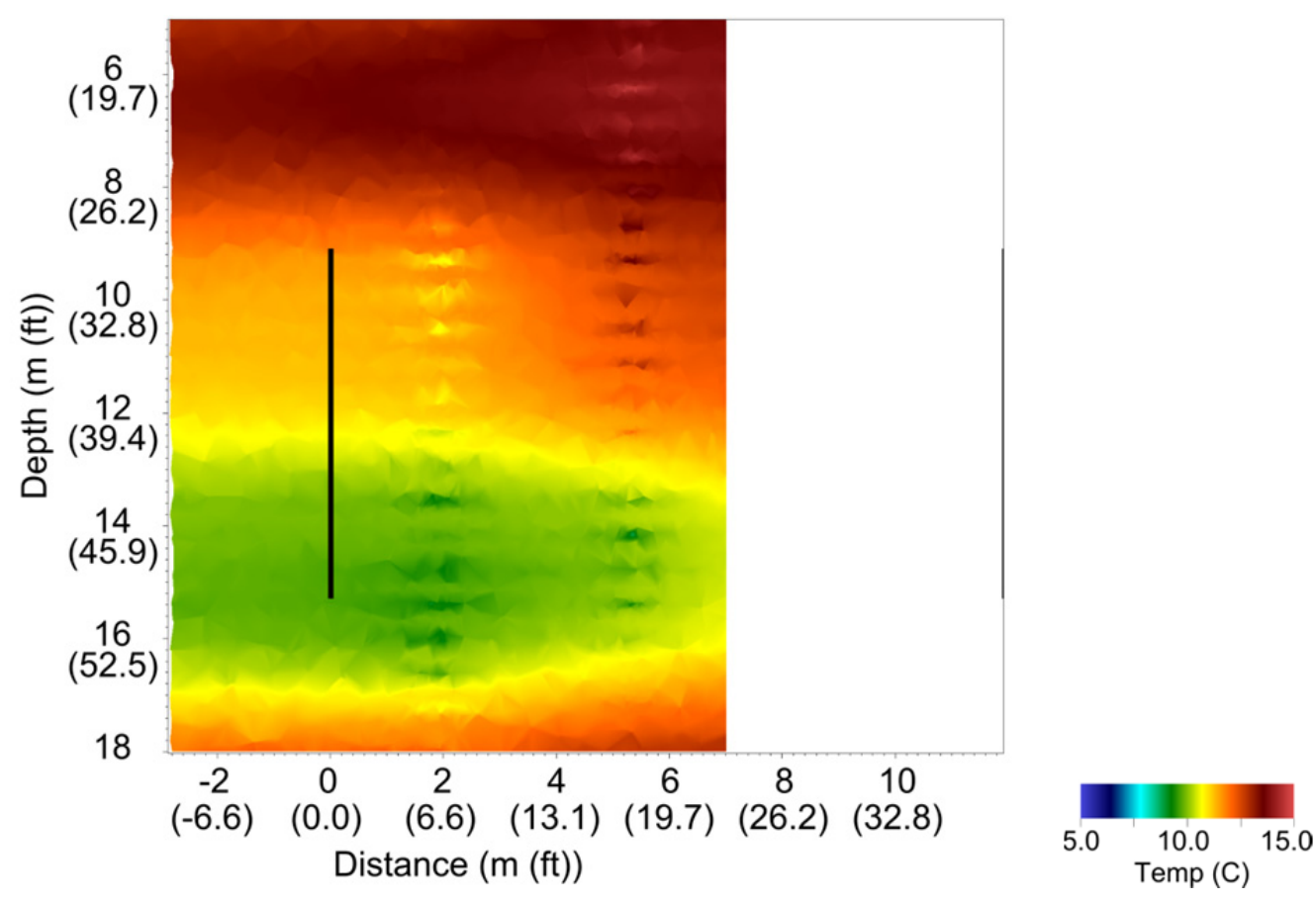

February 28, 2011 (Desiccation Day 42)
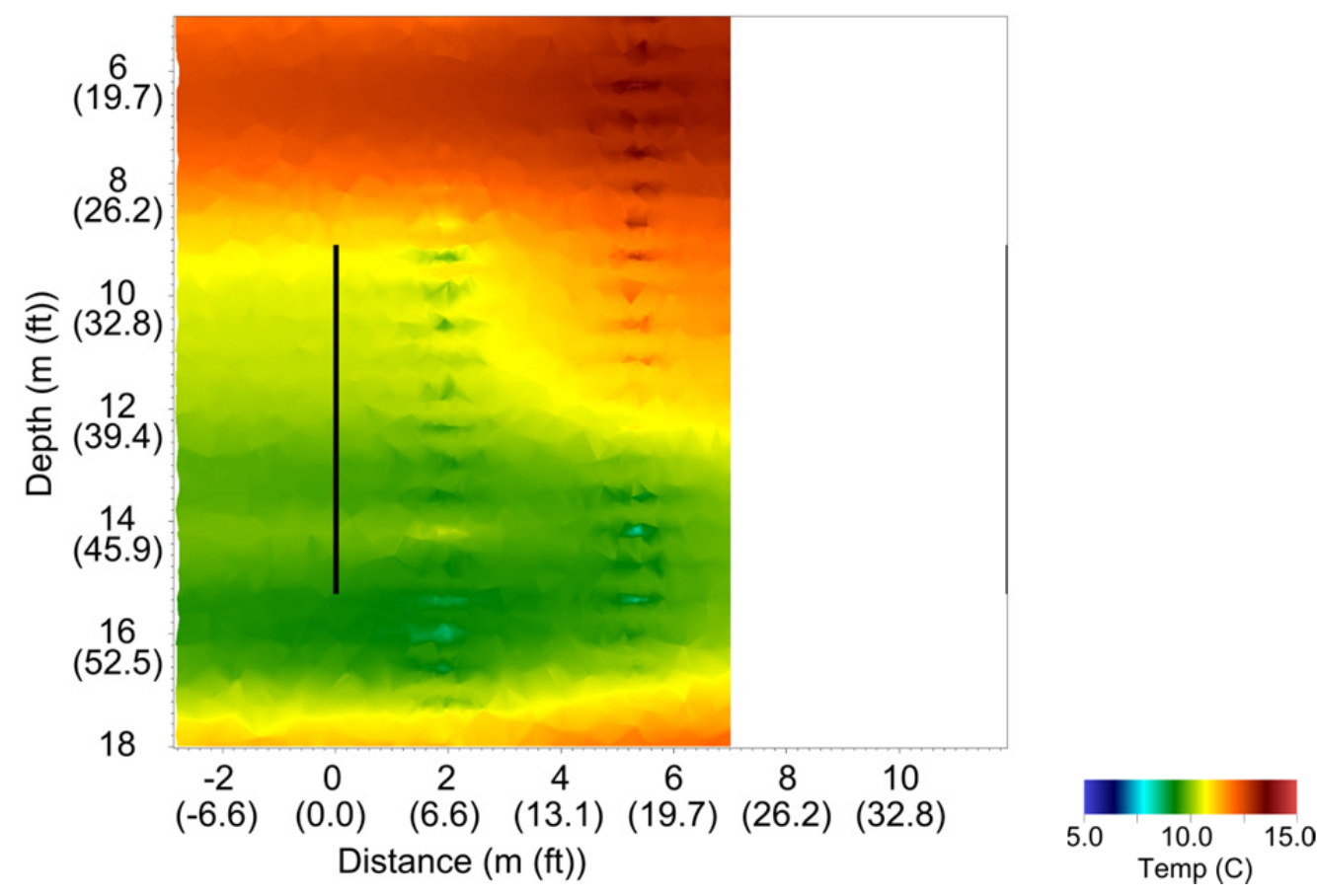

March 14, 2011 (Desiccation Day 56) 


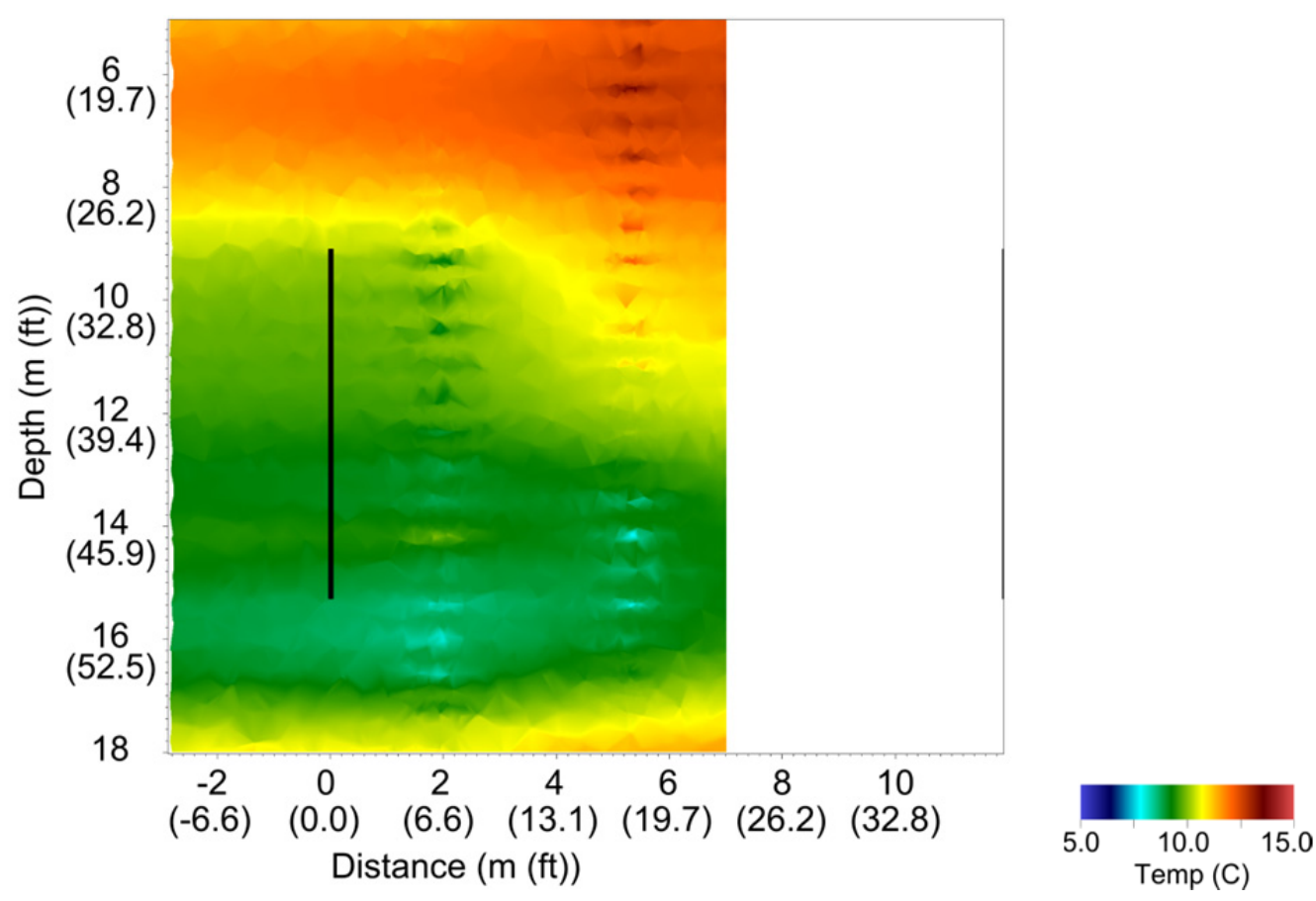

March 28, 2011 (Desiccation Day 70)

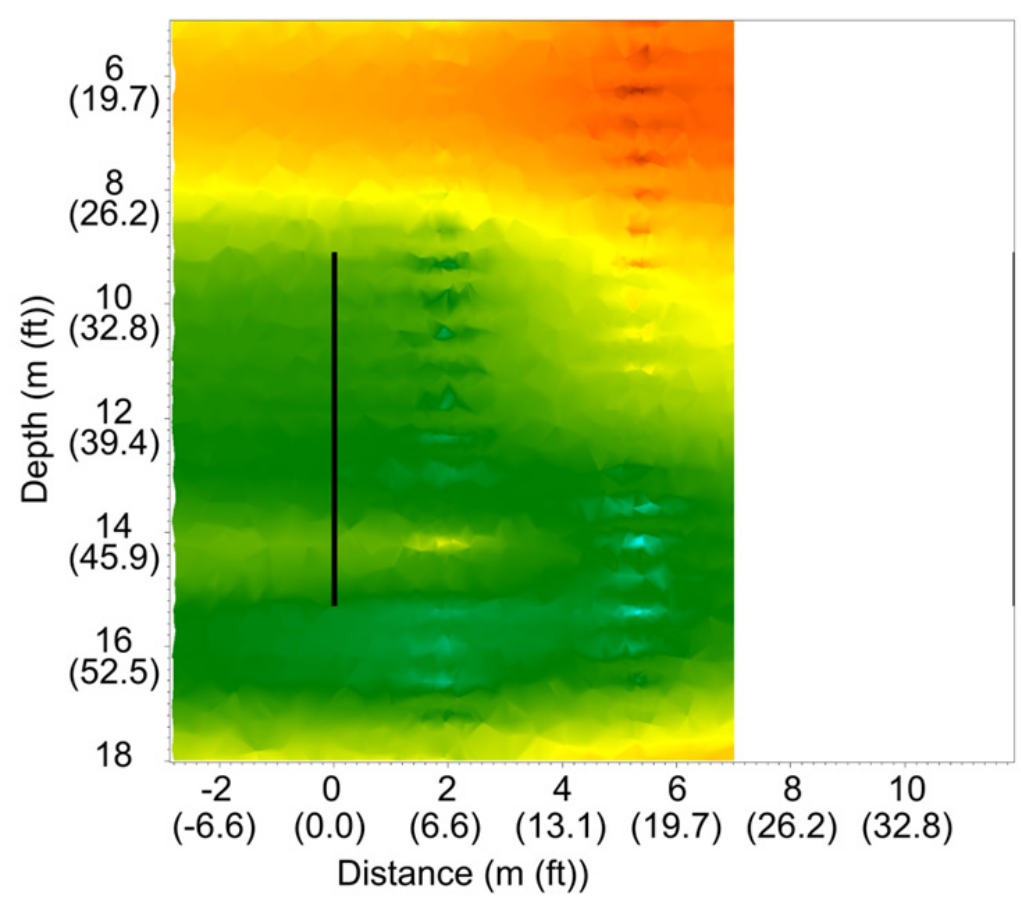

April 11, 2011 (Desiccation Day 84) 


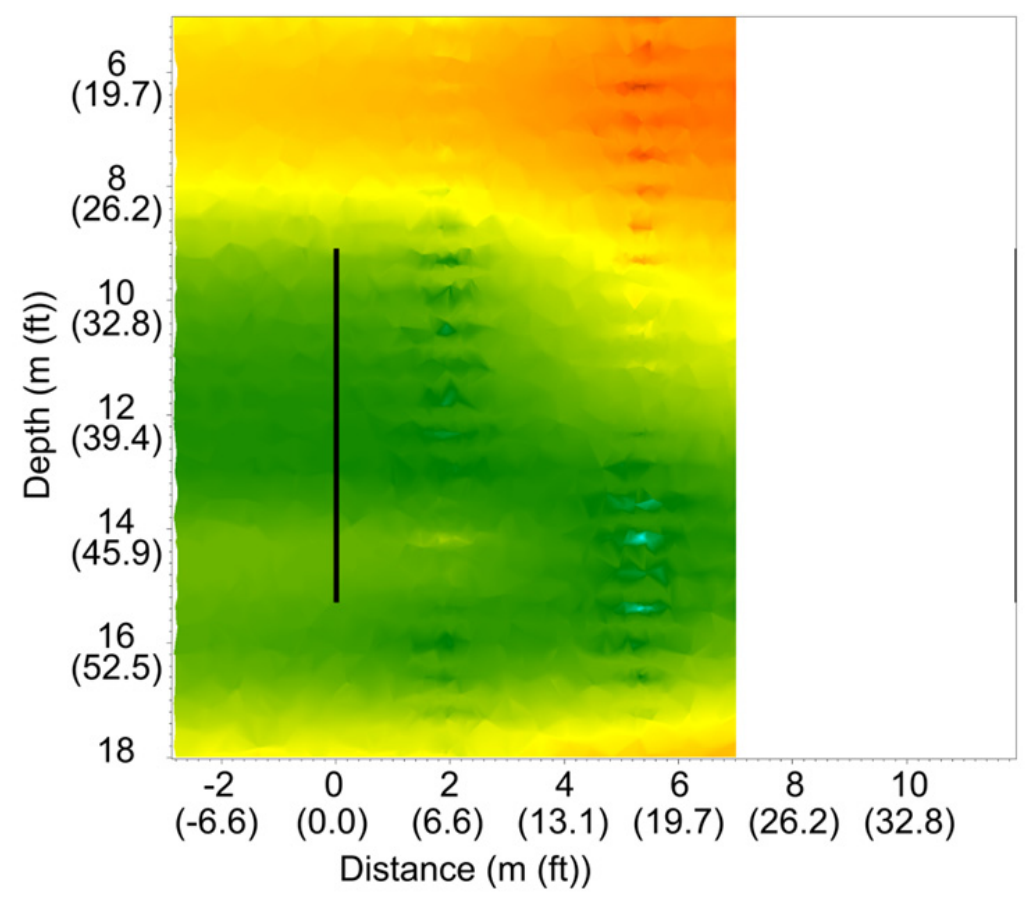

April 25, 2011 (Desiccation Day 98)

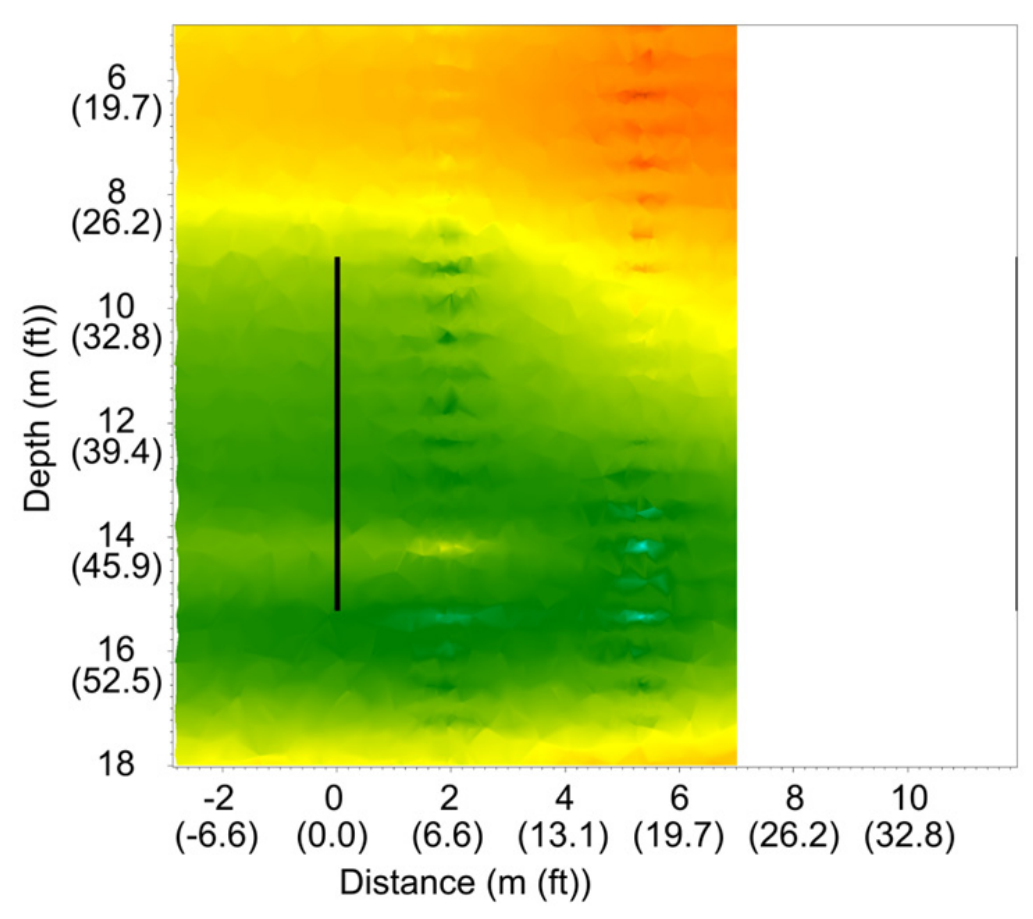

May 9, 2011 (Desiccation Day 112) 


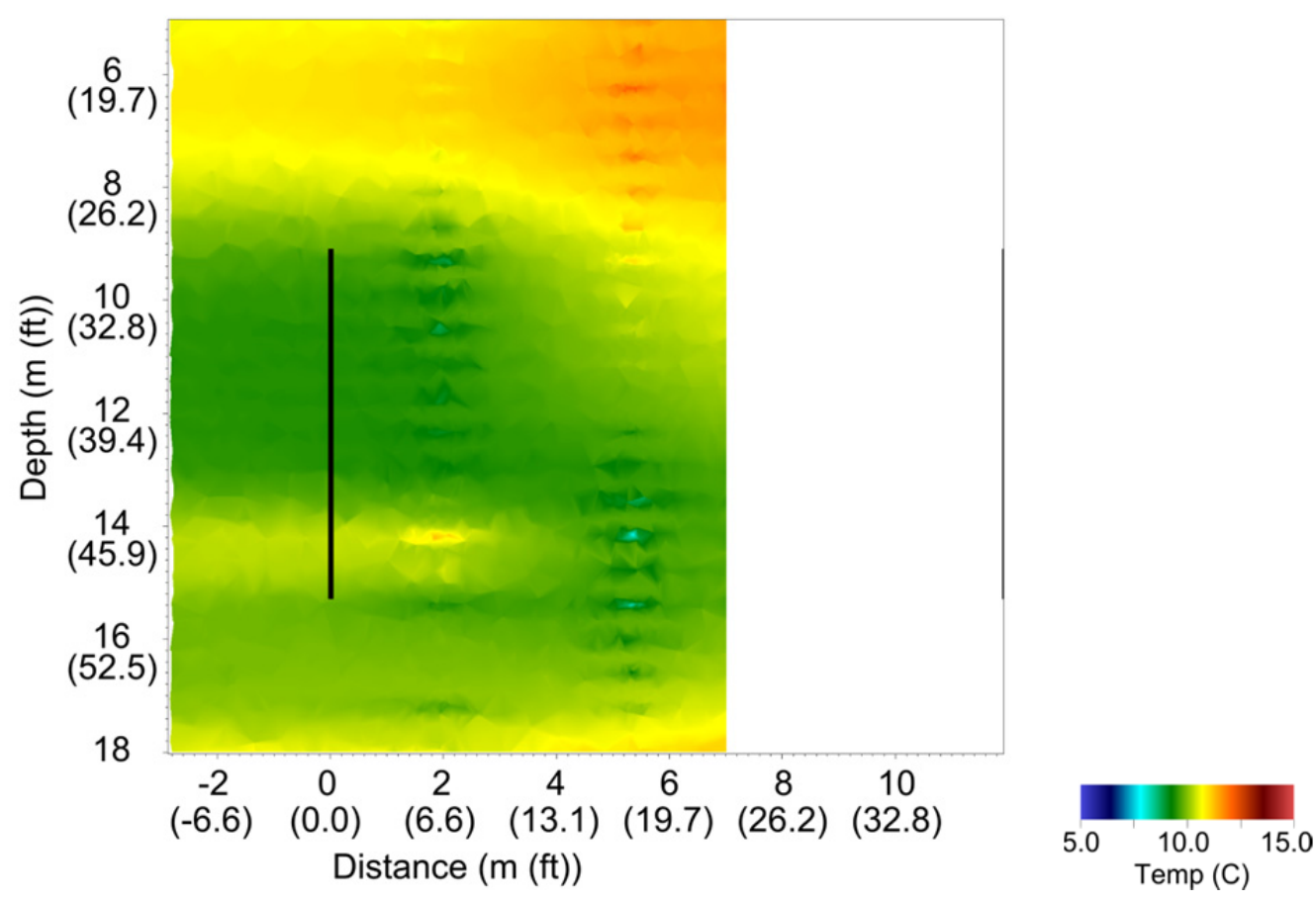

May 23, 2011 (Desiccation Day 126)
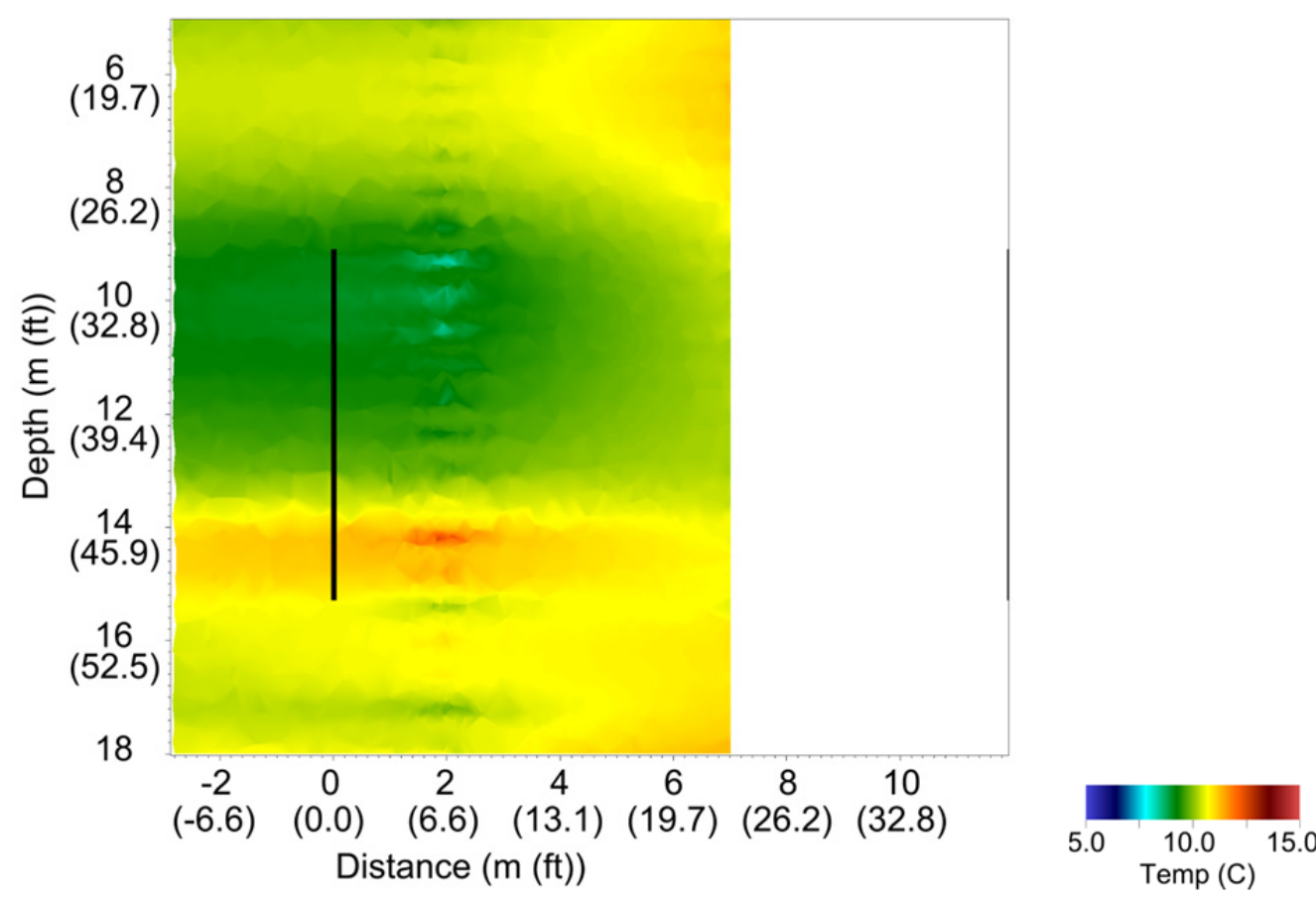

June 6, 2011 (Desiccation Day 140) 

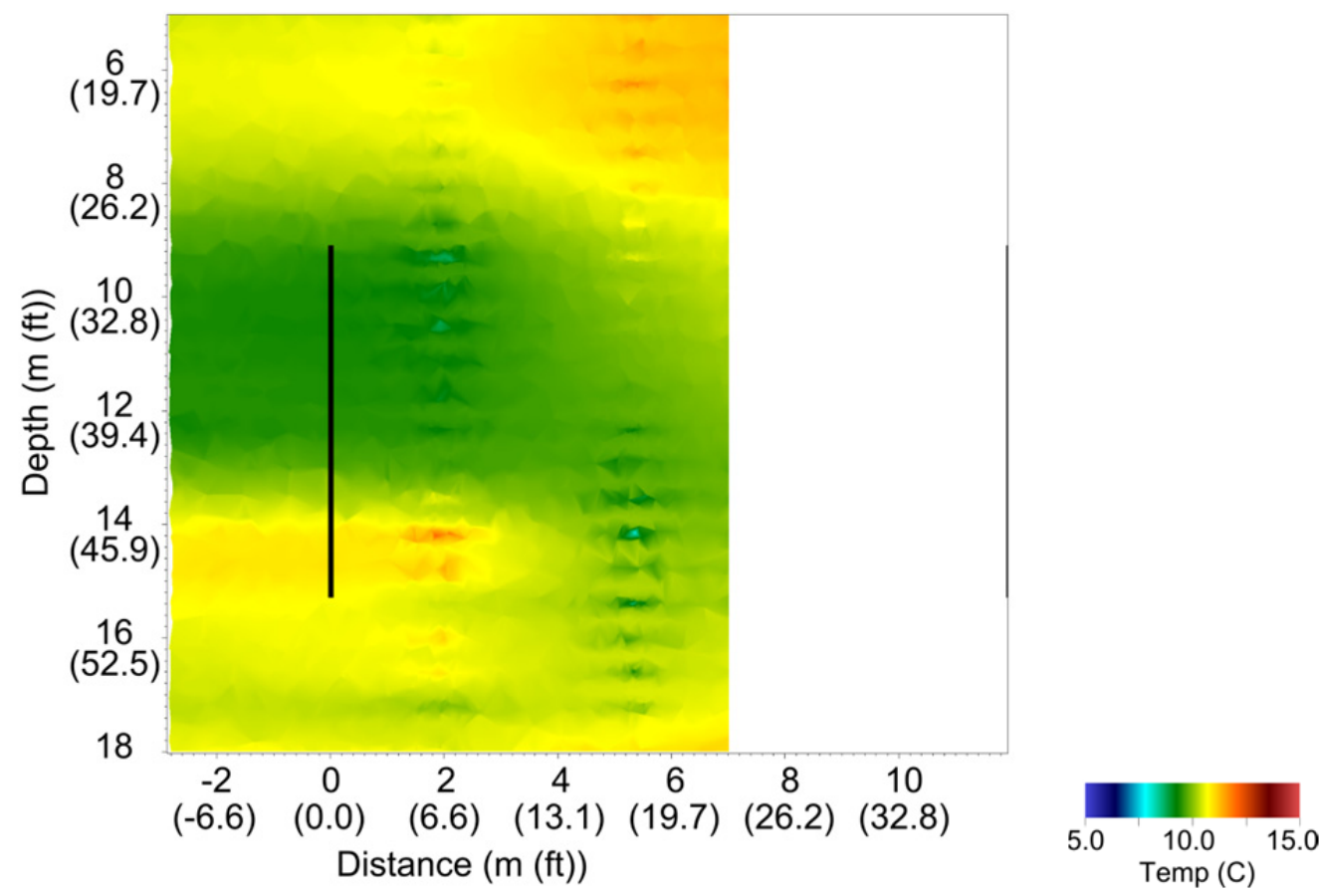

June 20, 2011 (Desiccation Day 154)

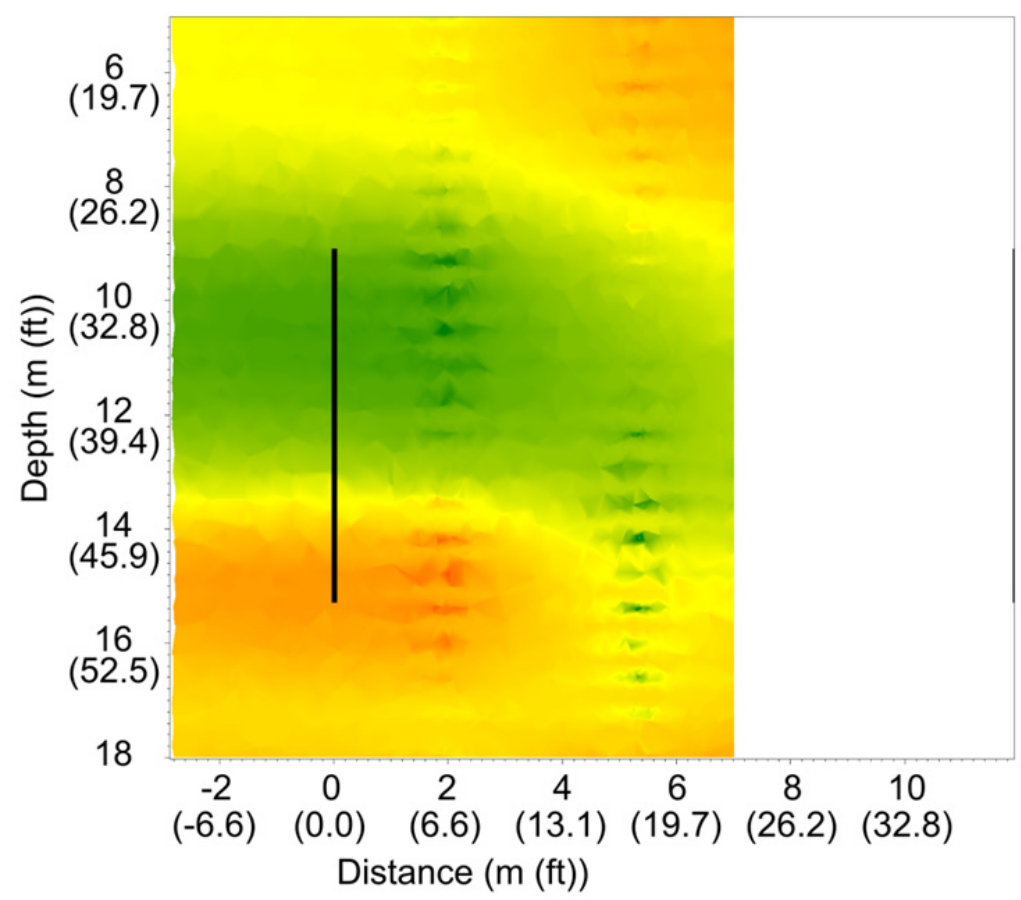

July 4, 2011 (Day 4 post-desiccation) 
Neutron Moisture Logging Data Interpolation

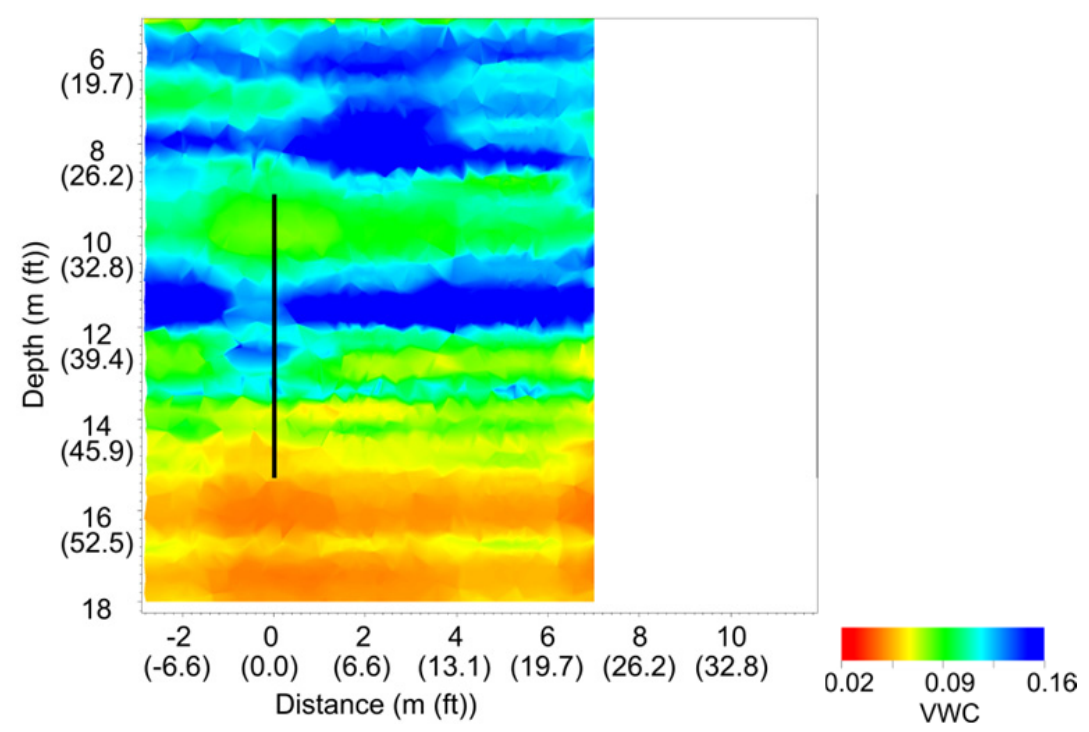

December 2010 (Baseline Pre-desiccation)
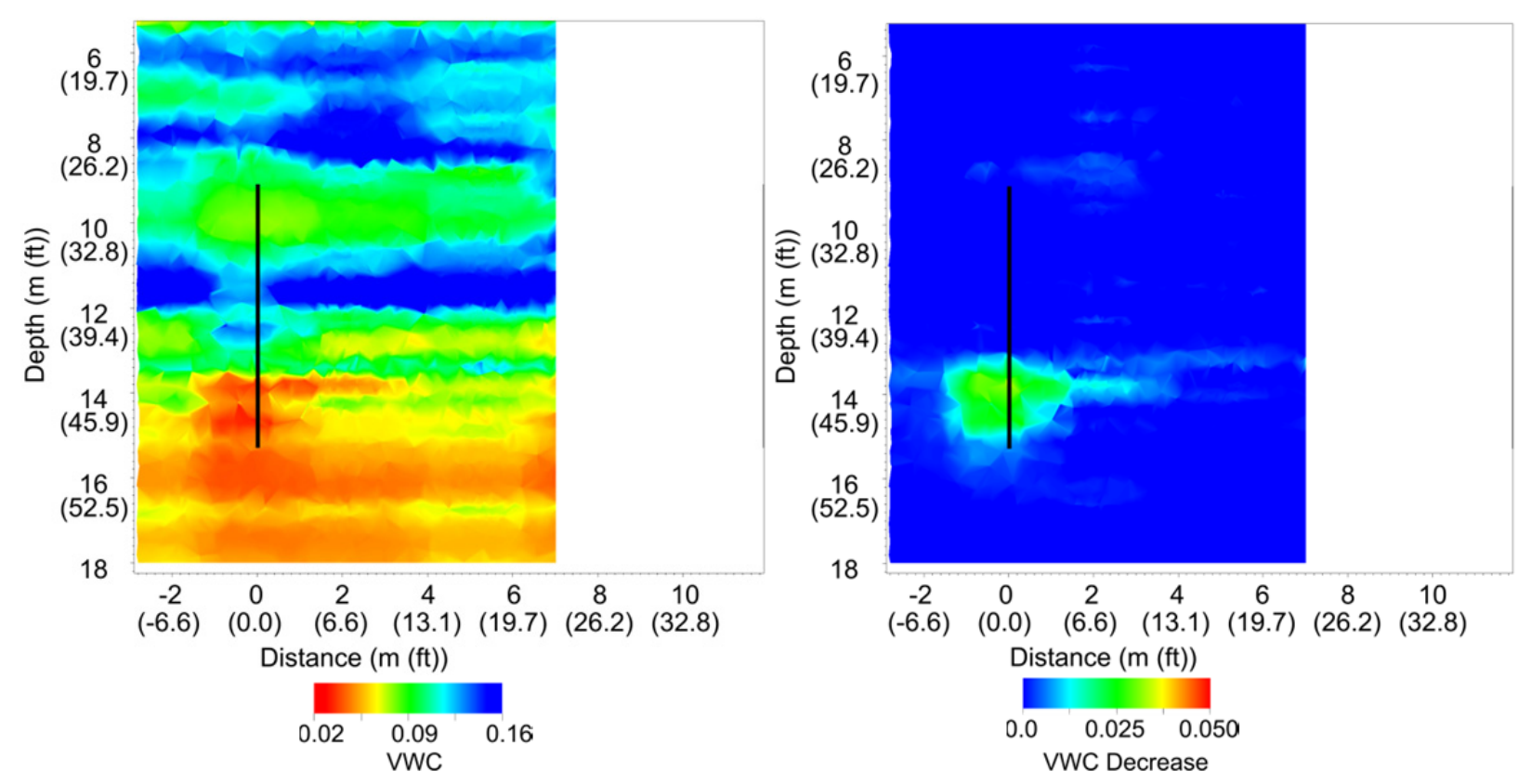

February 16, 2011 (Desiccation Day 30) 

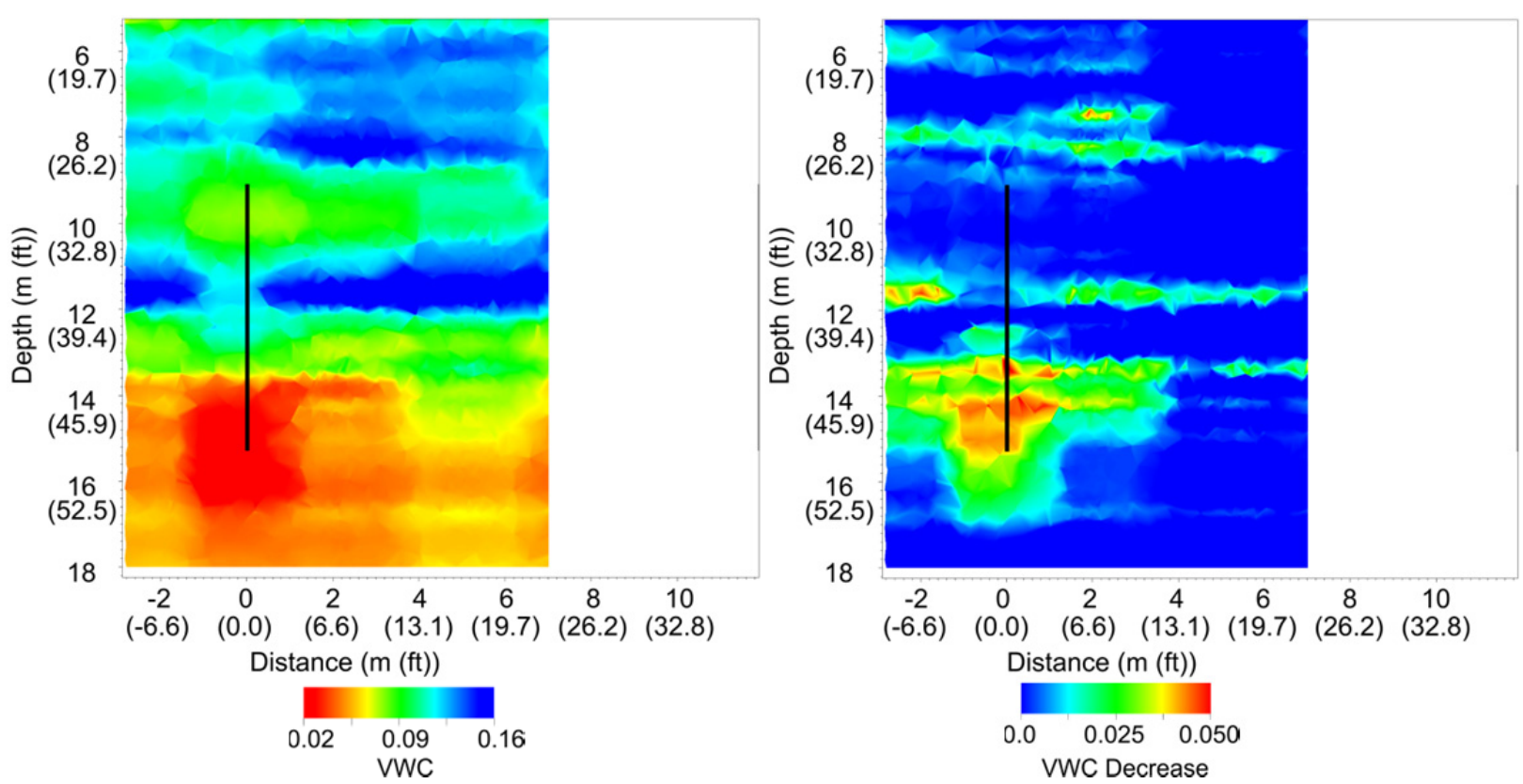

March 28, 2011 (Desiccation Day 70)
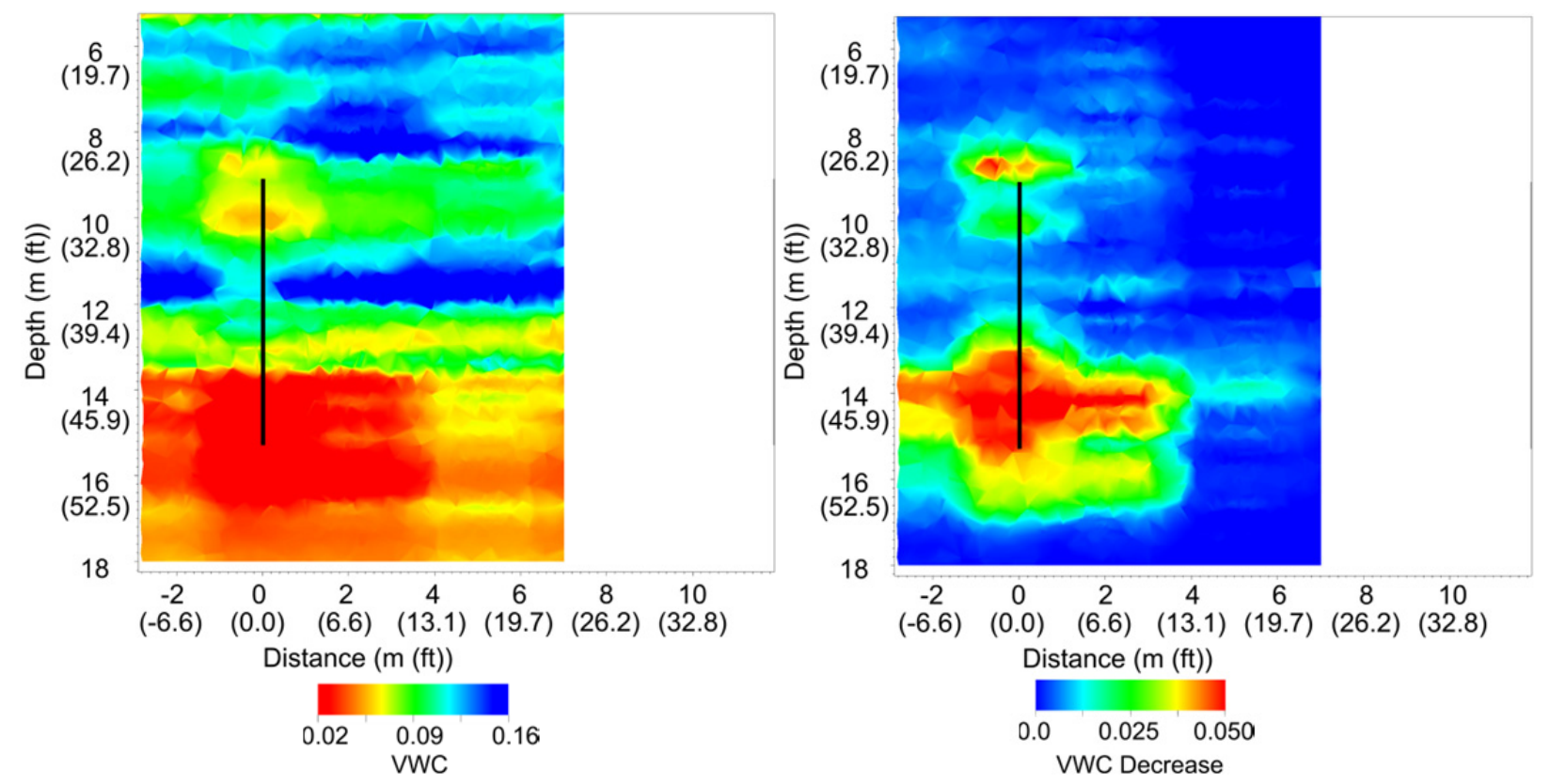

June 6, 2011 (Desiccation Day 140) 

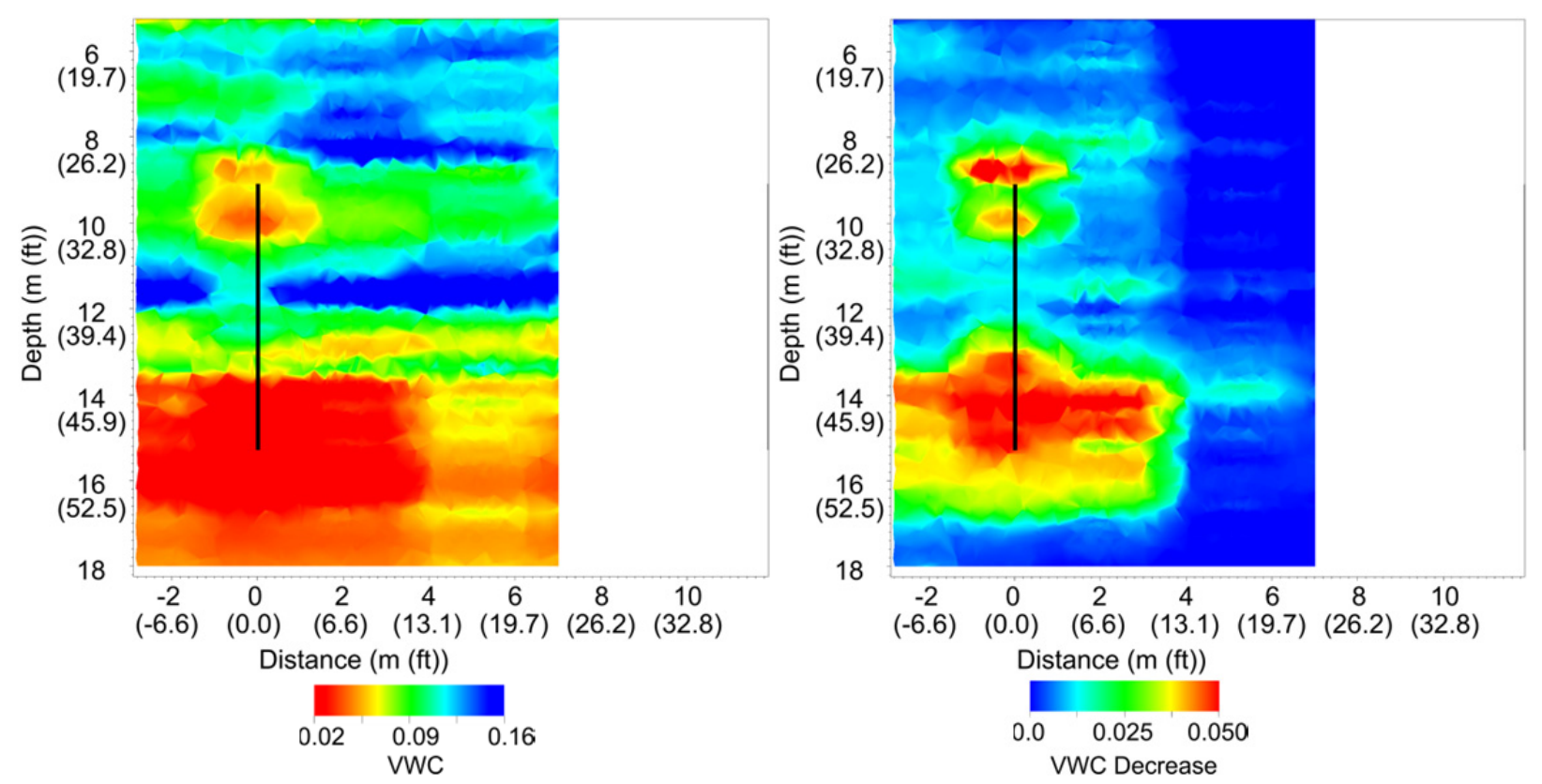

July 11, 2011 (Desiccation Day 175, considered representative of final desiccation moisture content where desiccation ended on day 164) 


\section{Electrical Resistivity Tomography Data Interpretation}

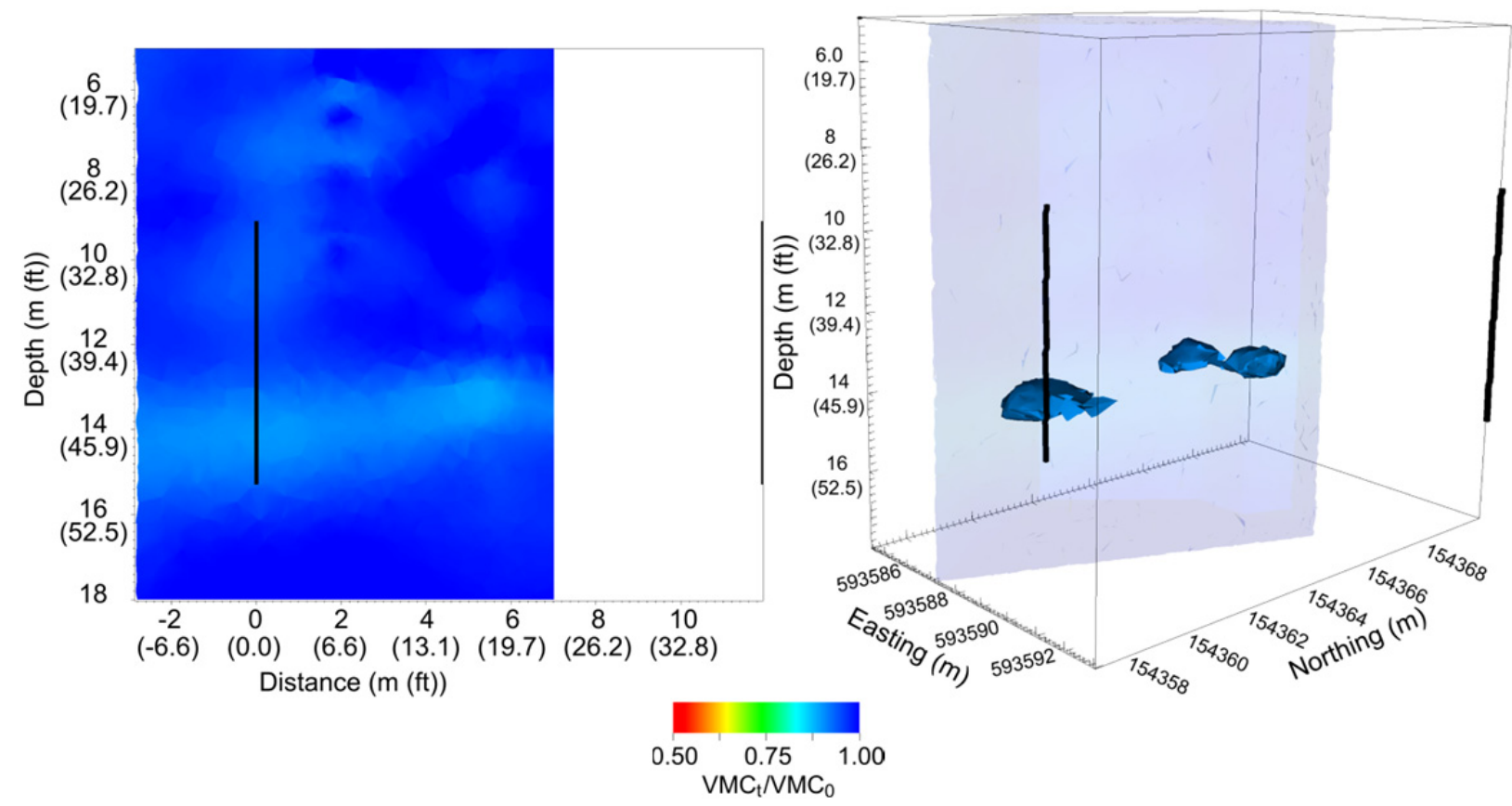

January 31, 2011 (Desiccation Day 14)

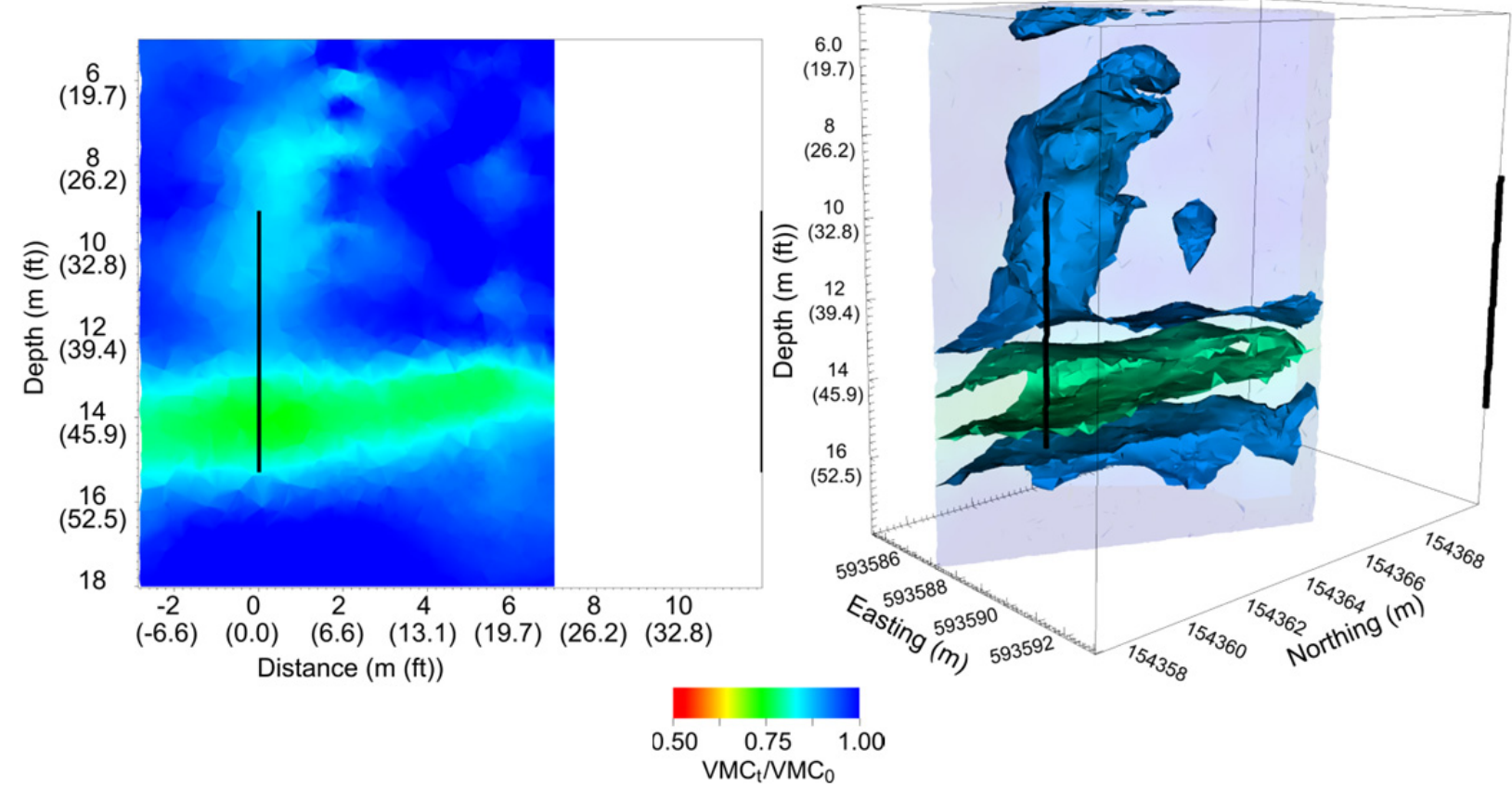

February 14, 2011 (Desiccation Day 28) 


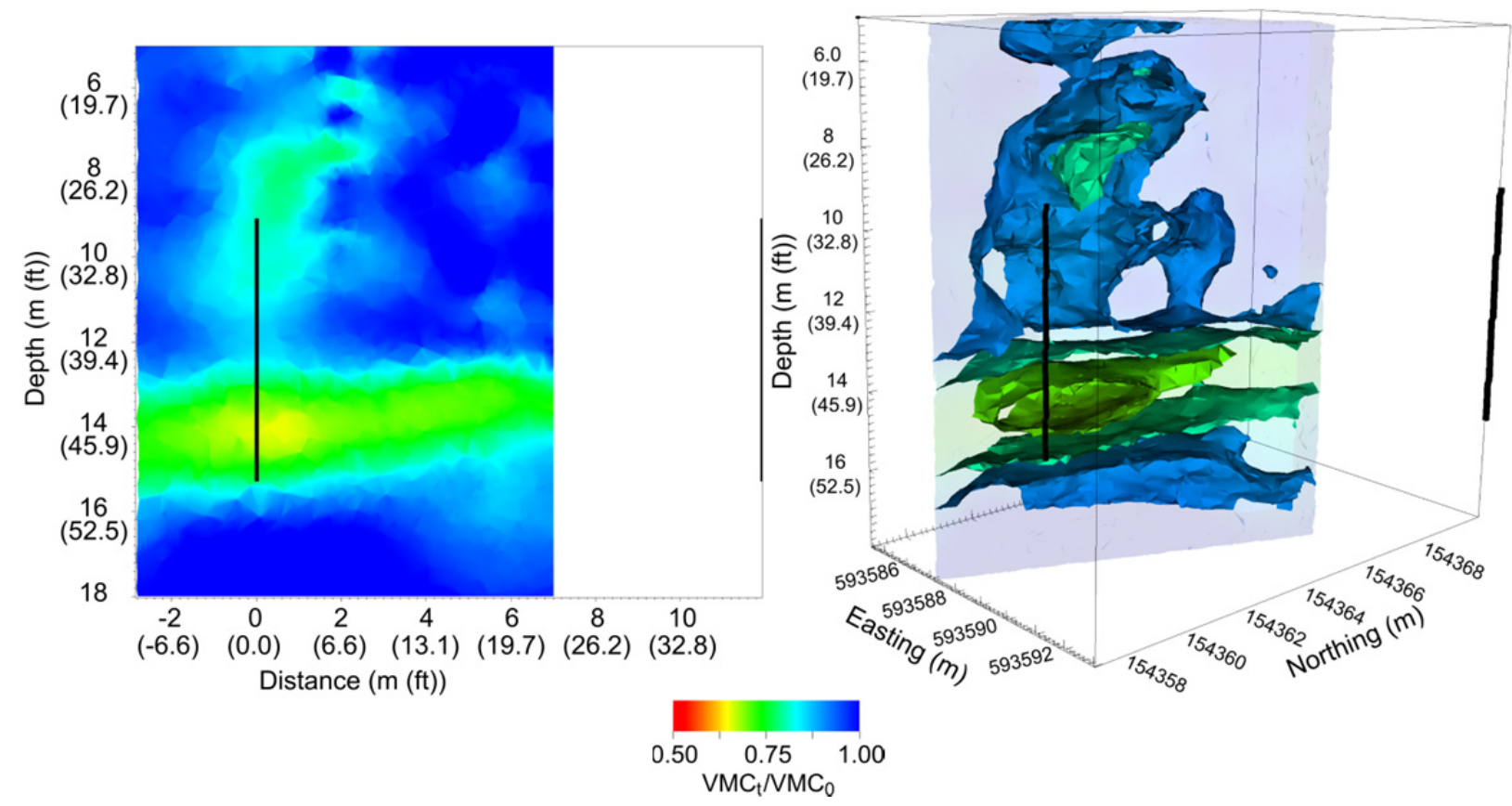

February 28, 2011 (Desiccation Day 42)

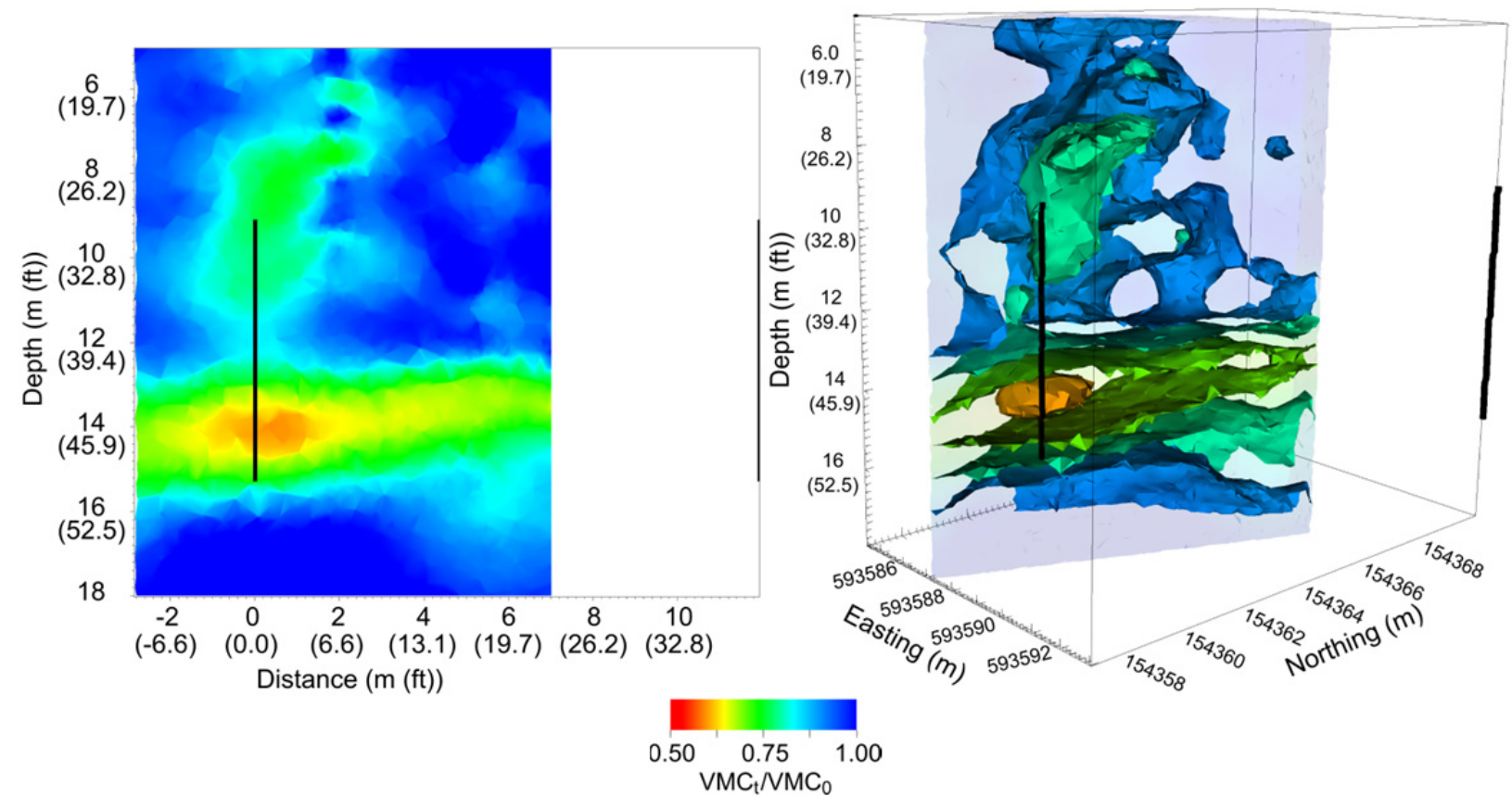

March 14, 2011 (Desiccation Day 56) 


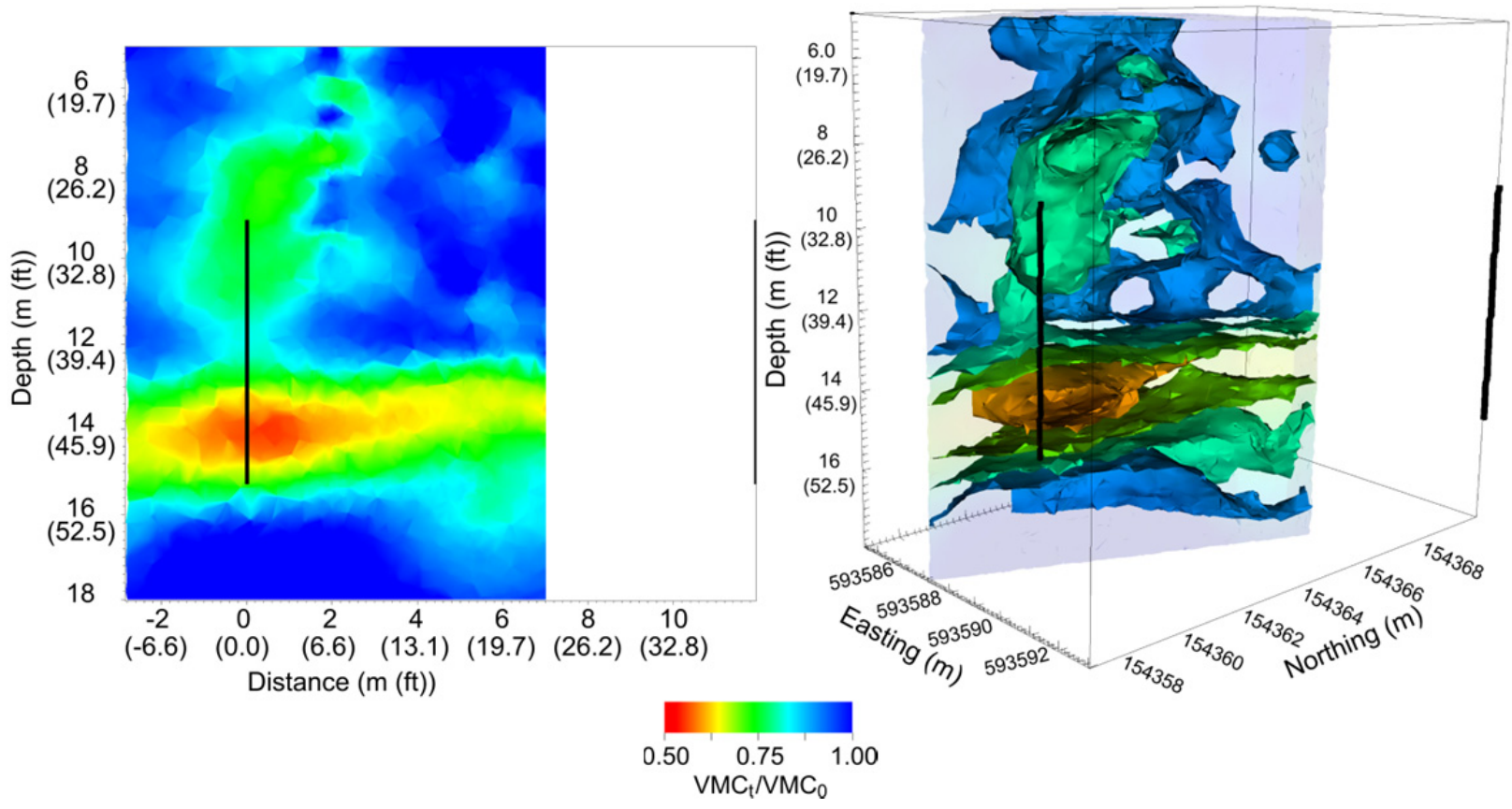

March 28, 2011 (Desiccation Day 70)

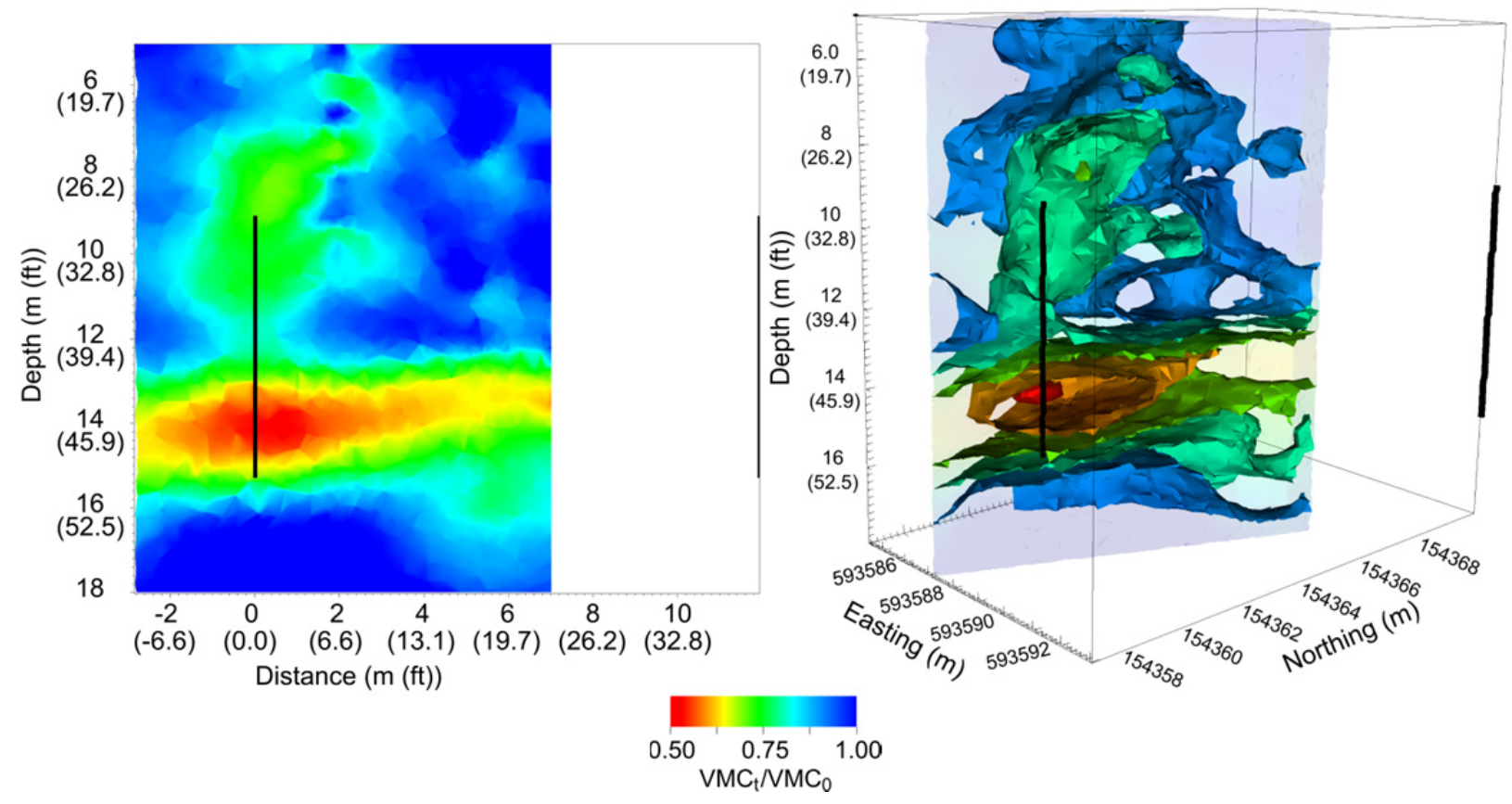

April 11, 2011 (Desiccation Day 84) 


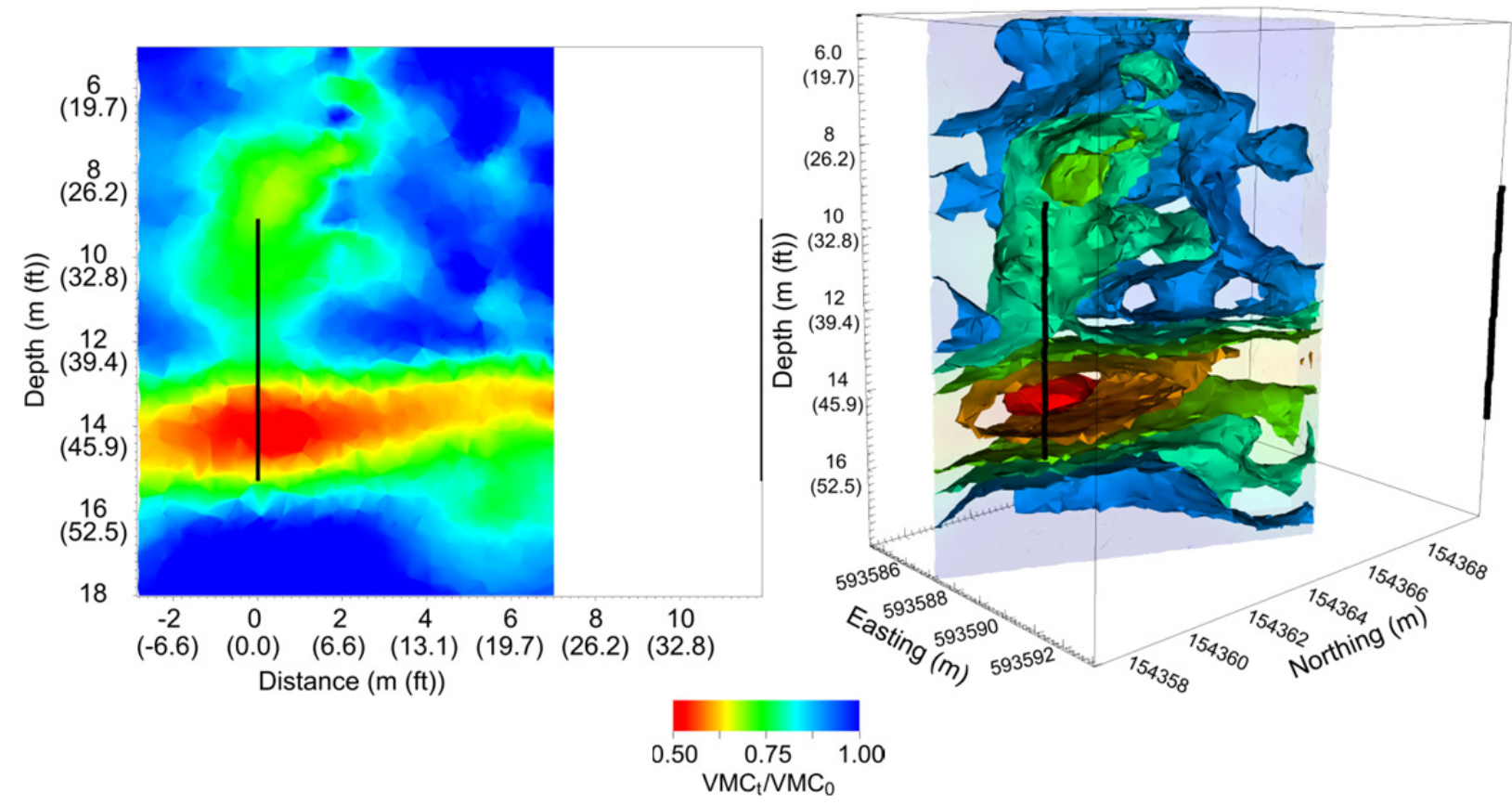

April 25, 2011 (Desiccation Day 98)

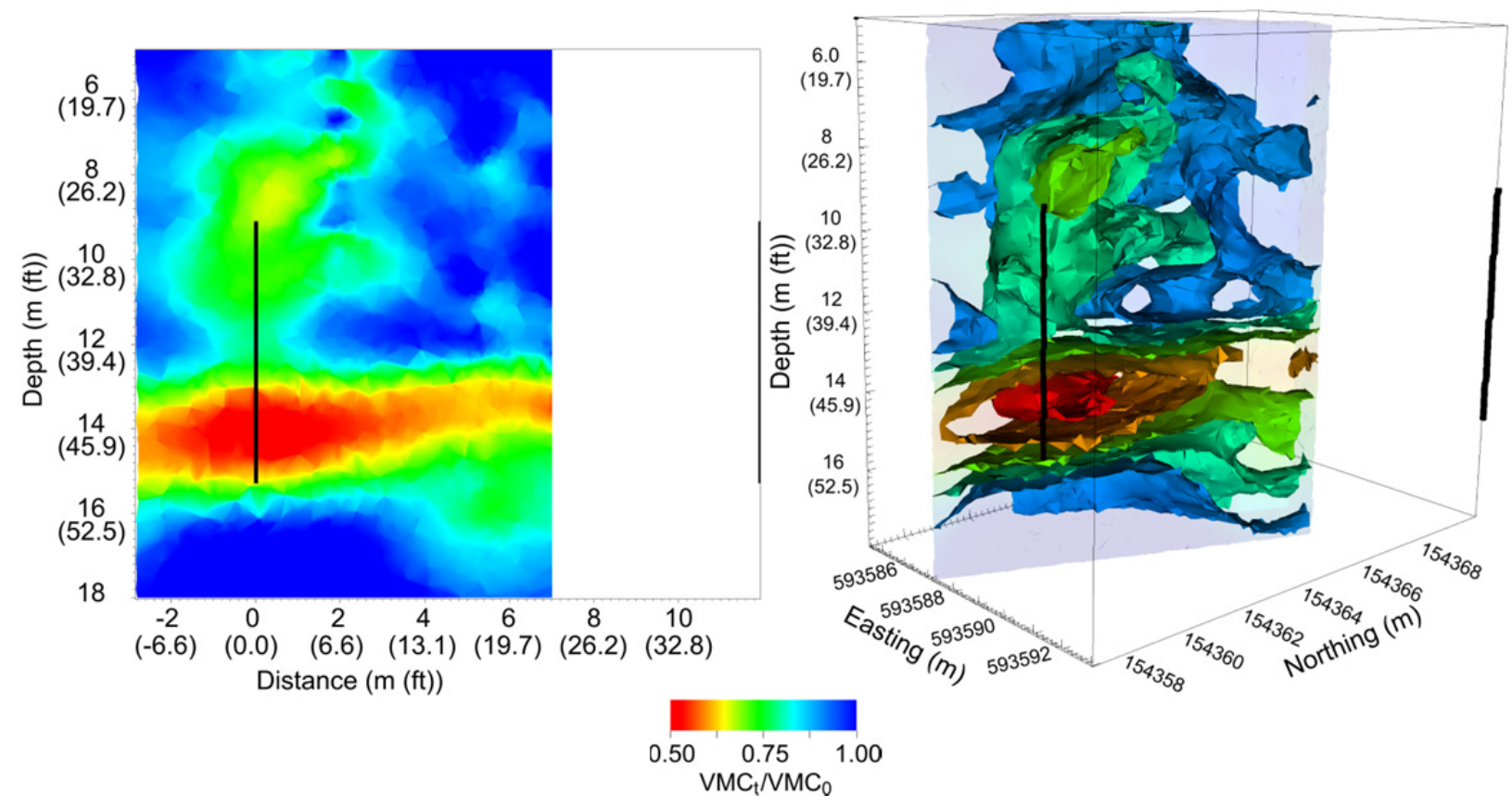

May 9, 2011 (Desiccation Day 112) 


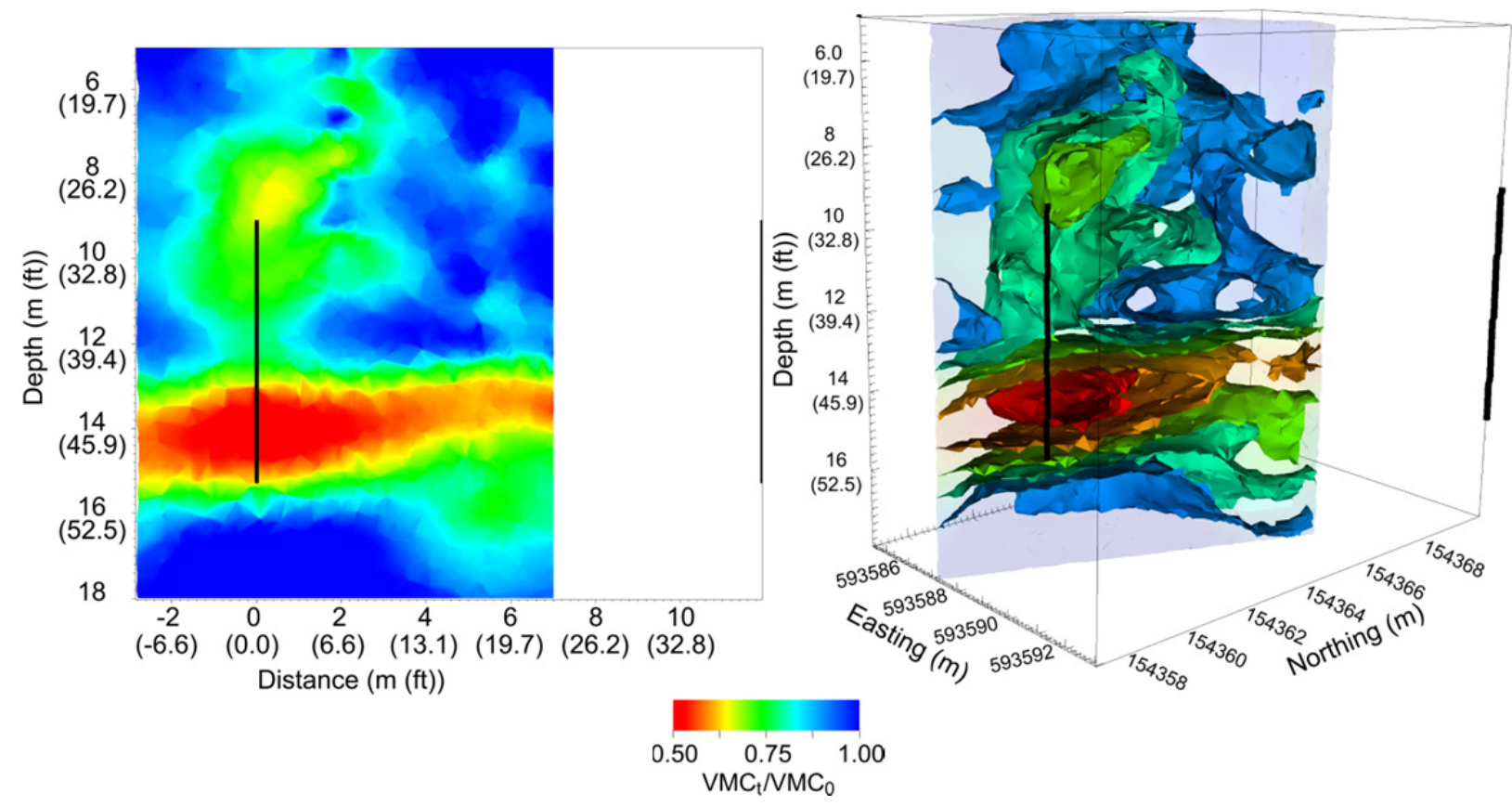

May 23, 2011 (Desiccation Day 126)

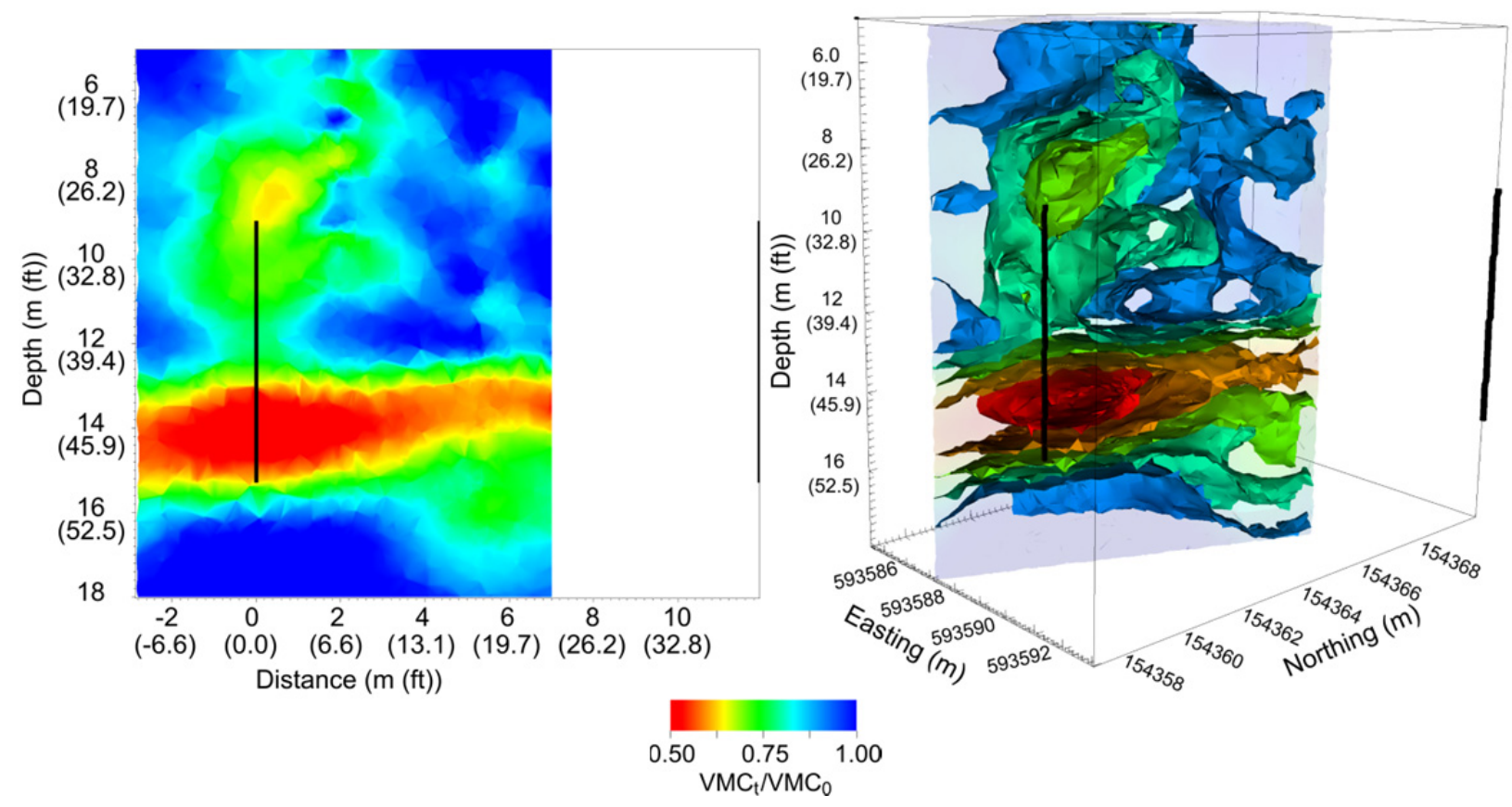

June 6, 2011 (Desiccation Day 140) 


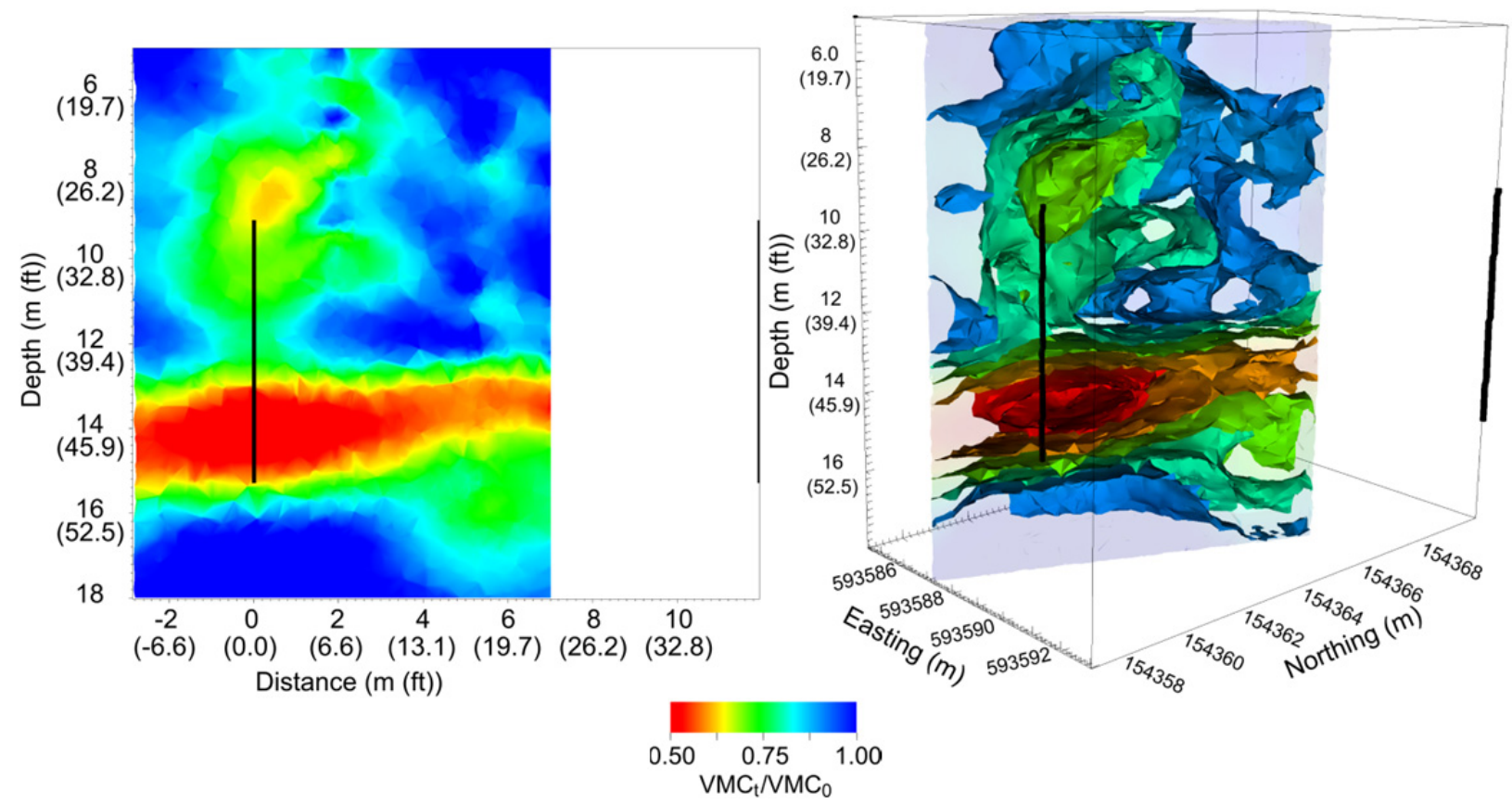

June 20, 2011 (Desiccation Day 154) 


\section{Ground Penetrating Radar Data Interpretation}
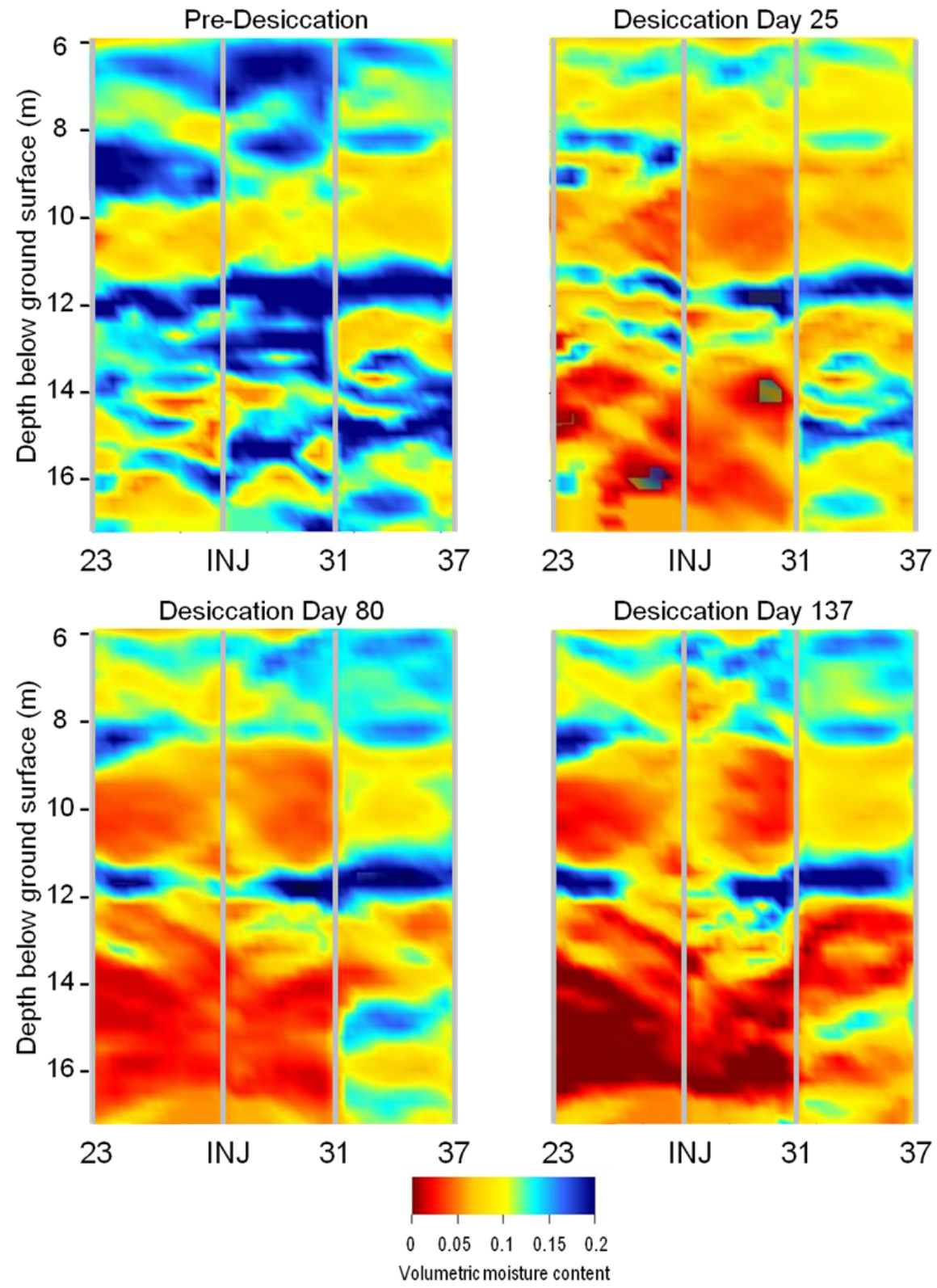

Active Desiccation (X-axis shows logging access locations where INJ $=$ the injection well and other locations represent the last two digits of the location name [i.e., $23=\mathrm{C} 7523$ ]) 


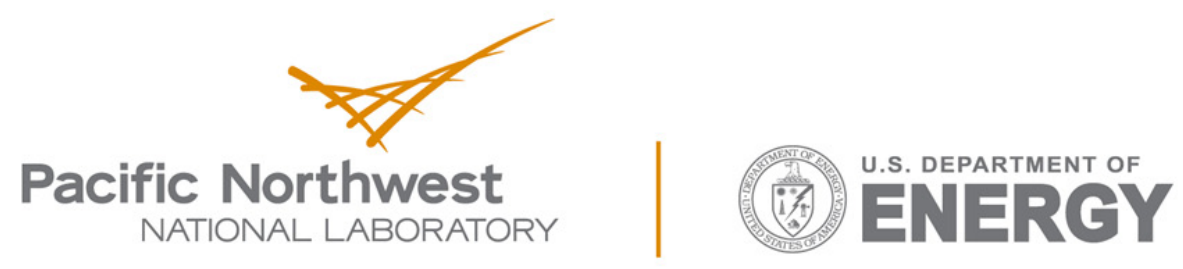

Proudly Operated by Battelle Since 1965

902 Battelle Boulevard

P.O. Box 999

Richland, WA 99352

1-888-375-PNNL (7665)

www.pnnl.gov 